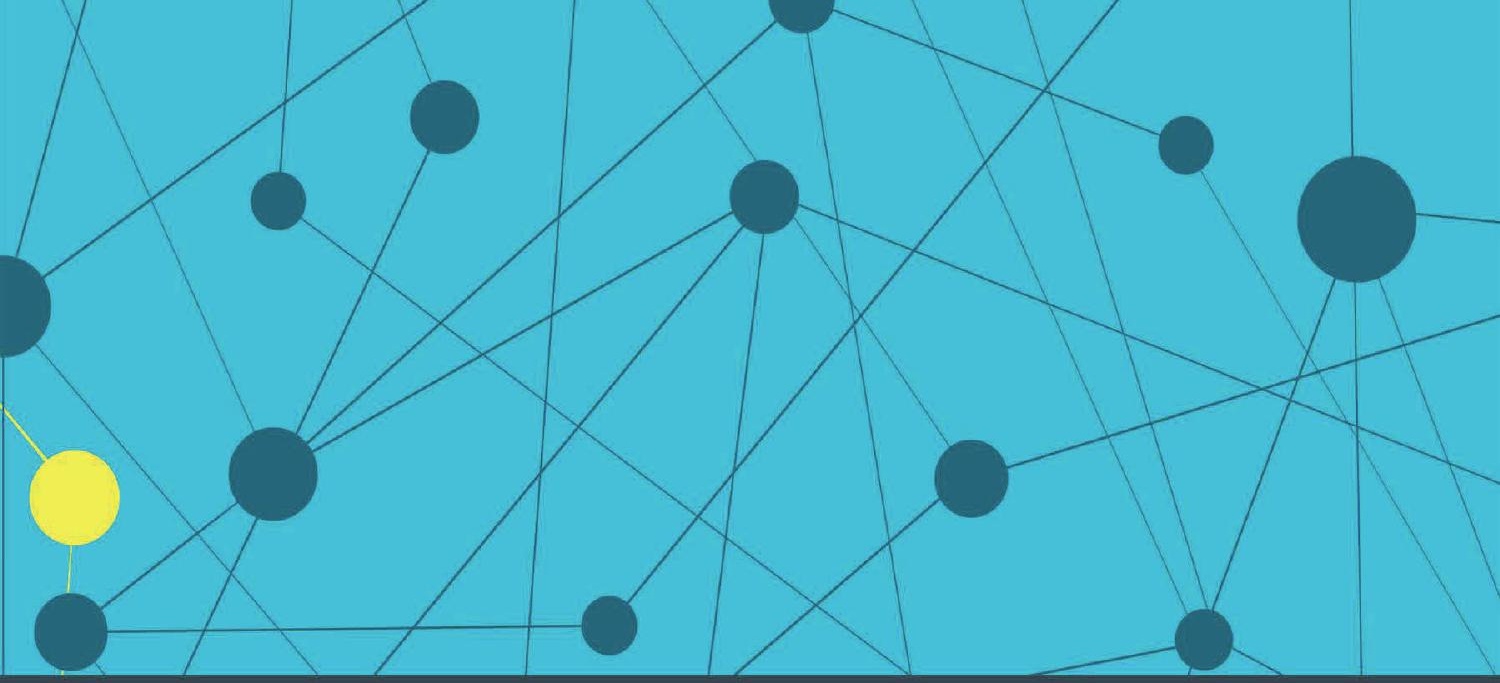

Routledge Studies in Cultural History

\title{
CULTURAL ORGANIZATIONS, NETWORKS AND MEDIATORS IN CONTEMPORARY IBERO-AMERICA
}

Edited by

Diana Roig-Sanz and Jaume Subirana

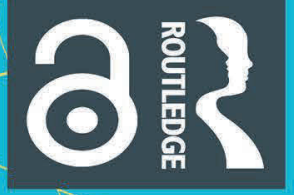




\section{Cultural Organizations, Networks and Mediators in Contemporary Ibero-America}

This book proposes an innovative conceptual framework to explore cultural organizations at a multilateral level and cultural mediators as key figures in cultural and institutionalization processes. Specifically, it analyzes the role of Ibero-American mediators in the institutionalization of Hispanic and Lusophone cultures in the first half of the 20th century by means of two institutional networks: PEN (the non-governmental writer's association) and the International Institute of Intellectual Cooperation (predecessor to UNESCO). Attempting to combine cultural and global history, sociology, and literary studies, the book uses an analytical focus on intercultural networks and cultural transfer to investigate the multiple activities and roles that these mediators and cultural organizations set in motion. Literature has traditionally studied major figures and important centers of cultural production, but other regions and localities also played a crucial role in the development of intellectual cooperation. This book reappraises the place of Ibero-America in international cultural relations and retrieves the lost history of key secondary actors. The book will appeal to scholars from international relations, global and cultural history, sociology, postcolonial studies, world and comparative literature, and new Hispanisms.

Diana Roig-Sanz is an ERC Starting Grant holder and a Ramón y Cajal senior research fellow at the Universitat Oberta de Catalunya.

Jaume Subirana is Associate Professor of Literature at Pompeu Fabra University. 


\section{Routledge Studies in Cultural History}

Revolutionary Ukraine, 1917-2017

History's Flashpoints and Today's Memory Wars

Myroslav Shkandrij

Post-Soviet Nostalgia

Confronting the Empire's Legacies

Edited by Otto Boele, Boris Noordenbos and Ksenia Robbe

Musical Culture and the Spirit of Irish Nationalism, 1848-1972

Richard Parfitt

Who Was William Hickey?

A Crafted Life in Georgian England and Imperial India

James R. Farr

Print Culture and the Formation of the Anarchist Movement in Spain, 1890-1915

James Michael Yeoman

Reform, Revolution and Crisis in Europe

Landmarks in History, Memory and Thought

Edited by Bronwyn Winter and Cat Moir

Tattoo Histories

Transcultural Perspectives on the Narratives, Practices, and Representations of Tattooing

Edited by Sinah Theres Klo $\beta$

Cultural Organizations, Networks and Mediators in Contemporary Ibero-America

Edited by Diana Roig-Sanz and Jaume Subirana

For more information about this series, please visit: www.routledge. com/Routledge-Studies-in-Cultural-History/book-series/SE0367 


\section{Cultural Organizations, \\ Networks and Mediators in \\ Contemporary Ibero-America}

Edited by Diana Roig-Sanz and Jaume Subirana 
First published 2020

by Routledge

52 Vanderbilt Avenue, New York, NY 10017

and by Routledge

2 Park Square, Milton Park, Abingdon, Oxon, OX14 4RN

Routledge is an imprint of the Taylor \& Francis Group, an informa business

(C) 2020 Taylor \& Francis

The right of Diana Roig-Sanz and Jaume Subirana Ortín to be identified as the authors of the editorial material, and of the authors for their individual chapters, has been asserted in accordance with sections 77 and 78 of the Copyright, Designs and Patents Act 1988.

The Open Access version of this book, available at www.taylorfrancis. com, has been made available under a Creative Commons AttributionNon Commercial-No Derivatives 4.0 license.

Trademark notice: Product or corporate names may be trademarks or registered trademarks, and are used only for identification and explanation without intent to infringe.

Library of Congress Cataloging-in-Publication Data

A catalog record for this book has been requested

ISBN: 978-0-367-28050-5 (hbk)

ISBN: 978-0-429-29940-7 (ebk)

Typeset in Sabon

by Apex CoVantage, LLC 


\section{Contents}

List of Figures viii

List of Tables ix

PART I

Politics of the Spirit 1

1 Cultural Organizations, Networks and Mediators: An Introduction

DIANA ROIG-SANZ AND JAUME SUBIRANA

2 Rebuilding a Europe of Intellectuals (1918-1939) 24

CHRISTOPHE CHARLE

3 Cultural Mediators and Their Complex Transfer Practices 46 REINE MEYLAERTS

PART II

Cultural Organizations

4 A Representative Organization? Ibero-American Networks in the Committee on Intellectual Cooperation of the League of Nations (1922-1939)

MARTIN GRANDJEAN

5 The 1933 Dubrovnik PEN Congress, or How to Deal with the Present That Was Already History 
vi Contents

7 The 1936 Meetings of the PEN Clubs and the International Institute of Intellectual Cooperation in Buenos Aires

ALEJANDRA GIULIANI

8 Barcelona on the International Map of Modernity: The Conferentia Club's Role in the Interwar Period

PART III

Cultural Mediators

9 Joan Estelrich and International Cooperation: From the Years of Expansió Catalana to His Activity for the PEN Club in the Early-Mid-1930s

SÍLVIA COLL-VINENT

10 The Spanish Center of the International PEN Through Its First Sumiller: From a Project of International Solidarity to an Expression of the Tensions of the Literary Society of Madrid (1922-1924)

LAURIE-ANNE LAGET

11 The International Relations of the Catalan PEN Until 1936: Guests, Congressors and Visitors

JOAN SAFONT PLUMED

12 The International Dimension of the Portuguese "Politics of the Spirit”: António Ferro, Júlio Dantas, Fidelino de Figueiredo

ÂNGELA FERNANDES

13 Between the Local and the International: Enrique Gómez Carrillo and Antonio Aita at the International Institute of Intellectual Cooperation

LAURA FÓLICA AND VENTSISLAV IKOFF

14 Torres Bodet and the "Male Pedagogies": Radiography of a Thought of Transcultural and Transnational Circulation 
15 Universalisms in Debate During the 1940s: International Organizations and the Dynamics of International Intellectual Cooperation in the View of Brazilian Intellectual Miguel Ozório de Almeida LETÍCIA PUMAR

List of Contributors 


\section{Figures}

4.1 Composition of the International Committee on Intellectual Cooperation Between 1922 and 1939, Highlighting the Ibero-American Personalities (Black)

4.2 Comparison Between a) the Proportion of Ibero-American Members Officially Appointed; b) the Proportion of Them Really Attending the Sessions (Without Substitutes); c) the Proportion of All Ibero-Americans Attending the Sessions Among All Participants (Members, Substitutes, Delegates, Secretaries, etc.)

4.3 Network of the 212 Participants in ICIC Meetings Between 1922 and 1939

14.1 The Little Sailor Becomes an Elegant Caballerito 274 14.2 Jaime and Josefina, a Romantic Young Couple 277 14.3 Torres Bodet as a Flâneur in Paris 280 14.4 The UNESCO Director at His Desk in Paris (c. 1950) 284 


\section{Tables}

2.1 French and Foreign Students 39

2.2 Ranking of Foreign Student Nationalities in France by Size Per Academic Year $\quad 40$

8.1 Number of Conferences According to Speaker Origin 154

8.2 Chronological List of Lectures Organized by Conferentia Club from 1929 to 1936

8.3 Alphabetical List of Lectures Organized by Conferentia Club from 1929 to 1936 
$\because$ Taylor \& Francis

Taylor \& Francis Group

http://taylorandfrancis.com 


\section{Part I}

Politics of the Spirit 
$\because$ Taylor \& Francis

Taylor \& Francis Group

http://taylorandfrancis.com 


\title{
1 Cultural Organizations, Networks and Mediators: An Introduction
}

\author{
Diana Roig-Sanz and Jaume Subirana
}

This collective volume sets the grounds for a new approach exploring cultural organizations at a multilateral level and cultural mediators as key figures in cultural and institutionalization processes. To do so, the book proposes an innovative conceptual and methodological understanding of the participation of these agents and agencies in international networks of culture that helped build modernity in contemporary time, specifically in the first half of the 20th century. Cultural Organizations, Networks and Mediators in Contemporary Ibero-America brings together microhistory and global history and addresses the importance of events, conferences, relations, and agents to capture local, national, regional, and continental connections as proposed today by global historians. Attempting to combine cultural and global history, sociology, and literary and transfer studies, the book stresses the need for an analytical focus on intercultural networks and cultural transfer and the transgression of fields through the overlap of actor roles and the multiple activities and multilateral programs that these mediators and cultural organizations set in motion.

The book addresses the fact that literature on aesthetic modernity tends to overlook Hispanic and Lusophone modernisms, as it keeps locating them on the peripheries and in doing so promotes temporal boundaries that mainly reflect an English-language bias. However, the interwar period saw an unprecedented increase of international cultural exchange driven by national and supranational bodies, and several cultural organizations, within an international scope, were founded to advance science, education, literature, religion, or arts (Vimr 2018). The international mobility of many Latin American mediators, who pioneered students exchange programs, were diplomats, traveled for professional commitments, political reasons, or exile and elicited greater international interest in the particular traits and local traditions of Latin American cultures and literatures (especially for indigenous cultures). In that respect, the book proposes a number of case studies that aim to analyze the role of Latin American, Spanish, Portuguese, and Catalan cultural mediators in the institutionalization of Hispanic and Lusophone cultures in the early 20th century by means of two institutional networks: PEN International (the 


\section{Diana Roig-Sanz and Jaume Subirana}

non-governmental writer's association) and its multiple national committees and the International Committee of Intellectual Cooperation and its executive branch, the Institute of Intellectual Cooperation (predecessor to UNESCO). In doing so, we provide an in-depth analysis of the crossings between these two major cultural organizations, which were also connected to associations and conferences such as the National Associations of Writers or the second American Conference of National Committees on Intellectual Cooperation that took place in La Havana in 1941. We seek to demonstrate that Hispanic and Lusophone cultural mediators not only took part in the international cultural arena but also played a crucial role in the multilingual and intercultural networks of the time. Thus, this book pursues two main goals: first to retrieve the lost history of IberoAmerican cultural mediators in institutional and intercultural networks and reappraise their role and second to contribute to a promising field of study by providing inspiring case studies for further research on cultural organizations; the institutionalization of cultures and literatures; and cultural mediators and their complex relations and overlapping roles across historical periods, disciplines, and geographies (Roig-Sanz \& Meylaerts 2018; Meylaerts, Gonne, Lobes \& Roig-Sanz 2016; Subirana 2018).

By mapping the intellectual sociability of a group of Ibero-American mediators through their contribution to international cultural organizations, we study how the mobility of these agents functioned as a shared transnational space for the institutionalization of Hispanic and Lusophone cultures, the dissemination of their various cultural and political national projects, and the increasing cosmopolitanism of the IberoAmerican field (by which we mean Spain, Portugal, and Latin America, which includes Brazil). The book shows how these agents positioned themselves in contemporary debates and were intricately connected on an international level through institutional networks. Within this framework, we define institutionalization as 1) the emergence of the first cultural policies for the standardization of the cultural field and 2) the inclusion of Hispanic and Lusophone writers and intellectuals in an institutional and transnational cultural network. The book also empirically questions the idea that cultural exchange among Latin American countries was non-existent. To do so, Cultural Organizations, Networks and Mediators in Contemporary Ibero-America features contributions from a group of leading international scholars (very well-known historians and literary and translation scholars) who have worked on intellectual history and the history of international cultural organizations, political philosophy, comparative literature, and translation history.

\section{Politics of the Spirit ${ }^{1}$ in the Light of Ibero-America}

At the request of John Middleton Murry, Paul Valéry wrote and published "The Crisis of the Mind" (originally in English) in two parts in 
The Athenaeum, April 11 and May 2, 1919. The first letter begins with these words:

We later civilizations ... we too know that we are mortal. We had long heard tell of whole worlds that had vanished, of empires sunk without a trace, gone down with all their men and all their machines into the unexplorable depths of the centuries, with their gods and their laws, their academies and their sciences pure and applied, their grammars and their dictionaries, their Classics, their Romantics, and their Symbolists, their critics and the critics of their critics . . . We were aware that the visible earth is made of ashes, and that ashes signify something. Through the obscure depths of history we could make out the phantoms of great ships laden with riches and intellect; we could not count them. But the disasters that had sent them down were, after all, none of our affair. Elam, Ninevah, Babylon were but beautiful vague names, and the total ruin of those worlds had as little significance for us as their very existence. But France, England, Russia ... these too would be beautiful names. Lusitania too, is a beautiful name. And we see now that the abyss of history is deep enough to hold us all. We are aware that a civilization has the same fragility as a life. The circumstances that could send the works of Keats and Baudelaire to join the works of Menander are no longer inconceivable; they are in the newspapers.

After the First World War, Western citizens were worried about the future of Europe, meaning Europe for them: Culture and Civilization. Valéry pictures an extraordinary shiver running through the marrow of Europe and how the Old continent was unable to recognize itself. Valéry wonders what will occur with the European spirit, and both mind and spirit will be (for him and for many thinkers and artists of his time) at the core of any potential solution to that huge crisis. Those who devoted their lives to the spirit were called to be the ones who could prevent the disaster happening again: artists and intellectuals in international scenarios were the frontrunners of a battle for spirit, and they were to stop the realm of thought and common sense from perishing. Thus, it is not by accident that, in 1919, the Society of Nations was formed and that two years later, in 1921, PEN International, the first world writer's organization, was established in London by Catherine Amy Dawson Scott, and only one year later, in 1922, the Society of Nations founded in Geneva the International Committee of Intellectual Cooperation (ICIC), which had in 1926 an executive branch in Paris called the International Institute of Intellectual Cooperation (IIIC) (Roig-Sanz 2013; Grandjean 2018).

PEN International and the International Committee of Intellectual Cooperation were two collective political and cultural endeavors that remarkably joined the individual role of great transnational intellectual figures 
such as Thomas Mann, Stefan Zweig, José Ortega y Gasset, Salvador de Madariaga, Paul Valéry, Henri Bergson, Béla Bartok, and Rabindranath Tagore. All of them aimed to foster suitable forums for dialogue and exchange based on trust and the establishment of connections between those who could go beyond the mistrust that the rise of nationalisms had begun to generate. A great piece of novelty in the 1920s and 1930s was the increasing presence of cultural organizations that were more diverse and articulate and participated in the network of international figures mainly composed of white Western men from the great nations. As we will see throughout the book, this sort of collaboration and joint effort will not be lacking in ambiguity; constraints; and even gender, social, and geographical biases, but it also sheds light into new voices, places, and connections that will emerge and join an international cultural debate on a worldwide basis. Indeed, these new agencies of cultural legitimacy took the shape of a network of connections rather than the usual touring of great intellectuals and, from a methodological perspective, help us to overcome the individual level of analysis and adopt a more collective approach.

Certainly, times were changing, and 1936 was a key date for both intellectual and political reasons. For the first time, the world conferences of the International Institute of Intellectual Cooperation, hosted in Paris, and the International PEN took place not in the Old continent but rather in Buenos Aires. In a similar vein, Adolf Hitler's political party had won the elections in Germany at the end of 1932, war had broken out in Spain in 1936, and a little later, in 1939, the Second World War would be declared. All those events proved that the spirit of Paul Valéry's two letters and the establishment of the Society of Nations and PEN International, as well as the foundation of the International Institute of Intellectual Cooperation, had not been enough to avoid the great disaster, a new Great World War. Indeed, Paul Valéry's title and concern remained relevant over time, and on November 21, 1932, the Portuguese António Ferro borrowed Valéry's title in the article "Política do espírito". This expression became the heading of the Portuguese State program for the promotion of arts (see Fernandes in this book), and all initiatives undertaken by Ferro were meant to support Portuguese culture.

Within this general framework, this book understands temporal boundaries as porous and permeable and proposes 1914 and 1946 as critical dates for the exemplary case study. August 1914 marks the outbreak of the First World War (see Charle in this book), 1946 the First UNESCO Conference held in Paris and the approval of the International Institute of the Amazon Hylea and the creation of Scientific Cooperation Offices in underdeveloped regions, namely Latin America, Africa, and Asia (see Pumar in this book). Within that period, beyond their differences, IberoAmerican countries also shared contemporaneous historical and cultural developments: for example, the writer's professionalization process, the 
rise of cultural periodicals, and market growth in publishing, particularly relevant in the 1950s. However, despite this rich environment for intercultural analysis, Ibero-American modernisms have often been seen as peripheral developments playing a small role in the significant cultural changes that took place after the 1900s and, particularly, after the First World War (Jameson 1998, 2002; Griffith 2007; Gargatagli 2013). European and US cultural producers did not include Ibero-American actors in their international channels of modernity, particularly driven from the Anglo-American, French, and German fields.

Indeed, the institutional development of cultures and national literatures as well as academic fields (Sapiro, Brun \& Fordant 2019) has proved to be diverse according to geographical zones, academic traditions, and disciplines. However, we have assumed that institutional processes were at the time widely developed in Central Europe and the English-speaking world, but they were less prominent or more fragile in Southern Europe or Latin America. Likewise, we have understood that modernity emerged in Europe and the United States and was literally reproduced or adapted overseas, but modern Europe and Latin America built themselves in a continuous and interrelated process. Cultural transfer and cultural dynamics are not linear, and we should move away from reductionist source-target binaries with hierarchical, unidirectional, and too-centered frames. IberoAmerica promoted institutional processes that often oscillated between their presence in many social fields and fragility and lack of presence in others (Gadea 2007).

Thus, due to its linguistic, historical, and cultural ties, the geographical focus of Ibero-America (that is, Spain, Portugal, and Latin America, including Brazil), provides an exemplary object of research, as it allows us to analyze the revitalization, institutionalization, and marketing processes of particular cultures and literatures that overcome the nation-state paradigm. This book does not understand Hispanic and Lusophone institutionalization processes as homogeneous phenomena; indeed, it aims to shed light on points of regional coincidence and divergence among its various manifestations. With awareness of the functional overlap between Hispanic and Lusophone mediators (contacts, exchanges, collaboration), the book also explores the role of Portuguese and Brazilian mediators and their networks as a point of reference and contrast (see Fernandes and Pumar). The comparison between Spain, Portugal, and Latin America and the idea of considering them as a relatively coherent constellation promotes the evaluation of intra- and international networks and test geographical concepts that show different channels of transfer in the migration of people, ideas, and texts. The Hispanic and Lusophone cases highlight how interest in intercultural aspects supported the construction of national identities (Thiesse 1999), offering a unique account of the crucial role of networks, cultural transfer (Espagne \& Werner 1987; Espagne 2013), and cultural mediators (Roig-Sanz \& Meylaerts 2018; 


\section{Diana Roig-Sanz and Jaume Subirana}

Meylaerts, Gonne, Lobes \& Roig-Sanz 2016) in the internationalization and institutionalization of a particular cultural field (Subirana 2018).

\section{Systems, Fields, Networks and Institutions}

Insofar as there is a basic distinction by Itamar Even-Zohar $(2002,2005)$ between culture understood as goods and culture understood as tools, we are ready to notice, first, that the cumulative, treasured, and measured goods and the possession of objects within a culture often grant status as much as wealth and, secondly, that tools as sets of instruments within a culture serve the purpose of better organizing individual and especially collective life, for example, making it more comfortable and effective. Thus, the study of literature (historically) has mainly focused on the analysis and evaluation of written works seen as assets of the author (to whom we grant, let's not forget, the right of legacy over them), while it has also been instrumental in organizing the collective heritage of the writer's community. In addition to the view of works as goods, the other great academic focus of the study of literature has traditionally illuminated the life and role of individuals (novelists, storytellers, playwrights, or poets). This is why, by convention and tradition, is commonly understood that literature consists of books, on the one hand, and, on the other, of their authors. Only secondarily (and from Russian formalism onwards) has it been assumed that literature, as Claudio Guillén (1971) states, builds up "systems"; that is to say, it manifests itself in the form of a "system" or a "literary field", as stated by Pierre Bourdieu $(1979,1992)$ and field theory.

Indeed, we have only recently supplemented the more conventional view with a new perspective that allows us to assess and value how "tools" may have contributed to organize literature understood as a network, that is, as a set of activities, figures, and relationships: we refer to publishing houses and literary series; journals, magazines, and newspapers; literary prizes and awards; public cultural activities; institutions; literary criticism; literary translation and literary translators; the teaching of literature; the study of readers; and so on. In a different vein, the actor network theory (Latour \& Woolgar 1986; Latour 1987) also reminds us the traditional struggle between agency and structure and how networks are built on shifting and dynamic relationships.

Certainly, the fields of international relations and global history are evolving considerably, and literary scholars and cultural historians have become familiar with new theoretical perspectives that come from other disciplines: sociology, anthropology, cultural studies, and global history. However, many of these works seem particularly inclined to theoretical and methodological reflections, and they are less involved in exploring case studies or, when they do, they prefer to focus on major institutions and large centers of cultural production, a particular case, geography, and 
period, or, in the case of literature, on major figures (mainly writers) and those considered more central literatures. The debate over terminology and the fact that concepts such as "network" or "institution" have traveled across many disciplines also leads to discussion of how these terms overcome conceptual discrepancies or how can we accurately use them applied to our field of study. The term "institution" has been widely used in sociology, political and economic science, and law, and it has been mainly related to a dynamic understanding of how society is organized (that is, how we institutionalize or establish norms; see Carbó Catalan forth.). Another meaning of "institution" refers to a static conception of the term that has to do with fixed social relations, actions, behaviors, beliefs, and values (Guéry 2003). Finally, "institution" has often been used as an equivalent of "organization". As Hatch puts it, institutions are "powerful influences on behavior and important mechanisms of civilization and society" $(2011,56)$. We should also distinguish between "institution" and "organization" because not all "institutions" are "organizations", but all "organizations" seem to be "institutions" (Hodgson 2006). Ménard (1995) also distinguishes between "institution", "a longstanding historically determined set of stable, abstract and impersonal rules, crystallized in traditions, customs, or laws, to implement and enforce patterns of behavior governing the relationships between separate social constituencies", and "organization", which he defines as "an institutional arrangement designed to make possible the conscious and deliberate coordination of activities within identifiable boundaries, in which members associate on a regular basis through a set of implicit and explicit agreements, commit themselves to collective actions for the purpose of creating and allocating resources and capabilities by a combination of command and cooperation" (see Carbó Catalan forth.) In that respect, the importance of literary and cultural organizations has been little recognized in the making of the Spanish and Portuguese literary "systems" and "fields". Indeed, current literature does not go far beyond the view of books and authors, and much is lacking in literary studies regarding the analysis of "organizations" (entities, institutions, clubs), ${ }^{2}$ both public and private, more or less formal, and more or less stable over time. Institutionalization has also built on four main axes: 1) teaching and education at the undergraduate, masters, and doctoral levels; 2) research institutes; 3) journals; and 4) professional organizations, networks, associations, and conferences (Rotger, Roig-Sanz \& Puxán Oliva 2019), the latter being at the core of this book.

Likewise, many studies on cultural diplomacy and "soft power" have mainly focused on unilateral actions and bilateral cultural agreements (Haigh 1974; Northedge 1953, 1986), but multinational and cultural cooperation has a specific history and impact across boundaries and states (Renoliet 1999; Pernet 2007; Dumont 2008; Grandjean \& Van Leeuwen 2018) that has been overshadowed. Literature on cultural and 


\section{0}

international organizations has also privileged the narrative of their historical development (Laqua, Van Acker \& Verbruggen 2018), and, as mentioned previously, it has often focused on the role of major multinational and non-governmental institutions such as the International Telegraph Union or General Postal Union at the end of the 19th century. Literature has also retained the role of major figures in important centers and channels of cultural production (London, Paris, Vienna, or New York). However, other regions, cities, and localities also played important roles in the organization of congresses and in the development of important forms of intellectual cooperation, for example, the case of the first conference of the American Commissions of the International Institute of Intellectual Cooperation, which took place in Santiago, Chile, in 1939 or the First Conference of Argentinean Publishers and Printers in 1938 (Giuliani 2018). In a similar vein, we also know very little about the international relations and roles of other key secondary actors. Thus, this book offers insights into an under-analyzed body of actors, branches, and committees of international organizations such as PEN International and the International Institute of Intellectual Cooperation, which promoted institutional networks and intercultural transfer in less-studied settings such as Buenos Aires, Sao Paulo, Mexico D.F., Havana, Santiago de Chile, Barcelona, Madrid, Lisbon, or Dubrovnik. We aim to transcend traditional geographic and linguistic frontiers and take comparative case studies at a large scale to convey agency, individual and collective histories, events, and locality within a global perspective.

We also argue against a standard (and Western) model and look at a broad and changing geography in the analysis of institutionalization processes by stressing the experience of less-studied cases from Spanish America, Brazil, Spain, and Portugal and non-state languages such as Catalan. By drawing on the activities of cultural organizations and mediators, topics still insufficiently addressed, we are able to corroborate (or not) prevailing conceptions regarding ethnicity (white), class (middle and upper), age (young in the case of the Catalan PEN, older in the case of the Spanish PEN), gender issues (the contribution of women in institutional networks or cultures: the Chilean Gabriela Mistral, the Argentinians Victoria Ocampo and Norah Lange, the Catalan Isabel Llorach), the role of less central languages (for example, Portuguese and Catalan), and genres and topics (for example, the circulation of specific themes in correspondences or the reference to specific movements or specific issues such as humanism or pacifism).

Finally, the study of institutionalization processes must take into account influential factors such as the cultural and the social but also the economical and the political. For example, the institutionalization of cultural policies in Portugal was related to Modernism and avant-garde, as well as to Estado Novo and Salazar's dictatorship (see Fernandes in this book), and the same goes for Brazil during the so-called Estado 
Novo promoted by Getúlio Vargas. Likewise, the condemnation of the Nazi regime and the book burnings in Germany, as well as the case of Ernst Toller, founder of the German PEN in exile, were at the core of the intrigues and discussions at the 1933 Dubrovnik PEN Congress (see Škrabec). And one of the debates of the PEN congress held in Barcelona in 1935 focused on whether action should be taken to persuade the Haitian government to reconsider the case of imprisoned Haitian writer Jacques Roumain (see Rachel Potter in this book). In a similar vein, the power relations between Latin America, Europe, and the United States were also key issues in the shaping of Ibero-American institutionalization processes. For example, the absence of English-speaking writers at the meeting of the International Institute of Intellectual Cooperation in Buenos Aires in 1936 was understood as a new proof of the United States being the cradle of the utilitarian and materialist Caliban and an opportunity for Latin America to break with an historical relationship of domination that would allow it to recover national sovereignty (see Laura Fólica and Ventsislav Ikoff in this book).

Thus, this volume aims at including issues that have not been sufficiently addressed from a literary perspective, such as the analysis of literature in relation to human rights or materials closely related to the history of international cultural organizations that have been traditionally ignored in literary studies. Indeed, many literary scholars have mostly used literary or literary historical texts, but we still know very little about other materials (for example, letters or institutional documents) that will clearly help to recognize the role and impact of Ibero-American mediators in institutional, intercultural, and multilingual networks. By tracing how Ibero-American mediators fully participated in the first waves of institutional development and took an active part in institutional and multilingual networks, the book will also decenter world literary history and will prove how transnational cultural processes affected various places simultaneously.

\section{Agents and Cultural Organizations: Towards a Network and Cultural Mediation Approach}

As stated, Cultural Organizations, Networks and Mediators in Contemporary Ibero-America offers the reader a wide spectrum of examples that aim to analyze the institutionalization of Ibero-American cultures through the international and intercultural networks that key cultural mediators succeeded in building via their participation in international cultural organizations. The book stresses cultural interchanges, cultural movements, and multi-stranded connections through "soft power" across borders, nations, regions, and continents and focuses less on discursive products and more on the reality and materiality of institutional mediating practices and individuals: their active part in transferring cultural 


\section{Diana Roig-Sanz and Jaume Subirana}

products into another culture or their role in transnational and transregional networks. For example, Hermon Ould, Secretary of English and International PEN from the beginnings until his death in 1951, was a key actor who succeeded in connecting the Catalan writer Francesc Trabal in his exile in Chili and the Chilean writers with the tragic fate of Benjamin Crémieux, General Secretary of the French PEN killed in Buchenwald (Llopis \& Subirana 2018). Thus, examples such as the ones included in this book open up novel lines of inquiry regarding their impact in these institutional networks of culture until the Second World War and highlight the, until now, largely ignored role of Ibero-American cultures in the first waves of institutional developments. Spanning a large geographical scale, we aim to shed light on conceptual and methodological issues to deal with the analysis of cultural international organizations from a network and cultural mediation approach, as well as to offer both unexplored figures and overshadowed scales in their relations to the wider world to demonstrate the impact and prominent role of Ibero-American cultural mediators, who were part of a transnational, multilingual, highly connected, and mobile elite. Following these central themes, this collective volume proceeds in three parts.

The first part of this book sets the grounds for a new approach exploring transnational organizations and cultural mediators as key figures in cultural and institutionalization processes from a global perspective. The French historian Christophe Charle proposes an innovative and inspiring hierarchy of three different forms of intellectual organization: official, semi-official, and indirect, where the mobility of students is highlighted. The mobility of students is an aspect that this book does not analyze in depth but that has certainly played a role. Just to give some examples (which are not included in this book), the Student Exchange program established by the Junta para la Ampliación de Estudios, in Madrid, and other financial aid established by the Mexican, Argentinean, and Catalan governments enabled writers and intellectuals to travel abroad. That is the case, for example, of the Catalan Manuel de Montoliu and the Argentinean Carlos Astrada, who traveled to Germany, or the case of the Mexican Jaime Torres Bodet, a key figure for Mexican educational institutions (see Mauricio Zabalgoitia in Part 3). The chapter by Christophe Charle also illustrates a fruitful cross-pollination of exchanges of ideas in some of the meetings organized by the International Institute of Intellectual Cooperation and the League of Nations, such as Frankfurt 1932 and Madrid 1933.

Reine Meylaerts, on her side, deploys thrilling theoretical, and methodological frameworks such as those proposed by complexity theory (Marais 2015; Marais \& Meylaerts 2018) or her invigorating remarks about how to conceptualize a cultural mediator through different examples in the Belgian cultural field (Meylaerts, Gonne, Lobes \& Roig-Sanz 2016; Roig-Sanz \& Meylaerts 2018). Meylaerts discusses polysystem 
theory, descriptive translation studies, and translation sociology as dominant models to analyze cultural transfer and cultural interaction and suggests an epistemology of complexity to identify and interpret systems and processes that lack order and stability to produce universal rules about behavior and outcomes. This view is particularly inspiring for a network approach, as the simplicity paradigm allows us to analyze parts and wholes, but it does not go in depth in the interrelationships between "parts and parts" and "parts and wholes". In that respect, we are also interested in reviewing existing theoretical frameworks on the notion of the "network" as a metaphor but also as a research approach (Grandjean 2014) in order to advance on its application within global and cultural history, as well as literary studies. Within this framework, the chapter by Mauricio Zabalgoitia (Part 3) introduces an interesting variation of the network's metaphor, that of conceptual flows, which he calls transcultural flows.

The second part focuses on the analysis of congresses and meetings organized by the Committee on Intellectual Cooperation of the League of Nations, in the case of Martin Grandjean's chapter, and International PEN: Dubrovnik, in the case of Simona Škrabec; Barcelona, by Rachel Potter; and Buenos Aires, by Alejandra Giuliani, as well as the chapter by Gabriella Gavagnin on less-known cultural organizations such as Conferentia Club, held in Barcelona between 1929 and 1936 for a bourgeois feminine audience. Gavagnin sheds light on one of these not sufficiently well-known women, Isabel Llorach, and also analyzes the internationalization of independent institutions such as the Conferentia Club, which deployed an incredibly intense and invigorating program of international lectures. The chapters by Simona Škrabec and Alejandra Giuliani explore, respectively, the crucial Dubrovnik PEN Congress in 1933 and the international network of connections between Yugoslavia's leftist intellectuals and the fundamental meeting of the Institute of Intellectual Cooperation held in Buenos Aires in 1936, which aimed to reinforce relations between Europe and the Americas and which coincided with the XIV Congress of International PEN. Both chapters also allow us to have a better understanding of the role of cultural mediators such as the Slovenian Izidor Cankar (see Škrabec) and the Dominican Pedro Henríquez Ureña (see Giuliani). The list of attendees in the case of Giuliani draws up a list of names that brought into play their symbolic capital and appear repeatedly throughout this book: for example, Alcides Arguedas (Bolivia), Alfonso Reyes (Mexico), Carlos Reyles (Uruguay), Enrique Díez Canedo, and Joan Estelrich (Spain and Catalonia, see Coll-Vinent in this book), or Fidelino de Figueiredo (see Fernandes).

On a methodological level, Martin Grandjean's chapter suggests three different forms of networks: that is, how agents organize themselves, who met whom, and the network of the documents. Within an impressive work in the archives, Grandjean shows that many were the voices that 


\section{4}

fostered international cooperation in all its forms and tried to integrate intellectual debates. Grandjean examines institutional documents such as the archives of the League of Nations, in Geneva, using digital tools that as he reminds us are means but not ends. In that respect, Cultural Organizations, Networks and Mediators in Contemporary Ibero-America also highlights the need to use digital tools and digital methods when examining a large corpus of data and institutional documents. Grandjean's and Ventsislav Ikoff's and Laura Fólica's contributions point to the discussion on how big data approaches (Meyer \& Schroeder 2015) and data mining, KDD, or data sharing (Borgman) made a splash in the humanities (Burnard) and the social sciences. Considering that big data approaches have scarcely been developed in Ibero-American academia overall, this approach will yield significant results in reframing networks and re-evaluating actors and influence. For example, Grandjean's chapter does not conclude that Ibero-America was globally represented in the International Committee on Intellectual Cooperation, and neither did Ibero-American mediators occupy high positions (the presidency or vice-presidency). However, the diplomatic conference held in Paris in 1938 already showed a different proportion: Western Europe only represented a quarter of all participants, and the largest group of diplomats and intellectuals came from Latin America (one-third). The Latin American delegation showed an increase in the diversity of actors and countries represented, and the Peruvian Francisco García Calderón was for the first time the fourth vice-president of the conference. Indeed, two important milestones were about to occur: the Pan-American Conference of Intellectual and Cultural Cooperation would take place in La Havana in November 1941, and the Inter-American Office would also be organized in Cuba in 1943.

Finally, the third part of the book presents some case studies on agents taking part in these institutional networks of culture. Thus, we have a better understanding of the role of cultural mediators such as the Guatemalan Enrique Gómez Carrillo and the Argentinians Victoria Ocampo and Antonio Aita (see Fólica and Ikoff); the Spanish Júlio Casares, Blas Cabrera, Leonardo Torres y Quevedo, José María Quiñones de León, and José Castillejo, as well as the Catalan Joan Estelrich (see Coll-Vinent); the Spanish Ramón Gómez de la Serna (see Laget); the Portuguese António Ferro, Júlio Dantas, and Fidelino de Figueiredo (see Fernandes); the Mexican Jaime Torres Bodet (see Zabalgoitia); or the Brazilians Miguel Ozório de Almeida (see Pumar) and Aloysio de Castro (see Grandjean in Part 2).

The analysis of their profiles and habitus results in a majority of nationalist intellectuals, as well as a proportion of leftist writers who expanded their networks abroad: to the Atlantic space, as well as Europe and the United states. The chapter by Sílvia Coll-Vinent shows how nationalistic purposes were at the core of the Catalan Joan Estelrich, who 
had received a twofold mission: on the one hand to disseminate Catalan culture abroad in the framework of the Spanish Primo de Rivera dictatorship and on the other to materialize a political national project. The chapter by Laurie-Anne Laget focuses on the figure of the international writer Ramón Gómez de la Serna and reminds us of the checkered history of the first Madrid PEN Club. Laget's and Coll-Vinent's chapters also show the struggles inside the Spanish literary field and two different models in the dynamics of the Spanish PEN and the Catalan one (see also Safont in this book and Subirana 2018). Laget also reviews the idea of "network" as an opportunity for Spanish writers to take part in the dynamics of cultural exchanges from an horizontal perspective, which would allow us to revise the traditional perception of Hispanic modernity as a peripheral one. In that respect, Laget understands Gómez de la Serna as a nodal point in a social network of Spanish and international contemporary writers, though the international purpose that was at the heart of the foundation of the Spanish PEN Club turned into national and local purposes, as the Spanish center was understood as a way of giving visibility to agents already dominant in the Spanish literary field instead of promoting new actors in the international cultural arena (see Laget).

Thus, whereas some cultural mediators advocated internationalism and universalistic aims (for example, the Argentinean group Sur led by Victoria Ocampo), others such as Antonio Aita (secretary of the Argentinean National Committee of the International Institute of Intellectual Cooperation) put forward Americanism and internationalism side by side (see Fólica \& Ikoff in this book); stressed the indigenous and AfroAmerican cultures of Latin America (see Enríquez Ureña in the chapter by Giuliani); or were involved in the debates on a temporary center for international cooperation in America, as was the case for the Brazilian Miguel Ozório de Almeida (see Pumar). Likewise, other intellectuals appropriated cultural organizations as powerful platforms for condemning Nazism or the restriction of freedoms (as in the case of Yugoslavia's writers; see Škrabec, or Haiti; see Potter). In any case, all of them participated in the cultural arena and played a prominent role in institutional and multilingual networks, helping them revitalize their local milieu. Indeed, many of these cultural mediators were also related to newspapers and journals, as in the case of the Portuguese António Ferro (the editor of Orpheu, 1915; see Fernandes in this book), the Catalan Joan Estelrich in La Veu de Catalunya (see Coll-Vinent), or the previously mentioned Victoria Ocampo and Sur (see Giuliani and Fólica and Ikoff). We also see major differences between national committees that were dependent on the state (such as Argentina and Brazil) and those that constituted an autonomous body (for example, the case of Chile).

Certainly, a cultural mediator approach can also shed light on lessknown cultural endeavors such as the Catalan PEN (see Joan Safont in this book), which became the third affiliation in the history of this 
worldwide association of writers (the English one was founded in 1921, the French in February 1922, and the Catalan in April 1922; see RoigSanz 2013; Subirana 2018). While Catalonia always undertook its own cultural projects apart from Spain, Catalan mediators played a leading role in the internationalization of the Hispanic field (see also Coll-Vinent). A year prior to the Spanish Civil War, PEN delegates from around the world attended the Barcelona PEN Congress. Hosted by Catalan writers, including the recently imprisoned and released Catalan linguist Pompeu Fabra, other delegates included International PEN President H. G. Wells; Italian F. T. Marinetti, who spoke in favor of a PEN global bureau of translations; Indian PEN President and theosophist Sophia Wadia, who received a standing ovation for her speech in favor of communication between Eastern and Western cultures; and German writer in exile Klaus Mann, who talked on behalf of Nazi victims (see also Škrabec's chapter for the 1933 Dubrovnik PEN Congress). Indeed, one of the main debates was centered on PEN's role as a worldwide organization devoted to the defense and protection of the rights of authors to freedom of expression. This is an old discussion: as John Ralston Saul, former PEN international president (2009-2015), puts it, "when I arrived people were still arguing about whether we are a literary organisation or a freedom for expression organisation. From the beginning I said this is an irrelevant argument. These are the same thing. You can't have one without the other" (Ralston Saul 2018).

In that respect, our book examines how these agents and agencies (institutions and events), and these old debates, renegotiated and renegotiate hierarchies both within and among cultures. The chapter by Laura Fólica and Ventsislav Ikoff rethinks the relationship between Latin American mediators with the Old Continent, as well as the sympathies and tensions with both North and South America and their indigenous and Afro-American origins. They also analyze how Latin America was perceived by their European colleagues. Specifically, they trace the trajectory by the Guatemalan Enrique Gómez Carrillo and Antonio Aita, both representatives of the Argentinean National Committee. Finally, the chapter by Letícia Pumar describes how the Brazilian Miguel Ozório de Almeida helped establish a center for international cooperation in the Americas when the activities of the Paris Institute ended. Ozório de Almeida was a member of both the International Institute of Intellectual Cooperation and the International Commission of Intellectual Cooperation. Within the aim of renegotiating old hierarchies, Ozório de Almeida criticized at UNESCO the idea of cooperation as assistance rather than mutual support between intellectuals and scientists from all over the world (see Pumar).

This book therefore gives voice to scarcely known agents and agencies, and it also reveals how these institutions played a role in shaping international literary and cultural exchanges. We are interested in providing a network and cultural mediation approach for the study of cultural 
organizations from a supranational perspective. A network approach can also hint at different clusters of male and women who are closely related, or not. In that respect, the chapter by Mauricio Zabalgoitia shows how homosociability, in the case of the diplomat Jaime Torres Bodet, is shaped from the Colonial through the Porfiriato and also represents the building of the national unification process. At the same time, we see how Torres Bodet builds himself as a "modern male" after his residencies in Madrid, Paris, Brussels, The Hague, and Buenos Aires, which allows us to examine intercultural actors and cultural organizations and institutions as part of a transnational and highly connected space. Indeed, we are convinced that a transnational approach and the analysis of mediators, understood here as actors shaping regional, transregional, national, and transnational literatures, are vital tools for unraveling the still-unexplored implications that derive from the vast movement of people in an interconnected world.

However, we still have some challenges ahead: from a theoretical and methodological perspective, it would be good to advance in some of the conceptual issues that this book raises: for instance, we still need to agree on the different meanings of "institution" and "organization" applied to cultural history and literary studies. These terms are often vague and used simultaneously or as equivalents. In that respect, we also have to clarify the way in which we study literature in relation to "international institutions" and "cultural organizations", literature in relation to "human rights", or, more specifically, the discussion about the profile of these institutions. We should also verify the mediator's profile and corroborate (or not) those prevailing conceptions previously mentioned regarding ethnicity, class, age, gender issues (we are now aware of Gabriela Mistral, Victoria Ocampo, Norah Lange, and Isabel Llorach, but there were other women, and it's urgent to shed light on them), the role of less central languages (for example, Catalan and Portuguese), and genres (the circulation of poetry and theatre vs. the novel or the circulation of specific topics in the correspondences we could analyze: the mention of specific movements or specific themes such as humanism or pacifism).

From a conceptual point of view, the book also sheds light on inspiring conceptual frameworks such as those proposed by Rachel Potter in relation to an "international literary public space" and "multiple networks and maps". This notion of "multiple networks" includes a wide range of connections that compose political networks, human rights networks, conceptual networks, and linguistic maps, in which many of the IberoAmerican mediators could be included (for example, the Bolivian Alcides Arguedas), but much work can be still done. Another huge challenge is to reconstruct the history of institutionalization processes and cultural organizations when data is missing or when archives are non-existing, as in the case of the Croatian PEN Club (see Škrabec).

Finally, the contributions gathered in this book show the connections between one mediator and another and the networks they succeeded in building and offer accurate knowledge on the international 


\section{8}

Diana Roig-Sanz and Jaume Subirana

and intercultural networks that were established. However, new social and institutional connections between Southern Europe and nations of the Global South (Latin American countries, in our case) and accurate accounts of exchange, circulation, and multidirectional flows are a few of the challenges awaiting the field. Likewise, the crossings between the PEN Club and the International Institute of Intellectual Cooperation, as well as with other local institutes and organizations within an international scope (such as Conferentia Club; see Gavagnin) or private initiatives such as the support given by the Guggenheim Foundation or the Rockefeller Foundation (see Pumar in this book) also deserve further research. This collective volume is a step forward, but there is still much work to be done.

\section{Conclusions}

Cultural Organizations, Networks and Mediators in Contemporary IberoAmerica analyzes the role of Spanish, Catalan, Portuguese, and Latin American cultural mediators in the institutionalization of Hispanic and Lusophone cultures in the early 20th century by means of institutional networks such as PEN International and the different PEN centers and the International Institute of Intellectual Cooperation (the former UNESCO). As mentioned previously, we have defined institutionalization as 1) the emergence of the first cultural policies for the standardization of the cultural field and 2) the inclusion of Hispanic writers and intellectuals in an institutional and transnational cultural network. This book helps revise the traditionally peripheral position of Hispanic and Lusophone modernity in existing bibliography and demonstrates that Hispanic and Lusophone mediators not only took part on the international cultural arena but played a crucial role in the multilingual and intercultural networks of the time. In that respect, we map the intellectual sociability of a group of mediators through their contribution in international organizations, conferences, and associations and study how the mobility of these agents mostly functioned as a shared transnational space for both the institutionalization of culture, the dissemination of the various cultural and political national projects, and the increasing cosmopolitanism of the Hispanic and Lusophone field. The book also provides an analysis of the crossings between the International Institute of Intellectual Cooperation and PEN International, the worldwide writer's association. This is work that had not been undertaken and sheds light on the crossings of two of the most important international cultural organizations of the time.

In short, this book provides more knowledge on intellectual organization (Charle) and new theoretical frameworks (Meylaerts) to understand cultural interaction and cultural transfer and focuses on the international and intercultural networks that were established and on how these networks were built from a twofold perspective: that of the congresses 
and meetings organized by PEN (for example, Dubrovnik, in the case of Simona Škrabec; Barcelona, by Rachel Potter; and Buenos Aires, by Alejandra Giuliani) and by the International Committee of Intellectual Cooperation (Grandjean), and a second approach focused in case studies: the Argentinians Victoria Ocampo (Giuliani) and Antonio Aita (Fólica and Ikoff) and the Dominican Pedro Enríquez Ureña (Giuliani); the Guatemalan Enrique Gómez Carrillo (Fólica and Ikoff); the Catalan Joan Estelrich (Coll-Vinent); the Spanish Ramón Gómez de la Serna (Laget); the Portuguese António Ferro, Júlio Dantas, and Fidelino de Figueiredo (Fernandes); the Mexican Jaime Torres Bodet (Zabalgoitia); and the Brazilian Miguel Ozório de Almeida (Pumar). The book also has a focus on the internationalization of specific institutions, such as the Conferentia Club, in the chapter by Gabriella Gavagnin, or Joan Safont in the case of the Catalan PEN.

Also, we discuss some theoretical and methodological reflections and review existing theoretical frameworks on the notion of the "network" as a metaphor but also as a research approach. We think that we advance in this task and we may now integrate in our object of study interesting theoretical and methodological frameworks such as those proposed by Reine Meylaerts (the complexity theory) or her inspiring remarks about how to conceptualize a cultural mediator through the different examples she gave on the Belgian literary field. The chapter by Rachel Potter also made us think in this "international literary public space" and in other potential networks and maps already underlined: political networks, linguistic maps, and human rights networks, in which we can include some relevant agents (for instance, Alcides Arguedas; see Giuliani).

To sum up, this book is aimed at scholars working in a wide range of fields: international relations, cultural and postcolonial studies, global and cultural history, sociology of culture, anthropology, literary studies, world literature and comparative literature, and, of course, new Hispanisms. It is aimed at postgraduates, researchers, and academics rather than undergraduate students and will sell primarily to the international academic library market, though it might also be an engaging read for a wide-ranging audience (professional writers among it). The topic has an international appeal and does not assume a great amount of prior (specialist) knowledge. The focus on social and cultural networks and connections between agents and agencies from Latin America and Southern Europe and accurate accounts of exchange, circulation, and multidirectional flows in less studied settings can certainly draw the attention of Latin American scholars and Western scholars working in those fields, but it may also be of great interest for Asian and African scholars working in similar case studies and fields. As said, the investigation on how cultural practices overcome traditional geographic and linguistic barriers and flow across the world is nowadays a stimulating area of research, so 
we anticipate that this book will be of great interest considering its interdisciplinary character: international relations and organizations, literary studies and world literature, transfer studies, sociology, cultural history, global studies, or history of diplomacy. We have gathered a list of top scholars who are diverse in terms of their affiliations and geographical origins (United Kingdom, Canada, France, Belgium, Switzerland, Bulgaria, Slovenia, Spain, Portugal, Italy, Argentina, Brazil, and Mexico) and who have published widely from a global perspective in their own disciplines.

The editors wish to thank all authors for their contributions to the volume, and Laura Fólica, Gabriella Gavagnin, Víctor Martínez-Gil, and Ventsislav Ikoff for their strong commitment to the original research project that formed the basis of this book. We would also like to thank some institutions that have been crucial for the funding of this research: specifically, the Spanish Ministerio de Economía; Industria y Competitividad, which founded the $\mathrm{R}+\mathrm{D}$ project "Mapping Hispanic modernity. Cross-border Literary Networks and Cultural Mediators (1908-1939)" (FFI2016-76055-P); the program Internationalization at Home "La Caixa"; and the Arts and Humanities Department at UOC. Special thanks should also be given to our publisher, Routledge, and to Max Novick, for his interest, openness, and patience. Audaces fortuna iuvat.

\section{Notes}

1. We take this expression from Paul Valéry, who understood Europe as a space lacking a 'Politics of Spirit', in the sense that nations and individuals were only focused on their own interests.

2. A brief historical note. The first organization of modern writers that we have proof of (before there were, for example, the baroque academies) was the "Société des gens de lettres de France", founded in 1838, inspired by Honoré de Balzac and formed by 24 writers, including Balzac, Victor Hugo, Alejandro Dumas, Théophile Gautier, or George Sand, and declared of Public Utility in France as early as 1891 . After that, and falling closer to what we understand today as an association of writers, a number of Nordic organizations were founded: the Den norske Forfatterforening, DnF (Association of Writers of Norway) in 1893, or the Suomen Kirjailijaliitto (Union of Finnish Writers) in 1897. As already stated, we will have to wait until 1921 for the the first world writers organization to be launched in London: the PEN Club.

\section{Bibliography}

Borgman, Christine. L. 2007. Scholarship in the Digital Age: Information, Infrastructure, and the Internet. Cambridge, MA and London: The MIT Press.

Bourdieu, Pierre. 1979. La Distinction. Paris: Seuil.

Bourdieu, Pierre. 1992. Les Règles de l'Art. Paris: Seuil.

Burnard, Lou. 2013. 'The Evolution of the Text Encoding Initiative: From Research Project to Research Infrastructure', Journal of the Text Encoding Initiative [online], (5), June. http://jtei.revues.org/811; DOI: 10.4000/jtei.811. 
Carbó Catalan, Elisabet. forthcoming. Cultural Institutions and Intellectual Networks: Between Cultural and Political Action in Iberoamerica, doctoral thesis. Barcelona: Universitat Oberta de Catalunya.

Dumont, Juliette. 2008. L'institut International de Coopération Intellectuelle et Le Brésil (1924-1946): Le Pari de La Diplomatie Culturelle. Collection Chrysalides, no. 4. Paris: IHEAL-CREDAL.

Espagne, Michel. 2013. 'La notion de transfert culturel', Revue Sciences/Lettres [en ligne], 1 mis en ligne le 01 mai 2012, consulté le 05 août 2019. http://jour nals.openedition.org/rsl/219; DOI: 10.4000/rsl.219.

Espagne, Michel and Werner, Michael. 1987. 'La construction d'une référence culturelle allemande en France: Genèse et histoire (1750-1914)', Annales, 4, juillet-août, 969-992.

Even-Zohar, Itamar. 2002. 'Literature as Goods, Literature as Tools', Neobelicon, 29(1), 75-83. http://itamar.even-zohar.com/papers/lit-as-goods.htm.

Even-Zohar, Itamar. 2005. Papers in Culture Research. Tel Aviv: Tel Aviv University. Gadea, Carlos A. 2007. 'La Dinámica de la Modernidad en América Latina: Sociabilidades e institucionalización', Revista Austral de Ciencias Sociales, 13, $55-67$.

Gargatagli, Ana. 2013. 'El primer Ulises español: cinco reflexiones', 1611 A Journal of Translation, History 7. www.traduccionliteraria.org/1611/art/gargata gli3.htm.

Giuliani, Alejandra. 2018. Editores y Política. Entre el mercado latinoamericano de libros y el primer peronismo (1938-1955). Temperley: Tren en Movimiento.

Grandjean, Martin. 2014. 'La connaissance est un réseau: perspective sur l'organisation archivistique et encyclopédique', Les Cahiers du numérique, 10(3), 37-54. https://doi.org/10.14647/87204.

Grandjean, Martin. 2018. Les réseaux de la coopération intellectuelle. La Société des Nations comme actrice des échanges scientifiques et culturels dans l'entredeux-guerres'. Lausanne: Université de Lausanne.

Grandjean, Martin and Van Leeuwen, Marco. 2019. 'Mapping Internationalism: Congresses and Organisations in the Nineteenth and Twentieth Centuries', In International Organizations and Global Civil Society: Histories of the Union of International Associations, edited by Daniel Laqua, Wouter Van Acker, and Christophe Verbruggen. London: Bloomsbury, 225-242.

Griffith, Roger. 2007. Modernism and Fascism. London and New York: Palgrave MacMillan.

Guéry, Alain. 2003. 'Institution: Histoire d'une notion et de ses utilisations dans l'histoire avant les institutionnalismes', Cahiers d'économie politique, 44, 7-18.

Guillén, Claudio. 1971. Literature as System: Essays Toward the Theory of Literary History. Princeton: Princeton University Press.

Haigh, Anthony. 1974. Cultural Diplomacy in Europe. Strasbourg: Council of Europe.

Hatch, Mary Jo. 2011. Organizations: A Very Short Introduction. Oxford: Oxford University Press.

Hodgson, Geoffrey Martin. 2006. 'What are institutions?', Journal of Economic Issues, 40(1), 2-4.

Jameson, Fredric. 1998. The Cultural Turn: Selected Writings on the Postmodern. London: Verso.

Jameson, Fredric. 2002. A Singular Modernity. London: Verso. 


\section{Diana Roig-Sanz and Jaume Subirana}

Laqua, Daniel, Van Acker, Wouter and Verbruggen, Christophe. 2019. Organizations and Global Civil Society: Histories of the Union of International Organizations and Associations. London: Bloomsbury.

Latour, Bruno. 1987. Science in Action: How to Follow Scientists and Engineers through Society. Cambridge, MA: Harvard University Press.

Latour, Bruno and Woolgar, Steve. 1986 [1979]. Laboratory Life: The Construction of Scientific Facts. Princeton, NJ: Princeton University Press.

Llopis, Moisès and Subirana, Jaume. 2018. 'Francesc Trabal a Xile: activisme cultural trasplantat', Els Marges, 115, 49-74.

Marais, Kobus. 2015. Translation Theory and Development Studies: A Complexity Theory Approach. New York: Routledge.

Marais, Kobus and Meylaerts, Reine. 2018. Complexity Thinking in Translation Studies: Methodological Considerations. Milton: Routledge.

Ménard, Claude. 1995. 'Markets as Institutions versus Organizations as Markets', Journal of Economic Behavior and Organization, 28, 161-182.

Meyer, Eric T. and Schroeder, Ralph. 2015. Knowledge Machines: Digital Transformations of the Sciences and Humanities. Cambridge, MA: The MIT Press.

Meylaerts, Reine, Gonne, Maud, Lobes, Tessa and Roig-Sanz, Diana. 2016. 'Cultural Mediators in Cultural History: What Do We Learn from Studying Mediators' Complex Transfer Activities in Interwar Belgium', In The Circulation of Dutch Literature, edited by Elke Brems, O. Réthelyi, and Tom Van Kalmthout. Leuven: Leuven University Press.

Northedge, Frederick Samuel. 1953. International Intellectual Co-Operation Within the League of Nations: Its Conceptual Basis and Lessons for the Present. London: University of London.

Northedge, Frederick Samuel. 1986. The League of Nations: Its Life and Times, 1920-1946. Leicester: Leicester University Press.

Pernet, Corinne. 2007. 'Culture as Policy: Cultural Exchanges Between Europe and Latin America in the Interwar Period', Puente@Europa, 5(3/4), 121-126.

Ralston Saul, John. 2018. 'John Ralston Saul Interview', Writersfreeexpression. com. https://writersandfreeexpression.com/2018/10/16/john-ralston-saul-inter view-part-one-we-can-get-every-nobel-prize-winner-in-the-world-to-stand-upfor-either-carlos-fuentes-or-for-that-part-time-journalist-thats-how-we-work/ Accessed August 4, 2019.

Renoliet, Jean-Jacques. 1999. L'UNESCO Oubliée, La Société Des Nations et La Coopération Intellectuelle (1919-1946). Paris: Publications de la Sorbonne.

Roig-Sanz, Diana. 2013. 'Dues fites en la col-laboració catalana a l'IICI, la UNESCO i el PEN Club Internacional (1927 i 1959)', In Lectures dels anys cinquanta, edited by Enric Gallén and José Francisco Ruiz Casanova. Lleida: Punctum, 155-189.

Roig-Sanz, Diana. 2019. 'The International Institute of Intellectual Cooperation: Translation Policies in the Interwar Period (1925-1946)', In Routledge Handbook of Translation History, edited by Christopher Rundle. London: Routledge.

Roig-Sanz, Diana and Meylaerts, Reine. 2018. Literary Translation and Cultural Mediators in Peripheral Cultures: Customs Officers or Smugglers? London and New York: Palgrave MacMillan.

Rotger, Neus, Roig-Sanz, Diana and Puxán-Oliva, Marta. 2019. 'Towards a Cross-Disciplinary History of the Global in the Humanities and the Social 
Sciences', Introduction to the Special Issue Historicizing the Global: An Interdisciplinary Perspective. Journal of Global History, 14(3).

Sapiro, Gisèle, Brun, Eric and Fordant, Clarisse. 2019. 'The Rise of the Social Sciences and Humanities in France: Institutionalization, Professionalization, and Autonomization', In Shaping Human Science Disciplines: Institutional Developments in Europe and Beyond, edited by Christian Fleck, Matthias Duller, and Victor Karady. London and New York: Palgrave MacMillan.

Subirana, Jaume. 2018. 'El PEN y la internacionalización de la literatura catalana', In Construir con palabras: escritores, literatura e identidad en Cataluña (1859-2019). Madrid: Cátedra, 155-178.

Thiesse, Anne-Marie. 1999. La création des identités nationales. Paris: Seuil.

Vimr, Ondrej. 2018. 'Early Institutionalised Promotion of Translation and the Socio-Biography of Emil Walter, Translator, Press Attaché and Diplomat', In Literary Translation and Cultural Mediators in 'Peripheral' Cultures: Customs Officers or Smugglers?, edited by Diana Roig-Sanz and Reine Meylaerts. London and New York: Palgrave. 


\title{
2 Rebuilding a Europe of Intellectuals (1918-1939)
}

\author{
Christophe Charle
}

At the outbreak of the war in August 1914, the vast majority of organized militant workers and intellectuals-even socialists-in France rallied with few exceptions behind the union sacrée in spite of the ideals of pacifism and republican universalism introduced in the nineteenth century. The nineteenth-century Europe of intellectuals, which was a cultural reality in many domains (the arts, science, and even literature), collapsed with the large-scale European conflict that seemed to ruin with long-lasting effect all European, universalist, and pacifist ideals inherited from the Enlightenment. The feeble voice of Romain Rolland and his pacifist manifesto, Au-dessus de la mêlée, and militant worker minorities who rejected the "treason" of internationalism by the labor movement and the Second International were all that remained of the pacifist legacy and ideals of the nineteenth century. Rolland, despite the "neutral" title of his book, in reality supported the Allied cause when he denounced the positions of writers such as Thomas Mann and Gerhart Hauptmann; in one chapter he advocated the Swiss confederation model to build a European confederation "which would be a fine example for the rest of Europe". ${ }^{1}$

Thomas Mann responded in articles that he would take up again in Reflections of a Nonpolitical Man (1918). In this essay, he denounced the "European spirit" embodied by Rolland: "If national democracies gathered to form a worldwide European democracy, nothing would remain of the German essence" (Reflections, 41). Thomas Mann was equally keen to settle the score with his own brother, Heinrich, who was himself convinced that the war would pave the way to European unification. ${ }^{2}$ These debates on the meaning of the history of Europe would reemerge as soon as the war was over.

\section{A New Europe of Intellectuals Between the Wars?}

The magnitude of the disaster caused by the world war; the sense of the "decline of Europe" - the title of a work published in 1920 by the geographer Albert Demangeon; or even that of the West-the title of a 
best-selling book by Oswald Spengler that appeared the same year; the fear of Bolshevism, which was equated with Asian barbarism; and the phobia of Americanization that was the obsession of certain French and German essayists rekindled arguments in favor of a reconciliation of intellectuals to rebuild lasting peace.

These reconciliations were either official, via bodies linked to the League of Nations (LN); semi-official, via associations or journals that campaigned for a new Europe in various countries; or indirect, via academic exchanges, which we will examine later on.

\section{Outline of an Official Intellectual Europe}

Some intellectuals (generally the oldest and most recognized) relied on the principles of President Wilson and the possibilities opened up by the establishment of the LN. The latter enlisted, in particular, a cultural organization dominated by great European intellectuals, the International Committee on Intellectual Cooperation, which was mainly populated by intellectuals from countries on the winning side. Following the Locarno Treaties and Germany's entry into the LN, it later opened up to figures from the defeated nations. The Committee thus in fact embodied an international intellectual directory dominated by Europeans (between three quarters and two thirds depending on the year). ${ }^{3}$ Outside this elitewhich included Henri Bergson, Marie Curie, Paul Valéry, Paul Painlevé, and Edouard Herriot on the French side; the physics Nobel laureate Hendrik Lorentz and historian Johan Huizinga from the Netherlands; Albert Einstein, another Nobel Prize laureate, from Germany; and Hellenist Gilbert Murray from Great Britain-there were also, in various European countries, associations that supported the LN, which primarily recruited from left-wing or pacifist intellectual circles.

Others believed it necessary to go further than this model based on the parliamentary system of nations or diplomatic procedures and that Europe must be organized according to a long-term federal model.

\section{Pro-European Movements}

Among the groups promoting this project, of which the Briand project (1929-30) was an implementation attempt, the best-known and most lasting was the Paneuropean Movement: Paneuropa was the title of the manifesto of the Count of Coudenhove-Kalergi, who came from the diplomatic milieu and the aristocracy of central Europe.

The work was published in Vienna in 1923, and it too started from the premise of a European decline in the face of powers outside Europe: "Can Europe, in its political and economic fragmentation, guarantee peace and independence in view of the rapidly growing non-European world powers?" 4 
This movement was clearly part of a defensive and conservative vision of Europe. It adopted the symbol of a red cross on a yellow background surrounded by an area of blue. The cross evoked Europe's first conquering movement-the crusades: the yellow background symbolizing the light of reason (therefore the Enlightenment or civilization) that would bring about Europe by essence. The Paneuropean project was limited to the continent in the strictest sense, challenging the inclusion of the British Empire and the Soviet Union, the former for being outside Europe, the latter for having abandoned democracy. ${ }^{5}$ The Franco-German reconciliation, which the Locarno Treaties and then the Briand project of 1929 attempted to implement, would therefore be key.

A well-known German intellectual at the time, Maximilien Harden, who edited the magazine Die Zukunft, published a book the same year containing similar ideas about reconciling the major powers: Deutschland, Frankreich, England (Berlin: Erich Reiss Verlag, 1923); it was primarily concerned with economics from the perspective of competition with the rest of the world. Great Britain was considered non-Europeanas it had been by Coudenhove-Kalergi-and accused of overburdening Germany with reparations while not having undergone the devastation France had. ${ }^{6}$

Another pro-European intellectual, Kurt Hiller, promoted similar ideas. He criticized parliamentary democracy and proposed an aristocracy of the mind to guide democracy; he was head of the Das Ziel magazine, which Walter Benjamin, Otto Flake, Max Brod, and Heinrich Mann contributed to. Hiller advocated an alternative electoral system to blind universal suffrage. He envisaged the upper house being open to writers "in the widest sense of the term" but rejected any domination by German academics or journalists: the former since they were reactionary, the latter since they had no sense of responsibility. Hiller's ideas were also similar to those of Heinrich Mann, who in Geist und Tat (1910) assigned intellectuals the task of finding a mode of political action based on the mind. The same utopia of a government of "the best" can also be found in the thinking of Coudenhove-Kalergi. In each case, these European projects accompanied a highly elitist vision, even though they were new elites that were favored. ${ }^{7}$

The pacifist leagues generally united behind the LN, and it was only later that they showed an interest in the United States of Europe project. While many previous writers could lay claim to the idea, Paneuropa was chosen as the movement's slogan. The 1923 work ensured the success of the term as well as Coudenhove-Kalergi's ability to retain the monopoly in the long term. He relied on a whole backdrop of idealist philosophy and aligned with a new ethics to respond to the present moral crisis. He referred in particular to Goethe, Nietzsche, and Jean-Marie Guyau. In Goethe he saw the positive side of the Enlightenment, against Voltaire on the negative side. On a practical level, in 1923, he created the 
Paneuropean Union, which published a magazine that ran for 138 issues until 1938. The print run grew to 8,000 copies, with a smaller edition in French. However, more than half of the articles were written by the publication's founder, revealing the narrowness of its support network but also his authoritarianism. There were local unions in the main European countries, and the league benefited from the financial support of sponsors from the business community. But Coudenhove-Kalergi was very protective of its ideological autonomy. It remained a movement of elites from the upper echelons of society. Its focal point was primarily located in central Europe (Austria, Germany, Switzerland, Czechoslovakia), while in France, membership remained fairly low. Coudenhove-Kalergi attempted to influence important politician sympathizers, in particular Edouard Herriot and Aristide Briand.

The movement's first international congress took place in Vienna in 1926 and was preceded by a questionnaire sent to various figures, among German-speaking intellectual supporters were Thomas Mann, Franz Werfel, and the historian Emil Ludwig; some were rather affected by the bombastic narcissism of the organizer, who saw himself at the center of everything. The final program of nine points was shorter than in Coudenhove-Kalergi's book. ${ }^{8}$

There were other associations at the same time championing similar ideas, such as Prince Karl Anton von Rohan's Kulturbund or Verband für europäische Verstandigung (1926), which supported a vision of "Mitteleuropa" that favored Austria's Anschluss.

These movements attempted to lobby French parliamentarians who were considered to be key to Franco-German reconciliation. ${ }^{9}$ And the parliamentarians played their part. In March 1927, the former Sorbonne professor and member of parliament Emile Borel created a Fédération pour l'Entente européenne (Federation for European Agreement) and organized a meeting at the Sorbonne on February 23, 1928.

Adding to these external rivalries were internal tensions between local branches and the central headquarters, in particular between the German branch and Vienna, the general organizing headquarters of Paneuropa. Coudenhove-Kalergi, being very protective of his power, was keen not to give in to something that was leading to crises and resignations in the German branch; this did not help the movement's popularity in Germany.

The first general assembly of the French branch took place on May 2, 1927, and involved politicians Louis Loucheur (president), Léon Blum and Joseph Barthélémy (vice-presidents), and Gaston Moch, Francis Delaisi, Lucien Romier, Paul Claudel, Paul Valéry, and Jules Romains. Aristide Briand was the president of honor; to establish a Franco-German balance, the honorary presidency was offered to Gustav Stresemann, who turned down the position. The Social Democrat Chancellor Hermann Müller also refused to get involved with the movement despite Coudenhove-Kalergi's invitations. In fact, the German Foreign Minister 
also rejected the Treaty of Versailles, which left him unable to join the movement since it was based on acceptance of the treaties.

The pacifist Carl von Ossietzky supported the Paneuropa project (in 1926 in Die Weltbübne), which he found to be more concrete than the utopias of other pacifist movements, but he also criticized its choices for being colonialist and too concerned with capitalist interests to the detriment of social problems.

\section{Intellectual Meetings for Europe}

\section{What Should Europe Be?}

In 1915, Jules Romains had written an article aimed at the Americans, denouncing the absurdity of war. Despite some overlap with points made in Romain Rolland's Au dessus de la mêlée (Above the Battle), his text, which was not published until 1931, was different in that it envisaged, even before the end of the war, the need to reconfigure Europe by getting rid of nationalism and its historic disagreements:

Europe in 1915 is a place of ghosts [. . .] The European of today does not view himself as European.

The geographical, living unit of Europe is hidden from his eyes by the ghosts we speak of. He fights for shadows, whose inconsistency has been covered up by the rhetoric of rulers and certain writers [...].

Europe is intoxicated by history; and as soon as it tries to walk resolutely towards new forms of life, it is taken and thrown to the ground by an excess of fever. ${ }^{10}$

In 1919, Paul Valéry published two texts on the "crisis of the Spirit", first in the form of two letters in the Nouvelle Revue française and The Athenaeum. He commented on the discrepancy between the size of the European territory and the power of its intellectual abilities. ${ }^{11}$ Its extreme maturation has led to its fall. This analysis partly chimed with Spengler's contemporary theory of the decline of the West.

On the German side, the most dramatic turnaround regarding perspectives on Europe was that of Thomas Mann. In October 1922, he gave a conference in Berlin called "On the German Republic". Although he was heckled by nationalist students, he adopted a favorable position towards European humanism, which represented a move away from his previous "Germanic" vision in Reflections of a Nonpolitical Man (1918). Goethe, Novalis, Nietzsche, Stefan George, and Gerhart Hauptmann were called to support his new theory, while they had been used in reverse some years before. Mann established an equation between Europe, democracy 
humanitas, and the perfection of works of art. ${ }^{12}$ His text tore apart Spengler's theories.

In 1923, André Gide, in turn, pondered the "future of Europe" in an article that he would revisit in 1924 in Incidences. ${ }^{13}$ Gide continued the debate with Spengler in a response to an investigation by the Revue de Genève of summer 1923. He denounced the impasse of Maurice Barrès's nationalism (as it happened, Barrès died in December 1923), saying that the mind of the modern writer must be Europeanized. He announced a possible renaissance and a "union of difference", but also rejected internationalism: ${ }^{14}$

European countries can no longer aspire to real progress in their own culture in isolation, or without the indirect collaboration of other countries [. . .]; equally, from a political, economic, or industrial point of view-in fact from any point of view-the whole of Europe is going to ruin unless each country agree to consider more than its own salvation [...]. In truth, the issue of Europe scarcely occupies minds-or, more precisely: it occupies very few minds. The sense of a common interest wakes only when faced with a common threat, and until now, the sense of threat has done no more than pit the peoples of Europe against one another. It has become a habit, and that is why it is so difficult today to consider collapse as a common threat.

The true European spirit is opposed to nationalism's infatuation with isolation; it is also opposed to the depersonalization of internationalism. I have said it many times and for a very long time now: We best serve general interests by being as specific as possible; and this is true for countries as well as for individuals. But this truth should be strengthened by the following: In abandoning oneself, one finds oneself.

And while this is equally true for countries, we cannot discern it as long as politics dominates, subjugating morality. The truth is, political issues interest me less and seem less important than social issues, and social issues less important than moral issues. I believe that for the most part, the former boil down to the latter, and that for all that we deplore today, what is important is to go after the man rather than institutions-and that it is first and foremost he who must be reformed. ${ }^{15}$

Many intellectuals at the time sought a definition of Europe in terms of culture, which was often contrasted with that of the East: for example, Heinrich Mann, Hugo von Hofmannsthal, Paul Valéry, and Edmund Husserl.

The reconciliation of points of view among intellectuals of former enemy countries took a spectacular turn on 20 January 1926, during 
Thomas Mann's conference at the Carnegie Endowment for International Peace in Paris. The conference was published in L'Esprit international under the title "Les tendances spirituelles de l'Allemagne d'aujourd'hui" ("Contemporary German Intellectual Trends"). Mann clearly declared himself as European: ${ }^{16}$

The excessively brutal contact to which European nations have been subjected by the war represents a great step forward on the path leading to a relative unification of our continent.

Mann defended Franco-German rapprochement while recognizing intrinsic differences and assigning particular responsibility in this domain to writers:

The situation of the writer, conscious of his time, in the state and society of today, has become more burdened with responsibility in terms of subjective and objective points of view-not, of course, in an immediate fashion, but silently, and it is not going too far to say that, overall, nothing can be done in Europe against the will of the intellectual class, against its discrete will that acts indirectly. ${ }^{17}$

The following year, Julien Benda's La trabison des clercs also endorsed a return to the universal against the treason of nationalism (embodied by Action française) or the class perspective (represented by communism). It was therefore necessary to support LN but also to create European myths and heroes. Benda proposed a purely idealistic, somewhat francocentric vision of Europe, particularly in Discours à la nation européenne, which was purposefully paradoxical. ${ }^{18}$

\section{Conferences of Writers and Intellectuals}

These humanistic and idealistic visions of Europe culminated in the conference of the International Committee on Intellectual Cooperation (ICIC) in Frankfurt in 1932 on the occasion of the centenary of Goethe's death. ${ }^{19}$ Thomas Mann saw in the figure of the wise man of Weimar an example to resolve the dilemma of German culture torn between the national and the European spirit. Paul Valéry took this further, seeing in the figure of Goethe the possible existence of a "society of intellectuals" that went beyond borders:

Some men give the idea-or the illusion—of what the world, and particularly Europe, could have become, if political power had been mixed further with intellectual power, or at least if the relationship of the two had been less uncertain. The real would have subdued ideas; 
the spirit would have, perhaps, ennobled actions [. . .] Goethe was one of these men. ${ }^{20}$

The discussion continued in May 1933 at the talks held in Madrid on the theme of the "future of culture". The conference was chaired by Marie Curie. The key figures were Miguel de Unamuno, Manuel García Morente, Jules Romains, Paul Langevin, Paul Valéry, and so on. Manuel García Morente introduced the debates with a pessimistic speech, influenced by Spengler, which he had translated into Spanish:

It is science that, in my opinion, threatens our culture today, as for three or four centuries scientific progress has been so great that it has become absolutely impossible for any intelligence to dominate all human knowledge [. . .]. Specialisms become more restricted by the day. ${ }^{21}$

And, even more concerning in Morente's opinion was that the rest of humanity found itself distanced from science-more and more cut off from ordinary life. Then he developed the banal themes of the era of the standardization of life linked to large industry and mass production. This massive expansion spread to literature, which had become a profession just like any other in which it was important to please the greatest number of people. Next, he denounced mass population and the retreat towards regressive solutions as less than ideal: the sacrifice of freedom in favor of dictatorships, collective submission through nationalism or corporate interests (Avenir de la culture, 21-23). He saw in this Madrid meeting the beginnings of a "society of intellectuals" to revive the universality and humanism introduced by the Renaissance (Avenir de la culture, 24).

Immediately after him, Jules Romains largely took issue with this pessimistic picture, leaning on nostalgia for the Republic of Letters of the Ancien Régime. In view of the problems of specialization, the author of Knock proposed the encouragement of a "general climate of coordination, synthesis, and balance, even among a small number of people". ${ }^{22}$ Romains viewed the "standardization" rebuked by Morente as an old phenomenon, even if its pace of distribution had accelerated as a result of modern technology. He also rejected Morente's final elitist speech. He, conversely, advocated sharing culture more widely, even if this were to the detriment of a certain elitism:

What is the most dangerous for the future of civilization: is it to have a small core of high culture surrounded by immense and impenetrable barbarism? Or is it to have a culture that does what it can to filter through this density, this mass, in order to change it? [. . .] 
The greatest danger, in my opinion, is precisely this enormous and impenetrable mass of humanity around a culture in which it is not involved in any way. ${ }^{23}$

According to Jules Romains, civilization is more threatened when there is a cultural separation between a small elite and the ignorant and barbaric majority. For this reason, he welcomed, despite certain reservations, the effort of the Russian Revolution to abolish this division. He also contested the idea that man's liberation, which began in the Renaissance and continued throughout the nineteenth century, had been achieved. This still concerned only a minority of countries and men (Avenir de la culture, 39). For Salvador de Madariaga, another significant figure in the debates and one linked to the LN, "intellectual workers" had an immense task:

To create and develop faith in the organic unity of humanity [. . .]. It is a question of clearly understanding the human universe as consisting of a universal unit built on science and reason, and in which all men of all races and colors must find their cultural goal.

(Avenir, 150-51)

The physicist and left-wing thinker Paul Langevin endorsed a culture and education of the people and welcomed the Spanish republican government's efforts in this area (Avenir, 164).

For the Spanish historian Gregorio Marañón, the "intellectual must adopt an attitude that is free from vanity, but aware of its responsibility" (Avenir, 186):

If intelligent men must shape the world of the future, they must be even more concerned to lead by the example of their behavior as much as by their word.

Otherwise, they will be, as now, at the mercy of the violence of rulers, which nourishes the disdain and hatred of the crowd.

(Avenir de la culture, 187)

With the deterioration of the international situation in Europe at the beginning of the 1930s, the European project became increasingly problematic, including among intellectuals. Yet the ritual of the ICIC talks continued, even if their function changed.

We see this in the talks on the "future of the European spirit" held October 16-18, 1933, in Paris. These were opened and chaired by Paul Valéry. Count Hermann von Keyserling began the session with a philosophical vision of history with a metaphysical and spiritual focus whereby he asserted that the powers of the mind were currently overwhelmed by what he called "telluric forces": 
Resolutions of intellectuals that crush a measure or an event, millions of men and their bosses do nothing but laugh, since for public opinion, in the sense of historical consciousness, the smallest minority that I presuppose here has very little prestige and, therefore, no real power. Pure and simple opposition or negative criticism can only exacerbate the enmity of those who have given themselves, body and soul, to revolutionary telluric forces, and increase the threat that the survival of traditional culture is facing in every country. ${ }^{24}$

European intellectuals' despondency was also manifested in the high number of absences among those invited: Thomas Mann, Selma Lagerlöff, Oswald Spengler, H.G. Wells, Franz Werfel, and Stefan Zweig all gave their apologies. Nevertheless, the debates were led, especially thanks to the involvement of the British writer Aldous Huxley, who was very critical of contemporary mass culture. Historian Johan Huizinga as well as Art historian Henri Focillon emphasized, rather, the role of Europe's cumulative intellectual legacy. The essayist Julien Benda, known for his work Trabison des clercs, and Sorbonne philosophy professor Léon Brunschvicg, for their part, defended the virtues of Western rationalism in the face of racist ideologies. Georges Duhamel, Salvador de Madariaga, Emile Borel, and Jules Romains still wanted to believe in the future of the European project and the role intellectuals could play if they rallied together. Jules Romains argued, even more so than in Madrid, for the effective commitment of men of culture, while the president of the debates, Paul Valéry, rejected the subjugation of the "mind" by "politics," which was considered subordinate. ${ }^{25}$ The meeting ended in the creation of a society of European studies, a compromise solution between the contemplative approach of some and the more activist approach of others. Paul Valéry accepted the presidency with vice-presidents of other nationalities, but without any British participation. The society was dissolved in 1939 after having held various more modest symposia. ${ }^{26}$

Despite the high selectivity of participants to these meetings-recruited among celebrities or from academic spheres-the debates revealed significant differences between them-even between those of the same nationality-in spite of their professions of humanist and spiritualist faiths. Supporters of a pessimistic vision of history were in regular conflict with those who were still optimistic regarding Europe and its future. Similarly, elitist intellectuals clashed with proponents of a democratic widening of culture, just as those who advocated the autonomy of cultural objectives came up against pragmatists who wished to forge political alliances and popularize the idea of Europe with ordinary people. This was the case, for example, for Jules Romains:

I reproach the League of Nations for being too purely administrative, rational, and calm—of being too exclusively an organization of 
bureaucratic wisdom. I would like it to incite popular and passionate demonstrations among crowds; I would like there to be processions with costumes and music; I would like us to fill the sky with explosions of fireworks. ${ }^{27}$

Another fracture line concerned the opposition between literary and scientific culture. For the former, science and its applications were a threat to "civilization", which was associated with literary and humanist heritage. The few scientists present at these meetings struggled against this negative vision held by the tenants of literary culture. They believed that the rise of irrationalism (of which fascism was evidence) was rather due to the weakness of science teaching. This was, for example, the opinion of the British geneticist J.B.S. Haldane:

We will continue to come up against these problems until we make science part of education-not only for specialists but for all learned men-to the same extent as is the case for Greek culture and Latin. ${ }^{28}$

Faced with these differences, which tended to increase during meetings, the presidents of the talks sought rather to maintain the ideal of unanimity of minds removed from national and political stakes. Hence Marie Curie in Madrid:

We can recognize that the dream of the future requires a synthesis of national cultures and the subordination of differences that are primarily political in nature, towards the universal goal of culture and civilization. ${ }^{29}$

Following a long discussion, to give the impression of having made progress, participants would develop motions of recommendations at the end of meetings to send to politicians. To conclude the Madrid talks, Valéry called for a society of minds and welcomed the fact of great Spanish intellectuals holding power with the Republic. ${ }^{30}$

\section{Reasons for the Failures and the Responsibility of Intellectuals}

There were multiple reasons for the failure of these efforts to form an intellectual Europe. The first was the division between the two "Europes": that of the victors and that of the defeated. This took a long time to recede, despite the multiple conferences of the 1920s that aimed to resolve the problems left behind by the treaties. For a very long time, resentment between nationalist intellectuals on the two sides prevented dialog both at the top and at the grassroots. The boycott of German and Austrian scientists, decreed by the French and the English in retaliation for the solidarity they displayed with Germany in the famous "Manifesto of the 
Ninety-Three" (1914), banned the practice of international scientific congresses at which all European intellectual powers were represented until the end of the 1920s.

The first international congress of social science and the humanities to which German scientists were invited was, for example, the Historical congress held in Oslo in 1928. It was at this congress that Marc Bloch proposed his famous text, symbolically titled: "Toward a Comparative History of European Societies". ${ }^{31}$ Beyond methodological proposals of significance for the discipline, it clearly contained an indirect political dimension. Bloch believed that, in order to evade the traps of nationalism, it was necessary to rewrite the history of Europe in a new way. Lucien Febvre would attempt to do the same thing in his book on The Rhine, in which he analyzed the river historically more as a link between the north and the south of Europe than as a border between France and Germany. ${ }^{32}$

A second set of reasons is related to the domination of the intellectual scene by the traditional figures of the writer, the philosopher, and the rigor of the historian, as implied by the composition of the discussions at the various conferences cited. Representatives of the social and natural sciences still only held a marginal status or in turn adopted, with few exceptions, the same general humanist and elitist discourse barely audible to a wider audience. These European or pro-European intellectuals in fact only addressed the elite or the upper middle classes. They consistently displayed mistrust of the "masses" or cultural "democracy" that were associated with American bad taste or seen as responsible for bringing communist or fascist dictatorships to power. Intellectual anti-fascism tried to adopt a more democratic position after 1933, but split, in turn, regarding the attitude to take towards intellectuals won over by Stalinism who claimed to assume the monopoly of the spread of culture to the lower classes or even to advocate a literature that was subject to political directives (socialist realism).

All this goes to explain that the dominant reading of this period is rather negative in accordance with the success of totalitarian regimes, extreme nationalist movements in the new countries created by the Treaty of Trianon, and the political failure of the LN in the 1930s when confronted with Mussolini's fascism and the aggression of Hitler or of militaristic Japan. And this all gives the impression that these ideological debates surrounding a new more political or practical vision of Europe derived from idealistic minorities that were scarcely in tune with deep currents of opinion. The serious political and economic crises that struck most countries indeed allowed extreme nationalist movements to seize power in a few key states, driving the whole of Europe to the bottom of the abyss once again.

However, this purely catastrophic reading of the early twentieth century ignores several elements without which the renewal of the idea of 
Europe in the second half of the century and the possibility of international action by intellectuals in France, Germany, or Italy would have been impossible in this regard after these tragic episodes. The first was the existence of a strong pacifist sensitivity among the young intellectual generations of countries on the winning side (primarily in Great Britain and in France), yet not forgetting that this also occurred in Germany, such as with the writer Erich Maria Remarque. His books on the war and post-war run counter to extreme right-wing theses, and his strong circulation proved that not all the German population was ultra-nationalist at this point, as a certain teleological historiography written in light of Hitler's rise to power claims. We should remember that Remarque's novels also resonated strongly in Europe and were translated into its main languages. All Quiet on the Western Front was even adapted for cinema, and its screening in Germany provoked incidents organized by the extreme right. ${ }^{33}$

The second phenomenon that is widely ignored in historiography is the renaissance of and increase in university exchanges (either between students or subject-specific or scientific communities) that erased, from the middle of the 1920s, the legacy of the policies of ostracism and boycotting the opposing camp instigated by the war of 1914 . We will take a further look at this aspect now.

\section{Other Forms of European Intellectual Networks}

\section{Student Exchanges (1920s-30s)}

The war very quickly motivated academics to rally to the national cause and imposed an instrumental conception of research based on the objectives of national defense. Some scholars were directly involved in meeting the demands of the military, making the resumption of contact between former enemy academics even more difficult.

At the end of the war, this resulted in a reorientation of the trends of student and teacher exchanges and above all in lasting ruptures between certain nations who continued a sort of scientific cold war against scientists and academics of former enemy nations. Therefore, the two enemy "Europes" continued to compete on academic grounds far beyond the end of hostilities. The same was true for relations between student organizations.

However, the situation did not stay this way owing to the spread of pacifist and pro-European ideology or quite simply because of the need felt by students from certain European countries to make up for local academic shortcomings by setting out to study at universities in other European countries. Thus, new trends of exchange formed or were revived, which contributed, therefore, to creating a milieu that was favorable to a new construction of an intellectual Europe. This played an indirect political 
role in international relations as well as in the development of the debate on the future of Europe. We should not forget, indeed, that students and academics were at that time the main source of future intellectual or political elites. Some of them went on to make up the generations that engaged in the construction of Europe in the 1950s, encouraged by this earlier European experience at the end of the 1920s or during the $1930 \mathrm{~s} .{ }^{34}$ It is therefore important to reconstitute this little-known intermediary link in Europe's underground construction.

A major imbalance at the beginning of the twentieth century characterized student exchanges within Europe: the majority of foreign students came from central, eastern, and southern Europe and studied in European countries farther to the west (mainly Germany, Austria, France, and Switzerland). ${ }^{35}$ The war did not alter these uneven flows, even though it interrupted relations with the country that was the greatest exporter of students-and above all of female students-before 1914: Russia.

On the other hand, the new nations formed as a result of treaties continued to send their future elites to be educated abroad according to traditional linguistic, cultural, and political affinities. This produces a profile of two European subgroups of student exchanges: the first, centered on the French-speaking space, attracted students from Poland, Romania, Yugoslavia, Greece, and Bulgaria who were already, prior to 1914, more likely to be found in Paris than in Berlin or Vienna; the second, centered on the German-speaking space-and now more on Berlin owing to the territorial division of Austria-Hungary-attracted students (often from German-speaking households) from the former Greater Hungary, the former Austrian Empire, the Baltic countries, and Turkey.

\section{The German Case}

German student exchanges with the rest of Europe were impeded not only by the country's diplomatic isolation before the Locarno Treaties, but also by the economic and political disruptions that made life for foreign students difficult during a period in the 1920s: we should not forget the revolution in Munich and Berlin in 1918-19, the coups d'état in 1920 and 1923, hyperinflation, and the rise of mass unemployment from 1930 that also affected graduates and incited xenophobia that was not conducive to welcoming non-German speaking students. The graphs relating to the two main German universities, Berlin and Munich, show the size of these fluctuations, which indicates a troubled climate. At the same time, and conversely, the hyperinflation of the early 1920s may have had paradoxical effects since it gave far superior purchasing power to anyone holding foreign currency. For foreigners from poor countries, it cost less in the end to study in Germany than it did at home. A second factor that favored exchanges was the government's willingness to end diplomatic isolation by attracting students from the least hostile 
countries, hence the creation of DAAD (Deutsches Akademisches Austausch Dienst) in 1925. Despite these efforts, the position and international influence of German universities on the whole decreased in comparison with pre-1914. Around 1900, foreign students made up approximately $7 \%$ of Germany's university population, whereas they represented no more than $4 \%$ in the 1930s (but the overall student population was higher). Even in the most international universities such as Berlin and Munich, after a brief return to the pre-war level in 1923 (no doubt thanks to inflation), there was a downward slope and a level of $6-8 \%$ in Munich and $8-10 \%$ in Berlin, which was much lower than levels in France of $13 \%$ in the 1920 s and $22 \%$ around $1930 .{ }^{36}$ If we analyze where these students came from, we see that they scarcely contributed to the Europeanization of academic Germany since the vast majority were in fact German speakers; in other words, this represented a continuation of cultural exchange within Germany's traditional zone of influence going back to the nineteenth century. In $1928,53 \%$ of foreign students in Germany claimed to be German-speaking from birth $(49 \%$ among students in technical higher education); in 1934, the arrival of Hitler further increased this bias, with $62 \%$ of German speakers among foreign students at universities. ${ }^{37}$

However, we should not paint too bleak a picture of Germany's cultural close-down towards Europe as measured by this indicator, first of all, because $47 \%$ of foreign students were nevertheless non-German speaking, and above all because these percentages, while in relative decline, relate to larger overall populations than before 1914. In absolute figures, we therefore find rather similar respective populations of 994 in 1928 and 1,077 in 1933 in Berlin, compared with 1,216 in 1914,, 495 in 1928, and 587 in 1933 compared with 614 in 1914 for Munich.

If we now consider from a fresh perspective the European awareness that this expatriation, although temporary, provoked among these students, two factors should be highlighted. In Germany, foreign students primarily came from Poland (often from former German territories), Romania (German-speaking from the former Austro-Hungarian Empire that was now part of the new Romania), and from the German part of the former Habsburg Empire (the German minority from Bohemia and Austrians). We therefore have a frustrated ideological community of defeated nations that encountered German students to be themselves, on the whole, attracted by nationalist ideas, and even soon by Nazi ideas, which was hardly conducive to a peaceful European vision; instead, this partly paved the way for the phenomena of the collaboration of elites in these countries in the context of the future Germanized Europe of the 1940s.

The second common trait of these foreign students in Germany was their orientation towards medicine and scientific studies-a precise professional training goal including gaining prestigious German qualifications to establish their career on their return home. Nevertheless, this 
was also a double-edged sword-and this was a recurring theme in most European countries in the 1930s-as this type of relatively universalist training (unlike law or the arts) also allowed students to stay to work in their host country while unemployment was still rampant in their country of origin. This was a strong temptation since many of these countries were struck by the crisis in such a way that they could no longer absorb their graduates as they had done previously. This presence of foreigners at universities, rather than bringing nations closer together, contributed therefore to fueling the xenophobia of native students, who perceived them as dangerous competitors when unemployment was on the rise. We also see this phenomenon in France in the 1930s.

\section{The French Case}

Initially, it was a very different case, since not only did France become the main host country, but the government also encouraged these exchanges to better assert its European dominance in the 1920 s by attracting the future elites of the new nations that France had helped create with the treaties of Versailles, Saint-Germain-en-Laye, and Trianon. There was undeniably a genuine European university policy defined by governments and French academic elites. This policy aimed to be open to LN universalism and, at the end of the 1920s, it backed an ideology of European reconciliation, since, after the Locarno Treaties, governments encouraged the resumption of academic exchanges even with Germany.

Apart from Switzerland, France was the European country that welcomed the highest percentage rate of foreign students at the time: $22.1 \%$ at the start of the 1930 s against $16.6 \%$ in 1925 and $6.1 \%$ in 1900 . We must not therefore underestimate, mutatis mutandis, this vehicle of internationalization, which began in the interwar period and reached a level equal or even superior to what we call "globalization" today. With the economic crisis and the advent of dictatorships in certain countries, there was a relative decline, but in absolute figures, France still welcomed more students than before 1914 .

These students (especially, increasingly, those studying literary subjects) were highly concentrated in Paris, which made them more

Table 2.1 French and Foreign Students ${ }^{39}$

\begin{tabular}{llllllllll}
\hline & 1921 & $23 / 24$ & $24 / 25$ & $25 / 26$ & $27 / 28$ & $28 / 29$ & $30 / 31$ & $34 / 35$ & 1938 \\
\hline French Total & 49,931 & 50,891 & 52,960 & 58,507 & 64,531 & 69,961 & 78,674 & 82,218 & 74,832 \\
Foreign Students & 6,477 & 6,421 & 8,790 & 12,014 & 14,368 & 14,973 & 17,281 & 12,133 & 8,817 \\
$\%$ & 12.9 & 12.6 & 16.6 & 21.0 & 22.2 & 21.4 & 21.9 & 14.5 & 11.7 \\
Total Paris & 21,185 & 22,155 & NA & NA & 26,889 & 27,350 & 31,886 & 36,044 & 34,252 \\
Foreign Students & 3,564 & 3,266 & NA & NA & 6,596 & 6,931 & 7,741 & 6,828 & 5,106 \\
$\%$ & $16.8 \%$ & $14.7 \%$ & NA & NA & $24.5 \%$ & $25.3 \%$ & $24.2 \%$ & $18.9 \%$ & $14.9 \%$ \\
\hline
\end{tabular}




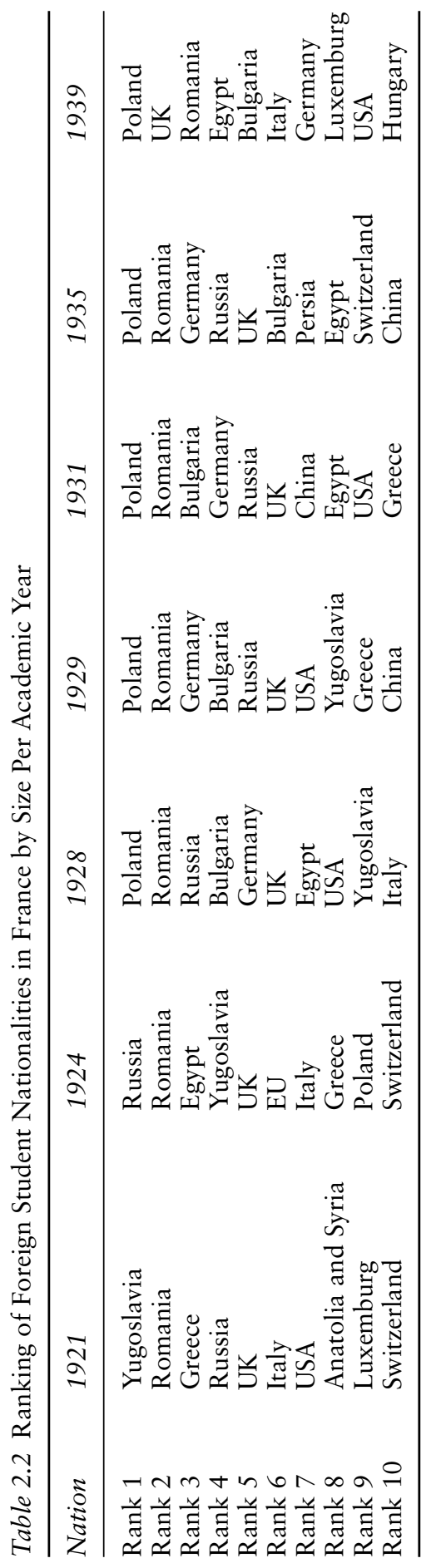


visible: in $1935,56.3 \%$ of foreign students attended institutions in Paris. In some provincial universities, they also formed the majority in certain faculties: in Grenoble, there were 816 foreign students to 362 French studying arts subjects in 1927/28, and in law, 330 to 259 French. ${ }^{40}$

The ranking of nationalities shows the persistence of pre-war trends with the dominance of Eastern Europe at the top of the table. If we weight these rankings by student population of each country, the unrivaled attraction of France according to European area is even more striking: the Balkans (Romania, Bulgaria, Yugoslavia, and Greece) come out very clearly on top ahead of the great advanced nations, whether enemy or ally (Great Britain, United States, Czechoslovakia, and Germany). These students indeed came first and foremost with the aim of gaining professional training and to compensate for the shortcomings of their home universities. We find them above all concentrated in medicine and in scientific and technical studies: those from central and eastern Europe represent $60 \%$ of foreign students ${ }^{41}$ (institutions that trained engineers in science faculties), or even in the development of research (Institut Pasteur). A second group from more southern countries was orientated towards the study of law.

A third, strongly feminized group came to learn about the French arts and civilization or to gain knowledge of the language, either with a general cultural aim or to become language teachers and spread French culture in their countries. We therefore find once again the classical division of labor between the sexes multiplied by social origin: the female inheritors of cosmopolitan elites, great consumers of French culture from before 1914, and students from dominated nations climbing the social ladder who sought modernization at the lowest cost. In law, the rate of foreign students was $9.4 \%$ in 1931 compared with $8.7 \%$ in science, $47.3 \%$ in the arts, and $16.3 \%$ in medicine.

\section{The Avant-Garde Perspective}

The artistic or literary avant-garde, which began to spread internationally from the end of the nineteenth century, was revived by this European, transnational-even global—-tropism. It was further accentuated by the flight to the West of opponents of Bolshevism or of the Stalinization of Soviet Russia, then of antifascist intellectuals and artists from Italy, and finally of anti-Nazis and Jewish intellectuals from Germany and Austria. Similarly, the PEN Club attempted to come to the aid of the PEN clubs in countries that had come under dictatorship rule such as Germany, and later Catalonia after the Spanish Civil War. ${ }^{42}$ Intellectual or artistic Europe still did not exist, but there were reduced images of it in certain cosmopolitan capitals such as Berlin and Paris in the 1920s, and later in 
London and New York, and even in Mexico or Buenos Aires in the 1930s and 40s.

Surrealism, a predominantly French movement in the beginning, became truly international, that is to say essentially European when Europe was experiencing its darkest hours: Surrealist groups formed in Belgium, Prague, and Spain. This intellectual or artistic Europe of exiles that featured figures as significant for the intellectual and cultural life of the twentieth century at the time or in the future as Kandinsky, Chagall, André Breton, Einstein, Freud, Alexandre Koyré, Hannah Arendt, Norbert Elias, Raymond Aron, Claude Lévi-Strauss, and so on was not a simple resurgence of groups of exiled European liberals of the nineteenth century. For many among them, most of all the youngest, permanent exile implied a radical change of national horizon and forced a more or less complete mental conversion, leading to new ideas in some cases about the world, Europe, and the role of intellectuals.

The real landmark event in the international mobilization of avantgarde intellectuals was the Congrès des écrivains pour la défense de la culture ("congress of writers for the defense of culture", 21st-29th June at the Paris Mutualite conference center). The debates that took place there were considerably more political than the previously held ICIC talks, revolving around antifascism and the attitude to take in relation to communism, intellectuals, and Communist Party and USSR sympathizers. In 1937, a second congress was held in Valencia and then Madrid and Paris to mark the effective solidarity of European intellectuals with the combat taking place in the Spanish Republic against the Franco rebellion, which was seen as on a par with international fascism.

Despite the indisputable cross-border protest reflected in these gatherings, whose tone was far more political than that of the congress of "great intellectuals", this proved to be as disappointing as the other forms of reconciliation mentioned in this chapter.

\section{The Deficiencies of the European Public Space}

The contradictory scene we have just depicted reflects the paradoxes of intellectuals and of Europe between the wars, combining utopia and generosity, incantation, and impotence. All this is linked to the persistent deficiencies of the European public space. Many explanations have been proposed for the lack of a European public space and for intellectuals' incapacity to find an intermediary space for the confrontation of ideas between the national and the global level. The best known and most enduring are: linguistic divisions; the absence of transnational media; differences in historical and political legacies, even among the closest countries; and the very different views of the role of intellectuals in centralized national political states such as France and Great Britain and decentralized contexts such as Italy or Germany. But these are less relevant to the 
interwar years. Most meetings that we have mentioned were still taking place in French, or in some cases involved polyglot intellectuals or had the use of translators. The problem of mutual comprehension would increase with the replacement of French with English and the marginalization of universalist intellectuals inspired by the French model owing to their difficulty to adapt to this new situation.

As Hartmut Kaelble emphasizes, ${ }^{43}$ we must stop comparing the European public space (and the "European" intellectual field) with the idealtype of the national space, and compare it instead to composite spaces such as Latin America, the Arab world, or Africa. The public space in Europe has always historically functioned through partial transfers between relatively autonomous and unevenly connected centers according to the linguistic, ideological, or political affinities of different national spaces (France-England, France-Germany, France-Italy, Italy-Germany, Germany-central Europe, Russia-western Europe, etc.). For a very long time, the absence of an identifiable European political space as a result of the delay in the establishment of a representative democracy in Europe guided general or transnational debates towards a recollection of the past, or, conversely, towards the future, utopia, and abstraction. This is also one of the idiosyncrasies of the various transnational movements mentioned here.

The parallels between the interwar era and the present moment are striking. Just like after 1925, post-Cold War intellectual debates rekindled owing to the reunification of the continent after the fall of the Berlin Wall, as well as the since-dashed hopes surrounding the opening up of the east, have slid from enthusiasm to disillusionment and euro-skepticism, and even the resurgence of nationalism based around "sovereignty". Several episodes during the first decade of the twentyfirst century further reinforced this mood that is reminiscent of the 1930s: the diverging attitudes of countries with regard to the war in Iraq in 2003; the failure of the European referendums in 2005; the rise of extreme right anti-European parties in Italy, France, Hungary, Austria, Switzerland, the Netherlands, Belgium, Poland, Germany, and so on; and the economic crisis of the eurozone from 2008 that divided northern and southern Europe.

As before the war, intellectual reflection conveys the same uncertainty between the "experts" who stick to the outline of the circumstances according to the technocratic methods of the moment, self-styled prophets of new planetary or environmental apocalypses, and the specialists who reason on their level the scarcely visible or scarcely heard defined issues of the wider public. The only provisional conclusion that we can take from this comparison between two moments is that periods of the greatest European pessimism have often been those that have led to unexpected rebounds further down the line. We hope that this will be the same for the present moment. 


\section{Notes}

1. Romain Rolland, Au dessus de la mêlée (Paris: Ollendorff, 1916), 49, quoted by Pascal Dethurens, Ecriture et culture. Ecrivains et philosophes face à l'Europe, 1918-1950 (Paris: Champion, 1997), 37.

2. Ernest Schonfield, “The Idea of European Unity in Heinrich Mann's Political Essays of the 1920s and Early 1930s", in Europe in Crisis: Intellectuals and the European Idea 1917-1957, ed. Mark Hewitson \& Matthew D'Auria (New York: Berghahn Books, 2012), 257-270.

3. Jean-Jacques Renoliet, L'Unesco oubliée: Société des nations et coopération intellectuelle (Paris: Publications de la Sorbonne, 1999), in particular: 184-185. There were also Czechs, Polish, Hungarians, Portuguese, Italians, Danish, Norwegians, Spanish, Japanese, North and South Americans, and Indians.

4. Anne-Marie Saint Gille, La Paneurope, un débat d'idées dans l'entre-deuxguerres (Paris: Presses de l'Université de Paris-Sorbonne, 2003); Landry Charrier, Karine Rance \& Friederike Spitzl-Dupic (eds.), Circulations et réseaux transnationaux en Europe, XVIIIe-XXe siècles, acteurs, pratiques, modèles (Berne, Berlin, Bruxelles: P. Lang, 2013).

5. Elisabeth du Réau, L'idée d'Europe au XXe siècle, des mythes aux réalités (Paris: Editions Complexe, 2001), 81; Saint Gille, Paneurope, 25.

6. Saint Gille, Paneurope, 50-51.

7. Saint Gille, Paneurope, 58-60.

8. Saint Gille, Paneurope, 149-151.

9. Karl Hool, "Europapolitik im Vorfeld der deutsche Regierungspolitik. Zur Tätigkeit proeuropäischer Organisationen in der Weimarer Republik", Historische Zeitschrift 219 (1974): 33-94.

10. Jules Romains, Problèmes d'aujourd'hui (Paris: Kra, 1931) (text written in 1915).

11. Dethurens, Ecriture et culture, 80-81. Texts are reprinted in Paul Valéry, Variété I (Paris: Gallimard, 1924).

12. Dethurens, Ecriture et culture, 91-98.

13. André Gide, Incidences (Paris: Gallimard, 1924).

14. Dethurens, Ecriture et culture, 99-106.

15. Revue de Genève, 1923, reprinted in Incidences, 33-34 (italics from Gide).

16. Reprinted in Cahiers de l'Herne, “Thomas Mann”, 1973, 259-265, here 259.

17. “Thomas Mann”, 260.

18. Dethurens, Ecriture et culture, 198-204.

19. Annemarie van Heerikhuizen, "Paris 1933. A 'société des esprits" chaired by Paul Valéry", in "European Encounters", European Studies 32 (2014): 139-154 in particular, 143.

20. Entretiens sur Goethe à l'occasion du centenaire de sa mort: avec deux dessins inédits de Goethe (Paris: Institut international de coopération intellectuelle, 1932), 44-45.

21. L'Avenir de la culture, entretiens de Madrid 3-7 mai 1933 (Paris: Institut international de coopération intellectuelle, 1933), 12.

22. Avenir de la culture, 28.

23. Avenir de la culture, 34.

24. L'Avenir de l'esprit européen (Paris: Institut international de coopération intellectuelle, 1933), 25-26.

25. Avenir de l'esprit européen, 303.

26. Dethurens, Ecriture et culture, 265-278.

27. Avenir de la culture, 41.

28. Avenir de la culture, 57-58. 
29. Avenir de la culture, 217.

30. Avenir de la culture, 282-284.

31. First published by the Revue de synthèse historique, 46, 1928, reprinted in Mélanges historiques (Paris: Editions de l'EHESS, 1983), 16-40.

32. Lucien Febvre, Le Rhin. Histoire, mythes et réalités, edited P. Schöttler (Paris: Perrin, 1997) (1st ed. 1931-1935).

33. A l'ouest rien de nouveau (Im Westen nichts neues, Berlin: Propyläen Verlag, 1929); Après (Der Weg Zurück Berlin: Propyläen Verlag, 1931); Les camarades (die drei Kameraden, Amsterdam, 1936).

34. Students of the twenties were born around 1900 and reached middle age at the beginning of the fifties when European institutions were founded; those who studied in the thirties could participate in the process of building Europe in the sixties.

35. Victor Karady, "Student Mobility and Western Universities: Patterns of Unequal Exchange in the European Academic Market, 1880-1939", in Transnational Intellectual Networks, ed. C. Charle, J. Schriewer \& P. Wagner (Frankfurt, New York: Campus, 2004), 372-373.

36. Fritz K. Ringer, "Admission”, in A History of University in Europe, (18001945), ed. W. Ruëgg, vol. 3 (Cambridge: Cambridge University Press, 2004), 247, table 7. 5 .

37. Victor Karady, "La migration internationale d'étudiants en Europe 18901940", Actes de la recherche en sciences sociales 145 (Fall 2002): 55.

38. Taken from Hartmut Titze, Wachstum und Differenzierung der deutschen Universitäten 1830-1945 (Göttingen: Vandenhoeck \& Ruprecht, 1995), 90.

39. Sources: Annuaire statistique de la France and Nicolas Manitakis, "Etudiants étrangers, universités françaises et marché du travail intellectuel (fin du XIXe-années 1930)", in Construction des nationalités et immigration dans la France contemporaine, ed. E. Guichard \& G. Noiriel (Paris: Presses de l'ENS, 1997).

40. Manitakis, “Etudiants étrangers . .”, 125-126.

41. Manitakis, "Etudiants étrangers ..”, 138.

42. Richard A. Wilford, "The PEN Club, 1930-50", Journal of Contemporary History 14.1 (January 1979): 99-116, in particular, 103.

43. Hartmut Kaelble, "The European Public Sphere", in Building a European Public Sphere from the 1950s to the Present, ed. Robert Frank, Hartmut Kaelble, Marie-Françoise Lévy \& Luisa Passerini (Bruxelles: PIE, Peter Lang, 2010), $28 \mathrm{ff}$. 


\title{
3 Cultural Mediators and Their Complex Transfer Practices
}

\author{
Reine Meylaerts
}

\section{Introduction: A Research Journey}

The models and concepts of polysystem theory (Even-Zohar 2005), descriptive translation studies (Toury 2012) and translation sociology (Simeoni 1998; Heilbron 2008; Meylaerts 2008) have been instrumental in many respects for a better understanding of cultural interactions, cultural transfer and cultural dynamics. Let me take my own research journey as an example here. For many years, I have been studying cultural history in Belgium, mainly through the literary and cultural interactions between the Flemish ${ }^{1}$ and Francophone Belgian literatures. I analyzed literary translations during the interwar period (1920-1940), which was, quantitatively speaking, the period in which literary translations counted for more than $50 \%$ of all translations published in Belgium. Moreover, literary translations from Flemish into French reached their highest number in Belgian history: at no other point in time would the annual number of book translations from Flemish into French be higher in Belgium. Applying the models and concepts of polysystem theory (PST) and descriptive translation studies (DTS), I analyzed the preliminary norms ${ }^{2}$ or selection criteria for these translations and discovered that the overwhelming majority of literary translations were Flemish regionalist novels translated into French. Moreover, since, as a rule, there is no symmetry in literary interference (Even-Zohar 2005, 62), translations from French into Flemish were almost absent. These preliminary norms appeared perfectly in line with the socio-linguistic, socio-cultural and socio-political context of multilingual interwar Belgium. Translations took place against the background of an ongoing linguistic conflictknown as the language question-between Francophone and Flemishspeaking groups, in which some Flemish-speaking groups were striving for their linguistic, cultural and political emancipation. The origin of this conflict was the institutionalization of French as the main language of the administration, the legal and political systems, education and the army in Belgium, while Flemish, although spoken by a majority of the people, remained a less institutionalized minoritized language. In the North of 
the country, that is, Flanders, linguistic oppositions went hand in hand with social stratification. The lower classes spoke Flemish (or rather, one of several Flemish dialects), while the upper classes spoke French. A large group of Flemings, mostly from the middle classes, were bilingual: speaking French was the best guarantee for social advancement. Consequently, Flemish translations of Francophone literature were not needed since the average middle-class Flemish interwar reader was bilingual and thus perfectly capable of reading French. The Francophones, on the other hand, had no linguistic or political benefit in learning Flemish and thus needed French translations. Moreover, following further insights of PST (Even-Zohar 2005, 46-52), I argued that Francophones' interest in Flemish literature was the perfectly logical answer to a perceived threat. Indeed, in a period of heightened linguistic struggles in which the Flemish minority culture was striving for emancipation, for equal linguistic, political and cultural rights, and thus threatening the dominant position of the Francophones, the translations of Flemish regionalist novels into French confirmed a simple, picturesque and backward Flanders in which simple peasants were quietly living in their small villages. As such, the translations were part of a conservative Francophone answer to the emancipation claims of the Flemish minority: they contributed to the stability of the receiving system. As for the operational norms, ${ }^{3}$ when comparing source and target texts, I discovered that the use of popular, familiar or even vulgar language, often independently from the source text, also contributed to confirming the image of a backward, popular and inoffensive Flanders, not the Flanders of the emancipation claims (for a more elaborate version, see Meylaerts 2004a).

This type of analysis is frequent in translation studies-and in many other disciplines. It decomposes a complex aggregate of interrelated elements into a number of elementary, simple units. It then shows how these units follow a number of general patterns (e.g. the previously mentioned preliminary and operational norms) which together form a logical unity or system-here the system of Flemish literary translations into French in interwar Belgium. This type of analysis shapes order in the chaos: it makes more or less linear causality claims, and it holds the promise of a certain generalization or even predictability and determinism. EvenZohar's "Laws of Literary Interference" (Even-Zohar 2005, 53-72) or the search for empirical generalizations and universals of translation (Chesterman 2011) are illustrative of this tendency in translation studies. Although this type of analysis may be correct, it is too simple. It holds a danger of simplification and of being blinded by the concepts and models used (which of course applies to any theoretical model). Since the very start of my research on literary and cultural interactions in Belgium, I was indeed struggling with several questions that cast doubts on my insights, which were contradicting the insights of DTS and PST and made me aware of some blind spots in my analysis. Let me give some 
examples. Analyzing the reception of Flemish translations into French, I discovered how these translations were also read and reviewed in the Flemish source culture. This finding contradicts one of the most important tenets of DTS: that translations are facts of the target or hosting culture (Toury 2012, 17-34). Breaking away from an almost exclusive focus on the source text and culture, Toury's focus on the target text and culture has indeed functioned as a Copernican revolution "by reorienting studies on translation, which until then had concentrated predominantly on the source text as the yardstick for an evaluative analysis of the target text as a mere reproduction thereof" (Assis Rosa 2010, 98). However, as has been observed by other translation studies scholars (see, e.g. Pym 1998) and as is illustrated by my own findings, this emphasis on the target culture is too simple: it reduces the numerous complex relationships between source and target cultures to a unilateral one. Similarly, when reconstructing the translation process, I discovered that some Flemish authors participated in the translation of their texts, which is another illustration of complex relationships between source and target cultures and which goes against translation studies' conceptualization of a clear separation between the roles of author and translator. Moreover, it proved impossible to make generalizations, let alone predictions, with regard to translatorship. Why did a successful translator suddenly stop translating? Why did a perfect bilingual refuse to translate? Why did a Fleming, a supporter of the Flemish emancipation, take on the role of translator into French? In a general climate of language struggles and seemingly clear divisions between the choice of Flemish or French as a writing language, why did some Flemings write in French to promote the Flemish cause? On a more abstract level, I was struggling with the complex relations between source and target culture, between translators and norms, between the individual and the collective or between agency and structure, all of which translation studies has traditionally conceptualized in a simplified manner as binary oppositions. These and other questions kept me busy, looking for models that would allow a more complex understanding of cultural contacts, cultural transfer, cultural history and dynamics. They all pointed to a need to conceptualize exceptions, randomness, complexity, change. In other words, they pointed to the need for an epistemology of complexity based on the insights of complexity theory that is precisely designed for dealing with the previously mentioned issues. This is what, from a translation studies and more in general a social sciences perspective, has, for example, been proposed by Marais (2015), Byrne and Callaghan (2014) and Cairney (2012). Let me try to explain some of complexity theory's key insights and explore what it can bring to translation studies in general ${ }^{4}$ and to a better understanding of cultural interactions, cultural transfer and cultural dynamics in Belgium in particular. 


\section{The Paradigm of Order and Simplicity}

The following quotation gives a good synthesis of what complexity theory stands for.

Complexity theory is generally sold as a new approach to science in which we identify (and then explain) systems or processes that lack the order and stability required to produce universal rules about behaviour and outcomes. When applied to the sciences as a whole, it is described as a revolutionary break from the "reductionist" approach to science and the "paradigm of order" (...), or as a new "way of thinking" and "seeing the world"; as a "world of instability and fluctuations" when in the past it was seen as "stable" (Newton's laws are often used as an example of the old way of thinking).

(Cairney 2012, 347)

Complexity theory indeed challenges the notions of disjunction, abstraction and reduction that together constitute the "paradigm of simplification" (Morin 2008, 3). Reductionism has been the dominant approach to science since the 16th century (Mitchell 2009, ix) and has been wrongly associated with the only way to do "good science". In the words of Edgar Morin, one of the fathers of complexity theory, reduction means "the search for elementary, simple units, the decomposition of a system into its elements, the origination of the complex to the simple"(Morin 2008, 33). Such a view mutilates reality, which is necessarily complex, "by imposing a simple conceptualization on a complex reality" (Marais 2015, 19). This Newtonian paradigm believes in order, determinism and predictability. It started in the natural sciences and went from there on to the social sciences. It also underlies some of the conceptualizations in translation studies, as Marais rightly argues. The paradigm of simplicity causes binary thinking, which enables us to see the one and the many but prevents us from seeing that the one is simultaneously the many, that difference is similarity and that the universal is the particular. The paradigm of simplicity can see parts and wholes but not the interrelationships between parts and parts and parts and wholes. It cannot deal with complexity or paradox. Although reduction will remain an important characteristic of science (Morin 2008, 33; Marais 2015, 15), we need to supplement it with an epistemology of complexity.

\section{An Epistemology of Complexity}

A complex system is defined by a network of rich interactions which change over time. It is not the number of parts interacting which defines complexity but rather the nature of their interactions. These interactions are non-linear, meaning that one cannot add up the interactions in a 
system in order to measure their effects. In other words, "nonlinearity describes the property of a system whose output is not proportional to its input" (. . .). Small effects can have large consequences and vice versa.

(Human 2016, 427)

Complexity applies to the behavior of bacteria or ants, to the brain, to political theory, computers, urban life, translation and transfer and so on. "Complexity (...) promotes a relational and processual style of thinking, stressing organizational patterns, networked relationships and historical context" (Bousquet 2011, 45).

\section{Hierarchy}

In its widest sense, complexity theory sees reality as hierarchical. Reality is seen as consisting of levels of existence that emerge from one another: the physical is given, and out of it emerges, in hierarchical order, the chemical, the biological, psychological and social.

The key point is that everything has evolved by the same processcomponent parts interact to form complex systems that display new characteristics as a result of their complex interactions. The new and possibly unique emergent properties define new entities. These new entities may form complex systems performing on the next "higher" evolutionary level.

(Chamberlin 2009, 93)

The following two examples, the first from the biological, the second from the social, can illustrate this idea of hierarchy. "The complexity of living systems is largely due to networks of genes rather than the sum of independent effects of individual genes" (Mitchell 2009, 275). "Genetically, humans are very similar to many other species. (...) $90 \%$ of our DNA is shared with mice and more than 95\% with chimps" (Mitchell 2009, 277-278). "The reason we humans can share so many genes with other creatures quite different from us is that, although the genes might be the same, the sequences making up switches have often evolved to be different" (Mitchell 2009, 279-280). Similarly, the social is the form the psychological takes through particular new interactions among parts of the previous level or through particular new organizations between the parts. The "more" has not been added from the outside. The "more" is the new relationships, the new organization, the new links and connections. In this way, complexity theory, in a complex, paradoxical way, maintains a monist view of reality as well as avoiding a reductionist view (Marais 2015, 29). Crucial in this complexity view is the notion of selforganization. In complex systems, the notion of self-organization means 
that "agents act locally with no view of contributing to the whole. The whole emerges, through self-organization, from the local interactions" (Marais 2015, 31).

\section{Nonlinearity and Emergence}

Two other key concepts of complexity theory are nonlinearity and emergence. A complex system is characterized by nonlinearity, meaning that "the whole is different from the sum of the parts"(Mitchell 2009, 23). Consequently and importantly, nonlinear change or nonlinear causality means that similar causes need not lead to similar results: small differences in initial conditions may exert major influences on the eventual results, and historical influences on systems may differ so that end results differ. Therefore, predictability and linear cause-and-effect relationships are highly questionable in complex systems. This should prevent translation studies scholars from understanding too superficially the function and effect of various translation strategies in cultural transfer. Moreover, the "notion of nonlinearity questions the easy lines of causality drawn in many studies of agency in translation. (...) Indicating one cause and effect relationship between, say, a translation/translator and a particular development in society, is thus highly questionable"(Marais 2015, 34).

What about emergence, then? "Emergence is a characteristic of a system which cannot be found or reduced to the properties of the parts which constitute that characteristic. (...) What emerges cannot be found inside the individual properties of the components but is a result of their interaction" (Human 2016, 428). So, for example, social systems are characterized by emergence: they are not decomposable into their components because their nature emerges from the interaction between their components, not from the nature of the individual components. Translation is also an emergent phenomenon: its nature emerges from the complex interaction between source and target culture linguistic, literary, cultural, political, ... components. Methodologically speaking, emergence represents "an epistemological shift from studying substance or stability to studying relationships, process, or change based on substance or the complex relationship between them" (Marais 2015, 50). This means that, in order to really understand the nature of translation, it is essential to study the complex processes through which translations come into being instead of just studying the finished product.

Moreover, nonlinearity and the emergent nature of social reality challenge translation studies to rethink its conceptualization of the relationships between structure and agency, between determinism and freedom, between cause and effect. The complex relationships between translators and norms, that is, between structure and agency, between structural determinism and agentic freedom, have been key points of attention in my own research on literary translations in Belgium (see, e.g. Meylaerts 2008, 


\section{Reine Meylaerts}

2013). According to Marais, theories of agency in translation assume very simple arguments concerning intentions and actions when they argue for the ways in which translators are agents of change. "Translation Studies assumes rather than argues a causal link between individual action and social system and the field can benefit from conceptualizing agency from a complexity perspective" (Marais 2015, 90). From a complexity perspective, social structures emerge from bottom-up interactions between individuals, and these structures, once emerged, have a downward causative effect on the individuals whose interaction caused the structure (Marais 2015, 37). People's (individual or collective) actions are thus a contingent outcome of "structural and contextual elements working in interaction with conscious, rational and affective interpretations of meaning" (Byrne and Callaghan 2014, 111). Their actions therefore comprehend "both the reflexivity of agency and the non-reflexive, reproductive elements that are consistent with the structural context" (Byrne and Callaghan 2014, 111). People's reflexive deliberations relate their personal identity and their social identity and constitute the "mediatory process between structure and agency" (Byrne and Callaghan 2014, 121). This implies "neither determined behavior nor full agentic freedom but rather that the outcomes of interactions are uncertain, acted out in every social situation" (Byrne and Callaghan 2014, 123). Rules or norms are therefore never the "laws by which actors' behavior can be determined or predicted because regularities are always the achievement of actors, within contexts, including those of time and place so that their actual achievement is never certain" (Byrne and Callaghan 2014, 124). As a consequence, the "age-old tension between society and individual and between structure and action is viewed as a complex paradox that should not be resolved. Both are and both cause the other to be" (Marais 2015, 37). One cannot separate individual and society. The determination of causation is bidirectional or complex (from agency to structure to agency, from the local to the global to the local, that is, upward and downward causation). Or, in the words of Byrne and Callaghan, we are "no longer dealing with the cause but rather with multiple interacting causes" $(2014,189)$. Complexity theory thus adds to our understanding of the complex, paradoxical relationship between agent and structure. This understanding also contains benefits for translation studies: translators' strategies and choices are the result of a complex interplay between structure and agency, between norms and individual freedom, and a translator acts as much upon norms as norms act upon him/her. Also, a single specific translation strategy may respond to different or even contradictory overarching objectives.

\section{Binary Thinking}

As will have become clear, complexity theory also subverts traditional binary oppositions: structure/agency, universal/particular, local/global, 
general/specific, $\mathrm{mind} /$ body, . . . and also source/target, original/translation, monolingual/multilingual. All these oppositions, which have structured Western thinking, must be reconceived according to complexity theory because they force us to choose and prevent us from seeing the interrelationships between them. Or, in the words of Şerban:

The doctrine of coincidentia oppositorum, the interpenetration, interdependence and unification of opposites, has long been a characteristic of mystical thought. Whereas Western philosophers have maintained a system of binary oppositions and the principle of non-contradiction, mystics have often held that their experience can only be described in a way that violates this principle and goes beyond what appear to be mutually exclusive terms. In fact, according to the 1922 Nobel Prize winner for Physics, the Danish Niels Bohr, there are superficial truths, the opposites of which are obviously false, and profound truths, whose opposites may equally be right. Translation and alchemy are two arts of transformation which endeavour to join together entities that are, or look, distinct, and to create a substance described as possessing unusual properties. Indeed, the outcome of the translation act stands in a relationship at the same time of difference and of identity with something other than itself. In other words, a translation is the same as, and at the same time different from, that of which it is a translation, a transmutation of.

(Şerban 2012, 41)

Complexity theory claims the refusal to choose between order and chaos, universality and particularity. Source and target both are constitutive of translation and are related to one another "at the edge of chaos": the creative space or moment where new meanings are created, boundaries are tested and conceptualizations questioned. Stable and unstable, predictable and unpredictable, known and unknown, certain and uncertain: all these hold simultaneously and should not be resolved.

In sum, complexity theory "engages with the methodological foundations of all scientific practice across all domains and fields" (Byrne and Callaghan 2014, 57). It represents "an epistemological shift from studying substance or stability to studying relationships, process, or change based on substance or the complex relationship between them" (Marais $2015,50)$. That is, analysis should be focused not on parts but on the relationships and connections between parts and between parts and wholes. In other words, the focus should be not on phenomena but on processes, that is, on "the way in which phenomena are the result of the interaction of their constituent parts" (Marais 2015, 18). This new kind of science, which is able to study both relationships and things, should thus also be able to synthetize and not only to analyze. 


\section{Reine Meylaerts}

\section{Understanding Belgian Cultural History}

What insights would we gain if we would supplement the paradigm of simplicity with an epistemology of complexity when analyzing the literary and cultural interactions between the Flemish and Francophone Belgian literatures and cultures in the interwar period? Let me try to illustrate this by taking some of the previously discussed insights as a starting point.

\section{Binary Oppositions: Source and Target}

An analytical focus on the process of translation and on the relationships and connections between the different parts of the process that eventually form the translated text reveals how "source" and "target" elements both constitute the reality of translation and are related to one another "at the edge of chaos", in an unstable equilibrium. Following the traces of the translation process, I indeed discovered that the Flemish authors often intervened in the selection, translation and publication process. They proposed or objected to book titles for translation, they corrected first drafts, co-translated certain parts of their novels or re-translated them, they took part in the search for possible publishers and so on (for more details, see Meylaerts 2004b). In other words, the roles of author and translator interact in complex ways in the translation process and are at times indistinguishable. The source author (literally and metaphorically speaking) co-constitutes the translation (process), co-determining the selection and the outlook of the translated text, that is, the preliminary and operational norms. As for the operational norms, some Flemish authors would object to keeping source text elements (e.g. proper names) untranslated in the target text or against translating key stylistic features of their original in the translation. ${ }^{5}$ The logic behind these participating authors and their choices was largely unpredictable and partly paradoxical in that these authors made parts of the original less constitutive of the translation. Moreover, following the traces of the reception process, I discovered that the French translations were also reviewed in the Flemish press and read by Flemish readers. In other words, the translations were facts not only of the target but also of the source culture and potentially modified Flemish readers' views on the Flemish originals and their authors (bidirectional causation). Flemish reactions to French translations moreover ranged from utterly positive to extremely negative and were partly unpredictable. Given the fact that the translations of Flemish regionalist novels into French confirmed a simple, picturesque and backward Flanders and thus were part of a conservative Francophone answer to the emancipation claims of the Flemish, one would expect the most negative reactions from the promoters of the Flemish emancipation. However, some among them were supportive of these translations, for which they were then 
criticized by some of their colleagues (for more details, see Meylaerts 2004a). Two observations can be made here. First (and see also subsequently), people's actions and perceptions are a contingent outcome of interactions between their reflexive agency and structural and contextual elements. The outcomes of these interactions are uncertain and therefore cannot be determined or predicted. Complexity theory considers that

[h] uman dynamics are nonlinear and often incapable of being understood from a Newtonian view of the human condition. (. . .) These human dynamics exist in a multilayered social field that contains various factors that affect how conflict originates, how conflict is addressed, and how conflict is resolved. (...) Human dynamics, especially in conflictual areas, are unpredictable and difficult to impossible to control.

(Brack et al. 2011, 4)

Second, in several respects, the distinctions between source and target texts, languages, cultures and cultural agents . . . are equivocal. Source and target both constitute the reality of translation. Especially in multilingual cultures like interwar Belgium, transfer activities are part of continuous processes and imply complex interactions and multiple effects that cannot be hypothesized by translation studies' binary conceptualization (source vs. target). "We often fall into the trap of thinking of a boundary as something which separates one thing from another. We should rather think of a boundary as something that constitutes that which is bounded. This shift will help us to see the boundary as something enabling rather than confining" (Cilliers 2001, 141, quoted in Byrne and Callaghan 2014, 155). There is "no safe 'inside' of the system (....) Everything is always interacting and interfacing with others and with the environment; the notions of 'inside' and 'outside' are never simple or uncontested" (Cilliers 2001, 142, quoted in Byrne and Callaghan 2014, 156). In multilingual interwar Belgium, boundaries between "source" and "target" (cultures and texts) were indefinite, so that translations, both as a process and as a product, were also part of the source culture, co-determining, for example, the textual translation strategies and the reception of the translated novels. (Meylaerts 2004b, 289) These insights are not really new, but take on new relevance in the light of complexity theory. Complexity theory sees culture as an emergent phenomenon, which means that cultural processes do not have fixed boundaries and that therefore boundaries should be explained, not assumed (Marais 2015, 50). The boundaries between source and target text, literature, culture, are complex, fuzzy and unstable, unpredictable, as is evidenced by studying the transfer process: the interactions between transfer processes of all kinds question clear, stable and predictable distinctions between source and target. We should therefore be aware of the danger of conceptual blindness. If our concepts 


\section{Reine Meylaerts}

don't fit reality, we shouldn't adapt reality but our concepts and better articulate between them, or redefine them.

\section{Conceptualizing a "Translation" and a "Translator"}

Complexity theory with its focus on interaction processes is perhaps even more instrumental for avoiding reductionist definitions of the concepts of "translation" and "translator". Complexity theory urges translation studies to be process- and actor-oriented in order to conceptualize translation as an emergent phenomenon: every translated text is the result of complex and non-linear interactions that cannot be added up in order to measure their effects and to understand the final product as a translation. The analysis of the translation process can reveal the multiple interacting transfer practices of which the target text is the surface result: translation, multilingual writing, self-translation, adaptation, summary, parody, plagiarism, pastiche and so on. In other words, translation is just one among many transfer modes taking sense and shape in relation to all other transfer modes. Such an approach to translation can crucially contribute to a better understanding of literary and cultural history. Maud Gonne's research (Gonne 2017) on the serial novels published by Georges Eekhoud, a Belgian Francophone writer, under the pseudonym of Gabriel d'Estrange, can serve as an example here. In these serial novels, which were presented as originals and published simultaneously in Flemish and in French, the final product was the result of interacting processes of individual writing (by Georges Eekhoud), collective writing (Eekhoud together with Jan Bruylants and Julius Hoste), bidirectional translation (the Flemish and Francophone versions serving respectively and alternatively as source text for the other language version), adaptation (e.g. of a theatre play into a serial novel), plagiarism (e.g. of a foreign-language literary work), self-plagiarism and recycling (from one serial novel into another). Moreover, some self-plagiarized parts of these serial novels were afterward used in Eekhoud's prestigious Francophone novels, published in Paris under his own name (Georges Eekhoud). The rationale between all these activities and their interactions followed a complex, fuzzy and unstable, unpredictable logic, impossible to capture by just comparing the two versions in a simple and linear source-target comparison. As already mentioned, translation can be seen as an emergent phenomenon, as the result of complex and non-linear interactions. In order to really understand the nature of translation, it is therefore essential to study the complex processes through which translations come into being.

What about the concept of translator, then? How do we understand what translators do, especially for those aspects that don't fit in the paradigm of simplification, where translators' behavior doesn't fit in the dominant pattern of translational, literary or cultural norms? More in general, how can we write a cultural history that allows us to understand 
the complex interactions between individual and society, which questions easy lines of causality between individual action and social system, in which the determination of causation is bidirectional or complex (from the local to the global to the local, that is, upward and downward causation)? As a starting point, I would plead for studying translators as cultural mediators, that is, as actors clustering a variety of dialectically interacting roles and thus transgressing conceptual and disciplinary boundaries. It does not make sense to split up fields (literature, culture, politics, ....) nor to split up mediators' activities (writing, translating, ....). Again, an analytical focus on cultural mediators and the transfer processes they embody makes it possible to study cultural transfer and cultural history as they develop and change over time and to enhance our understanding of cultural dynamics.

Let me once again illustrate this with examples from translators/ mediators in interwar Belgium. Due to the Flemish emancipation claims (cf. supra), there was considerable discussion and even conflict about the form of a "Belgian" cultural identity in general and about the necessity or even desirability of cultural transfers and translation between the two language communities to construct this Belgian culture in particular. A simplified picture of mediators, corroborated by the insights of DTS and translation sociology (cf. supra), shows them as perfect bilinguals, belonging to the target culture- a picture that we don't need to abandon as such. It is, however, important to complement it with an epistemology of complexity in order to understand those aspects that remain obfuscated by the more traditional models. It is indeed interesting to notice that most mediators were of Flemish origin (the source culture), that they saw themselves often as Flemish and Francophones, as belonging to source and target culture, as incapable or unwilling of choosing sides. This becomes evident both in their practices (as they combined translation, bilingual writing and self-translation) and perceptions. Flemishborn poet-translator Camille Melloy (1891-1941) spoke only Flemish until the age of twelve. Like many of his contemporaries, he then went to a Francophone secondary school which made him a perfect bilingual. As an adult, Melloy became a Francophone poet and translator of Flemish literature. Melloy saw himself as a Francophone poet, "exclusively formed by French books", ${ }^{6}$ and he took a firm stand against what he called "the primitive ideology of the supporters of the Flemish Movement". ${ }^{7}$ At the same time, he stressed himself to "belong to a purely Flemish family, whose Flemish origins can be traced in the past to the 13th century". ${ }^{8}$ He moreover left open the possibility of becoming a Flemish writer ("It is not impossible that I'll start writing in Flemish one of these days ...") ${ }^{9}$ and was a prolific translator and friend of Flemish novelists. This made him consider himself "only a shabby Fleming" who handled "only vigorously the French language". ${ }^{10}$ A contemporary bilingual colleague of Melloy, Fleming Roger Avermaete, described himself and his 


\section{Reine Meylaerts}

friends as "decidedly internationalist-individualist, French-writing Flemish militants. This variety of the human fauna has remained a rarity". ${ }^{11}$ Avermaete and Melloy occupied both so-called Flemish and Francophone positions and saw themselves as belonging at once to the Flemish and to the Francophone Belgian literatures and cultures. They are a good example of how it makes no sense to choose between source and target, between Flemish and Francophone, between author-translator, between national-international, individual-collective: all these hold simultaneously and should not be resolved.

\section{Agency}

Complexity theory also questions easy lines of causality between individual action and social system and conceptualizes agency from a complexity perspective. The kind of predictive thinking that was criticized in the introduction assumes that things happen as the system predicts: there was a drive to translation from Flemish to French, and everybody was in on the act. A complexity view may hold that individual agents acted in some local/personal interest, which then can have an effect on the systemic level, which was not necessarily what they were agents for or intended. With regard to interwar Belgium, it is in this respect interesting to notice that some perfect bilinguals undertook hardly any transfer activities and that some of the most influential mediators were monolinguals who created new transfer practices and new frames of reference, promoting the idea of a "real" bilingual (Dutch and French) Belgian literature and culture. Monolingual Gaston Pulings (1885-1941) promoted Flemish theatre (the Vlaamsche Volkstooneel) among the Francophones. According to him, theatre settings, costumes and gestures created common frames of reference in which the language differences were irrelevant. Therefore, Francophones should attend performances of the Vlaamsche Volkstooneel even if they were entirely in Dutch.

If Flemish literature has penetrated so easily the French public, this is mainly due to its playwrights. In order to follow the writings of novelists, storytellers, poets, a profound knowledge of the language is needed, knowledge which is not needed to evaluate a play, the setting and the performance of the actors helping to understand. Go to see Flemish plays!

(Pulings 1929, 26) ${ }^{12}$

Monolingual Paul Vanderborght (1899-1971) was director of the Lanterne Sourde group, which was seen as one of the most important cultural networks of the interwar period. For Vanderborght, conferences on Flemish literature formed the main platform on which he established cultural mediation between the two language groups. Approximately 
ten conferences were organized in Brussels between 1925 and 1931. In May 1925, Vanderborght organized a manifestation in honor of the Flemish playwright Herman Teirlinck. At that occasion, speeches were given in French and in Flemish, without translation, as is testified by a contemporary:

This way, both national languages kept, one and the other, their character and their own rights. This procedure, based on the free associations of the two languages and the two cultures in Belgium, appeared completely new at that moment, all the more since it was adopted, without any political intention, by a group in which most writers expressed themselves in French. It was successful and often repeated in other similar meetings of La Lanterne sourde, which has as such contributed to bring the Francophone and Flemish Belgian writers closer to each other.

(La Nervie 1932, 5) $)^{13}$

And the contemporary critic concluded: "The work of reconciliation between French and Flemish language Belgian writers, freely undertaken by 'La Lanterne Sourde', has not been in vain" (La Nervie 1932, 8). ${ }^{14}$ Next to more conservative and much more frequent initiatives of translations of regionalist Flemish novels (see previously), Vanderborght's and Puling's rather exceptional and innovative roles as cultural mediators were based on non-translation and perceived as the most successful way to create a common Belgian culture. Not surprisingly, all these manifestations were extensively and positively covered in the Flemish press.

Small, unique actions by individual agents can cause large effects (or vice versa). The determination of causation is always bidirectional and complex: from agency to structure to agency, from the local to the global to the local and so on. As a consequence, we are "no longer dealing with the cause but rather with multiple interacting causes" (Byrne and Callaghan 2014, 189). The age-old tension between agency and structure, between translators/mediators and context should be reconsidered as a complex and continuous interaction between determinism and freedom, with uncertain outcomes. Complexity theory thus adds to our understanding of the complex, paradoxical relationship between agent and structure, an understanding that has benefits for translation studies' conceptualization of translators and mediators as agents of change, and of cultural dynamics at large.

\section{Conclusion}

Of course, we can continue to study cultural interactions, cultural transfer and cultural dynamics from a polysystemic and descriptive translation studies perspective. But searching for order, generalization, reproducibility, 
predictability is only one part of doing "good science". In order to really understand how cultural relations develop and evolve, we need to supplement it with a complexity theory approach, which can bring a much more nuanced understanding of the complex interactions and sometimes paradoxical and non-linear cause-effect relations that characterize cultural transfer and cultural dynamics. From a methodological viewpoint, we therefore need to adopt a relational and processual approach, with a clear eye for organizational patterns, networked relationships and historical context. In any case, instead of eliminating complexity, we should conceptualize it. Scholarly thought needs to be able to live with disorder, complexity, paradox. Or, as Prigogine said: "the new rationality looks at fluctuations, instability, multiple choices and limited predictability" (quoted in Marais 2015, 21).

\section{Notes}

1. Flemish was the term used at the time for the variants of Dutch that were spoken in Belgium. Therefore, we will also use this term here.

2. Preliminary norms govern a.o. the choice of works (or authors, genres, etc.) to be translated. On norms: see Toury (2012, 61-92).

3. Operational norms govern decisions made during the translating process, e.g. the choice of textual-linguistic material to replace source text material. On norms: see Toury $(2012,61-92)$.

4. My presentation of complexity theory in the following paragraphs is largely based on Meylaerts (2017, 48-51) and Marais and Meylaerts (2018,1-18).

5. E.g. objecting against translating Flemish dialect, very frequently used in direct speech, by French dialect in the translation.

6. "formé exclusivement par des livres français" (Vanclooster 2001); all translations into English are mine.

7. "l'inévitable idéologie de primaire des flamingants sur les déracinés” (Melloy 1941)

8. "une famille purement flamande, dont les origines flamandes peuvent être contrôlées dans le passé jusqu'au XIIIe siècle" (Vanclooster 2001).

9. "Het is niet onmogelijk dat ikzelf een dezer dagen mij aan het"schrijven zet in het Vlaamsch ..." (H.B. 1934, 4).

10. "Ik ben immers maar een verloopen Vlaming en hanteer maar flink de fransche taal.” (Melloy 1937).

11. "beslist internationalistische-individualistische fransschrijvende flaminganten. Deze variëteit van de menselijke fauna is trouwens een zeldzaamheid gebleven" (Avermaete 1959).

12. "Si la littérature flamande a pénétré si facilement ces dernières années parmi le public français, elle le doit principalement à ses auteurs dramatiques. Pour suivre les écrits des romanciers, des conteurs, des poètes, il faut une connaissance approfondie de la langue, connaissance qui n'est pas nécessaire pour juger une pièce, les décors, le jeu des acteurs aidant à la compréhension. Allez voir des pièces flamandes!"

13. "les deux langues du pays gardant ainsi, l'une et l'autre, leur personnalité et leurs droits propres. Ce procédé, fondé sur la libre association des deux langues et des deux cultures en Belgique, apparaît alors tout nouveau, d'autant plus qu'il a été adopté, en dehors de tout esprit politique, par un groupement où la plupart des écrivains s'expriment en français. Il réussira et sera, maintes 
fois repris, dans d'autres réunions similaires de "La Lanterne Sourde", qui a contribué ainsi au rapprochement confiant des écrivains belges de langue française et de langue flamande".

14. "L'œuvre de rapprochement entre les écrivains belges de langue française et de langue flamande, librement entreprise par "La Lanterne Sourde", n'aura pas été vaine."

\section{References}

Assis Rosa, Alexandra. 2010. "Descriptive Translation Studies (DTS).” In Handbook of Translation Studies, edited by Yves Gambier and Luc van Doorslaer, 94-104. Amsterdam: Benjamins.

Avermaete, Roger. 1959. "Letter to Ger Schmook." Correspondence Roger Avermaete, conserved at the Letterenhuis, Antwerp.

Bousquet, Antoine and Curtis, Simon. 2011. "Beyond Models and Metaphors: Complexity Theory, Systems Thinking and International Relations." Cambridge Review of International Affairs 24 (1):43-62. doi: 10.1080/09557571.2011. 558054.

Brack, Greg, Lassiter, Pamela S., Hill, Michele B. and Moore, Sarah A. 2011. "Ecosystemic Complexity Theory of Conflict: Understanding the Fog of Conflict." Journal of Humanistic Counseling 50 (1):3-15.

Byrne, David and Callaghan, Gill. 2014. Complexity Theory and the Social Sciences: The State of the Art. New York: Routledge, Taylor \& Francis Group.

Cairney,Paul.2012."ComplexityTheoryinPoliticalScience andPublicPolicy.” Political Studies Review 10 (3):346-358. doi: 10.1111/j.1478-9302.2012.00270.x.

Chamberlin, William. 2009. "Networks, Emergence, Iteration and Evolution." Emergence: Complexity and Organization 11 (4):91-98.

Chesterman, Andrew. 2011. "Translation Universals." In Handbook of Translation Studies, edited by Yves Gambier and Luc van Doorslaer, 175-179. Amsterdam and New York: John Benjamins.

Cilliers, Paul. 2001. "Boundaries, Hierarchies and Networks in Complex Systems." International Journal of Innovation Management 5 (2):135-147.

Even-Zohar, Itamar. 2005. Papers in Culture Research. Tel Aviv: Tel Aviv University.

Gonne, Maud. 2017. Contrebande littéraire et culturelle à la Belle Époque: le "hard labour" de Georges Eekhoud entre Anvers, Paris et Bruxelles. Leuven: Leuven University Press.

H.B. 1934. "Camille Melloy. Van een Vlaamschen pater die den Franschen Edgar Poe-Prijs voor poëzie won.” De Standaard, 9 juni 1934.

Heilbron, Johan. 2008. "Responding to Globalization: The Development of Book Translations in France and the Netherlands." In Beyond Descriptive Translation Studies: Investigations in Homage to Gideon Toury, edited by Anthony Pym, Miriam Shlesinger and Daniel Simeoni, 187-198. Amsterdam: Benjamins.

Human, Oliver. 2016. “Complexity: E-Special Introduction.” Theory, Culture \& Society 33 (7-8):421-440. doi: 10.1177/0263276415600105.

La Nervie. 1932. Special issue devoted to "Lanterne sourde." Brussels.

Marais, Kobus. 2015. Translation Theory and Development Studies: A Complexity Theory Approach. New York: Routledge.

Marais, Kobus and Meylaerts, Reine. 2018. Complexity Thinking in Translation Studies: Methodological Considerations. Milton: Routledge. 


\section{Reine Meylaerts}

Melloy, Camille. 1937. Lettre à Stijn Streuvels. Correspondence Camille MelloyStijn Streuvels, 1934-1941, Archief en Museum voor het Vlaams Cultuurleven, Antwerp.

Melloy, Camille. 1941. Lettre de Camille Melloy à Marcel Lobet. Correspondance Camille Melloy-Marcel Lobet, 1932-1941, Archives et musée de la littérature, Bruxelles.

Meylaerts, Reine. 2004a. L' aventure flamande de la Revue Belge langues, littératures et cultures dans l'entre-deux-guerres, Documents pour l'histoire des francophonies Europe. Bruxelles Bern Berlin: PIE-P. Lang.

Meylaerts, Reine. 2004b. "La Traduction dans la culture multilingue: A la recherche des sources, des cibles et des territoires." Target: International Journal of Translation Studies 16 (2):289-317.

Meylaerts, Reine. 2008. “Translators and (Their) Norms: Towards a Sociological Construction of the Individual." In Beyond Descriptive Translation Studies: Investigations in Homage to Gideon Toury, edited by Anthony Pym, Miriam Shlesinger and Daniel Simeoni, 91-102. Amsterdam and Philadelphia: John Benjamins.

Meylaerts, Reine. 2013. "The Multiple Lives of Translators.” TTR Traduction, Terminologie, Rédaction 26 (2):103-128.

Meylaerts, Reine. 2017. "Studying Language and Translation Policies in Belgium: What Can We Learn from a Complexity Theory Approach?" Parallèles 29 (1):45-59.

Mitchell, Melanie. 2009. Complexity: A Guided Tour. New York: Oxford University Press.

Morin, Edgar. 2008. On Complexity. Translated by Robin Postel. Cresskill: Hampton Press.

Pulings, Gaston. 1929. "Herman Teirlinck.” La Scène Catholique, 25-27.

Pym, Anthony. 1998. Method in Translation History. Manchester: St. Jerome.

Şerban, Adriana. 2012. "Translation as Alchemy: The Aesthetics of Multilingualism in Film; Translation as Alchemy: The Aesthetics of Multilingualism in Film.” MonTi: Monografías de Traducción e Interpretación 4 (2):39-63.

Simeoni, Daniel. 1998. "The Pivotal Status of the Translator's Habitus." Target $10(1): 1-39$.

Toury, Gideon. 2012. Descriptive Translation Studies: And Beyond: Revised Edition. Amsterdam and Philadelphia: John Benjamins.

Vanclooster, Stijn. 2001. "Camille Melloy: een Gezelliaan dicht in het Frans." Zacht Lawijd 1 October (1):34-39. 


\section{Part II}

\section{Cultural Organizations}


$\because$ Taylor \& Francis

Taylor \& Francis Group

http://taylorandfrancis.com 


\section{A Representative Organization? \\ Ibero-American Networks in the Committee on Intellectual Cooperation of the League of Nations (1922-1939)}

\section{Martin Grandjean}

\section{Introduction: Organizing "Intellectual Cooperation” After the First World War}

How to choose the people who will coordinate the restructuring of science at an international level and promote intellectual exchange after the First World War? World-renowned scientists whose popularity will "lead by example", great academic administrators familiar with institutional issues or diplomats representing the great victorious powers to secure political support? This is the question to be answered by the Secretariat of the League of Nations in the autumn of 1921. The Assembly having endorsed the creation of an International Committee on Intellectual Cooperation (ICIC), the task of the Japanese Under Secretary-General Inazo Nitobe is to name the twelve most appropriate personalities.

In the context of a nascent League of Nations whose primary missions are focused on economic issues in a troubled Europe, intellectual issues are not a priority. Yet, and the development of the first true cultural diplomacy strategies in several states during the 1920s proves it, these twelve appointments have an undeniable political character.

The purpose of this article, falling within the framework of our research on the networks of intellectual cooperation (Grandjean 2018), is to conduct a study of the constitution of the ICIC by reversing the focus usually consisting of commenting on the presence of a few famous personalities (Albert Einstein, Marie Skłodowska Curie, Henri Bergson, etc.) to question the nomination process and to highlight the contribution of several Ibero-American representatives. Without proposing an exhaustive inventory of all the publications that describe intellectual cooperation, it is worth noting that most studies either adopt a very institutional approach like Northedge (1953) or Pham (1962) or focus on international issues, as in Laqua (2011b) and Laqua (2011a). It is also not uncommon for the Committee to be mentioned as a cultural actor in the biographies of its members, without always describing its structure and work with precision. Moreover, and because of this vagueness, the Paris perspective is often preferred to the Geneva viewpoint because of the archives of the 
International Institute of Intellectual Cooperation (IIIC), later founded in the French capital to assist the ICIC in its work, and considered the ancestor of UNESCO. ${ }^{1}$ With regard to Ibero-American personalities, this sometimes implies a focus on the Spanish writer and diplomat Salvador de Madariaga and his involvement in the Institute. ${ }^{2}$ It should also be noted that the various projects of the League concerning intellectual cooperation and their relationship with the Iberic and Latin-American world have already been well studied in Pernet (2007), Dumont (2008), Dumont (2012), Roig-Sanz (2013), Pernet (2014), Dumont (2016) and Roig-Sanz (2016). However, the following pages do not attempt to embrace the question of international cultural relations regarding these countries but to take the Committee on Intellectual Cooperation's microcosm as our object and to question its representativeness. ${ }^{3}$ Here, the challenge is to try to understand the appointment mechanism and in particular the notion of "national culture" that is often used to explain the balance between national representatives within the ICIC.

In the following pages, it will be seen that the principle that governs the appointment of these experts has two distinct periods. Foremost, the initial appointment of the first twelve members in 1922 is a kind of test that does not show great diversity. It is only when it comes to replacing resigning members that the Secretariat and the more political bodies of the League attempt to define a systematic renewal method implicitly based on the influence of nations or groups of nations in other instances of the institution.

While we may sometimes seek to explain the genesis of the Committee on Intellectual Cooperation by going back to the internationalist and pacifist movements of the end of the nineteenth century, its creation in the early 1920s has little to do with the great projects of "international universities" or "parliament of intelligences" of the time. At the end of the First World War, the League of Nations is indeed a construction of a new kind that differs very much from the Belle Époque conceptions that saw the flowering of technical congresses and private associations (Grandjean and Van Leeuwen 2019): in this new world order, the Member States centralize their negotiations in a single place that quite bypasses the previous modes of organization. But while the League seeks to embrace all the modalities of a global and peaceful coexistence, it remains an instrument primarily designed to settle economic and political issues. The scientific and intellectual questions are very secondary, and the already tight bookkeeping of the institution will never allow assignment of a significant budget to intellectual cooperation.

But in the momentum of the first years, many are the voices that call to think of international cooperation in all its forms and to integrate the intellectual questions. Chaired by Miguel Gastão da Cunha, representative of Brazil, the meeting of the Council of March 1st, 1921, in Paris, 
takes note of the report of Quiñones de León on this subject entitled "Organization of intellectual work". In his report, the representative of Spain recalls that even though

the Covenant is silent on the relations of the League to what may be called voluntary associations of private character [...], from the general tone of the Covenant we infer that the League should exercise its good offices in the interest of all international undertakings that will contribute to the advancement of good will and mutual understanding among the nations. ${ }^{4}$

This notion of mutual understanding is a fundamental argument in favor of intellectual cooperation, but it is also clear-in the report and subsequent discussions-that the League would prefer that this task continue to be the prerogative of private associations. In the course of the debates, the project of setting up a highly formalized technical organization, like the International Labor Organization, is then gradually revised to prepare the establishment of an advisory committee. On September 8, 1921, the Fifth Commission of the Assembly is finally asked to take a decision on the report by the French senator Léon Bourgeois proposing the creation of the ICIC. On the proposal of the Chilean delegate Manuel Rivas Vicuña, the commission asks the Belgian Henri La Fontaine to make a presentation on the question of intellectual work. Co-founder of the Union of International Associations (UIA), this Nobel Peace Prize laureate is well placed to talk about it since he has been fighting for many years with his colleague Paul Otlet for these issues to be taken into consideration (Rayward 2003), (Laqua 2009). Presenting how their Belgian experiments can be a source of inspiration, he expresses "the ardent hope that the League of Nations can build itself on existing foundations", 5 implying that the UIA could become an official satellite of the League.

But rather than prepare for the creation of a very bureaucratic structure in Geneva or the integration of Belgian institutions, the ICIC adopted with Bourgeois's report of autumn 1921 will gradually be stabilized by acquiring a permanent status but keeping its more deliberative rather than executive nature. In fact, the Committee as such has above all the merit of bringing together personalities from various horizons and sending a signal to the world of science and culture. However, it has never had the means to go far beyond this relatively symbolic role since its missions have never been precisely defined and because its small size made it a place whose continuity was very dependent on the personalities that compose it. The name of the Committee itself is also a symbolic element of this indecision. The difficulty of defining precisely what "intellectual cooperation" is can be considered an element that prefigures the future complications when it will come to agreeing on concrete actions to be 
carried out under such a label. In an internal note of 1922, Inazo Nitobe thus recalls the terminological wandering of the first years:

In French the term "Organization internationale du Travail intellectuel" was consistently used; but in English this Committee has been called by various names, giving rise to a good deal of misunderstanding. In the Assembly resolution the term "International Organization (sometimes 'Coordination') of Intellectual Work" was used, and this title was adopted in the earlier documents relating to it. It naturally led to a mistaken idea that the object of the Committee was to start an organization something like the International Labour Office for intellectuals [...]. This notion has continued long and spread widely. Then it was also believed by outsiders that the Committee would deal with questions of education, and hence terms such as "Committee on International Education", "Intellectual Intercourse and Education", and "Intellectual Development Committee" were used by correspondents. ${ }^{6}$

He adds that the Secretariat had taken an active role in stabilizing this new nomenclature. In order to avoid misunderstanding and to "better assert the character of the committee", he admits in this note that he has systematized the use of the term "intellectual cooperation" in the Secretariat's correspondence. However, this term is very strongly marked by the will of some delegates-French in particular-to make this committee a body that deals with educational issues related to the need to build a world of mutual understanding. In fact, the ICIC concentrated on coordinating scientific and cultural exchanges in circles wishing to be associated with its work (all the learned societies and international organizations created before the war did not necessarily look favorably on the centralization induced by the League).

\section{The Appointment of the First Committee: Priority to Personalities Over Nationality}

Beginning the designation process in December 1921, Inazo Nitobe writes to the Secretary General Eric Drummond that "the committee should be as small as possible, for economic reasons and efficiency". ${ }^{7} \mathrm{He}$ recommends that it should be composed of only seven or eight members, while the resolution allows the appointment of twelve experts. In the same note, he finds "highly desirable that an American and a German be invited", if possible directly by the Council as a mark of good will towards these two nations, which have not joined the League. Very concretely, he envisages the participation of personalities from the following countries: Great Britain, France, Italy, Belgium, Colombia, India and Norway, and why not also Spain, Czechoslovakia and Austria. The under-secretary general 
specifies that the representative of Norway could be a woman, indicating that he already thinks about the candidature of the zoologist Kristine Bonnevie, member of her national delegation to the League. It is obvious that the selection of certain other countries in this list is also due to informal and convincing applications (Colombia, India, Norway or Czechoslovakia aren't prominent members during the first years of the League).

On the morning of January 14, 1922, the twelfth meeting of the sixteenth session of the Council is not yet ready to make the appointments as initially planned, ${ }^{8}$ but Nitobe has already started to put names on a list that remains confidential. ${ }^{9}$ This list will increase in the following months: at the end of March, no less than fifty-eight names are communicated to the Council ${ }^{10}$ (they are followed by a dozen other late proposals). Since this list serves as a basis not only for the composition of the ICIC of 1922 (it already contains most of the members who will actually be appointed) but will also later be a pool of candidates, it is worthwhile to look at the representation of Ibero-American personalities within it.

Among them are Cecilio Báez, Paraguayan professor of international law and Rector of the University of Asunçion; the former Portuguese Prime Minister Afonso Costa, director of the Faculty of law at the University of Lisbon; the Ambassador of Colombia in Bern, Francisco-José Urrutia Olano, who will then sit at the Permanent Court of International Justice; or the Brazilian law professor Francisco José de Oliveira Viana. But not all of them are lawyers, as there are also representatives of the sciences, like the Spanish professor of histology Santiago Ramón y Cajal, also president of the Junta para Ampliacion de Estudio; the engineer Leonardo Torres y Quevedo, director of the Electrico-Mecanico laboratory of Madrid, the former director of the Museo Nacional of Buenos Aires and the Argentinian Conseijo de Educacion Angel Gallardo or the Brazilian Aloysio de Castro, director of the faculty of medicine of the University of Rio de Janeiro. On the humanities side, Uruguayan Carlos Vaz Ferreira, philosophy lecturer at the University of Montevideo, and Spanish philology professor Ramón Menéndez Pidal are also listed.

Despite this inventory, Spanish-speaking and Portuguese-speaking personalities are largely underrepresented among the candidates. They represent only $14 \%$ of the list, while the founding members of the League of Nations have seventeen Iberian and Latin American countries out of forty-two $(40 \%) .{ }^{11}$ However, at this point, it appears that if everyone within the Secretariat agrees to consider that personal skills of a candidate qualify him more than his nationality, the wish to select leading scientists is quickly overtaken by the very empirical constitution of this list. Even if Léon Bourgeois declares a few months later, at the award ceremony of his Nobel Peace Prize, that the ICIC is "a Committee composed of the most eminent scientists, the widest and highest intelligences" (Haberman 1972), the composition of the ICIC is mainly the product of a bargain between the diplomats seating in the Council of the League. 
Moreover, as the definition of the ICIC is not clear for everyone in these early years, the profiles are extremely diverse. Then, the status of their applications is quite variable: if some names are proposals or suggestions from third parties that do not engage the person concerned, others are formalized applications, as this is the case for the French philosopher Henri Bergson, who explicitly gives his approval to his Ministry of Foreign Affairs (Renoliet 1999, 23). But even if all the personalities that appear on this document are not mentioned for the same reasons, some having been registered following the prospects of the Secretariat and others because they are parachuted by governments that see there a good opportunity to take part of the decisions on this matter, this list is a fundamental tool for Inazo Nitobe. A detailed analysis of these profiles shows that beyond the twelve scientists appointed in 1922, at least thirteen others will participate in the work of the Committee, of which eight will do so very directly as members or substitutes (Grandjean 2018, 539-541). This list, even imperfect, is therefore a reservoir, a resource that will be mobilized by the Secretariat for several years.

But while the very unequal representation of nations in this list might suggest that the future ICIC itself will be composed in the same way, it must not be forgotten that the implicit rule of national quotas (one representative per country) could, on the contrary, prejudice countries with a large number of candidates competing with each other. We can therefore see this list as a testimony to the interest of nations in intellectual cooperation, more than an estimate of their immediate influence on the appointment decision. The low proportion of Ibero-American candidates therefore seems to reflect above all the moderate interest of intellectual cooperation (or its centralization by the League) in these circles. It also indicates that nationals of these countries have generally fewer relays in Geneva and within the League than some of their colleagues. In the end, the wide variety of backgrounds and the international reputation of a small number of the candidates facilitate the decision of the Council, as Nitobe recalls some months after the appointment: "As the list contained names very well-known in each country, there was little difficulty in the Council making a choice". ${ }^{12}$

On May 15th, 1922, the Council holds at Geneva the seventh meeting of its eighteenth session under the presidency of Quiñones de León and adopts a new report by Léon Bourgeois. ${ }^{13}$ In the wake, eleven people are appointed to sit in the new ICIC, the Council keeping the possibility to appoint a twelfth thereafter, in order to have some time to evaluate a North American candidacy. ${ }^{14}$ Among the Ibero-American candidates, Aloysio de Castro and Leonardo Torres y Quevedo have been selected. The Brazilian and the Spanish will sit at the same table as the FrenchPolish chemist Marie Skłodowska Curie, the Belgian Minister Jules Destrée, the German physicist Albert Einstein, the Italian senator Francesco Ruffini, the British philologist Gilbert Murray, the Swiss professor of 
literature Gonzague de Reynold, the Norwegian zoologist Kristine Bonnevie, the Indian economist Debendra Nath Bannerjea and of course the French Henri Bergson, who will become a few months later the first president of the Committee.

The American astronomer George Ellery Hale is finally appointed, after having initially refused for health reasons. ${ }^{15}$ But it is his compatriot Robert Andrew Millikan, who already assists him during the first session of the ICIC, who will definitively take his place at the autumn 1922. ${ }^{16}$ The nomination of the other representative of a non-member nation is also not without difficulties: Albert Einstein, after agreeing on May $30,{ }^{17}$ announces on July 4 that he is reconsidering his decision. ${ }^{18}$ Panic seizes the Secretariat, as the officers rely on a personality like the German scientist to guarantee a certain visibility to the Committee. On Bergson's advice, the under-secretary general, Bernardo Attolico, writes to Einstein to urge him to reconsider his judgment, which will surely cause "a deep disappointment" to the members and the public. ${ }^{19} \mathrm{~A}$ few days and telegrams later, it becomes clear that Einstein gave up because "the assassination of the minister [Walther] Rathenau, of which he was a personal friend, saddens him so much that he prefers to refrain now from any political action". ${ }^{20}$ Fortunately, on July 28 , a telegram from the director of the League of Nations Information Section Pierre Comert inform the Secretariat that "our friend withdraws his resignation and promises full cooperation [...]". ${ }^{21}$ The German physicist will use his right to withdraw from the ICIC again a few years later, before returning once more (Wonsch 2004).

\section{The Formalization of the Renewal Mechanism and the Notion of "Culture": A Challenge for Small Nations}

The principle of a committee standing above political stakes and bringing together experts selected for their own personal scientific achievements, in order to pursue the ceaseless quest for a body where all cultures, nationalities, disciplines and academic organizations are represented, is one of the greatest paradoxes of the International Committee on Intellectual Cooperation. Immediately, Nitobe recognizes that this intention does not resist the international functioning of the great machine that is the League of Nations: "In the nomination of members, nationality was to be ignored in principle, and only the personal merits of individual candidates were to count. Such an ideal principle of appointment was hard to follow".22

And this tension is not only a transfer of the global issues that are being expressed in the Assembly or a consequence of the complex representativeness of the secretariat (Dykmann 2015)(Gram-Skjoldager and Ikonomou 2017), but it takes a particular form within the framework of the Section of International Bureaux since relatively different conceptions 


\section{Martin Grandjean}

of the notion of "intellectual cooperation" exist according to whether one has a French, Belgian, Scandinavian or Anglo-Saxon view (Saikawa 2014). In the fall of 1923, the ICIC, aware of this problem, tries to clarify its own representativity principle: "it is desirable [...] for the Committee to include, as far as possible, representatives of the principal branches of intellectual activity and at the same time representatives, not of nationalities, but of the principal cultural groups." 23 While this notion of "culture" or "cultural group" may seem obscure or very reductive today, it is perfectly in tune with the context of the League of Nations at the time. Already in the 1920s, but even more after the Second World War, the institution (and the ICIC with it) is often analyzed as a place of opposition between Latin and Germanic (or Anglo-Saxon) cultures. ${ }^{24}$ Intellectual cooperation is also often considered to be monopolized by the Latins, and in particular by France since the creation of the IIIC in Paris in 1926. However, even if the Committee does have a majority of representatives of the very large Latin cultural group during the 1920s, this trend subsequently diminished in the 1930s (Grandjean 2018, 295). And to use this criterion implies that there is some kind of unity among the nations concerned, which is anything but obvious. Moreover, hiding behind these so-called "cultural groups" to justify the composition of the ICIC is hard to defend since three-quarters of its first members come from Western Europe. With the exception of a Brazilian, an American and an Indian (Bannerjea works, however, in Germany), all the personalities summoned in 1922 come from a region that represents only a small proportion of the world's population. This distribution is not surprising compared to the main centers of scientific activity of the early twentieth century; it reflects the lack of diversity of the members of the Council.

Less than a year after the appointment of the Committee, the question of representation becomes an internal policy issue since the Assembly of the League is seized by "legitimate requests formulated by the Romanian, Serbian-Croat-Slovene and Czechoslovakian, Spanish-speaking Americans, Asians, as well as Irish and Finno-Ugric delegates", ${ }^{25}$ questioning the diversity of the ICIC and proposing to include representatives of nations or groups concerned. The intense debates of the Fifth Commission of the Assembly on this subject do not lead to concrete measuresintegrating the representatives of all the States wishing to participate is not realistic-but shows the growing interest of nations hitherto neglected. ${ }^{26}$ Yet this concern for cultural diversity and its expression at the Assembly is complex. Indeed, these delegates offer the representatives of the "old nations" 27 an argument that could be turned against them since they have spontaneously gathered together by region or language group to submit their resolution. De facto, one could consider that if a "Spanish-speaking American" personality sits in the ICIC, more than a half of the continent could be considered represented if it is agreed that it forms a single "cultural group". 
An increase in the number of members seems anyway inevitable to allow better representation, to organize rotations within these more or less defined groups. This extension is already perceived as a victory. In an exalted speech, the Romanian writer Elena Văcărescu welcomes this decision while positioning herself as the spokesperson of South America, Asia and Eastern Europe. She is joined by the Venezuelan delegate, the historian and diplomat Caracciolo Parra-Perez, who recalls "the growing interest that several [Spanish-speaking American] countries have for the development of intellectual relations between peoples". ${ }^{28}$ As the discussion continues, the Portuguese delegate Joâo Pinheiro Chagas, diplomat and journalist, puts more particularly the emphasis on the principle of representation and confesses bitterly "to be a little surprised to have to note that the question of whether a State has a culture enabling it to be included in an intellectual committee depends on a more or less benevolent judgment of the Council". ${ }^{29}$

However, increasing the representativeness of the Committee without jeopardizing its fragile budget is a project made all the more difficult as travel is a cost item proportional to the remoteness of the countries concerned. And they are naturally far away since the main countries of Western Europe are already represented in the ICIC. This budgetary issue is of great concern to the Secretariat, and several extra-European appointments will be discussed in financial terms. The discussion concerning the integration of a Chinese representative in 1926 is a good example: "the nomination of a Chinese member in the ICIC would be possible if the Chinese government refrained from inciting other countries to make the same demands at the Assembly". ${ }^{30}$ For some time, therefore, the lack of representativeness is reduced by the appointment of "correspondents", who attend the meetings without being paid by the League.

But that same summer 1924, the ICIC already gathers fourteen members. It turns out that the unexpected return of Albert Einstein, whose seat has meanwhile been assigned to his former Dutch professor Hendrik Lorentz, pushes the Council to reintegrate him without waiting for the departure of another member. Inspired by this example, the delegate of Uruguay asks the Council to appoint a representative of the Spanishspeaking American nations (Brazil and Spain are already represented): on June 16, Leopoldo Lugones, editor of La Nación (Buenos Aires) and professor of aesthetics at the National University of La Plata, is appointed by the Council, bringing to three the number of Ibero-American personalities (see Figure 4.1).

Gradually, this very subjective functioning is adopted, and the first renewals show that it becomes obvious that the Council tries to maintain a certain balance: when a member resigns, he is replaced by a national of the same country or of a neighboring country. This is the case when preparing the succession of Torres y Quevedo in 1926: the Spanish ambassador Quiñones de León takes the lead and insists on being replaced by 


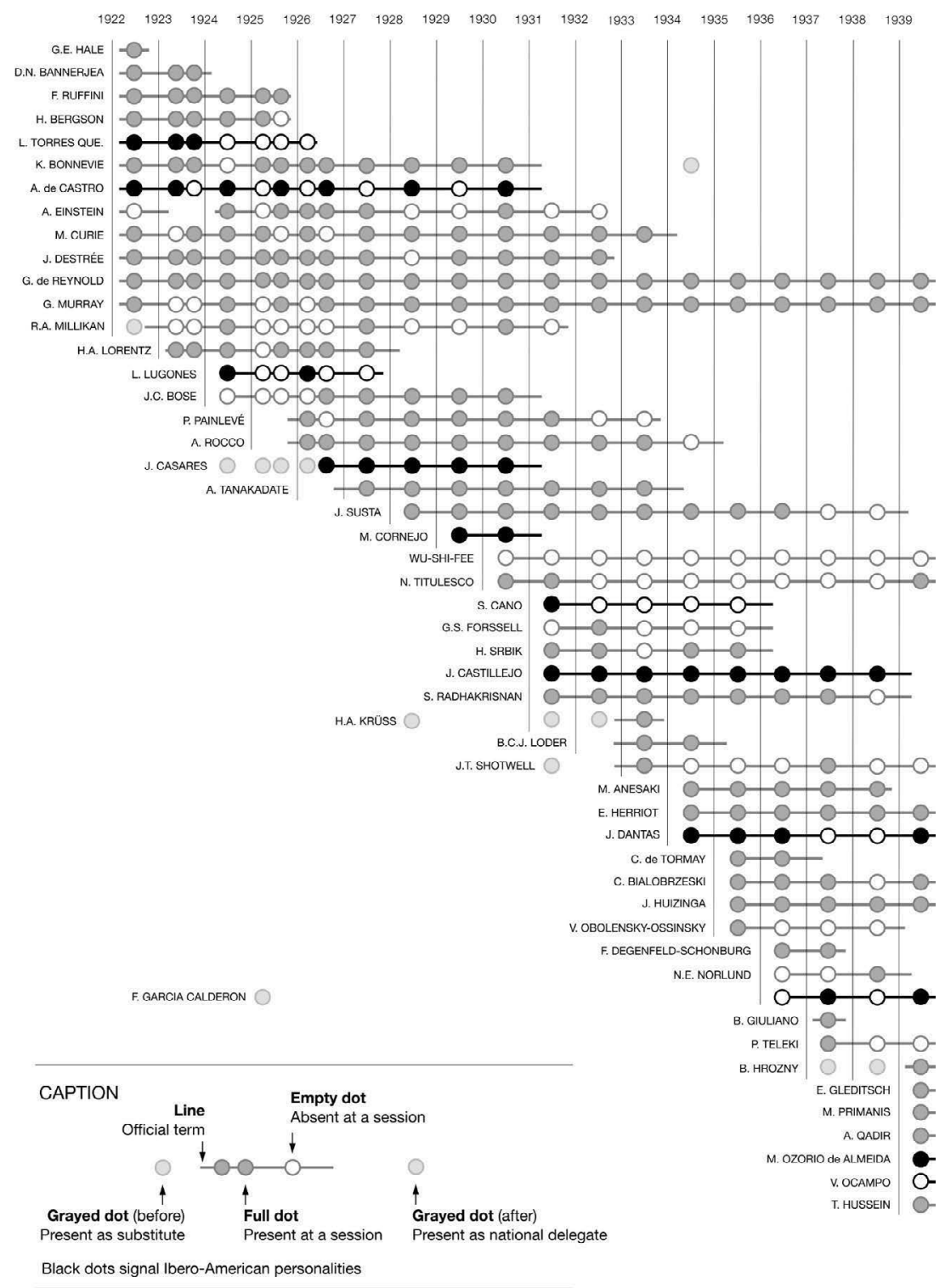

Figure 4.1 Composition of the International Committee on Intellectual Cooperation Between 1922 and 1939, Highlighting the Ibero-American Personalities (Black).

someone who will bring "the reflection of the Spanish intellectuality" 31 to the ICIC. This episode is interesting for two reasons: first, it explicitly shows that the cultural criterion, whether for the representation of "Spanish-speaking American nations", or "Spanish intellectuality", is 
fully integrated by the diplomats who renew members. Second, it highlights the existence of a two-tier system between nations having a fixed seat and those that share one: the inflexibility of the main European powers forces the ICIC to grow rather than replace from time to time a French, British, Italian, German or Spanish representative with a personality from a less involved country.

All this contributes to the establishment of a certain "rhythm" for the Committee that leaves its temporary status in the summer of 1926 to become a permanent body of the League of Nations. ${ }^{32}$ With this stabilization, the term of office is officially fixed at five years (it was not fixed as long as the Committee was temporary). ${ }^{33}$

The ICIC is increased a few months later to fifteen members, integrating the Japanese physicist Aikitu Tanakadate, emeritus of the University of Tokyo (nominated in December 1926 but seated for the first time at the next session in July 1927). ${ }^{34}$ Viscount Ishii, Japanese representative in the Council, explicitly stipulates on this occasion that this candidature is justified by the withdrawal of Inazo Nitobe from his position of director of the Section. ${ }^{35}$ This new increase, forced by an influential member of the Council, is the last one to proceed in such an unexpected way: at the beginning of the 1930s, the Committee profoundly reforms its organization as well as that of the Paris Institute. Enacted on September 9, 1930, on the basis of a recommendation of the twelfth session of the ICIC, ${ }^{36} \mathrm{a}$ new system states that one-third of the Committee must be replaced each year. This de facto reduces the term of office of the members to three years and forces many long-standing members to leave. The number of members is increased to eighteen in 1934, a figure that will now vary only in 1937 to reach nineteen members. Figure 4.1 makes the acceleration of the renewal of the ICIC very visible since 1931: the increase in the number of new arrivals generally varies between three and six per year, whereas it was instead between one and two during the 1920s. This visualization of the mandates' duration also makes visible the generally stable representation of Ibero-American members (in black on Figure 4.1, see also Figure 4.2). It also shows that the year 1930 is a real turning point in terms of the representation of the concerned countries. Indeed, while the 1920s still see two or three terms overlap, the arrival of the Columbian journalist and ambassador Baldomero Sanín Cano and the Spanish law professor José Castillejo in 1931 happens as all their Ibero-American colleagues leave, creating a steep transition for this "cultural group".

While the Brazilian Aloysio de Castro demonstrates a long-standing commitment to the ICIC, since he remains there for the entire decade, his early Spanish colleague Leonardo Torres y Quevedo is replaced in 1926 by Júlio Casares, a journalist and lexicographer who is a member of the Spanish delegation to the League and had already replaced him during the last three years. The third seat created for the Spanish-speaking Americans in 1924 is filled again after the departure of the Argentinian Leopoldo Lugones by the Peruvian senator and professor of sociology 


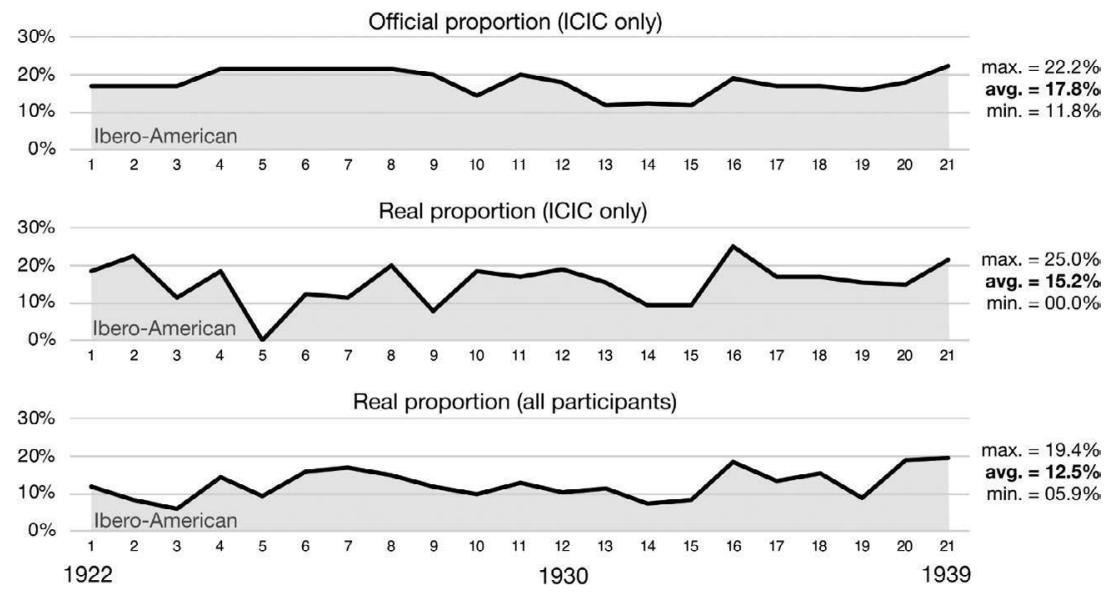

Figure 4.2 Comparison Between a) the Proportion of Ibero-American Members Officially Appointed; b) the Proportion of Them Really Attending the Sessions (Without Substitutes); c) the Proportion of All IberoAmericans Attending the Sessions Among All Participants (Members, Substitutes, Delegates, Secretaries, etc.).

Mariano Cornejo Zenteno in 1929. But the latter remains only two years in the Committee. With Castillejo replacing Casares, the Spanish delegation is still present after the turn of 1930, while Cornejo's South American seat moves from Peru to Colombia. But it will be necessary to wait for the appointment of the president of the Portuguese Academy Júlio Dantas in 1934 for the Portuguese language to once again be represented at the ICIC. Rarely present, Sanín Cano is replaced in 1936, and his seat returns to Peru with the appointment of the writer and diplomat Francisco García Calderón Rey. The very last session of the Committee, finally, sees the appointment of the Brazilian Miguel Ozório de Almeida and the Argentinian Victoria Ocampo. The first will therefore sit only once, while the second is not even present in Geneva in 1939.

\section{Compared to Official Balance, a Weaker Ibero-American Real Presence}

To list the members of the ICIC is a duty for most of the researchers who have attempted to describe the Committee without limiting themselves to the initial composition of 1922. Thus, if Bekri $(1990,245-48)$ and Löhr $(2010,286-88)$ reproduce the list established by Pham (1962) without modifying it, probably on the basis of Council documents, Renoliet $(1999,184-185)$ draws up a table whose data are more faithful to the documents of the Committee. But it is limited to mention the officially 
appointed members. Based on the minutes of the twenty-one sessions, which accurately describe participants' attendance and absences, Figure 4.1 confronts this data with a reality that quick statistical studies do not generally take into account: the repeated absence of some members considerably modifies the balance and almost nullifies the conclusion based on the official presence of the experts. As trying to understand the composition of the ICIC also means highlighting the "minor" participants of these sessions (the many substitutes, secretaries, delegates of national commissions or other institutions), taking the attendance rate into account gives very useful quantitative information to qualify the investment of each one, if not in the global work of intellectual cooperation, at least in these annual sessions that can be considered the backbone.

To sit for many years does not always mean to be actually present during the sessions: among the twelve personalities who benefit from a mandate covering ten sessions or more, only five concretely participate at least ten time. In terms of actual attendance, there is indeed a twospeed Committee, between the members who attend almost all the sessions for which they are elected and those who are absent most of the time. Among the first absentees, Albert Einstein is particularly exemplary since-if we exclude the two sessions of 1923 consecutive to his temporary resignation - he takes part only in one out of two sessions until his definitive resignation in 1932. It is, however, George Hale's substitute, Robert A. Millikan, who appears to be the most absent during the first decade of the ICIC since he only attended a quarter of the sessions. The representation of the United States of America is all the more diminished in the Committee, as the compatriot replacing Millikan in 1933, the professor of history at Columbia University James T. Shotwell, is no more assiduous since he only attends two sessions out of seven until 1939. Is this the sign of a lack of interest or material and temporal constraints? While it is true that it is easier for the Swiss Gonzague de Reynold to attend sessions in Geneva or Paris than for a South American or Asian scientist, our analysis shows no conclusive correlation between distance and absenteeism (personalities living in India or Japan are very present, for instance). This observation should remind us that the nationality of a scientific or diplomatic personality participating in the works of the League of Nations is only a very vague indicator of the real distance they travel to join the sessions: many of them are attached to European universities or an embassy near Geneva.

Unlike those who are rarely present, others are active participants, such as the philologist Júlio Casares (Madrid) who, because he is part of the Spanish diplomatic delegation to the League, replaces his fellow Leonardo Torres y Quevedo four times before sitting himself for the next five sessions, without any absence.

Overall, the increase in the number of members, from a minimum of twelve to a maximum of nineteen, does not change the total attendance 
rate at ICIC sessions. It usually varies between $60 \%$ and $80 \%$, with two occurrences below the $50 \%$ mark: the fifth session, "convened fairly quickly" 37 in May 1925, where only six out of fourteen members are present, and the twentieth session in July 1938, where seven out of seventeen members actually sit. On this occasion, president Gilbert Murray wonders if he shouldn't rejoice in this situation "since it allows the Committee to enter into relations with other remarkable personalities who replace them". 38

And in terms of absenteeism, how are Ibero-American members performing? Here, taking these nationalities as a category only makes sense in a study of their international networks and in relation to the assumption that they represent a "cultural group" in the sense of the 1920s. It is therefore not a question of comparing their representation to that of other national or groups (since the coherence of the Spanish- and Portuguese-speaking group is very relative, and defining these other groups is also ambiguous) but rather of comparing its evolution in time. The first of the curves of Figure 4.2 indicates, session after session, the proportion of these personalities appointed to the ICIC. This is a theoretical value that tells us about the official balance and the place left to the representation of Ibero-American nations. If the evolution is relatively stable over time (between two and three representatives, exceptionally four in 1939), there is an obvious disparity between the nations since Spain is systematically represented in the Committee from 1922 to 1938. The remaining one or two seats go to representatives of Latin America until the appointment of the Portuguese Júlio Dantas in 1934 (during the next five years, the Iberians are more numerous than the Latin Americans). In fact, Spanish-speaking experts are still largely in the majority even though there are officially only three sessions without Portuguese-speaking experts (the latter having a higher rate of absenteeism).

The second curve of Figure 4.2 completes the first one since it takes the absences into account, in proportion to the real presence of all ICIC official members. As a result, on rare occasions (the second and sixteenth sessions, in particular) the actual proportion of Ibero-Americans exceeds the theoretical proportion due to the absence of many other members of the Committee. But, on average, these representatives are less present in person than their colleagues. The graphs also state that at the fifth session (1925), no Ibero-American experts were present.

The third curve of Figure 4.2 covers all the people attending the Committee's sessions, including substitutes, international civil servants and invited experts of diplomats. If their presence is significant enough in the second half of the 1930s, it is clear that Ibero-American are very largely underrepresented, especially among the auxiliary actors that will be the focus of the following paragraphs. 


\section{Beyond the Official Members, a Multitude of Other Participants}

In the shadow of scientific and political figures, whose brilliance is never forgotten in the written history of the institution, hides a population at least three times more numerous: the substitutes, secretaries and delegates from third-party institutions. And their importance is all the more crucial for the ICIC, as they-in addition to ensuring the link with the other bodies of the League of Nations and beyond-are sometimes the guarantors of the continuity of the work and spirit of intellectual cooperation. These personalities are anything but "secondary characters".

Even if their names are rarely recalled in this context, it is of course among the international civil servants of the Secretariat of the League that we finds the individuals who concretely "make" the intellectual cooperation on a daily basis, a statement corroborated by a systematic analysis of the archives of the Committee (Grandjean 2017, 389-390). To these members of the Secretariat are added representatives of the International Labor Office, experts convened to deal with technical questions or the direction of the Paris IIIC after its creation. But if we concentrate on Spanish and Portuguese-speaking personalities, who are not widely represented among these categories of international civil servants, two main groups emerge. In the first place, the substitutes are the most important group since the absences of certain members makes it necessary to ask many colleagues or diplomats to serve temporarily. Then there are the delegates of the "national committees" of intellectual cooperation (NCICs), structures created by the national academies or universities in the most active countries at the request of the ICIC. They serve as local relays and, from time to time and especially from 1933, are solicited by the League and invited to participate in the plenary sessions. It often happens that the most prominent personalities of these national committees are also those that the titular members choose to replace them.

The Venezuelan diplomat Alberto Zérega Fombona, professor in Caracas and Paris, is the first to replace an Ibero-American member of the Committee when he participates as Castro's substitute in 1923. He's followed by the Uruguayan writer Juan Antonio Buero, delegate to the PanAmerican conference in Santiago de Chili in 1923 and senator, who replaces Lugones in 1925. Replacing Castro in 1926, the Brazilian diplomat Elizeu de Montarroyos will also participate to the works of the ICIC in 1934 and 1938 as a delegate from the Brazilian NCIC. The same year, Lugones is replaced by the Argentinian vice-consul in Geneva Alejandro Unsain and the next year by the Ecuadorian writer and ambassador in Paris Gonzalo Zaldumbide, who will come back twice in 1934 and 1935 as a delegate from his state. In 1927, the Brazilian senator and engineer Paulo de Frontin, director of the Polytechnic school of Rio de Janeiro, sit as substitutes for Castro. This latter is replaced two years later by 
the Brazilian physician and writer Júlio Afrânio Peixoto, member of the Brazilian Academy and Parliament, professor at the University of Rio de Janeiro and member of the Brazilian NCIC.

The arrival of Baldomero Sanín Cano in 1931 is synonymous with many replacements since he only personally attends one in five sessions. The Columbian writer Antonio José Restrepo acts as his substitute in 1932, followed by the pedagogue Agustín Nieto Caballero in 1934 and the Chilean delegate to the Assembly and writer Manuel Rivas Vicuna in 1935. During the last years of the ICIC's work, García Calderón is also replaced by the plenipotentiary secretary in Switzerland Víctor Andrés Belaúnde (1936); Dantas by the Portuguese writer Virgínia de Castro e Almeida, member of her country's delegation to the League (1937-1938) and Ocampo by the Argentinian delegate Carlos Alberto Pardo, already present the year before as an external expert (1938-1939). A significant proportion of these personalities are also members of their national committees, but we note that some individuals also participate directly as representatives of their NCIC. In 1934, this is the case of the Mexican senator Pedro de Alba, assistant director of the Union of American Republics (Pan American Union) and delegate to the Assembly. And, in 1938, the Chilean NCIC is represented by the law professor Francisco Walker Linares, correspondent of the Information Section and delegate.

But to understand the implication of these apparently peripheral personalities in the work of the ICIC, such a list is not sufficient since it does not reflect the context in which they participate in the sessions. This is why a structural analysis (Grandjean 2014) is necessary to bring out information that not only describes the mere presence of an individual at one or more sessions of the Committee but also allows us to show the relations that are woven together when two are attending the same sessions. Figure 4.3 visualizes these co-presence relationships as a network of the 212 individuals who took part in at least one of the twenty-one sessions of the ICIC.

In this network diagram, two people are connected by an edge if they participate in the same session. The size of the edge is directly proportional to the number of co-presences of the two individuals connected. For example, Aloysio de Castro is connected by an edge more than twice as thick to Júlio Casares as to Leonardo Torres y Quevedo since he sits five times with the first and only twice with the second. If this data visualization concerned only the members of the Committee, the network would be perfectly redundant with Figure 4.1 since this information is already contained in the attendance list. However, this network is now based on a complete inventory of those who participated in the sessions, ${ }^{39}$ highlighting the very large proportion of non-ICIC members and their sometimes much more central position than some regular members often absent. Note also that the size of the nodes is proportional to the number of sessions the individuals attended. We remark the presence of 


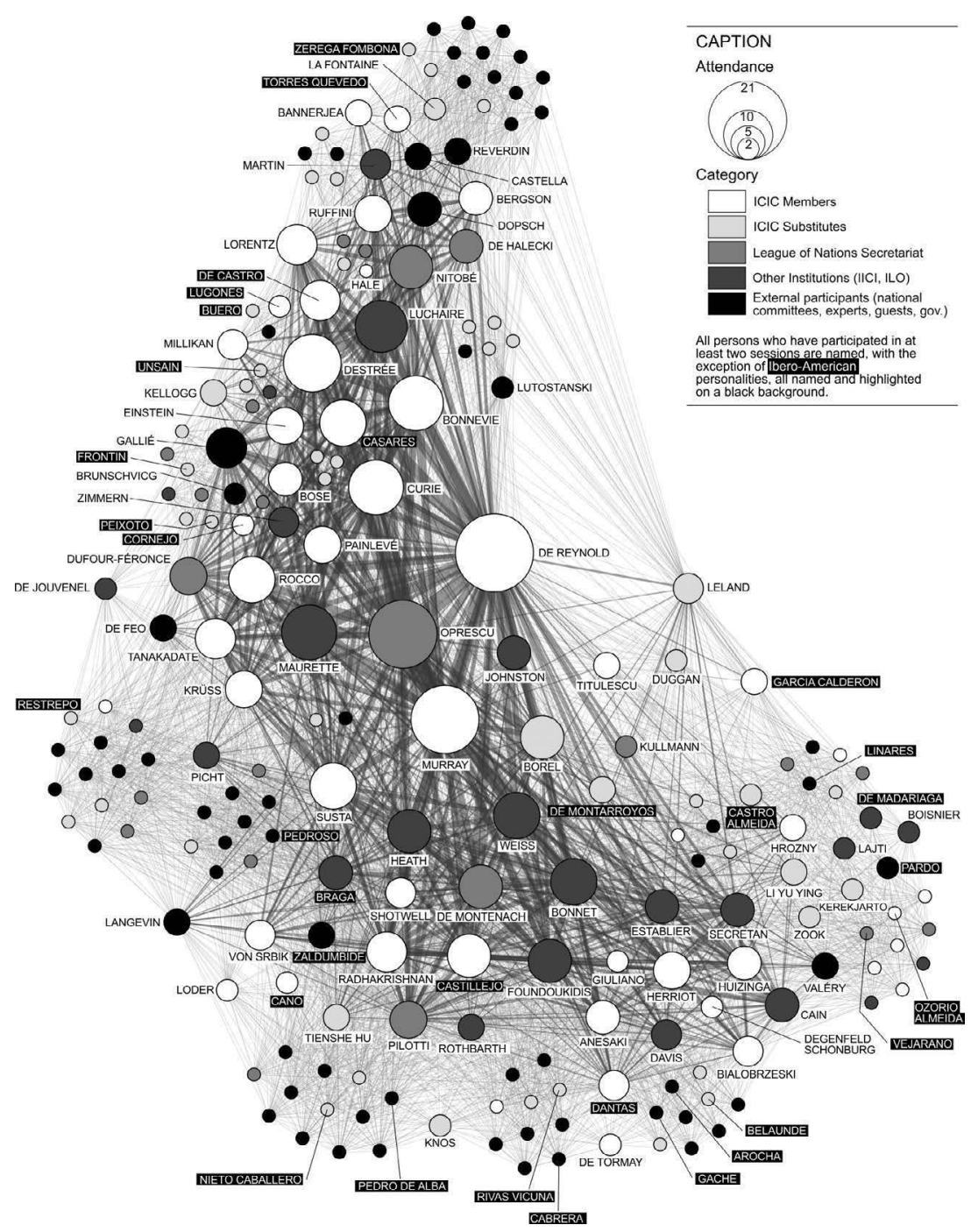

Figure 4.3 Network of the 212 Participants in ICIC Meetings Between 1922 and 1939.

a myriad of poorly connected people in the margins: more than half of the people who participated attended only one session (58\%). And while the majority of them are delegates of national committees or occasional substitutes, there are still about ten ICIC members among them.

The structure of the network naturally depends very much on the temporality of the Committee: as most members, experts or secretaries 
usually sit during one to five years, the neighborhood of an individual is logically composed of people who participated in the activity of the ICIC during the same period as he. At the top, we find the main members of the first Committee of 1922, around their first president Henri Bergson and under-secretary general Inazo Nitobe. This group is densely connected with the region of the graph containing more central characters, Jules Destrée, Kristine Bonnevie, Júlio Casares and Marie Skłodowska-Curie in the first place, who will all remain in the Committee until 1930 (and after the departure of the first two presidents). The separation with the newcomers of 1931, including, for example, the philosopher and future Indian Prime minister Sarvepalli Radhakrishnan or José Castillejo, is quite clear: it is Gonzague de Reynold, Gilbert Murray and the former Czech minister and history professor Joseph Susta (the latter entered in 1928 and thus met a good part of the original members) who are acting as an interface between the former ICIC, above, and the new one at the bottom.

This comprehensive approach also highlights several Spanish or Portuguese-speaking personalities who do not attend sessions as substitutes or delegates of a NCIC. Taking part in five sessions between 19311934 and in 1939, the Franco-Brazilian journalist and writer Dominique Braga is more present at ICIC meetings than many official members! His position of technical advisor on literary questions at the Parisian IIIC (Dumont 2008, 105-146) makes him one of the most active representatives of the Portuguese language in the circles of intellectual cooperation. But several Spanish personalities are also part of the occasional participants. This is the case of the professor of law and delegate to the League Manuel Martínez Pedroso, who attends the meeting of 1933 on behalf of the Committee on moral disarmament. In 1935, Blas Cabrera represents the Council of scientific unions, followed by Salvador de Madariaga in 1938 and 1939 on behalf of the International Museums Office (dependent on IIIC), and Felix Vejarano serving as a member of the secretariat of the International Bureaux Section of the League in 1939 as well. With regard to other nationalities, we note the presence of the permanent Venezuelan delegate Manuel Arocha in 1936 and the Argentinian writer and diplomat Roberto Gache the same year.

But whatever the reason for their involvement, Ibero-American personalities rarely occupy central positions. Representing $15 \%$ of the total number of individuals having attended an ICIC session, few can boast of having sat with a significant number of colleagues. This is, for example, the case of Casares or Castro, but also of people like Montarroyos or Zaldumbide who, because they each participated in three sessions of the Committee, far exceed regular members such as Lugones, Cornejo or Sanín Cano. García Calderón's situation is structurally interesting because having a big gap between his first participation (replacing Lugones in 1925) and his last (official Peruvian member in 1939), he collects a network of 
very distant relations. His place in the graph is therefore similar to that of the American historian Waldo Leland, who replaces Robert A. Millikan in 1923 to return only in 1935, 1937 and 1938 to replace the political scientist James T. Shotwell.

\section{Conclusion: The Late Rise of the Latin American Countries}

The active and long-term involvement of experts such as Aloysio de Castro, Júlio Casares or José Castillejo, however, does not allow us to conclude that the Ibero-American world has been globally represented in a satisfactory way in the International Committee on Intellectual Cooperation. If, in terms of numbers, Spanish-speaking and Portuguese-speaking personalities often match the Italian, Asian or Scandinavian representatives, they never occupy official positions (presidency, vice-presidency, responsibility for a sub-committee) and are rarely among those who actively participate in the sessions and structure the debates, unlike the French and English, who are constantly overrepresented and greatly benefit from their popularity as leading scientific and political figures.

But the under-representation of Ibero-American experts in the ICIC is counterbalanced by a third period, which follows the two distinct moments that we have described in these pages (the setting up and then the enlargement of the Committee): the post-League of Nations period. While the League suffers from its repeated diplomatic failures in the course of the 1930s, the actors of intellectual cooperation gradually seek to preserve their achievements, in particular by conferring to the Parisian IIIC an increased autonomy that would allow it to continue its activity if the states all withdrew from Geneva. In July 1937, a large meeting of National Committees, ICIC and IIIC directors therefore validates "the study of an intergovernmental agreement [. . .] whose purpose would be to offer other governments interested in intellectual cooperation the possibility of associating themselves with the commitments made by the French Government". ${ }^{40}$ Clearly, it is therefore a question of bypassing the League of Nations, still the place where the States are supposed to meet, so that they sign without its intermediary an international act guaranteeing an independent financing of the IIIC. Elizeu Montarroyos, who is close to the ICIC since he participated in three sessions and is the Brazilian delegate to the IIIC, proclaims during this meeting that "it is [. . . a marriage, a union of Intellectual cooperation with the Governments". ${ }^{41}$ Despite the appearance of a "coup from the base against the Secretariat" (Renoliet 1999), the Assembly of the League validates this proposal and therefore convenes a diplomatic conference to be held the following year at the Quai d'Orsay in Paris.

In December, forty-five nations take part in the diplomatic conference by delegating a plenipotentiary, ${ }^{42}$ but the composition of this new coalition is very different from the balance that prevailed in the ICIC. Western 
Europe only represents a quarter of the participants (whereas in the same year it holds more than $40 \%$ of the seats in the ICIC). The largest contingent of this diplomatic conference comes from Latin America (onethird), despite-and perhaps in reaction to?-the very low representation of this continent in the ICIC (6\% in 1938). With Argentina, Brazil, Chile, Colombia, Costa Rica, Cuba, the Dominican Republic, Ecuador, Guatemala, Haiti, Mexico, Panama, Paraguay, Peru, Uruguay and Venezuela, this Latin American delegation shows an increase in the diversity of actors interested in intellectual cooperation at a time where several major European powers are divesting themselves (note that Spain and Portugal are present at the diplomatic conference). And, for the first time, a Latin American has an official responsibility: the Peruvian Francisco GarcíaCalderón is one of the four vice-presidents of the conference. ${ }^{43}$

On December 3rd, 1938, less than half of the States signed the Act. Among the twenty-one nations ready to rebuild the IIIC, France is finally the only major Western power to carry the project, alongside China, Spain, the Netherlands, Switzerland, Portugal, Egypt, Poland Romania, Monaco and ten Latin American States: Argentina, Brazil, Chile, Cuba, the Dominican Republic, Ecuador, Paraguay, Peru, Uruguay and Venezuela. And yet they must ratify the act, a procedure whose duration varies greatly from one State to another. On May 1st, 1939, thirty-seven states signed the act, but eleven of them-including Portugal and Mexicoactually ratified it. The international act thus officially enters into force on January 31, 1940, and is then promulgated by the French government a month later. But the International Institute of Intellectual Cooperation is no longer active, most of the meetings having been postponed, and will be closed on June 9, a few days before the German troops enter Paris.

Less affected by the Second World War, Latin America will be a fertile ground for many initiatives inspired by the activities of the ICIC and the IIIC, such as the repeated plans to create an Inter-American Office or Institute, in discussion since $1929^{44}$ and about to materialize in 1943 in La Havana. ${ }^{45}$ The "Pan-American Conference of Intellectual and Cultural Cooperation" is organized in the same city in November 1941 (Pernet 2014, 349-354), and IIIC Director Henri Bonnet participates, having left Paris for the United States. ${ }^{46}$ This third period, which sees the legacy of the ICIC and its Institute springing again momentarily in Latin America, outside the institutions of global (European) governance, suggests that the political bickering of the old European nations within the League-and especially France's flagrant seizure of intellectual cooperation-were all obstacles to the development of a genuine grassroots movement, where intellectuals can organize themselves and for themselves.

\section{Notes}

1. This institute was inaugurated in Paris in 1926 and completed the Geneva Committee. Due to its large size, it quickly becomes a key element, although 
the ICIC retains the leadership of what is known since the early 1930s as the "Organization for Intellectual Cooperation" (OIC). This Parisian focal point is particularly strong in Renoliet (1999).

2. See IICI (1933) Note that two of the letters by Paul Valéry and Salvador de Madariaga from this volume have recently been reissued (Valéry and Madariaga 2016).

3. To this end, we make special use of the League of Nations archives (United Nations Office at Geneva), abbreviated LNA. About these collections, see Habermann-Box (2014). It should be noted, as a complement, that Louis (2016) conducted a historical study of the representativeness of the International Labor Organization.

4. Quiñones de León J., "Organisation du travail intellectuel”, Journal officiel de la Société des Nations, vol. 2 no. 2, March/April 1921, p. 177.

5. Actes de la deuxième Assemblée de la Société des Nations, Genève 1921, Commissions (II), p. 333.

6. "Observations on the International Committee on Intellectual Cooperation", Inazo Nitobe, August 18, 1922, LNA 14297/22652, p. 1.

7. Note from Inazo Nitobe to the General Secretary, 22.12.1921, p. 1, LNA $13 / 14297 / 18183$.

8. "Appointment of a Committee for the Consideration of Questions of Intellectual Co-Operation", Report presented by Hanotaux and adopted by the Council on January 14, 1922, published as an annex (310) to the Journal officiel de la Société des Nations, vol. 3 no. 2, February 1922, pp. 174-175.

9. "Candidats recommandés par des associations pour les fonctions de membres de la commission de coopération intellectuelle”, January 12, 1922, LNA 13/14297/18183.

10. "Liste des noms proposés pour la commission pour la coopération intellectuelle", March 1922, LNA 13/14297/19608.

11. Argentina, Bolivia, Brazil (-1926), Chile (-1938), Colombia, Cuba, Spain (-1939), Guatemala (-1936), Honduras (-1936), Nicaragua (-1936), Panama, Paraguay (-1935), Peru (-1939), Portugal, Salvador (-1937), Uruguay, Venezuela (-1938). With these first countries, four new one will join the League: Costa Rica (1920-1925), the Dominican Republic (1924), Mexico (1931), Ecuador (1934). In total, they represent 33\% of the sixty-three countries that have once been members of the League.

12. "Observations on the International Committee on Intellectual Cooperation", Memorandum by Inazo Nitobe, August 18, 1922, LNA 13/14297/22652, p. 4.

13. "Nomination of a Committee on Intellectual Co-Operation", Report presented by Léon Bourgeois and adopted by the Council on May 15 1922, published as an annex (354) to the Journal officiel de la Société des Nations, vol. 3 no. 6, June 1922, pp. 679-680.

14. "Appointment of a Committee to Examine Questions Concerning Intellectual Co-Operation", Journal officiel de la Société des Nations, vol. 3 no. 6, June 1922, pp. 535-536.

15. Telegram from Hale to the Secretary General, May 22 922, LNA 13/14297/ 21013.

16. Letter from Millikan to Drummond, October 13,1922,LNA 13/14297/21013.

17. Letter from Einstein to the Secretary General, May 30, 1922, LNA 13C/14297/ 20823.

18. Letter from Einstein to the Secretary General, July 4, 1922, LNA 13C/14297/ 20823.

19. Letter from Attolico to Einstein, July 12, 1922, LNA 13C/14297/20823.

20. Dispatch, July 21, 1922, LNA $13 \mathrm{C} / 4297 / 20823$.

21. Telegram from Comert to Attolico, July 28, 1922, LNA 13C/14297/20823. 
22. "Observations on the International Committee on Intellectual Cooperation", Memorandum by Inazo Nitobe, August 18, 1922, LNA 13/14297/22652, p. 3.

23. "Vœux adoptés par la commission", December 8, 1923, LNA 13C/14297/ 32690.

24. Pham $(1962,29)$ is devoting considerable development to it, partly taken up by Renoliet.

25. Resolution 1 from report Bardoux at the 4th Assembly of the League, 16th plenary meeting, September 27, 1923, Actes de la quatrième Assemblée au Journal officiel (supplément spécial n¹3), p. 109.

26. Minutes of the Fifth Commission, 8th meeting (September 17, 1923) and 13th meeting (September 22, 1923), Actes de la quatrième Assemblée au Journal officiel (supplément spécial n¹8), pp. 34-38, 53-57.

27. Report of the Fifth Commission (Bardoux) to the 4th Assembly of the League, 15 th plenary meeting, September 27, 1923, Actes de la quatrième Assemblée au Journal officiel (supplément spécial $\mathrm{n}^{\circ} 13$ ), p. 102.

28. 15th Plenary session of the 4th Assembly of the League, September $27 \mathrm{~m}$ 1923, Actes de la quatrième Assemblée au Journal officiel (supplément spécial n¹3), p. 104.

29. 16th Plenary session of the 4th Assembly of the League, September 27, 1923, Actes de la quatrième Assemblée au Journal officiel (supplément spécial n¹3), p. 107.

30. Letter from Drummond to Oprescu, August 301926 (Saikawa 2014, 153).

31. Letter from Quiñones de León to the General Secretary, May 14 1926, reproduced in a note to the Council, June 1, 1926, LNA 13C/14297/51451, p. 1.

32. "Regulations Defining the Duties of the Secretariat of the Committee on Intellectual Co-Operation", Appendix VI of the report of the 8th session of the ICIC, published as an annex (898a) to the Journal officiel de la Société des Nations, $7^{\mathrm{e}}$ année no. 10 October 1926, p. 1305.

33. Journal officiel de la Société des Nations, $7^{\mathrm{e}}$ année no. 7 July $1926,14^{\mathrm{e}}$ session du Conseil, $3^{\mathrm{e}}$ séance (June 9, 1926), p. 869.

34. "Appointment of a Japanese Member on the Committee on Intellectual Cooperation", Journal officiel de la Société des Nations, $8^{\mathrm{e}}$ année no. 2, February $1927,43^{\mathrm{e}}$ session du Conseil, $2^{\mathrm{e}}$ séance (December 7, 1926), p. 129.

35. Letter from Ishii to the General secretary, reproduced as an annex to the Journal officiel de la Société des Nations, $8^{\mathrm{e}}$ année no. 2 février 1927, 43 session du Conseil, $2^{\mathrm{e}}$ séance (December 7, 1926), p. 217.

36. Journal officiel de la Société des Nations, $11^{\mathrm{e}}$ année no. 11 novembre 1930, $60^{\mathrm{e}}$ session du Conseil, $2^{\mathrm{e}}$ séance (September 9, 1930), p. 1306. The recommendations and reports of the ICIC are in the annex 1230, p. 1374.

37. CICI, Procès-verbal de la cinquième session, May 11-14, 1925, C. 286. M. 104. 1925. XII, p. 4.

38. CICI, Procès-verbal de la vingtième session, July 11-16, 1938, p. 2.

39. These data are taken from the attendance lists published in the introduction to the ICIC minutes. They do not include all the people actually present in the room but only the individuals who have an official reason to participate (not the public and possible journalists, for example). The list is completed with the names of any person speaking in the minutes if he's not officially mentioned in the first pages (these omissions are very rare).

40. "Rapport général: résolutions et vœux", appendix to the "Actes de la deuxième conférence générale des commissions nationales de coopération intellectuelle", Paris, July 5-9, 1937, document C.530.M.369.1937.XII, LNA 5B/14390/32496, p. 88. 
41. "Procès-verbaux des séances de la Conférence diplomatique concernant la coopération intellectuelle", Paris, 4th plenary meeting, December 2, 1938, LNA 5B/33863/35946, p. 68.

42. "Communication du Gouvernement Français au sujet de l'Acte international concernant la Coopération intellectuelle", communicated to the Council, January 14, 1939, LNA 5B/33863/36476, p. 1.

43. "Procès-verbaux des séances de la Conférence diplomatique concernant la coopération intellectuelle", Paris, 1st plenary meeting, November 30, 1938, LNA 5B/33863/35946, p. 9.

44. CICI, Procès-verbal de la onzième session, première séance, July 22, 1929, LNA C.342.M.121.1929.XII, pp. 13-14.

45. "Pour une collaboration intellectuelle", dispatch from the Swiss Telegraphic Agency, October 22, 1943, LNA 5B/318/41160. See also (Dumont 2008).

46. Letter from Anker to Rosenborg, June 23, 1942, LNA 5B/318/41160.

\section{References}

Bekri, Chikh. 1990. L'UNESCO : une entreprise erronée ? Paris: Publisud.

Dumont, Juliette. 2008. L'institut International de Coopération Intellectuelle et Le Brésil (1924-1946): Le pari de la diplomatie culturelle. Collection Chrysalides, no. 4. Paris: IHEAL-CREDAL.

Dumont, Juliette. 2012. 'De la coopération intellectuelle à la diplomatie culturelle : le parcours du Brésil dans l'entre-deux-guerres'. Caravelle (99): 217-238.

Dumont, Juliette. 2016. 'Un panaméricanisme à la brésilienne ? Le projet d'Institut Interaméricain de Coopération Intellectuelle (1926-1930)'. Nuevo Mundo Mundos Nuevos. Nouveaux mondes mondes nouveaux-Novo Mundo Mundos Novos-New world New worlds. https://doi.org/10.4000/nuevomundo. 69108.

Dykmann, Klaas. 2015. 'How International Was the Secretariat of the League of Nations?' The International History Review 37 (4): 721-744. https://doi.org/1 0.1080/07075332.2014.966134.

Gram-Skjoldager, Karen, and Haakon A. Ikonomou. 2017. 'The Construction of the League of Nations Secretariat: Formative Practices of Autonomy and Legitimacy in International Organizations'. The International History Review: 1-23. https://doi.org/10.1080/07075332.2017.1409792.

Grandjean, Martin. 2014. 'La connaissance est un réseau: perspective sur l'organisation archivistique et encyclopédique'. Les Cahiers du numérique 10 (3): 37-54. https://doi.org/10.3166/LCN.10.3.37-54.

Grandjean, Martin. 2017. 'Analisi e Visualizzazioni delle Reti in Storia. L'esempio della Cooperazione Intellettuale della Societa delle Nazioni'. Memoria e Ricerca 55 (2): 371-393. https://doi.org/10.14647/87204.

Grandjean, Martin. 2018. 'Les réseaux de la coopération intellectuelle. La Société des Nations comme actrice des échanges scientifiques et culturels dans l'entre-deuxguerres'. Lausanne: Université de Lausanne. https://halshs.archives-ouvertes. fr/tel-01853903.

Grandjean, Martin, and Marco Van Leeuwen. 2019. 'Mapping Internationalism: Congresses and Organisations in the Nineteenth and Twentieth Centuries'. In International Organizations and Global Civil Society: Histories of the Union of International Associations, edited by Daniel Laqua, Wouter Van Acker, and Christophe Verbruggen, 225-242. London: Bloomsbury. 
Haberman, Frederick W. 1972. Nobel Lectures, Peace 1901-1925. Amsterdam: Elsevier Publishing Company.

Habermann-Box, Sigrun. 2014. 'From the League of Nations to the United Nations: The Continuing Preservation and Development of the Geneva Archives'. In Networking the International System: Global Histories of International Organizations, edited by Madeleine Herren, 15-30. Switzerland: Springer.

IICI. 1933. Pour une Société des Esprits, lettres de Henri Focillon, Salvador de Madariaga, Gilbert Murray, Miguel Ozório de Almeida, etc. Correspondance 1. Paris: Institut international de coopération intellectuelle.

Laqua, Daniel. 2009. "Transnational Endeavours and the "Totality of Knowledge": Paul Otlet and Henri La Fontaine as "integral Internationalists" in Finde-Siècle Europe'. In Internationalism and the Arts in Britain and Europe at the Fin de Siècle, edited by Grace Brockington, 247-271. Oxford: Peter Lang. http://nrl.northumbria.ac.uk/2231/.

Laqua, Daniel. 2011a. Internationalism Reconfigured Transnational Ideas and Movements between the World Wars. London and New York: I.B. Tauris.

Laqua, Daniel. 2011b. 'Transnational Intellectual Cooperation, the League of Nations, and the Problem of Order'. Journal of Global History 6 (2): 223-247.

Löhr, Isabella. 2010. Die Globalisierung Geistiger Eigentumsrechte: Neue Strukturen Internationaler Zusammenarbeit, 1886-1952. Kritische Studien Zur Geschichtswissenschaft, Band 195. Göttingen: Vandenhoeck \& Ruprecht.

Louis, Marieke. 2016. Qu'est-ce qu'une bonne représentation? L'Organisation internationale du travail de 1919 à nos jours. Paris: Dalloz.

Northedge, Frederick Samuel. 1953. International Intellectual Co-Operation Within the League of Nations: Its Conceptual Basis and Lessons for the Present. London: University of London.

Pernet, Corinne. 2007. 'Culture as Policy: Cultural Exchanges between Europe and Latin America in the Interwar Period'.Puente@Europa 5(3/4): 121-126.

Pernet, Corinne. 2014. 'Twists, Turns and Dead Alleys: The League of Nations and Intellectual Cooperation in Times of War'. Journal of Modern European History 12 (3): 342-358.

Pham, Thi-Tu. 1962. La coopération intellectuelle sous la Société des Nations. Genève: Droz.

Rayward, W. Boyd. 2003. 'Knowledge Organisation and a New World Polity: The Rise and Fall and Rise of the Ideas of Paul Otlet'. Transnational Associations 1 (2): 4-15.

Renoliet, Jean-Jacques. 1999. L'UNESCO oubliée, la Société des Nations et la coopération intellectuelle (1919-1946). Paris: Publications de la Sorbonne.

Roig-Sanz, Diana. 2013. 'Dues fites en la collaboracio catalana a l'IICI, la UNESCO i el PEN Club Internacional (1927 i 1959)'. In Lectures dels anys cinquanta, edited by Enric Gallen and José Francisco Ruiz Casanova, 155-189. Lleida: Punctum.

Roig-Sanz, Diana. 2016. 'The International Institute of Intellectual Cooperation: Translation Policies in the Interwar Period (1925-1946)'. In EST Conference, Aarhus.

Saikawa, Takashi. 2014. From Intellectual Co-Operation to International Cultural Exchange: Japan and China in the International Committee on Intellectual Co-Operation of the League of Nations, 1922-1939. Heidelberg: Universität Heidelberg. 
Valéry, Paul, and Salvador de Madariaga. 2016. Correspondance pour une Société des Esprits. Edited by Jean-Michel Rey. Estru Mediterraniu. Ajaccio: Albiana, Università di Corsica.

Wonsch, Danielle. 2004. 'Einstein et la commission internationale de coopération intellectuelle'. Revue d'histoire des sciences 57 (2): 509-520. https://doi. org/10.3406/rhs.2004.2227. 


\title{
5 The 1933 Dubrovnik PEN Congress, or How to Deal with the Present That Was Already History
}

\author{
Simona ̌̌krabec
}

Perhaps you're searching through memory for the shapes of all printsfootsteps in the snow, old songs and cognac in the evening, small white towns with castles and turrets, the smell of Sunday afternoons, the river running under granite bridges. As if this, too, escapes you. Here, under the empty sky of ancient tribes you never heard about, you'll end your way. I, of course, always return. You don't. Which makes all the difference.

(Aleš Debeljak, 1990. Translated by Christopher Merril)

Before I begin, it is worth recalling that no one knows exactly who took part in the International Congress of PEN Clubs ${ }^{1}$ held from 25 to 28 May 1933, in Dubrovnik. It is probably impossible to reconstruct a complete list of all those who participated. In his account of the historic Congress of 1933, Branko Matan tells us that, "First of all, I had to face the fact that the archive materials were either lost or inaccessible. The archives of the Croatian PEN Club no longer exist, because-to quote a chroniclerthey were destroyed by the Club members themselves in the period from 1941 to 1960, out of fear" (Matan, 1993: 10).

Were the people who destroyed these materials right to be so frightened? I will here offer just a handful of simple facts to give you an idea of the context that we are talking about. Let's begin with the person who was responsible for organizing the event: "The president of the Serbian center was none other than Svetislav Stefanović, an expert in German and English, the future Kulturträger in the Ljotić and Nedić collaborationist government who, at the end of World War II, was executed by firing squad" (Matvejević, 1984: 57). Another person, Mirko Kus-Nikolajev, Ernst Toller's Croatian translator, was "from 1941 to 1951 under the permanent and very real threat of execution”. As far as Toller's suicide on 22 May 1939 in New York is concerned, Kus-Nikolajev smiled bitterly when he read that the writer had taken his own life because he was "incurably ill", remarking that, "He stepped out of life because life had sucked him dry. Is it possible that he will be forgotten? Why not-he only believed in man. And what is man today?" (Matan, 1993: 151). 
What is more, Speak Now or Never, the volume published by Matan on the historic Congress of 1933, was the result of another PEN Congress held in Dubrovnik, this time in 1993, in the middle of another war, just after the Serbs had bombed the city: "The sun was shining, the houses were roofless", the poet Slobodan Novak remarked to an American poet, adding that, "Poets understand absences" (Merril, 1999: 139). In his prologue, Matan makes the point about the Balkan conflicts of the 1990s that, "War is a world of heated dialogues. War is, also, a world in which nobody listens and no one is heard. A noisy world plagued by total deafness" (Matan, 1993: 11).

The German delegation was also absent from the 1993 Congress. On 15 March 1993, Gurt Heidenreich, president of the German Centre, sent a telegram saying that they could not commit to taking part in a Congress in a country that was at war. Croatia was a country in which there was no press freedom, and they simply could not be seen to support it through the gesture of taking part in an international meeting. Once again, in the 1990s, we see the same message that we saw back in 1933, namely that it is not possible "to take sides in a political conflict, to support one political view against another in countries that are not ours" (Matan, 1993: 10).

\section{Yugoslavia in 1933}

In an enthusiastic article profiling Louis Adamic, the journalist, who describes him as "the handsomest man I know", talks about his arrival in the United States from his tiny village in Slovenia: "He arrived alone, knowing not a word of English, with the address of a distant relative in his pocket, with no definitive plans. At that time, he was not quite fifteen years old" (Hindus, 1934: 4). Nevertheless, Adamic was a quick learner and became a very well-known novelist in his adopted homeland. During the 30s, according to an account by Henry Seidel Canby, he was sent to Yugoslavia with a grant from the Guggenheim Foundation and dispatched with the following instructions: "You are a bright young fellow, go over and see why Mussolini keeps bothering these good people, and why the dictatorship in Belgrade does not give the plain folk a chance to run things their own way: and after you come back and tell me what is happening" (Canby, 1934: 1).

And that is exactly what happened. Adamic and Canby, who was editor of The Saturday Review of Literature magazine, were both present at the Dubrovnik Congress. Canby was the only PEN delegate from New York, and he was the person who brought a ready-made resolution for approval by the General Assembly "which kept the conference from being one more disaster on the rocks of chauvinism. The sole issue before the conference, indeed, was the question of chauvinism vs. internationalism 


\section{Simona $\breve{S} k r a b e c$}

in literature, forced upon the congress by events and by the delegation from the Berlin P.E.N. Club" (Matan, 1993: 133).

Adamic's description in his "Letter from Yugoslavia" gives us an idea of the situation that he encountered in the Balkans: "Here let me remind you that the country is under a military-fascist dictatorship, established four years ago mainly for the benefit of the ruling hegemony in Belgrade, and their masters, the European money-imperialists [. . .] to keep them under their command as the first line of defense against Russia and communism". He continues with a chilling description of the way that censorship worked throughout the whole of Yugoslavia at that time, and how it came down especially hard on publications in Croatia, which included the city of Dubrovnik:

Balkan fashion, there is no definitive law covering the censor's function; in each city where things are being printed the censors perform differently, but everywhere their power is unlimited, and they exercise it as the local situation demands from time to time. The head censor in Zagreb, capital of Croatia, was recently heard to boast, "I can confiscate a menu card!"

(Matan, 1993: 38-41)

We should therefore not be surprised that, following his decisive actions at the Congress, Ernst Toller was literally lifted aloft during his tour of cities like Belgrade and Zagreb. ${ }^{2}$ Student activists praised him as an example to be followed. The Yugoslavs at that time were suffering under a harsh dictatorship, and they therefore turned Toller into a hero who would also guide them in their struggle for democratic and civil rights.

In other words, the regime that was gestating in Germany following Hitler's appointment as German Chancellor on 30 January 1933 was not the only situation giving rise to extreme concern on the continent. Mussolini in Italy and King Alexander I of Yugoslavia had already drastically restricted the freedoms of their citizens with the use of extreme violence. ${ }^{3}$

Everything that we are able to recount here has been reconstructed from reports or correspondence sent by some of the delegates and from articles published in the press rather than from any form of original documentation. The sources make it necessary to apply a real archaeological approach, combined with the acuity of a detective, as each correspondent added or left out the information that he or she deemed significant, depending on the political or ideological point of view he or she was defending. Even information as basic as how many people took part in the event and the names of the delegates varies enormously, depending on the source. Henry Seidel Canby reported that PEN had 54 centers in 40 different countries, and he put the number of official delegates and members present in Dubrovnik at 400. This is the figure that is most often repeated in other reports, though it is difficult to ascertain how many people attended the event as ordinary members of the public and 
how many were invited dignitaries or the partners of delegates (Matan, 1993: 133-137).

Dubrovačka tribuna, the local newspaper, helpfully published the names of the delegates from Slovenia, Croatia and Serbia on 25 May 1933. The last of these three delegations was the largest, and the newspaper mentions that it included around 30 authors, giving their full names, one of whom was the already-mentioned Svetislav Stefanović (who was executed by firing squad as a collaborator shortly after the war), along with authors who would soon become internationally acclaimed, such as Ivo Andrić, Jovan Dučić and Desanka Maksimović. Of the Croats, the newspaper mentions only eight names, and the one that is probably most familiar to us in the international sphere is that of the sculptor Ivan Meštrović. The Slovenian delegates were all leading intellectuals, some of them highly politicized. The only member of the Slovenian delegation of any international significance was the writer, influential art historian and skilled diplomat Izidor Cankar.

Andrić, Dučić and Cankar were, then, part of the diplomatic corps of the "first" Yugoslavia, a state that was created with great expectations after the Great War but which by 1933 had become an oppressive dictatorship. Andrić served as Vice-Consul in Madrid from April 1928 until June 1929. Among some of the work he produced during his time in the city are his essays on Simon Bolivar and Francisco de Goya, which have, however, still not been translated into Spanish. The truth is that it is not possible to attribute Andric with any kind of active role as a cultural communicator between Spain and the Yugoslavia of the time.

Dučić is probably the most controversial figure. He began his diplomatic career at a very early age, and after a brief stay in Athens, he arrived in Madrid as first secretary to a Serbian mission even before the end of the First World War, remaining until 1924 when he took up the role of delegate to the League of Nations in Geneva. He returned to Madrid as Ambassador of the Kingdom of Yugoslavia in 1940, and it was here that he remained trapped when the Kingdom was dissolved following the Nazi bombardment of Belgrade on 6 April 1941. From Madrid, he fled straight to the United States with help from family connections, and there he quickly became an activist for the more chauvinistic elements of the Serbian diaspora, right through to his death in 1943. His political texts during this final period are quite simply chilling. "The poet Jovan Dučić, who before the Second World War praised Mussolini and who then, speaking from the USA during the war, attacked the majority of his former collaborators", nevertheless went down in history as a great diplomat, as demonstrated for example by the publication of his work Acta Diplomatica (Diplomatic Letters) in 1952 (Grdina, 2009: 10).

We also cannot ignore Andrić's role in the political arena:

No one was happy to restore Albania's 1913 borders. The Serbian dynasty enlisted none other than Ivo Andrić to sort out its 


\section{Simona Škrabec}

Albanian policy. In a secret memorandum, dated 1939 and finally published in Croatia in 1977, the Nobel laureate advocated the partition of Albania, assimilating Catholic and Orthodox Albanians and deporting the Muslims to Turkey-a hateful document that gives further weight to Charles Simic's observation that it is time to dismantle "the myth of the critical independence of intellectual”.

(Merril, 1999: 230)

Of these three, Izidor Cankar was the one who had the most solid career in an academic sense. He created the modern history of art course at the University of Ljubljana, practically from scratch, and he devoted many years of his life to teaching and research work. His contribution in this area was extremely influential. He also wrote a large amount, though it is not his literary works that have ensured him a place in history but rather his political skill and his cultural activism in all senses of the word. Though extremely interesting, his connections with the Hispanic world have hardly been studied until now. Cankar was Yugoslavia's Ambassador to Argentina, and he lived in Buenos Aires from 1936 until the fall of the Kingdom of Yugoslavia in April 1941. He then accepted the post of Ambassador to Canada in the name of the Yugoslavian government in exile in London, from 1942 to 1944. After returning home, with Josip Broz Tito now head of state, he was appointed Ambassador to Greece from 1945 to 1947 . He retired in 1947 and from then on did not play any active role in the political sphere.

The figure of Izidor Cankar was important in Dubrovnik because he voted in favor of the resolution on behalf of the Slovenian Centre, in contrast to all the other Yugoslav delegates (Matvejević, 1984: 60). The president of PEN in Serbia, Stefanović observed that the burning of books in Nazi Germany was a simple act of vandalism, without any consequences, "done by German students in the zeal of youth and euphoria of victory of their national revolution" (Matvejević, 1984: 60). There is no data regarding the Zagreb Centre vote, and we do not even know whether it voted as an independent Centre. ${ }^{5}$

However, we should note a particularly important point that was made by Louis Adamic to his American readers: "Hence most of the really or potentially good and important writers do not write at all, or else go for their subject matter outside of Yugoslavia or into the distant past, or both". The case of Miroslav Krleža is a good example:

All of his important books and plays deal with the past, namely, with the war or the decadence of the bourgeois class which developed in Zagreb while the city was under Austria-Hungary. They are extremely effective historical social studies. However, he doubtless could write even more powerful and important plays and novels 
about contemporary life in Yugoslavia; only, if he wrote them, he could not print them today or for some time to come.

(Matan, 1993: 39)

Ivo Andrić, who won the Nobel Prize in 1961, is the best example of someone who escapes into the distant past in order to avoid facing up to the political circumstances of the moment. His novel, The Bridge on the Drina (1945) is still read today as a kind of illustration that allows one to "understand" the Balkans. It is the account of a Bosnian city, Višegrad, over a number of centuries. However, we should bear in mind that the action in the novel ends in 1914 with the outbreak of the First World War, just as the first Austrian grenades are landing on the mythical bridge. Ivo Andrić therefore consciously avoids all the burning questions that surround this territory, and he never attempts to explain what happened in the Balkans between 1914 and 1945. And this, I'm afraid, is how the Balkans are seen today in the eyes of the world, as a place that is trapped in a particular moment in time and that will never catch up with the present.

Orientalism, the exclusion of whole regions from any right to their own history and evolution, continues to persist today in respect of the Balkans. Even though Louis Adamic was dispatched to the country of his birth to provide an expert analysis for the Americans, an influential force at that time, and although Canby devoted four highly enthusiastic pages to the volume for a very important New York book club, The Native's Return (1934) did not offer any kind of insight into the old and immutable idea of the Balkans as an isolated region that was condemned to suffer permanent conflict. This idea of the Balkans as an atavistic society, incapable of any kind of evolution, is also maintained in the hefty travel volume Black Lamb and Grey Falcon (1941), published to great acclaim by Rebecca West and still seen as a fascinating chronicle by the majority of its readers; I would remind you that the British writer had been the lover of the then president of PEN, H. G. Wells, with whom she had her only child, born in 1914. And finally, the region is also described in the novels of Ivo Andrić, the only Yugoslav Nobel laureate. In other words, it is precisely the most widely known literature that reinforces all the prejudices and lack of understanding of social and political structures in the Balkans. The consequences of such persistent blindness are far-reaching. The wars of the late twentieth century cannot be untangled from this indifference and lack of understanding that both Europe and the United States have shown towards the "South Slavs".

In 1985, Tomaž Šalamun even dedicated a series of offensive satirical poems to Louis Adamic. ${ }^{6}$ Šalamun also eventually made his name as a poet in the United States and decided that the time had come to treat the blighted peninsula as an equal, without exoticism or embellishment. It is impossible to read a collection of poems such as A Ballad for Metka 
Krašovec and not be affected, not feel forced to revise the ways in which we judge history and construct identities, whether our own or those of our eternal rivals and enemies.

If there was one delegate present in Dubrovnik in 1933 who understood the necessity of mining these mechanisms for the broadcasting of negative myths on distant realities, it was J. V. Foix. Foix had the awareness to see what was fragile and invisible. His contribution with regard to this Congress was not political in the sense of an Ernst Toller, who was capable of articulating a discourse that has become written into history and is still stirring in the clarity of its explanation and firm commitment to the truth. The short prose works that Foix published about his trip, along with his reflections written in a surrealist style, are all colored with a poetic wisdom that would have had the capacity to disrupt the inertia of the 1930s. However, this poetic vision, with its ability to provide nuance, never triumphs, as we all know. ${ }^{7}$

Foix said that the only thing that was out of the ordinary in those towns in Dalmatia were the poets who had turned up and flooded the streets with their extravagances. He added that, "We are not tempted by travel notes. Tourism has made this genre redundant. If we read them it is to convince ourselves of their uselessness. Rhetoric. Frequently pedantic rhetoric. Some of these travelers-writers or journalists-have a childish sensibility that is similar to that of amateur ramblers". Without realizing it, in this short note, J. V. Foix redeemed centuries of disregard for the Balkans in western culture. Just as he was able to paint a literary picture of the contradictions in his own Catalonia, on this brief trip the poet looked around him with his own eyes and consciously ignored those preconceived ideas. Or, as he himself put it, when faced with any monument "we must deliteralise ourselves" (Domènech, 1999: 258-259).

\section{"La Catalogne avec sa femme toujours d'accord"}

Despite the seriousness of the issues dealt with in Dubrovnik, the matter of how many international delegations attended this meeting in 1933 remains a mystery. The most optimistic of accounts came from the Parisian publication, Le Temps, which reported that 67 countries attended, while the Völkischer Beobachter put the number at only 21. The Manchester Guardian and other newspapers of the time, along with the official report on the Congress submitted to PEN News in June, quoted a figure of 26 delegations (Matan, 1993: 56, 74, 79). This must be the correct figure, as it corresponds with the number of votes counted when the Resolution of Tuesday 26 May 1933 was submitted for approval. This was the Resolution that was voted on in the afternoon following lengthy debate and the one that caused the Berlin delegation to abandon the assembly in protest. The votes cast show 10 centers in favor and 2 against, with 14 delegations abstaining. ${ }^{8}$ 
It should be noted from the start that the majority of the individual delegations did not vote resoundingly in favor of the Resolution approved by the general assembly, and the result pointed to the sides being very finely balanced. In truth, the Berlin PEN Club delegation comprising Edgar Schmidt-Pauli, Hanns Martin Elster and Fritz Otto found more than just a few sympathetic ears in Dubrovnik. Contrary to what is generally reported about the 1933 Congress, the majority of PEN Clubs that were present in Dubrovnik did not confirm that it was necessary to reinforce commitment to the principles by which the organization was governed. On the contrary, many of the delegates indicated, if only by their abstention, their tolerance for the serious purges that were taking place in Europe's political and cultural circles, beginning with the Italian fascists and culminating, following consolidation in dictatorial states such as Yugoslavia, with the lethal methods of the Nazis.

Some of the delegates present in Dubrovnik would go on in later years to become firm proponents of cultural-and racial-purity in the manner expressed by Nazi ideology. Aside from the President of PEN Serbia, Stefanović, who was executed after the war for collaboration, and the Swiss, Hungarian and Greek delegates who openly opposed the Constitutive Resolution, at least two other names should be mentioned. Holland's Jo van Ammers-Küller, the successful author of novels dealing with feminist subjects that brought her international fame between the two world wars, leapt from her seat after the vote and cried, "If Galsworthy were alive, this would never have happened! I am Jewish. But it has never been held against me. I have tried with all my might for a reconciliation, because the future of the PEN Club lies in its non-political character. I have done it although I am a Jew. This is the end of the Pen Club" (Matan, 1993: 130-131). After the war, Ammers-Küller's work was banned because of her support for the Nazi occupation, but she was nevertheless not pursued by the authorities and soon returned to the commercial market, though she never regained the fame she had enjoyed before the war.

A much more serious case is that of Grete von Urbanitzky, who led the Austrian delegation. In 1933, the Vienna Club was irreconcilably split between its liberal authors and those that subscribed to the völkisch ideology, who in addition to Urbanitzky also included Felix Salten. ${ }^{9}$ It is more than likely (though I have not been able to find any information to this effect in any article or report) that the two delegations that voted against PEN's Constitutive Resolution were the Germans and the Austrians, something that was particularly serious in the latter case, as this was still five years prior to the country's annexation by the Third Reich. Following this unexpected capitulation to Nazi principles by its president, the Vienna Centre convened a meeting on 28 June 1933, at which it approved a declaration in protest against the "subjugation of individual spirit" and fiercely condemned the events of the German Spring. The 


\section{Simona Škrabec}

declaration was signed by 25 members in favor, while 15 members voted against. The people who signed this "anti-German" manifesto in Vienna could be directly said to make up the list of 25 authors that the National Socialist newspaper Deutschösterreichische Tages-Zeitung called "ninety per cent Jews", which can be read as a "shortlist of authors forced into exile in 1938" (Bores and Hanuschek, 2014: 492).

Nevertheless, it was the Austrian PEN in exile that, thanks to the efforts of Paul Frischauer, who was also present in Dubrovnik in 1933, succeeded in converting PEN International into a "relief organization" that coordinated assistance for writers in danger. The letter asking for funds to provide temporary shelter for threatened writers was signed jointly by General Secretary Hermon Ould and the English president of PEN, Margaret Storm Jameson, and sent out on 16 June 1938. This solidarity among authors around the world in the face of serious crises has continued from that moment right through to the present day. One of the first authors to find refuge in the United Kingdom was Hermann Broch, who in 1938 was put up for several months at the Scottish home of his translators, Willa and Edwin Muir. Muir was one of the delegates present in Dubrovnik and was also involved in organizing the Congress in Edinburgh the following year (1934). Fortunately it was this vital, tightly knit and mutually supporting aspect of the PEN network that survived following the meeting in Dubrovnik, though we should not forget that this freedom was not won easily. Not all the intellectuals gathered there on the Dalmatian coast were initially aware of just how dangerous this ideology of purity was. Some, such as Grete von Urbanitzky and Hermann Burte, never renounced their "ideals".

It is therefore important to remember that no resolution explicitly condemning the Nazi regime was actually voted on in Dubrovnik. Canby brought a ready-made resolution from New York that extended and qualified the founding principles approved at the Brussels Congress in 1927. We are talking about a basic formula involving an undertaking to respect freedom of expression and to affirm that literature knows no boundaries and that writers, especially in times of war, undertake to respect works of art beyond any political or national passion that they may have. This simple acceptance of the PEN Charter was all that was asked of the delegates who attended. ${ }^{10}$

As already mentioned, we know that, in contrast to the other delegations from Yugoslavia, Izidor Cankar voted in favor of the Constitutive Resolution that was approved before the general assembly. J. V. Foix also voted in favor, with an amusing flourish that he himself later confirmed in an interview. When it was his turn to confirm his vote publicly before the assembly, he said, "La Catalogne avec sa femme toujours d'accord". It seems that this reference to his wife, Victoria Gili, whom he had married in 1931, brought him instant fame among everyone present (Guerrero, 1996: 257). But however much he may have wanted to suggest 
that his remark was simply a charming anecdote about his social life, Foix's decision to express robust support for respect and understanding between nations in all conditions does him great credit. He had been sent to Croatia to win approval for Barcelona's candidature for the 1935 Congress (which was indeed approved unanimously), but it is important to stress that he did more than just complete this easy task. Foix formed an active part of that silent and difficult internal revolt within an international organization that had reached a turning point: "When even the League of Nations dares not censure its members who openly violate the rules agreed upon, there is still one public forum left, that of the PEN Club, which has the courage to raise its voice and expose each case of persecution of free thought" (Matan, 1993: 131).

We should here go into a little detail about the events that surrounded the approval of this Constitutive Resolution. At the first session on 26 May, Henry Seidel Canby's proposal was immediately withdrawn before being voted on, because the Belgian delegate, René Lyr (René Vanderhaeghe), with support from Benjamin Crémieux and Jules Romans from France and many other delegates who immediately added their names to the motion, wanted to fine-tune the way the resolution was worded. Even though it appears that the initial intention was specifically to condemn the Nazi regime and denounce recent events such as the book burnings and the new rules for admission to PEN in Germany in line with its Gleichschaltung policy, this ended up being completely reversed. While the assembly continued with a series of unimportant debates, almost all the delegates with voting rights held a "secret" meeting, though the president and secretary general were not present, and there are no official minutes of the confidential talks that took place. Those delegates who wanted to simply withdrew at lunchtime to seek an agreed solution with the delegation from the Berlin PEN Club. When they left the assembly, the idea was to come up with a compromise that might satisfy both sides.

Some hours later, the three skilled negotiators that had been sent by Hitler's government, all terrible and little-known writers but clever diplomats who were accustomed to using distortion and false promises to obtain everything they proposed, ${ }^{11}$ came back to the room in which the assembly was being held with a proposal which is now very hard to believe. The Germans had convinced the French and the other delegates during this recess that what was necessary was to approve the text proclaiming general principles of peaceful co-existence (the wording of which was not very different from the one originally brought by Canby from New York, as the changes were minimal) and to let the Germans and whoever else wanted to abstain. That was all. The Nazi strategy worked to perfection with all the delegates who had withdrawn to hold the private meeting. Everyone assumed from the start that there was no problem in not allowing Ernst Toller and Schalom Asch from Palestine to talk to the assembly in order to give their accounts of the persecution 
of both political opponents and the Jews. They all thought that, to avoid any confrontation, it was a good idea to prevent any discussion in the assembly that might influence the vote and any final decision.

Luckily, this secret agreement did not work. The president, H. G. Wells, immediately halted this attempt to silence the assembly and the PEN Board. First, he allowed the organization's general secretary, Hermon Ould, ${ }^{12}$ to put two key question to the members from Berlin: did they condemn the book burnings and was it true that they had agreed certain new statutes that prohibited German authors from becoming members of the association if they were communists or of a "similar orientation"? The Berlin delegates refused to answer because these questions were not included on the agenda [sic!]. The basic strategy employed by the Nazis was one of extreme formalism that allowed them to evade any direct condemnation for the actions or the ideas they were defending. Afterwards, President Wells immediately offered the floor to Toller, with the famous words "Speak now or never", because even Toller himself was willing to let the occasion pass and allow the delegates to vote, saying that he would speak the following day. ${ }^{13}$

In other words, PEN's constitutional principles were confirmed in 1933 by only ten delegations, against 16 countries that regarded them as expendable, despite the historic circumstances. The Nazi regime was not condemned, nor was the Berlin delegation formally expelled. Edgar Schmidt-Pauli, Hanns Martin Elster and Fritz Otto Busch left of their own accord, leaving an angry letter of protest, which they handed personally to Wells in front of all those present.

In the autumn, representatives from the Berlin Club were once again summoned to a meeting of the International Board, held in London on 8 November 1933. The Board was headed up by H. G. Wells as president, along with PEN founder Catharine Amy Dawson Scott and Secretary General Hermon Ould, whose importance in this affair was extraordinary. The other members of the executive board were Hanns Martin Elster (Germany), Kanden Bandrowski (Poland), Antal Rado (Hungary), Svetislav Stefanović (Yugoslavia) and W. M. Westerman (Holland). In front of this gathering of representatives, Dawson Scott personally put it to Elster, "That in the opinion of this Committee, clause 3 of the communication to members of the German Centre [which prohibited communists and other similar people from becoming members] dated 16 March 1933, is incompatible with the general constitution of the P.E.N." (Bores and Hanuschek, 2014: 120).

If they did not renounce the vetoing of members on the basis of their political ideas, Berlin PEN would have to be expelled from the international network. However, this expulsion never happened. The Germans replied in a letter that was even angrier than the one delivered in Dubrovnik, saying that they did not want to be members of a club that did not recognize the principles they were defending. This is such a serious and chilling paradox that we must bear in mind how these events are 
framed by the history of the time. Nazism saw both human rights and its own ideology of exclusion to be on a par with one another. Both were a way of achieving peace. The reply sent to London on 18 November said that PEN Berlin had decided voluntarily to leave the PEN network. The note ended, "We, Germany's literary authors, shall continue to work for peace, though we shall do so following the only path that we consider to be correct and successful" (Bores and Hanuschek, 2014: 120-121).

PEN's Constitutional Charter defended one vision of the world, while the Nazis had another; it's as simple as that. The worst thing about Nazism was exactly that; its followers were never willing to accept that their ideology was so poisonous that it could have brought about the end of humanity. And what is most sad is that. in 1933, so many other delegates and intellectuals fell so easily under its influence, abstaining from the vote and averting their gaze from its horror.

It seems that J. V. Foix and his tender anecdote regarding the vote went practically unnoticed at the Congress. He returned from his trip with some papers and explanatory material that is today preserved at his Foundation in Sarrià, where one can also see that his passport was issued just before he boarded the ship bound for Trieste and that this was the only foreign trip on which he was accompanied by his wife, whom he had only recently married but with whom he would not end up sharing the rest of his life. With the characteristic attention to detail for which he was so well known, Foix made tiny annotations on the pages of La Publicitat regarding the smallest, most poetic details of the trip.

Foix observed and described events from his incorruptible point of view, attempting to avoid being an activist on any subject. It is possible that he was not aware of the many intrigues that I have described; the plots and conflicts are greatly played down in the articles he wrote about the Congress. He was an intelligent man, however, and he was never in any doubt as to what he had to vote for in his country's name.

In Catalonia, culture itself was crushed without a passing thought just after the agreeable Congress in Barcelona in the Spring of 1935. The meeting of 1935 was one that was worthy of a club that first and foremost sought to keep its members entertained. Delegates attended meetings for a maximum of two hours a day, and the rest was devoted to visits to museums, receptions, banquets and suppers "strictly by personal invitation", walks and excursions. Those who attended were offered the opportunity to spend an entire weekend in Mallorca, and documents of the time include instructions about the cold lunch awaiting them at the hotel: "People taking the trip to Mallorca are kindly requested to pick up their lunch baskets for excursions from their hotels. Otherwise, if they would like a hot lunch at restaurants in Sóller, Pollença or Porto-Cristo, they must make the relevant payment". A happy world that was about to be shattered ...

What happened next? As Stefan Zweig indicated in the title of his famous memoir, The World of Yesterday, it simply came to an end. 


\section{Simona Škrabec}

However, though it is possible that no one in Catalonia today is aware of the importance of this fact, the Barcelona Congress was also attended by France Bevk: "Our club's independence also enabled us to elect France Bevk as one of our members, despite the fact that he had Italian citizenship and lived in Italy" (Matan, 1993: 53). A quarter of what today is Slovenia formed part of Italy between 1918 and 1943, and from 1920 this territory was subjected to a systematic policy of repression, with violence and coercion affecting every facet of life. Bevk, the author of well-loved children's books, novels that followed an agenda and autobiographical writings, did not make much of a mark on Catalan culture. The truth is that in Barcelona he was just another author, but the hospitality of this club of clubs allowed him to feel like a free man for a few days, an equal among the writers from all the other countries. This is a value that PEN has preserved right through to the present and one that we must never forget; the importance that meetings may have, not only because of what is said or done, but also because they allow oppressed people and nations that are in danger of disappearing to remain part of the world and its culture, a part of the future.

As a conclusion, we have these hopeful words from France Stelè regarding the meeting in Barcelona:

The greatest difficulties were experienced with the club's Italian centre, whose president Marinetti not only approved of the Abyssinian War but glorified and praised it. Already during the 13th congress convened in Barcelona the question arose whether or not to lay down our arms and disband the organization. It was the small literary circles of small countries in particular who still clung to the belief that the PEN Club-or rather the idea behind it—constituted some kind of protecting power and argued in favor of its continued existence.

(Matan, 1993: 156)

H. G. Wells resigned in Barcelona as a "disillusioned man". Despite all of these obstacles, the bonds between writers and poets were always preserved. The relationship between Slovenia, Croatia and Catalonia proved to be especially fruitful, and in the beginning was directly promoted through their PEN Centers. This led to the translation of an anthology by Srečko Kosovel into Catalan (1985) and an anthology by Martí i Pol into Slovenian (1983), following the translation of a general anthology of Catalan poetry into Slovenian in 1981. Subsequently, Tonko Maroević became the first person to translate directly between Catalan and Croatian, with a selected anthology published in 1985 .

When I began translating, a lot of the hard work had already been done: I just had to brush the dust off some of the books that at the time had been half forgotten and follow the path they had marked out. One of the first authors I translated was Foix, personally chosen by me. He was the poet who had most moved me in those early years of my own 
voluntary exile and adjustment to a new country, because in his prose, which from the outset is so strange, I recognized the country in which I had ended up. Through his eyes, I came to understand how the Catalans viewed their own circumstances, and I recognized the defenses that they had developed in order to survive within the crevices of a sheer cliff, in a world that to them was always hostile, without language, without room to grow.

Foix is just one of many Catalan authors marked by the dictatorship who found a way of opening up a space that wasn't there, installing themselves and living within this artistic circle, to the point that they were able to expand the horizons of the world as a whole. Their attitude and their creativity cannot be measured using the objective parameters of normal political life. In cases such as theirs, art is an autonomous space, ruled by conscience and therefore capable of transforming its surroundings. From these barely visible, tiny cracks, it has the capacity to provoke revolutionary changes in both social and political life.

In a video that can still be easily found on the Net, Pau Casals gives a cello masterclass and impresses on a student that she must find space to take a breath where the notes themselves don't leave even a fraction of a second to breathe. It's not what's written, he says, but the emotion that one must get across. ${ }^{14}$ And it is this emotion that, in the end, is capable of changing the world and making it a more habitable place. Art and creativity have the capacity to undermine regimes and dictatorships. They create space where none exists. During Franco's time, Catalan art and literature created an explosion that brought down the walls of the prison in which Catalan culture had been condemned to die. Thus, the colors of Joan Miró or Joan Ponç still shine from within, right through to the present day.

In Dubrovnik in 1933, many people had suffered dramatic experiences like that of Ernst Toller. Others, like J. V. Foix, were visiting the club from their comfortable lives in prosperous countries that were keen to grow; in Spain at the time, one could not imagine the dark clouds that were about to precede the storm. Nevertheless, the poet knew that it was necessary to vote because he had memories, historical memories of an oppressed and struggling people. However agreeable those walks along the seafront, or that refined supper at the Ritz Hotel two years later, members of the PEN "clubs" did not meet up purely for social reasons. They believed in a better world, and they believed it strongly. And those of us who are here today are in their debt, because without organizations such as this, neither Europe nor the rest of the world would be the way they are.

\section{Notes}

1. Founded in 1921 by Catharine Amy Dawson Scott, the organization originally took the form of a typical "dining club". However, as clearly illustrated by its 1933 Congress, PEN soon moved on from its glamorous but rather hollow beginnings to become an institution with the power to create 


\section{Simona Škrabec}

powerful international networks and with an engaged and politically committed membership. At the same time it dropped the name "Club". The organization is today known as PEN International, and it acts as the hub for more than 100 independent centers (rather than clubs) around the world.

2. Miroslav Krleža was not present in Dubrovnik, but there is a record of a meeting between him and Ernst Toller in Zagreb, together with his translator.

3. On 6 January 1929, the Yugoslav king introduced a dictatorship, suspending the constitution and changing the country's name from the Kingdom of Serbs Croats and Slovenes to the Kingdom of Yugoslavia. Alexander was determined to stamp out unrest in the young country through enforced centralization, banning political parties, dissolving parliament, suspending the constitution and forcing the people to identify with a single nation, that of Yugoslavia. Alexander I was assassinated while on a visit to Marseille on 9 October 1934. He was succeeded to the throne by his cousin Paul [Pavle], because his heir, the Prince, was still a minor. While still Prince Regent, Paul was overthrown in a coup d'état after he had signed the Tripartite Pact with the Axis Powers on 25 March 1941. He was succeeded by Alexander's son, Peter [Petar] II, who formally abdicated in 1945 when the Socialist Federal Republic of Yugoslavia was founded. In any case, he had immediately fled into exile with his government on 6 April 1941, when Yugoslavia was attacked by Germany. With this flight from a country at war, both the government and the dynasty from the "first" Yugoslavia ceased to be a decisive factor in the struggles that developed in the Balkans during the Second World War.

4. In addition to the episode referred to with regard to the Albania Memorandum, a great deal of controversy also surrounds Andrić's diplomatic service in Berlin between 19 April 1939, when he was sworn in before Hitler, and 5 April 1941, the day before the attack on Yugoslavia, when all Yugoslav diplomats were declared persona non grata in Germany. Especially dramatic was the fact that, as ambassador, he may be considered responsible for the entire mission (more than 200 people) being held in Germany rather than allowing them to leave and seek refuge in a neutral country, as provided for under international agreements. The diplomats were interrogated by the Gestapo and then sent to Belgrade. There, 11 diplomats were detained and sent to prison or to German concentration camps on serious charges of espionage and treason. Andrić remained completely silent in public during the war, living alone in a flat in Belgrade, where he wrote three novels, $\mathrm{Na}$ Drini ćuprija (The Bridge on the Drina), Travnička hronika (Bosnian Chronicle) and Gospođica (The Woman from Sarajevo), which subsequently brought him fame with the award of the Nobel prize in 1961. After the war, in 1946, Ivo Andrić was named president of the Yugoslav Writers' Union by the Tito government. In Yugoslavia, the Writers' Union was a highly political organization, as demonstrated by the controversy surrounding the accusation of plagiarism made against Danilo Kiš in the 1960s and the fact that the author was forced to go into self-imposed exile as the result of the pressure to which he was subjected.-Karaulac, Miroslav, Andrićeve godine u diplomatiji. Belgrade: F. Višnjić, 2008.

5. No mention can be found regarding whether the Croatian delegates were acting as representatives of an independent Centre, either in Branko Matan's book (1993) or in the Predrag Matvejević article (1984), even though both works originate directly from PEN in Croatia. It is also worth recalling that both the Slovenian and Serbian Centres were founded in 1926. PEN Serbia was supported by Ivo Andrić, and its founding members included the already mentioned Dučić and Stefanović, along with Miloš Crnjanski, among others. 
PEN in Zagreb was founded in February 1927 by the editor of Nova Evropa Ćurin and the sculptor Ivan Meštrović, among others. All three Centres stopped operating during the Second World War. The first to reopen was the Serbian Centre, following an initiative by Ivo Andrić in 1961. The Slovenian Centre was also fully operational by the following year, 1962. The first Bled Congress, which is still held every year, took place in 1965, and was the first to be attended by the USSR delegation as an observer.

6. The name of the village in which Adamic was born is "Blato", which literally means "Bog". This was used by Tomaž Šalamun in a series of satirical poems attacking Adamic and his enthusiastic patriotism in a collection of poems entitled A Ballad for Metka Kraševec, 1985. The Spanish translation by Xavier Farré was published in 2013, while my own translation into Catalan was published in 2016.

7. Foix, J.V.; Carbonell, Josep. Revolució catalanista. Barcelona: Monitor, 1934. As we know, this book aroused a great deal of controversy, to the point that it became regarded as the poet's "cursed" book: "Given the widespread accusation of having written a handbook for Catalan fascism, J. V. Foix disowned Revolució catalanista for the rest of his life. [. . .] He was rightly afraid of being misunderstood and misinterpreted and it is true that his public image after the war, though politically and socially moderate, was coloured by his radical past".-Guerrero, Manuel. J.V. Foix, investigador en poesia. Barcelona: Empúries, 1996, 269.

8. The Times (29-5-1933) reported that there were 12 votes in favor. Matan, Branko (ed.). Speak Now or Never. Zagreb: P.E.N. Center \& Most/ The Bridge, 1993, 73. The official result of the vote was published on page 116 of P.E.N. News from June 1933.

9. His most famous work is Bambi (1923). It was translated into English in 1928 and was an immediate success. In 1933, the author sold the rights to the cinema director Sidney Franklin, who in turn transferred them to the Walt Disney Studios, which used the story as the basis for its classic animated film of 1942.- - About Austrian literature between the wars see: Schulte, Hans; Chapple, Gerald (eds.). Shadows of the Past: Austrian Literature of the Twentieth Century. New York: Peter Lange, 2009.

10. PEN Centres are not tied to any particular country or even to the representation of a particular language or culture. It is the members of each centre who decide on the bases for their association, though they all undertake to respect the principles of the PEN Charter. Indeed, it was these principles that sparked the fevered debate that took place in Dubrovnik. The current version of the Charter, with the amendments approved at the Lviv Congress in September 2017, can be found here: www.pen-international.org/wp-content/ uploads/2011/04/The-PEN-Charter-.pdf

11. The correspondence sent by the envoys from Berlin, collected in a volume edited by Joseph Wulf, is chilling. What is most notable is how all three correspondents denounce each other with accusations of failure and lack of diplomacy. They also sent detailed reports to Berlin on the other people taking part in the Congress. Thus, Jo van Ammers-Küller visited the house of Hanns Martin Elster in October 1933, and Elster also invited Erich Kochanowski along to take tea with her ... . signing off with "Heil Hitler" at the end of his letter. He also recommended the Romanian professor, San-Giorgiu, as a strong sympathizer with the Nazi cause. Also mentioned among the delegates who gave enthusiastic support to the Germans in Dubrovnik are the people from the Swiss Centre in Bern, Emanuel Stickleberger and Herman Burte-Wulf, Joseph. Literatur und Dichtung im Dritten Reich. Eine Documentation. Frankfurt; Berlin; Vienna: Ullstein, 1983, 68-101. 


\section{Simona Škrabec}

12. The day before the book burnings, 9 May 1933, Hermon Ould sent a confidential letter to Berlin in which he demanded an explanation regarding the elections at the Centre and the new rules on the admission of members, which had turned PEN Berlin into one of Germany's first wholly Nazi organizations.-Fisher, Ernst. "Das Zentrum in der Weimarer Republik". Handbuch PEN, 2014, 71-132.-See also: Barbian, Jan-Pieter. The Politics of Literature in Nazi Germany: Books in the Media Dictatorship. Translated by Kater Struge. New York: Boomsbury, 2013.

13. Toller, Ernst. Die neue Weltbühne [Prague; Zürich] 24 (15-6-1933).

14. I am grateful to Ira Zorko for making me aware of this moment in the Pau Casals masterclass.

\section{Bibliography}

Adamic, Louis (1933). “A Letter from Yugoslavia”. [New York] The Saturday Review of Literature (27-5-1933). [Reprinted: Matan, Branko (ed.) Speak Now or Never, 1993, 38-41].

Adamic, Louis (1939). The Native's Return: An American Immigrant Visits Yugoslavia and Discovers His Old Country. New York: Council on Books in Wartime.

Aman, Klaus (2014). "Der österreichiche PEN-Clubs in den Jahren 1923-1955”. Bores, Dorothée and Hanuschek, Sven (eds.) Handbuch PEN. Geschichte und Gegenwart der deutschsprachigen Zentren. Berlin and Boston: Walter de Gruyer, 2014, 481-532.

Barbian, Jan-Pieter (2013). The Politics of Literature in Nazi Germany. Books in the Media Dictatorship. Translated by Kater Struge. New York: Bloomsbury.

Bores, Dorothée, and Hanuschek, Sven (eds) (2014). Handbuch PEN. Geschichte und Gegenwart der deutschprachigen Zentren. Berlin and Boston: Walter de Gruyter.

Canby, Henry Seidel (1933). “The P.E.N. Club Conference”. [New York] The Saturday Review of Literature (24-6-1933). [Reprinted: Matan, Branko (ed.) Speak Now or Never, 1993, 133].

Canby, Henry Seidel (1934). 'The Native's Return' by Louis Adamic. New York: Book-of-the-Month Club, February, 1-3.

Domènech, Joan de Déu and Panyella, Vinyet (1999). Àlbum Foix. Barcelona: Quaderns Crema, 258-259.

Fisher, Ernst (2014). "Das Zentrum in der Weimarer Republik". Bores, Dorothée and Hanuschek, Sven (eds.) Handbuch PEN. Geschichte und Gegenwart der deutschsprachigen Zentren. Berlin and Boston: Walter de Gruyer, 2014, 71-132.

Foix, J.V. and Carbonell, Josep (1934). Revolució catalanista. Barcelona: Monitor. Grdina, Igor (2009). "Predgovor”. Rahten, Andrej (ed.) Izidor Cankar. Diplomat dveh Jugoslavij. Ljubljana: Studia Diplomatica Slovenia.

Guerrero, Manuel (1996). J.V. Foix, investigador en poesia. Barcelona: Empúries.

Hindus, Maurice (1934). “Louis Adamic”. Canby, Henry Seidel (ed.) 'The Native's Return' by Louis Adamic. New York: Book-of-the-Month Club, 4.

Karaulac, Miroslav (2008). Andrićeve godine u diplomatiji. Belgrade: Višnjić.

Matan, Branko (1993). Speak Now or Never: The 1933 Dubrovnik PEN Club Congress. Zagreb and Dubrovnik: P.E.N. Center \& Most/The Bridge. 
Matvejević, Predrag (1984). “The Fiftieth Anniversary of the P.E.N. Congress in Dubrovnik". The Bridge [Zagreb] 1-2 (1984), 57-60.

Merrill, Christopher (1999). Only the Nails Remain: Scenes from the Balkan Wars. New York: Rowan \& Littlefield.

Schulte, Hans and Chapple, Gerald (eds.) (2009). Shadows of the Past: Austrian Literature of the Twentieth Century. New York: Peter Lange.

Stelè, France (1963). "In Commemoration of the Thirteenth Anniversary of the 11th International Congress of the P.E.N. Club". [English translation: Matan, Branko (ed.) Speak Now or Never, 1993, 153-157].

Toller, Ernst (1933). Die neue Weltbühne [Prague; Zürich] 24 (15-6-1933). [English translation: Matan, Branko (ed.) Speak Now or Never, 1993, 63-66].

Vidaković, Aleksandar (1933). "PEN club and the Germans at the Dubrovnik Congress”. Srbski književni glasnik (16-6-1933). [English translation: Matan, Branko (ed.) Speak Now or Never, 1993, 130-131].

West, Rebecca (1941). Black Lamb and Grey Falcon: A Journey Through Yugoslavia. New York: The Viking Press.

Wulf, Joseph (1983). Literatur und Dichtung im Dritten Reich: Eine Documentation. Frankfurt, Berlin and Vienna: Ullstein, 68-101. 


\title{
6 International PEN and the Republic of Literature
}

\author{
Rachel Potter
}

Just after the First World War, a group of London writers created an international writers' organisation called International P.E.N. (an acronym for Poets, Playwrights, Essayists and Novelists). Harnessing the seventeenth- and eighteenth-century idea of writers as a Republic of Letters, its founder Catharine Amy Dawson Scott collected together a group of Edwardian and feminist writers, including John Galsworthy, H. G. Wells, May Sinclair, Radclyffe Hall, Vita Sackville-West, Rebecca West and Joseph Conrad. Soon afterwards, Dawson Scott and Galsworthy, PEN's first president, persuaded many of the most prominent global writers to become honorary members. They included W. B. Yeats, Rabindranath Tagore, Maurice Maeterlinck, Selma Lagerlöff, Thomas Mann, Heinrich Mann, Robert Musil, Alfonso Reyes and Knut Hamsun.

By 1930, the organisation had an international president; an executive committee; a series of rules; a set of principles; annual Congresses in different cities around Europe; forty-three centres in thirty-four countries stretching from London to Mexico City, China and South Africa and a membership of over three thousand writers.

If the longstanding idea of writers as a Republic of Letters was often invoked by PEN members to describe their organisation, they also viewed it in relation to a number of other, contemporary organisational structures. Dawson Scott labelled PEN a 'Literary League of Nations' in 1926. H. G. Wells, international president from 1933 to 1936, called it an 'intellectual and aesthetic world republic' in 1936. After the war, in 1946, International President Desmond MacCarthy, alert to the changing arena of international relations, asked delegates to think of PEN as though it 'were UNO', and in 1947, US delegate Manuel Komroff called PEN a 'little United Nations." ${ }^{1}$

These phrases capture PEN's precise sense of the contemporaneous international governmental organisations through which the literary republic or public sphere might be imagined-from the league to a pictured world republic to the united nations.

This chapter explores the implications of the PEN organisation and these comparisons with other international organisations for the idea 
that literary writers and literature itself constitute a Republic of Letters. Where in the past this phrase had described networks of connection, collaboration and patronage grounded in the salon culture of major European cities, the creation in 1921 of a global organisation with rules and principles was a literary republic in a different form.

Pascale Casanova explores the materialist idea of literature as a global 'republic' in her 2004 book The World Republic of Letters. She adopts Bourdieu's sociological theory of cultural production and cultural capital to discuss literature's materialist transnationalism within an international 'social space' defined by a shifting global marketplace. The mid-nineteenth century 'literary field', as Bourdieu describes it, was constructed as a 'world apart' because of the mirroring and production, by Flaubert and others, of the rules of the social space within which literature and literary value were produced. ${ }^{2}$ Bourdieu's philosophy of the literary field as a mirroring and crafting of the codes of social space is extended through Casanova's focus on global literary networks. She brings to life the international public sphere as a network of individualised connections between writer, text, editor, publisher, translator and audience. These networks are focused in the geographical locations of specific urban centres, such as Paris, London and New York, and regulated by the market, or by literary values and dissemination avenues at a tangent to, but connected to, market values. ${ }^{3}$ Not only did these networks determine the dissemination of texts, they also produced the criteria through which literary value was decided.

When Dawson Scott founded the PEN organisation in 1921, it was the first time writers had attempted to create an international literary organisation. This chapter takes the organisation itself as its object of study and argues that an exploration of its structure and activities exposes a complex set of values at a tangent to Casanova's international 'social space' of literature. What comes into view is writers collaborating across national borders in consciously crafting the literary public sphere. We witness the creation of literary networks of collaboration and exchange that build upon existing publishing, linguistic and dissemination networks and consciously extend them. We see writers identifying the nature of their cultural capital and putting it to use in defending writers and literature. The organisation evolved from a dining club interested in promoting friendliness among writers from around the world into an international organisation forced to decide upon its rules, structure and commitments. In the 1930s, it committed itself to the activist defence of the rights of writers to freedom of expression, particularly of writers in prison and in exile. The literary field exposed in this chapter, far from simply being an arena of competing individualised interests, is a social space that also incorporates forms of collectivist and free-speech activism. I argue that this activism is distinct from the competing interests that define Bourdieu's and Casanova's literary field; exposing the substance and parameters of this activism, 
and factoring it into accounts of the period, is essential to understanding interwar literary culture.

\section{Organisations}

During the early decades of the twentieth century, there was intense political and literary thinking, both utopian and more practical, about the substance and structure of international organisations. Ideas and images of world republics, world governments, cosmopolises and superstates were promoted and debated. After the First World War, with the actual establishment of the League of Nations, the structure and shape of the international arena was importantly reshaped by what Leonard Woolf insightfully predicted would be the creation of a 'heavier structure of international organisations'. ${ }^{4}$ In addition to the League of Nations organisations, hundreds of new intergovernmental and non-governmental organisations sprang up in the post-war period. Akira Iriye and Glenda Sluga have persuasively argued that both the new international organisational structures of the League and these new non-governmental organisations (NGOs) were central to the history of twentieth century international relations. In the cultural realm, in particular, the specific activities of cultural organisations, Iriye suggests, produced an international landscape defined by both governmental and grassroots NGOs. He reveals how the activities of cultural and human rights organisations sometimes worked beyond the diplomatic and foreign policy interests of the nation state, and the profit interests of multinational corporations and businesses, and constituted a field of international relations not necessarily consonant with the interests of nation states, or the profit motive. ${ }^{5}$ Their centrality to environmental and human rights politics for the last one hundred years has involved the promotion of self-legislating values of rights and environmental protection.

But while NGOs such as Amnesty International and world organisations such as UNESCO have been central to histories of human rights policy and advocacy, ${ }^{6}$ the role of NGOs has not featured in discussions of literature in its international dimensions-as a 'Republic' of lettersor the more specific question of literature's relationship to human rights history. $^{7}$

In the 1920s and 1930s, PEN members liaised quite closely with the League of Nations on various initiatives, including harmonising international translation and copyright. They would go on to work with other government and intergovernmental organisations, including helping the British government by identifying legitimate refugee writers in the late 1930s and during the Second World War and when PEN became an advisory organisation to UNESCO in 1948.

In this chapter, I follow the lead of Iriye and Sluga by seeing internationalism as a synchronous arena of structures and values in which 
organisations played an important role. It is no accident that PEN saw itself in relation to a long history of transnational literary networks and the 'heavier' pragmatic structures promoted by the League, the UN and interwar NGOs. Both were important for the more metaphysical claims made on behalf of writers as a literary republic and as defenders of authorial rights to freedom of expression, and it was in the negotiation of these two things that the interwar literary public sphere was shapedand reshaped.

\section{What Kind of Public Sphere?}

The founding members of the PEN Club often stood outside the organisation to which they belonged and thought hard about what it-and by extension an international collection of writers-represented or should represent. PEN members realised in its early years that their rationale as a collective body, a club and any power or influence they might claim lay in harnessing two kinds of cultural capital. One was enlisting famous writers, and the other was to claim that the Club represented an international network of literary centres.

In fact, the two were brought together. PEN, from the start, proudly listed its fifteen or so honorary members, many of whom had already won the Nobel Prize for Literature, on all correspondence and policy documents, but they did so by arranging this list by nationality and alphabetically. So India, coupled with the name Rabindranath Tagore, was listed prior to Ireland, coupled with W. B. Yeats, and Sweden, linked to Selma Lagerlöff. The effect was to harness the prestige of its authorial membership and the breadth and strength of the national literatures they, at some level, represented. While Tagore was the most globally prestigious representative of Indian literature, Indian literature was also seen to be internationally important because of Tagore's globally acknowledged writing.

This dual focus on individualised authorial cultural capital and the author as representative of national literatures grounded PEN's international organisational network. But PEN was also a grassroots organisation which focused on extending its network into as many cities in the world as possible. PEN centres sprang up in most European cities, as well as New York in 1922, and then further afield. The PEN structure meant that each centre was semi-autonomous, run by the writers living in that particular city, but each centre was connected to the umbrella organisation and signed up to its basic principles, created by John Galsworthy as a declaration and agreed upon in 1927.

The PEN structure not only facilitated grassroots collections of writers; it also exploited existing networks and affiliations. One such network was that of the Hispanic connections prominent in International PEN. From early on, Spanish and South American writers were central 


\section{Rachel Potter}

to the PEN organisation. PEN centres were founded in Madrid and Barcelona in 1922, Mexico City in 1923, Santiago in 1925, Buenos Aires in 1929, La Paz in 1932, and Bogotá in 1936.

These centres were often linked up to one another. When the Mexico Centre was established in 1923, for instance, its list of forty-four members included writers residing in other places including Paris, Santiago, Buenos Aires, Stockholm, Brussels, New York and, most prominently, five members in Madrid, including Carlos Pereyra and Alfonso Reyes.

These networks cut across nation states, which often contained in themselves a number of different literary-linguistic cultures. From the start, for instance, the Barcelona and Madrid centres were completely separate and viewed from the central International PEN organisation as representing distinct 'national' literatures. At the 1923 London PEN Club dinner hosted for foreign friends, for instance, there was one table devoted to Barcelona, with Josep Maria López-Picó as special guest, and one to Madrid, with Gregorio Marañón as special guest.

\section{What Kind of Internationalism?}

If PEN members committed themselves, from the organisation's founding, to the principle of international friendliness, the nature of both its internationalism and its status as a literary public sphere was a source of fierce contestation in the 1920s.

At the 1925 Paris Congress, for instance, a discussion was held about forming an executive committee of the PEN Club, and the discussion led, inevitably, to questions of representation. Who should have representation on the executive, and how should this be decided in the context of a global organisation of writers? The decision was taken to divide the literary public sphere into representative literary groupings based on language. Each representative language comprised a number of different nations. So, the French language represented and was represented by French, Belgian and French-Swiss (Romandie) writing. German language, in turn, represented German, Austrian and Swiss-German writing. The Spanish language represented a vast geographical map, as it represented Spanish, Mexican, Central American, Antilles (Caribbean) and Spanish South American writing. The other two representative languages were Portuguese and English. Importantly, Catalonia was described as a literature apart: 'La Catalogne constituent un groupe distinct'.

The language of the main Imperial powers, and the maps of influence they engendered, were seen as the representative literary languages of an imagined international public sphere. Imperial histories lingered in the very linguistic connections linking Buenos Aires and Madrid, while literary identity was seen as formed by regional affiliations grounded in history and tradition. This was a squeezed and stretched literary public sphere, a map of linguistic and literary affiliations not consonant with the 
boundaries of nation states. But the focus on the linguistic foundation of literary identity also made space for autonomous cultural nationalisms within nation states. Notice that in addition to Catalonia's position outside all five representative literatures, there were many other languages and cultures that were just simply and implicitly positioned outside. In the 1930s, the president of Italian PEN, Futurist and Fascist F. T. Marinetti, would complain vociferously about the absence of any reference to Italian language and culture and would highlight the cultural imperialism of the language question at the Buenos Aires Congress of 1936.

These debates were a literary version of those taking place in the intergovernmental political sphere about the role and structure of the League of Nations and the rights of minority populations within the newly constituted states of the post-war settlement. After the Paris Peace Conference of 1919, the 'big three' (France, Great Britain and the United States), as they were called, decided upon the territorial changes of Eastern Europe. They also created the first-ever minority treaties which sought to protect the rights of what were called 'national', rather than the more familiar idea of religious, minorities. They asked the new minority states to give basic rights to all citizens and equal treatment to minorities.

Despite the League emphasis on the rights of minority populations and of small nations to self-determination, this did not extend to what were seen as 'established' nation states such as Britain. The big three resisted the creation of a universal system of minority rights, instead imposing minority rights protections on the newly constituted minority states of Eastern Europe. The hypocrisy of this lopsided system was a consistent source of disagreement throughout the 1920s. One of the key arguments was that minorities in established nation states such as Britain had become successfully assimilated over time and therefore required no such protections. Among British commentators, as Mark Mazower shows, what was striking was 'the degree to which even the most radical British internationalists accepted the imperial framework of world politics.'

By recognising and accommodating Catalonia's linguistic and cultural autonomy as a minority within the Spanish state and the extensive global networks represented by the Spanish language, the PEN organisation in some respects replicated the dual logic of the League. But some centres saw minority rights as directly in conflict with PEN's internationalist ideals. Prague PEN President Karel Čapek was forced to deal with the desire of German-speaking writers in Prague to found a separate Germanlanguage PEN centre in 1926. Čapek wrote in anguished terms to Ould:

Under the present circumstance the committee of the P.E.N. Club of Prague would not consider it advisable to establish in Prague two centres-one for authors writing in Czech the other for authors writing in German. One of the chief purposes of the P.E.N. Club is to promote the bringing together of the different nationalities. ${ }^{9}$ 


\section{Rachel Potter}

Čapek insisted that the aspiration to Czechoslovakian cultural unity should override the recognition and representation of cultural differences grounded in linguistic and national identities, both within the PEN organisation, and in Czechoslovakia more broadly. There were two kinds of nationalism at work here. One aspired to represent the new territorial Czech sovereignty created after the war; the other was grounded in an imagined polity grounded in linguistic identity. While this was a particularly vexing question in Prague, where the dominant literary language was German, the issue was not confined to Czechoslovakia. The conflict between these different understandings of internationalism was one of the main preoccupations of International PEN in the mid- to late 1920s.

A few months prior to Čapek's letter, at the 1926 Berlin Congress, Ould had proposed that delegates consider whether a PEN centre could be established to 'represent a literature not attached to a homogeneous territory'. Piérard, the Belgian representative, believed that this question was really directed at his country, with its French and Flemish literatures, and he strongly argued against, insisting that in Belgium the Flemish and Wallons constituencies met in 'perfect amity'. The German delegate, Federn, commented that the question was also a live one in Poland where Warsaw Jews were keen to establish their own centre. He reported that he had received a number of telegrams from Warsaw PEN emphatically rejecting the formation of a Yiddish 'chapter' of the Warsaw Centre. ${ }^{10}$

The debate over Poland's Jewish community was a kind of literary mirror of the broader political debates taking place in the League of Nations about the rights of Poland's Jewish community. Poland's treatment of its German, Jewish and other minority populations had spearheaded the minorities rights League legislation in 1919. The desire of Warsaw Jewish writers to create a separate 'Yiddish' chapter was fuelled both by their perilous position, in terms of civic and cultural rights, within the Polish state and their sense of belonging to a linguistic and literary community that transcended the Polish territorial borders.

Federn's comments resisting Jewish attempts to create a separate PEN centre in Warsaw, meanwhile, suggestively captured Germany's contradictory position on minority rights. Germany's own treatment of its minority Jewish populations conflicted sharply with its strong defence of the rights of ethnic German minorities in Eastern European states, a defence that would lead not only to its decision to depart from the League in 1933, but also the collapse of the minority rights regime as a whole.

The different status of minority populations informed the debates at the PEN Congress in Brussels the following year, where the question of what kind of constituency a PEN centre was supposed to represent was debated at length. It hinged on whether a PEN centre should be created on the basis of territorial sovereignty or a community bound by 'literary' ties, a word used to designate a mixture of linguistic and cultural connections, what French delegate Crémieux referred to as 'literatures 
without territorial base'. Some ways of understanding a literary heritage not grounded in territory entailed, however, what Cremieux labelled a 'literary nationalism', something, as he pointed out, which was 'against the spirit of PEN'.

The divisions and debates within PEN over whether literary internationalism should be grounded in the recognition of territorial, linguistic and cultural tradition or should override it arose from and were facilitated by the PEN organisation. These debates, in Bourdieu's language, 'mirrored' to some extent the space or logic of League internationalism. The values at stake, however, rather than being 'social' values, were more obviously cultural-political, involving distinct understandings of what culture was for. Was it a shared and unifying cosmopolitan force originating in the individual author and communicating across national boundaries, or was it a means of binding together and expressing national, linguistic, religious or racial particularity? Such questions continue to be live ones in debates about the politics of world literature and the erasure of cultural and linguistic particularity that the category sometimes entails.

The PEN Congress steering committee, in its pragmatic way, formulated three proposals to decide on the matter: first that the PEN Club should have only one separate centre in every city, but that second, it was fine to have several sections in each country, and third, that each section should be under the control of the central national committee. After an active debate, Cremieux proposed an amendment that in exceptional circumstances, a section could be granted provisional autonomy by the International Committee, as long as it was subsequently approved by Congress. It was this fourth principle that allowed the Yiddish Polish PEN Center, composed of Jewish Poles, to be founded on a 'nonterritorial' basis three years later.

At the same time that Galsworthy, and the PEN organisation, were laying out PEN's founding principles, that 'literature, national though it be in origins, knows no frontiers and should remain common currency between nations in spite of political or international upheavals' and that works of art are 'the patrimony of humanity at large', these same individuals were exposing and exploring the fraught issues connected to such transnational visions. How to embrace a transnationalism without erasing cultural difference? There was a clear imbalance between the universal rhetoric and the importance for many writers of consolidating, expressing and asserting the specific features of cultural and linguistic identity in a broader context of political and civic inequality.

The commitment to an internationalism specifically counter to 'literary nationalism', as Cremieux put it, informed the pragmatic PEN resolutions on the issue. Galsworthy tried to tread a line through these debates. In 1927, when he addressed the Edinburgh centre, he argued that PEN's internationalist principles were grounded in a strong sense of cultural 


\section{Rachel Potter}

identity and used the word 'national' to denote a Scottish culture distinct from English literature. Nobody in the PEN club, he argued, 'believed that the spark of literature was anything but deeply national'.

At a speech delivered in Hamburg in 1929, Galsworthy expanded on the importance of recognising minority cultural and literary identities to further a pan-European cultural internationalism. He insisted that when it came to intellectuals, whom he labelled 'the bearers of culture in Europe', it was not 'the frontiers of States' that were determinate, but the appertaining to this or that group of culture'. The transcript, which has been translated rather clumsily, reads 'to that the individual feels belonging to, from his free inner decision'. ${ }^{11}$

Here, the writer's freedom resided in their right to choose the community to which they belonged, while the broader banner of European culture was constituted by a mosaic of cultural communities that cut across State frontiers.

Galsworthy's claim that literary internationalism was grounded in the localism of communal identity, however, was counterbalanced by other PEN voices which emphasised a more vigorous transnationalism. Ferdinand Goetel, president of the Polish PEN Club, observed in his opening address at the 1930 Warsaw congress that every member attending was a 'very watchful and sensible observer on his own account', but that they were at the same time the 'eye and ear of his whole nation'. The idea that writers were conduits for national sounds and sights was the ground for the organisation's collectivism. He commented on this collectivity in the following badly translated words of the transcript: 'Every congress means for people willing to stand such a test to give answer to the questions of hundred intellects also a sever [sic] examination'. ${ }^{12}$ He delightfully described the PEN club as the 'living bridge where we can meet without passport and visa, beyond all terrestrial and mental frontiers'.

PEN congresses were a breeding ground for such metaphors of national and individual transcendence; balanced and in many respects defined against its national and political factions. But the issue of number-a numerical collectivity-that Goetel mentions here is interesting. Number was often invoked by PEN members to suggest the extent of its grassroots membership. As Galsworthy highlighted in a letter of 1930, the organisation had forty-three centres in thirty-four countries with a membership of over three thousand writers, 'including all the most important creative writers'. As he said, this collectivity 'is not animated by a mere vague internationalism, it believes in the national spirit; but it tries to bring together the various national spirits and to weld them by better understanding'.

Goetel's hundred intellects and Galsworthy's three thousand writers from thirty-four countries serve to underpin the metaphysical flourishes of Goetel's 'living bridge' beyond frontiers, and Galsworthy's welded 'better understanding'. The anonymous factor of number, the individuality of 
authorial celebrity and the national representativeness of writers were brought together in PEN's visions of itself as an international literary public sphere. They were the foundation for the organisation's claims that it constituted a credible literary public sphere and for its activation of this sphere in the service of politicised, rights-based ends in the mid-1930s.

\section{From Minority Rights to Individual Rights}

As the political situation in many countries disintegrated and PEN expanded its centres and networks further afield, so the constituent parts of PEN's public sphere altered and the balance of power shifted.

A year prior to the outbreak of the Spanish Civil War, PEN delegates from around the world descended on Barcelona for its annual Congress. Hosted by Catalan writers, including the recently imprisoned-and released-Catalan linguist and president of Catalonia PEN Club, Pompeu Fabra, other delegates included International PEN President, H. G. Wells; Rome PEN President F. T. Marinetti; Indian PEN President and theosophist Sophia Wadia; German writer in exile Klaus Mann; Storm Jameson, who would take up the presidency of English PEN a couple of years later; Henry Canby, US PEN president; Benjamin Crémieux, French PEN president and Professor Entwistle, Scottish delegate.

As it turned out, it was a pivotal historical moment both for the International PEN organisation and for Catalan PEN.

The unfolding global events of Hitler's consolidation of power; the 1933 Dubrovnik PEN Congress, where Berlin PEN had been thrown out of the organisation because of its exclusion of Jewish and Socialist writers and the changing nature of Soviet international cultural politics had produced a tense political stand-off amongst writers about how to deal with Nazism and Fascism and the fate of refugee writers. In Spain itself, meanwhile, the Madrid and Barcelona PEN centres, which had been inactive during the late 1920s and early 1930s, had been recently reformed because of the political situation. ${ }^{13}$ The Madrid Centre, for instance, had been recently reformed in 1935 with a roster of prominent members including José Ortega y Gasset, José Martínez Ruiz, Melchor de Almagro San Martín, Enrique Díez Canedo, Melchor Fernández Almagro, Antonio de Obregón and José María Salaverría. ${ }^{14}$

The debates at this congress reveal the change of focus within the PEN organisation during the early 1930s, as the disagreements about internationalism made way for discussions of the individualised rights of the author in exile or in prison.

When the Congress opened, the international PEN president, H. G. Wells, caused uproar by delivering a controversial speech in which he announced his incipient resignation as PEN president. Angering many, he argued that the Club must cease to devote its energies to banquets and 


\section{Rachel Potter}

sight-seeing and instead become an international group of intellectuals willing to fight for the right to free expression and address the problems of the day.

This open attack on PEN's political ineffectiveness, from its own president no less, was a blow to many; for others, it was a welcome wake-up call to PEN members that they needed to politicise their efforts in defence of writers in the face of unfolding world events. A week later, the huge, well-publicised, Communist-funded popular front Congrès international des écrivains pour la défense de la culture (June 1935) took place in Paris. It flamboyantly and explicitly promoted its politicised Communist commitment to fighting a cultural battle against Fascism and represented a stark contrast to the stated 'apoliticism' of PEN's commitment to writers' rights.

In face of this competition from more politicised anti-Fascist writers' groups, as well as unfolding political events, PEN became more forthright in staking out its values and the nature of its activism. The Congress opened with a discussion of a joint proposition issued by the English and American centres.

The 1927 PEN founding principles had been added to and changed in subsequent years. The 1933 'Canby Resolution', as it was called, stipulated that PEN should 'guard the spirit in its freedom', that PEN was founded to foster 'goodwill and understandings between the races and nations' and that writers should avoid being used 'as weapons of propaganda in the defence of persecution'. ${ }^{15}$ The 1934 'Raymond Resolution', meanwhile, declared that 'The PEN stands for liberty of expression throughout the world and views with apprehension the continual attempts to encroach upon that liberty in the name of social security and international strategy'. ${ }^{16}$

These values, resolutions and declarations required a balancing act between universalist claims and the more specific acknowledgement of conflicts and interests. If we note the language used in the Galsworthy, Canby and Raymond resolutions mentioned previously, we can see this balancing act in action, as well as a series of shifting coordinates and changing values, from the interest in internationalism as a counter to war-time nationalism (1927) to a focus on defending the writer from anti-Semitic racial persecution (Dubrovnik; 1933) to the attention to free expression (Edinburgh; 1934). While the acknowledgement of the racial persecution of fleeing German-Jewish writers was paramount in Dubrovnik in 1933, the defence of the 'inalienable right' to free expression, a right of the person transportable across borders, was important in the face of imprisoned and refugee writers at the Edinburgh Congress in 1934.

The joint Anglo-American proposition at Barcelona both invoked and consolidated the defence of an author's rights. It reaffirmed the conviction that 'freedom of expression and publication is an inalienable right of 
all creative workers, that any censorship of literature hinders authors in their work, is treason to the rights of conscience and should be resisted by all authors, whatever the nature of the censorship. ${ }^{17}$

The resolution deployed an Anglo-American language of natural law, citizen's rights and duties and constitutional freedoms, brought together to create a literary version of a writer's constitution. Here, freedom of expression is a right that cannot be alienated-transferred to someone or something else. We would normally understand an inalienable right politically as something that cannot be transferred to the state, such as one's conscience. An author's inalienable rights, meanwhile, would conventionally be understood as the literary patrimony that persists even after ownership has been transferred to a publisher. The idea of an inalienable right, however, presupposes a nation state to which a right might—or might not—be transferred. The resolution extends earlier PEN resolutions on freedom of expression into a natural right of the creative worker irrespective of sovereign status. The universalised register of the declaration shifts the location of rights to the 'creative' worker as such, as though the right to expression is an integral part of what it means to be a creative human. It is authors who are asked to resist censorship wherever they find it, as though 'creative workers' were a sociological category or demographic grouping that can secure or uphold the right of free expression.

The de-tethered nature of the rights being claimed here informs the declaration as a whole. All creative persons have sacrosanct rights of conscience whose violation is a form of 'treason' against humanity. The inalienable rights of expression and conscience are balanced with authorial obligations, a kind of literary version of citizen's duties: 'the first duty of every author is the pursuit of truth'. The citizen-writer's duty to truth, meanwhile, is guaranteed by governmental responsibilities: the 'first duty of all governments to the author is to see that he is not hampered in that pursuit'.

The nation state is both present and absent in this declarationinalienable rights, treason, resistance and the duty of both writers and governments would normally be understood with reference to the state. However, the transnationalism of the declaration has pushed the state to one side and replaced it with the literary community and literature itself.

But what could this humanist language of authorial rights, humanity and rights possibly mean in practice? Was it so much hot air? It was followed by a more specific principle:

Congress recognises that in a certain number of countries author members of the Federation of the P.E.N. are not in a position to put the foregoing principles into practice. It falls upon the Executive Committee to make such protests or demands as may be necessary whenever the occasion arises in these countries. ${ }^{18}$ 
The organisation's declaration that it would protest on behalf of authors 'not in a position' to enjoy these rights was significant, as it represented a shift in the PEN Executive Committee policy. In the past, it had tended to leave it to the national PEN centres to take action on cases of literary censorship or imprisoned writers and thereby avoid intervening in censorship issues in other jurisdictions. In effect, the final statement of this declaration put into place the idea that the PEN Executive could and should take action to defend imprisoned, exiled, stateless and unprotected writers, even in parts of the world without a PEN presence.

The inalienable rights language and the decision to take action to defend unprotected, stateless writers were entwined. The issue of unprotected writers was paramount at the Congress. They were symbolised by the situation of writers in Catalonia, Germany and Haiti.

Pompeu Fabra, who, as Barcelona PEN president, opened the Congress on 21st June, had recently been released from prison. He had been imprisoned in late autumn of 1934 because of his position as president of the Republican Universitat Autònoma de Barcelona. On 6th October, troops of the Second Spanish Republic suppressed a Catalan government uprising led by Lluis Companys and threw a number of prominent Catalans in prison.

Exiled German writer Klaus Mann, meanwhile, put forward his own resolution in defence of persecuted writers:

The P.E.N. Clubs in all countries solemnly protest against the incarceration and ill-treatment of German authors in Germany. Authors of all the countries united in the P.E.N. Club demand the release of their colleagues Ludwig Renn and Carl Ossietzky. ... They demand the immediate release of the journalist Berthold Jacob who was illegally abducted from Switzerland. ${ }^{19}$

The broader principles of the US-British resolution were here fleshed out in the description of the specific situation in Germany, and the precise mention of three individual writers-Renn, Ossietzky and Jacob. Mann's motion was carried unanimously, with one dissenting voice from the Dutch delegate, who objected to the 'stating of names'.

Importantly, however, it was not just the plight of European-German and Catalan-writers that exemplified the need for a human rights language.

Another debate focused on whether action should be taken to persuade the Haitian government to reconsider the case of imprisoned Haitian writer Jacques Roumain, who was languishing with malaria in a jail in Port-au-Prince. His case was brought to light vividly at this congress as an example of the persecution and destruction of a writer's right to free speech.

Roumain was leader of the nationalist movement in Haiti against the US occupation from 1915-1934. He was imprisoned four times between 
1928 and 1936, but this had not prevented him from founding the Haiti Communist Party in 1934. In the 1930s, he wrote militant journalism denouncing Fascism and in support of the Spanish Revolutionaries. He would go into exile in 1942 as a diplomat in Mexico City. His most famous novel, Gouveneurs de la rosée, published in 1944, has been read as an important work bridging a politicised Haitian indigénisme and literary cosmopolitanism, an example, as Valerie Kaussen argues, of panAfrican 'cultural decolonization', or what Paul Gilroy has labelled 'a distinctive counterculture of modernity'. ${ }^{20}$

At the PEN congress, his case was raised by the US delegate, Henry Canby. Roumain had been brought to Canby's attention by the 'Committee for the Release of Jacques Roumain', based in New York, a group sponsored by Langston Hughes, Jean Toomer, Theodore Dreiser, Edmund Wilson, Alfred Kreymbourg and many others. This committee claimed that Roumain had been imprisoned after he became interested in the Scottsboro case in 1934 and asked a New York friend to send information. When the friend, replying by letter in French, said he would send written materials, or 'materiaux', the authorities had seized on the ambiguity of the word 'materiaux', which they claimed referred to bombs, to throw Roumain in jail.

In Barcelona, Canby argued that an 'error of justice had been committed' and moved that the government of Haiti be asked to reconsider the case. The motion was carried unanimously.

While the PEN Executive had awarded itself the right to protest against the dire situation of imprisoned writers in Germany, where there had once been a strong PEN centre which had been thrown out of the organisation, it here also granted itself the authority to defend an imprisoned writer in a country which had never had a PEN centre. It thereby adopted the mantle of an organisation that could and should speak for all writers in every country.

It is no coincidence that at the moment Canby decided to take action to defend Roumain, he also helped draft a resolution giving the PEN Executive the power to defend writers in countries not necessarily with a PEN presence. The development of PEN's 'inalienable' rights language was fuelled by the desire to extend PEN's reach beyond the centres and structures of the organisation. In effect, the drafters of the resolution required a language that was sufficiently transnational to connect imprisoned Catalan writers, refugee German writers, writers fleeing Austria and imprisoned writers in Haiti. They also needed to allow themselves the right to take action on behalf of writers from all parts of the world.

\section{Global Networks}

But not all PEN centres were happy about these changes or found such rhetoric palatable. Canby acknowledged that 'there seemed to be a certain amount of divergence of opinion in the attitudes of the delegates 


\section{Rachel Potter}

towards the proper function of the P.E.N.' and whether the emphasis should be on 'social activities' or 'the protection of the right of authors to freedom of expression' ${ }^{21} \mathrm{He}$ recommended that delegates go back to their national centres and consult their members.

Some of the disagreement rested on a tension between what was seen as the imperialism of this universalist language and the recognition of cultural difference, a tension that was structurally similar to the conflict between internationalism and minority 'national' literatures discussed in the first part of this chapter.

While All-Indian PEN President Sophia Wadia delivered a speech which criticised the imperialism of Western cultural understandings by extolling the rich tradition of Indian philosophy and literature, the president of Rome PEN, F. T. Marinetti, attacked PEN's attempts to take a more active role in furthering writers' rights from a different direction. Marinetti would turn up at PEN congresses throughout the 1930s and insist that the organisation stick to its proper role of discussing literature rather than politics. At Barcelona, he delivered an eloquent speech on the subject of contemporary Italian literature, expressing regret that so many brilliant writers were unknown outside Italy.

If PEN's 1920s internationalism was defined in relation to the rights of 'national literatures', then its creation of a universalised language of writers' rights took place at the same time as the international landscape was re-shaped through the creation of Fascist and Communist cultural networks and non-Western PEN members called for an internationalism that reached beyond Europe and acknowledged the particularities of cultural difference.

These drives pointed in opposite directions, but both were the product of an organisation expanding out from a US-European centre.

This expansion would, in turn, be fuelled by the fleeing exiled European writers who began to make their escape by journeying west and south. Where in the 1920s, ambitious writers from Buenos Aires, Santiago or Mexico City would travel to Madrid or Paris, now the migration of writers pointed in the opposite direction.

The Hispanic linguistic literary maps linking writers in Buenos Aires and Mexico City with those in Barcelona and Madrid made such migrations possible, and the implications of migration would be important at the Buenos Aires Congress the following year, which opened on 5th September, 1936, two months after the outbreak of the Spanish Civil War.

Both the splits in Spanish culture and the scattering of writers from Spain were already clear to see. Madrid delegates Enrique Díez Canedo, Melchor de Almagro San Martín and honorary members José Ortega y Gasset and Gabriel Alomar would all end up living in exile from Spain, Ortega y Gasset and San Martín in Buenos Aires, Díez Canedo in Mexico and Alomar in Egypt.

At Buenos Aires, these writers brushed shoulders with Franco supporter José María Salaverría, who attended on behalf of the Madrid 
Centre. Also present was the Catalan writer Joan Estelrich, who was a member of the conservative Lliga Catalonia, who asked the Congress not to scorn politicians, who have 'their own afflictions as you all, and are not always oblivious to the rights of intelligence'.22

If Spanish writers were very much present at the Congress, the issue of Spain was also, unsurprisingly a major topic. Wells sent a message of support but was unable to attend the Congress. He spoke of Spain as 'now a torn and distressful land'; its 'distresses are largely due to the intensity of its reactions to the mighty social forces that are reshaping our world'. It is out of the Spanish war that Wells 'believes' that 'the will and intelligence of mankind will triumph over all the traditions and perplexities that divide us so sorely today', and that in what he calls the 'ultimate synthesis' of intelligence, 'the minds that use the Spanish language as their medium will play a major part'. ${ }^{23}$

Wells's faith that the will and intelligence of mankind would triumph over the divisions afflicting the world was ironic, given the splits not only within Spanish culture but also in evidence at the Buenos Aires Congress more broadly. What was more striking was the extent to which the gathered writers were unable to transcend the 'mighty social forces' reshaping the world, the extent to which the prospect of a Fascist Confederation of writers vied with other networks within the umbrella of the PEN organisation. Never before had the Fascist-Communist-liberal splits been so clear.

Such splits were paramount in the situation of Spanish and Catalan writers. On 11 September, Melchor de Almagro San Martín, who was already living in exile in Buenos Aires, went so far as to propose a 'Pact of Non-Aggression among writers'. Spanish PEN, he declared, had always attempted to accommodate writers with opposite political views. By aping the diplomatic language of militaristic foreign policy initiatives, he ironically suggested the sheer level of political infiltration and violence into PEN debates. It had certainly been true that Congresses had become increasingly acrimonious during the 1930s and that this violence reached a peak at Buenos Aires. In his Pact, San Martín used the PEN language of fraternity to expose the problems that ensue when violence and aggression seep into literature:

The PEN Clubs have been founded to promote cordiality among writers. Without this cordiality, no wide diffusion of artistic works becomes possible, nor can the literatures of the world cooperate to their mutual advantage. The artist must work in a state of perfect serenity. . . . Spiritual serenity requires self-control and respect for others. ${ }^{24}$

The Pact of Non-Aggression obliged members 'not to indulge in insults when we polemize' [sic]. San Martín's plea for the civilised, polite exchange 


\section{Rachel Potter}

of opinion saw self-control and respect as a literary form of political pacifism: 'As we long for peace among writers-the writers of each nation and the writers of the whole world-this scheme embodies our will'. The speech received 'Loud applause'.

At the same moment that Wells was envisaging a universal synthesis of values arising from the violence of the Spanish Civil War, San Martín was asking writers themselves to commit themselves to non-aggression by promoting pacifist principles and the civilised exchange of opinion.

\section{Conclusion}

This discussion of International PEN as a twentieth-century literary republic in concrete form has revealed the extent to which the international sphere was reshaped by the creation of new international organisations after the First World War and the impact of this reshaping on the idea of writers as a 'republic' of letters. The history of the PEN organisation traced in this chapter also reveals the changing fate and focus of writers in the context of Civil War, persecution and exile. It also exposes the shifting structure and preoccupations of the organisation itself. I have argued that the history of the organisation reveals a series of debates and decisions with parallels to a broader political 'space' of international relations. The imperialist assumptions of the dominant League nations and the debates that took place within the League about the rights of minority populations infiltrated the discussions within PEN about the identity of national literatures. The emerging language of universal rights in the mid-1930s, defined against a backdrop of transnational Fascist and Communist political networks, was mirrored in PEN's internal debates about the rights of writers in prison and in exile, as well as its humanist defence of the individualised right to free expression. The demands by non-Western nations that a meaningful internationalism extend beyond the US-Europe nexus of power were similar to debates that took place within PEN's Congresses about whether literature constituted a kind of cosmopolitan transcendence of sovereignty, whether literature was a 'universal' value linked to inalienable rights and freedoms or whether universal values were a new framework for Western cultural imperial power.

But in addition to these crossovers, I have also argued that the very structures of these organisations were central to the understanding of what a literary international sphere or republic of letters, could or should be. The debates about literary identity, universal values and internationalism within PEN were facilitated by the international structure of the organisation. The organisation's crafted public sphere was distinct from the literary arena seen as an international marketplace. It was not only that the PEN organisation provided a forum for international debate, disagreement and-sometimes—collaboration, it was also that the organisation itself formed part of the international landscape in which Fascist, 
Communist and liberal internationalisms and ideas of what literature was for competed with, and defined, one another.

\section{Notes}

1. Desmond MacCarthy, Proceedings of the 18th Congress, Stockholm, Sweden, June 2-6, 1946, p. 10, PEN Records, Folder 4; Report from Manuel Komroff, vice president, American Center, appointed delegate to represent The PEN at Congress of International Organizations invited by the United Nations, to Hermon Ould, 24.4.47, pp. 1-2, PEN Records, Box 42, Folder 5. I would like to thank the Harry Ransom Center at the University of Texas at Austin for their kind permission to quote throughout this essay from their PEN archival holdings. Thank you also to the Harry Ransom Center for awarding me a Research Fellowship in 2015, which allowed me to undertake preliminary research into the PEN archives held there, and the Leverhulme Trust, for awarding me a Research Fellowship, which gave me the opportunity to study further the PEN archive. Thank you also to the many librarians and archivists at HRC, for their help and advice when I visited the archive. I would like to say a particular thank you to Joan Sibley, who gave invaluable advice when I was at HRC, and more recently helped me with regard to the HRC re-cataloguing of PEN materials.

2. Pierre Bourdieu, The Rules of Art: Genesis and Structure of the Literary Field, trans. by Susan Emanuel (1992; Cambridge: Polity Press, 1996), p. 48.

3. Pascale Casanova, The World Republic of Letters, trans by M. B. Debevoise (Cambridge, MA: Harvard University Press, 2004).

4. Leonard Woolf, International Government: Two Reports by L. S. Woolf (1916; London: Forgotten Books, 2012), p. 12.

5. See, for instance, Akira Iriye, Cultural Internationalism and World Order (Baltimore: The Johns Hopkins University Press, 1997) and, most importantly, Global Community: The Role of International Organizations in the Making of the Contemporary World (Berkeley: University of California Press, 2002).

6. See, for instance, Glenda Sluga's discussion of UNESCO in Internationalism in the Age of Nationalism (Philadelphia, PN: University of Pennsylvania Press, 2013).

7. See, for instance, Joseph Slaughter, Human Rights, Inc: The World Novel, Narrative Form, and International Law (New York: Fordham University Press, 2007) and Elizabeth Anker, Fictions of Dignity: Embodying Human Rights in World Literature (Cornell: Cornell University Press, 2012).

8. Mark Mazower, No Enchanted Palace: The End of Empire and the Ideological Origins of the United Nations (Princeton: Princeton University Press, 2009), p. 32.

9. Karel Capek, Letter to Hermon Ould, 26th November 1926, pp. 1 \& 2; PEN Records, Box 9, Folder 5.

10. Rough Notes of the 4th Congress, Berlin, Germany, May 16-19, 1926, p. 3; PEN Records, Box 79, Folder 18.

11. John Galsworthy, Speech to Hamburg PEN Centre, n.d. (1929?), PEN Records, Box 78, Folder 5.

12. Ferdinand Goetel, Opening Address of the 8th Congress, Warsaw, Poland, June 20, 1930, PEN Records, Box 80, Folder 6.

13. PEN News, No. 53, February 1933, PEN Records, scrapbook 1930-1934, Box 114, Folder 1.

14. Report of the PEN International Executive Committee, November 4 1935, p. 3 , PEN Records, Box 99, Folder 2. 


\section{Rachel Potter}

15. [Canby Resolution] Henry Seidel Canvy, American Resolution, PEN News, No 56, June 1933, p. 6.

16. [Raymond Resolution] Raymond, Ernest, 12th Congress, Edinburgh, Scotland, June 17-22, 1934, motions, resolutions, and discussions, PEN Records, Box 82, Folder 3.

17. [Anglo-American Proposition] Anglo-American joint resolution, Proceedings of the 13th Congress, Barcelona, Spain, May 20-25, 1935, p. 1, PEN Records, Box 82, Folder 6.

18. [Anglo-American joint resolution, Proceeding of the 13th Congress, Barcelona, Spain, May 20-25, 1935, p. 1, PEN Records, Box 82, Folder 6.

19. Klaus Mann, Resolution, Proceedings of the 13th Congress, Barcelona, Spain, May 20-25, 1935, p. 5, PEN Records, Box 82, Folder 6.

20. Paul Gilroy, The Black Atlantic: Modernity and Double Consciousness. Harvard University Press, 1993, p. 36.

21. Henry Seidel Canby, Proceedings of the 13th Congress, Barcelona, Spain, May 20-25, 1935, p. 6, PEN Records, Box 82, Folder 2.

22. Joan Estelrich, International Congress of the P.E.N. Clubs (14th: 1936: Buenos Aires, Argentina), trans. by Orzábal Quntana, Arturo (1937; Buenos Aires: La Bonaereuse), p. 200.

23. H.G. Wells, 'Messages Addressed to the Congress', International Congress of the P.E.N. Clubs (14th: 1936: Buenos Aires, Argentina), p. 37.

24. Mr De Almagro San Martin, International Congress of the P.E.N. Clubs (14th: 1936: Buenos Aires, Argentina), pp. 163-64. 


\title{
7 The 1936 Meetings of the PEN Clubs and the International Institute of Intellectual Cooperation in Buenos Aires
}

\author{
Alejandra Giuliani
}

\section{Introduction}

In September 1936, two important international meetings of writers and intellectuals were held in the city of Buenos Aires. One of them, the XIV International Congress of the PEN Clubs, was held between the 2nd and 15th of the month and was attended by eighty-six delegates from forty countries. Among them were Jules Romains, Jacques Maritain, Emil Ludwig, Filippo Tommaso Marinetti, Alfonso Reyes, Joan Esterlich and Enrique Díez Canedo. The other event was the Seventh Conversation of the Organization of Intellectual Cooperation of the Society of Nations (entretien) and was held from the 11th to the 16th of the month. The Permanent Committee of Arts and Letters was the section of the Institute that organized the entretien and was chaired by Paul Valéry. The idea of hosting the entretien in Buenos Aires arose from the proposal of Antonio Aita, secretary of the PEN Club of Argentina, to the International Committee of Intellectual Cooperation. Participants at this event included Carlos Ibarguren, Francisco Romero and Juan B. Terán (Argentina); Stefan Zweig (Austria); Alcides Arguedas (Bolivia); Afranio Peixoto (Brazil); Luis Piérard (Belgium); Baldomero Sanín Cano (Colombia); Enrique Díez Canedo and J. Estelrich (Spain); Georges Duhamel, Jules Romains and Jacques Maritain (France); R. H. Mottram and W.J. Entwistle (England); Giuseppe Ungaretti (Italy); Alfonso Reyes (Mexico); Fidelino de Figueiredo (Portugal); Pedro Henríquez Ureña (Dominican Republic); Emil Ludwig (Switzerland) and Carlos Reyles (Uruguay) (Comisión Argentina de Cooperación Intelectual, 1937). The objective of this chapter is to contribute to the knowledge that there were intellectuals in both meetings who brought their own sense and legitimacy to the international literary space-not only as authors but also as editors, publishers, translators and directors of editorial collections-(Sanz Roig, 2013: 12). The intellectuals who participated in the meetings of 1936 brought into play their international capital, their role as Spanish-American cultural mediators in the networks of international modernity.

This work will focus on the historical analysis of relevant official publications of the PEN Club and the Argentinian Committee of Intellectual 


\section{Alejandra Giuliani}

Cooperation on both meetings. We will also take into consideration the Argentine press, which reported profusely on the PEN Clubs Congress and, to a lesser extent, on the so-called entretien. This chapter analyzes mainly the interventions of Victoria Ocampo in the PEN Clubs Congress and of Pedro Henríquez Ureña in the entretien. In addition, the work mentions central topics of the interventions of other cultural mediators in the meetings: Francisco Romero, Eduardo Mallea, Carlos Reyles and Alcides Arguedas.

A constant in those meetings was the presence of the Sur group, which, as a publishing network (Sapiro, 2016: 72-73), acted in liaison with the international PEN Clubs and the Intellectual Cooperation networks. Important members of Sur were part of the delegations to the meetings, not only in the Argentinian delegation, but also in those of American countries. In first place, there was the presence of Victoria Ocampofounder and Director of the Sur magazine and then of the publishing house-as vice-president of the Organizing Committee of the PEN Clubs Congress. Then, we also observed that another member of the Argentinian delegation to Congress, the writer Eduardo Mallea, was a central member of the Sur group. Additionally, the philosopher Francisco Romero, frequent collaborator in the magazine, represented Argentina at the entretien, and the literary critic and writer Pedro Henríquez Ureña, founder and member of the collaboration committee of Sur group, also did so-albeit on behalf of his country of birth, the Dominican Republic. Likewise, the Mexican writer Alfonso Reyes (member of the magazine's collaboration committee) and the Uruguayan Carlos Reyles (from Sur and Ercilla orbits) were delegates to both meetings.

\section{Between the International Literary Circuit and the Cultural and Political Spaces of Argentina}

Buenos Aires was a city with a dynamic cultural field where frequent conferences were held, attracting foreign visitors, and where academic and artistic institutions were created, such as the distinguished Asociación Amigos del Arte (Friends of the Arts Association), which gathered prestigious international intellectuals. The year 1936 also marked the launch of the local edition; publishers multiplied and consolidated their presence in the Hispanic-American book market. Such growth soon became institutionally registered in a congress of publishers and printers, Primer Congreso de Editores e Impresores Argentinos (1938) (Giuliani, 2016: 93-119). It was an intellectual field with high interest in learning about and discussing world events (First World War, fascisms, Spanish Civil War), in debating on the role of intellectuals in political and social life and denoting a self-image of being an active participant in discussions about international problems. The Spanish Civil War, which had begun shortly before the meetings to which we refer, had a strong impact on 
this cultural space. It generated strong public statements from the Buenos Aires cultural world in favor of the republican side (Gramuglio, 2010: 340). The writer Jules Romains, one of the members of the French delegation to the PEN Clubs Congress, summed up the response of the city to these meetings some time later: "I have attended demonstrations of this kind in many countries: I have never seen an interest in the crowd in collecting the slightest echoes like those in Buenos Aires. The sessions of the PEN Club, for example, that sometimes were devoted to somewhat difficult issues, rather abstract (...) were followed with incredible passion" (Comisión Argentina de Cooperación Intelectual 1939: 89-90). However, such cultural modernization occurred under a conservative and restrictive political regime, where strong authoritarianism prevailed as well as the exclusion of the largest political party. Argentina was ruled by an alliance of fractions of conservative parties and the Armed Forces. Antiliberal and anti-republican Catholic nationalist intellectuals were in charge of the state offices of culture (Cattaruzza, 2009: 135).

The fact that the Argentinian government had allowed the PEN Clubs Congress resulted in a majority of pro-government nationalist intellectuals as members of the Organizing Committee and as Argentine delegates. Four of the six members of the delegation belonged to that fraction: Carlos Ibarguren, Manuel Gálvez, Juan Pablo Echagüe and Antonio Aita (who was also active facilitator and secretary of the Congress). However, as was also the case in other national literary fields, while the literary space of the nationalist writers was primarily local, the Sur group projected its links to the Atlantic space-to Europe and the United States. Therefore, when defining a delegation to an international congress, the other two vacancies of the delegation arose from a negotiation. They were for two international cultural mediators from the Sur group, the main international literary publishing network at that time with a local base: Victoria Ocampo, director of Sur magazine and, to a lesser extent, Eduardo Mallea, writer of her group. According to the writer Manuel Gálvez, who had presided over the PEN of Argentina, the presence of Victoria Ocampo and Mallea in the organizing committee generated arduous negotiations, and only after long and laborious meetings were they able to decide who the guests of honor of the congress would be. According to the testimony of Gálvez, Ocampo and Mallea proposed only avant-garde writers and all those who "had innovated little in terms of form" were rejected by them (Gálvez, 1982: 287).

The case of the delegates from Argentina to the entretien was different, where the presence of Sur group was only tangential. This was because the Argentinian Committee of Intellectual Cooperation was a state office ruled by the Ministry of Justice (Ministerio de Justicia y de Educación de la Nación). The national intellectual cooperation committees formed the link that united the international organizations of intellectual cooperation with the cultural activities of each country. The 
composition of the national committee could take the structure that it decided. In some countries, such as Chile, it constituted an autonomous body with representation of the main local cultural forces; in others, such as Argentina-and Brazil-were entities dependent on the State (Walker Linares, 1943: 2-13).

Its officials chose delegates with professional and ideological profiles that were far from that of Victoria Ocampo. Though not prestigious in the literary field, these delegates to the entretien were prestigious intellectuals of the local political-institutional scene: Carlos Ibarguren, a historian of the catholic nationalism, as well as president of the Argentinian Academy of Letters, and Juan Terán, member of this institution and of the Supreme Court of Justice (Suprema Corte de Justicia de la Nación). Yet Francisco Romero, an internationally prestigious philosopher and frequent collaborator to Sur magazine, was part of the argentine delegation (until September 1936, Francisco Romero had been the author of notes in issues 1, 2, 21 and 23 of Sur).

\section{Victoria Ocampo at the PEN Clubs Congress}

PEN International officially proposed the following topics for debate in the congress: the social function of writers, the exchange of literary works among countries and their dissemination, bonds among writers and the translation of their works and concepts from literary philosophy such as intelligence and life and the future of poetry. The first three topics mentioned were of Victoria Ocampo's interest; in other words, this writer's interest comfortably shared space with the ones to be part of an international literary congress. It is no surprise, then, that Victoria Ocampo delivered the first speech on the commitment of writers to society.

Given that the work of Sur is well known, and considering the scope of this publication, we only want to point out here some central points that allow the best understanding of Ocampo's cultural mediation character. The strong identification between Sur and the universalistic work of its director has already been highlighted by specific historiography, but a prestigious voice of the time clearly summarized that identification. In 1939, Paul Valéry, in a bibliographical exposition organized by the Argentinian Committee of Intellectual Cooperation in Paris, said on the Argentinian periodical publications "It would be unforgivable not to mention among them that the dear and spirited Sur is argentine and universal at the same time. It is the soul of Victoria Ocampo. There is no more enthusiastic and knowledgeable interlocutor for European literature in Argentina than the publisher of Sur" (Comisión Argentina de Cooperación Intelectual, 1939: 53).

Historiography has also highlighted the multilingual vocation of Victoria Ocampo, who belonged to a family of the Argentinian elite. Governesses who transferred the French language naturally to the girls of her social status educated her-even in the mid-1920s, Victoria Ocampo did 
not know how to write in Spanish; her literary language was French, and she also mastered the English language. The literary critic Beatriz Sarlo, in her characterization of the figure and work of Ocampo, affirms that she made the travel stories "her genre”. For Beatriz Sarlo, Ocampo's work, Sur magazine and the publishing house catalogue represented a continuous flow between places and languages: "If she were to be defined in one word, I would say: translator, in all the meanings of the term. She carried books to and from, Europe to America, from Argentina to Europe. Translator, to her it would not have seemed little" (Sarlo, 2007b:140). Regarding the work of Victoria Ocampo, Sarlo also describes: "She transcribed texts in foreign languages, she talked with foreigners, she described foreign places, and she used foreign words" (Sarlo, 2007a: 99-100).

Thus, translations were at the core of the publishing project of Sur, performed by intellectuals of the group. With its new translation practices, Sur was a pioneer in the publishing field of the Southern Cone, a place shared with the Chilean publisher Ercilla. Only in 1938, translations began to be developed by Losada, Sudamericana and Emecé, among other main literary publishing houses of Buenos Aires. Their projects were different in many aspects from the ones of Victoria Ocampo's publishing house. Ocampo herself explained that both her magazine and her publishing house had been dedicated to "launching foreign and national authors who later went on to the category of best-sellers, in the hands of other publishing companies commercially powerful and who understand the business". And she remarked that "Sur was never a commercial company but a cultural one" (Willson, 2004a: 85).

Sur magazine registered PEN Clubs Congress in its pages, in the days before its beginning, as a literary event of utmost importance. The issue of the magazine published in August 1936 was entirely devoted to publicizing the work of international delegates. Almost as an official organ of the congress, Sur even published a complete list of the delegates and guests of honor by country, a list that then appears with the same typography and organization in the book of minutes of the Congress, published in 1937. In that issue of Sur magazine, an initial note written by Victoria Ocampo-who also read it on the radio and which then was published by the Argentinian PEN—focused on the political commitment that should be sustained by the writers and emphasized the opportunity that the Congress meant regarding exercising such commitment. In a world in which totalitarianism and wars closed the dialogues and encounters, Victoria Ocampo did not present the Congress in literary terms but highlighted its political importance. She stated: "In short, these writers are here to nourish from each other, not to devour each other. And this is the outstanding lesson that intellectuals can and should give the world today" (Sur 23: 8-9).

In her presentation at the PEN Clubs Congress, Victoria Ocampo took up the conceptual axis of the discourse that Jules Romains had displayed on behalf of the foreign delegations: the fact that the writers met in 


\section{Alejandra Giuliani}

defense of freedom, against all hateful wars. Only Ocampo-unlike Jules Romains, who spoke from his status as a writer-shifted the role of the énonciateur:

I see myself in this Congress representing the "common reader", as Virgínia Woolf and Johnson would say. I am that rather educated reader, more or less endowed, but always curious, and eager, and ever passionate in his readings. In all, I represent those readers who read for their own pleasure, without discipline and for whom you, gentlemen, write; since you could not do without them.

(PEN Club de Buenos Aires, 1937: 40)

She invited the writers to get involved in reality in those times "of crisis and universal anguish" and asked them to speak not as "men of action" but from the commitment of intelligence. She also added that the common reader needed the "intellectual and spiritual" strength of writers, who influenced them more than the "forces of money and armies" (PEN Club de Buenos Aires, 1937: 39-42). Victoria Ocampo was far from speaking from the periphery; she did so from the status of the universal reader of the new society, a mass society. Moreover, her exposition reflected the adherence to the Republican side of the Spanish Civil War, just as Sur magazine had already done. In fact, Sur magazine has been analyzed as an intellectual-editorial network case of special interest to get involved in the republican side of the contest. Victoria Ocampo had signed with other members of Sur-such as Jorge Luis Borges, Pedro Henríquez Ureña, Eduardo Mallea and Francisco Romero, among others-a letter on July 30, 1936, addressed to the Ambassador of Spain in Argentina, Enrique Díez Canedo, expressing the adhesion and solidarity for the Republic and for the democratic cause. (Macciuci, 2004: 34-35).

Victoria Ocampo spoke from the place of "the reader" in a congress of "writers" and did it from what she called-following Virgínia Woolf-the common reader. This fact shows how immersed she was in the Atlantic modernity. In effect, the common reader's sense referred to a new cultural reality. She referred to a different reader segment in comparison with the traditional "scholar reader" - who read for academic purposes-and from the "popular reader", who was a result of the massive culture that changed western European culture in the first decades of the 20th century (Mollier, 2013: 17-22). She did not refer to an uneducated reader who read mostly newspapers, popular magazines and cheap novels, although this one shared with the common reader that both arrived at their readings through the publishing market proposal. Besides, the common reader differed from the traditional scholarly reader, especially in their reading purposes. The first one carried out his reading practices mainly for the purpose of recreation; he read, in her words, for pleasure. Victoria Ocampo registered in the congress the elusive voice of the anonymous 
reader, who asked his writers to be attentive to the tremendous reality of those times.

For Ocampo, the anonymous reader asked the intellectuals to abandon their lives strictly focused on writing and to commit themselves to the difficult political situation. Using literary images-taken from Aldous Huxley's latest novel at the time, Eyeless in Gaza, which Ocampo considered largely autobiographical—she said that the writer should leave his place as spectator of social drama; he could no longer remain "comfortably seated in the stalls, with theater glasses". The distance between writers and readers did not make writers happy, since it was no longer compatible "with a minimum of love for men and their present anxieties". However, as we said before, the commitment to social reality that Victoria Ocampo required from the writers should be very different from that of the men of politics or, in her words, men of action. She said:

The writers (...) can no longer be satisfied with remaining seated in their stalls and contemplating the spectacle of the current frenzy with their theater glasses. (. . .) But their way of not being seated and of not continuing to look at the drama with glasses (there are those who seem to need a telescope, so far from life) will never be of the same nature as the man of action, or what has been agreed to call it that. This is at least what the common reader longs for, anxious to see certain problems resolved intellectually and spiritually.

(PEN Club de Buenos Aires, 1937: 41-42)

In her speech, Ocampo indirectly criticized the passivity of some writers regarding the advance of fascism, and, at the same time, she stated the type of political commitment she expected from literature's world.

After her speech, the writer Filippo Marinetti-who adhered to fascism in Italy-confronted Ocampo, affirming that it was not true that the ideal of a writer was to write for the street reader. He said that the great writers wrote mostly for a minority. Ocampo intervened, expressing, "I have not said that they wrote but published, which is very different" (PEN Club de Buenos Aires, 1937: 48). It was the voice of a modern publisher who directed the construction of a publishing catalog (Chartier, 1993: 31-32), and, although she sought the creation of tastes, considered the pre-existence of a reader with his own reading interests. So, by differentiating writing from publishing, Ocampo moved the problem from the world of writing to the publishing space and thus placed writers as agents in that field, together with readers and publishers. Then, a year after the Congress, Victoria Ocampo returned to what she interpreted as "the bad intention" of Marinetti in the second part of her Testimonios (Testimonies), where she devoted a section to analyzing writings by Virgínia Woolf. She did so regretting not having answered the Italian writer at the time, to emphasize the difference between writing for "any 


\section{Alejandra Giuliani}

ignorant reader" and for a common reader: "He does not have a method but a passion: reading. He does not accept methods outside of his tastes, his inclinations and his instinct". In this way, Ocampo placed herself as a common reader (Ocampo, 1941: 55-56).

The director of Sur played a key role in the PEN Clubs Congress since she addressed the two central themes of the meeting. One of them was the main official theme, the political commitment that writers should assume. Her speech referred to the intellectuals who supported the republican side in the Spanish Civil War, as she had already done in Sur. The other theme, treated in many other speeches, was the participation of writers and readers in the publishing world, in book production and distribution. The dominant approach focused on the links between writers and translators and on the problems of intellectual property. Certainly, one feature of modernity at that time was the deployment of an international circuit of books and periodicals. Writers were inserted into it and were attentive to what rights should be recognized on their published texts. It was companies now, not writers any longer, who launched the works into the market circuit. An echo of this concern was the main concept expressed during the days of the PEN Clubs Congress: the issue of possible controls that the writers could have over objects that no longer were their own. Even in Victoria Ocampo's speech, the problem of how writers lost their knowledge of the increasingly broad and anonymous world of readers emerged. Let us point out at this point that the problem of the writers in the publishing market reappeared in the PEN Clubs Congress when the subjects of translations and economic aid of the State to writers were approached. Then, in the closing session, the secretary of the Congress, Antonio Aita, presented on behalf of the Argentine and Italian delegations a project on unification of the right of intellectual property "as the only means of ensuring that intellectual work is not appropriate by unscrupulous publishers" (PEN Club de Buenos Aires, 1937: 166-168).

\section{Pedro Henríquez Ureña at the International Institute of Intellectual Cooperation Entretien}

The Intellectual Cooperation proposed cultural relations between Europe and America as the main theme for the entretien of Buenos Aires. Participants had officially been asked in written communications prior to the conference to discuss the relevance of these links. At the opening of the meeting, the Catalan intellectual Joan Estelrich presented a synthesis of the specific topics and points of view set forth in the submitted papers, which the participants later developed in their interventions. Estelrich classified the papers according to the past, present and future of the links between the cultures of Europe and America. He stressed that those referring to the past contained items such as "the influence of the discovery of America on the European spirit" and "the characteristics of 
the civilization that has been created in the New World following colonization." Then, he referred to the considerations of the present time, highlighting the text by Pedro Henríquez Ureña, which he considered "a panorama of the current Latin-American culture, just as it expresses itself in the domain of art and thought". Estelrich pointed out that the objective in it was to confront the cultures to establish positions about whether Latin American culture was autarkic compared to that of Europe and then, on that basis, discuss the issue "of literary nationalism". Finally, Esterlich considered the issue of the future of the links between cultures. Interestingly, he proposed concrete questions for the discussion: "What do Latin Americans expect from Europe? Which are, within their deep dynamism, the aspirations of Latin American thought? Does this thought lead to a new humanism? What does Latin America represent for Europeans? Has the vision of Latin America as a possible refuge for Western European culture been presented here to some Europeans?"(Comisión Argentina de Cooperación Intelectual, 1937: 17-18).

Before the First World War, cultural relations between Europe and Latin America had tended to develop more in one direction, that is, the expectation that Latin Americans learn about the European culture, but Europeans were almost ignorant of Latin Americans. Then, from the 1920s, both the governments and some intellectuals from Latin American countries intervened to change this unidirectional interest. This change can be explained by the regrettable fact that the devastating destruction of the First World War and then the rise of fascism had deteriorated the prestige of Europe in the eyes of Latin Americans (Pernet, 2007: 66-73). Hosting the PEN Clubs International Congress and the entretien for the first time outside Europe, with the outstanding presence of numerous regional intellectuals, was considered a relevant opportunity to advance in that sense. Moreover, selecting Europe-Latin America as topic for the entretien reinforced the idea.

Delegate presentations emphasized common points between both cultures, especially about the idea of being part of the broad horizon of Western culture. However, the interventions of Latin American intellectuals focused more on developing the specific characteristics of culture-or cultures-in Latin America. On the assumption that Europe knew little about Latin American culture, the objective, in some cases explained by the speakers, was to develop the relevant aspects necessary to reverse the situation and get Europeans to know-and recognize-the culture of the New World.

Such was the purpose of Pedro Henríquez Ureña's presentation. A literary critic and translator born to an educated family in the Dominican Republic, he lived in Mexico, Cuba and the United States after graduating in his own country. Henríquez Ureña also visited Spain, where he deepened his reflections on the links between the Old and the New World. In the mid-1920s, he settled in Argentina, where he lived by the time he was 


\section{Alejandra Giuliani}

summoned to represent his native country in the entretien. Ureña was a member of the Argentinian academic and intellectual field, where he maintained multiple links with intellectuals and academic and cultural centers of various countries of America and Europe. He was also Victoria Ocampo's friend, and she had summoned him for the foundation of Sur so that the Dominican intellectual was part of the project from the initial nucleus. Since 1931, after an essay on the writer José Martí, Henríquez Ureña had started a very active collaboration in the magazine, attended meetings of the steering committee, published articles and notes of his authorship and visited the offices of Sur several days a week. He usually took part in the Sunday afternoon meetings that Victoria Ocampo held in her villa in San Isidro, where he stood out for his vast literary knowledge. Henríquez Ureña publicly adhered to the republican ideas when in 1931 the Republic was established there, and during the Spanish Civil War he collaborated with the intellectual activities promoted by the Spanish exiles in Argentina (Zuleta Álvarez, 1997: 283-286).

A central concern in the work of Pedro Henríquez Ureña is that of culture. He considered that American cultural identity was defined in the link between local cultures and the Hispanic culture. In the years before the entretien, his lectures and publications showed his interest in this topic. In October 1933, for example, he spoke at the University of La Plata about the cultural and non-biologicist character of the so-called Hispanic American race. Ureña considered that the language was depository of the cultural values that united the Hispanic-American culture. For this reason, he fought for the unity of the Hispanic America within the community of the Spanish language. At the time of the entretien, the work of Henríquez Ureña had specialized in literary criticism and linguistic studies on the Spanish language (Zuleta Álvarez, 1997: 281). As key architect of the modern concept of Hispano-American culture, his work analyzed and linked the diverse cultural expressions of the American continent and also how they linked with European culture (Díaz Quiñones, 2010: 65). Such articulation was condensed in the title of his speech for the entretien: Spanish America and Its Originality. His dissertation focused on presenting a detailed analysis of the political and artistic culture of America. He characterized in detail every component that he considered relevant and distinctive of Latin American societies in relation to both the European cultural heritage and regional ties and differences. He linked cultural diversities by bringing them together in an American unit.

In his dissertation, Henríquez Ureña also analyzed the links between American Indian cultures and the process of the European conquest of America, expressing that

no inferiority of the indigenous has hindered the spread of Western culture. Only deep historical ignorance would pretend to despise the Indian, who is the creator of great civilizations (. . .) There is no 
incapacity, the conquest decapitated the Indian culture, destroying its superior forms (not even the art of reading and writing the Aztec hieroglyphs was conserved), it only kept popular and family forms. The indigenous population was numerous and over-disseminated and given that only a small portion of it was fully incorporated into the European-type civilization, nothing replaced those higher forms of their native culture for the majority of the indigenous population.

(Comisión Argentina de Cooperación Intelectual,

1937: 184)

Then, Ureña considered that both indigenous and African American cultures influenced and were alive in the present of American societies. With that statement, the Dominican intellectual differed from what was also expressed in the entretien by another Latin American intellectual, the Argentine Catholic Hispanic Carlos Ibarguren. He relegated the preColumbian societies to the historical and archaeological past and only considered European heritage present in the culture of the American people. Henríquez Ureña presented the difficult problem of the social and political insertion of the indigenous peoples in the American countries. As he stated, it could not be resolved based on European political models. That is to say, he placed the question of the links between indigenous and descendants of Europeans as a specifically American problem (Comisión Argentina de Cooperación Intelectual, 1937: 34)

After going through political forms since the European conquest and dwelling on the American specificity of caudillismo, he presented the social relations around indigenous work, such as the encomienda, differentiating it from the traditional slavery to which black workers of African origin were subjected.

In addition, he said that Europe had little interest in Latin America because it was not yet powerful enough to generate curiosity. Therefore, it is possible to deduce that Ureña's interest in spreading the cultural potential of American countries lay on this precise point. He elaborated extensively on authors and literary movements of the American continent in general and especially of Argentina, classifying groups of writers, pointing out vanguards and mentioning the dissemination work of Victoria Ocampo (Comisión Argentina de Cooperación Intelectual, 1937: 31-41).

Later, he clarified a point that divided the positions of some of Europeans and Latin Americans: to what extent did Europe continue to influence America or its discredit was such that it could be interpreted as "the death of European culture in America". In parallel with the position that Ocampo had adopted in the PENS Congress-when she spoke in the name of the common reader-Henríquez Ureña positioned the average person who, he maintained, was disappointed by Europe, but from a political point of view. He affirmed that the traditional nineteenth-century image 


\section{Alejandra Giuliani}

was an America incapable of organizing. He said that before the First World War, "the naive soul of the public was stunned" and since then the disappointment had begun, because "Europe no longer teaches peace nor organization". That is to say, the time had come for the Americans to put aside the traditional European political tutelage and stop being minor in a political sense (Comisión Argentina de Cooperación Intelectual, 1937: 122-123).

\section{Other Participants in the Buenos Aires Meetings}

Another member of the Argentinian delegation, the writer Eduardo Mallea, represented Sur in the PEN Clubs Congress. He spoke on the supremacy of reason-"reason as revolution and fight"—and about the guiding mission of intelligence. In an abstract way, Mallea's exposition dealt with the autonomy of reason over race, state, religion and the temporal and biological order (PEN Club de Buenos Aires, 1937: 136-139).

Francisco Romero also represented Argentina in the entretien: antipositivist philosopher, professor at the universities of Buenos Aires and La Plata, who had international acquaintances and continuous contributor to the prestigious magazine Nosotros. Romero was also an assiduous author of Sur. He had been summoned by Victoria Ocampo to publish an article on Ortega y Gasset. At the entretien, when faced with criticism that the Spanish intellectual had received, Romero came out in his defense.

According to the philosopher Enrique Dussel "Romero, in his own way, represented to our La Plata river area what Ortega had meant for the Iberian Peninsula" (Dussel, 1970: 83).

The ideas presented by Francisco Romero in the entretien collaborated with the purpose of Henríquez Ureña to spread the typical topics of the New World culture among European intellectuals, focusing more on their currents of thought. Romero sought in his intervention, above all, to encourage the integration of Western thought. One of the final phrases of his exposition sums up the idea: "Our America welcomes the different expressions of European thought and is able to merge them into unity. Thus, I also look forward to a distinctively Latin American philosophy. Yet, to my understanding, such peculiarity should consist in turning us into a 'western' philosophy" (Comisión Argentina de Cooperación Intelectual, 1937: 217).

Another participant, Carlos Reyles, was part of the Uruguayan delegation to the PEN Clubs Congress and to the entretien. The writer, who was within the orbit of Sur, represented Victoria Ocampo's publishing house two years later at the Primer Congreso de Editores e Impresores Argentinos (First Congress of Publishers and Printers of Buenos Aires) in 1938. There, he coordinated the work of publishing entrepreneurs for 
a collective project on the circulation and dissemination of Argentinian edition books on the international circuit (Giuliani, 2018). Reyles based his speech at the entretien on a request for continued and deeper cooperation between the intellectuals of the two continents, Europe and America. That cooperation, he explained, should materialize; he proposed that Europeans should make a future selection of bibliographical works and recommend them to the Americans who, in turn, would do the same (Comisión Argentina de Cooperación Intelectual, 1937: 201-216).

Before the start of the meetings, upon his arrival in Buenos Aires, the local newspaper La Nación had interviewed Carlos Reyles. The Uruguayan writer anticipated his proposal of bibliographical cooperation to the journalist, and then the press interpreted his words as part of his commitment with a Chilean publishing house, Ercilla, that had published work by Reyles. Luis Alberto Sánchez, one of the directors of Ercilla publishing house, arrived at that time in Buenos Aires. According to the newspaper article, Sánchez, as part of the Chilean delegation to PEN Clubs Congress, had arrived in Buenos Aires on behalf of "a publishing house in Santiago" to carry out his task of selecting works of writers. It is worth mentioning that Luis Alberto Sánchez was not officially part of the Chilean delegation to the PEN Clubs Congress: this was integrated by Domingo Melfi and Mari Yan.

A partial reconstruction of Ercilla's publications of the year 1937 allows us to affirm that the publishing company considered the meetings in Buenos Aires a strategic opportunity to amplify its already solid links with prestigious European and North American authors. For example, Ercilla published in 1937 three works translated into Spanish by Stefan Zweig, the Austrian delegate to the PEN Clubs Congress in Buenos Aires: El candelabro enterrado (The Buried Candelabrum), Una conciencia contra la tiranía: Castellio contra Calvino (The Right to Heresy: Castellio against Calvin) and Fouché. Retrato de un politico (Fouché). At that time, Ercilla also published works belonging to other delegates to the 1936 meetings. Therefore, in addition to Sur, another Southern Cone publisher, Ercilla, acted in the 1936 meetings as a publishing network gathering works and writers of Western modernity in a powerful catalog. Ercilla already had an important catalog of continental reach (Subercaseaux, 2010: 133).

Surely, at that time, Ercilla was also preparing the first edition of Un pueblo enfermo (A Sick People), a work published months after Alcides Arguedas, its author, participated in both 1936 meetings as a delegate from Bolivia. From the dissertation that Henríquez Ureña had made, the question of the serious situation of the indigenous peoples in the American countries generated the interest of the European participants of the entretien. Belgian writer and journalist Louis Piérard asked if other delegates could explain more about the indigenous situation in their countries (Comisión Argentina de Cooperación Intelectual, 1937: 44-45). 
In this context, Alcides Arguedas, in his only intervention that was transcribed in the meeting minutes, spoke about the worrying cultural situation of native people in Bolivia. He affirmed that in his country:

almost nothing has been done to find a solution to the indigenous problem; this, however, is particularly interesting because the indigenous race represents the majority of the population, approximately eighty percent. However, political leaders have considered the problem of education and instruction of this people, secondary; it is less interesting than other problems relating more to people than to institutions ... Politics worries us excessively and prevents us, as we would have liked, from dedicating ourselves to improving the situation of the indigenous people. Only recently we have begun to deal with this serious issue.

(Comisión Argentina de Cooperación Intelectual, 1937: 46-47)

Arguedas considered the social insertion of the native population a very serious problem, especially in terms of their possibility of formal education. In this way, the writer was able to disseminate in an international forum such specificity of the social problems of his country, which was, at the same time, the priority topic of his literary interests. In that same direction, a few years later, Losada, a new and thriving publishing house, would publish his Raza de Bronce (Race of Bronze).

\section{Final Words: Networks in the 1936 Meetings in Buenos Aires}

The literary and intellectual network from PEN International and Intellectual Cooperation linked with the Latin American publishing circuits that were in creation and held a clear Atlantic presence. In this sense, it is also worth noting the role of Nascimento publishing house, which in the 1920s had published a selection of Anatole France's work, prefaced and translated by a young Pablo Neruda. This house, based in Santiago de Chile, performed the relevant task of gathering and articulating titles and intellectuals (Reyes, 2014).

In 1937, its owner, Carlos Nascimento, decided to publish a testimony about the days of the PEN Clubs Congress: the book El Congreso de escritores de Buenos Aires. Notas e imagines (The Congress of Writers of Buenos Aires. Notes and Images). Its author was Domingo Melfi, a journalist and writer who was delegate to the Congress by Chile.

In addition, it should be added that most of the Latin American delegates to the 1936 meetings that we analyzed converged a short time later in the creation and launch of what would be one of the largest HispanicAmerican literary publishing networks, Losada. They were part of the 
founding group who directed collections and selections or participated as authors. Thus, the creation of Losada publishing house generated an articulation and cultural legitimization in which Henríquez Ureña's work, for example, was highly relevant. Gonzalo Losada entrusted him with the direction of a book collection entitled Las cien obras maestras de la literatura y el pensamiento universal (One Hundred Masterpieces of Literature and Universal Thought), in which the Dominican intellectual selected, prefaced, carried out critical studies and also translated workslater, Henríquez Ureña was in charge of the Colección Americana (American Collection) of the publishing house Fondo de Cultura Económica. Likewise, Francisco Romero led the Biblioteca Filosófica (Philosophical Library) in Losada, which, according to Enrique Dussel, intended to continue to the Biblioteca de Occidente by Ortega y Gasset (Western Library).

Above all, Victoria Ocampo and the nucleus of writers and critics that is often referred to as the Sur group displayed a cosmopolitan and modernizing voice since the founding of her magazine (1931)—and later with the beginning of her book catalog (1933). Their implicit agenda was to mediate between languages and cultures, understanding that "the new" was a result of an active relation within the completely American and European cultural scene and not the product of only one of them (Gramuglio, 2010: 343).

The 1936 Buenos Aires meetings were the stage for the expression of this project. In those September days, Victoria Ocampo, Pedro Henríquez Ureña, Alfonso Reyes and other intellectuals condensed in their speeches the encounter between distant territorialities and intercontinental topics mediated by languages and societies. They generated a new hub that linked the literary and intellectual networks of the international PEN Clubs and the Intellectual Cooperation with the literary and publishing networks that were directed from the South to the international cultural space.

\section{Bibliography}

Cattaruzza, Alejandro (2009). Historia de la Argentina. 1916-1955. Buenos Aires: Siglo Veintiuno Editores.

Chartier, Roger (1993). Libros, lecturas y lectores en la Edad Moderna. Madrid: Alianza.

Comisión Argentina de Cooperación Intelectual (1937). Europa-América Latina. Buenos Aires: Comisión Argentina de Cooperación Intelectual-Institut International de Cooperation Intellectuelle.

Comisión Argentina de Cooperación Intelectual (1939). La Vida y la Cultura en la Argentina. Buenos Aires: Comisión Argentina de Cooperación Intelectual.

Comisión Nacional de Cooperación Intelectual (1941a). La difusión de la cultura Argentina. Buenos Aires: Comisión Nacional de Cooperación Intelectual.

Comisión Nacional de Cooperación Intelectual (1941b). El libro argentino en América. Buenos Aires: Comisión Nacional de Cooperación Intelectual. 


\section{Alejandra Giuliani}

Díaz Quiñones, Acadio (2010). "Pedro Henríquez Ureña y las tradiciones intelectuales caribeñas". In Historia de los Intelectuales en América Latina, Vol. 2, directed by Carlos Altamirano. Madrid and Buenos Aires: Katz, 65-81.

Dussel, Enrique (1970). "Francisco Romero, filósofo de la modernidad en la Argentina”. In Anuario de Historia del pensamiento argentino. Mendoza: Universidad Nacional de Cuyo, 79-106.

Gálvez, Manuel (1982). Entre la novela y la historia (Recuerdos de la vida literaria III). Buenos Aires: Hachette.

Giuliani, Alejandra (2016). "El Primer Congreso de Editores e Impresores Argentinos (1938)". In Anuario CEEED, No 8, Año 8. Buenos Aires: Facultad de Ciencias Económicas, Universidad de Buenos Aires, 93-119.

Giuliani, Alejandra (2018). Editores y Política. Entre el mercado latinoamericano de libros y el primer peronismo (1938-1955). Temperley: Tren en Movimiento.

Gramuglio, María Teresa (2010). "Sur. Una minoría cosmopolita en la periferia occidental". In Historia de los Intelectuales en América Latina, Vol. 2, directed by Carlos Altamirano. Madrid and Buenos Aires: Katz, 192-210.

La Nación (newspaper of Buenos Aires), September 1-30, 1936.

Larraz, Fernando (2010). Una historia transatlántica del libro. Relaciones editoriales entre España y América latina (1936-1950). Gijón: Ediciones Trea.

Macciuci, Raquel (2004). "La Guerra Civil española en la revista Sur”. In Sociohistórica 15-16. La Plata: Universidad Nacional de La Plata, 29-63. www. sociohistorica.fahce.unlp.edu.ar

Manzoni, Celina (2010-2011). Vacilaciones de un rol: los intelectuales en 1936. Seminario de investigación. Salamanca: Instituto de Iberoamérica, Universidad de Salamanca. http://americo.usal.es/iberoame/sites/default/files/Seminario\%20 de\%20Investigacion\%2010-\%2011\%20Manzoni.pdf

Mollier, Jean-Yves (2013). La lectura y sus públicos en la edad contemporánea. Ensayos de historia cultural en Francia. Buenos Aires: Ampersand.

Ocampo, Victoria (1941). Testimonios. Segunda Serie. Buenos Aires: Sur.

PEN Club de Buenos Aires (1937). XIV Congreso Internacional de los P.E.N. Clubs. Discursos y Debates. Buenos Aires: PEN Club de Buenos Aires.

Pernet, Corinne (2007). "La cultura como política: los intercambios culturales entre Europa y América Latina en los años de entreguerras”. In Puente@ Europa 3-4, 66-73.

Reyes, Felipe (2014). Nascimento. El editor de los chilenos. Santiago de Chile: Ventana Abierta editores.

Sanz Roig, Diana (2013). "Bourdieu después de Bourdieu. Hacia un nuevo rumbo en la teoría de los campos". In Bourdieu después de Bourdieu, compiled by Diana Sanz Roig. Madrid: Arco and Libros, 9-47.

Sapiro, Gisele (2016). La sociología de la literatura. Buenos Aires: Fondo de Cultura Económica.

Sarlo, Beatriz (2007a). "Victoria Ocampo o el amor de la cita”. In La máquina cultural. Maestras, traductores y vanguardistas. Buenos Aires: Seix Barral, 77-148.

Sarlo, Beatriz (2007b). Escritos sobre literatura argentina. Buenos Aires: Siglo XXI Editores.

Subercaseaux, Bernardo (2010). Historia del libro en Chile. Desde la Colonia hasta el Bicentenario. Santiago de Chile: LOM ediciones.

Sur Magazine, 1-27, Buenos Aires, 1931-1936. 
Walker Linares, Francisco (1943). Cooperación Intelectual. Santiago de Chile: Publicaciones de la Comisión Chilena de Cooperación Intelectual.

Willson, Patricia (2004a). La Constelación del sur. Traductores y traducciones en la literatura argentina del Siglo XX. Buenos Aires: Siglo Veintiuno.

Willson, Patricia (2004b). "Página impar: el lugar del traductor en el auge de la industria editorial". In Historia crítica de la literatura argentina 9, directed by Sylvia Saitta. Buenos Aires: Emecé, 123-142.

Willson, Patricia (2007). “Traductores en el siglo”. In Punto de Vista 87. Buenos Aires: Punto de Vista, 19-25.

Zuleta Álvarez, Enrique (1997). Pedro Henríquez Ureña y su tiempo: vida de un hispanoamericano universal. Buenos Aires: Catálogos. 


\section{Barcelona on the International Map of Modernity \\ The Conferentia Club's Role in the Interwar Period ${ }^{1}$}

\section{Gabriella Gavagnin}

\section{Premise: Conferences and Circulation in Transnational Literary Mediation Processes}

While the international literary mediation processes that characterized the evolution of modernity throughout the first half of the twentieth century centered on writing, either public (books, magazines, translations, and essays) or private (letters), on the side, various forms of oral communications and personal contact reinforced these exchanges as well as the circulation and dissemination of literary production. We may distinguish two main forms of oral exchange, among others: those among agents whose roles were rather homogenous and those between people who spoke before publics whose roles were quite different. The first kind would include academic or institutional gatherings-either large or small-among writers and academics. In contrast, the second kind of oral activities encompass those organized by writers or academics for didactic purposes, with either general or specific audiences who play a more receptive role and attend for pleasure. Throughout the Interwar decades, the most active and prominent figures in literary modernity increasingly traveled between cities, countries, and continents to address a broader and more varied public using the conference model-a genre that began to mold into various contexts, going from the erudite to the performance. This study will focus on this model's role in the spread of Catalan culture-that of the common reader, the critic, academics, poets, and writers - to an active and prestigious international scene.

Founded during the Interwar period, the Conferentia Club was a cultural institution in the city of Barcelona that intensely promoted international exchange and, in a prime exhibition of the cultural policy of Noucentisme, hosted Catalonia's most hegemonic cultural movement during the first decades of the twentieth century, amassing some of its main features. The club was founded in 1929 with the goal of organizing conference cycles two seasons per year: spring (March-June) and fall (October-December). These sessions articulated over two yearly courses developed from the first year (spring of 1929) to the eve of the Spanish 
Civil War (spring of 1936) quite regularly: the only significant incident was a delay in the course scheduled for the fall of 1934, given a number of convulsive political events. ${ }^{2}$ As a whole, the club's performance was remarkable, both quantitatively and qualitatively. Notably, throughout the fifteen courses that took place over eight years, the club celebrated one hundred forty-four conferences: the equivalent of three or four per month. ${ }^{3}$ Beyond the thematic variety and the renown of those invited to give the conferences, the speakers' international quality is also worth highlighting: one hundred six were given by foreigners (although some did live in Spain at the time, such as Hugo Obermaier, Gertrud Richert, and Gustavo Pittaluga, who worked in universities, as well as the Jewish speakers Lene Schneider-Kainer, José Arnaldo Weissberger, Paul Ludwig Landsberg, and Atina Wiskeman). Of the remaining thirty-eight conferences, Catalans gave twenty-seven (though some had moved outside of Catalonia, such as Eduardo Marquina and Antoni Ribera, or abroad, such as Josep Pijoan and Joaquim Nin). This means that 73.6 percent of the speakers were international. It is also worth noting that beyond the one hundred forty-four conferences organized specifically for members of the Conferentia Club, some foreign speakers took on a number of additional conferences (at least twenty, according to the still-rough inventory we have registered so far) to take advantage of their stay-which is still common practice today-in collaboration with other institutions that offered up their own spaces and auditoriums. This broadened the impact of their stay beyond the members of the Club. From an organizational point of view, the influence of those cultural networks that managed to expand the events put forward by foundations, associations, and mediating cultural entities is clear.

\section{The Conferentia Club: Its Public and Conference Format}

Before delving into the geocultural characteristics of the club's speakers, I would like to mention several sociological details that may provide a context for these gatherings. In April of 1929, newspapers announced the club's creation and described its mission:

With its half-British, half-Latin name [a name thus summarizing the Noucentista spirit of communion between classicism and modernity], a group of Barcelonans of varied social status and disciplines founded a society whose sole objective is to put on cultural conferences. ${ }^{4}$

However, as was later clarified by Carles Soldevila, the indefatigable and hardworking secretary, whom Manent (1994, p. 48) later called the "perpetual secretary", the Conferentia Club was created to "provide a spiritual nourishment [spiritually educating the public was another Noucentista feature] that most of our society can digest" (Soldevila 1936). 
The initiative's promoter, the politician and patron Francesc Cambó, was even more explicit when he wrote of the club's circumstances and aspirations in his memoire. Cambó asserted that he had been inspired by a will to curb the contrasts between the elegance and refinement that "ladies and damsels in high society" were taught in the Barcelona of the time and their "excessive ignorance" (Cambó 1981, p. 400)—a contrast that seemed completely passé in the midst of Noucentisme. A clear social pursuit characterized this proposal: "Why not connect the intellectual cream of the crop with the most elegant of Barcelona's feminine society? The women would gain culture, while the men would learn manners." 5 Cambó noted that the Sociedad de Cursos y Conferencias (Society of Courses and Conferences) that the director of the Residencia de Estudiantes (Student Residency) had founded in Madrid in 1924 preceded his initiative, ${ }^{6}$ even though, in contrast to the Barcelona club, this Madrid society was heavily subsidized, as the Dirección General de Bellas Artes (Ministry of Fine Arts) contributed more than half of the Madrid society's annual budget (Ribagorda 2008). In our view, the institutional model closest to the Conferentia Club's was that of the Universite des Annales, founded in Paris in 1907 by Yvonne Sarcey, who served as director for decades. This initiative was founded under the discourse of social responsibility for bourgeois women, offering them the appropriate spiritual and cultural knowledge for the role in childcare they were raised to assume (Martin-Fugier 1990). They organized courses to complement the education of high-class women according to the university calendar, that is, from November to May. In parallel to a more practical course that took place midday, there was another, the Cinq à six littéraire, which, as the title suggests, took place from 5:00 to 6:00 p.m. every day, covering subjects such as morality, hygiene, French literature, history, foreign literature, the arts, and music. This second course is the most akin to the Conferentia Club's and was particularly analogous in terms of the social composition of its public, its didactic character, the subjects taught, the central role that literature played, and even in terms of some organizational aspects: the private nature of the institution and its female leadership. Indeed, even though the Conferentia Club's promoter was the male Francesc Cambó, a bourgeois woman, Isabel Llorach, always held and boasted the club's presidency. A certain letter from June of 1936 between Cambó and the critic Joaquim Folch i Torres is highly illustrative in this sense. Folch i Torres requested finance from the Conferentia Club for a conference cycle on El Greco that was to accompany an exhibition of El Greco's work in Sitges. Cambó advised the following: "Regarding the Conferentia Club, it would be best for you to address the President, Miss Isabel Llorach, who is quite protective of her presidential prerogatives. As almost always is the case, she will most likely consult me and you may rest assured that my opinion regarding your wishes is positive" (cited by Domènech 2013, pp. 92-93). The fact that the club's model was quite 
different from the Sociedad de Cursos y Conferencias's was well understood by Llorach herself: the press mentioned that she was planning to found a Conferentia Club in Madrid as well, in order to share its mission and cut down on speakers' traveling costs. ${ }^{7}$

As for the public, according to the founder's intentions, the Conferentia Club's activities addressed Barcelona's aristocracy and high bourgeoisie beyond the academic and intellectual world. The conferences were to host elegant and refined soirées that never lacked a touch of harmony and, of course, worldliness, providing these cultural events with social distinction. The events were members only as of the third conference, reinforcing the prestigious and selective character that had been hoped for from the start. The conferences began at 7 and were preceded by teatime at 6 in the evening. The tea ritual always ended at a prudent time, since the public, though grateful and faithful, was not generally willing to change its domestic customs: if events went on for too long, there were always a few members of the public who would unscrupulously leave the room. ${ }^{8}$ Often, events were followed by a brief photography session, which would provide material for the Catalan bourgeoisie's newspaper par excellence: La Vanguardia. Once in a while, distinguished authorities would appear in the photographs, but usually one could find the speaker encircled by a few high-society women. Indeed, the public was made up of mostly women, married and single, who were duly dressed for the occasion. ${ }^{9}$ News articles often highlighted their presence, ${ }^{10}$ as well as any exceptions to the norm. For instance, we are told that the public that came to see Dannie Heineman, a Belgian-American engineer and businessman who spoke of economics, also included "[male] politicians, economists, and writers, [who] joined the generally female public that follows the 'Conferentia Club's sessions with almost addicted enthusiasm". ${ }^{11}$

Indeed, the Conferentia Club became the benchmark social space for high-society women in Barcelona, to the point that María Luz Morales designated it this social class's prototypical place for conversation in an article on the 1934 municipal elections in Catalonia-the first call to the ballots in which women could participate in full right: "Se habla, se habla. Se habla no más que de política ... y de las elecciones que tenemos encima. Los hombres, en el Ateneo y en la peluquería. Las damas, en la primera fila de 'Conferencia Club', y las obreras, en la fábrica ..." "They talk, they talk. They talk of nothing but politics .... and the upcoming elections: the men, in the Ateneu and the barbershop; the women, in the first row of the 'Conferentia Club'; and the workingwomen, in the factories"). ${ }^{12}$ These conferences' format, conceived especially for this public, always upheld several characteristics: the conferences combined the goal of guaranteeing the spread of modern culture by allowing people to access the most current debates and theories of the time, with communications strategies that favored this non-specialized public's reception, using a sufficient dose of visual spectacle to secure the conference-goers' 
attention. Charismatic speakers such as André Maurois, Hermann von Keyserling, Emil Ludwig, Elena Văcărescu, and Paul Valéry easily seduced the public. Humor was also widely appreciated, as with René Benjamin, Georges Duhamel, and Ramón Gómez de la Serna. Meanwhile, slide projections complemented some of the conferences, which were never lacking in conferences on the visual arts, archaeology, or anthropology, as was the case with Hugo Obermaier, Gertrud Richert, Lionello Venturi, Giovanni Stepanow, Dario Lupi, Giancarlo Castagna, Henri Focillon, Eustache de Lorey, Mario Meunier, and Walter Gropius. Sometimes, conferences on literature or the performing arts would be complemented with a brief reading (as with Francis de Miomandre, André Billy, Paul Valéry, Giuseppe Ungaretti, Federico García Lorca, and Ernst Toller), a theater production (as was the case with Madame Dussane and Gabrielle Réval), music recitals (with speakers such as Jean-Aubry, Wanda Landowska, Alfred Cortot, Charles Oulmont, Andreas Liess, and Joseph Canteloube), or even ballet (as was the case with Atina Wiskeman).

These performances had a remarkably positive impact on the public and were no doubt one of the determining factors behind the conferences' success as a whole. Good performances, which led the director to invite participants back more than once, ${ }^{13}$ did not go unnoticed. And neither did any shortcomings:

If any criticism of the speaker must be made, we could note his monochromatic tone. [. . . If one could ban monotony, if monotony were banned from Gérard Bauër's conference, we would find ourselves before a proper speaker who practices what we would call 'chop' in tennis, which would consequently turn the conference into a wise and conservative game. ${ }^{14}$

Sometimes, the brilliance of certain speakers made the mediocre ones stand out. The critic Rafael Tasis i Marca praised Giovanni Stepanow's expository virtuosity, as he "succeeded, for an hour and a half, without stopping to catch his breath or drink water, in giving a subject as archaeological and bookish as Etruscan art and history the passionate interest of a crime novel" and added that "people lamented that professor BoschGimpera [recently elected as dean of the University of Barcelona] did not similarly project his slides during his conference on Empúries". ${ }^{15}$

Some reflections of the time reclaimed the modern conference as an innovative didactic instrument that could be considered a true artistic genre: each conference is autonomous within the form, which can be more conventional or conservative. As it transmits culture orally, its freshness of ideas closely ties into the originality of the exhibition. If, on the one hand, María Luz Morales would consider that the modern speaker's mission is more akin to theater than to a nineteenth-century lecture, merging the task of the author with that of the actor like Greek poets or Medieval 
troubadours, ${ }^{16}$ then Estelrich would insist, on the one hand, on the social responsibility behind this efficient, humanitarian task and, on the other, on the purely histrionic character a conference needs in order to weave all manner of subjects:

The conference is a spectacle. Its content could provide the foundations for a thesis, the test for a new discovery, an overview of an art period, a monograph on an author, or the synthesis of a historic moment. To become a conference, literature, science, and criticism had to be turned into spectacle. The originality of this spectacle, in contrast to other performances [. . .] resides in the fact that it tests personality. Without a personality, there is no speaker. Modesty does not make a genuine speaker. The most successful speakers are also the most daring, the least modest, the least respectful, and the most original. In a conference, the subject won't be worth our time if it cannot incarnate the speaker's personality to the extent that we cannot truly tell if the topic is an excuse to unveil the speaker, or if the speaker is an excuse to unveil the topic. To prove successful, the conference has to be produced as if both were true. The personified spectacle marks the conference's resources and process. ${ }^{17}$

This theorization illustrates the significant role that the first avant-garde must have played in the conference-spectacle model that became so admired and refined during the Interwar decades. ${ }^{18}$ Despite being a performance, the conferences managed to attract intellectuals who were more in sync with avant-garde practices. As the avant-garde poet Carles Sindreu wrote in his chronicle on Madame Dussane's conference, his friend Sebastià Gasch, who signed the Manifest Groc (Yellow Manifesto) sat among the spectators at the Ritz, "and most likely wrote: diction $\mathrm{x}$ gesture conference." 19

In the same chronicle, Sindreu makes it clear that the acting was not devised for artists and writers, who, like Gasch or himself, enjoyed the performance nonetheless:

Grandiloquently, in certain climactic moments his energetic voice penetrated us like a sword and we would feel its charge in the solar plexus. Nevertheless, his words seemed to cover everything in velvet, and one could suppose they emanated from the heart of a flower of still-budding petals. Madame Dussane marveled all of the women in the public, and almost all of the men. It is worth noting that the admirable actress mostly addressed the female public, as this party was thrown for them.

This specificity on the public's gender rather strongly conditioned the topics speakers chose, often placing the role of women in literary and 
cultural history at the center of their discourse. As examples, we could point out André Maurois, Ferran Soldevila, Elena Văcărescu, and Paul Valéry. André Maurois dedicated five conferences under the cycle Cinq visages de l'amour (Five faces of love) to five memorable heroines of French literature. Soldevila reviewed the female protagonists of Catalan history, Văcărescu focused on the queen Reina de Saba, and Valéry spoke of what he called the "twilight of women" to flesh out the evolution of the contemporary feminine figure in poetry. In contrast, the conferences that Maurois and Valéry gave in different institutions during their stayMaurois at the French Institute and Valéry at the Catalan poet's circle "Amics de la Poesia"-mostly focused on theoretical concepts and their own ideas and poetic experiences. ${ }^{20}$

Thus, the format and topic tended to respond to whomever constituted the majority in the audience. There was no shortage of academic sessions, to which the audience reacted maturely, despite the fact that Soldevila insisted that a conference should not be "a lesson in a university course, a rally speech, or a discourse for academic specialists". ${ }^{21}$ One conference detailed in journalistic pieces is especially interesting when it comes to understanding the extent to which this faithful and attentive public-both demanding and curious-appreciated the initiative's cultural specialization. The Romanist Ernest Gamillscheg from the University of Berlin, a disciple of Meyer-Lübke and a friend of several Catalan philologists, was invited to give his speech Linguistic Typology. The Song of "El mio Cid". In his intervention, he spoke on the philological problem of trying to identify the interpolation of verses by different authors in the song of "El mío Cid", analyzing the verses' rhythmic curvature and applying an innovative methodology that transferred linguistic typology theories of musical origin to textual philology. His discourse, though interesting and original, was still quite technical and probably not very appealing for a soiree at the Conferentia Club. Yet the organizers chose him despite his style: when the fall of 1931 program was announced, the organizers specified that "special attention was given to alternating between the positive value of a learned speaker and the undoubted benefit of an exquisitely performed speech".22 Gamillscheg was thus the learned speaker who inaugurated the new cycle. According to an article in La Vanguardia, ${ }^{23}$ the room was "very crowded" but not a full house, like other times, because many members had yet to come back from summer vacation, even though it was already October 27. The crowd, numerous despite it all, fell silent

[which most likely was quite uncommon, since the conferences tended to elicit laughter among the crowd] to keep from interrupting this professor's curious and interesting lesson, though the topic was perhaps somewhat advanced for some of the young women whom one might call frivolous. 
These young women's reactions made everything clear:

The interest with which the entire auditorium followed the conference stood as proof of the knowledge and culture of the crowd that regularly attended events at the Conferentia Club.

Soon enough, the organizers had created, quickly and successfully, a wellcultured, habitual, and expectant public for their conferences, ${ }^{24}$ a feat they found surprising and almost hard to believe. This can be inferred from a text by María Luz Morales on the club's insemination:

An auditorium, three-fourths women ... and not any less attentive and fervent because of it, even before the most abstract topics. Could we dare say that this is the first time among us this miracle has happened? ${ }^{25}$

The insistence with which writers alluded to this topic over the years is surprising. Even when the system was quite established, in $1936, \mathrm{La}$ Vanguardia published an article dedicated exclusively to eulogizing the public that listened to André Maurois's cycle of conferences with expectation, attention, and silence. ${ }^{26}$ This article is especially interesting because it efficiently describes the different pieces that composed the members of the club, not just its main figures. On the one hand, one could find the most obvious public for scientific and academic conferences: experts and involved professionals, insiders, "intellectuals, professors, writers, and artists". On the other hand, one could also find "plenty of students, young aristocrats, women who have become known as 'niñas bien'," that is, lots of high-class youths ("niñas bien" and "pollos pera") who significantly built up the member accounts of the Conferentia Club. ${ }^{27}$ The involvement of high-class women and youths, usually not mixed up in such cultural spaces, proved key for the Conferentia Club to become a mediator of international exchange.

Cambó managed to build the Conferentia Club as a private entity thanks to the Catalan aristocracy and high bourgeoisie. The board of directors reflected the weight of this social class: besides the presidentthe wealthy bourgeois Isabel Llorach-sat the viscount of Güell as vice president, ${ }^{28}$ as well as many aristocratic spokespersons. ${ }^{29}$ This ambitious and rich programming of prestigious speakers from abroad relied on a self-financed system of member fees. ${ }^{30}$ There were three member categories: protector members, who paid a minimum fee of 250 pesetas per year, had a right to three invitations and could acquire up to six if they paid 500 pesetas; subscriber members, who paid 50 pesetas per year for one invitation; and special subscriber members who would pay 25 pesetasa fee reserved for professors, students, artists, and writers. ${ }^{31}$ Besides a few financing endeavors by the club's founders, ${ }^{32}$ the entity's social base, 


\section{Gabriella Gavagnin}

especially the contributions of dozens of society youths and women, guaranteed the funds for the club's expenses. The club's ability to recruit members from this sector proved relevant and was addressed in some of the comments on the public we referred to previously: the club managed to have this social class finance these acts, "departing from the custom of considering it [the conference] a free way of passing the time". ${ }^{33}$ Thanks to the commitment of this chunk of society, the club registered many members in just the first few months, a registration number which the director considered "almost definitive" by December of 1929:34 in October of 1930, the club had registered four hundred seventy-five members, out of a maximum of five hundred established in the statutes (Soldevila 1930), and the member list published in the appendix of the 1931 annual report (Conferentia Club 1931, pp. 277-291) registered five hundred sixty-three, more than double the amount registered by the Sociedad de Cursos y Conferencias in Madrid, which had signed up two hundred twenty-nine by its second year (Ribagorda 2008, p. 286). Among the club's members, fifty-five were protector members, while the remaining five hundred eight were subscriber members. There were two hundred fifty-one women members, that is, around 45 percent of the total. We can infer that the club's success highly surpassed expectations from a number of testimonies as well as from several organizational problems that turned up in the club's beginnings. ${ }^{35}$ In contrast, an attempt to publish texts based on the conferences, a common practice at the Université des Annales, which had its own publication, Conférencia, le journal de l'Université des Annales proved unsuccessful at the club. Though a few initiatives did take place, none managed to secure continuity. ${ }^{36}$

\section{The International Dimension}

Its insurmountable, or at least unforeseen, success made the Conferentia Club a leading space for international exchange at a level unprecedented in Catalonia, a feat not planned out in the initial project. Carles Soldevila was quite explicit about this when speaking of the club, before the war interrupted its activities: "Even though the Conferentia Club was not officially created to promote international exchange [...], it clearly made headway in this sense" (Soldevila 1936). We could say that, somehow, the club came upon it. We could also say that it took advantage of this platform to transform its originally local objective ("Why not connect the intellectual cream of the crop with the most elegant of Barcelona's feminine society?" was Cambó's original thought, as stated previously) into a modernizing and internationalizing effort of broad social scope, to which many intellectuals of the time already aspired. It is no coincidence that Carles Soldevila complained, almost a year before the Conferentia Club's founding, that "at home, conferences go no further than the livingroom in which they find themselves today". ${ }^{37}$ 
The impression that the foreign component dominated the scene, to the detriment of the national one, was heeded from the beginning. Nonetheless, this perspective was not always praised-some called the club's tendency to prioritize foreigners provincial, such as María Luz Morales, but she also criticized the club's Parisian counterpart as endogamous. In her view, it was equally shameful "that those who abandoned themselves to the 'Université des Annales' ignored Keyserling and Ortega y Gasset, as it would be for members of the "Conferentia Club" to ignore speakers like Pedro Corominas, who, at this moment, is taking his words far [. . .], or Estelrich, 'Gaziel,' and Soldevila". ${ }^{38}$ The organizers perhaps did heed these complaints, as we may note that, first of all, they created more spaces for local speakers (up until the day of Morales's article, the proportion of foreign speakers was above 92 percent (twenty-six of twenty-eight conferences), while at the end, the proportion dropped to 74 percent) and, second, they promoted pedagogical initiatives to create local conferences. Specifically, at the end of the spring course in the summer of 1932, the director of the Conferentia Club launched a pilot training course for the young debutant speakers among her members-a public that already had a good ear for conferences-at the Ritz Hotel, including, for example, Guillermo Díaz-Plaja and Octavi Saltor.

In any case, the marked internationalism in each of the fifteen courses organized in the 1930s is an indisputable fact. The speakers' geocultural backgrounds are certainly worth our time. For starters, one could highlight the geocultural diversity of the club's activities-a remarkable feat for the time. Just a glance at the speakers' biographies reveals thirteen politico-national and cultural-linguistic identities. Nonetheless, two elements undermined this variety-which was distributed homogenously through time, with the goal of ensuring pluralism within each course. First of all, these courses entirely lacked English culture, despite English's remarkable international scope at the time. Said absence stands out despite the club's somewhat British name and the love of English culture that the club's secretary professed. Second, we could highlight the club's heavy bias toward French culture, which accounted for 50 percent of foreign conferences, and the meager presence of other areas (especially central European and Slavic ones), which altogether accounted for fifty-three conferences: the same amount that French artists and intellectuals boasted alone. From greatest to least, we can count eleven conferences by Italian speakers, ten by Germans, eight by Keyserling-an Estonian who moved to Germany-five by Austrians, three by Belgians-including one Belgian-American, one French-Belgian, and one Walloon- ${ }^{39}$ three by Poles, three by Romanians, three by Giovanni Stepanow-a Russian who moved to Italy - three by Swiss French speakers and two by Swiss German speakers, one by the Chinese Cheng Tcheng, ${ }^{40}$ who was exiled in France, and one by the Cuban diplomat de la Luz León. 
Table 8.1 Number of Conferences According to Speaker Origin

\begin{tabular}{llllll}
\hline Season & Spanish & French & Italian & German & Other \\
\hline Spring 1929 & 1 & 2 & & 1 & 2 \\
Fall 1929 & 1 & 3 & 1 & 1 & 3 \\
Spring 1930 & & 5 & & & 4 \\
Fall 1930 & 2 & 5 & 1 & 1 & 1 \\
Spring 1931 & 4 & 3 & 1 & & 2 \\
Fall 1931 & & 3 & 2 & 1 & \\
Spring 1932 & 74 & 8 & & 1 & 3 \\
Fall 1932 & 4 & 4 & & & 1 \\
Spring 1933 & 3 & 2 & 2 & 2 & 1 \\
Fall 1933 & 3 & 3 & 1 & 1 & 3 \\
Spring 1934 & 4 & 2 & & 1 & 2 \\
Fall 1934 & 2 & 3 & & & 2 \\
Spring 1935 & 3 & 2 & 2 & 1 & 2 \\
Fall 1935 & 2 & 7 & & & 32 \\
Spring 1936 & 2 & 1 & 1 & & \\
Total & 34 & 53 & 11 & 10 & \\
\hline
\end{tabular}

Both of these circumstances can be attributed to linguistics. Soldevila (1936) himself said so: "The limits of our scarce polyglot skills have forced us to favor French writers and scientists. Unfortunately, there are not enough English-speaking Barcelonans in the Conferentia Club. Nor German speakers." The most common languages that speakers used to communicate were, first of all, French, which people from all thirteen countries of origin used, meaning that a total of eighty-seven conferences took place in French, thirty-four of which were carried out by people who were not French themselves; second, Spanish, accounting for ten conferences (besides the Italian Pittaluga and the Cuban speaker, the rest were all German-speakers: Richert, Gropius, Weissberger, Vossler, Gamillscheg, Liess, Lorand i Keyserling); and last, Italian, which was used by the Italians as well as by the Austrian Däubler. In other words, only speakers who could use one of these three languages would even be considered -42 and Italian could only be used from time to time, since it was not as accessible to the public as French, as the secretary also noted when commenting on how hard it was for Germans to adapt to the club's histrionic conference style:

Countries like France, a nation for all literary and social genres, can easily send their masters. Germany, where quality specialists abound in extraordinary numbers, can also help us, but it's clear that our public has a hard time with the Teutonic professors' thick and turgid exhibitions, considering they have to use a language that is not their own in order to make themselves understood in Barcelona. Italian can be used to an extent. With some effort, an educated Catalan can 
understand Italian. However: one does have to make a small effort and not just rely on the knowledge of Dante's tongue we all think we possess. $^{43}$

Meanwhile, the near complete absence of Latin Americans (only the Cuban José de la Luz León spoke) cannot be explained linguistically, but is in all likelihood due to traveling costs. Collaborations with other cultural bodies could be attributed to similar economic pressures, as speakers also attempted to use their resources as efficiently as possible. This phenomenon is relevant considering that it consolidated a network of institutions and intellectual relations that amplified the effects of mediation in broad social and cultural spaces. As stated previously, when a speaker came to the club, collaborating institutions would also program a calendar of two or three conferences in other auditoriums. Thus, private and public institutions such as the University of Barcelona, the Ateneu Barcelonès, the Bernat Metge Foundation, ${ }^{44}$ the French Institute, the Italian Cultural Institute, the Chamber Music Association, and Amics de la Poesia worked with the Conferentia Club to host the speakers the club had invited. Tadeusz Zielinski, Paul Mazon, Antoine Meillet, Alexandre Moret, Ernest Bovet, Adolf Keller, and Emil Ludwig spoke at the Ateneu; Karl Vossler, Jean Piaget, and Ernest Gamillscheg spoke at the University of Barcelona; Jean Malye, Raymond Lantier, Henri Focillon, Georges Duhamel, and André Maurois spoke at the French Institute; and Arturo Farinelli, Massimo Bontempelli, and Piero Misciattelli spoke at the Italian Cultural Institute. Meanwhile, as previously noted, Paul Valéry gave his second conference at Amics de la Poesia. Even though most speakers came through the Conferentia Club's initiative, some foreigners spoke at the club after originally receiving invitations from other organizations. For instance, Ernest Bovet, secretary general of the Swiss Association for the League of Nations, was already in Spain when he went to the Ritz Hotel, as he had traveled from Zurich to Madrid to participate in a League of Nations conference. Meanwhile, the missionary Giancarlo Castagna was in Barcelona for his cycle of conferences on Japan organized by Institut Ramon Llull at the Council Seminary; likewise, Jean Piaget was already in Barcelona to teach at the Technical Teaching Courses organized by Alexandre Gali from the Provincial Council. Similarly, the academics Pietro Romanelli and Tadeusz Zielinski had come to the University of Barcelona to participate in the IV International Archeological Congress and the VI Congress of the International Federation of Intellectual Unions, respectively. In terms of relationships with other institutions, we should highlight several speakers' ties to the PEN Club, an institution that no doubt helped establish international contacts. For example, the president of the German PEN Club, Theodor Däubler, was one of the first foreign hosts of the Conferentia Club. The writer Carles Riba, who had met Däubler at Oslo during the PEN International Conference of 1928, 


\section{Gabriella Gavagnin}

invited him (Guardiola 1989, pp. 357-361). Ernst Toller, who first came as a Conferentia Club speaker in 1931 and returned to Barcelona in 1935 for the PEN International Club, as well as the Belgian Louis Piérard, who founded the Belgian PEN chapter, also stand out.

To make a long story short, I would like to end with a reflection on the scope and breadth of the Conferentia Club's internationalization. What did it mean to favor exchange? According to Soldevila (1936), it meant that "among the hundreds of people in the audience, some will pick up more than a furtive impression" and "among the dozens of speakers who stop by Barcelona, some may learn a thing or two they will never forget, which will then live on as an echo in their written works and views". First of all, it would pave a two-way street for teaching and learning culture: an inward and outward exchange, that is, an example of histoire croisée (Werner and Zimmermann 2003). Second, when considering the social classes involved, it meant that local writers, who paid a discounted rate and had little means to travel through Europe, now had the chance to meet foreign writers they would not have directly accessed otherwise, hold conversations with them, establish contact for several days, exchange books, and perhaps wield epistolary bonds. Newspaper articles, as we have seen previously, highlight the well-known intellectuals among the club's public. In one notable article, the journalist Ramon Planas pointed out the undeniable benefits that these activities, which were programmed for a mundane public, had across various social mediums, despite the limits and distortions that the showy entertainment model imposed upon the conferences' contents:

If we look at the big picture, we may observe that, without this snobbery, it would be impossible for us to make contact with the great figures of European intellect and thus get a breath of fresh air from these other-and superior-civilizations. Contrasting ideas cannot but do good, and the physical presence of these renowned persons attracts a multitude of curious people, who can easily become impassioned with spirit. Besides the vain and mundane crew of curious onlookers who, after their "six o'clock tea", go to conferences instead of dancing, a minority of fervent intellectual followers who are committed to the cultural cause can now enjoy a pleasure that would otherwise prove nearly inaccessible. ${ }^{45}$

All in all, the toll that the droll conferences took, even when making something deliberately frivolous, as with "the passage of 'Temps perdu' in which Marcel narrated the unpleasant sensations of his first kiss with Albertina" just to make the public laugh, is worth our while, since it consolidated a broad and ambitious amalgamation of personalities in contemporary European culture. 


\section{Notes}

1. This chapter is part of the $\mathrm{R}+\mathrm{D}$ project "Mapping Hispanic Modernity. Cross-border Literary Networks and Cultural Mediators (1908-1939)" (FFI2016-76055-P), funded by the Spanish Ministerio de Economía, Industria y Competitividad.

2. The club's activities reopened after a long decade, in 1949. Nonetheless, this second phase, which went on almost until the end of Franco's regime and which has only recently been revisited by critics (Balcells 2017), was quite different from the first phase, given the substantial loss of the club's international dimension.

3. An initial inventory of the topics and speakers, found at the bottom of a sheet to prepare the club's last year of activity, was published in Alexandre Galís critique on the club's history (1984, pp. 107-114). The tables published in the appendix, which, for the first time, also include each conference's date and venue, are based on information found in the press of the time, specifically, in the newspapers La Vanguardia, La Veu de Catalunya, La Publicitat, and the weekly Mirador. Excluding any other cited sources, the information on the conferences' development is also based on news sources.

4. La Veu de Catalunya, 20/04/1929.

5. The initiative took place within a sociocultural context in which the increasingly literate female public was becoming the new and growing target of all kinds of publications, with notable peaks in the republican period (Real 2006, pp. 31-94).

6. The personal relationships among organizers from both bodies can be appreciated when considering the fact that the Conferentia Club invited distinguished members of the Madrid society's board of directors as speakers, including Gregorio Marañón, Pedro Salinas, and Manuel García Morente.

7. Isabel Llorach's words were ironically reported in the weekly newspaper Mirador (n. 93, 06/11/1930, p. 1): "Now we're looking into opening a Conferentia Club in Madrid, and we'll collaborate with the speakers, you know? That way the intellectuals can come at half price".

8. This anecdote was published in an article on the musician Joaquim Nin's conference in the newspaper La Vanguardia (07/04/1934), which noted that this was not the first time audience members had left early.

9. This was humorously described in an article on Hermann von Keyserling's first visit: "In the Equestrian Circle's room we found the best of each house. The public for Ortega i Gasset's conference. It sure was nice. On the couch to the right, one could find the ladies from the Conferentia Club's board, with their toilettes dernier cri. On the couch to the left, we could find some pensive men next to doctor Bellido, who was distracted, or maybe abstracted, from paying so much attention" (R.M., "Les elegants reunions del Conferentia Club. Hermann von Keyserling”, Mirador, n. 66, 01/05/1930, p. 4). Or the ad hoc wardrobe of the women at Gérard Bauër's conference: "A conference lady's hat, I would call it, since it allows for a dainty and exact viewing of the conference through some not-quite shaped wings" (Carles Sindreu i Pons, “Conferentia Club. Gérard Bauër”, Mirador, n. 125, 25/06/1931, p. 6).

10. And they don't miss the chance to make an ironic comment either: "Once in a while, among the women's whispering, a shaven man would cough in an attempt to make the meeting slightly more masculine, but it was all vain" (C. Sindreu i Pons, “Conferentia Club. Federico García Sanciz”, Mirador, n. 122, 04/06/1931, p. 6).

11. La Vanguardia, 03/12/1930. 
12. María Luz Morales, “¿A quién votarán nuestras mujeres? La incógnita del voto femenino", La Vanguardia, 25/10/1933.

13. The philosopher Keyserling, who took on eight conferences, the actress Béatrix Dussane from the Comédie Française, and the Russian art critic Giovanni Stepanow, who surprised the public with screenings from a magic lantern during his last conference, all spoke over three different seasons ( La Vanguardia, 21/12/1933). The French writers René Benjamin and André Maurois and the Polish harpsichord player Wanda Landowska all came more than once as well.

14. Carles Sindreu i Pons, "Conferentia Club. Gérard Bauër", Mirador, n. 125, 25/06/1931, p. 6.

15. R[afael] T[asis] M[arca], “Conferencia Club”, Mirador, n. 255, 21/12/1933.

16. M[aría] L[uz] Morales, "Conferencia Club" [under the section "Temas femeninos"], La Vanguardia, 22/11/1930.

17. Joan Estelrich, "'Conferentia Club'. L'art de la conferència”, La Veu de Catalunya, 29/07/1931.

18. A few decades after the Second World War, this genre's reputation had radically changed. We can attest to the conference's fall from grace in a text by Guillem Díaz-Plaja, who had witnessed the Conferentia Club in its prime and spoke of the "highly select school for culture" (1978, p. 113) with longing: "Yes, I know. The conference is a discredited art, an unjustly and stupidly discredited art. Is following the example of a tedious or monotone speaker enough to vilify a performance that would allow us to directly listen to the brilliant and wise words of an intellectual? We all remember plenty of truly brilliant conferences" (1978, p. 112).

19. Carles Sindreu i Pons, "“Conferentia Club'. Madame Dussane”, Mirador, n. $119,14 / 05 / 1931$.

20. According to La Vanguardia (15/02/1936), Maurois spoke of his first literary impressions; Valéry's conference, titled "Poésie et poémes" ("Poetry and poems"), elicited plenty of comments from the public (Llanas 2003). This thematic dichotomy was especially present in the way Morales described both of Valéry's conferences in his literary memoir: "What Valéry told the poets" and "What Valéry told the ladies" (Morales 1973, p. 137 and 139).

21. Myself [C. Soldevila], "Conferències i conferenciants", La Publicitat, $16 / 07 / 1929$.

22. La Veu de Catalunya, 21/10/1931.

23. Fernán-Téllez, “Gamillscheg en Barcelona”, La Vanguardia, 29/10/1931.

24. Even the ironic comments published in Mirador regarding some women's bewilderment before Apollinaire's calligrammes, as read by André Billy, don't fall far from this premise. The episode narrates an exception, meaning that the women were generally well composed: "Among the distinguished public of the Conferentia Club, we could also find a few loud women. It is worth noting that, in general, the public was very well behaved. Of course, there were a few exceptions. As a comment to the following verses, 'La rue est déserte-la concierge est malade-trois becs de gaz-une femme poitrinaire ...' one of the women yelled in full spirit: 'Yes, indeed, the whole thing is retarded' (Sí, vaya; tots tarats)" (cited from the anecdote section "Mirador indiscret”, Mirador, n. 57, 27/02/1930). María Luz Morales, "Conferencia Club" [under the section "Temas femeninos"], La Vanguardia, 22/11/1930.

25. María Luz Morales, "Conferencia Club" [under the section "Temas femeninos”], La Vanguardia, 22/11/1930.

26. Fernán-Téllez, “Cuando algo vale”, La Vanguardia, 19/02/1936.

27. Balcells (2017, p. 57 i 60 ) notes that, while there were five members on the board with nobility titles, there were proportionally fewer nobles among the 
club's members, as published in the society's 1931 annual report, constituting just fifteen of the five-hundred fifty members. In terms of the percentage of women, they constituted 18 percent of the protector members and 45 percent of the subscriber members.

28. Elvira Elias, the wife of Feliu Elias, l'Apa, who attended the sessions at the Ritz once a month, highlighted the organization's nucleus: "[the] triumvirate composed of the Baron of Güell, the wealthy heiress Isabel Llorach, and the writer Carles Soldevila” (2012, p. 89).

29. The composition of the Board of Directors is detailed in an article published in La Veu de Catalunya on 20/04/1929. Besides the previously cited positions, we could also find vice-secretary Pere Bosch-Gimpera, treasurer Eusebi Bertrand i Serra, and the following spokespersons: the duchess of Santàngelo, la marquise of Vilanova i Geltrú, the baroness of Güell, Francisca Bonnemaison, the widow of Verdaguer, Ângela Bosch d'Esquerdo, Maria Despujol de Ventosa, Mercè Garí, the widow of Comalada, Pilar Moraleda d'Arnús, Concepció de Pallejà de Balaguer, Lluís Bosch Labrús, Joan Estelrich, Miquel Ferrà, August Pi i Sunyer, Nicolau Rubió i Tudurí, Miquel Vidal Guardiola. On the sociocultural and ideological composition of the club's directors, cf. Balcells 2017.

30. We can understand the president's comment on opening another venue in Madrid to mitigate the expenses of bringing foreign speakers, published in the magazine Mirador (cf. note 6), in this context.

31. The announcement publicizing the club's subscription system was published in La Vanguardia and La Veu de Catalunya just once, at the start of operations, on April 20 and 21, 1929, respectively. Given the great response, the club felt no need to publish the announcement again.

32. For instance, Francesc Cambó paid for Keyserling's first trip (Soldevila 1930: 6).

33. La Vanguardia, 10/02/1932. Little before the Conferentia Club's founding, Carles Soldevilla had lamented the fact that this oral way of transmitting culture was not considered a professional activity: "as long as we fail to create universal systems to pay speakers, it will be impossible for our empty pulpits to be continuously filled in a dignified manner" "Full de Dietari. L'organització de conferències”, La Publicitat, 28/04/1928.

34. The first two cycles sparked plenty of interest. On the occasion of Giovanni Stepanow's conference, on December 9, 1929, La Veu de Catalunya warned readers that "'Conferentia Club' would like to remind us that, given the increased and almost definitive number of members, it will have to limit invitations to protectors and subscribers." In fact, as of the third conference, only members were allowed access. Even in the fall of 1929, newspapers specifically noted that one required a personal invitation to attend.

35. The most pressing problem at the beginning was finding an adequate space, first in terms of capacity and second in terms of acoustics and decor (Soldevila 1930). Over the first year, conferences took place in various places (the Ateneu, the Chamber of Property, and the Equestrian Circle, for instance), which were sometimes confirmed little before the conference date. Eventually, the club consolidated its conferences at the Ritz Hotel's ballroom (the club's official address from the beginning). As of 1931, the Ritz hosted conferences regularly, with a few exceptions at the prestigious Sala Studium, an old gold-masonry workshop that Masriera turned into a theater in 1933.

36. For instance, the magazine $O c$ agreed to publish the conferences in Occitan translation (Alquézar, p. 89). Further, the vice president, Eusebi Güell i López, funded a volume that included the fifteen conferences that took place over the first two years (Conferentia Club 1931). 
37. C[arles] Soldevila, "Full de Dietari. L'organització de conferències", La Publicitat, 28/04/1928.

38. M[aría] L[uz] Morales, "Conferencia Club" [under the section "Temas femeninos"], La Vanguardia, 22/11/1930.

39. It is worth noting that several speakers are hard to categorize in specific politico-national contexts: we grouped Dannie Heineman (who was born in the United States to an American father and German mother, but moved to Belgium for work) and Franz Wiener (a Belgian from a Jewish-German family that moved to Paris, who later became a French citizen and changed his name to Francis de Croisset) as Belgian. We also grouped as Austrian José Weissberger (who was born of a Jewish-Austrian family in the Austro-Hungarian Empire and later became a Spanish and then an American citizen) (PérezFlecha 2016) and Arnold Lorand, a famous doctor given his famous publications on the clinical work he did in the bohemian city of Carlsbad (Ingold 2011). We grouped Emil Ludwig (who became a Swiss national in 1932) and Hugo Obermaier (who became a Spanish national in 1924) as German and grouped Gustavo Pittaluga (who later became a Spanish national) as Italian.

40. The Romanian poet Văcărescu and the Polish musician Landowska also established themselves in France.

41. The four conferences used in the pilot course for debutantes are also included.

42. In the conference lists announced at the beginning of each season, we can find several people who did not end up speaking, such as the French Paul Hazard, Jules Romains, Marc Chadourne, Léon Daudet, etc.; the Italian Giovanni Papini, Luigi Pirandello, and Giovanni Gentile; the German and Austrian Werner Jager, Thomas Mann, and Rudolf Kassner; the Slavic Nikolai Berdiàiev; and the Portuguese Leonardo Coimbra.

43. Myself [Carles Soldevila], "Conferències i conferenciants", La Publicitat, $16 / 07 / 1929$.

44. The club's relationship with Fundació Bernat Metge, which Cambó founded in 1922 and was directed by Joan Estelrich, was especially intense. On top of a healthy group of Greekists and Latinists, the president (Paul Mazon) and secretary (Jean Malye) of the Association Guillaume Budé, an affiliate of the Bernat Metge Foundation, were invited during the club's first year of activity.

45. Ramon Planas, "Després de Maurois. Conferenciants i snobs”, La Publicitat, 20/02/1936.

\section{Bibliography}

Alquézar i Montañés, Manuel (ed.). La correspondència entre Loïs Alibert i Josep Carbonell $i$ Gener: materials per a l'estudi de la codificació de la llengua occitana. Barcelona: Institut d'Estudis Catalans, 1992.

Balcells, Albert. "El Conferència Club d'Isabel Llorach i Carles Soldevila entre 1929 i 1936 i la seva reconstrucció a partir de 1949”. Cercles. Revista d'Història Cultural 20, 2017, pp. 41-69.

Cambó, Francesc. Memòries (1876-1936). Barcelona: Alpha, 1981.

[Conferentia Club] Conferències de l'any 1929. Vol. 1, Conferentia Club, 1931.

Díaz-Plaja, Guillermo. Retrato de un escritor. Barcelona: Pomaire, Cop., 1978.

Domènech, Ignasi. “Joaquim Folch i Torres i l'exposició d'El Greco al Palau Maricel de Sitges el juny del 1936". In Antiquaris, experts, col-leccionistes $i$ museus. El comerç, l'estudi $i$ la salvaguarda de l'art a la Catalunya del segle $X X$. Bonaventura Bassegoda and Ignasi Domènech (eds.). Barcelona: Universitat de Barcelona, 2013. 
Elias, Elvira. Una senyora de Barcelona. Curated by Joan Miquel Nodrà Nogueres. Ajuntament d'Areny de Mar/Publicacions de l'Abadia de Montserrat, 2012.

Galí, Alexandre. Història de les institucions i del moviment cultural a Catalunya 1900-1936. XI. Biblioteques populars i moviment literari. Barcelona: Fundació A. Galí, 1984.

Guardiola, Carles-Jordi (ed.). Cartes de Carles Riba, vol. 1. Barcelona: Institut d'Estudis Catalans, 1989.

Ingold, Nikolaus. "Light Showers" as Vitality Boosters: Sunlamps and the Hygienic Lifestyle in an Industrialized Environment. In The Proceedings of the 18th Annual History of Medicine Days: Conference 2009. Lisa Peterman, Kerry Sun, and Frank W. Stahnisch (eds.). Cambridge Scholars Publishing, 2011, pp. 105-126.

Llanas, Manuel. "Notes sobre la recepció de Paul Valéry en les lletres catalanes”. In Professor Joaquim Molas. Memòria, escriptura, història, vol. 1. Barcelona: Universitat de Barcelona, 2003, pp. 589-599.

Manent, Albert. "Carles Soldevila, un home de lletres”. Llengua \& Literatura 6, 1994, pp. 43-52.

Martin-Fugier, Anne. La bourgeoise. Paris: Grasset, 1990.

Morales, María Luz. Alguien a quien conocí. María Curie, Keyserling, Gabriela Mistral, Valéry, Víctor Catalá, García Lorca, Malraux. Barcelona: Juventud, 1973.

Pérez-Flecha González, Javier. "El marchante y coleccionista José Weissberger y la incautación y depósito de su colección en el Museo Nacional de Artes Decorativas". Además de. Revista on line de artes decorativas y diseño 2, 2016, pp. 139-152.

Real, Neus. Dona i literatura a la Catalunya de preguerra. Barcelona: Publicacions de l'Abadia de Montserrat, 2006.

Ribagorda, Álvaro. "El Comité Hispano-Inglés y la Sociedad de Cursos y Conferencias de la Residencia de Estudiantes (19 23-1936)". Cuadernos de Historia Contemporánea 30, 2008, pp. 273-291.

Soldevila, Carles. Memòria del Secretari Sr. Carles Soldevila llegida a la Junta General del dia 25 d'octubre de 1930. Barcelona, 1930 [after in Conferentia Club 1931: 269-273].

Soldevila, Carles. "Conferència Club”. La Revista 21/1, 1936.

Werner, Michael and Zimmermann, Bénédicte. "Penser l'Histoire croisée: entre empirie et réflexivité". Annales. Histoire, Sciences Sociales 58/1, 2003, pp. 7-36. 


\section{Appendix A}

Table 8.2 Chronological List of Lectures Organized by Conferentia Club from 1929 to 1936

Date, venue, and title of each lecture are based on information found in the press of the time, specifically, in the newspapers La Vanguardia, La Veu de Catalunya, La Publicitat, and the weekly Mirador.

Names and addresses of the venues mentioned in the list:

Ateneu $=$ Ateneu Barcelonès-carrer de la Canuda 6

Cambra = Cambra Oficial de la Propietat Urbana de Barcelona—via Laietana 22

Casal del Metge $=$ via Laietana 31

Cercle $=$ Cercle Eqüestre - passeig de Gràcia 38-40

Ciutadella $=$ Museu de la Ciutadella - Parc de la Ciutadella

Ritz = Hotel Ritz-Gran Via de les Corts Catalanes 668

S. Mozart $=$ Sala Mozart $—$ carrer de la Canuda 31

S. Studium $=$ Sala Studium - carrer Bailén 72

As for the lecturers' origins, we specify the city or territory in which they regularly resided and worked during those dates, if possible. In case this information is unknown or the lecturer did not have a stable residence in that period, we specify birthplace. We have also added birthplace when it linguistically and politically differed with the territory in which the lecturer fixed his stable residence. Birthplace appears in italics.

The first fifteen lectures were compiled in a volume (Conferentia Club 1931): from author's written text for Vossler's, Serra Húnter's, Zielinski's, Pujol's, and Meunier's; from shorthanded versions for Meillet's, Däubler's, Romanelli's, Welter's, Mazon's, Pelliot's, and Stepanow's; from summaries extracted from press articles for Moret's, Bovet's, and Iorga's. 


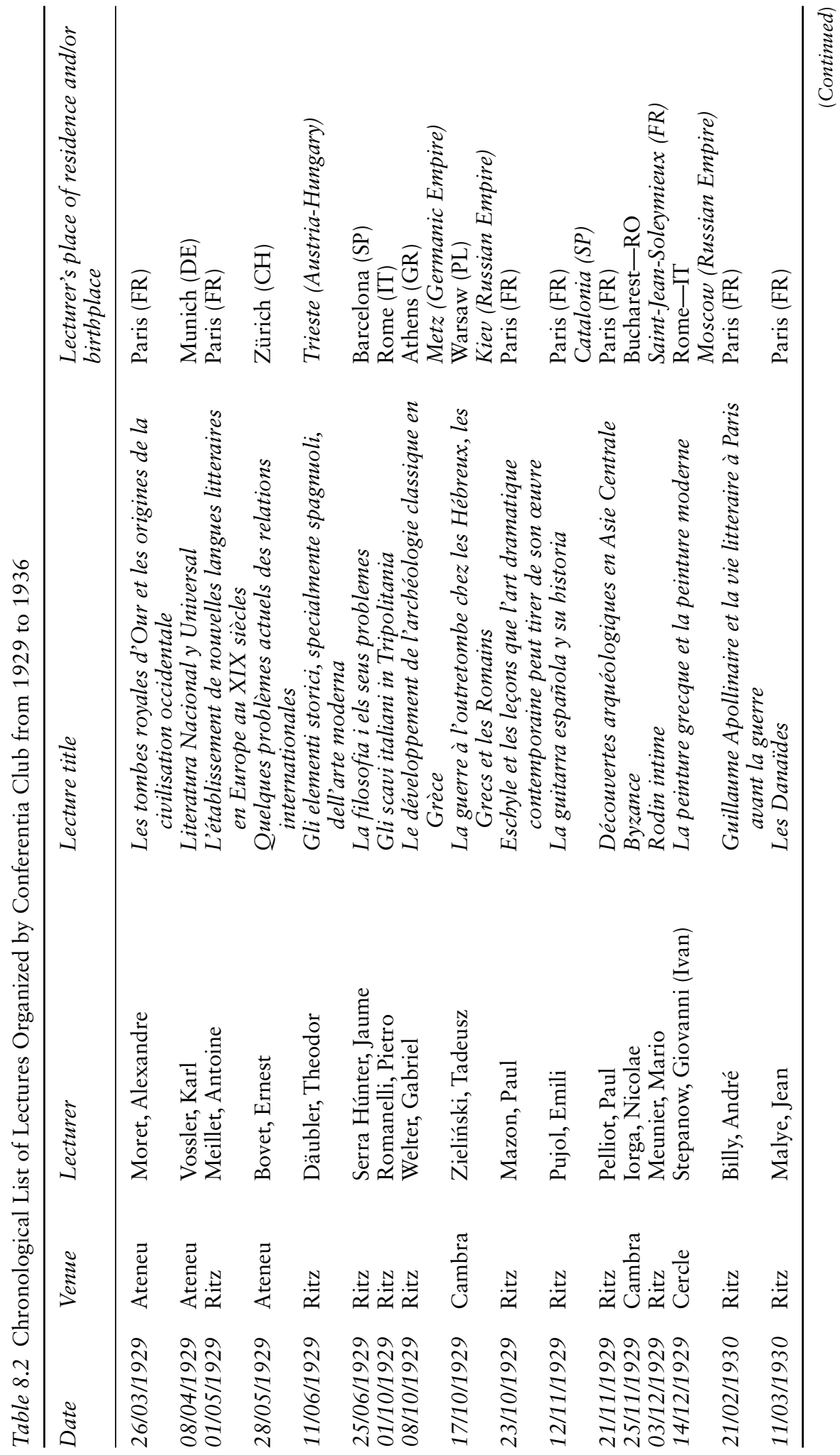




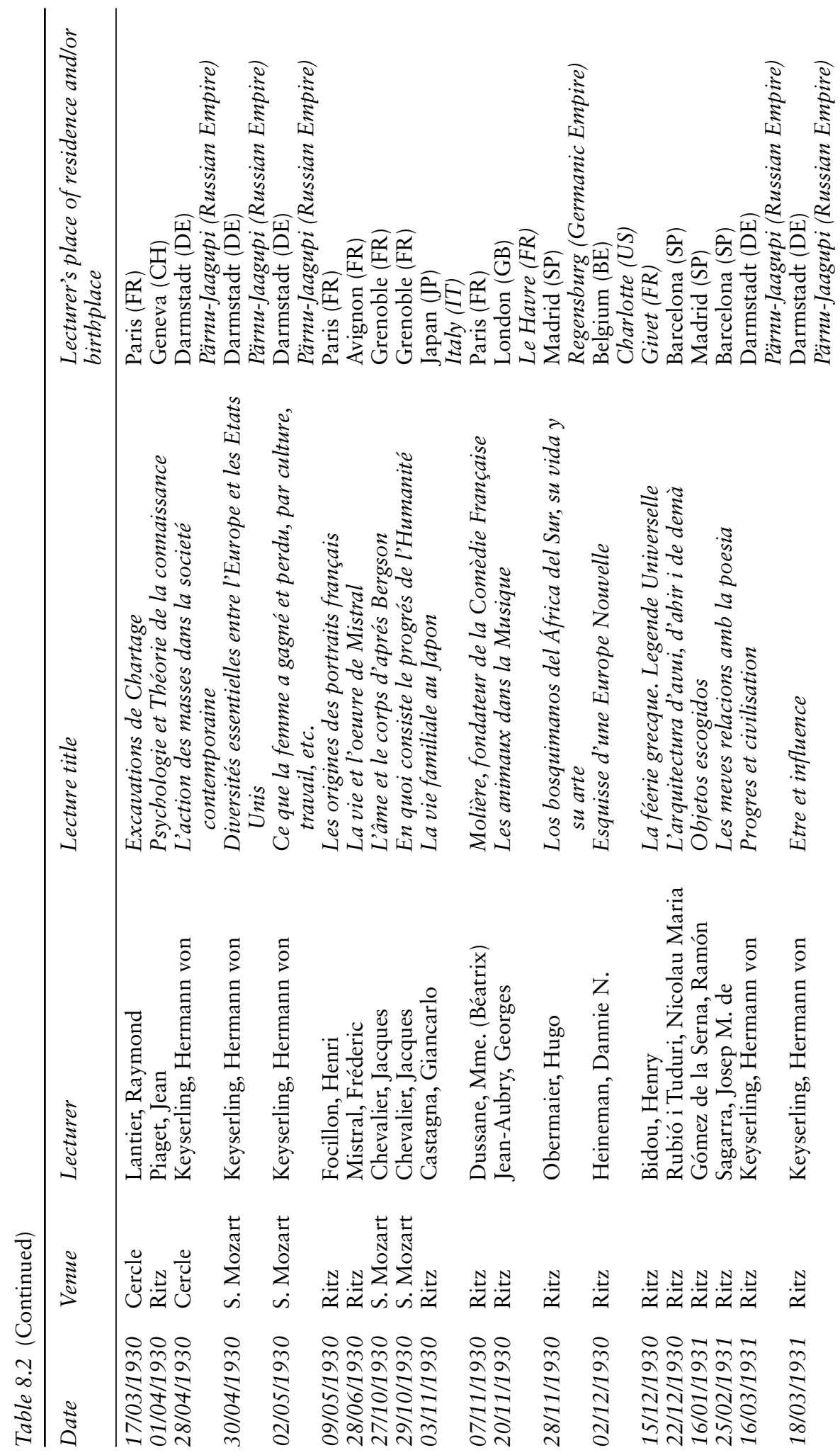




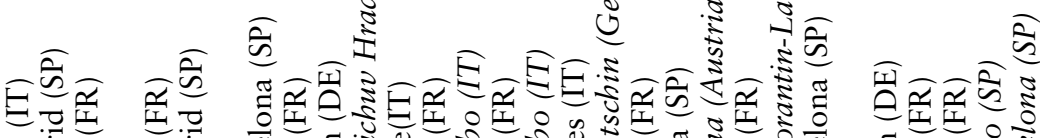

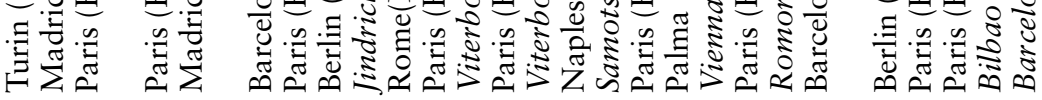

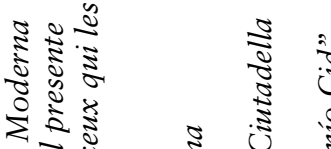

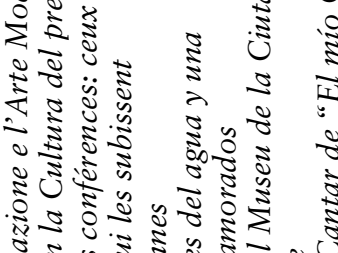

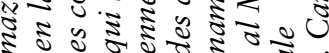

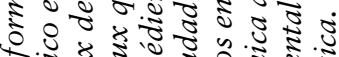

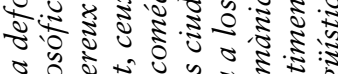

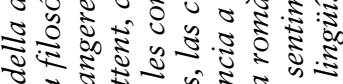

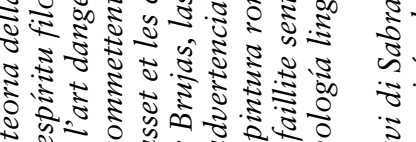

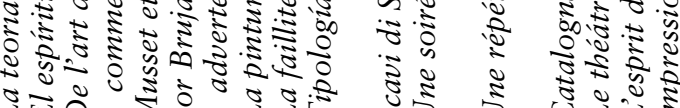

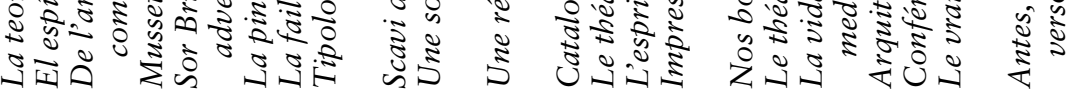

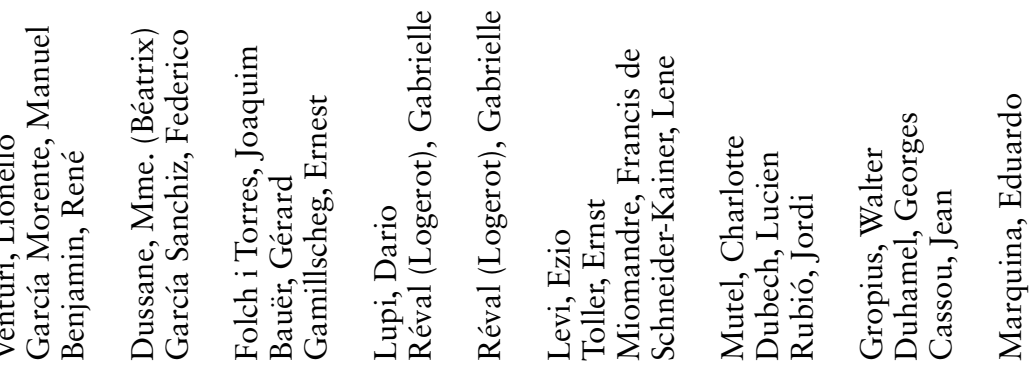

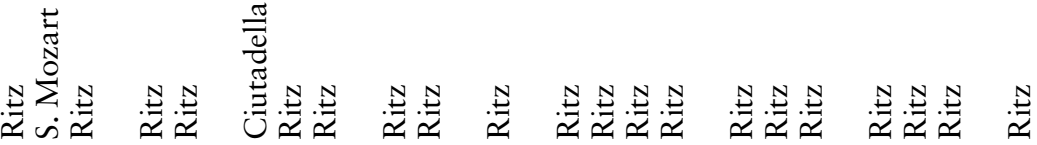

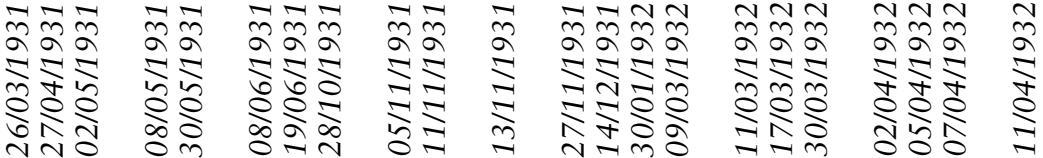




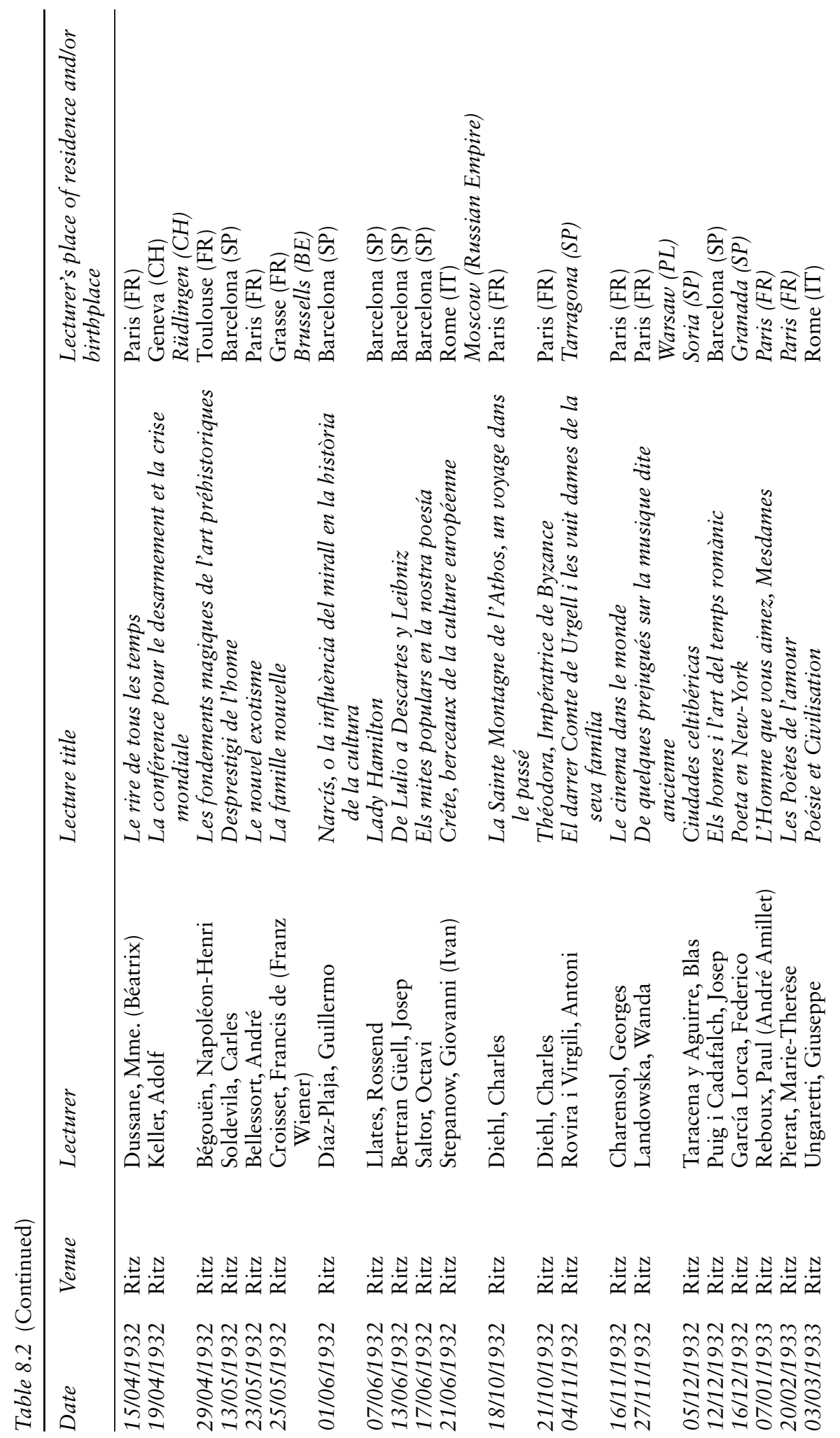


$\frac{\sqrt{2}}{2}$

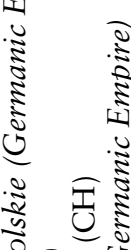

$\widehat{\bar{N}} \frac{0}{0}$

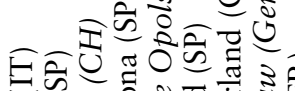

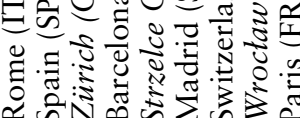

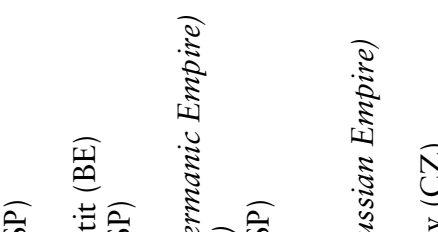

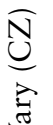

$\widehat{\underline{2}} \widehat{\underline{n}}$

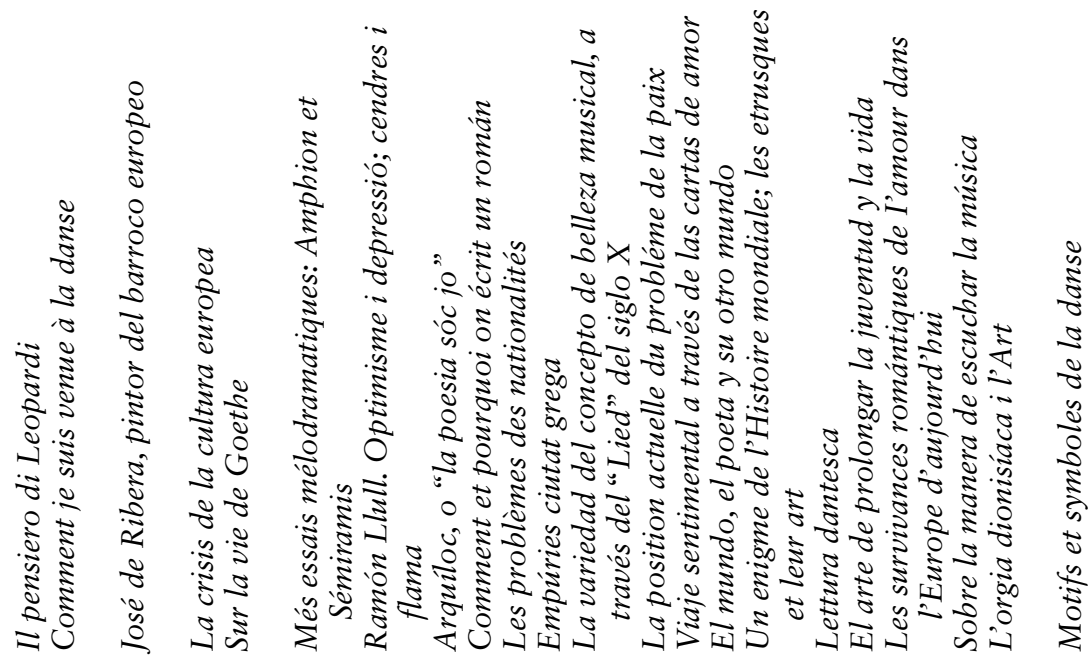

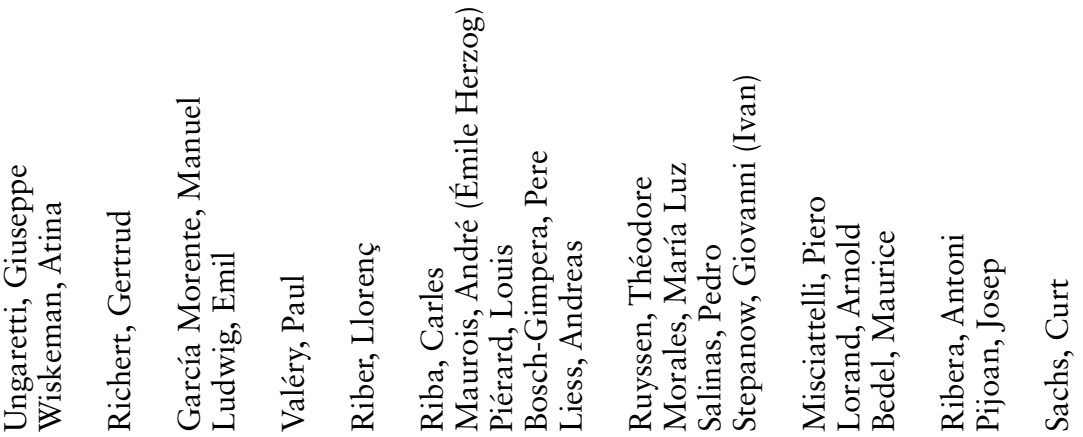

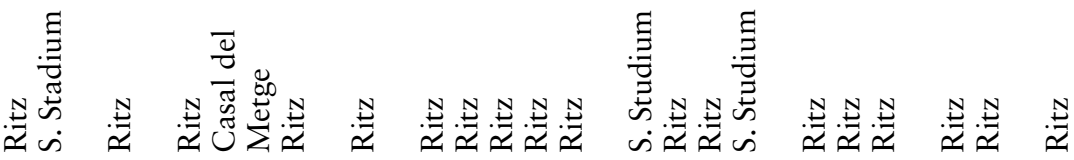

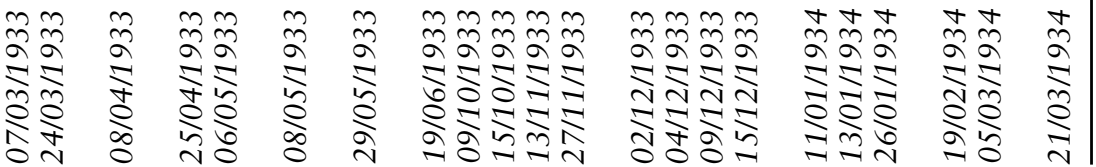




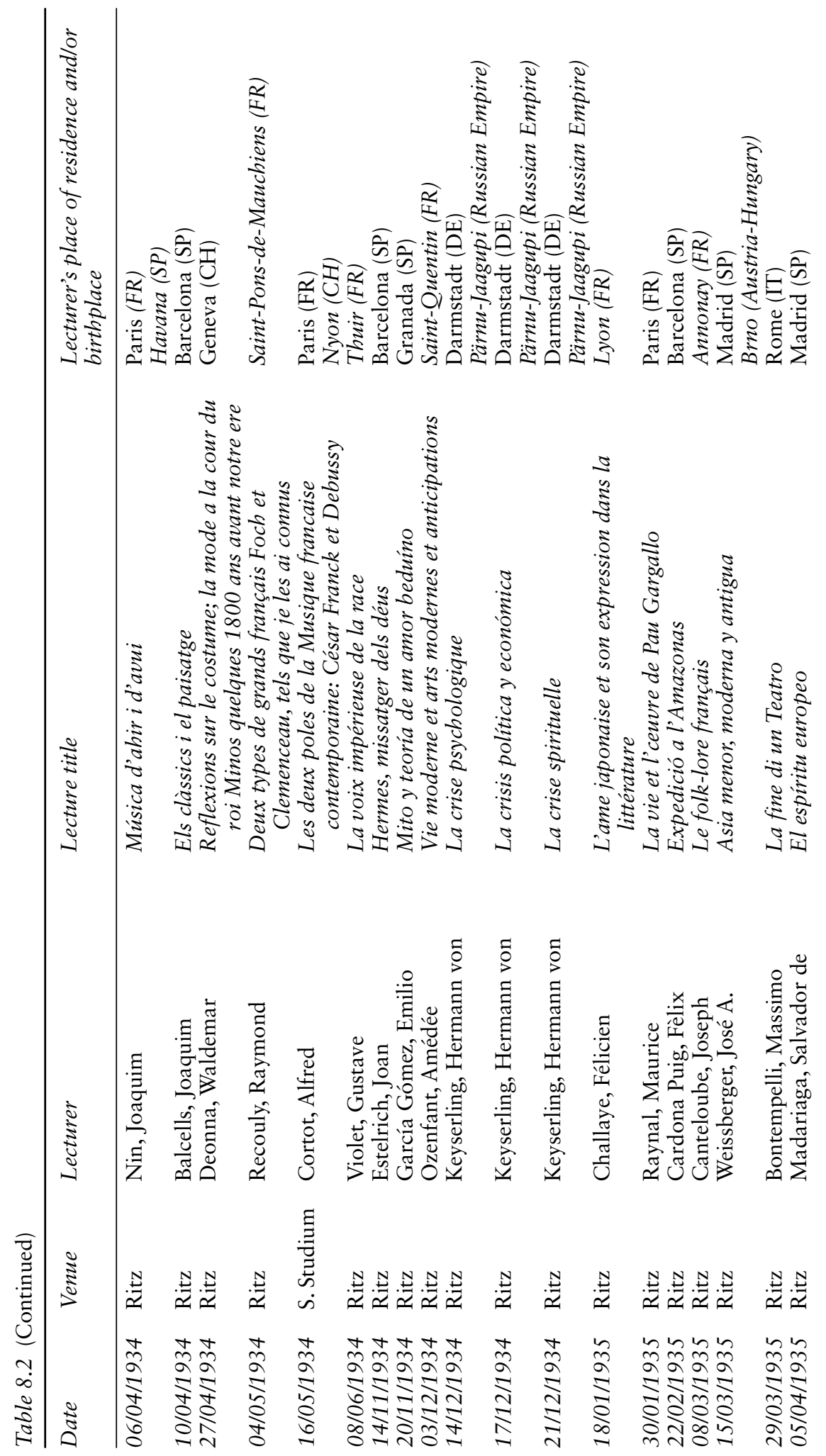



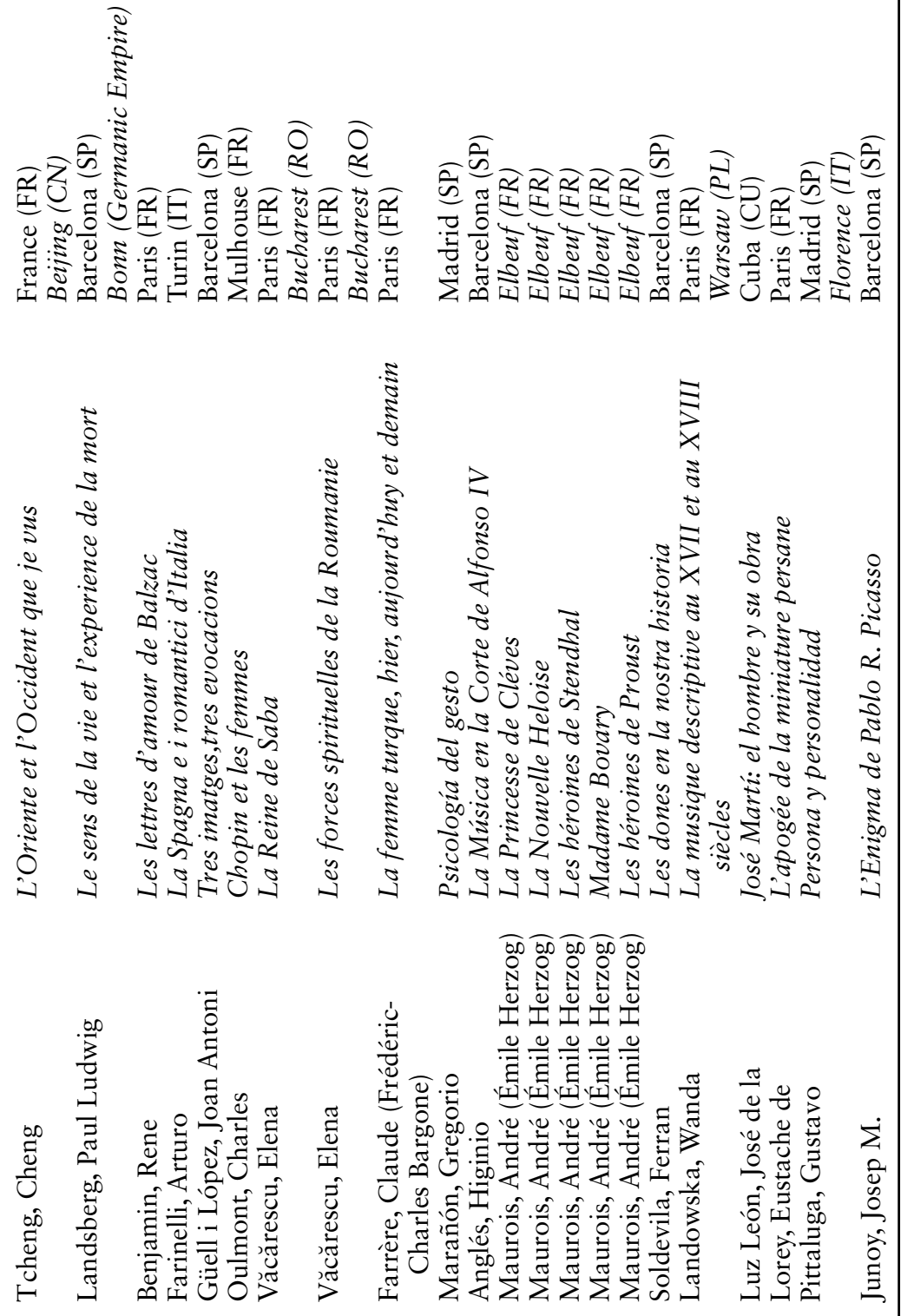

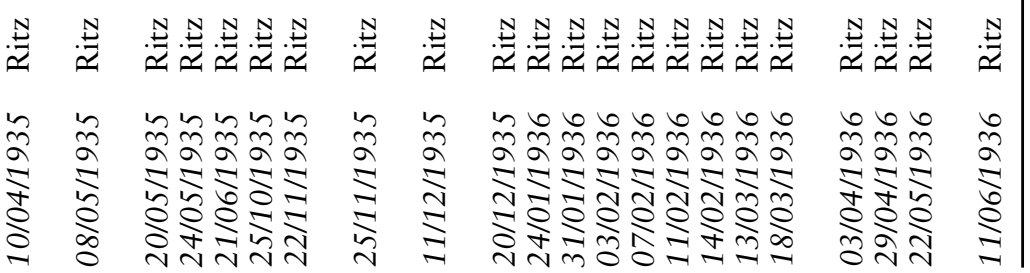




\section{Appendix B}

Table 8.3 Alphabetical List of Lectures Organized by Conferentia Club from 1929 to 1936

\begin{tabular}{ll}
\hline Lecturer & \\
\hline Anglés, Higinio & Date \\
Balcells, Joaquim & $24 / 01 / 1936$ \\
Bauër, Gérard & $10 / 04 / 1934$ \\
Bedel, Maurice & $19 / 06 / 1931$ \\
Bégouën, Napoléon-Henri & $26 / 01 / 1934$ \\
Bellessort, André & $29 / 04 / 1932$ \\
Benjamin, Rene & $23 / 05 / 1932$ \\
Benjamin, René & $20 / 05 / 1935$ \\
Bertran Güell, Josep & $02 / 05 / 1931$ \\
Bidou, Henry & $13 / 06 / 1932$ \\
Billy, André & $15 / 12 / 1930$ \\
Bontempelli, Massimo & $21 / 02 / 1930$ \\
Bosch-Gimpera, Pere & $29 / 03 / 1935$ \\
Bovet, Ernest & $13 / 11 / 1933$ \\
Canteloube, Joseph & $28 / 05 / 1929$ \\
Cardona Puig, Félix & $08 / 03 / 1935$ \\
Cassou, Jean & $22 / 02 / 1935$ \\
Castagna, Giancarlo & $07 / 04 / 1932$ \\
Challaye, Félicien & $03 / 11 / 1930$ \\
Charensol, Georges & $18 / 01 / 1935$ \\
Chevalier, Jacques & $16 / 11 / 1932$ \\
Chevalier, Jacques & $27 / 10 / 1930$ \\
Cortot, Alfred & $29 / 10 / 1930$ \\
Croisset, Francis de (Franz Wiener) & $16 / 05 / 1934$ \\
Däubler, Theodor & $25 / 05 / 1932$ \\
Deonna, Waldemar & $11 / 06 / 1929$ \\
Díaz-Plaja, Guillermo & $27 / 04 / 1934$ \\
Diehl, Charles & $01 / 06 / 1932$ \\
Diehl, Charles & $18 / 10 / 1932$ \\
Dubech, Lucien & $21 / 10 / 1932$ \\
Duhamel, Georges & $17 / 03 / 1932$ \\
Dussane, Mme. (Béatrix) & $05 / 04 / 1932$ \\
Dussane, Mme. (Béatrix) & $07 / 11 / 1930$ \\
Dussane, Mme. (Béatrix) & $08 / 05 / 1931$ \\
Estelrich, Joan & $15 / 04 / 1932$ \\
Farinelli, Arturo & $14 / 11 / 1934$ \\
Farrère, Claude (Frédéric-Charles Bargone) & $24 / 05 / 1935$ \\
Focillon, Henri & $11 / 12 / 1935$ \\
Folch i Torres, Joaquim & $09 / 05 / 1930$ \\
Gamillscheg, Ernest & $08 / 06 / 1931$ \\
& $28 / 10 / 1931$
\end{tabular}




\begin{tabular}{|c|c|}
\hline Lecturer & Date \\
\hline García Gómez, Emilio & 20/11/1934 \\
\hline García Lorca, Federico & $16 / 12 / 1932$ \\
\hline García Morente, Manuel & $27 / 04 / 1931$ \\
\hline García Morente, Manuel & $25 / 04 / 1933$ \\
\hline García Sanchiz, Federico & $30 / 05 / 1931$ \\
\hline Gómez de la Serna, Ramón & $16 / 01 / 1931$ \\
\hline Gropius, Walter & $02 / 04 / 1932$ \\
\hline Güell i López, Joan Antoni & $21 / 06 / 1935$ \\
\hline Heineman, Dannie N. & $02 / 12 / 1930$ \\
\hline Iorga, Nicolae & $25 / 11 / 1929$ \\
\hline Jean-Aubry, Georges & 20/11/1930 \\
\hline Junoy, Josep M. & $11 / 06 / 1936$ \\
\hline Keller, Adolf & $19 / 04 / 1932$ \\
\hline Keyserling, Hermann von & $28 / 04 / 1930$ \\
\hline Keyserling, Hermann von & $30 / 04 / 1930$ \\
\hline Keyserling, Hermann von & $02 / 05 / 1930$ \\
\hline Keyserling, Hermann von & $16 / 03 / 1931$ \\
\hline Keyserling, Hermann von & $18 / 03 / 1931$ \\
\hline Keyserling, Hermann von & $14 / 12 / 1934$ \\
\hline Keyserling, Hermann von & $17 / 12 / 1934$ \\
\hline Keyserling, Hermann von & $21 / 12 / 1934$ \\
\hline Landowska, Wanda & $27 / 11 / 1932$ \\
\hline Landowska, Wanda & $18 / 03 / 1936$ \\
\hline Landsberg, Paul Ludwig & $08 / 05 / 1935$ \\
\hline Lantier, Raymond & $17 / 03 / 1930$ \\
\hline Levi, Ezio & $27 / 11 / 1931$ \\
\hline Liess, Andreas & $27 / 11 / 1933$ \\
\hline Llates, Rossend & $07 / 06 / 1932$ \\
\hline Lorand, Arnold & $13 / 01 / 1934$ \\
\hline Lorey, Eustache de & $29 / 04 / 1936$ \\
\hline Ludwig, Emil & $06 / 05 / 1933$ \\
\hline Lupi, Dario & $05 / 11 / 1931$ \\
\hline Luz León, José de la & $03 / 04 / 1936$ \\
\hline Madariaga, Salvador de & $05 / 04 / 1935$ \\
\hline Malye, Jean & $11 / 03 / 1930$ \\
\hline Marañón, Gregorio & $20 / 12 / 1935$ \\
\hline Marquina, Eduardo & $11 / 04 / 1932$ \\
\hline Maurois, André (Émile Herzog) & $09 / 10 / 1933$ \\
\hline Maurois, André (Émile Herzog) & $31 / 01 / 1936$ \\
\hline Maurois, André (Émile Herzog) & $03 / 02 / 1936$ \\
\hline Maurois, André (Émile Herzog) & $07 / 02 / 1936$ \\
\hline Maurois, André (Émile Herzog) & $11 / 02 / 1936$ \\
\hline Maurois, André (Émile Herzog) & $14 / 02 / 1936$ \\
\hline Mazon, Paul & $23 / 10 / 1929$ \\
\hline Meillet, Antoine & $01 / 05 / 1929$ \\
\hline Meunier, Mario & $03 / 12 / 1929$ \\
\hline Miomandre, Francis de & $30 / 01 / 1932$ \\
\hline Misciattelli, Piero & $11 / 01 / 1934$ \\
\hline Mistral, Fréderic & $28 / 06 / 1930$ \\
\hline Morales, María Luz & $04 / 12 / 1933$ \\
\hline Moret, Alexandre & 26/03/1929 \\
\hline Mutel, Charlotte & $11 / 03 / 1932$ \\
\hline
\end{tabular}


Table 8.3 (Continued)

\begin{tabular}{|c|c|}
\hline Lecturer & Date \\
\hline Nin, Joaquim & $06 / 04 / 1934$ \\
\hline Obermaier, Hugo & 28/11/1930 \\
\hline Oulmont, Charles & 25/10/1935 \\
\hline Ozenfant, Amédée & 03/12/1934 \\
\hline Pelliot, Paul & 21/11/1929 \\
\hline Piaget, Jean & 01/04/1930 \\
\hline Piérard, Louis & $15 / 10 / 1933$ \\
\hline Pierat, Marie-Therèse & $20 / 02 / 1933$ \\
\hline Pijoan, Josep & 05/03/1934 \\
\hline Pittaluga, Gustavo & $22 / 05 / 1936$ \\
\hline Puig i Cadafalch, Josep & $12 / 12 / 1932$ \\
\hline Pujol, Emili & $12 / 11 / 1929$ \\
\hline Raynal, Maurice & $30 / 01 / 1935$ \\
\hline Reboux, Paul (André Amillet) & 07/01/1933 \\
\hline Recouly, Raymond & $04 / 05 / 1934$ \\
\hline Réval (Logerot), Gabrielle & 11/11/1931 \\
\hline Réval (Logerot), Gabrielle & 13/11/1931 \\
\hline Riba, Carles & 19/06/1933 \\
\hline Riber, Llorenç & $29 / 05 / 1933$ \\
\hline Ribera, Antoni & $19 / 02 / 1934$ \\
\hline Richert, Gertrud & 08/04/1933 \\
\hline Romanelli, Pietro & $01 / 10 / 1929$ \\
\hline Rovira i Virgili, Antoni & $04 / 11 / 1932$ \\
\hline Rubió i Tuduri, Nicolau Maria & $22 / 12 / 1930$ \\
\hline Rubió, Jordi & $30 / 03 / 1932$ \\
\hline Ruyssen, Théodore & $02 / 12 / 1933$ \\
\hline Sachs, Curt & $21 / 03 / 1934$ \\
\hline Sagarra, Josep M. de & 25/02/1931 \\
\hline Salinas, Pedro & $09 / 12 / 1933$ \\
\hline Saltor, Octavi & $17 / 06 / 1932$ \\
\hline Schneider-Kainer, Lene & 09/03/1932 \\
\hline Serra Húnter, Jaume & $25 / 06 / 1929$ \\
\hline Soldevila, Carles & $13 / 05 / 1932$ \\
\hline Soldevila, Ferran & 13/03/1936 \\
\hline Stepanow, Giovanni (Ivan) & $14 / 12 / 1929$ \\
\hline Stepanow, Giovanni (Ivan) & $21 / 06 / 1932$ \\
\hline Stepanow, Giovanni (Ivan) & $15 / 12 / 1933$ \\
\hline Taracena y Aguirre, Blas & $05 / 12 / 1932$ \\
\hline Tcheng, Cheng & $10 / 04 / 1935$ \\
\hline Toller, Ernst & $14 / 12 / 1931$ \\
\hline Ungaretti, Giuseppe & 03/03/1933 \\
\hline Ungaretti, Giuseppe & 07/03/1933 \\
\hline Văcărescu, Elena & $22 / 11 / 1935$ \\
\hline Văcărescu, Elena & $25 / 11 / 1935$ \\
\hline Valéry, Paul & 08/05/1933 \\
\hline Venturi, Lionello & $26 / 03 / 1931$ \\
\hline Violet, Gustave & 08/06/1934 \\
\hline Vossler, Karl & 08/04/1929 \\
\hline Weissberger, José A. & $15 / 03 / 1935$ \\
\hline Welter, Gabriel & $08 / 10 / 1929$ \\
\hline Wiskeman, Atina & $24 / 03 / 1933$ \\
\hline Zieliński, Tadeusz & $17 / 10 / 1929$ \\
\hline
\end{tabular}




\section{Part III}

\section{Cultural Mediators}


$\because$ Taylor \& Francis

Taylor \& Francis Group

http://taylorandfrancis.com 


\title{
9 Joan Estelrich and International Cooperation
}

\author{
From the Years of Expansió \\ Catalana to His Activity for the \\ PEN Club in the Early-Mid-1930s
}

\section{Sílvia Coll-Vinent}

Joan Estelrich i Artigues was an international cultural mediator from the early twenties up to the mid-thirties. He was born in 1896 in Felanitx, on Majorca. He was the son of a Civil Guard who moved to Minorca with his family from 1907 to 1914; there, while studying his A levels (bachillerato), young Joan got involved in local newspapers and very soon became quite a popular figure, so much so that when he was only 15 , he led the campaign for a Minorcan Conservative MP at the Spanish Cortes. After a couple of years spent in Palma working in journalism, Estelrich settled in Barcelona around 1917, where we can find him contributing to La Veu de Catalunya, the conservative Catalan newspaper, and various other magazines and cultural ventures such as La Revista, where he disseminated the work of Kierkegaard (Graña 1996; Jorba 2012, 596-598). He actively took part in the Philosophy Seminar organized by Eugeni d'Ors, and on d'Ors' initiative he published in 1918 an extract of William Morris' utopian novel News from Nowhere. This early relationship with d'Ors, his mentor, ended up definitely marking Esterlich's career. As early as the autumn of 1917, he was introduced to the Conservative politician and leader of Lliga Regionalista de Catalunya, Francesc Cambó, and from then on, he devoted his entire professional life to serving as Cambó's cultural agent and was particularly involved in directing a major cultural venture founded in 1922, the Fundació Bernat Metge, dedicated to publishing Greek and Latin classics in bilingual editions (Franquesa 2013). From July 1919, he had been equally busy in internationalizing the Catalan question on the cultural front, more specifically in France.

To account for the immense amount of activity that Joan Estelrich undertook as cultural agent up to 1958, working as Spanish Delegate for UNESCO (he died suddenly in Paris on 20 June 1958), we must have a look at Joan Estelrich's personal archive held at the Biblioteca de Catalunya. It is an archive made up of 350 boxes, and covers the institutional activities in which he was involved in Catalonia and abroad, with press cuttings of all sorts of cultural events; the outlines of projects he 
carried out (finished and unfinished); typed manuscripts of lectures and speeches given in Catalonia, Europe (specially in France and Italy) and South-America, by him or others who worked with him; personal diaries and a huge trove of correspondence with Catalan, French, Italian and South American writers, journalists, editors and intellectuals, organized into three periods (pre-1936, 1936-1939 and 1939-1958). They include Sorbonne professors such as Léon Brunschwicg and Paul Hazard, writers and philosophers such as Benedetto Croce and Hermann von Keyserling, journalists and editors-in-chief of cultural newspapers, such as Albert de Falgairolle and Gabriel Boissy. Likewise, writers at the peak of their fame such as Paul Valéry are among his many European correspondents (Jorba 2010). The archive is thus an invaluable tool to map out the cultural network he helped to build first from Barcelona and second from Paris, as well as to map the intellectual milieu in which he was deeply involved as Cambó's first cultural agent: as the appointed representative of Expansió Catalana in France in the early twenties up to his activity as a UNESCO member, as well as his work for the Committee of European Nationalities of the Society of Nations and other related institutions.

I shall concentrate on his work for the PEN Club in the preparations for its 13th congress in Barcelona. My aim is to help contextualize a piece of information concerning the history of the Catalan branch of PEN—a history that has been studied by Jaume Subirana (Subirana 2011, 2018)—drawing the attention to some documents from Estelrich's personal archive of which I provide an English translation in the Appendices: the statutes he drafted to be approved a year or a year and a half before the 13th PEN congress took place in Barcelona in June 1935 (Appendix A); the internal statutes and program of expansion of the directive committee of the PEN Club of Catalonia (Appendix B), and a detailed program of activities concerning the international congress of PEN Clubs, meeting in Barcelona in 1935 (Appendix C). ${ }^{1}$

Any approach to Estelrich's involvement in PEN's Catalan delegation should be made in the light of his previous experience as Cambó's international cultural agent, particularly his work in the field of culture in France. Estelrich was assigned a primary mission: to disseminate Catalan culture abroad, and more specifically to transnationalize a political project. In Cambó's mind, this project meant playing politics while working on culture and building up a journalistic network in Catalonia, the Iberian Peninsula and beyond. This is a central idea in understanding Estelrich's intellectual career as a whole. When he started working for Cambó in Expansió Catalana, politics meant counterbalancing the politically repressive effects of the Primo de Rivera dictatorship through a platform that was working the purpose of disseminating Catalan culture abroad (Gavagnin 2005, 135-139; Corretger 2008; Coll-Vinent 2010, 43-48); throughout the mid-late twenties and early thirties, politics meant carrying out para-diplomacy to spread the national question at the various 
congresses organized by the Society of Nations through the Commission of National Minorities (Núñez 2001, chap. IV, V and VI). At the time of Spanish Republic, politics meant involving Estelrich as an MP in the Spanish Parliament to put forward various cultural initiatives and to carry out various missions for the Union Interparlamentaire (Estelrich 2012, 136). And during the Spanish Civil War, politics meant placing Estelrich in the Paris propaganda office to work for the Burgos government as the director of the bimonthly magazine Occident (Massot 2001). And so on and so forth. He was obviously not alone in the job, yet in terms of culture and journalism in France, Estelrich was a leading voice on Cambó's team, which also included Alfons Maseras and Albert de Falgairolle, among others.

We may now briefly outline the core ideas around which this transnational cultural venture was carried out, at least from the years of Expansió Catalana in the early-mid thirties up to our PEN documents from around late 1933. First of all, his work was like a propagandistic campaign run under the overarching aim of putting Catalonia and its capital, Barcelona, on the map from the cultural perspective. This was carried through under a particular impetus: the drive of humanism, the new humanism understood as a sort of actualization of humanities for the 20th century, which thus connected the Catalan effort (first the Fundació Bernat Metge, plus other humanistic ventures) with the French and European classical and humanistic efforts by actively participating in various forums and entretiens organized by classical associations (Coll-Vinent 2014; Coll-Vinent and Cabré 2014). We can now trace all the work Estelrich performed in that context paper by paper, letter by letter and through the cultural press, which is conducive to that aim. "Institutional durability" was a sort of motto, a key word guiding Cambó's ventures.

The classical heritage was at the core of Cambó's campaign, which furthermore stimulated sociability among more conservative French intellectuals, such as the leader of Action Française, Charles Maurras. A first move, for instance, was to launch the FBM as a subsidiary branch of the Association Guillaume Budé, and the FBM was presented with honors in Paris, at the Sorbonne, in April 1926. Yet the cultural peak in Cambó's team's effort came in 1929 with the International Exhibition in Barcelona. Barcelona has grown up as cultural capital since the time of the Great War (Ucelay da Cal 1997). In 1929, the city gathered cultural momentum, concentrating symbolic value as a cultural capital; the Exhibition provided a glorious time for the city and a great excuse to move on the dissemination of the Catalan question abroad and more particularly in France (Brion 1929).

A vivid illustration of how this symbolic use of the city worked in the French cultural scene can now be found through the papers from Estelrich's personal archive. More specifically, I would like to draw attention to the picture of the Barcelona International Exhibition published on 


\section{Sílvia Coll-Vinent}

the 10th of August 1929 on the front page of the Parisian Comoedia, a widely read cultural newspaper run by Boissy. ${ }^{2}$

This picture clearly conveys Barcelona's symbolic “classical” capitalthe Paris of the Mediterranean, as they called it-which they wanted to project worldwide. An idealized cultural image of the city, a classical city: showing the Avenue Maria Cristina pointing at one of the most curious aspects of the Exhibition-I am transcribing from the photo captionthis avenue opens at the front of the National Palace, a continuation of the great avenues of Barcelona, running through vast flourishing gardens with fountains, and flanked by glass pylons which offer passers-by a magical light display at night. In an age of growing totalitarianisms, this idea of a capital projected had a contagious effect over the city, over the classical heritage mixing with propaganda. The consolidation of Barcelona as cultural capital was definitely an asset in Cambó's strategy to ensconce the Catalan question since the early years of Expansió Catalana. Such an endeavor of internationalization might be viewed within the dynamics between center and periphery, much along the same line that has been explored in analyzing the role of literary organizations in the processes of dissemination of the Catalan literary system (Gavagnin and Martínez Gil 2011, 8-9). We may recall, for instance, the passage that Jules Romains wrote in the pages of the Nouvelle Revue Française just after the end of the Great War. Barcelona, according to the French writer, was a cultural capital, fighting back a time of war through the institutional consolidation of national libraries, national museums, universities, an Institute for Catalan Studies and other initiatives (Romains 1920). Barcelona was second to Madrid, yet it was still a European city, and since the Great War, culturally powerful and relevant (Charle 2002, 32).

In 1929, we find then Estelrich busy organizing another venture started by his boss, the Conferentia Club, also conceived as a platform to expand this new humanism among Barcelona's bourgeoisie in an organized fashion (Balcells 2017, 42-48, 56-63; Gavagnin, [pp.]). If we look at the prospectus he wrote-the preface to the lectures collected in 1929-you can see how the idea of two capitals is clearly put forward: "Culture in the Peninsula"- -he writes- "is not centralized, as it is in France, not distributed, as it is in Germany and Italy; it is polarized in a few places, a few core centers". One core center was Madrid, the Spanish capital; the other was Barcelona. The activity of the Conferentia Club reflected this programmatic stance:

The nuclear center, the center of Barcelona, has been a kind of revelation for the majority of foreign congressmen who had come with centralized prejudices, forgetting that good thought is condensed not where there is an official political capital, but where there is a collective spiritual atmosphere. To this international elite, our Barcelona will count as the capital of the spirit, as a city of culture; and it will 
become something else than a revolutionary city, the old city of the conflict and bombs.

Madrid and Barcelona were the two branches of PEN in Spain. Many Catalan writers had participated in the effort to organize the Catalan branch of International PEN (a subsidiary of the London headquarters), as Jaume Subirana has studied: Joaquim Folguera most of all, in helping articulate the Catalan delegation of PEN with Central Branch in London, and Pompeu Fabra, who was the president, among many others. Still, Estelrich's role in organizing the intellectual Catalan delegation of international institutions, which he was particularly active in doing in the mid-twenties, is indisputable, as can be proved, for instance, by his involvement, back in 1927, in organizing the "grupement intellectuel de Barcelone" for the International Institute for Intellectual Cooperation within the League of Nations. ${ }^{3}$

Therefore, it should come as no surprise that when the PEN congress in Barcelona scheduled for June 1935 was approaching, Estelrich was the man in charge of organizing the meeting. He seems to assume further functions within the PEN Catalan branch while drafting the organization's statutes accompanied by a couple of appendices, which are ultimately the documents I have translated into English in the Appendices. In the draft preceding the statutes, Estelrich departed from the official recognition of Barcelona as independent site from Madrid as a triumph for the future of the PEN Club. He ascertains that "the international relationships offered the normal functioning of an entity such as our PEN Club can still be very useful for the spiritual expansion of Catalonia". ${ }^{4}$ He then suggested a scheme for a more permanent restructuring that would allow for ongoing efforts with the desire to benefit from present and future relationships with foreign writers and publishers' organizations.

In Article 2 of the statutes Estelrich drafted for the PEN Catalan delegation, he claims the aim of the organization: to promote friendship among all writers worldwide; to stimulate social life among men of letters of Catalonia; to contribute to the free exchange of international thought via the dissemination of Catalan literature; the conditions and applications for membership; the fees and obligations of members; the admission requisites; the functions of the General Board, which include the effort to expand Catalan literature and tend to the relationships between Catalan PEN and other PEN delegations, and finances; the dissemination of Catalan literature (in French, English, Italian and German) through anthologies of every literary genre (poetry, prose, novel and drama); the selection of works to be translated and published; the contacts with foreign magazines and publishing houses for publishing agreements; the distribution and organization of review services; the invitation of Conference speakers and experts to Barcelona and so on. As we may read in Article 17, all 
this work was to get started in 1934. As we learn from his personal documentation, Estelrich was member of the Directive Committee, together with Lluís Nicolau d'Olwer and Joan Puig i Ferrater. Such a committee was charged with putting forward a scheme to coordinate the dissemination of Catalan literature abroad, as we learn from Appendix B, and to promote contacts and agreements with foreign publishers and literary journals and magazines to publish Catalan authors and exchange copies.

The archive also contains twenty-three documents and letters concerning the meetings of the Catalan PEN Directive Committee usually held at the Ateneu Barcelonès, from May 1933 to February 1936, on various organizational matters of the 13th Congress of PEN in Barcelona such as the arrangements to organize invitations for speakers and participants: with H. G. Wells; with G. B. Shaw, who declined; with Azorín, as representative of Castilian literature, who also declined; in the archive, we can also find calls of meetings and the response to Marinetti's polemical declarations. ${ }^{5}$ Estelrich, moreover, seemed to be in charge of the organizing the Congress itself in June: he wrote an entire detailed program (see Appendix C), which culminated with a trip to Majorca, his homeland. Cultural tourism was certainly an element attracting the many speakers who came to Barcelona, invited by Expansió Catalana, the Conferentia Club or the PEN Club, to enjoy the beauties of an interesting capital, as well as to enjoy the Mediterranean weather and landscape.

All in all, the activity Estelrich carried out through the Catalan PEN mirrors his earlier campaign while working for Expansió Catalana back in the early and mid-twenties, aimed at organizing a translation policy for Catalan literature, developing a cultural network of writers and journalists, endowing Catalan writers abroad with visibility, and consolidating a network of cultural relationships with writers, philosophers and intellectuals sympathetic to the classical and humanistic cause in which he and his boss were so deeply involved. The two-capital strategy, so core to the national project both Estelrich and Cambó worked on enthusiastically throughout the twenties and early thirties, seemed to have been favorably received as far as some French intellectuals were concerned, as well as from a British perspective, as we learn, for instance, from the report Henry Seidel Canby wrote in the Saturday Review à propos of the PEN's 13th Congress. Here I reproduce the same passages from the report that Estelrich marked in pencil, which is also found in his PEN dossier:

Of Barcelona, that beautiful modern city built against a historical background, it is unnecessary to speak, except to say that the delegates profited a first-hand experience with Catalonia and the Calalonians, finding there and among them a rich and vigorous culture flourishing in a national minority, in close contact not only with Spanish, but also with the other European cultures, yet surprisingly 
original and fecund in its own right. [. . .] With visits to Montserrat, Tarragona, and Majorca, this interesting and enjoyable Congress ended. Much credit for its success was due to the Catalonian authors. Srs. Raurell, Manent, Benet, and many others, and to the President of the Catalonian Centre, himself recently out of prison where he had been confined as a result of the recent attempt of Catalonia to secure the rights of a federal state in the Spanish republic.

(Canby 1935)

The Spanish report published in Madrid newspaper $\mathrm{Ya}$ was not so sympathetic. In it, José María Alfaro regretted the absence of the "Spanish" PEN at the conference-although we know from the previous arrangements that a letter was sent to Azorín, who declined-and regarded the entire congress as a secessionist ploy:

Porque un solo punto quiero poner a la meditación de todos, ya que otros se enlazan a éste en lógico e inevitable encadenamiento. $\mathrm{Y}$ es el de la responsabilidad de los que dejan que la voz de España, brincando sobre nuestro idioma, quede ausente de aquellas próximas reunions, que en tierras que cantan en nuestra lengua misma, van a celebrar los escritores de todos los países. Y no ya solo lo de nuestra ausencia, porque hay más: que, en cambio, si han de acudir los que en "Pen Clubs" y fuera de ellos hacen del flameo una lengua-como bien acaban de demostrar en Barcelona-hincapié para sus maniobras secesionistas.

(Alfaro 1935)

\section{Notes}

1. "Estatuts del PEN Club de Catalunya"; "Estatuts interiors i programa d'expansió del Comitè Directiu del PEN Club de Catalunya"; "Reunió internacional dels PEN Clubs a Barcelona l'any 1935”. English translations are provided in Appendices, followed by a transcription of the original documents: Joan Estelrich's Archive (Fons Joan Estelrich), box "PEN Club (Catalunya)". Biblioteca de Catalunya. Barcelona.

2. See Comoedia in Gallica: https://gallica.bnf.fr/ark:/12148/bpt6k7650694c. item. This picture was most probably sent by Alfons Maseras, also involved in the campaign of Expansió Catalana, who was then Barcelona correspondent for Comoedia, working in close relationship with Estelrich (Corretger 1995, 241-42 and 2008: 109). On the relationship between Joan Estelrich and Gabriel Boissy, papers held at the Fons Joan Estelrich include a postcard (Triumphal Arch) and a sketch by Rino Anzi drawn à propos of the Mediterranean Congress in Monaco, in which both Boissy and Estelrich participated (L'Éclaireur de Nice, 1 November 1935).

3. See letter by Julien Luchaire, Director of the Institut de Coopération Intellectuel (Société des Nations, Paris, 18 February 1927), in which he asks Estelrich for a report on intellectual activity carried out in Catalonia. As for the 


\section{Sílvia Coll-Vinent}

constitution of a National Commission, since they were state based, Luchaire suggests to Estelrich to come to terms with the Junta para la Ampliación de Estudios in Madrid, then functioning as the Spanish National Commission.

4. Untitled and undated typed draft. Fons Joan Estelrich, box "PEN Club (Catalunya)". Biblioteca de Catalunya. Barcelona.

5. See documents and correspondence in Fons Joan Estelrich, box "PEN Club (Catalunya)". Biblioteca de Catalunya. Barcelona.

\section{Bibliography}

Alfaro, José María. I935. “Ante la reorganitzación del 'Pen Club’ español. De la insolidaridad de los escritores de España”. Ya, June 27.

Balcells, Albert. 2017. "El Conferència Club d'Isabel Llorach i Carles Soldevila entre 1929 i 1936 i la seva reconstrucció a partir de 1949”. Cercles. Revista d'Història Cultural, (20), 41-69.

Brion, Marcel. 1929. "La Catalogne et l'Europe”. Revue de Catalogne, 1 (March), 36-39.

Canby, Henry Seidel. 1935. “The P.E.N. Club Meeting”. Saturday Review, August $10,19$.

Charle, Christophe. 2002. "Introduction: Pour une histoire culturelle et symbolique des capitales europeennes". In Capitales culturelles, capitales symboliques. Paris et les expériences européennes: XVIII-XX, directed by Christophe Charle et Daniel Roche. Paris: Publications de la Sorbonne, 9-22.

Coll-Vinent, Sílvia. 20го. "Joan Estelrich i la cultura europea del seu temps". In Actes de les jornades d'estudi sobre Joan Estelrich (Palma-Felanitx 17, 18 i 24 d'octubre de 2008). Barcelona: Publicacions de l'Abadia de Montserrat, 37-58.

Coll-Vinent, Sílvia. 20I4. "Joan Estelrich, un humanista en temps convulsos". Cercles. Revista d'Història Cultural, 17, 77-100.

Coll-Vinent, Sílvia and Lluís Cabré Ollé. 2014. "Joan Estelrich, profeta d'un nou humanisme i agent cultural”. In Fènix o l'esperit de Renaixença, edited by Joan Estelrich. Barcelona: RBA-La Magrana, 9-43.

Corretger, Montserrat. 1995. Alfons Maseras: intel-lectual d'acció i literat. (Biografia. Obra periodística. Traduccions). Barcelona: Publicacions de l'Abadia de Montserrat.

Corretger, Montserrat. 2008. "El funcionament d'Expansió Catalana (1919_ 1928) contra la Dictadura". In Escriptors, periodistes $i$ crítics. El combat per la novel.la (1924-1936). Barcelona: Publicacions de l'Abadia de Montserrat, 99-125.

Estelrich, Joan. 1931. "Prefaci”. In Conferentia Club. Conferències de l'any 1929: vol. 1. Barcelona: Conferentia Club, 1-5.

Estelrich, Joan. 2012. Dietaris, edited by Manuel Jorba. Barcelona: Quaderns Crema.

Franquesa Gòdia, Montserrat. 2013. La Fundació Bernat Metge, una obra de país (1923-1938). Barcelona: Publicacions de l'Abadia de Montserrat.

Gavagnin, Gabriella. 2005. Classicisme i Renaixement: una idea d'Itàlia durant el Noucentisme. Barcelona: Publicacions de l'Abadia de Montserrat.

Gavagnin, Gabriella and Víctor Martínez Gil. 2011. "Presentació". In Entre literatures. Hegemonies i perifèries en els processos de mediació literària, edited by Gabreilla Gavagnin and Víctor Martínez Gil. Lleida: Punctum, 7-10. 
Graña, Isabel. 1996. "Pròleg. Joan Estelrich (1896-1958): presència, acció i intervenció en la cultura catalana del segle XX”. In Entre la vida i els llibres, edited by Joan Estelrich. Barcelona: Publicacions de l'Abadia de Montserrat, v-xxvii.

Jorba, Manuel. 2010. "Un arxiu per a unes memòries: el fons Joan Estelrich de la Biblioteca de Catalunya". In Actes de les jornades d'estudi sobre Joan Estelrich (Palma-Felanitx 17, 18 i 24 d'octubre de 2008. Barcelona: Publicacions de l'Abadia de Montserrat, 155-183.

Jorba, Manuel. 2012. "Cronologia”. In Dietaris, edited by Manuel Jorba and Joan Estelrich. Barcelona: Quaderns Crema, 595-609.

Massot i Muntaner, Josep. 2001. "Joan Estelrich i la propaganda franquista a París (1939-1942)". In Escriptors i erudits contemporanis. Segona sèrie. Barcelona: Publicacions de l'Abadia de Montserrat, 107-153.

Núñez Seixas, Xosé-Manoel. 2001. Entre Ginebra y Berlín. La cuestión de las minorías nacionales y la política internacional en Europa, 1914-1939. Madrid: Akal.

Romains, Jules. 1920. "Le mouvement des esprits en Catalogne". La Nouvelle Revue Française, 7, 619-622.

Subirana, Jaume. 2011. "Organitzacions literàries i mediació: el cas del PEN català". In Entre literatures. Hegemonies i perifèries en els processos de mediació literària, edited by Gabriella Gavagnin and Víctor Martínez-Gil. Lleida: Punctum, 59-79.

Subirana, Jaume. 2018. "El PEN y la internacionalización de la literatura catalana". In Construir con palabras: escritores, literature e identidad en Cataluña (1859-2019). Madrid: Cátedra, 155-178.

Ucelay da Cal, Enric. 1997. "Introducció: la crisi de la postguerra”. In Història de la cultura catalana, VIII: Primeres avantguardes 1918-1930, directed by Pere Gabriel. Barcelona: Edicions 62, 31-80. 


\section{Appendix A \\ Statutes of the PEN Club \\ of Catalonia}

Art.1.- An entity is constituted with the name of PEN CLUB OF CATALONIA, based in Barcelona and adhered to the International Association of Writers and Editors with the name of PEN CLUB OF LONDON.

Art. 2.- The aims of the PEN CLUB OF CATALONIA are the promotion of friendship amongst all writers worldwide; the stimulation of social life amongst men of letters of Catalonia; the promotion of comradeship amongst Catalan writers and the contribution, with the dissemination of Catalan literature, to the free exchange of international thought.

Art. 3.- Membership will be allowed to all Catalans complying with the following conditions:

a. To have published a fictional or critical book, original or translated, in Catalan.

b. To be proprietor or literary director of a publishing house.

c. To have published literary articles in Catalan, on a regular basis, in some newspapers.

Membership will also be open to foreign writers either residing permanently or accidentally in Catalonia, or belonging to another Center of the PEN CLUB, or who have applied for membership to another Center, and been accepted.

Art. 4.- The condition of protective member will be attributed to those willing to pay a quote not inferior to 50 pesetas. They will enjoy the same rights as members except for the right of voice and to vote within the Directive Committee. They will not be eligible for any of the committees.

Art. 5.- Members shall be required to pay an annual fee of 25 pesetas. Members are required to attend, at least, a supper from those organized by the Club during the year. Failing to attend, members will be required to pay a fine equivalent to the annual fee.

Art. 6.- Members will be entitled to attend meetings and suppers organized by the Club; to receive the publications; to attend the 
shows organized by the Club; to get information concerning colleagues, Centers, editors, etc. from abroad; to consult the works received by the Club from other Centers; to be taken into account in all manifestations of the PEN CLUB OF CATALONIA.

Art. 7.- Registering at the Club may be effective by an admission request or by invitation. The admission request should be addressed to the Club's President. It will be submitted to deliberations of the Directive Committee. Member registration will be produced as a result of a vote. To be admitted it is required the majority of votes in the Directive Committee.

For a writer to become member of the Club, it is required the proposal from a member of the Directive Committee, to be adopted by the affirmative vote of two-thirds of the votes cast. Invitation does no exempt members from payment of the annual fee.

Art 8.- Request of termination of membership should be done in writing, by letter addressed to the President.

The Directive Committee may agree to grant a member's leave at the suggestion of a member of the Committee, by the two-thirds of the votes.

Art 9.- A General Board Meeting will be called annually following eight days' notice. Each calling will be followed by an agenda in which a question-and-answer turn for members shall be included. All members have a voice and a right to vote and a right to put forward propositions on any matter concerning the aims of the Club. To reach the Board's agreement it is required the majority of votes casted by members attending the meeting. The Directive Committee will be in charge of implementing the agreements.

Art. 10.- The celebration of the extraordinary General Board Meeting may be called on the Directive Committee's initiative, following a request signed by more than ten members, accounting for the reasons which might have prompted it. The extraordinary General Board Meeting shall take place within the following two weeks.

Art. 11.- The subjects to be treated at the General Board shall be the following:

a. Registration and cancelation of members.

b. Club's finances.

c. Election of the Directive Committee.

d. Directive Committee's administration and ratification of agreements.

e. Election of the Honor Committee.

f. Any matters concerning the aims included in art. 2.

On no circumstances shall the General Board deliberate on political questions.

Art. 12.- The General Board shall elect the Directive Committee which shall include a novelist, a playwright, a poet, a journalist, an 
essayist, and a critic. The Board shall nominate amongst them the President of the Committee, who shall be the President of the Club. The Committee shall nominate the remaining positions in the first meeting after the election.

The positions within the Committee are re-electable.

This Committee shall manage the Club. It will take care of the finances. It will nominate the representatives of the Center in the international meetings of PEN Clubs. It will organize the meetings and ordinary suppers and the homages to visiting writers. It will be in charge of the dissemination of Catalan literature. It will take care of the relationships of the Club with other PEN Centers. It will draw the programs and organize the shows (one or two per year) in order to obtain funding for the Club. By the beginning of the economic year, it will submit the budget to be approved by the General Board. It will manage the Club's Offices and will nominate and dismiss their staff.

The General Board shall partially renew the Directive Committee every two years. For the first reshuffle it will elect three members; for the second, four, and so on and so forth.

Art. 13.- The General Board shall elect five writers, either members or non-members of the PEN Club, who shall form the Honor Committee. These positions are held for life and the General Board shall provide them as they remain vacant. Members shall not resign from them. Those who not being members are elected to be part of this Committee may resign in writing on answering back the written communication in which such requisite shall be specified. These Honor Committee members shall have the same rights as members except for the right to vote in the General Board meetings.

The Honor Committee may address the Directive Committee to submit the initiatives or guidelines which they might consider appropriate and may attend collectively or by a representative of any of its members the ordinary deliberations of the Directive Committee, to which they shall always be called, except for those meetings called to deliberate matters concerning the task of expansion of Catalan literature.

Art. 14.- The Club's sources of income are the following:
a. Membership's fees;
b. Patrons' donations;
c. Subsidies which might be obtained;
d. Benefits from shows organized by the Club;
e. Sales of the Club's publications.

Art. 15.- The Directive Committee shall draft every year a budget project which shall be submitted for approval to the General 
Board by the beginning of the economic exercise. Expenditures not included in the budget may not be verified. An extraordinary General Board's meeting may be called for the concession of extraordinary loans. A monthly supervision of expenditures shall be required. The general accounts shall be submitted for approval to the General Board.

Art. 16.- The dissolution of the entity shall be agreed by three quarters of the Club's members. If agreed, the goods of all sorts in possession of the Club shall be handed to the Casa de la Caritat of Barcelona, except for books, journals and magazines, which shall become property of the Biblioteca de Catalunya.

Barcelona.

\section{[Estatuts del PEN Club de Catalunya}

Art. 1.- Es constitueix, amb termini il-limitat, una entitat amb el nom de PEN CLUB DE CATALUNYA residenciada a Barcelona i adherida a l'Associació internacional d'escriptors i editors anomenada PEN Club de Londres.

Art. 2.- Les finalitats del PEN CLUB DE CATALUNYA són el foment de l'amistat entre tots els escriptors del món; estimular la vida social dels homes de lletres de Catalunya; crear un vincle de companyonatge entre els escriptors catalans i col-laborar en el lliure canvi del pensament internacional, amb l'expansió de la literatura catalana.

Art. 3.- Podran ésser socis tots aquells catalans que es trobin en una de les següents condicions:

a. Haver publicat un llibre d'imaginació o de crítica original o traduit, en llengua catalana.

b. Ésser propietari o director literari d'una editorial.

c. Haver publicat articles literaris en català en algun periòdic amb una certa continuïtat.

També podran ésser considerats com a socis els escriptors estrangers que residents, definitivament o accidentalment, a Catalunya pertanyin o hagin pertangut a un altre Centre del PEN CLUB o sense haver-hi pertangut demanin per ésser-ho i llur proposta sigui admesa pel Comitè Directiu després de l'informe que sobre el peticionari hagi emès el Centre del seu país.

Art. 4.- Podrà ésser soci protector qui, àdhuc sense ésser escriptor, pagui una quota anual no inferior a cinquanta pessetes. Tindrà els mateixos drets dels socis llevat de la veu i el vot en les Juntes Generals. No podrà ésser elegit per a integrar cap dels Comitès.

Art. 5.- El soci ve obligat a satisfer anualment una quota de vint-icinc pessetes pagadora per fraccions. És obligació del soci assistir, 
almenys, a un sopar dels que organitzi el Club durant l'any. Si no assisteix a cap, pagarà una penyora igual a una quota anual.

Art. 6.- Els socis tindran dret a assistir a les reunions i sopars que organitzi el Club; a rebre les publicacions que editi; a entrar, sense localitat, als espectacles que organitzi; a demanar i obtenir les informacions que desitgi respecte a companys, Centres, editors, etc. de l'estranger; a consultar les obres que rebi l'entitat dels altres Centres; a ésser tingut en compte en totes les manifestacions col-lectives del PEN CLUB DE CATALUNYA.

Art. 7.- L'ingrés a l'entitat podrà ésser per sol-licitud o per invitació.

La sol-licitud haurà d'ésser adreçada al Senyor President del Club. Serà sotmesa a les deliberacions del Comitè Directiu, el qual fallarà sense apel-lació. Cada ingrés de nou soci serà el resultat d'una votació. Per a ésser admès cal obtenir la majoria dels vots presents en la reunió del Comitè Directiu en la qual sigui presentada la sol-licitud.

Per a convidar un escriptor a esdevenir soci del Club caldrà que un membre del Comitè Directiu presenti la corresponent proposta la qual haurà d'obtenir les dues terceres parts dels vots dels membres del Comitè Directiu. Aquest convit no eximirà el soci del pagament de la quota.

Art 8.- Per a donar-se de baixa del Club caldrà fer-ho per lletra adreçada al President.

El Comitè Directiu podrà donar de baixa d'ofici a un soci quan ho acordi, a proposta d'un membre del Comitè, per les dues terceres parts dels vots de la totalitat dels seus components. Aquesta mena de baixes hauran d'ésser sotmeses a l'aprovació de la Junta General i necessitaran, per a ésser vàlides, el vot de la meitat més un dels assistents a la reunió.

Art 9.- Cada any serà celebrada una Junta General convocada amb vuit dies d'anticipació. A la convocatòria s'acompanyarà l'ordre del dia, en la qual es reservarà sempre un temps a preguntes i proposicions dels socis. Tots els socis hi tenen veu i vot. Podran presentar proposicions sobre qualsevol assumpte relacionat amb les finalitats del Club. Els acords de la Junta han d'ésser presos per majoria de vots dels assistents a la reunió. Els executarà el Comitè Directiu.

Art. 10.- La celebració de la Junta General extraordinària podrà ésser convocada per iniciativa del Comitè Directiu a proposta d'una sol-licitud signada per més de deu socis, explicant l'assumpte que la provoca. La Junta General extraordinària tindrà lloc, a més tardar, quinze dies després.

Art. 11.- Seran objecte de les deliberacions de la Junta:

a. Les altes i baixes dels socis.

b. Les finances del Club. 
c. L'elecció del Comitè Directiu.

d. La gestió del Comitè Directiu i la ratificació dels seus acords.

e. L'elecció del Comitè d'Honor.

f. Tots aquells assumptes que puguin ésser compresos en les finalitats expressades en l'art. 2.

Sota cap pretext la Junta General podrà deliberar mai sobre qüestions polítiques.

Art. 12.- La Junta General elegirà el Comitè Directiu integrat per un novel-lista, un dramaturg, un poeta, un periodista, un assagista i un crític. La Junta nomenarà d'entre ells el President del Comitè que serà el President del Club. Els altres càrrecs seran distribuïts pel mateix Comitè en la seva primera reunió després de l'elecció.

Els càrrecs del Comitè directiu són reelegibles.

Aquest Comitè dirigirà el Club. Curarà de l'administració de cabals. Designarà els representants del Centre a les reunions internacionals dels PEN CLUBS. Organitzarà les reunions i sopars corrents i els homenatges als escriptors que ens visitin. Serà l'encarregat de realitzar l'obra d'expansió de la literatura catalana. Curarà de les relacions del Club amb els altres Centres del PEN. Confeccionarà els programes i organitzarà els espectacles (un o dos a l'any) per a procurar cabals al Club. Sotmetrà, abans de començar l'any econòmic, el pressupost a l'aprovació de la Junta General. Regentarà les Oficines del Club, en nomenarà i n'acomiadarà el personal.

La Junta General renovarà parcialment el Comitè Directiu cada dos anys. Per a la primera renovació elegirà tres socis, per a la segona quatre i així successivament en les renovacions posteriors. Art. 13.- La Junta General elegirà cinc escriptors, socis o no del PEN CLUB, que formaran el Comitè d'honor. Aquests càrrecs són vitalicis i la Junta General els anirà proveint a mesura que vaquin. Els socis no poden renunciar-los. Els que no essent socis, siguin elegits per a formar part d'aquest Comitè, podran renunciar-hi per escrit responent a la lletra de comunicació que els serà adreçada i en la qual es farà constar aquest requisit. Aquests membres del Comitè d'Honor tindran els mateixos drets que els socis llevat del vot en les Juntes Generals.

El Comitè d'Honor podrà adreçar-se al Comitè Directiu per a exposar-li les iniciatives o directrius que cregui oportunes i podrà assistir col-lectivament o representat per qualsevol dels seus membres a les deliberacions habituals del Comitè Directiu a les quals seran sempre convocats, llevat les que siguin convocades per a tractar afers relacionats amb l'obra d'expansió de la literatura catalana. Art. 14.- Els ingressos del Club provindran:

a. de les quotes dels socis;

b. dels donatius dels socis protectors; 
c. de les subvencions que puguin ésser aconseguides;

d. de la recaptació en els espectacles que organitzi; i

e. de la venda de les publicacions que pugui editar.

Art. 15.- El Comitè Directiu redactarà cada any un projecte de pressupost que sotmetrà a l'aprovació de la Junta General abans de començar l'exercici econòmic per al qual hagi estat formulat. No es podrà verificar cap despesa que no estigui prevista en pressupost. En cas excepcional caldrà convocar la Junta General per a l'atorgació de crèdits extraordinaris. Es portarà un compte mensual de despeses. Els comptes generals de l'exercici seran sotmesos a l'aprovació de la Junta General.

Art. 16.- La dissolució de l'entitat haurà d'ésser acordada per les tres quartes parts dels socis del Club. En cas d'ésser acordada, els béns de tota mena que pugui tenir passaran a propietat de la Casa de la Caritat de Barcelona, excepció feta dels llibres i revistes que passaran a propietat de la Biblioteca de Catalunya.

Barcelona.] 


\section{Appendix B}

\section{Internal Statutes and Program of Expansion of the Directive Committee of the PEN Club of Catalonia}

The Statutes of the PEN CLUB OF CATALONIA entrust to the Directive Committee the mission of coordinating the expansion of our literature. These Statutes restrict the faculties exclusive of that Committee and set the general guidelines to be followed in this field.

Art. 1.- For the expansion of Catalan literature, the PEN CLUB OF CATALONIA shall disseminate abroad the development of the work by Catalan writers, according to the extension and intensity established by the Directive Committee.

Art. 2.- The Committee will contact editors, literary magazines, writers, etc., in order to reach agreements which might consider appropriate to carry out the functions which has been entrusted with. These agreements may be established on economic collaboration schemes, sale of copies, publishing exchanges, etc., etc.

Art. 3.- Funding for this activity will be allocated in the general budget of the PEN Club and no expenditure shall be carried out beyond the entries consigned for that purpose. The Committee has the faculty to manage private donations or corporative management either for publications or for specific activities. In those exceptional cases, the Committee will act on an independent basis and will be the absolute arbitrator of its actions as long the decisions are approved unanimously. Should unanimity fail, an agreement shall be obtained from the five members of the Honor Committee consulted on that particular purpose. If by any of both ways approval does not obtain three quarters of the votes issued by members attending the meeting, including members of both Committees, the matter shall be submitted to the extraordinary General Board in the case it might circulate. Should the matter not circulate, a Commission shall then be nominated, formed by two members of each Committee and presided by the donor or the donors' representative, who shall deal with the question as a last resort. The Commission's agreement will become effective without appeal, and shall not be a matter for discussion in the General 
Board. Should any member trespass such prohibition, he will be required to resign.

Art. 4.- The Center's Offices shall open a dossier for each publication selected by the expansion's service. Such dossier shall include all documents related. This documentation shall enjoy the protection of the Directive Committee and shall not be consulted without permission.

Art. 5.- The expansion's task to be carried out currently includes the production of modern works. A dissemination program shall be drafted to update it.

It is advised to publish, so far, in French, in English, in German, and in Italian:

1. An anthology of short-story writers.

2. An anthology of poets.

3. A volume of Catalan drama.

4. A history of Catalan culture including the scientific, artistic and literary movements.

5. Three or four novels.

Art. 6.- The program detailed above might be gradually developed as a general selection within Catalan culture. Meanwhile, it is advised to get stared the dissemination of three currant publications.

Art. 7.- The selection of works, both those currently on the market and those described above, will be made by a committee board nominated the Committee.

Art. 8.- There will be a committee board for each literary genre. These committees will be formed by three different ways and will last for the time necessary for the task to be accomplished. Once the task is finished, the committee board shall be dissolved. These tasks shall be rewarded, though modestly, insofar as it is possible.

Art. 9.- The committee boards nominated to carry out the selection shall organize their work by themselves, with no restrictions. Once an agreement is reached, they will draw a rapport (consigning particular votes, if necessary) accounting for their decisions and proposing to the Directive Committee the selected works to be translated.

Art. 10.- Once the selected works are accepted by the Directive Committee, it shall proceed to commission, from the expansion's service, the literal translation of the selected works in any of the four languages mentioned above. These literal translations shall be the basis for the marketing with publishers.

Art. 11.- The authors of selected works shall be kept updated about negotiations which shall be carried out on their name, and will sign the contracts when appropriate. In case the PEN Club 
subsidizes the publications, the Directive Committee will acquire the agreed number of copies and shall be in charge of their distribution. Such requirement shall not be included in the contract signed by authors.

Art. 12.- The Directive Committee will see to the appointment of interviews with foreign literary magazines, journals and publishers which might be interested in the publication of internationally reputed works, through an agreement which shall guarantee for Catalan writers an equal treatment with writers of other languages.

In magazines, journals and publications a service shall be established nationwide, to ensure publication in our newspapers of reviews about works promoted, literary reviews, etc. This service shall as well guarantee an equality of treatment in the long term.

Works referred to in the first paragraph will be commissioned by the Directive Committee at the suggestion of three members nominated for each genre. Should the foreign magazine or journal fail to proceed with payment, the PEN Club may assume it if our signatures on these magazines are deemed necessary.

Art. 13.- The dissemination service will take care of volunteer members of the PEN Club (selected by a Commission nominated by the Directive Committee) to make sure they get the necessary copies to proceed to review in Catalan newspapers or to spread literary movements, campaigns, news, etc. which might be of interest for other countries.

Catalan newspapers and magazines are advised to pay special rates for such reviews.

Art. 14.- The Directive Committee shall try to get invitations from foreign institutions addressed to reputed Catalan intellectuals to give lectures or courses on their specialization. Travel expenses shall be charged to the PEN Club if not covered.

Art. 15.- This dissemination service shall be run by the Committee and carried out by the Secretary and its administration staff.

Art. 16.- These internal statutes should be of private use and within the exclusive knowledge of the Directive Committee. This Committee should comply with them unless rectifications are introduced, which shall be approved by two thirds of the Committee's members. In the first meeting to be attended after being elected by the General Board, they shall be advised on the contents of these statutes and shall be given a copy of them.

Art. 17.- The management of this service is to get started in the year 1934. During the six months before it shall be organized; the commissions shall be nominated; the necessary relationships shall be established, and future agreements shall be formalized. 


\section{[Estatuts Interiors I Programa D'expansió del Comitè Directiu del PEN Club de Catalunya}

Els Estatuts del PEN CLUB DE CATALUNYA encomanen al Comitè Directiu la missió de coordinar l'expansió de la nostra literatura. Aquests Estatuts limiten les facultats reservades a aquest Comitè i assenyalen les directrius generals a les quals hauran d'ésser subjectades la seva actuació en aquest aspecte.

Art. 1.- Per al servei d'expansió de la Literatura Catalana, el PEN CLUB DE CATALUNYA donarà a conèixer a l'estranger el desenvolupament de l'obra dels escriptors catalans en l'extensió i intensitat que determinarà el Comitè Directiu.

Art. 2.- Per a aquesta finalitat, el Comitè es posarà en relació amb els editors, revistes literàries, escriptors, etc. que calgui, establint amb ells els convenis que estimarà oportuns per a la millor realització del seu comès. Aquests convenis podran ésser establerts a base de col-laboració econòmica, compra d'exemplars, reciprocitat editorial, etc. etc.

Art. 3.- Els cabals per a aquesta activitat seran els que es consignin en el pressupost general del PEN CLUB i no podrà fer-se cap despesa superior a les partides habilitades per a aquesta obra. El Comitè resta autoritzat, de totes maneres, per a gestionar donatius de particulars o Corporacions per a edicions o activitats determinades. En aquests casos, excepcionals, el Comitè actuarà amb plena independència i serà l'àrbitre absolut de les seves accions mentre les gestions siguin aprovades per unanimitat dels assistents a la reunió convocada expressament per a tractar d'aquests assumptes. Si no hi ha unanimitat, quedarà aprovat l'acord pel qual es decidiran els cinc membres del Comitè d'Honor convocats i consultats a l'efecte. Si d'aquesta manera cap de les dues propostes d'acord no obté les tres quartes parts dels votants que assisteixin a la reunió compresos els membres dels dos Comitès, la qüestió serà llavors portada a la Junta General extraordinària si l'assumpte pot ésser divulgat. Si es creu que no ho pot ésser, llavors es nomenarà una comissió integrada per dos membres de cada Comitè i presidida pel donant $\mathrm{o}$ un representant dels donants, que entendrà en l'afer en darrera instància. L'acord d'aquesta Comissió serà portat a efecte sense apel·lació, i no podrà ésser objecte de deliberació en Junta General. El membre que infringís aquesta prohibició deixaria de pertànyer a l'entitat.

Art. 4.- Les Oficines del Centre obriran un dossier a cada obra que elegeixi el servei d'expansió. En aquest dossier constaran tots els documents que hi facin referència. Aquesta documentació estarà sota la tutela del Comitè Directiu i no podrà ésser consultada sinó amb la seva autorització. 
Art. 5.- L'obra d'expansió a realitzar actualment ha de tenir en compte tot el volum de producció moderna. Per tant, cal esbossar un programa de difusió que posi aquesta tasca al dia, i anar-la desenrotllant.

Caldria, doncs, editar, de moment, en francès, anglès, italià i alemany:

1. Una antologia de contistes.

2. Una antologia de poetes.

3. Un volum recull d'obres dramàtiques.

4. Una història de la cultura catalana que comprengui el seu moviment científic, artístic i literari.

5. Tres o quatre novel-les.

Art. 6.- El programa descrit en l'article anterior podrà ésser desenrotllat paulatinament perquè es tracta d'una recopilació general de la cultura catalana. Mentrestant pot començar la difusió normal que consistirà en la tramitació de la publicació de tres obres, si fos possible, de la producció anual.

Art. 7.- La selecció de les obres tant les que vagin apareixent com les que han estat descrites per a formar el resum de la nostra cultura, serà realitzada per unes ponències que nomenarà el Comitè.

Art. 8.- Hi haurà una Ponència de selecció per a cadascun dels gèneres de literatura que hagin de seleccionar-se. Aquestes Ponències es composaran de tres maneres i duraran el temps que tardin a executar la tasca encomanada. Una vegada aquesta hagi terminat la Ponència quedarà dissolta. Per poc que sigui possible, i per modestament que es faci, la tasca de les ponències serà retribuïda.

Art. 9.- Les Ponències de selecció organitzaran llur treball de la manera que els plagui, sense cap limitació. Una vegada arribats a un acord, redactaran una curta memòria (fent constar els vots particulars si n'hi haguessin) donant compte del resultat de llurs estudis i proposant al Comitè Directiu l'adopció dels textos escollits per a ésser traduits.

Art. 10.- Una vegada acceptats pel Comitè Directiu es procedirà a encarregar al traductor del Servei de difusió la traducció literal de les obres a qualsevol dels quatre idiomes esmentats més amunt. Aquestes traduccions literals serviran de base per a comerciar les obres amb els editors.

Art. 11.- Els autors de les obres seleccionades seran tinguts al corrent de les negociacions que es faran en llur nom i seran els signants dels contractes quan aquests s'arribin a establir. En els casos de subvenció de l'edició per part del PEN CLUB, el seu Comitè Directiu sortirà com a adquirent del nombre de volums necessari, o responsable del lliurament de la suma convinguda, sense que aquesta condició formi part del contracte establert amb l'autor. 
Art. 12.- El Comitè directiu procurarà concertar amb revistes i publicacions estrangeres importants que editin treballs de celebració internacional, un conveni per mitjà del qual els autors catalans puguin intervenir amb tracte d'igualtat amb els escriptors d'altres llengües.

En les revistes i publicacions estrictament nacionals es procurarà establir un servei de reciprocitat que consistirà a publicar en els nostres diaris i periòdics treballs de divulgació, crítiques de llibres, etc. servei que ens donarà, a la llarga, igualtat de tracte.

Els treballs als quals fa referència el primer paràgraf d'aquest article, seran encarregats pel Comitè Directiu a proposta també d'una ponència de tres membres nomenada per a cada gènere de producció. Aquests treballs de col-laboració estrangera seran remunerats pel PEN CLUB en el cas que la revista no aboni honoraris i calgui no obstant, pel seu prestigi, tenir-hi les nostres signatures. Art. 13.- El Servei de difusió curarà de rebre i lliurar als socis del PEN CLUB que s'ofereixin (seleccionats per una Ponència designada a l'efecte i nomenats pel Comitè directiu si hi està d'acord) els llibres que es rebin per a la crítica corresponent als diaris catalans o les recensions dels moviments literaris, campanyes, notícies, etc. que puguin servir-se per a justificar l'interès del PEN CLUB per als altres països.

S'hauria de procurar que els diaris i revistes catalans abonessin per aquests treballs preus superiors a les altres colllaboracions, la diferència dels quals ingressaria a la caixa del PEN CLUB per a atendre aquest Servei.

Art. 14.- El Comitè directiu gestionarà que cada any almenys un intel-lectual català competent en una matèria determinada sigui convidat per alguna institució estrangera a donar una conferència o curset sobre una disciplina de la seva especialitat. Les despeses d'aquest viatge serien a càrrec del PEN CLUB en el cas que la suma abonada pel curset o conferència no bastés per a atendre les despeses de viatge.

Art. 15.- Aquest servei de difusió serà dirigit pel Comitè i executat pel Secretari i el personal d'Oficines a les seves ordres.

Art. 16.- Aquest articulat serà d'ús privat i de coneixement exclusiu del Comitè Directiu. S'hi atendrà absolutament a menys que introdueixi rectificacions que hauran d'ésser aprovades per les dues terceres parts dels membres del Comitè. A la primera reunió a la qual assisteixin els membres del Comitè acabats d'elegir per la Junta General, els serà donat coneixement del seu contingut i els en serà lliurat un exemplar.

Art. 17.- La gestió d'aquest servei començarà l'any 1934. Durant els sis mesos que manquen serà organitzat; seran nomenades les ponències; establertes les relacions necessàries, etc. deixant la formalització de tot contracte per a l'any 1934.] 


\section{Appendix C \\ International Meeting of PEN Clubs in Barcelona in the Year 1935}

Dates of Congress: 22nd, 23rd, 24th, and 25th June

- Attendance of organizers of the Barcelona Congress at the Scottish Congress to be celebrated in 1934, to learn about the organization.

- Processing of mail correspondence, three days after Scottish Congress' closure.

- Establishment of agreements with hoteliers in favor of delegates and members of foreign Centers.

- Free tickets for trains (from the frontier), buses, theatres, etc.

- Free stays for delegates and their wives for each Center.

- Publication of a prose, verse, art and archaeology anthology of Catalonia, to be offered to Congressmen.

- Publication of the Congress' Commemorative stamp.

- Translation of documents into each of the delegation's languages.

- At least two members of the PEN CLUB of Catalonia will be assigned for each delegation. They should be able to speak their own language.

- Books and tourist pamphlets shall be provided.

- Dates of Congress will be the 22nd, 23rd, 24th, 25th June 1935.

- First draft timetable:

21st: 4 p.m.: Reception of Congressmen at Palau de la Generalitat

6 p.m.: Opening of the Congress

10 p.m.: Concert offered by Orfeó Català

22nd: 10 a.m. Trip to Sitges

1 p.m.: Lunch at Terramar

4 p.m.: Visit to Tarragona

6 p.m: Second session in Escornalbou

9 p.m.: Dinner

11 p.m.: Pau Casals' Concert in Escornalbou's Gardens

23rd: 9 a.m.: Breakfast in Escornalbou

10 a.m.: Visit to Poblet and Santes Creus

2 p.m.: Lunch 
6 p.m.: Third session in Montserrat

Dinner and night in Montserrat

25th: Morning free

4 p.m.: Closing session.

Night: boat trip to Majorca

26, 27 and 28: Majorca

\section{[Reunió internacional dels PEN Clubs a Barcelona l'any 1935}

Dates del Congrés: 22, 23, 24 i 25 de juny

- Assistència de l'organitzador del Congrés de Barcelona al Congrés d'Escòcia celebrador l'any vinent de 1934 per a conèixer l'organització.

- Començar la tramesa de la correspondència de convit, tres dies després de clausurat el Congrés d'Escòcia.

- Establir convenis amb els hotelers a favor dels Delegats i membres dels Centres estrangers.

- Aconseguir de les companyies ferroviàries (des de la frontera), autobusos, teatres, etc. bitllets gratuïts de lliure circulació.

- Estada gratuïta dels delegats i llurs mullers per cada Centre.

- Editar un llibre antològic de prosa, vers, art, arqueologia, etc. de Catalunya per a oferir als Congressistes.

- Editar un segell commemoratiu del Congrés.

- Edició de tota la documentació relativa a cada delegació en la seva llengua.

- Cada delegació estrangera comptarà des de l'arribada amb dos o més socis del PEN CLUB DE CATALUNYA encarregats d'atendre'ls. Es procurarà que parlin l'idioma de la Delegació.

- Els seran facilitats llibres i follets de turisme.

- Les dates del Congrés seran les de 22, 3, 4 i 25 de juny de 1935.

- Primer projecte de calendari:

Dia 21: A les 4: Recepció dels Congressistes al Palau de la Generalitat A les 6: Inauguració de les sessions del Congrés

A les 10: Concert de l'Orfeó Català.

Dia 22: A les 10 Sortida a Sitges

A la 1: Dinar a Terramar

A les 4: Visita a Tarragona

A les 6: 2a sessió a Escornalbou

A les 9: Sopar

A les 11: Concert Pau Casals als jardins Escornalbou

Dia 23: A les 9: Esmorzar a Escornalbou

A les 10: Visita Poblet i Santes Creus

A les 2: Dinar 
A les 6: 3a Sessió del Congrés a Montserrat

Sopar i dormir a Montserrat

Dia 25: Lliure el matí

A les 4: Sessió de clausura

Nit: Sortida cap a Mallorca

Dies 26-27 i 28: Mallorca] 


\section{The Spanish Center of the International PEN Through Its First Sumiller}

From a Project of International Solidarity to an Expression of the Tensions of the Literary Society of Madrid (1922-1924)

\section{Laurie-Anne Laget}

The history of the beginnings of the Spanish Center of the International PEN has already been the subject of excellent studies by Brigitte Adriaensen and Álvaro Ceballos Viro (2011), as well as Raquel Sánchez García (2008) and Miguel A. Iglesias (2003). These studies have revealed that the story of the first Madrilenian Club was troubled, to say the least. It was founded shortly after the London Club, to serve an ideal of internationalization of the Spanish culture, but its development was complicated: the first board of directors was only in place for about two years, until Azorín was replaced by Ramón Pérez de Ayala; then, the Club disappeared for almost a decade. In this chapter, I will focus on how the Club was received in Spain and how the debates around it show the struggles inside the Spanish literary field. What began as an international collaborative project ended by revealing the conflict around the literary hierarchies in the Spain of the time. ${ }^{1}$

This might seem odd because a few writers' associations were born in Spain precisely in 1922: the Catalan Section of the International PEN had its founding dinner on April 19th, a couple of weeks before the Spanish PEN foundation, and the Association of Escritores Españoles was created that same year to defend the rights of the Spanish authors. It seems that the idea of building some form of literary network was taking shape at the time in Spain. In this context, the foundation of the Madrilenian PEN Club could be considered as part of this intent to build a network that served the interests of Spanish writers by creating an international network for them-understanding the term "network" as an opportunity to take part in the dynamic of cultural exchanges from a perspective of horizontality that would allow us to revise the traditional positioning of Hispanic modernity as peripheral. At least, this is how the Spanish Center of the International PEN based in Madrid was presented in theory. 
However, I will show that, in practice, the Madrilenian literary scene was opposed both to adopting this idealistic vision of international relationships between writers and to the possibility of creating a shared transnational space. I'll explain why by using the figure of Ramón Gómez de la Serna, the first-and only-sumiller of the Spanish PEN, whose trajectory perfectly illustrates the first years of existence of the Spanish Center based in Madrid, as well as the way this participation in the PEN International both depended upon and illustrated how the Spanish literary field worked.

\section{Ramón Gómez de la Serna, a Sumiller with an International Profile Able to Serve a Project of Intellectual Solidarity}

Analyzing the first Spanish PEN through the case of its sumiller seems quite appropriate because of the profile of Ramón Gómez de la Serna: in 1922, when the first Spanish Center of the International PEN was founded, Gómez de la Serna had already successfully achieved his professionalization as a journalist and writer by becoming the nodal point of a social network of contemporary authors, editors-in-chief, artists and publishers in Spain. ${ }^{2}$ The soirées he organized at the Café Pombo or the Lardhy restaurant (tertulias and banquets to commemorate literary events) gathered part of Madrilenian literary society and draw considerable attention to him. In this sense, Ramón Gómez de la Serna was particularly sensitive to the importance of communicative tools and performing skills for any modern man of letters. That predisposed him to understand what was at stake in a project such as the one of the International PEN, precisely at a time he was expanding his network at an international level in order to consolidate his position as a well-known public figure of the literary scene.

The first crucial moment in this process happened almost by chance: it was the release of his first book, Greguerías, in 1917, which Azorín reviewed in positive terms. Azorín was then a prestigious figure who could, as a critic, mark the value in the literary field of another writer. When he published a three-page article in $A B C$ (at the time one of Spain's best-distributed newspapers), Azorín became the one responsible for boosting Ramón Gómez de la Serna's career for good and opening for him the door of an internationalization process. Indeed, Valery Larbaud discovered his prose thanks to Azorín's article and immediately met the Madrilenian at the Café Pombo to ask for his authorization to translate his prose into French. This meant Ramón Gómez de la Serna was able to access the French market and numerous journals, provided by a wellknown and valued writer, critic and translator. During the following six years, Larbaud published numerous articles on Gómez de la Serna in the French press: for instance, in Littérature, the journal of the Surrealists, as well as in Les Écrits Nouveaux, Les Nouvelles Littéraires and La Revue 
Européenne, among others. Thanks to that introduction with a lot of fanfare in France, Larbaud was relayed by Jean Cassou, who became Ramón Gómez de la Serna's new translator and literary agent: Cassou translated La viuda blanca y negra (1924), which inaugurated the wondrous contract Gómez de la Serna signed with the publishing house Simon Kra, who guaranteed to publish some fifteen of his titles in ten years. ${ }^{3}$

By then, Ramón Gómez de la Serna had fully entered into the dynamics of internationalization. As part of this process, he made repeated trips to Europe (more precisely to Paris-where he presented several of the translations of his books-but also London and Naples, as well as Switzerland and Portugal and, later on, to Berlin). ${ }^{4}$ At the same time, he started to be published occasionally in the French, British or Italian press and, a few years after the first translations of his novels into French, the Italian publisher Corbaccio also started to translate a whole series of Gómez de la Serna's novels. ${ }^{5}$

There is no doubt that the foundation of the International PEN, in England, precisely at that time of intense international activity, was, for Ramón Gómez de la Serna, an opportunity to expand his network and access new markets.

It is likely that, because of his friendship with Azorín-who would become the first president of the Spanish Center of the International PEN-and, as a result of his self-promotion strategy through the activities he developed in his Pombo circle: tertulias, banquets and receptions in honor of foreign artists and writers, Ramón Gómez de la Serna was appointed as the sumiller of the first Spanish Club founded on July 5th, 1922, only eight months after the British seat was founded.

The version he gave in retrospect (in 1935) of the founding of the Spanish PEN is the following:

Un día, ya en la tregua de después de la guerra, llegaron unos ingleses rubios y altos para que se fundase en Madrid un Pen Club.

Entre Azorín y yo compusimos un nuevo teatro del Pen Club y citamos a la primera función en Lardhy. ${ }^{6}$

Traduiimos por "poetas, ensayistas y novelistas" la sigla. [. . .]

Imprimimos un libro de señas en que fueron inscritos todos los escritores españoles, figurando Palacio Valdés junto a los más jóvenes creacionistas. [...]

Se gozaba una cosa que está sobre rencillas, escuelas y otras zarandajas: la contemporaneidad. Porque iquién sabe lo que va a hacer de todos la posteridad ni a quién va a colocar delante, detrás o en ningún sitio!

(Gómez de la Serna 1935, 7)

Here, Gómez de la Serna defends the intellectual project of the International PEN, which he sums up in the equalizing idea of contemporaneityanother way to formulate the idea of horizontality that underlies the 
notion of networks-and provides a representation of unity of the Madrilenian writers reunited in the Club, spanning from Palacio Valdés to the creacionistas.

The chronological spectrum of the Club members is certainly large: for the year 1922, it brings together personalities from the literary scene, academics and diplomats born between 1842 (Enrique de Leguina) and 1903 (José de Ciria y Escalante), although most of the members are, in fact, writers born between 1870 and 1890 (72 out of 115). Absolutely all of them are either journalists or writers (35 are linked to $A B C$ or Blanco $y$ Negro and another 25 to the Orteguian constellations of El Sol and La Voz). Some ten had been part of the board of directors of the Ateneo. Half of the youngest members ( 10 out of 21 ) assisted on a regular basis to the Ramonian tertulia of Pombo.

Based on these facts, I claim that there is a networking logic at work within this first list of Club members-the same networking logic which, de facto, animated the International PEN, as Ramón Gómez de la Serna observes:

Cambiábamos impresiones sobre el más allá y nos sentíamos como rotarios de la literatura, engranada nuestra pequeña rueda dentadamejor sería decir "incisiva"-con la gran rueda internacional. Todos parecíamos recibir noticias de más allás diferentes. Estábamos durante toda la comida en comunicación directa con Inglaterra.

Nos sentíamos realizando un acto mundial.

(Gómez de la Serna 1935, 7)

Despite his final comment (Spain is only a "small wheel”), Ramón Gómez de la Serna, as the Club sumiller, adopts the rhetoric of internationalization as a promise of "direct communication", that is to say, the entrée into a shared symbolic space: this is what emphasizes the image of the gear and the last sentence of the text.

What Gómez de la Serna is doing is echoing the principles formulated in the announcement of the founding of the Club:

Semejante a los de Londres, París, Bruselas se ha constituido en Madrid un centro literario con la única misión, y no es poco, de fomentar las relaciones de camaradería entre los profesionales y los amigos de las letras. ${ }^{7}$ [. . .] Estará en comunicación con sus similares del extranjero. [. . .] Organizará comidas de confraternidad, a las que asistirán los socios y a las que serán invitados los hombres de letras de otros países. [. . .] Será algo que sentará bien a la vida intelectual, dándole cordialidad y una mayor cohesión de clase, de oficio y de gremio.

([Anonym] 1922, 14)

The first list of club members, published in 1922, was also preceded by a statement on the objectives of the Club which, as we would expect, 
insisted on the international logic of "recíproco conocimiento de las literaturas":

Los socios de un Club son socios de todos los demás. [. . .] Se ruega a los socios de los P.E.N. que manden sus libros a los Secretarios de los Clubs extranjeros. Persíguese con esos envíos, el dicho conocimiento mutuo de los escritores y de las literaturas.

(Lista provisional de socios del P.E.N. 1922)

Among the activities organized by the Spanish PEN in order to fulfill that logic of bringing together the literary family, there were several banquets advertised in the press: Melchor de Almagro San Martín, a member of the board of directors of the first Spanish PEN, mentions at least six banquets throughout the first year, as well as the participation of Gregorio Marañón and Ramón Pérez de Ayala —as the representatives of Spain—in the 1922 London International Congress. The first reception held for an international figure was the one for Gabriela Mistral in 1925. As for Ramón Gómez de la Serna, the Cercle Littéraire International (the French Center of the International PEN) had invited him twice to Paris, in 1925 and 1928, two occasions on which he honored the reception that had been expressly organized.

However, a meticulous reading of Ramón Gómez de la Serna's account of the founding of the Spanish Club forces us to refine this first ideal picture of how it worked:

¿Qué iba a pasar cuando se viesen reunidos escritores a los separaba el género, la inspiración y la enemistad?

Nunca se había intentado en España una cosa así, y la primera experiencia podía ser grave. En el viejo comedor del restaurante prócer, academia de fuentes y bandejas de plata, se sentaron pacíficamente los más diversos escritores.

[...] Hubo una sobremesa larga, hasta con discursos.

Después de formaron grupos confraternizadores y nos reunimos en parejas deambulatorias con tipos que de otra manera no bubiésemos tratado nunca.

Se repitieron los banquetes y se reunió la necrópolis con la casa de maternidad.

(Gómez de la Serna 1935, 7)

The way Gómez de la Serna presents the founding of the Spanish PEN is striking, as it is associated with an unprecedented challenge. Far from the previous image of unity, he insists upon the heterogeneity of the first club members ("escritores a los que separaba", "los más diversos escritores", "tipos que de otra manera no hubiésemos tratado nunca", and the last striking image of the contrast between "la necrópolis" and "la casa de maternidad"). 
Even in the statement of the first list of club members, the following sentence is noteworthy: "El mejor medio de afirmar el imperio de la Inteligencia, es colocar la Inteligencia por encima de las rencillas, pasiones y banderias" (by the way, the exact same expression Gómez de la Serna will use later, in 1935, when evoking the beginnings of the Club). This reminder of the "quarrels" and "rivalries" is particularly significant. Although the initial ambition of the Spanish Club was "to bring together the entire literary family", "giving it cordiality and a greater cohesion of class, office and profession", the troubled history of the first Center, in the twenties, revealed that what Spaniards perceived in that Club had more to do with the inherent tensions within the Spanish literary field rather than with an international collaborative project.

\section{Revealing the Conflicts Around the Symbolic Value of Writers and the Realities of Madrid's Literary Sociability}

La vida literaria y artística de Madrid tiene, naturalmente, su juego, su combate, su politica. Su política propiamente literaria, al margen de la nacional.

José Moreno Villa

Since its very first year of existence, the Spanish Club received strong critics in the press, like this one:

Se reunió a comer por vez primera-era su institución en España-, y a los postres se escindió, según parece. Se resquebrajó como un flan en que ha caído agua o como un pastel excesivamente seco.

Y esto, ¿por qué razón? [. . .] el motivo de la división es cosa de raíz, entra en el sutilísimo terreno de la psicología y de la sociabilidad de los literatos. El literato, ¿es un ser sociable? Nosotros creemos que sí. [...] Pero precisamente porque cada artista que tiene personalidad enfoca los problemas de arte de un modo completamente distinto, resulta que la convivencia entre literatos se hace imposible a no serdada la especial idiosincrasia de los nuestros-en un pugilato horrible de arañazos, mordiscos y golpes.

(Blanquerna 1922, 1)

The last image, of the "pugilato horrible de arañazos, mordiscos y golpes", seems the exact opposite of the cordiality the promoters of the International PEN wished for. There is an obvious contradiction-one in several-between the ideas of sociability or solidarity and of competition and individualism.

Over the following months, the debate on the Spanish Club would precisely crystallize in terms of the lack of coherence within the profession. 
Brigitte Adriaensen and Álvaro Ceballos Viro observed that several writers started to doubt the viability of the banquets and drew attention to the function of class exclusion that the price of the menu could have (Adriaensen and Ceballos Viro 2011, 261). For instance, Alberto Insúa wrote:

Como Azorín habia querido, y a mi parecer con razón, que las reuniones del PEN Club tuviesen un aire aristocrático-el de la "aristocracia de las letras"-, que se guardase en ellos la tenue, que dicen los franceses, celebrábanse los banquetes en Lhardy o en algún otro restaurante relativamente caro para la época. Pero no faltaban los club-men que hubiesen preferido, por más económicos, a los filetes de lenguado à la Meunière y las pechugas a la Villeroi, el cochinillo y el cordero del horno de Botín y la tortilla de patatas del café de San Isidro. Azorín no prestaba atención a las protestas, nunca estridentes, de los chambergos, las pipas y las chalinas. No simpatizaba con la bohemia. Así, pues, los ágapes mantuvieron su buen tono, y si se hubieran celebrado de noche habrían exigido el smoking o el frac.

(Insúa 1959, 364)

Even more explicitly, Rafael Cansinos Assens used that argument to justify the fact that he never took actively part in the club, and this allows us to understand that beyond the economical aspect, admission or nonadmission among the members of the Club had a symbolic dimension:

Se han inscrito en él nuestros escritores de primera fila . . Lo cual es una razón para que yo no lo haga .. . Me repugna todo lo que signifique reglamentación de la Literatura, pues tiende a crear castas $y$ en adelante, habrá la aristocracia literaria del Pen Club . . . condicionada como la antigua del Ateneo, por una cuota que muchos no podrán pagar.

(Cansinos Assens 2005, 329)

This leads us to understand that the discussions about the Madrilenian Club can shed some light on the positions that different writers of the Spanish literary scene would hold. Cansinos Assens' way of insisting on the "primera fila", the "castas" or the "aristocracia" portrays the Club members as an exclusive and elitist group, and the foundation of the Spanish Center of the International PEN ended up revealing conflicts about the symbolic value of writers and the realities of Madrid's literary sociability.

In fact, it is interesting to remember that, in the months following the creation of the first Spanish PEN, a polemic on the use of banquets raged. A League Against Banquets (Liga contra el banquete) was created 
subsequently and explicitly against Ramón Gómez de la Serna. The polemic lasted four months, during which eleven banquets were organized and largely reported in the press, one of which was organized by the Spanish PEN.

Mariano Benlliure y Tuero, the founder of the League, condemned the way the Madrilenian literary scene had, according to him, turned into a "sociedad de bombos mutuos". The arguments justifying this opposition to the "microbio de la banquetomanía" were these: the dissemination strategy primed over the literary quality of the work; the fear of "making enemies" obliterated the writer's independence; and the critic failed to accomplish its purpose, as it always appeared to be too unanimous. Ramón Gómez de la Serna replied immediately by announcing a "banqueting month" (April) that opened, precisely, with the PEN Club "confraternity act".

It is quite interesting to see how Ramón Gómez de la Serna changed the announcement of this act into a declaration of intentions:

Somos partidarios de los banquetes. No se puede fundar una Liga contra los banquetes, como no se puede fundar una Liga para no saludar a los amigos.

Cada vez estamos más convencidos que es el acto más completo de homenaje, y si no estuviésemos convencidos, nos hubiera cerciorado el primer acto que han realizado los antibanquetistas: ;un té de honor! Ha sido gracioso; se han sentado todos los comensales como en los banquetes; ha costado diez pesetas y sólo han tomado té.

(Gómez de la Serna 1923, 1)

Seeing in the "tea of honor" a parody of a banquet, Ramón Gómez de la Serna reminded his anti-banquet readers that "the seat next to the great man [at the homage table] is already taken". Obviously, the issue of taking sides became more important than the banquet in itself. And those sides were clearly made visible because the national press regularly published lists of the members of the League versus the attendants to the repeated banquets organized during the "banqueting month" of April $1923 \ldots$

We are obviously facing a system of power and Ramón Gómez de la Serna did not hide his position of strength in that respect:

Yo, que soy especialista en banquetes y lo que me distingue en su preparación es la rapidez en tomar mis medidas, elegir la oportunidad de la fecha y del sitio, encargado también de los del P.E.N., que preside Azorín y del que soy sumiller, eso me ha acabado de dar experiencia.

(Gómez de la Serna 1999, 445) 
His position as sumiller of the PEN sanctioned the Ramonian monopoly and was the cause of the violence of the attacks:

Fui objeto de una agresión por preparar mis honestos banquetes. Fue una de esas escaramuzas en que aprovechando cualquier cosa los que estaban envidiosos, suspicaces, salieron a la palestra.

(Gómez de la Serna 1999, 446)

Beyond the symbolic quarrel, what is at stake here concerning the League Against Banquets is an attempt at redefining the literary field through dissidence. It is extremely clear, indeed, that the strongest critical voices are heard from the margins of the scene. Despite numerous biographical coincidences with Ramón Gómez de la Serna (both were born in 1888 , both had a career in law and both dedicated themselves to literature at an early age, initially as journalists), Mariano Benlliure y Tuero, head of the League, did not take part in Azorín or Gómez de la Serna's circle. This is why he tried to create a new space for socializing, with the ambition to dominate, and why he rejected the power inherent to the banquet of symbolic assignation of a position in the literary scene.

In doing so, however, he challenged the established order. To borrow Pierre Bourdieu's expression, without a proper acknowledgement of the Rules of Art and its stakes, the struggle is vain. As Bourdieu puts it:

Chaque nouvel entrant doit compter avec l'ordre établi dans le champ, avec la règle du jeu immanente au jeu, dont la connaissance et la reconnaissance (illusio) sont tacitement imposées à tous ceux qui entrent dans le jeu. La pulsion ou l'impulsion expressive [. . .] doit compter avec l'espace des possibles, sorte de code spécifique, à la fois juridique et communicatif, dont la connaissance et la reconnaissance constituent le véritable droit d'entrée dans le champ.

(Bourdieu 2006, 444) ${ }^{8}$

In this sense, is very significant how the polemic ended: the debate is concluded with ... a banquet in honor of Luis Bagaría, a cartoonist who was himself opposed to the banquets and became a key figure of this controversy by systematically mocking them in his work. In his speech of gratitude to the banquet, Bagaría was left without option and had to explicitly recognize:

No soy muy amigo de los banquetes; es más, soy enemigo de esa clase de fiestas que cien veces he pretendido criticar con mi lápiz. Pero la vida está llena de contrasentidos; y por uno de ellos, estoy en estos instantes [...] bajo el influjo de una vanidad satisfecha; estoy, acaso, 
en el momento más dichoso de mi vida, gracias precisamente a un banquete.

By confronting one of the internal mechanisms of how the field constitutes itself, antibanquetism was doomed to failure, which comforted the state of the field and confirmed dominant positions.

The logic of group association in the case of the Spanish PEN offers a very similar dynamic to that of the controversy about banquets. There is a board of directors (equivalent to the organizing committee of the banquets), whose members are chosen amongst the agents of the literary field that already enjoy a symbolic capital: Azorín—after a failed attempt in 1913-was about to become a member of the Real Academia (in 1924), and Ramón Gómez de la Serna already had an international profile and was also a recognized organizer of literary events. As far as the Club members are concerned, they were made visible by appearing in the list of Club members first published in 1922 and updated in 1923 (respectively titled Lista provisional de socios del P.E.N. and Lista rectificada de socios del P.E.N.), the same way the attendants of the banquets were named in the press and, by doing so, were recognized as socially and culturally "distinguished" agents of the literary field.

That's the reason, when José Montero Alonso interviewed Ramón Gómez de la Serna in 1926 and asked him whether an Association of Writers in Spain would be possible and relevant, he received a drastically negative answer, which explicitly echoed the 1923 banquet controversy:

Por haberlo visto de cerca sé que no puede llegarse a resultados positivos . . . Las cuestiones de tendencia, de bandería, de amor propio, surgen inmediatamente. Un Comité directivo, sea el sea, engendra en seguida el descontento en grupos que aspiran a su vez a convertirse también en Comités directivos.

(Montero Alonso 1926, 6)

In other words, the Spanish PEN conceived itself as a space for solidarity, but that solidarity was confronted by a literary field in constant expansion and mutation-because of the new readers and new markets that had been rising since the 1910s (Mainer 2004, 181-218). The Madrilenian literary field seemed too violent to be able to enter a dynamic of confraternity and overcome the tensions that caused its division. Thus, the international logic of "conocimiento mutuo" underlying the foundation of the Spanish Club can be interpreted, in the end, only in national-if not local-terms: in Spain, and particularly in Madrid, the PEN Club was understood as a way to give visibility to agents already dominating the literary field, instead of promoting new agents at an international level. 
In this sense, the case of the Madrilenian PEN club invites us to rethink the role of literary institutions. Although they are perceived as spaces of solidarity, in reality they are a symbolic space used to position oneself within the literary field (national, or international in the case of the PEN).

As a consequence, the analysis of the Spanish case also induces us to revise the approach to how networks work. At first, we associate networks with a cartographic representation of relations. We cannot, however, forget that this map we are drawing has its own hierarchy at different levels. For instance, if we recall the profile of the Madrilenian Club members, 72 out of 155 are aged between 40 and 50 years old, that is to say that they are not what you would call "young" writers (only three of them can be associated with the avant-garde, such as the ultraista movement). As a consequence, they are all immersed in a defensive logic to hold their dominant or, at least, established position in the field. The horizontality we first associated networks with is, therefore, an optical illusion.

All in all, networks are nothing more than a geography of power, and the failure of the first Madrilenian Club can only be explained because of the relationships of power that made it impossible for this space of international exchange to work.

\section{Notes}

1. I'm talking here about the local literary field-and not about the national one-because the case of the Catalan section of the PEN followed a very different dynamic, as the paper of Silvia Coll-Vinent demonstrates.

2. I dedicated a book to the first steps of Ramón Gómez de la Serna's literary career (Laget 2012).

3. In reality, only five titles were translated into French: La veuve blanche et noire (1924), Le docteur invraisemblable (1925), Le cirque (1925), Gustave l'incongru (1927) and Ciné-Ville (1928).

4. Most of these trips are mentioned in a vivid way in the following chapters of Ramón's autobiography (Gómez de la Serna 1948): XLIII, VI (Paris), LXIV (Portugal), LXV (Naples), LXVI, LXXI (Paris).

5. Seven titles were published in only two years' time: Il dottore inverosimile (1927), Campionario, Circo, Seni, Gustavo l'incongruente, Il casino delle rose (1928) and Grand Hôtel (1929).

6. There is another version of the founding of the Spanish Club: the one Melchor de Almagro San Martín gave in 1935, when the second Spanish PEN was about to be founded in Madrid. In this version, the former member of the board of directors of the Spanish Club identifies Ramiro de Maeztu as the real founder. At the time, Maeztu had been living in London for several years "en trato $y$ comunión con los escritores londinenses". On the contrary, the role played by Ramón Gómez de la Serna is mostly symbolic, which is something interesting because it points out the strategical interest of linking the Ramonian persona with the newly founded Club: "Deseoso el comité de unir a su labor la figura singular de Gómez de la Serna, patriarca de la cripta pombiana, creó para él un cargo a medida, donde pudiese mostrar sus grandes condiciones de simpatía y organización, que se bautiza con el arcaico nombre de sumiller. Justo es confesar que su primero y único titular supo enaltecerlo. El viejo P.E.N. recuerda 
agradecido a su sumiller o chambelán de antaño" (Almagro San Martín 1935, $18)$.

7. This first sentence proudly declares that Madrid has entered into the dynamics of the European cultural capitals of that time and that Spain now belongs to a "short list" of fifteen countries, members of the PEN international solidarity.

8. Translation by Susan Emanuel: "Each new entrant must reckon with the established order in the field, with the rule of the game immanent in the game, and knowledge and recognition (illusio) of the game are tacitly imposed on all those who take part in it. The expressive drive or impulse [. . .] must take account of the space of possibles, a sort of specific code, simultaneously juridical and communicative, whose cognition and recognition constitute the veritable right of entry into the field" (Bourdieu 2016, 270).

\section{Bibliography}

Adriaensen Brigitte and Álvaro Ceballos Viro. "De kortstondige lotgevallen van de PEN-clubs tijdens het interbellum in Spanje." Nederlandse Letterkunde 16(3), December, 2011, 258-275.

Almagro San Martín, Melchor de. "El P.E.N. Club español despierta de su letargo." Ahora, November 15, 1935, 18-19.

Anonym. "Un Club literario.” ABC, May 6, 1922, 14.

Anonym. "El acto de anoche en el Palace. Un homenaje nacional al caricaturista Bagaría.” El Sol, May 4, 1923, 4.

Blanquerna. "De la sociabilidad, los escritores y los espejos." La Correspondencia de España, July 11, 1922, 1.

Bourdieu, Pierre. Les règles du jeu. Paris: Seuil, 2006 [1992].

Cansinos Assens, Rafael. La novela de un literato. 3. Madrid: Alianza Editorial, 2005 [1995].

Gómez de la Serna, Ramón. “La vida. Valery Larbaud.” El Sol, April 8, 1923, 1.

Gómez de la Serna, Ramón. "Los Pen Club.” Ahora, June 15, 1935, 7.

Gómez de la Serna, Ramón. Automoribundia (1888-1948). Buenos Aires: Sudamericana, 1948.

Gómez de la Serna, Ramón. La Sagrada Cripta de Pombo. Madrid: Visor, 1999 [1924].

Hernández Cano, Eduardo. "Campo literario y formación del canon. Algunas notas sobre los años 1919-1924.” in Actas del I Congreso Internacional de Filología Hispánica, edited by José Antonio Calzón García et al., 547-558. Oviedo: Ediciones de la Universidad de Oviedo, 2008.

Iglesias, Miguel A. "El segundo P.E.N. Club madrileño, una sociedad de intelectuales de derechas en la crisis de los años treinta.” RILCE 19(1), 2003, 87-108.

Insúa, Alberto. Memorias. III. Amor, viajes y literatura. Madrid: Tesoro, 1959.

Laget, Laurie-Anne. "'La cuestión palpitante y manducante': los ecos de la vida literaria en la prensa a través de la polémica de los banquetes (1923)." in Literatura hispánica y prensa histórica (1875-1931), edited by Javier Serrano Alonso and Amparo de Juan Bolufer, 823-837. Santiago de Compostela: Universidade de Santiago de Compostela, 2009.

Laget, Laurie-Anne. La fabrique de l'écrivain. Les premières Greguerías de Ramón Gómez de la Serna. Madrid: Casa de Velázquez, 2012.

Lista provisional de socios del P.E.N. (Poetas. Ensayistas. Novelistas). Club internacional de escritores. Madrid: Tipografía de Nieto y Compañía, 1922. 


\section{Laurie-Anne Laget}

Lista rectificada de socios del P.E.N. (Poetas. Ensayistas. Novelistas). Club internacional de escritores (Noviembre de 1923). Madrid: Tipografía de Nieto y Compañía, 1923.

Mainer, José Carlos. La doma de la Quimera. Madrid: Iberoamericana, 2004 [1988].

Montero Alonso, José. "Lo que preparan nuestros escritores.” La Libertad, October 22, 1926, 6-7.

Sánchez García, Raquel. El autor en España (1900-1936). Madrid: Fundamentos, 2008. 


\title{
11 The International Relations of the Catalan PEN Until 1936 Guests, Congressors and Visitors
}

\author{
Joan Safont Plumed
}

\section{Founding Ambition}

On February 28, 1922, in a letter addressed to an unidentified person in the English PEN, the anthropologist and writer Josep Maria Batista Roca announced the first members of the hypothetical committee of Catalan PEN: the director of La Revista and noucentista poet Josep Maria LópezPicó, who was to be the president; poet and translator- "translator of Tagore's poems in Catalan", Batista declared to his contact-Josep Maria Millàs-Raurell; writer and journalist Carles Soldevila; and Josep Barbey, "all well-known among the young intellectual peoples". ${ }^{1}$

Shortly thereafter, on April 19, at Barcelona's Hotel Ritz, the founding meal of the Catalan branch of the PEN Club took place. Around the founding table were gathered López-Picó; the writer and translator Josep Maria Millàs-Raurell; Batista Roca; a young English professor, the poet John Langdon-Davies, who had arrived in Catalonia a year before and who was preparing an anthology of Catalan poets to translate and publish in English; and the young humanist, philosopher, and economist Joan Crexells, who left for Munich a few days later. According to Josep $\mathrm{Pla}$, Crexells was "perhaps the best, the most cultured, the most complete, one of the richest natures of young (very young) man to breathe the air of this land", 2 and his premature death just four years later hit the Catalan intellectual world hard. This Catalan PEN group became the third in the world, after the English and French. López-Picó was elected president of the managing board of Catalan PEN, and Millàs-Raurell was its secretary until the beginning of the Spanish Civil War. The married writers Carles Riba and Clementina Arderiu did not attend the dinner; some weeks earlier they had gone to Germany, where they spent a year. Riba had been awarded a scholarship from the Pedagogy Council of the Mancomunitat of Catalonia; he frequented the lectures of Karl Vossler and along the way discovered the poetry of Hölderlin. Riba's teacher López-Picó told him about the dinner in a diary-like letter from Barcelona: "Day 19. First dinner of the PEN Club, Catalan branch, at the Ritz. Poets, editors, essayists, novelists, a contemporary cosmopolitan herd that wants the certainty of a banal monthly dinner with murmuring company. However, 


\section{Joan Safont Plumed}

we began modestly with a basis of Crexells, Millàs-Raurell, Batista, and a young English professor, whose name we have forgotten." ${ }^{3}$

To understand this speed when forming a Catalan PEN Club, one must keep in mind the historical moment for Catalan culture and language. Nearly a century after the beginning of the so-called Catalan Renaixença, a modern national culture had begun to be articulated, with its own institutions, the Mancomunitat of Catalonia and later the Republican Generalitat, with the interruption of Primo de Rivera's dictatorship; its own intellectuals connected to the main currents of European thought; its own narrative, poetic, and dramatic works, which had a widening audience; its own place within a growing mass public, including press, radio, magazines, and books; and its own constant dialogue with the works of the writers, poets, novelists, and dramatists of the cultural environment. The project of the post-noucentism generation continued to situate Catalan culture at the European level, and in this sense the visits of foreign writers in Catalonia, translations and publications into Catalan, and the stints of Catalans as press correspondents, diplomats, or students fed Catalan culture in the twenties with modernity, new vision, and exposure. If, for the post-war international literary world, PEN was a way of bringing nations and writers together after the Great War, for Catalans it was a way of participating directly in this cosmopolitan construction by means of an international organization of intellectuals, without intermediaries and on an equal playing field. The premature foundation of Catalan PEN, just after the English and French, gives a sense of the open and global mentality of Catalan culture. A few days later, on May 5, the managing board, presided by López-Picó, organized a luncheon in honour of the French poet and novelist Jules Romains, future president of PEN International, who was in the city on those days to give a cycle of conferences at the French Institute and who, moreover, had published an article about Catalan literature. ${ }^{4}$

A year after its formation, the Catalan PEN Club plenary was composed of Clementina Arderiu, Carles Riba, Pompeu Fabra, Josep Barbey, Joan Estelrich, Joaquim Horta Conill, Josep Farran Mayoral, Marià Manent, Lluís Nicolau d'Olwer, Joan Puig Ferrater, Carles Soldevila, Magí Morera i Galícia, Alexandre Plana, Josep Maria de Sagarra, Miquel Ferrà, Enric Martínez Ferrando, Alexandre Galí, Ventura Gassol, and Lluís Bertran Pijoan. The respected and celebrated linguist and father of modern Catalan, Pompeu Fabra, was chosen president. In May 1923, the first International Congress of the PEN Club took place in London. With the English novelist and dramatist John Galsworthy as president, 164 writers attended, representing the eleven PEN centres that were then in existence. ${ }^{5}$ Pompeu Fabra and Josep Maria Millàs-Raurell went as representatives of the Catalan centre. A few months after, on September 13, 1923, the Captain General of Catalonia, Miguel Primo de Rivera, headed a coup d'etat that resulted in a dictatorial regime sanctioned by 
King Alfonso XIII. The situation of deep social crisis, the unravelling of the Restoration system, the bloody war in Morocco, and the radicalization of the Catalanist and workers' movements had been detonated by the appearance of an "iron surgeon" who intended to resolve all the great problems of the country with a hard hand. The dictatorship that began was especially hostile to Catalanism and especially to Catalan language and culture, which also had consequences for the activity of PEN. The highly active Millàs-Raurell, in a letter to Galsworthy early in 1924, commented:

All the expressions of our national soul are persecuted by the Mili-
tary Directory of Spain, and the popular authorities, that represents
the aim of Catalunya, and all the aspirations and ideals of our people,
has been driven away from the places they have been elected by our
country. I think, nevertheless, that a near future shall permit to us the
public demonstration of our national aims and that shall facilitate
the organisation of one May international meeting at Barcelona.

As Millàs-Raurell explained, the Mancomunitat of Catalonia was dissolved and many of its cultural institutions had been denatured or had to survive clandestinely. Thus, the PEN Club, with its headquarters at the Barcelona Ateneu, immediately became one of the centres of affirmation of a Catalan culture repressed and persecuted by the dictator and prompted its presence in the world in search of solidarity and wider reach. Catalan writers found in the PEN Club a means to increase international exposure in a domain where culture had pre-eminence over state. In this way, Catalan PEN became the global representative of a culture persecuted by a dictatorial government, a premonition of what would shortly thereafter happen in Europe.

For the first day of Sant Jordi during the dictatorship, and as a form of affirmation, Catalan PEN organized various events. After a reorganization, the newest president emerged: Magí Morera Galícia, a lawyer, politician, and translator of William Shakespeare. He headed the club, with López-Picó; Millàs-Raurell; poet and politician Jaume Bofill Mates; poet and repeat winner of the Jocs Florals Joan Maria Guasch Miró; and Ramon Suriñach Senties, author of El tresor dels pobres. This was the committee that on April 22 informed the poet, dramatist, and Nobel candidate, Àngel Guimerà, of his appointment as honorary member of the International PEN Club, a restricted group which already included Englishman Thomas Hardy, Irishman William Butler Yeats, Belgian Maurice Maeterlinck, Russian Maxim Gorky, Germans Hermann Sudermann and Gerhart Hauptmann, and Frenchman Anatole France. On April 23, the PEN organized a supper at the Hotel Colón presided by Àngel Guimerà, Narcís Oller, Víctor Català, Jaume Bofill Mates, Clementina Arderiu, and Magí Morera. Bofill Mates had been part of the political structure of the 


\section{Joan Safont Plumed}

Mancomunitat, which in that moment was eviscerated and on the verge of being dissolved by the regime, and in 1922 had founded the party Acció Catalana, of which he was the president. In his dual role of poet and nationalist politician, Bofill gave an important speech that invoked the Catalan language as "the lady of the rose in hand", on behalf of whom he implored an imaginary fairy who could grant three wishes, while referring to the period of persecution experienced by Catalan language and culture:

My lady: Let every people love its natural language. Only he who has a mother and honours her with dignity knows to be respectful towards women. Hate for an alien tongue, the persecution of a civil language, would be more than an injustice; it would be an injustice and an impropriety. [...] My lady, let all of those men-if there are some-whether within or outside of Catalonia, Catalans or strangers, who hate our word and our culture, and cannot desist from combatting them, let them have a personal, decorous, and fervent word, inborn or borrowed, that they may know, love, and honour [. . .] I ask you, my lady, for a third gift, this one for us: the gift of the unity of all Catalans in love for our tongue, in fidelity to our tongue. May she be the rhythm [censored] of our life, the gentle echo that, speaking of the death of each of us, makes Catalan tradition immortal! ${ }^{7}$

Bofill finished the speech asserting:

Ladies, gentlemen: I just spoke as a member of the P.E.N. Club of Catalonia. With this title alone, I propose to you that our Club, on the occasion of this its first event, greet the honourable president of the Central P.E.N. Club of London, Mister John Galsworthy, one of the great authors of contemporary British theatre. By addressing us here, in contributing our collaboration, we recognize and we confess our smallness. But we hope that every man of spirit will find significant this meeting of Catalonia's men of letters, held in the middle of Barcelona on this very day.

\section{4-1926. Illustrious Visitors}

On the occasion of this first meeting of Catalan PEN, the first attempt was made to bring from London to Barcelona a figure such as John Galsworthy, George Bernard Shaw, H. G. Wells, or G. K. Chesterton, as an international observer and figure of authority from the International PEN Club, an initiative that did not work out but was the first step in bringing Chesterton to the city. From the foundation of Catalan PEN, one of its priorities has been inviting foreign writers to visit.

Accordingly, the great French writer and poet Paul Valéry, founding member of the French PEN Club, came to visit a few weeks later. His stay 
in Barcelona, after coming from Madrid, had been possible under the auspices of the Mallorcan Joan Estelrich, director of the Bernat Metge Foundation and great cultural activist in Catalonia in the interwar period. He moved comfortably in the most select environments of international cultural diplomacy and probably had become friends with Valéry, author of Le cimetière marin, in the context of the Institut international de coopération intellectuelle of the League of Nations. Valéry arrived in Barcelona on May 23, 1924, and Estelrich met him at the station, along with the historian and archaeologist Pere Bosch-Gimpera; the Latinist Joaquim Balcells; the Flemish psychologist Georges Dwelshauvers, director of the Mancomunitat's Institute of Experimental Psychology (which had just been dissolved by the dictatorship that also forced out a majority of the professors of the Mancomunitat's main schools and institutions); the young journalists Rossend Llates and Joan Mínguez; the poet Carles Fages de Climent; the essayist and illustrator Cristòfor de Domènech; and the translator and teacher Carles Magrinyà, who represented the Institut d'Estudis Catalans, the Barcelona Ateneu, the PEN Club, and the Amics de la Poesia, respectively, led by the director of the French Institute, Monsieur Bertrand. ${ }^{8}$ The visit programme included a conference organized by the Amics de la Poesia at the Barcelona Ateneu, which was attended by the best and brightest of Catalan intellectuals. The writer Carles Soldevila was in charge of introducing the Occitan poet, who in front of an auditorium filled, according to the chronicles, with "a very distinguished audience; among which were beautiful ladies and prestigious intellectuals and artists", spoke of his literary career and presented his ideas on poetry, in addition to reciting Le cimetière marin and addressing some words to Catalan writers. ${ }^{9}$ The day before, the PEN Club had honoured Valéry with a supper at the Hotel Colón, which was attended by Pere Coromines, López-Picó, Estelrich, Alexandre Plana, Vicenç Solé de Sojo, Adrià Gual, Carles Soldevila, Maseras, Domènech, and Millàs-Raurell. "I almost feel, southerner as I am, your compatriot", asserted Valéry, ${ }^{10}$ who left this letter before his departure:

Hotel de Oriente | Rambla del Centro, 20-22 | Barcelona || le 26 mai 1924 || Messieurs et chers Camarades, I Je vous adresse à tous mes remerciements les plus profonds pour votre accueil si cordial et si aimable. J'ai trouvé ici une vie intellectuelle dont l'intensité et la diversité m'ont surpris et enchanté. Barcelone est un grand port qui pense... Je n'en vois pas beaucoup d'autres dans le monde! I Je vous serre les mains à tous avec la plus grande gratitude... Au revoir! I Paul Valéry. ${ }^{11}$

On the 18th of July, in a letter from Millàs-Raurell to Marjorie Scott, daughter of the Club's founder and PEN's secretary, he gives her two pieces of news: the first one is Valéry's presence at the May dinner of Catalan PEN. The other one is the death of Àngel Guimerà, honorary president of 


\section{Joan Safont Plumed}

Catalan PEN and honorary member of PEN International. He also takes the opportunity to tell her:

The next autumn and winter we shall invite several writers, besides

Mr. Chesterton. They shall be Messrs. Pirandello, Charles Vildrac and Maeterlinck. The French and Italian have yet accepted, but we don't know the address of Mr. Maeterlinck ad we can't write to it. Will you to send us his address ad write him that our invitation? ${ }^{12}$

Thus, on the 13th of December, the writer Luigi Pirandello, president of the Italian PEN, arrived in Barcelona. ${ }^{13}$ As the press pointed out, Catalan PEN-which had organized the trip in agreement with the theatrical entrepreneur Josep Canals, who had decided to renovate the Catalan theatre and bring the most innovative currents of the international scene to Barcelona in collaboration-hosted him at the Hotel Colón in the Catalan capital. The reason for the visit was an invitation to give a lecture at the Romea Theatre, followed by the premiere of The Cap and Bells, translated into Catalan by Josep Maria de Sagarra, who dedicated a cover article to it in La Publicitat:

Pirandello has come to talk and search, to walk and smile, with his big black hat and his silk scarf, and his back a little heavy with the weight of glory and grazes of fate. Catalan men of letters have received him as he merits, and Barcelona has realised who the man who has eaten and slept in the Colomb Hotel for four days is.

The men of letters will invite him to see Catalonia, and they will eat like good brothers around this master of mental disillusionment, who is "mad" at all the "regisseurs" and theatre directors.

On Wednesday, Pirandello will speak from the stage of Romea; we think that all the people of good taste will come to listen to him. ${ }^{14}$

Sagarra and Millàs-Raurell accompany him at all times during his stay, which brings him to Sitges, to the Ateneu, the Library of Catalonia and Liceu, and of course, to the dinner in his honour, one of the highest attended of those organized by the Catalan PEN: Josep Puig Cadafalch, Jaume Bofill Mates, Josep Maria de Sagarra, Rossend Llates, Tomàs Garcés, Joan Mínguez, Josep Maria Millàs-Raurell, Josep Maria López-Picó, Josep Farran Mayoral, doctors Pi Sunyer and Pittaluga, Ramon d'Alós, Joan Crexells, Cristòfor de Domènec, Alexandre Plana, Carles Soldevila, Josep Maria Batista Roca, Francesc Madrid, Adrià Gual, and so on. His Catalan translator also acts as an interpreter when Àngel Ferran interviews him for La Publicitat, where the Italian playwright asserts that:

Barcelona, Catalonia, I like it because it seems to me that I am in my dear Sicily. The climate, the air, the tone of the voice of its inhabitants, 
even in the vivacity of the character you can see the brotherhood of our people. And not by the past domination, but by the community of blood. ${ }^{15}$

In L'Esquella de la Torratxa, the artist in words Màrius Aguilar also writes about the famous guest:

We have had, we still have, Luigi Pirandello, as a guest of Barcelona. Pirandello is the one who has been described as a genius of Columbus, the discoverer of theatrical Americas, the met physicist of the stage, the Einstein of psychological relativities. Little by little, life becomes a Pirandellian interpretation, as his comedies are released. There are men, scenes, stories, pirandellians. We feel like pirandellians. We see others as pirandellians, and we have created verbs, adjectives, gerunds and adverbs based on Pirandello. This unique man, a fascinating and disquieting man, this universal man, who is one of the select few and who is familiar with people, stops at Colón, visits Sitges, visits Catalonia, holds solemn banquets, and gives lectures at Romea. ${ }^{16}$

A few days later, Millàs-Raurell writes a new letter to Miss Scott, saying the following:

This month we have had the visit of Pirandello. You can see our dinner in the photo. I send you here whit, and also the description of the two toasts. Mr. Puig Cadafalch, our well-known archaeologist, as the member that has visited the last another (the Romanian one) of our Pen Centres, has given to Pirandello the salutation of our delegation. In the same dinner, Dr. Pittaluga, of the Spanish Pen has been present. ${ }^{17}$

In his letter, Millàs mentions to Miss Scott that she has written to Chesterton, proposing that he visit Catalonia the next summer, and asks her for the addresses of Rabindranath Tagore and Gerhart Hauptmann, Nobel Prize winners for Literature in 1913 and 1912, and Maxim Gorky, to invite them to visit Catalonia. In this way, he also uses this piece of writing to tell her that the following month, the guest at the PEN Club dinner will be the French poet and playwright Charles Vildrac, also a member of French PEN. As in the case of Pirandello, Vildrac visited Barcelona to give a lecture and attend the premiere of the plays Le Paquebot Tenacity, Michel Auclair, translated by Carles Soldevila, and Le Pèlerin, which premiered in Barcelona before being shown in Paris, as announced in the theatrical section of the press. On January 15, 1925, Vildrac and his wife arrived in Barcelona, where they were received by Soldevila, Sagarra, and Millàs-Raurell, among others. ${ }^{18}$ The latter is responsible for writing an 
article on Charles Vildrac's theatre ${ }^{19}$ under a notification by the PEN Club of Catalonia announcing the "fourth general dinner" planned for the 18th of January at the Hotel Colón, where the visitors are staying. As you can read in the chronicle, the dinner in honour of Vildrac was presided over by the poet Clementina Arderiu, the president of PEN Magí Morera Galicia, and Carles Soldevila, active member of PEN and the link to another essential organizer of cosmopolitan evenings and foreign visits in the interwar period, the Conferentia Club. Carles Riba was in charge of glossing on Vildrac when it came to desserts. ${ }^{20}$

In a new letter from Millàs to Miss Scott-where the trust between the correspondents is evident from the good wishes for Scott's forthcoming wedding and the announcement that Millàs is also planning to marry that year-the Catalan informs the secretary of International PEN that:

The last month of January the guest of honour of our dinner has been M. And Mme. Charles Vildrac, the French Poet and Dramatist. The salutation has been made by our Poet Carles Riba. Vildrac and his wife have spent six days in Barcelona a we have had always care to give agreeable their stay here. ${ }^{21}$

Millàs-Raurell also took the opportunity to say to her, maybe answering her questions on that matter, that: "We have very few women as members of our Club ad they assist rarely at our dinners. In Catalunya it is not plenty case the women devoted to literary matters". In this regard, it should be noted that one of few women honoured with a dinner was the Italian writer Maria Luisa Fuimi, invited to give a lecture at the Casa dels Italians in Barcelona. ${ }^{22}$

Two years later G. K. Chesterton's visit to Barcelona was made possible at the invitation of the Catalan PEN Club. The British writer was involved in the objectives promoted by PEN of cooperation and connection between writers committed to liberty and democracy, and this became clear on his journey to Spain in 1926, with a stay of over a month in Catalonia. ${ }^{23} \mathrm{He}$ arrived in Barcelona at the end of April, accompanied by his wife, his niece, and the Catalan poet Josep Maria Junoy, a converted Catholic like Chesterton and his guide during the visit. On May 5 , he gave a speech at the University of Barcelona, and the next day the PEN honoured him with a dinner at the Ritz. ${ }^{24}$ Josep Maria de Sagarra immortalized the dinner with one of his articles in La Publicitat:

Chesterton at the table between Nicolau d'Olwer and Josep Maria Junoy; on the other side of Nicolau d'Olwer was Mrs. Chesterton; I was at a distance that allowed me to observe without impertinence, but without missing a detail. [...] When Nicolau d'Olwer had offered him the dinner in a warm and elegant manner, Chesterton remained in a proper drowsiness. Who knows what sort of exotic sails glide 
through the blue water of his eyes! Afterwards, Chesterton spoke: in standing up, his thorax and stomach became impressive; it seemed to us that the prow of a great ship came towards us over the tablecloth. [...] Chesterton said the polite things that one says at banquet toasts, but among these polite things he said some words spoken only by angels and the truly inspired. He spoke a bit tongue-tied; like a man who has drunk too much and drags his syllables. He said the most beautiful and delicate things as though he were embarrassed, without any pomposity whatsoever and with a certain anguish; he only smiled twice, when his incisive spirituality pierced like a dagger. He finished his speech without a hint of toughness, like a bull struck in the neck with a hammer: that enormous mountain of flesh fell leaden into the chair. ${ }^{25}$

In his speech, transcribed by Batista Roca, Chesterton assured them:

I would have liked to remain unnoticed, but you have done me the great honour of finding me. The PEN Club exists to create a kind of international republic of letters and to create a spirit of brotherhood between the literati of all countries. [...] The union of peoples, until now, had meant only the union of politicians, which is to say, the least representative people of each population. If it were the poets who would bring them together, it would make them love the land of the others. Today, I did not understand your language, but I have understood how sweet and gentle your language can be. ${ }^{26}$

After a month's stay in Catalonia, Chesterton's journey was a success, and upon returning to England, the creator of Father Brown wrote about it and published his impressions: The Observer published "Mr. Chesterton on Spain" and dedicated some lines to Josep Maria Junoy in the backpage column of the Illustrated London News, titled "Our Notebook". With these travels, the Catalan PEN Club was able to internationalize the situation of Catalan culture during the dictatorship of Primo de Rivera.

\section{Barcelona International Congress}

The intense participation of Catalan PEN in the PEN conferences and international meetings revealed its involvement in the international projection of Catalan culture and the dynamism of a Club created not long before, able to send different representatives to various European cities each year. Catalan literature was showing itself directly to the world, and belonging to the international writers' club served as a publicity platform for Catalan letters, making clear its modernity and desire for openness. In any case, between 1930 and 1932, Catalan PEN did not participate in international meetings. With the end of the dictatorship of Primo de 


\section{Joan Safont Plumed}

Rivera, the parenthesis of the so-called dictablanda, the proclamation of the Second Republic in 1931 and the approval of the Statute of Autonomy in 1932, they had experienced an especially intense period, which perhaps explains this brief phase of crisis and this pause in Catalan culture's international presence. The new Catalan government included a member of Catalan PEN, the poet Ventura Gassol, who had been a delegate to the 1927 Brussels congress.

In 1933, however, the poet J. V. Foix travelled as Catalan delegate to the historic congress in Dubrovnik, organized by the Yugoslavian PEN Centres. Millàs-Raurell joined as "un de nos jeunes écrivains d'avantgarde, très fin poète". ${ }^{27}$ On his way to the Croatian city, Foix wrote two poems, dated in Trieste and Ljubljana, that were included in the volume On he deixat les claus ...., and he sent various articles to the newspaper La Publicitat, where he normally wrote and which had sent him off awaiting his articles. ${ }^{28}$ As Foix explained, the congress marked the ascendancy of Adolf Hitler to the German chancellery a few months prior, and the first steps of the Nazi regime, and it was a milestone in the life of PEN, which had also approved its statutes.

Besides intervening in this decisive debate, Foix took a request back to Barcelona. The Catalan PEN secretary had suggested to Hermon Ould, in the letter telling him that Foix would be the delegate, their desire to organize the next PEN Congress in Barcelona:

En occasion des entretiens que nous avons eu avec notre Gouvernement, notamment avec M. Ventura Gassol que vos connaissez bien et qui est maintenant, dès la proclamation de notre République, chargé du portefeuille d'Instruction Publique, en occasion, donc, de ces entretiens avec M. Gassol, celui-ci a exprimé son désir de voir définitivement organisé notre Club en le reliant à toute une organisation d'institutions culturales qui auront la protection du Gouvernement. Il a dit qu'il serait heureux d'offrir pour l'année 1935 Barcelone comme siège du XIIIe Congrès International des Pen Clubs. C'est cela que je vous ai avancé par télégramme et je serais très content d'apprendre que le Congrès a voté notre ville pour la visiter la susdite année. ${ }^{29}$

In the final stages of the last sessions of the congress, on May 27, Foix sent a postcard to Carles Riba telling him that Barcelona had been accepted as seat of a next international gathering: "Dear Riba: our proposition has just been approved: in 35 the PEN Congress will be in Barcelona. Unanimous. Lately the Serbians almost went too far. The congress is official on state and city level. Greetings. Foix". ${ }^{30}$ "The prestige of Catalonia", as Foix titled one of his accounts, was higher than ever:

The prestige of our land's name is right now, however, among the most brilliant. In a romantic castle overshadowing the inoffensive 
reefs of the Adriatic, the reception given by more than four hundred congress-goers to the motion I presented in the name of the PEN Club of Catalonia to propose that the thirteenth International Congress, to be held in 1935, would take place in Barcelona, was very emotional for me. A cordial and effusive welcome like few others, and a unanimous response that obliges us all to work, not only to uphold our first rank position in the noble competition among PEN Clubs to make the coming receptions insurmountable, as happened in Yugoslavia, but also to see the prestige of the names of Catalonia and Barcelona on a more solid ground. ${ }^{31}$

One year later, Pompeu Fabra was re-elected, and at the assembly of May 15, 1934, the statutes were approved and a Managing Committee nominated. It was a time of organization, of re-founding, of full hope, with sights placed on the congress of 1935. In January, Fabra and the founders López-Picó, Batista Roca, and Millàs-Raurell had called to writers to join the organisation, which enjoyed the support of the Generalitat of Catalonia and the City Hall of Barcelona, to begin preparations for the international congress in May of the following year, in a political context that was starting to become complicated. Millàs explained it in this way to the secretary general:

Vous aurez suivi les mouvements politiques de chez nous, parmi lesquels nous nous sommes trouvés malgré notre condition apolitique. La question politique semble, au moins chez nous, en Catalogne, un peu stabilisée malgré les troubles sociaux, et j'ai trouvé un bon accueil partout pour la constitution définitive de notre Club, ce que sera réalisé les mois de mai, et surtout pour la célébration ici de la réunion internationale des PEN Club pour l'année 1935. Tant la vie de notre Club comme le Congrès auront le patronage officiel ce qui a été très aisé d'obtenir, puisque le Conseiller d'Instruction Publique de la Catalogne, dès la Proclamation de la République notre bon ami M. Ventura Gassol, dont vous m'aviez entretenu une fois il y a des années. ${ }^{32}$

In the congress that year, 1934, which took place in June in Edinburgh, the choice of Barcelona as seat for the following congress was confirmed, and Catalan PEN joined the International Executive Committee for the first time, with the election of the poet Marià Manent- "jeune poète très au courant de la littérature anglaise, traducteur de Keats and R. Brooke"- 33 who attended along with Carles Riba and secretary Millàs-Raurell.

Nevertheless, the events of October 1934 brought the detention and imprisonment of the government of the Generalitat (Pompeu Fabra himself, president of the board of the Autonomous University, was also detained), the suspension of the Estatut, and the establishment of a state of exception, all of which endangered the congress, which had already 


\section{Joan Safont Plumed}

been in preparation for some time. A few days before, on September 25, Millàs had written to Hermon Ould that the organizing committee of the XIII International Congress of the PEN Club in Barcelona was to be constituted that week, which had to approve the programme and the proposal of inviting a guest of honour for every PEN Centre, in addition to the official delegation. After the events of October, it seemed doubtful from London that they could even hold the congress, and Millàs was tasked with calming the International Committee by way of his letters to Ould.

Vous aurez suivi les événements qui se sont déroulés chez nous et qui ont terminé par la chute et la prison de notre Gouvernement et de notre bon ami M. Gassol. Nos amis ne sont plus au pouvoir. Néanmoins j'ai prévenu il y a longtemps ces contingences et j'ai composé notre Comité de membres de tous les partis politiques catalans. Actuellement nous sommes et état de guerre en nous avons les militaires dans nos Corporations administratives mais cela ne peut pas s'éterniser et je compte que bientôt nous saurons quelque chose définitive à propos de la normalisation de la vie civile.

Notre président M. Pompeu Fabra qui est assisté à a la première réunion des PEN Club à Londres a été aussi arrêté et il est comme tous les autres au "Ciudad de Cadiz". Il était aussi le Président du Patronat de l'Université Autonome et c'est sous ce titre qu'il a été emprisonné.

Si je dois vous avancer mon impression personnelle au sujet de ce qui concerne notre réunion du mois de mai je vous dirai que je suis convaincu que le Congrès sera tenu à Barcelone et qu'en mai la paix sera définitivement établie, mai en ce moment je ne peux pas vous donner cette impression favorable comme une assurance absolue. Pourtant j'espère que si la réunion du Comité Internationale a lieu à la moitié Novembre, nous serons porteurs de bonnes nouvelles et il nous sera possible d'y assister. ${ }^{34}$

In the letter that Catalan PEN sent to the other centres invited to the congress, they did not hide reality:

La situation politique de notre pays n'est pas, malheureusement, normale. Notre action culturale et politique, qui s'était développée jusqu'ici avec une liberté presque absolue est à nouveau très sérieusement limitée comme résultat des évènements révolutionnaires du mois d'octobre dernier. Malgré les difficultés de l'instant, et bien qu'il ne nous sera peut-être pas possible de vous offrir le programme que nous avions préparé, nous tâcherons de faire de notre mieux pour suivre l'exemple des deuze magnifiques réunions précédentes. ${ }^{35}$

From May 20 to 25, 1935, Barcelona hosted the XIII International Congress. One hundred sixty-five writers, representing 25 centres around the 
world, met in the city in a congress that was a success. The participating delegations represented the centres from Argentina, Flemish and Francophone Belgium, Bulgaria, Czechoslovakia, Denmark, England, exiled Germany, Holland, Hungary, India, Lithuania, New Zealand, North America, Norway, Palestine, Poland (in the end excused due to the death of Marshal Josef Pilsudski, highest leader of the country), Romania, Scotland, South Africa, Sweden, Yugoslavia with delegates from Ljubljana and Zagreb, and the Yiddish centre. Among the attendees were Ernst Toller, voice of German writers in exile, together with Klaus Mann, son of Thomas Mann; the former avant-gardist Filippo Tommaso Marinetti, in the Italian delegation; and Jawaharlal Nehru, as delegate from an India still under British domain. The British delegation was one of the most numerous, with 23 delegates, among them H. G. Wells and Hermon Ould, president and secretary of the International Executive Committee of the PEN Club. The Catalan group was formed of 55 members, headed by a Directory Committee presided over by Pompeu Fabra and including Rafael Benet, Joan Estelrich, Josep Maria López-Pico, Lluís Nicolau d'Olwer, Josep Pous i Pagès, Carles Riba, and Carles Soldevila, with Josep Millàs-Raurell as secretary. The official delegation included the historian and politician Lluís Nicolau d'Olwer, Carles Riba, and Clementina Arderiu, all three former delegates to previous congresses. Five days before it began, La Publicitat had already spread the news of the preparations and assured readers that "We are sure that this feast of brotherhood among writers of all literatures must find among us the kindness and affection merited by the intellectual stature of our illustrious guests". ${ }^{36}$ Two days beforehand, it was announced that many writers had already registered for the congress: Josep Maria de Sagarra, Carles Riba, Clementina Arderiu, López-Picó, Maria Teresa Vernet, Andreu Nin, Joan Llongueras, Tomàs Garcés, Marià Manent, Francesc Sitjà, Ramon Suriñach Senties, Carles Soldevila, Josep Pous i Pagès, J. V. Foix, Josep Carner Ribalta, Alfons Maseras, Joan Santamaria, Manuel Marinel-lo, Marçal Olivar, Ramon d'Alòs-Moner, Joan Francesc Vidal i Jové, and so on. "As you can see, the Catalan literati are prepared to give foreign writers a cordial welcome without prejudice", asserted the newspaper. ${ }^{37}$

The day before the inauguration, a writer very connected to the PEN, J. V. Foix, wrote in the pages of La Publicitat, where he published frequently, an extensive article which highlighted what was most important about that international gathering: "Those of us who have witnessed recent congresses know that the PEN Club has debated, above all during the last two years, the most transcendent questions that we can sum up with this proposition: THE WRITER'S FREEDOM". ${ }^{38}$ In this regard, Foix once again demonstrated that PEN rose above the political divisions of states by representing "the peoples who do not enjoy their political rights", and defended German writers from Nazi persecution. "The Barcelona Congress, perhaps the most important of those that have been held until now, sets forth very important questions about the freedom of 


\section{Joan Safont Plumed}

writers, intellectual exchange, the duty of intellectuals, the persecution of writers in antidemocratic regimes, etc.". These questions characterized the discussions that took place from May 21 at the Casal del Metge, headquarters of the conference. The day before, the most formal of the events had been completed, with the opening of the offices and with the governor general and the interim president of the Generalitat, Joan Pich Pon, receiving the delegates. The French delegate Benjamin Crémieux, who died in the Nazi extermination camp Buchenwald in 1944, gave thanks for the words of the authorities on behalf of the visitors. A session of the International Executive Committee took place at the Font del Lleó, followed by a luncheon, after which the delegations visited the Museu d'Art de Catalunya; in the evening the painters, sculptors, and musicians of Catalonia offered a reception at the Círcol Artístic, with a concert of Catalan songs performed by Concepció Badia d'Agustí, accompanied on piano by Robert Gerhard and Pau Casals. ${ }^{39}$

On Tuesday the 21st, La Publicitat, which was distributed to attendees free of charge, addressed the PEN delegates on the front page:

In greeting the congress-goers of different national PEN Clubs, gathered fraternally under the banner of international association of writers, we vow that their stay in Catalonia will not only be pleasant-of that we have no doubt-but that their decisions will favour the realisation of these principles of international solidarity that are common to us all. Knowing the nations in order to truly understand them; knowing the people in order to love them. And loving your own even more; to hear so many and such diverse languages in order to prove again that freedom is just one language: that of the intelligence of the spirit, which we pronounce differently but can all understand. Congress-goers of the PEN Clubs: [censored] they receive you with the accustomed cordial dignity. The land of Ramon Llull, who represents the highest ambition of unity and universality of the Middle Ages, could not receive you in any other way. ${ }^{40}$

In the cultural pages, on the occasion of the congress's inauguration, Joan Teixidor offered a "diagram of contemporary Catalan poetry", Josep Miquel Vergés covered Catalan literature in the Renaixença, and Martí de Riquer classical Catalan literature. ${ }^{41}$ The sessions began with a speech by the hosting Club's president, Pompeu Fabra. "Non-Catalan congress attendees, you who have honoured us with your presence, be welcome among us, and may your stay in Catalonia continue pleasurably". H. G. Wells replied by alluding to the work of the Minister of Culture and PEN member Ventura Gassol, at that moment in prison with the entire Catalan government, and to "the difficulties of liberal writers in all countries, and to the increasingly widespread coercions that are invading Europe and limiting the freedom of the spirit”. The debate was agitated, 
especially focused on freedom of speech and the creation of writers in a world increasingly subdued by new totalitarianisms. The proposition of the English and American centres, which affirmed "that all literary censorship constitutes an obstacle for authors and an offense to the rights of the spirit, and writers must combat this censorship, of whatever kind it may be", was approved, despite the reservations of Marinetti, representative of fascist Italy, who made distinctions between writers and thought that freedom of speech should only be respected in countries that were in a state of political tranquility. J. V. Foix wrote an account titled "Two Presidents", which was included in the volume Els lloms transparents:

Yesterday at the Casal del Metge, as I was listening to Wells and Fabra, I remembered so many other sessions chaired by those two eminent writers. Those of us who knew both of them agreed that Fabra was as British as Wells. As for me, I can affirm that each time that I have seen them exercise their presidential function, I have had the same presumption: that Wells and Fabra, absent, deserting, or evading the hundreds of congress attendees, hid the most expressively determined attitude behind their rigid distance. Their harsh stammer was no more than the emanation of the air that potentially contained the word, which in decisive moments could be clearly and justifiably sounded out: a curse. But it did not happen in this way: the session was peaceful, and the two chairmen had an audience hanging on their words. The evasive attitude of the two did not correspond to the same effort that we knew of civil restraint: to avoid closing debates with a frank, understanding word. You would say that yesterday both of them had Briticised the crowd. ${ }^{42}$

On the second day of sessions, the Italian Marinetti presented the state of culture in his country and proposed the creation of an International Bureau of Translation and the revival of the International PEN prize, a proposal that was approved. The Argentinian delegate Guillermo de Achaval asked to hold the XIV Congress in Buenos Aires, a proposal that was also approved. In addition, it was decided that the following meetings would be in Rome, Prague, and Stockholm. One of the culminating moments was the speech of the exiled German writer Klaus Mann, who took the stage "to express the situation of writers in Germany persecuted by the frenzy of racism and because of disagreement with Hitler's regime", which he illustrated with examples of expelled and even murdered writers. Mann wrote a declaration of protest against the Berlin regime, to which all of the delegations assented. His speech made a great impact. Toller also spoke, with a portending lecture entitled "The risk of the intellectual in today's Europe" ${ }^{43}$ In the last session, the central topic of debate was the publication of an international PEN magazine, a project presented by the Flemish delegation. During the three sessions, aside 


\section{Joan Safont Plumed}

from President Fabra, it was Josep Maria de Sagarra who was in charge of commenting on the debate and closing the sessions with thanks on behalf of Catalan writers. In Mirador, which dedicated quite a few pages to the congress, with an account by the writer and critic Rafael Tasis Marca and interviews with Wells and Crémieux, ${ }^{44}$ Sagarra wrote one of his "Aperitius", in which he appeared to be sceptical about the central topic of the PEN discussions, intellectual freedom:

The idea is to send a manifesto from the PEN Club to oppressive and dictatorial leaders; naturally, governments laugh and will laugh and have always laughed at the manifestos of intellectuals. This is an age-old question in the world, and I don't think it can be resolved in whole or in part by the poor writers. Socrates raised the question in Athens and drank the hemlock. The whole history of Europe is full of imprisoned, exiled, hung, burned, and quartered writers, because at a given moment their writing didn't quite satisfy the constituted powers. Right now, in Italy-even though at our congress Marinetti wanted to paint a pretty picture-and in Germany, Russia, and Yugoslavia, we've seen a series of specific cases that show the extent of the weakness of PEN Clubs and all similar societies that want to defend the freedom and rights of writers. ${ }^{45}$

Besides the debates and intellectual discussions, marked by the turbulence of European reality, the programme of events included excursions for the visitors, once the daily sessions were over, to Sitges, Tarragona, Montserrat, and Terrassa, where the group of visitors toured Romanesque churches guided by their restorer, Josep Puig Cadalfach. The conference's success was rounded off with a programme of activities that extended the stay of some of the attendees and included a getaway to the Costa Brava, a series of artistic and folkloric events, a water and sound show in Montjuïc, a concert by the Orfeó Català at the Palau de la Música, and a three-day trip to Mallorca. The closing gala dinner, on May 23 at the Hotel Ritz, was splendid. Josep Obiols designed the menu card, which offered "Germiny aux pailletés, Saumon de la Loire Montserrat, Chapon du Prat à la catalane, Pâté de Strasbourg en croûte, Salade, Bloc glacé Mireille, Mignardises, Fruit and coffee", all paired with Haut Sauternes wines and reserves from the Codorniu vineyards. Radio Barcelona was in charge of transmitting the speeches during dessert, as it had done with the inaugural speeches. Benjamin Crémieux was again tasked with saying a few words; he expressed his satisfaction with the fruits of the congress, especially for PEN's clear protest against cases of injustice against the spirit. Citing the poet Joan Maragall, the French writer wished prosperity to Catalan literature and to the country. Everything seemed to be calm then, but one year later, the European tragedy, which intellectuals could do little to stop, began with the military uprising of July 18, 1936. 


\section{Notes}

1. Letter from Josep Maria Batista i Roca to unknown addressee. Barcelona, February 28, 1922.

2. Pla, Josep. Homenots. Primera sèrie (Barcelona: Editorial Destino, 1969).

3. López-Picó, Josep Maria. Epistolari amb Carles Riba (Barcelona: Curial Edicions Catalanes, 1970).

4. La Veu de Catalunya, May 3, 1922. La Veu de Catalunya, May 4, 1922. La Veu de Catalunya, May 5, 1922. La Veu de Catalunya, May 6, 1922. Estelrich, Joan. "Jules Romains a Barcelona”. La Revista, 1922.

5. Watts, Marjorie. P.E.N. The Early Years 1921-1926 (London: Archive Press Ltd, 1971).

6. Letter from Josep Maria Millàs-Raurell to John Galsworthy, Barcelona, February 5, 1924.

7. "Parlament d'en Jaume Bofill i Mates en el sopar de Sant Jordi del P.E.N. Club", La Publicitat, April 26, 1924.

8. La Publicitat, May 25, 1924.

9. La Publicitat, May 26, 1924.

10. La Veu de Catalunya, May 28, 1924.

11. Letter from Paul Valéry to Catalan writers, May 26, 1924.

12. Letter from Josep Maria Millàs-Raurell to Marjorie Scott, Barcelona, July $18,1924$.

13. La Veu de Catalunya, December 13, 1924.

14. Sagarra, Josep Maria de. "Pirandello", La Publicitat, December 14, 1924.

15. Ferran, Ângel. "Un interviu amb Pirandello”, La Publicitat, December 17, 1924.

16. Aguilar, Màrius. "Pirandellana”, L’Esquella de la Torratxa, December 19, 1924.

17. Letter from Josep Maria Millàs-Raurell to Marjorie Scott, Barcelona, December 28, 1924.

18. La Veu de Catalunya, January 16, 1925.

19. Millàs-Raurell, Josep Maria. "El teatre de Charles Vildrac", La Veu de Catalunya, January 17, 1925.

20. La Veu de Catalunya, January 20, 1925.

21. Letter from Josep Maria Millàs-Raurell to Marjorie Scott. Barcelona, February $9,1925$.

22. La Veu de Catalunya, October 26, 1926.

23. Coll Vinent, Sílvia. G.K. Chesterton a Catalunya $i$ altres estudis sobre una certa anglofilia (Barcelona: Publicacions de l'Abadia de Montserrat, 2010).

24. La Publicitat, May 6, 1926. La Publicitat, May 8, 1926.

25. Sagarra, Josep Maria de. “G. K. Chesterton”, La Publicitat, May 11, 1926.

26. "Chesterton a Barcelona. L'àpat del P.E.N. Club", La Veu de Catalunya, May 8, 1926.

27. Letter from Josep Maria Millàs Raurell to Helmon Ould. Barcelona, May 18, 1933.

28. Foix, JV. "Un Congrés Internacional a Dubrovnik”, La Publicitat, June 2, 1933. "El Congrés de Dubrovnik", La Publicitat, June 6, 1933. "Una important moció de condemna de la política cultural nazi”, La Publicitat, June 7, 1933. "La delegació oficial alemanya abandona el Congrés", La Publicitat, June 8, 1933.

29. Note 27.

30. Postcard from JV Foix to Carles Riba. Dubrovnik, May 27, 1933.

31. "El prestigi de Catalunya", La Publicitat, June 18, 1933.

32. Letter from Josep Maria Millàs-Raurell to Hermon Ould, April 26, 1934. 
33. Letter from Josep Maria Millàs-Raurell to Hermon Ould, May 29, 1934.

34. Letter from Josep Maria Millàs-Raurell to Hermon Ould, October 26, 1934.

35. Letter from Josep Maria Millàs-Raurell to International Pen Centre. Barcelona, February 9, 1935.

36. La Publicitat, May 13, 1935.

37. La Publicitat, May 18, 1935.

38. Foix, JV. "El XIIIè Congrés Internacional de P.E.N. Clubs”, La Publicitat, May 19, 1935.

39. La Publicitat, May 22, 1935.

40. “Salutació als congressistes dels P.E.N. Clubs", La Publicitat, May 21, 1935.

41. La Publicitat, May 21, 1935.

42. Foix, JV. “Dos presidents: H.G. Wells i Pompeu Fabra”, La Publicitat, May 22, 1935.

43. La Publicitat, May 23, 1935.

44. Mirador, May 23, 1935. Mirador, May 30, 1935.

45. Sagarra, Josep Maria. "Pen Club”, Mirador, May 30, 1935.

\section{Bibliography}

Aguilar, Màrius. “Pirandellana”, L'Esquella de la Torratxa, December 19, 1924.

Cid, Josep Sebastià. El Centre Català del PEN. Setanta anys d'història. Barcelona: Ajuntament de Barcelona \& Centre Català del PEN, 1992.

Coll Vinent, Sílvia. G.K. Chesterton a Catalunya i altres estudis sobre una certa anglofilia. Barcelona: Publicacions de l'Abadia de Montserrat, 2010.

“Dos presidents: H.G. Wells i Pompeu Fabra”. La Publicitat, May 22, 1935.

"El Congrés de Dubrovnik". La Publicitat, June 6, 1933.

"El prestigi de Catalunya". La Publicitat, June 18, 1933.

“El XIIIè Congrés Internacional de P.E.N. Clubs”. La Publicitat, May 19, 1935.

Estelrich, Joan. Dietaris. Barcelona: Quaderns Crema, 2014.

Ferran, "Un interviu amb Pirandello". La Publicitat, December 17, 1924.

Foix, J.V. “Un Congrés Internacional a Dubrovnik”. La Publicitat, June 2, 1933.

"G.K. Chesterton”. La Publicitat, May 221926.

"Jules Romains a Barcelona”. La Revista, 1922.

“La delegació oficial alemanya abandona el Congrés”. La Publicitat, June 8, 1933.

López-Picó, Josep Maria. Epistolari amb Carles Riba. Barcelona: Curial Edicions Catalanes, 1970.

Medina, Jaume. Carles Riba (1893-1959). Barcelona: Publicacions de l'Abadia de Montserrat, 1989.

Millàs-Raurell, Josep Maria. “El teatre de Charles Vildrac”. La Veu de Catalunya, January 17, 1925.

“PEN Club”. Mirador, núm. 328. May 30, 1935.

Pla, Josep. Homenots. Primera sèrie. Obra Completa de Josep Pla. Volume 11. Barcelona: Editorial Destino, 1969.

Riba, Carles. Cartes de Carles Riba I. 1910-1938. Els orígens. Recollides i anotades per Carles-Jordi Guardiola. Barcelona: La Magrana, 1990.

Safont Plumed, Joan. Catalan PEN, an Example of Cultural Diplomacy. Barcelona: PEN Català\&Meteora, 2018.

Sagarra, Josep Maria de. "Hoste eminent. Pirandello". La Publicitat, Desember 14, 1924.

Soldevila, Carles. “Chesterton a les Rambles”. La Publicitat, May 1, 1926. 
Subirana, Jaume. "Organitzacions literàries i mediació: El cas del PEN Català". a Entre literatures. Hegemonies $i$ perifèries en els congressos de mediació literària. Barcelona: PUNCTUM/Grup d'Estudis de Literatura Catalana Contemporània, 2011.

Tasis Marca, Rafael. “El XIII Congres dels PEN Clubs”. Mirador, núm. 328. May 30, 1935.

"Una important moció de condemna de la política cultural nazi". La Publicitat, June 7, 1933.

Watts, Marjorie. P.E.N. The Early Years 1921-1926. Londres: Archive Press Ltd, 1971.

\section{Newspapers and Magazines}

La Veu de Catalunya [1899-1937], La Vanguardia [1881 to present], La Publicitat [1922-1939], L'Opinió [1928-1934], L'Esquella de la Torratxa [1872-1939], Mirador [1929-1938], Meridià [1938-1939], La Revista [1915-1936].

\section{Archives}

Harry Ransom Humanities Research Center, The University of Texas at Austin. 


\title{
12 The International Dimension of the Portuguese "Politics of the Spirit"
}

\author{
António Ferro, Júlio Dantas, \\ Fidelino de Figueiredo
}

\author{
Ângela Fernandes
}

When considering the Portuguese public panorama in the first half of the twentieth century, we should note the close connection between political evolution towards dictatorship and the growing process of institutionalization of cultural and artistic phenomena. In this process, the presence of António Ferro (Lisbon 1895-1956) is absolutely prominent. As a literary author and a public intellectual, Ferro was a leading figure, and his writings help us understand both the international connections and the national focus of the Portuguese state policy concerning the promotion of the arts, namely in the 1930s. ${ }^{1}$ In the newspaper article "Política do espírito" ["Politics of the spirit"], published on November 21st, 1932, António Ferro borrowed Paul Valéry's title and coined the expression and the key concept underlying what he considered the necessary future political and cultural intervention in Portugal, and soon the motto "politics of the spirit" became the heading of the state program to promote the arts. Indeed, a few months later, Ferro was invited to be the director of the SPN-Secretariado de Propaganda Nacional (the Office for National Propaganda), officially inaugurated in October 1933, and all initiatives promoted during the 30s and the 40s under his leadership were meant to be part of a comprehensive "politics of the spirit" aimed at the support and the enhancement of Portuguese culture.

In order to map the international dimension of the Portuguese "politics of the spirit" and also the international (namely European) connections of the Portuguese intellectuals of the time, we shall analyze not only Antonio Ferro's most relevant writings on this topic but also the testimonies of other protagonists of the Portuguese intellectual scenario. Among others, we should mention Júlio Dantas (1876-1962), who was the Portuguese representative in the League of Nation's International Committee on Intellectual Co-operation between 1933 and 1943 and delivered a speech on the "Política Internacional do Espírito" ["International Politics of the Spirit"] at the meeting in Paris, on October 16th-18th, 1933, and also Fidelino de Figueiredo (1888-1967), who participated in the 14th International PEN Conference in Buenos Aires, on September 5th-15th, 
1936, as the official Portuguese delegate, as well as in the seventh meeting of the League of Nation's International Committee on Intellectual Co-operation, also in Buenos Aires on September 11-16th, 1936. In a general sense, in all their writings, we may grasp the tensions between the Portuguese nationally focused politics of the regime and the international background where the avant-garde intellectual and conceptual frame had emerged. We shall analyze the way international references and examples are incorporated in these texts and how the ideas of international culture and relationships function in the arguments developed by these authors.

António Ferro's 1935 statements concerning his own literary life may be read as a key to understanding the changes undergone in the Portuguese public atmosphere in the 1920s and 1930s. In the speech delivered on February 21st, 1935, in Lisbon, during the award-giving ceremony of the first literary prizes of the SPN, in the presence of the head of government, António de Oliveira Salazar, Ferro explains in detail his concept of "politics of the spirit", stressing what it is and what it is not, and eventually recalls his own personal experience. In an explicit answer to those who may reproach some incoherence in his intellectual trajectory, Ferro alludes to his literary avant-garde experiments in the early 1920s. We may easily understand that, since some of those avant-garde works were then found shocking and even outrageous, ${ }^{2}$ they might now be associated with the artworks that, according to Ferro, "blemish" the spirit and must thus be repudiated by the "politics of the spirit". The image of the "combat", which had already appeared in the speech Ferro delivered at the inauguration of the SPN, ${ }^{3}$ is extremely vivid in this 1935 address, the target of this "war" being artistic "evil" (Ferro 1935: 11). But the point is that Ferro's former literary works might be included in this "evil"; therefore, he considers those old experiments as "dead stones from former times" and makes a plea for the artist's "right to evolve". He claims: "that was me, but it is no longer me!" (idem, 17) and adds that nonetheless he still feels himself in the avant-garde, but in a new sense; following Jacques Maritain, Ferro asserts that he is now following an "anti-modern avantgarde, against the mistakes of present time, and ultra-modern avant-garde heading to all the truths of the future" (idem: 17-18). ${ }^{4}$

António Ferro's words are very relevant as our starting point because, first, they show how the institutionalization of cultural policies in Portugal is linked to Modernism and to the avant-garde artistic dynamics and how, in an important way, it results from the international connections developed by many of its participants. On the other hand, these words also show the acknowledged change, in terms of art forms and contents or themes, undergone alongside the consolidation of the "Estado Novo" dictatorship: in the 1930s, artistic experiments and international connections are no longer guided by radical openness and freedom, but rather aim to be in line with the dominant nationalist political outlook, "fighting" against moral (and ideological) deviances. All those who did not 


\section{4 Ângela Fernandes}

understand this new political and artistic stance could not be part of the "ultra-modern avant-garde" promoted in the Portuguese "politics of the spirit", in Ferro's phrasing. These two main lines will organize this chapter. First, we will consider António Ferro's example in the panorama of the international connections of the Portuguese avant-garde and the international models of the "politics of the spirit", along with the need to justify this path with foreign examples. Then, we will analyze how the official "politics of the spirit" built itself as a defense of "healthy" and ordered art (Ferro 1935: 10), stemming from and reinforcing an idea of "national" culture that repeatedly prevailed in both public and academic discourses and that we may also find in rather different authors, such as Júlio Dantas and Fidelino de Figueiredo.

\section{António Ferro, Avant-Garde and International Connections}

During the 1930s the Portuguese authoritarian regime consolidated its system of cultural and artistic guidance by means of the previously mentioned SPN, a state organism created in September 1933. ${ }^{5}$ The date is very noteworthy in the history of Portugal since in this same year a new constitution granted the legal grounds to the "National Dictatorship" that had been established by the coup d'état of May 28th, 1926. António de Oliveira Salazar had become the head of the Council of Ministers in July 1932, and in November he granted several interviews to António Ferro, by then a well-known journalist and opinion-maker. These interviews, which were published as a book in 1933 under the title Salazar, o Homem e a Sua Obra [Salazar, the Man and His Work] and translated into several European languages in the subsequent years, constitute the clearest element of Ferro's direct contribution to consolidating the image of the Portuguese dictatorship on both internal and international grounds. ${ }^{6}$ Moreover, the interviews with Salazar in 1932 are Ferro's definite turning point to plunge into national political affairs after several years dedicated to the international panorama. We may argue that Ferro's willingness to intervene in national life in a "more rational way" (Acciaiuoli 2013: 78) grew precisely from his vivid international experiences and from all he thus learned concerning the new relationship, in the early 20th century, between art, rhetoric, public affairs and politics.

We should recall António Ferro had been close to the Portuguese artistic avant-garde movements since Orpheu (1915). He was the "editor" of this emblematic journal, which gathered remarkable collaborators, such as Fernando Pessoa, Mário de Sá-Carneiro and José de Almada Negreiros. However, it seems he was chosen as editor mostly because, as a minor, he would be "not answerable" by the law, if any problems might arrive due to the ground-breaking stance of the journal (Barreto 2011: 136); Ferro was close to the Orphen group, but not exactly in the group. 
Nevertheless, he represented the worldly taste of some Portuguese modernism, eager to get closer to contemporary international institutions and public personalities. Following this line, after 1919, Ferro became above all a journalist and, at Diário de Notícias, "he made a name for himself mainly as an international reporter, and only left to become Salazar's head of propaganda in 1933" (Barreto 2011: 144).

During his journeys in Europe and America during the 1920s, Ferro interviewed politicians, industrialists, artists and intellectuals such as D’Annunzio, Mussolini, Hitler, Pétain and Primo de Rivera, as well as André Citroën, Jean Cocteau, Douglas Fairbanks, José Ortega y Gasset and Miguel de Unamuno, among many, many others. These international interviews and reportages were published in Portuguese newspapers and eventually collected in different volumes that came out between 1927 and 1933: Viagem à Volta das Ditaduras [Travel around the Dictatorships], 1927; Praça da Concórdia [Concord Square], 1929; Novo Mundo, Mundo Novo [The New Word, A New World], 1930; Hollywood, Capital das Imagens [Hollywood, Capital of Images], 1931 and Prefácio da República Espanhola [Preface to the Spanish Republic], 1933.

In the 1927 book, we may find articles written during the visits paid to the countries where dictatorships had been established: Mussolini’s Italy, Primo de Rivera's Spain, and Mustapha Kemal [Atatürk]'s Turkey. Even if Ferro tries to picture himself as a brave and even impertinent interviewer, it becomes clear he is most respectful with his political interviewees and also quite sympathetic with authoritarian regimes and especially with the figure of the dictator as a man of action. In the Preface to Prefácio da República Espanhola, he clearly acknowledges his preference for "ideas that earn a body, that become men" (Ferro 1933: xx-xxi). And the idea that dictatorships are somehow inevitable is implied in the enigmatic closing sentences describing the meeting with Alejandro Lerroux in 1926:

I say farewell to Lerroux, Primo de Rivera's friendly enemy, with the growing certainty that the Dictatorship is a tall tree where everybody wants to hang themselves... Almost all enemies of dictatorships are dictators longing for their moment. The other people's dictatorship is always cruel, harmful, tyrannical ... only ours is the needed one, the redeeming one.

$\left(\right.$ Ferro 1927: 261) ${ }^{8}$

In the 1929 volume Praça da Concórdia, all twenty-two interviewees are French politicians, artists or industrialists, building what Ferro calls "my panorama of Paris, the panorama of the city of contrasts where everything is different and yet fraternally related" (Ferro 1929: 13). ${ }^{9}$ The large number of interviews and the focus on French life clearly show the central place of Paris and French culture and politics in the intellectual life of the 1920s, at least from a Portuguese point of view. But the North American 


\section{6 Ângela Fernandes}

new ways of life and artforms were also fascinating in the avant-garde milieu. António Ferro's early interest in cinema and jazz persists in the reportage he made in 1927, when travelling in the United States, and later gathered in the volumes about the "New World" and Hollywood. However, despite the worldly perspective, in these volumes there is a constant concern over national affairs and a more or less implicit comparison with the Portuguese way of life and its "authenticity". In the book about Hollywood, there is a general tone of reproach for its "unreality", and the very final sentences are most telling; to an aspiring Portuguese actress who might want to go to Hollywood, Ferro can only say: "Stay in Portugal, where you have already won, where men follow you and women envy you. Do not try so hard (...) Hollywood, what for? Is it not enough the mirror in your bedroom?" (Ferro 1931: 234). ${ }^{10}$

The interviews with Spanish leading figures that took place in 1930 were later collected in Prefácio da República Espanhola, which constitutes the closing volume of Ferro's international tours. This 1933 book is most significant at least for two reasons: on the one hand, it presents interviews that rapidly became somehow outdated due to the proclamation of the Spanish Republic in April 1931, and, as a consequence, Ferro justifies their re-publication claiming that the interview, as a contemporary genre, provides an important source for historiography-thus granting an added value to all his own previous work as an international reporter; on the other hand, Prefácio da República Espanhola allows Ferro to revisit the polemic concerning his description of the "iberianism" of the Republican politician Marcelino Domingo. In the 1930 interviews, Ferro had suggested that the Spanish Republicanism was driven by a federalist and Iberianist urge, somehow threatening Portuguese independence; this caused strong controversy, some considering such a reading was journalistic "manipulation", others willing to support Ferro, up to the organization of a reparation banquet (Cf. Acciaiuoli 2013: 74-75). From this episode, we may conclude that, in the period between 1930 and 1933, António Ferro had strengthened his public image as someone with a sound international background but who was mainly concerned with the protection and the promotion of national identity.

All these interviews and books show that Ferro became more and more aware of the ideological rules of the Portuguese authoritarian regime (and its censorship system), and his effort was towards finding the best way to justify it and give it both a cultural background and an artistic voice. Noticeably, the means he found to accomplish this consisted of being attentive and borrowing from international intellectual models. As mentioned previously, in the newspaper article "Política do espírito" ("Politics of the spirit"), published on November 21st, 1932, António Ferro was using Paul Valéry's expression just a few days after Valéry's address "La Politique de l'esprit. Notre souverain bien", at the Université des Annales on November 16th, 1932, and this is remarkable evidence of 
his interest and ability to be updated and informed about what was going on in Europe, namely in France.

Following Ferro's work and prestige as an international interviewer, and in line with the crucial importance of France in Portuguese cultural life, we should also mention the book Capital do Espirito [Capital of the Spirit], published in 1939 by the young journalist Luís Forjaz Trigueiros (1915-2000). The book gathers sixteen interviews with French writers and intellectuals, ${ }^{11}$ some of which had been published in Portuguese and Brazilian newspapers. The author justifies the importance of these interviews, claiming France was the true "capital of the spirit" (Trigueiros 1939: 24) and therefore the Portuguese "spiritual rebirth" should coincide with the "return" to French culture. ${ }^{12}$ The whole volume is an important testimony of the international networking of Portuguese intellectuals during the 1930s. On a more institutional level, one should consider the interview with Henri Bonnet (1888-1978), who was by then (between 1931 and 1940) the director of the League of Nation's International Committee on Intellectual Co-operation. Bonnet recalls the Portuguese delegates to the Committee, the writers Júlio Dantas and Virgínia de Almeida (1874-1945), and about the latter, he even mentions her book Vie de Camoens, published in Paris in 1934 (Trigueiros 1939: 137). ${ }^{13}$ Both Dantas and Almeida were rather traditional literary authors and also supporters of the Portuguese dictatorship, and we may thus understand that the international connections of the regime continue in the late 1930s, albeit in line with a more careful and conservative choice of the participants.

The meeting of Luís Forjaz Trigueiros with Henri Membré (18901952) in Paris, in 1937, is highlighted by Ana Hatherly in her article about the origins of the Portuguese PEN Club. In 1935, a delegation of the international PEN Club, including Membré and writers such as François Mauriac, Jacques Maritain, Maeterlinck, Gabriela Mistral and Jules Romain, had been invited by António Ferro to come to Lisbon, with the purpose of establishing some contacts that might lead to the creation of the Portuguese PEN. According to Hatherly (2006), there was no followup to this meeting, namely due to the "climate of war" in Europe, but we may infer that the topic of the social responsibility of intellectuals was well known in Portugal. And despite the official censorship, by then some news was published about the PEN Club and the political engagement of international writers. Ana Hatherly explains that Fidelino de Figueiredo, who was an independent delegate to the PEN, asked Ferreira de Castro (1898-1974), the director of Portuguese newspaper O Diabo, to publish a short text mentioning the message sent by the president of the PEN Clubs, H. G. Wells, to all the PEN delegates, calling for the active engagement of writers in favour of world peace. This piece of news appeared in the front page of the newspaper on November 3rd, 1935, but the ground was not favourable to the development of international commitments by 


\section{8 Ângela Fernandes}

Portuguese intellectuals. The efforts to create the Portuguese delegation of PEN, after 1945, was headed by a new generation of writers, clearly more concerned with the "defense of the democratic spirit" (Hatherly 2006).

\section{The Official "Politics of the Spirit" and National Culture}

The 1932 article "Política do Espírito" is an impressive example of Ferro's ability to invoke all sorts of international references, both historical (such as Napoleon) and contemporary (Thomas Mann, Sinclair Lewis, John Dos Passos, Katherine Mansfield, Pirandello and Marinetti, among others), and to lead the argument towards the Portuguese situation. After showing that all important European and American nations have learnt from Napoleon the importance of having a "politics of the spirit", that is, the necessity of protecting and developing literature and the arts along with all the material aspects of society, ${ }^{14}$ António Ferro points to the national panorama with incisive rhetorical questions: "What about our Country? What has been done? What are we doing? What do we hope to do?" (Ferro 1932/2003: 228). He then mentions the moment of national "financial economic and industrial rebirth" and, as its counterpart, makes a plea for the implementation of an "intelligent and steady" politics of the spirit (Ferro 1932/2003: 229).

These pleas did have some echo in the political sphere. As mentioned before, Ferro was appointed director of the new Office for National Propaganda created in 1933, and this constituted the possibility of implementing his concept of the "politics of the spirit" in Portugal, in a definite move towards a nationally centered perspective and action. Nevertheless, in António Ferro's later writings, we keep grasping the tension between the Portuguese morally and nationally focused politics of the new dictatorial regime and the international modernist background where the intellectual and conceptual frame of the "politics of the spirit" had emerged. In 1943, when celebrating the 10th anniversary of SPN, Ferro delivered a long speech where both personal and institutional issues were addressed. After mentioning in detail, and once again, his "evolution" since the time when he was a young "avant-garde iconoclast" (Ferro 1943: 10), he recalls the guidelines Salazar had given him upon the creation of SPN and that by then he sums up in a few short instructions: "Be truthful. Defend the essential. Protect the Spirit. (. . .) Do not spend much" (Ferro 1943: 13). ${ }^{15}$ In the analysis of the work he had done, Ferro affirms that most of SPN's deeds show that "nationalism and avant-garde are not incompatible words" and, on the contrary, "they may sometimes complete themselves"; moreover, to achieve the "divorce" between avant-garde and internationalism, the SPN should simply continue its work and promote the Portuguese popular art as "daring and free" (Ferro 1943: 17-18). ${ }^{16}$ These statements reveal that António Ferro was quite conscious of the 
conceptual and empirical opposition between the avant-garde international (or cosmopolitan) dynamics and the nationally focused mission of SPN; nevertheless, Ferro somehow aspired to overcome that opposition through the "politics of the spirit", and he seemed convinced that the avant-garde survived in "daring" national popular art.

Raquel Pereira Henriques explains that the goals of the SPN, namely "to strengthen the confidence of the Portuguese people and their consciousness of the national specificity", were clearly divergent from Ferro's cosmopolitan attitude, but he tried to "bridge the gap between modern art and popular art, movement and serenity, some universality and the publicized peace and beauty of the rural countryside" (Henriques 1990: 38 and 40). Eventually, it became quite clear that this was an impossible task, since "making the propaganda of what is strictly national was logically incompatible with promoting European authors" (Henriques 1990: 40). ${ }^{17}$ This difficult relationship with all kinds of foreign cultural phenomena is manifest also when analyzing the prizes awarded by the SPN. Starting in 1937, the prize "Camões" was awarded every two years to a literary or scientific work written by a foreign author, but it had to be dedicated to Portugal and Portuguese themes. Significantly enough, the first winner was the Swiss writer Gonzague de Reynold (1880-1970) with a book entitled Portugal (Pinto 2008: 96).

Fernando Rosas considers that, above all, António Ferro and Salazar did not share the same concept of propaganda, since the latter envisaged it as the public relations of the regime made necessary due to its enemies and detractors, whereas for Ferro it meant "the state's investment in the nurturing of souls at all levels". And this "modern" concept of propaganda grew from the journalist's international contacts, which made him more aware of the new priorities in cultural affairs and communication in an age of growing political massification. And that is why, in an early stage, "the avant-garde aesthetics goes together with the conservative ideology of the regime" (Rosas 2003: xxx-xxxi). ${ }^{18}$ However, the complex bureaucratic structure developed around the SNP during the $1930 \mathrm{~s}^{19}$ tended to favor traditional popular aesthetics, and the avantgarde dynamics (or just reminiscences) soon became a problem.

Besides the opposition between past and present (the "disordered and unhealthy" early avant-garde art vs. the "ordered and sound" contemporary art, as described by Ferro in his 1935 speech), a stronger opposition and paradox arose, since the international and cosmopolitan stance of most intellectuals would often be incompatible with the promotion of national, local, genuine art. In a study on "the continuum of modernism in the Iberian Peninsula”, Antonio Sáez Delgado claims:

Modernism performs a remarkable role in the traditional antagonism, on both sides of the aesthetic and ideological trenches, which divided artists into either defenders or detractors of cosmopolitanism. 
What was considered by some to be a great modernist banner of internationalism was interpreted by others, hostile to the "new", as a gesture of petulance or disdain towards the cultural identity of individual nations.

(Sáez Delgado 2011: 215)

The question of nationalism and the concept of national art or culture were issues discussed by Portuguese intellectuals since the late 19th century. ${ }^{20}$ No wonder that we may find this same discussion, with all its conundrums, in several Portuguese authors writing in the 1930s about the "politics of the spirit" or about Portuguese culture and literature. António Ferro was not alone in this duality and paradox, in this vision of the "foreigner" as both a fruitful relational horizon and a threatening element to the national.

The writer Júlio Dantas, who had been one of the most emblematic antagonists of the avant-garde young authors (we may recall, namely, Almada Negreiros's Manifesto anti-Dantas, from 1916), also had important international responsibilities in the 1930s. As described by Dantas's biographer, the writer delivered a speech on the "future of culture" in a meeting organized by the League of Nations in Madrid in May 1933 and was then nominated by Marie Curie to a position at the International Committee on Intellectual Co-operation (Guimarães 1963: 260-261). Already as an elected member of the Committee, Júlio Dantas participated in the conference that took place in Paris in October 1933. His address, published in the French proceedings of the conference, also appeared in a Portuguese translation under the title "Política Internacional do Espírito" ["International Politics of the Spirit"].

The text is very significant concerning the duality national vs. international. In a conference on the future of European culture, Dantas expressed his belief in the existence of an "European spirit", albeit rather "vague and unstable" (Dantas 1933b: 10-11); he thus claims this European spirit is in need of defense and promotion. The reasons for the weakness of the European spirit seem, however, insurmountable: Júlio Dantas draws a clear distinction between the "deep" national personalities and the "superficial" European personality, thus suggesting that the local and the national identities have solid (we might even say natural) grounds, whereas the international identity is just a cultural construct. Using very striking words, he explains:

We completely feel our national personality, as the expression of an ethnic, historical and linguistic complex; we do not have the consciousness of our European personality. (...) what we have as our own, as national, dwells deeply in the soul of the races, the solid stratification of ethic determinants and ancestral characteristics; in contrast, what we have in common, as European, lives only at the 
surface, floating in the realm of the ideas, in the speculative domain of science, in the high spheres where literary movements, aesthetic influences and philosophical doctrines circulate.

(Dantas 1933b: 17-19) 21

This description establishes a difference in kind between the national and the supra-national (European or other), and we must conclude such a difference is virtually impossible to overcome. Despite trying to defend the development of the "European spirit", Júlio Dantas proposes a concept of national belonging whose "deep" roots may not be matched by any other kind of common belonging. In this frame of mind, the European project of a "society of spirits" (Dantas 1933b: 21) can only be a weak, if not doomed, endeavor.

If Júlio Dantas represents a conservative stance, maybe unaware of its paradoxes, in line with the Portuguese dictatorship, the literary critic and historian Fidelino de Figueiredo stands for a clear dissident position towards the dictatorship 22 and a rather progressive line of thought. Figueiredo was a remarkable public intellectual, who had widely travelled and lived in Europe, Brazil and the United States since the 1920s, and was in touch with different international associations and networks; as mentioned previously, he was an independent delegate of the PEN Club, and in September 1936, he participated at the Buenos Aires meetings of both PEN (cf. Figueiredo 1937) and the League of Nation's International Committee on Intellectual Co-operation.

In 1935, Fidelino de Figueiredo published the ground-breaking essay Pyrene. Ponto de vista para uma introdução à história comparada das literaturas portuguesa e espanhola [Pyrene. A Perspective Towards an Introduction to the Comparative History of Portuguese and Spanish Literatures], which introduced the broad comparative interpretation of Portuguese and Spanish national literary traditions, along with reflection on the concepts and the methods employed in such a comparative study. In this volume, Figueiredo proposes to analyze the literatures of Portugal and Spain both as different realities and as a common Iberian tradition and draws several levels of "particularity" (or identity), thus suggesting that the comparative approach allows for the recognition of different, and sometimes contradictory, conformations of collective cultural or literary identities. This implies a significant cosmopolitan perspective, but somehow the essay also displays a very strong idea of the "national spirit" rooted in the concept of homeland ("pátria"). In the chapter on "literary nationality", Fidelino de Figueiredo claims:

My contemporary formula would be: literature is the artistic expression of a national spirit in a national language. Literary nationality has, thus, two essential bedrocks, homeland and language, and a dominating scope, emotion in art. Homeland gives the content, with 


\section{2 Ângela Fernandes}

its moral unity, its internal and relational problems, its restlessness; language provides the form, the instrument of expression.

(Figueiredo 1935: 17) $)^{23}$

The idea that it is the homeland that yields the "content" to any national literature stipulates the prominence of national belonging in the existence of artworks. Even if he does not elaborate, as Ferro did, on the potentialities of national popular art, Figueiredo is also, just as Dantas did, pointing at some unmatched national dimension of literature, and this is incompatible with any truly international stance on artistic phenomena. The essay Pyrene did not, therefore, go beyond the use of a supranational and comparative approach mostly intended to highlight national specificities.

We may thus conclude that, even when supporting international connections and approaches, Portuguese intellectuals in the first half of the 20 th century were deeply immersed in a strong concept of national culture. Consequently, the dominant thought during the implementation of the Portuguese "politics of the spirit" prevented any radical shift from the nationally based ideas of art, culture or collective life. From different perspectives, António Ferro, Júlio Dantas or Fidelino de Figueiredo were just expressing the (probably unacknowledged) limits of the internationalization of Portuguese modernity.

\section{Notes}

1. Detailed information on António Ferro's life and work may be found in the books by Raquel Pereira Henriques (1990) and Margarida Acciaiuoli (2013), and also in António Rodrigues's preface (1987) and José Barreto's article (2011). Some bio-bibliographical data is also available at the website of Fundação António Quadros (a foundation dedicated to one of António Ferro's sons), as a revised version of the book Retrato de Uma Familia [Portrait of A Family], by Mafalda Ferro and Rita Ferro (1999).

2. As explained by José Barreto, this was specifically the case concerning Ferro's most "controversial and scandalous work", the theatre play Mar Alto, performed in São Paulo in 1922 and in Lisbon in 1923 (Barreto 2011: 143).

3. In 1933, Antonio Ferro exclaimed he knew he was starting a "relentless war": "sei que vou para a luta, para a guerra sem tréguas!" (Ferro 1933/1948: 20).

4. My translation, as in all quotations, unless stated otherwise. Original Portuguese texts will be provided in footnotes. This is the relevant fragment of Ferro's speech: "Quando pretenderem barrar-nos o caminho lançando-nos ao rosto pedras mortas de outras idades, saibamos responder com aprumo e serenidade: "Esse fui eu, mas não sou eu!" / Quer isto dizer que renuncio, e deixo de estar na vanguarda? Iludem-se ou fingem iludir-se os que tal pensam. Sinto-me na vanguarda como nunca, numa vanguarda que vai para além do presente e se situa no futuro. (. . .) Como Jacques Maritain, (...) eu considero essa vanguarda anti-moderna contra os erros do presente e ultra moderna por todas as verdades que se contêm no futuro" (Ferro 1935: 17-18).

5. The law that created the SPN was passed on September 25th, and the official inauguration took place on October 26th, 1933. 
6. For a detailed explanation of the editorial history of this book, see the volume Entrevistas de António Ferro a Salazar, published in 2003 with a preface by Fernando Rosas.

7. "não quero esconder que simpatizo mais com ideias quando elas se corporizam, quando essas ideias são homens" (Ferro 1933: xx-xxi).

8. "Despeço-me de Lerroux, do amável inimigo de Primo de Rivera, com a certeza, cada vez mais profunda, de que a Ditadura é uma árvore alta em que todos se querem enfocar ... Quase todos os inimigos das ditaduras são ditadores que esperam o seu momento. A ditadura dos outros é sempre cruel, nefasta, tirânica . . . só a nossa é a precisa, só a nossa é a redentora" (Ferro 1927: 261).

9. "o meu panorama de Paris, panorama da cidade dos contrastes onde tudo é diferente e irmão" (Ferro 1929: 13).

10 "Fica em Portugal, onde já venceste, onde os homens te seguem, onde as mulheres te invejam. Não corras tanto . . . (. . .) Hollywood, para quê? Pois não te basta o espelho do teu quarto?" (Ferro 1931: 234).

11. Here is the complete list of interviewes: Georges Duhamel, Paul Valéry, Henri Massis, Luc Durtain, Claude Silve, Philippe Soupault, Jacques de Lacretelle, Henri Bonnet, Francis Carco, Léon Pierre-Quint, Frédéric Lèfévre, Jules Romains, Henri Membré, Albert Mousset, Gabriel Marcel, Georges Pagés and Georges Le Gentil.

12. In the preface to the book, Trigueiros exclaims: "que o nosso renascimento espiritual coincida com um regresso à França!” (Trigueiros 1939: 23).

13. Bonnet's words about Almeida are most laudatory: “a vossa brilhante escritora Vergínia [sic] de Castro e Almeida, autora de Vie de Camoes, que tanto prestígio tem na vida intelectual parisiense." (Trigueiros 1939: 137).

14. The relevant sentences of the article are most telling: "O desenvolvimento premeditado, consciente, da Arte e da Literatura é tão necessário, afinal, ao progresso duma nação como o desenvolvimento das suas ciências, das suas obras públicas, da sua indústria, do seu comércio e da sua agricultura. As nações podem viver, interiormente, sem dúvida, dessas necessárias actividades, mas vivem exteriormente, acima de tudo, da projecção da sua alma, da personalidade dos seus escritores e artistas" (Ferro 1932/2003: 226).

15. "Seja verdadeiro. Defenda o essencial. Proteja o Espírito. (. . .) Não gaste muito" (Ferro 1943: 13).

16. "Tantas realizações (. . .) demonstram, definitivamente, que nacionalismo e vanguardismo não são duas palavras incompatíveis, que, pelo contrário, algumas vezes se completam ....(. .) Eu sei que vanguardismo (detesto a palavra modernismo) e internacionalismo são duas palavras que andam quase sempre juntas. Mas para conseguir o seu divórcio bastará continuar o que temos feito: trabalhar pelo renascimento da nossa arte popular, audaciosa e livre" (Ferro 1943: 17-18).

17. "O Secretariado tem como objectivo reforçar a confiança do povo português e fortalecer a consciência da especificidade nacional" (Henriques 1990: 38); António Ferro tenta "conciliar a arte moderna com arte popular, o movimento com a serenidade, uma certa universalidade com a divulgada paz e beleza rurais" (idem: 40), mas "fazer a propaganda do que é estritamente nacional era, logicamente, incompatível com a divulgação de autores europeus" (idem: 40).

18. "Para António Ferro, e isso fica claro desde o seu célebre artigo no Diário de Notícias, a propaganda era muito mais do que um serviço de informação pública do Governo. (. . .) Era o investimento do regime na formação das almas a todos os níveis (. . .) Tudo servido por uma estética vanguardista, originalmente casada com os conteúdos ideológicos conservadores do regime" (Rosas 2003: xxx-xxxi). 


\section{4 Ângela Fernandes}

19. For a detailed description of the "ideology, institutions, agents and practices" of the activities of S.P.N. between 1933 and 1949, i.e., under the direction of António Ferro, see the study by Jorge Ramos do Ó (1999) and also the second chapter of the volume by Margarida Acciaiuoli (2013). A comprehensive approach to the Portuguese artistic phenomena from this same period is also provided by Ellen Sapega (2008).

20. Luís Reis Torgal explains nationalism was a topic central to both republican and monarchic ideologies and engaged Portuguese intellectuals from the whole political spectrum (Torgal 2004: 1088). For a comprehensive discussion of the phenomena of "nation building" in the Iberian Peninsula in early 20th century, see the book by Thomas Harrington (2015).

21. "Sentimos plenamente a nossa personalidade nacional, expressão restrita de um complexo étnico, histórico, linguístico; não possuímos a consciência da nossa personalidade europeia. (...) o que nós temos de próprio, de nacional, reside profundamente na alma das raças, na sólida estratificação das determinantes étnicas e dos caracteres ancestrais; ao passo que o que nós temos de comum, de europeu, vive apenas na superfície, paira no mundo das ideias, no domínio especulativo da ciência, nas esferas superiores em que se movem as correntes literárias, as influências estéticas, as doutrinas filosóficas" (Dantas 1933b: 17-19).

22. Information about Fidelino de Figueiredo's life and work may be found, e.g., in the collective volume published by the Portuguese National Library (Bibioteca Nacional) in 1989. António Soares Amora explains (pp. 13-15) Figueiredo's participation in the 1927 failed "coup d'état" against the 1926 "National Dictatorship" and his following imprisonment and exile.

23. "A minha fórmula actual seria: a literatura é a expressão artística dum espírito nacional numa língua nacional. A nacionalidade literária tem, pois, dois alicerces essenciais, a pátria e a língua, e um escopo dominador, a emoção de arte. A pátria dá a matéria, com a sua unidade moral, seus problemas internos e de relação, sua inquietude; a língua dá a forma, o instrumento de expressão" (Figueiredo 1935: 17).

\section{References}

AA.VV. 1989. Fidelino de Figueiredo 1888-1967. Lisboa: Biblioteca Nacional.

Acciaiuoli, Margarida. 2013. António Ferro: A vertigem da palavra. Lisboa: Bizâncio.

Almeida, Virgínia de Castro e. 1934. Vie de Camoens: le poete des Lusiades et le Portugal de son temps. Paris: Éditions Ducharte.

Barreto, José. 2011. “António Ferro: Modernism and politics.” In Portuguese Modernisms: Multiple Perspectives on Literature and the Visual Arts, edited by Steffen Dix and Jerónimo Pizarro, 135-154. London: Legenda.

Dantas, Júlio. 1933a. “Exposé de M. Júlio Dantas.” In L’Avenir de l'esprit européen. Entretiens, org. Émile Borel et al., 34-44. Paris: Societé des NationsInstitut International de Coopération Intellectuelle.

— 1933b. Política Internacional do Espírito. Lisboa: Portugal-Brasil, Sociedade Editora. ["Texto português do discurso pronunciado em Paris, na sessão inaugural da Conferência Cultural Europeia, em 16 de Outubro de 1933”].

Ferro, António. 1927. Viagem à Volta das Ditaduras. Preface by Comandante Filomeno da Câmara. Lisboa: Diário de Notícias. 
1929. Praça da Concórdia. Lisboa: Empresa Nacional de Publicidade.

1930. Novo Mundo, Mundo Novo. Lisboa: Portugal-Brasil.

1931. Hollywood, Capital das Imagens. Lisboa: Portugal-Brasil.

.1932/2003. "Política do Espírito.” In Entrevistas de António Ferro a Salazar, 225-229. Lisboa: Parceria A.M. Pereira.

1933. Prefácio da República Espanhola. Lisboa: Empresa Nacional de Publicidade.

—. 1933/1948. "Resposta de António Ferro ao Sr. Presidente do Conselho, na inauguração do SPN, a 26 de Outubro de 1933." In Catorze Anos de Política do Espírito-Apontamentos para uma exposição, 19-21. Lisboa: Secretariado Nacional de Informação.

-1935. A Política do Espírito e os Prémios Literários do S.P.N. Lisboa: Edições do SPN.

- 1943. Dez Anos de Política do Espírito 1933-1943. Lisboa: Edições SPN.

- 2003. Entrevistas de António Ferro a Salazar, with a preface by Fernando Rosas. Lisboa: Parceria A.M. Pereira.

Ferro, Mafalda \& Rita Ferro. 1999. Retrato de uma Família-Fernanda de Castro, António Ferro, António Quadros. Lisboa: Círculo de Leitores.

Figueiredo, Fidelino de. 1935. Pyrene. Ponto de vista para uma introdução à história comparada das literaturas portuguesa e espanhola. Lisboa: Empresa Nacional de Publicidade.

— 1937. "Discurso de Fidelino de Figueiredo, delegado de Portugal." In XIV Congreso Internacional de los P.E.N. Clubs, 5-15 de septiembre de 1936. Discursos y Debates, 79-82. Buenos Aires: P.E.N. Club de Buenos Aires.

Fundação António Quadros www.fundacaoantonioquadros.pt

Guimarães, Luís de Oliveira. 1963. Júlio Dantas: Uma Vida, uma Obra, uma Época. Lisboa: Romano Torres.

Harrington, Thomas. 2015. Public Intellectuals and Nation Building in the Iberian Peninsula, 1900-1925: The Alchemy of Identity. London: Bucknell University Press.

Hatherly, Ana. 2006. "Origens do PEN português.”/"Origins of the Portuguese PEN Club”. Translated by Mick Greer. http://www.penclubeportugues.org/ historial/origens/

Henriques, Raquel Pereira. 1990. António Ferro. Estudo e Antologia. Lisboa: Publicações Alfa.

Pinto, Rui Pedro. 2008. Prémios do Espírito. Um estudo sobre prémios literários do secretariado de propaganda nacional do Estado Novo. Lisboa: ICSImprensa de Ciências Sociais.

Ramos do Ó, Jorge. 1999. Os anos de Ferro. O dispositivo cultural durante a "Política do Espírito" 1933-1949: Ideologia, instituições, agentes e práticas. Lisboa: Editorial Estampa.

Rodrigues, António. 1987. “António Ferro: Uma modernidade pronta a viver.” In Obras de António Ferro 1. Intervenção Modernista, ix-xxvi. Lisboa: Verbo.

Rosas, Fernando. 2003. "Prefácio." In Entrevistas de António Ferro a Salazar, xi-xxxii. Lisboa: Parceria A.M. Pereira.

Sáez Delgado, Antonio. 2011. "The continuum of Modernism in the Iberian Peninsula, 1890-1936." In Portuguese Modernisms: Multiple Perspectives on Literature and the Visual Arts, edited by Steffen Dix and Jerónimo Pizarro, 214-225. London: Legenda. 


\section{6 Ângela Fernandes}

Sapega, Ellen W. 2008. Consensus and Debate in Salazar's Portugal: Visual and Literary Negotiations of the National Text, 1933-1948. University Park: Pennsylvania State University Press.

Torgal, Luís Reis. 2004. "O Modernismo português na formação do Estado Novo de Salazar. António Ferro e a Semana de Arte Moderna de São Paulo.” In Estudos em Homenagem a Luís António de Oliveira Ramos, 1085-1102. Porto: Faculdade de Letras da Universidade do Porto.

Trigueiros, Luís Forjaz. 1939. Capital do Espírito. Lisboa: Tipografia da Empresa Nacional de Publicidade.

Valéry, Paul. 1957. "La politique de l'esprit. Notre souverain bien.” In CEuvres I, edited by Jean Hytier, 1014-1040. Paris: Gallimard.

\section{Web references}

www.penclubeportugues.org/historial/origens/

www.penclubeportugues.org/historial/origins-of-the-portuguese-pen-club/ 


\section{Between the Local and the International}

Enrique Gómez Carrillo and Antonio Aita at the International Institute of Intellectual Cooperation $^{1}$

\section{Laura Fólica and Ventsislav Ikoff}

What was the relationship of Latin American intellectuals with Europe during the interwar period? What were their ideas on intellectual internationalization? How was Latin America perceived by European and Latin American intellectuals?

We aim to approach these questions from the perspective of the founding and activity of the Argentine National Committee on Intellectual Cooperation, as part of the International Institute of Intellectual Cooperation (IICI), which operated in Paris between 1925 and 1946. We will examine the profiles of the most prominent actors involved in the Committee, focusing mainly on the work of Argentine representatives Enrique Gómez Carrillo, delegate at the Argentine Legation from 1926 to 1927, and Antonio Aita, secretary of the Argentine National Committee from 1936 to 1940 . We review their positions on the concepts of "intellectual cooperation", "internationalism", and "Americanism", 2 as well as their relationship with national and foreign literature, based on an analysis of documents from the IICI archives kept at the UNESCO library in Paris.

\section{International Intellectual Cooperation}

International intellectual cooperation began to take shape in 1922 with the founding of the International Committee on Intellectual Cooperation (Commission internationale de coopération intellectuelle, CICI), a League of Nations organization based in Geneva that aimed to foster collaboration between countries and coordinate work and international relations in the fields of science and culture. CICI members included figures of the stature of Henri Bergson, Albert Einstein, Marie Curie, and Gilbert Murray. The Argentine poet Leopoldo Lugones was the only Latin American to be part of this distinguished group of intellectuals.

Due to practical difficulties at the CICI, such as the infrequent work sessions or the lack of personnel and funding (Lemke 2007, 204-205), a new organization was set up in 1925 and officially opened in Paris 


\section{8}

in 1926, named the International Institute of Intellectual Cooperation. The IICI was founded at the suggestion of the French government, which also financed its operations with an annual contribution of two million francs. The Institute was conceived as an executive organ of the CICI for the purpose of carrying out the projects commissioned by the Committee, and it functioned as a "bureau d'administration internationale". ${ }^{3}$

The IICI engaged with different aspects of intellectual work, studying topics such as copyright, the international organization of bibliography and the international exchange of publications, the circulation of books, publishing, and university exchange initiatives for lecturers and students.

The IICI existed for almost 20 years, until 1946, although it ceased operations between 1940 and 1944 due to World War II. After the war, the functions of the Committee and the International Institute of Intellectual Cooperation were inherited by UNESCO. In 1939, at the start of the war, the Institute cooperated with over forty national committees. In this chapter, we follow the steps that led to the consolidation of the Argentine Committee, which was a pioneer in establishing dialogue between Europe and Latin America.

\section{Enrique Gómez Carrillo, Forerunner of Argentine Cultural Internationalization}

Discussion over the Argentine representation at the IICI and possible forms of intellectual collaboration began early. In its first month of activity, November 1925, the president of the IICI, Julien Luchaire, contacted the Argentine Embassy in Paris (as well as the diplomatic representatives of other countries) to discuss initiatives that the country could undertake in the field of intellectual cooperation. Throughout 1926, correspondence between Luchaire and different representatives of the Argentine government became more frequent until the names of the Argentine delegates to the IICI were finally confirmed in September 1926.

The relationship between the Institute and a Hispanic country was not unique within the Ibero-American context. Shortly afterwards, in 1927, the Spanish delegation was established with Júlio Casares as representative, followed by Mexico, represented by Alfonso Reyes, in 1931. ${ }^{4}$ This almost simultaneous acceptance of the three initiatives should be understood as an effective response to a proposal made by the Institute itself. At the meeting of the Latin American delegates at the IICI in Paris on 13 May 1927, it was agreed that the creation of national committees in the different countries should be encouraged. These committees would function as a link between the cultural and scientific institutions of each country and the International Committee on Intellectual Cooperation in Geneva (Herrera León 2009).

In the Argentine case, during the year 1927, the Guatemalan poet and diplomat with Argentine citizenship, Enrique Gómez Carrillo (1873-1927), 
was responsible for carrying out the functions of representative for the Argentine delegation. He was chosen by the Argentine president, Hipólito Yrigoyen, for his outstanding position as an intellectual in Paris. Indeed, Gómez Carrillo had travelled to Europe for the first time with a scholarship to study in Madrid in 1890 but instead headed to Paris, like so many other Latin American writers who saw the French capital as the "Republic of Letters" where they would gain recognition (Casanova 1999). There he met Paul Verlaine, Leconte de Lisle and Oscar Wilde, among other writers, and embraced the life of the intellectual bohemia. In addition to writing narrative and essays, such as Literatura Extranjera and $\mathrm{La}$ nueva literatura francesa, he excelled mainly in Spanish-language journals as a chronicler for Argentina (La Nación, La Razón), Cuba (Diario de la Marina) and Madrid (El Liberal, Blanco y Negro, La Esfera, Pluma y Lápiz, El Imparcial, $A B C$ ), hence receiving the nickname "el príncipe de los cronistas" (the prince of chroniclers).

In June 1926, Gómez Carrillo informed Julien Luchaire, president of the IICI, of Argentina's interest in participating in international cooperation:

Quelques confrères argentins, desireux de voir leur pays figurer parmi les nations representées officiellement à votre Institut, ont eu l'idée de demander à leur Gouvernement de me désigner en qualité de delegué à cette Commission Intellectuelle.

Pour le cas où le Ministère des Affaires Etrangères de Buenos Ayres prendrait en considération ma candidature, je vous serai très obligé de bien vouloir me faire communiquer la marche qu'il faudrait suivre pour être agrée comme Delegué officiel, en me disant si cette delegation est compatible avec mon poste de consul à Paris. ${ }^{5}$

Luchaire responded positively regarding the compatibility of the post of delegate with that of Argentine consul and clarified that the appointment depended only on the national governments and would be free from interference by the Institute of Paris. Finally, Gómez Carrillo was elected as delegate by the foreign minister, Ángel Gallardo.

For his part, Luchaire, on behalf of the IICI, was flattered by the election of Gómez Carrillo as an Argentine representative, given his cosmopolitan character, considering him "un homme représentatif de la culture de la langue espagnole, bien qu'au cours de ses longs séjours en Europe le français fût devenu pour lui une seconde langue". ${ }^{6}$ Luchaire also proposed to him the creation of an "Argentine Library" with "the best authors" (which would be a precursor to the Ibero-American Collection).

During his time as delegate, Gómez Carrillo promoted the Institute and defended international intellectual cooperation. His letters to the director of the Institute reveal that in 1927 he published articles on the IICI in the Argentine newspapers La Época and El Diario, as well as in the Spanish newspaper $A B C$. These publications, of course, were well received by the 
director of the Institute, Julien Luchaire, who considered that "le terrain se prépare très bien là-bas et nous pourrons, l'année prochaine, y recueillir des fruits intéressants". ${ }^{7}$

The terrain was also being prepared at an institutional level. In July 1927, the Argentine Ministry of Foreign Affairs sent a note to Argentine universities and the Argentine Scientific Society with a report by Gómez Carrillo stating the need to create a national committee on intellectual cooperation. And indeed, the University of Buenos Aires, the National University of La Plata and the Argentine Scientific Society supported the idea of founding an Argentine committee, while Gómez Carrillo's enthusiasm left the impression at the IICI that an Argentine National Committee was about to be formed. Unfortunately, this project was suspended due to Gómez Carrillo's premature death only a few months later, in November 1927.

Despite his brief tenure as delegate, it is still interesting to highlight the internationalist ideas of Gómez Carrillo, which he himself exhibited in his article on the IICI published in the Madrid-based newspaper $A B C$ on 2 November 1927. Right from the beginning of the article, he points out the peripheral, albeit advantageous, position of Argentina as a country of the "New World" with respect to Spain in terms of intellectuality and cooperation. It is worth noting that in the same year a famous dispute about Madrid as the "intellectual meridian" of America was launched in La Gaceta Literaria by Guillermo De Torre as an attack on, above all, the declared Latin American Francophilia. This annexationist, though apparently fraternal, proposition of De Torre was met with a virulent response from, among others, the Argentine avant-garde magazine Martin Fierro. The magazine rejected Spanish primacy over Argentina in intellectual matters and suggested the literary recovery of the oral language of Rio de la Plata blended with foreign languages (Sarlo 1997, 211-268).

Gómez Carrillo opened his article by pointing the finger at Spain: "Every time there is talk of the International Institute of Intellectual Cooperation, Spanish Americans ask: 'Why has Spain remained outside this Association?'” And he went on to reply that Argentina, as a young country, had understood the role of the IICI better than Spain: "And it is that the Latin countries of the New World have understood, from the beginning, the importance of this Assembly of nations that march at the vanguard of progress for the moral propaganda of the peoples who speak Castilian. There, indeed, we can fraternize, without difference of ranks, with France, Italy and the British Empire".

And he added that "even in countries that at first sight seem inaccessible to European culture, intellectual centres have been created with the support of the great universities that adhere to our principles", that is, to the principles of the IICI. Although Spain had received the support of the Junta para la ampliación de estudios (Board for advanced studies) and 
the University of Barcelona, Gómez Carrillo judged this support as “a small thing": "And to think that it would be so easy to occupy a position of the first order there, at that centre, which is the most important one of universal intellectuality".

In fact, for Gómez Carrillo, Spain had lagged behind in intellectual matters and needed to recover its central place vis-à-vis Latin America. This concern of his can be seen from his encouragement for the country to join the institute despite having withdrawn from the League of Nations, since being a member of one was not a requisite for forming part of the other. Therefore, the hostility against Spain that seemed to surface in his first lines later became more nuanced in its virulence. At the end of his article, the diplomat considered Latin America to be in the subsidiary position of a "daughter" since, in his opinion, for it to reach the spiritual domination of the "Great Motherland" of the Castilian language, it was imperative for "Spain to appear next to her transatlantic daughters".

Finally, for Gómez Carrillo, this exercise of cooperation would unite the American continent with Spain and, more generally, with Europe, so that educational, bibliographical, scientific and archaeological networks to "inventory the treasures of the world" could be woven and "normal research methods" established. A "real network of publications" for distributing everything would need to be created as, in this way, "the practical results of the Institute's activities" could be seen. Gómez Carrillo was also aware that international cooperation was based on the recognition of the reciprocity of peoples: "One day or another, in effect, those who yesterday reached out, asking us for instruments of intellectual work, will offer us the fruit of their labours so that, through us, other countries in need can then take advantage of them", he stated in his article for $A B C$, not knowing that this would be the destiny of Argentina with the onset of the wars.

Gómez Carrillo's early ideas on cooperation between Europe and Latin America can be compared with the later words of Antonio Aita, who would institutionalize the national committee.

\section{Antonio Aita and the Institutionalization of Argentine International Cooperation}

After his death, Gómez Carrillo was succeeded by the new consul in Paris, Joaquín de Vedia. In fact, the Argentine representation before the IICI continued to be via diplomats, as the Argentine consul of the embassy in Paris continued to be assigned as delegate. This changed with the creation of the Argentine National Committee in 1936. Prior to that year, there had been a period of limited activity and collaboration between the Argentine government and the IICI. The only exception was the subsidy granted by Argentina for the translation and editing of the 


\section{Laura Fólica and Ventsislav Ikoff}

book Facundo by Domingo Faustino Sarmiento in the Ibero-American collection.

A more active exchange began in September 1935 when the secretary of the PEN Club of Buenos Aires, the writer and critic Antonio Aita (1891-1966), suggested to the director of the IICI, Henri Bonnet, that an entretien be held in Buenos Aires to coincide with the PEN International Congress of 1936 being held in the same city. Thus, in July 1936, in the midst of the preparations for these two events, the Argentine National Committee finally emerged.

Unlike Gómez Carrillo, Aita was not part of the diplomatic corps, nor was he a prominent journalist or writer, although his production of essays on Argentine and Latin American literature was not insignificant. ${ }^{8}$ Despite his low profile, Aita moved with ease in the cultural field and adopted French as the language for his epistolary exchange with Europe. It could be argued that his work was that of a cultural mediator interested in promoting intellectual relations between Europe and Latin America and earning him the nickname of "Tony Agita" (Tony Agitates) from Jorge Luis Borges and Adolfo Bioy Casares in one of their stories signed under the pseudonym Bustos Domecq.

However, Aita did not rub shoulders only with local writers, as his friendship with Borges and Bioy Casares or his connection with the magazine Nosotros (which published some of his books) testify: he also had access to the higher government echelons of the time, together with other nationalist intellectuals, such as Carlos Ibarguren or Juan B. Terán, who formed part of the National Committee. This is how he informed the IICI of the steps he had previously taken with respect to the government in order to create the Committee:

Monsieur Nogueira, pendant son séjour à Buenos Aires, m'a parlé de ce sujet et je m'en suis intéressé avec Monsieur le Président de la République, qui m'a fait l'honneur d'acceuillir avec grand intérêt mon initiative. Par la suite et d'accord avec les suggestions de Monsieur le Ministre de l'Instruction Publique j'ai fait quelques remarques sur le rôle développé par l'Institut à Paris et mes informations ont servi à cimenter les considérations du décrèt. ${ }^{9}$

It should be noted that Aita had direct access to the Argentine president at the time, Agustín P. Justo, who approved the creation of the Committee. A participant in the so-called "infamous decade", for its succession of conservative and unpopular governments, Justo had taken power fraudulently in 1932 with the support of the military that had overthrown Hipólito Yrigoyen, the democratic president from the Unión Cívica Radical (Civic Radical Union) party. Later, Aita himself referred to his personal contact with the president and his own influence in creating the national committee, explaining: 
I have accepted the Secretariat of the Committee because I have contracted a personal debt with President Justo, who, following my kind suggestion, created the Argentine Committee. This acceptance obliges me to rally my efforts in favour of an increasingly closer cooperation with cultural institutions abroad. ${ }^{10}$

The Argentine National Committee on Intellectual Cooperation was founded on 14 July 1936 by presidential decree. The decree was noticeably general in character and in no way specified any political or economic conditions; however, the justification for the decree did highlight the interest that existed in positioning Buenos Aires among the "main cities of the world" that made up the network of "spiritual cooperation". This network was understood as a broad exchange of knowledge-not restricted only to education-to enrich a "universal culture" shared among peoples through specific contributions from a national culture.

The first article of the decree detailed the Committee's objectives, which were: "to promote the development of intellectual relations with foreign countries and cultural exchange, receiving the contribution of scientific, literary, philosophical, educational and artistic knowledge of other peoples and bringing together, organizing and disseminating those produced through internal intellectual activity". These objectives showed that cooperation was understood in terms of equal and harmonious circulation of knowledge between countries, where knowledge seemed to be considered a spiritual element, free of material constraints. Likewise, thanks to this network of international reciprocity, local production was able to become part of a greater, "universal" cultural production; that is to say, according to this conception, the universal did not oppose the local or national, but rather enhanced and incorporated it. Past and future wars, however, showed the darkest face of rivalry between European nations.

The second article explained the Committee's organizational chart, which was composed of "nineteen honorary members, appointed by the Executive Power, whose mandate lasted five years and who could be reelected". The committee would appoint its president and vice president and propose to the Executive Power, through the Ministry of Justice and Public Instruction, the appointment of an external permanent secretary with a monthly salary of three hundred pesos-the national currency. This was precisely the position that Antonio Aita occupied from 1936 to 1946.

The third article published the list of Committee members and their public positions and included experts in law, literature and sciences, professors and deans and members of scientific academies. It is striking that the members came mostly from the well-off classes or from the country's power circles, including, for example, Bernardo Houssay, journalist and member of the Academy of Medicine and the Argentine Academy of Letters; Juan B. Terán, member of the Argentine Academy of Letters 


\section{4}

and minister of the Supreme Court of Justice; Ricardo Levene, historian, president of the Board of History and Numismatics, and former president of the National University of La Plata and Adolfo Bioy, lawyer and former minister of Foreign Affairs and Worship.

Notwithstanding this governmental decree, there is little doubt that the act that gave real existence to the Committee was a specific event: the "Entretien Europe-Amérique Latine" of the IICI, which took place in Buenos Aires between 11 and 16 September 1936. Due to the scale of the event and thanks to its secretary, Antonio Aita, who was also secretary of the PEN Club of Argentina, the Committee gained greater prominence and projection. Since Aita had participated in the organization of the PEN International Congress that was to take place in Buenos Aires in 1936, he knew how to take advantage of the visits by world-renowned writers to organize an entretien under the auspices of the IICI, the first in a Latin American country and thus to give more visibility to the Institute and Latin American intellectuals.

It should be noted that the meeting was financed by the Argentine Government and not by the PEN Club. This made it possible to take advantage of the presence of the writers invited to participate. In this respect, Aita clarified: "That is why the PEN Club, which has facilitated the possibility of this meeting, as well as President General Justo, with whom I was able to discuss the IICI's plans, have shown themselves to be keenly interested and willing to collaborate so as to ensure its success". ${ }^{11}$

Correspondence regarding the preparations of the entretien revealed an intense debate between Antonio Aita, Henri Bonnet and Dominique Braga as to the organization of the meeting, as well as to the subsequent translation and editing of the communications that took place in 1937.

In the extensive correspondence, it should be noted that the proposal by Aita to organize the first South American entretien was celebrated by Bonnet, since the previous meetings had taken place in Europe. The choice of subject, however, led to more discussion, since Aita initially thought of addressing the role of the PEN Club in international culture. Bonnet rejected this proposal because it was too specific and focused on a non-state institution, and pointed out that it would be better to adopt a more general topic regarding the role that writers should play in contemporary life. After much correspondence, in which Bonnet handed over the management to Braga (the former would not be able to attend the meeting, but the latter would), an agreement was reached to address the intellectual relations between Europe and America from two angles:

a. La littérature européenne en Amérique. Tendance et orientations de la littérature et de la pensée européenne. Problèmes qui se posent à elle. Influence de la pensée et des lettres européennes sur la pensée americaine. Rôle des valeurs culturelles européenes en Amérique dans le passé et le présent. 
b. Influence dans l'avenir de la littérature ibero-américaine dans la pensée mondiale. (Ce point est la contrepartie du précedent). Originalité de l'esprit américain. Ses points de vue sur les principaux problèmes de culture mondiaux, par exemple, machinisme, nouvel humanisme. Les apports nationaux américaines à la culture universelle. ${ }^{12}$

One European representative and one Latin American representative would tackle each of the two questions at two opening addresses. Likewise, it was agreed that some contributions would be previously requested in writing so that they could be distributed among the different attendees. As for the number of attendees, after an initial proposal of fifty participants by Aita, the number was eventually reduced to twenty. Bonnet and Braga preferred a greater Latin American presence and a proportional number of figures from Europe. The list of proposals was as follows:

- European writers: France 2; England 2 (Wells, Huxley); Spain 2 (Madariaga, Ortega); Italy 1; Germany 1; Central Europe or the Balkans 1; Northern or Eastern Europe 1 (Karel Čapek).

- American writers: USA 1; Mexico 1 (Alfonso Reyes); Puerto Rico 1 (Pedro Henríquez Ureña); Colombia 1 (Baldomero Sanín Cano); Perú or Chile 1; Uruguay 1; Argentina 3; Brazil 1 (Afranio Peixoto). ${ }^{13}$

The French participants, however, were the ones to attend the meeting in greater numbers. In contrast, it proved difficult to engage Englishspeaking participants. Although several options were considered (H. G. Wells, G. K. Chesterton, Virgínia Woolf and Aldous Huxley, among others), they refused for different reasons. Despite this situation, Aita asked for written communications from Waldo Frank (who would decline the invitation), Aldous Huxley and Count von Keyserling so that they could be shared for discussion with the other participants. ${ }^{14}$ Eventually, the English delegates to the PEN International Congress, Ralph Hale Mottram and William J. Entwistle, took part in the entretien. However, there is no indication that any representatives of the United States attended the meeting. The meeting was therefore finally entitled "Europe-Latin America".

Although Braga and Bonnet missed a greater representation of writers from Europe and the United States, Aita saw no need to insist on this point. The absence of English-speaking writers would demonstrate, in his opinion, the lack of interest, especially on the part of the writers from the United States-whom he derided as "Yankees"-in the intellectual discussion on cooperation, since they always tended to position themselves as a people superior to the rest of Latin America. This rejection was broadly related to the "arielista" current, which, following the Ariel essay (1900) by the Uruguayan writer José Enrique Rodó, regarded the United States as the cradle of the utilitarian and materialist Caliban, and Europe 


\section{Laura Fólica and Ventsislav Ikoff}

as the heart of the European humanist tradition (Pernet 2007, 66). In this respect, according to Aita, the entretien would represent an opportunity to break with the relationship of domination by the United States and recover national sovereignty. And he put it bluntly in a letter to Bonnet:

Je vous avouerai que déjà depuis nombre d'années je lutte contre cette politique d'infiltration yanquee qui cherche à dominer les peuples hispano-américains et je suis souvent préoccupé par cette question que je considère très grave puisqu'elle tend à nous isoler de l'Europe. Je me suis entretenu à ce sujet avec Monsieur Madariaga et si la Société des Nations manque de prestige et de popularité dans cette partie du continent américain nous le devons en grande partie à cette tactique tendencieuse et habilement déployée par la Maison Blanche. ${ }^{15}$

As for the quest for representation of the different European countries, as suggested by the IICI, Aita insisted that pursuing this principle would mean entering the field of politics, which he felt intellectual life should not "fall" into:

I have always believed and still believe that intellectual life has nothing to do with politics, and I believe that even in the absence of English writers, it [the entretien] is not in danger, as you think, since there will be eminent figures of contemporary literature and thought. Otherwise, it would fall into politics. It is not possible to fight against the indifference of the English writers toward everything that means an exchange with their colleagues from other countries. We have invited Wells, Chesterton, Huxley, Joyce, Walpole and Virgínia Wolf [sic] to participate in our congress. Some of these gentlemen have declined the invitation for various reasons, others have answered simply with their silence. Now, tell me frankly, if, in these conditions, one can talk about cooperation. ${ }^{16}$

Counter to the meager English presence, France acquired more prominence and became the compass to guide the Latin American writer. We can see that Francophilia was widespread at that time, as noted in Carlos Reyles's review in his article "Ecos del congreso argentino de los Pen Clubs": "There are Hispanic Americans willing to jump from the sphere of the particular to the sphere of the universal as resolutely as the French delegation, which showed the way". ${ }^{17}$

After much toing and froing with the invitations, the attendees at the entretien were finally Pedro Henríquez Ureña (Dominican Republic); Luis Piérard (Belgium); Enrique Díez Canedo and Joan Estelrich (Spain); Fidelino de Figueiredo (Portugal); Baldomero Sanín Cano (Colombia); Emil Ludwig (Switzerland); Afranio Peixoto (Brazil); Alfonso Reyes 
(Mexico); Carlos Reyles (Uruguay); Giuseppe Ungaretti (Italy); Stefan Zweig (Austria); Alcides Arguedas (Bolivia); R. H. Mottram and W. J. Entwistle (England); Georges Duhamel; Jules Romains and Jacques Maritain (France) and Carlos Ibarguren, Francisco Romero and Juan B. Terán (Argentina). ${ }^{18}$ In the report on the entretien, read at the Second General Conference of the National Committees on Intellectual Cooperation (July 1937), Aita evoked the spirit that guided the meeting and its main ideas on cooperation. ${ }^{19}$ Cooperation between America and Europe would be based on three activities: the dissemination of scientific knowledge ("disseminate scientific research efforts of a large group of specialists in public and private institutions"), the promotion of higher education ("pedagogy highlighting the efforts of governments to boost secondary, technical and university education") and the promotion of translation ("it would ultimately promote the translation of literary works by contemporary authors"). In the opinion of the secretary of the Argentine Committee, the mutual exchange of knowledge was crucial for a "coopération féconde" and to achieve it, writers could not remain isolated or confine themselves to what was merely local:

Quels peuvent être les apports de notre continent à ce problème vital, dont la solution préoccupe les esprits les plus perspicaces de notre époque? Il ne s'agit pas ici de prononcer des phrases pompeuses sur l'"autochtonisme" de notre culture; cette idée a amené bien des esprits à préconiser l'isolement comme remède à nos erreurs politiques, et ainsi a dirigé l'inspiration de nos écrivains vers une tradition locale. La remise en honneur d'une tradition peut être féconde, si elle contient les éléments qu'exige l'intelligence, à un moment de crise des valeurs tel que celui que nous traversons. ${ }^{20}$

Advocating against the defense of an exclusive national tradition, Aita advocated that the American peoples got to know each other better, but that did not mean adopting the formula "America for the Americans". Quite the contrary, Aita believed that, as secretary of the Committee, he had to ensure the universal spirit of the IICI and not the regionalism of the Committee. ${ }^{21}$ And he openly targeted American "provincialism": "Beaucoup d'esprits simples s'obstinent aveuglément à vouloir une Amérique pour les Américains, persistant ainsi à répondre par un provincialisme mesquin à l'indifférence que nous manifestèrent les Européens pendant de nombreuses années". 22

Aita maintained the opposition-common at the time and already observed in Gómez Carrillo-between the Old and the New Worlds, but instead of claiming a certain subsidiarity of the latter with respect to the former, he demanded that the Old Continent finally get to know America: "Connaissance sérieuse et directe de nôtre Continent que l'Europe a regardé avec une certaine froideure". ${ }^{23}$ Aita agreed that the "Old World" 


\section{Laura Fólica and Ventsislav Ikoff}

was the cradle of civilization; but the "New World", younger and less knowledgeable, would, on the other hand, have greater creative capacity due to its curiosity. In this respect, he described Latin Americans as "peuples à l'imagination féconde" (peoples with a prolific imagination) who "occupent de vastes territoires, dont la curiosité est toujours en éveil" (occupy vast territories and whose curiosity is always awake). For Aita, even if his tradition of knowledge was lesser ("même si sa culture était des plus superficielles"), the American man-Aita was speaking of the Latin American-possessed an "esprit sensible à toute entreprise idealiste. Romantique par atavisme et plein d'un noble détente" (a spirit that is sensitive to all idealistic endeavor, romantic by atavism and full of noble selflessness). In other words, the features of the American man were quite idealized in his writings: a romantic man who embraced with disinterest and curiosity any idealistic undertaking. In contrast, the European was described as belonging to a people of adventurers who depopulated and repopulated America. Likewise, Aita recognized the unequal relationship between America and Europe, not only referring to the Conquista (pointing a finger at Spain) but also to the disparate knowledge that some peoples had of others: America knew Europe (referring especially to France and England); Europe remained indifferent to America.

That being said, Aita recognized that the intellectual field was less developed in America ("un milieu qui n'a pas encore atteint ce niveau supérieur où prennent toute leur valeur critique la signification et la puissance que possède dans la vie sociale de la collectivité l'éffort de l'esprit"). For this reason, the writer there did not enjoy the same prestige that he would have in Europe. For Aita, the fight for the rights of the Latin American writer was crucial and, through the PEN Club, he asked the Argentine government to protect them:

Dans notre Amérique où l'écrivain n'a pas de hiérarchie sociale, il lui manque aussi les moyens de défense pour protéger la propriété de son effort intellectuel, et par le manque d'une législation avisée, l'écrivain est exposé à toute espèce de pirateries de la part d'éditeurs sans scrupules. ${ }^{24}$

He also asked the IICI to take a stand to defend writers' rights by creating unified international legislation that would protect authors from onerous contracts imposed by the publishers. He argued that an international framework of this kind would put more pressure on the Argentine government. It should be noted that intellectual property law 11.723 -still in force in Argentina-dates back to 1933.

Another of the events organized by Aita-which was supported by Dominique Braga and the IICI-was the Exhibition of Argentine books, inaugurated at the National Library of France in Paris in November 
1938. For the occasion, Aita brought in around 2000 volumes of national literature (novels, stories, poetry, theatre, criticism and essays), textbooks, books on science, law and social sciences, history and geography and the fine arts, as well as a selection of cheap books, another of luxury books and a selection of books translated and published in Argentina. ${ }^{25}$ For the exhibition, he also edited the bilingual volume Le Paysage et l'âme argentine. Descriptions, récits et légendes du terroir (1938). The exhibition was accompanied by a series of speeches-the inaugural address was read by Paul Valéry-and also showcased examples of Argentine paintings and graphics, again brought for the occasion by Antonio Aita.

Beyond its significance in recognizing Argentine book production in France and Europe, the exhibition also planted the seeds of a conflict within intellectual circles in Argentina. During the opening act, Paul Valéry praised Victoria Ocampo, director of the influential magazine Sur, as - in his opinion - the utmost advocate of French culture in Argentina: "[...] there is no more enthusiastic and knowledgeable interlocutor for European literature in Argentina than the publisher of Sur" (Comisión Argentina de Cooperación Intelectual 1939, 53). Ocampo, a famous writer and translator who came from a family of the Argentine oligarchy, had chosen French as her language of literary expression and enjoyed privileged access to European culture through her frequent travels and numerous intellectual friends and artists (Sarlo 2007, 75-148). Not long after Valéry's compliment, she was invited to join the International Committee on Intellectual Cooperation in 1939. It should be noted that Ocampo had known of the work of the Institute for some time, since her friend Gabriela Mistral, the Chilean representative before the IICI between 1926 and 1939, had invited her to visit it a decade earlier. In a letter dated 22 March 1929, the Chilean poet said:

\section{Admired Victoria Ocampo}

Greetings—only yesterday I learnt you were here. And it is very painful for me to leave without meeting you. I leave on Monday. Could you do us the honour of a visit to the Institute of Intellectual Cooperation, 2 rue Montpensier? Mr. Levinson has been notified in case you grant us the time and this grace.

(Mistral and Ocampo 2007, 43)

Ocampo's appointment to the International Committee in Geneva upset Antonio Aita. Aita was not related to the Sur magazine group, as he viewed it as a publication that disdained national literature in favour of that of Europe and North America. His disagreement with that decision was such that he presented his resignation as secretary of the Argentine National Committee to the IICI. In no uncertain terms, Aita reproached 
Bonnet for ignoring the Argentine National Committee in appointing Ocampo as a member of the Committee. Although he had nothing "to object personally to Mrs. Ocampo", Aita considered that she was:

[...] a writer who does not gravitate in the spiritual life of Argentina, who has never given her collaboration to undertakings of cultural exchange, who in her books does not reveal any concern for Argentine problems, who has never believed in the existence of Argentine literature, much less in the existence of an Argentine culture, and who has been designated precisely to represent it [Argentine culture] in the organization in Geneva. ${ }^{26}$

Aita suggested that it would be more appropriate to appoint Carlos Ibarguren, president of the national committee and member of the Academy of Letters, or men of science such as Bernardo Houssay or Alfredo Sordelli, both members of the national committee. Aita eventually rebuked Valéry-who proposed Ocampo's designation-for a sin of gallantry, asserting that "the gesture of courtesy is a precious instrument in human relations, but terribly baneful when applied to critical or historical analysis", since "from our May Revolution to the present day there has been a great number of Argentines to whom French culture is more indebted than to Mrs. Ocampo for its dissemination and evaluation". ${ }^{27}$ In response to Aita's anger, Dominique Braga sent a letter, with a broadly personal tone, in which he acknowledged the mismanagement of the International Committee in appointing Ocampo and asked him earnestly not to resign because they still had work to do together:

C'est avec une grande prudence, vous l'avez constaté, que nous procédons au choix de nos livres, des préfaces, des traducteurs, en consultant toujours les personnalités qualifiées. En ce qui concerne l'Argentine, nous sommes d'accord, nous nous sommes séparés bien assurés du programme que nous voulions réaliser, de la mission que nous incombait, à vous en Argentine, à moi ici. Vous ne pouvez pas nous quitter, Aita, vous ne le devez pas. Nous avons entrepris en commun une oeuvre, il faut que vous soyez avec nous jusqu'à ce que nous l'ayons menée à son terme. ${ }^{28}$

Aita did not eventually resign, but he warned that if a similar situation were to occur again, the links between the Argentine National Committee and the Institute would be damaged forever:

All these circumstances have made me abandon the decision I had made, following the appointment of Mrs. Victoria Ocampo; but I want to point out that this designation has not only been poorly received among those in this country who ply this trade, but that it 
has also affected some American commissions [. . . I think I have understood in one part of your letter that the initiative of Mr. Ozorio de Almeida, aimed to cause an exchange of correspondence on current issues, invites the members of the International Committee to obtain the respective replies from their countries. If this happens, with respect to Argentina, a delicate situation will again be produced, a situation which could have the consequences already indicated, for Mrs. Ocampo is completely disconnected from the Argentine Intellectual Cooperation, and any action that she takes, by indication of this organization, will be interpreted as an act of disregard towards ours. $^{29}$

Exactly the same situation that Aita referred to had taken place earlier, in the same year that Ocampo had been invited to participate in the preparation of the volume Pour une sociéte des esprits, part of the Correspondences series of the IICI. The volume compiled opinions of various intellectuals responding to a letter from Miguel Ozório de Almeida, president of the Brazilian Committee, who asked, shortly before the beginning of World War II, if the return to barbarism was inevitable in Europe and suggested that the "moral armament" of nations such as France or England should be supported..$^{30}$ For Latin America, Henri Bonnet, at the suggestion of Paul Valéry, had asked Ocampo to divulge the contents of Ozorio de Almeida's letter and gather answers from writers who she deemed relevant (the IICI had already requested the collaboration of Alfonso Reyes from Mexico, Gabriela Mistral from Chile and Baldomero Sanín Cano from Colombia). Ocampo gladly carried out this work among writers who were "amis de la France": "Soyez persuadé que si je puis vous rendre service et rendre service à un pays que j'aime comme le mien, c'est moi qui vous serai reconnaissante de m'en fournir l'occasion". ${ }^{31}$ And after a brief negotiation, Bonnet allowed her to publish the Latin American responses in her magazine Sur, with the exception of Ozorio de Almeida's letter, which was not published in that particular volume. Indeed, the responses were published in issue 61 of the magazine (Ocampo 1939, 115-121), dedicated to the War. The hypothetical situation that Aita was denouncing had already been caused by the International Committee, placing him in another situation which could lead to his potential resignation from the National Committee. In the end, the resignation was not made effective, since Aita and Braga continued to communicate throughout 1940 regarding the publication of a new issue of Correspondance, this time at the proposal of Aita.

Aita did not welcome the publication of these responses in Sur, not because of the content, but because of the way in which the initiative had been undertaken. On his part, he undertook the project of a new volume of Correspondance dedicated to analyzing the Europe-Latin America entretien (advancing an idea of the Spanish poet Salvador de Madariaga), 


\section{Laura Fólica and Ventsislav Ikoff}

which would be published by the Argentine National Committee and translated into English and French by the IICI. It would be a volume with contributions from Latin American intellectuals who were not present at the entretien of Buenos Aires but who could analyze what had happened at the meeting. Aita pointed out that he was not looking for a discussion about "politics or countryside passions", nor for geographic representation-as was the case at the entretien - since it would not be necessary for all countries to be present but only the names necessary for the "study of the culture of our times". The initial letter was entrusted to Peruvian diplomat Francisco García Calderón. The first answer was given by Aita and the second by the Argentine writer Ricardo Rojas. The volume would include other contributions, such as the ones of Uruguayan writer and philosopher Carlos Vaz Ferreira, the Ecuadorian writer and diplomat Gonzalo Zaldumbide, the Bolivian writer and politician Alcides Arguedas, the Chilean story-writer and playwright Eduardo Barrios, the Brazilian writer and politician Tristán de Athayde and the Venezuelan writers and politicians Rufino Blanco-Fombona and Arturo Uslar Pietri. Later, because he had taken part in the entretien, Aita considered replacing Arguedas with the Bolivian writer and politician Adolfo Costa du Rels or with the Cuban poet Mariano Brull.

It seems that the volume was left incomplete and unpublished, but we can still get an impression of the views of those who participated in it. The ideas put forward in Aita's letters completed his conception of cooperation, Americanism and internationalism. García Calderón's ideas were outlined in a letter from Ricardo Rojas: "It seems that in this direction", says Calderón, "the two worlds can continue collaborating in a safe and trusting friendship, without denying America its attitude of a disciple and with Europe considering with interest and sympathy how its norms and tutelary creations return to it from overseas with new vigor, and how its idealism survives in noble romantic lands". What did the other two correspondents respond? ${ }^{32}$ On the one hand, Aita maintained the topic of "peoples of the New World of a romantic nature" who have "older brothers" in Europe, that is to say, he maintained that "attitude of disciple" of one continent towards the other, suggested by Calderón. He pointed out that "America is nurtured by Europe", but added that it already had the foundations for creating an American culture that could be separate from the European one: "In America the foundations already exist, in technique, art, literary expression and philosophical understanding of life to advance a culture that will not be its own nor exclusive, but that will increasingly tend to separate from the European one without ignoring it". Aita nuanced the tutelary relationship described by Calderón, considering that it was time to develop an American culture, albeit nurtured by the European one. At this point, he rejected the regionalist ideas that he had labelled "isolationist", as we saw earlier, and he pointed out that, faced with Europe in crisis, "that theory of "America for the 
Americans' was fallaciously created and was later substituted by another, more romantic and universalist theory of 'America for humanity.' These two principles are antagonistic, but equally rhetorical". In short, for Aita, the key lay in mutual understanding, above all, on the part of Europe towards America. The ideal of knowledge ("the faith in the spirit") would nurture both "the old cultures" and "these new forms of intelligence that flourish on our continent amid frantic struggling"; that is, the romantic aspect (the love of ideas) prevailed again over the material constraints.

On the other hand, Rojas did not take long to respond with much more virulence to Calderón's statements. The Argentine writer judged Calderón for holding a "European rather than American" view on the matter, typical of the nineteenth century but anachronistic in the mid-twentieth century. Rojas considered that, in the first place, it was necessary to define what is meant by "Europe" and "America". He believed that for Calderón, "Europe" was reduced to France and England and perhaps by extension to "Spain and the Mediterranean". On the other hand, Calderón seemed to be unaware of the vital impulse sweeping through America. So, Rojas condemned the "tutelary attitude" that Calderón welcomed because it was precisely this attitude that "has sterilized us intellectually and subjected us economically". He urged Americans to "take possession of our land and our mind, which is also colonized". Rojas considered that Europe had always maintained a relationship, not a harmonious one, as Calderón and even Aita believed, but rather one of domination: "Europe has not looked towards it [America] other than as a field of exploitation or influence. The dilemma we face in the future consists of knowing whether we Americans should resign ourselves to that destiny or should aim towards our plenitude of life. The current crisis in Europe makes the dilemma more agonizing". And in that sense, he argued that the crisis was an opportunity to break with European tutelage ("not [to] have masters or guardians. And it is necessary to develop the skills for it") and especially with Spanish tutelage, since it was against Spain that "our America wages its war of emancipation". And although there was rapprochement due to speaking the same language, the "spiritual reconciliation" with Spain would respond-for Rojas-rather to an interest in "reviving the original essences of our history", where the indigenous, the Creole, as well as the European and the Spanish would re-emerge. Finally, Rojas did not consider there to be a common culture between Europe and America based romantically on the "faith in the spirit", as Aita suggested. While there could be an understanding of what happened in each of the two, the culture was particular to each of them, "it is not transplanted", "it is the spiritual creation of each people".

Unfortunately, it seems that the discussion did not continue with other writers, but this first exchange is useful, as it shows us how Aita maintained his ideas about an America intellectually indebted to Europe, but which was also in the process of becoming autonomous and developing 


\section{Laura Fólica and Ventsislav Ikoff}

its own identity. His moderate vision is not as Eurocentric as that of Gómez Carrillo or that of the "amis de la France" writers, who responded to Ocampo's call to support France in the war and break with neutrality. For Aita, it was time for Europe to look at America as an adult, although he still recognized the civilizing force of Europe, even if at the time this force was fatally threatened by totalitarian regimes. In short, far from the social-economic approach of Rojas, who spoke plainly of domination, Aita maintained a more idealistic and even romantic vision of the relationship between peoples, based on a faith in understanding hatched in minds that were unburdened by material constraints. He also defended the peculiarity of Argentine culture and its literature, without falling into "provincial" or "isolationist" reductionism. The unique identity was woven in dialogue with other identities, hence his trust in cooperation, which was based on the production of knowledge, teaching and translations.

On this last point-the translations-it is worth mentioning another of the IICI's projects in which Aita collaborated, namely the IberoAmerican Collection, which introduced representative works of the different nations, "traductions des textes notoires", in the words of Henri Bonnet, ${ }^{33}$ marking the willingness to set up an Ibero-American canon. ${ }^{34}$ The translation and publication of the volumes in the Ibero-American Collection were funded by each country. In the case of the Argentine translations, the Argentine government extended a grant of 700 pounds sterling (or 8,008.18 Argentine pesos at the time of the grant), decreed in May 1928. In exchange, it demanded 500 copies for distribution in public institutions such as schools, universities and libraries. The rest of the supposedly larger print runs of about 1,500 copies were commercialized and the profits invested in the publication of other works for the same country. The selection of titles for translation was made by a publication committee that had been specially designated for the collection and was agreed with national academies. During the whole process, it seems that the involvement of the Argentine National Committee was limited to assisting with logistical issues (e.g., procuring reference works for the translators). The first volume of Argentine literature, Sarmiento's Facundo (translated by Marcel Bataillon), had already been published in 1932, before the creation of the National Committee (1936-1945). It was followed by Las montañas by Joaquín V. González (1937, translated by Marcel Carayon) and Martín Fierro by José Hernández (translation by Marcel Carayon, a bilingual edition with a preface by Ricardo Rojas). The publication of this last volume was in peril due to the increased costs of publishing in France and the specific format of the volume. The organizers wanted to publish the translation along with the original text and a line-by-line literal translation. On that occasion, Antonio Aita managed to obtain an additional sum of 3,500 French francs from the Argentine National Committee to secure the publication. Aita also set 
about looking for funding for a fourth translation, for which Los indios ranqueles by Lucio Mansilla was considered. By indication of Dominique Braga, about 30,000-35,000 French francs would have been necessary for that volume; however, the archive holds no further information as to its destiny. Another volume, Facundo (Juan Facundo Quiroga) by Ramón José Cárcano (translated by Charles-Vincent Aubrun), was also prepared, ${ }^{35}$ although outside of the collection, as it was not considered a classical work and its author was still living.

The epistolary communication regarding the publication of these volumes treated other more material issues, such as the delayed payment of the Argentine subsidy, the request for more financial help, the increase in the cost of publishing in France, the type of paper and the number of pages. The discussions also concerned who should write the prefaces (which aimed to help the French reader) and who should do the translation (usually university professors with a recognized academic track record in Hispanic literature). Translators were concerned with advances, copyright terms, deadlines and some translation issues, especially the vocabulary of the gauchos.

With regard to the titles themselves, it is interesting to see that the canonical list of Hernández, Sarmiento and González was joined by the book of the historian Ramón José Cárcano, a multifaceted politician, who occupied many positions such as professor of law and history, dean of the Higher Institute of Agronomy and Veterinary Medicine, member of Parliament, governor of Córdoba, ambassador in Brazil and member of the Academy of Letters and History, among others. As a curious fact, it should be pointed out that at that time, in 1939, the post of Argentine ambassador in Paris was occupied by his son, Miguel Ángel Cárcano. Nevertheless, the translation of Cárcano's book was included largely due to the success of Sarmiento's Facundo $o^{36}$ and the interest in "un ouvrage historique qui éclairerait la période de la vie argentine où Sarmiento a puisé le sujet de son ouvrage classique Facundo", as Henri Bonnet explained. ${ }^{37}$

\section{Conclusions}

This chapter has chronicled how the Argentine Committee on Intellectual Cooperation took shape, first with the representation of Enrique Gómez Carrillo and later with that of Antonio Aita, who organized the entretien in Buenos Aires in 1936. We can consider both Gómez Carrillo and Aita "cultural mediators", active agents "across linguistic, cultural and geographical borders, occupying strategic positions within large networks and being the carriers of cultural transfer" (Roig-Sanz and Meylaerts 2018, 3). Both were interested in forging ties between Europe and Latin America and saw the League of Nations (and specifically the IICI) as an opportunity to strengthen the bond between both continents. Both 
conceived Europe as the cradle of civilization and agreed in thinking of Latin America as the "New World", as "a young nation", conceptualized in quite romantic terms, which would draw on the "Old World" to achieve its modernization.

Nevertheless, differences also existed in the way that this relationship was conceptualized. On the one hand, Gómez Carrillo displayed a more marked Eurocentrism than Aita, describing the American nations as being in a subsidiary relationship as "transatlantic daughters" of the "Great Homeland". For Aita, on the other hand, Europe needed to regard America on more equal terms and get to know it in depth rather than from a sense of mere picturesqueness. According to the Argentine delegate, Latin America had entered adulthood and should be explored and known beyond its exoticism. Aita also recognized the lesser degree to which the artistic field was institutionalized in Argentina and Latin America. The lack of legislation on writers' rights, among other concerns, accounted for an intellectual field that was not yet consolidated and was less professional than its European counterpart. For Aita, therefore, America was rather in the process of forming its own identity, and while the continent recognized the strength of the European tradition (especially the French one), it was also becoming autonomous from Europe and incorporating its own problems, such as those of the indigenous peoples. As for his own country, Aita tried to portray Argentina as in its adulthood (continuing the analogy of the young nation), while still relating it to the European humanist culture (although not its policy, which had brought confrontation to the continent) and, on the other hand, staying clear of the culture of the United States, regarded as merely utilitarian.

Furthermore, Aita believed that it was possible to achieve a spiritual community of intellectuals whenever men of letters left politics aside. It should be noted that this was suggested precisely in times of strong politicization of the cultural field, due to both the Spanish Civil War and World War II, which was in the making. In other words, the intellectual was not supposed to join one of the sides that separated the countries but transcend them in a more ecumenical community, guided by ideas of intellectual cooperation and cultural actions of a transnational nature, as seen in the translation of Latin American works for the Ibero-American Collection of the IICI. It is clear that at a time when Argentine works were being promoted internationally, a canon of "national" literature to be read in Europe was being prepared, based on a type of gaucho literature.

It has been demonstrated that the ideas about national literature pitted Aita, more inclined to nationalism, against the Sur group and against its highest representative, Victoria Ocampo, who was considered by the Argentine nationalistic side as favoring the foreign and as indifferent to local reality. Now, at this point, we should qualify this opposition since, on the one hand, Sur was also concerned with American identity and, on the other, Aita defended the national culture, although not in a way that 
was closed in on itself. In fact, he opposed what he called "isolationism" or regional "provincialism" and found in intellectual "cooperation" the key to the international relationship that would lead to the modernization of the American continent. It was a cooperation based on the spirituality of minds, which made up the "palace of thoughtful humanity", in the words of Gómez Carrillo, but also one that was detached from politicaleconomic dimensions, a view criticized by, among others, Ricardo Rojas, who was more aware of the material constraints that allowed or restricted the circulation of ideas, either locally or internationally.

The description of the Argentine delegation between 1926 and 1940, before the IICI, showed how the links between the Argentine, Latin American and European intellectuals were woven-sometimes in the spirit of cooperation and at other times in evident confrontation. It is clear that the interwar period was the appropriate time to propose a new relationship between Europe and Latin America in the hope of forming an international vanguard of reason that would put a brake on the looming Second World War. Unfortunately, this hope came to an end when the activities of the IICI and the respective committees were suspended in 1940 .

\section{Notes}

1. This chapter is part of the R\&D project "Mapping Hispanic Modernity. Cross-border Literary Networks and Cultural Mediators (1908-1939)" (FFI2016-76055-P), funded by the Spanish Ministry of Economy, Industry and Competitiveness and the ERC Starting Grant "Social Networks of the Past. Mapping Hispanic and Lusophone Literary Modernity (1898-1959)" (803860).

2. Consistent with the spirit of Gómez Carrillo and Aita, America and "Americanism" are used in this chapter in the broader sense referring to the American continent and, consequently, all and every people or nation on the continent, rather than to the United States and its people, as is usual in the English language.

3. Julien Luchaire, "La S. d. N. et le gouvernement français ont fondé l'Institut international de coopération intellectuelle". L'Europe nouvelle, 16 January 1926, pp. 76-77.

4. See Herrera León (2009) and the archives of both national committees (UNESCO FR PUNES AG 1-IICI A-III-27 and A-III-48).

5. "Several Argentine colleagues, eager to see their country among the nations officially represented at your Institute, had the idea of asking their government to appoint me as a delegate to this Intellectual Committee. In the event that the Ministry of Foreign Affairs of Buenos Aires takes my candidacy into consideration, I would be very much obliged if you would inform me of the procedure that should be followed to be approved as Official Delegate, and to tell me if forming part of this delegation is compatible with my post as consul in Paris". Enrique Gómez Carrillo to Julien Luchaire, 5.6.1926, UNESCO FR PUNES AG 1-IICI A-I-133.

6. "[A] man representing the culture of the Spanish language, although during his extensive sejourns in Europe, French became a second language to him". Biographical note of Gómez Carrillo, UNESCO FR PUNES AG 1-IICI A-I-133. 


\section{Laura Fólica and Ventsislav Ikoff}

7. "The terrain is being very well prepared there and next year we will be able to reap some interesting fruits”. Julien Luchaire to Enrique Gómez Carrillo, 14.9.1927, UNESCO FR PUNES AG 1-IICI A-I-133.

8. Aita's publications include: "Retratos imaginarios" (1917), "Notas al margen de la poesía argentina" (1929), "Aspectos de la literatura argentina" (1930), "La literatura argentina contemporánea 1900-1930" (1931), "La literatura y la realidad americana" (1931), "Expresiones" (1933), "Indagaciones" (1934), "Itinerarios" (1936), "Comentario" (1938), "Cuatro ensayos" (1939) and "Relatos del tiempo viejo" (1955).

9. "Mr. Nogueira, during his stay in Buenos Aires, spoke to me about this subject and I addressed it to the President of the Republic, who did me the honour of welcoming my initiative with great interest. Subsequently, and in agreement with the suggestions of the Minister of Public Instruction, I made some remarks on the role played by the Institute in Paris and my information served to cement the considerations of the decree". Antonio Aita to Henri Bonnet, 15.7.1936, UNESCO FR PUNES AG 1-IICI A-III-37.

10. Antonio Aita to Dominique Braga, 28.5.1937, UNESCO FR PUNES AG 1-IICI F-VI-5, doc. 86.

11. Antonio Aita in an interview with La Nación, a copy of which was sent to Henri Bonnet, 8.4.1936, UNESCO FR PUNES AG 1-IICI F-I-1-1a, doc. 239-242.

12. "a-European literature in America. Trends and directions of European literature and thought. The problems they are facing. The influence of European thought and letters on American thought. The role of European cultural values in America in the past and present.

b-Influence on the future of Ibero-American literature in world thought. (This point is the counterpart of the previous one). Originality of the American spirit. Its views on the main problems of world culture, for example, mechanization, new humanism. American national contributions to universal culture". Dominique Braga to Antonio Aita, 4.4.1936, UNESCO FR PUNES AG 1-IICI F-I-1-1a, doc. 244-246.

13. Ibid., adapted by the authors.

14. The volume dedicated to the entretien and published the following year by the IICI includes Keyserling's contribution but not Huxley's due to a supposed oversight by Braga.

15. "I will confess to you that for many years I have been fighting against this Yankee policy of infiltration, which seeks to dominate the HispanicAmerican peoples, and I am often worried by this question, which I consider very serious, since it tends to isolate us from Europe. I discussed this matter with Mr. Madariaga and if the League of Nations lacks prestige and popularity in this part of the American continent, we owe much of it to this tendentious and skillfully deployed tactic by the White House". Antonio Aita to Henri Bonnet, 8.4.1936, UNESCO FR PUNES AG 1-IICI F-I-1-1a, doc. 239-242.

16. Antonio Aita to Dominique Braga, 4.6.1936, UNESCO FR PUNES AG 1-IICI F-I-1-1a, doc. 191.

17. La Nación, November 1936.

18. The Spanish volume of the entretien, translated by E. M. S. Danero for the Argentine National Committee, includes the opening addresses by Georges Duhamel and Alfonso Reyes, along with communications from Enrique Díez Canedo, Pedro Henríquez Ureña, Carlos Ibarguren, Keyserling, Afranio Peixoto, Louis Piérard, Carlos Reyles, Francisco Romero, Baldomero Sanín Cano and Juan B. Terán. 
19. This chapter focuses on the events organized by Aita for the Argentine National Committee based on material from the IICI archives held at the UNESCO archives. For an analysis of the content of the communications read at the entretien, see Pernet (2007) and the chapter 7 in this volume "The 1936 Meetings of the PEN Club and of the International Institute of Intellectual Cooperation in Buenos Aires" by Alejandra Giuliani.

20. "What can the contribution of our continent be to this vital problem, the solution of which worries the most perceptive minds of our time? It is not a question here of uttering pompous phrases about the 'autochthonism' of our culture. This idea has led many minds to advocate isolation as a remedy for our political mistakes, and so has led the inspiration of our writers towards local traditions. The recovery of traditions can be fruitful if it contains the elements that intelligence demands at a time of crisis of values such as the one we are going through". Antonio Aita, "La Coopération intellectuelle entre l'Amérique et l'Europe", report to the Second General Conference of the National Committees on Intellectual Cooperation, July 1937. UNESCO, FR PUNES AG 1-IICI-A-21, 1.

21. Antonio Aita to Jean-Jacques Mayoux, 2.8.1945. UNESCO FR PUNES AG 1-IICI A-III-37.

22. "Many simple minds blindly persist in wanting an America for the Americans, thus continuing to respond with petty provincialism to the indifference shown by the Europeans for many years". Antonio Aita, "La Coopération intellectuelle entre l'Amérique et l'Europe", report to the Second General Conference of the National Committees on Intellectual Cooperation, July 1937. UNESCO, FR PUNES AG 1-IICI-A-21, 2.

23. "True and direct knowledge of our Continent, upon which Europe has looked with certain indifference."

24. "In our America, where the writer has no social stature, he also lacks the means of defense to protect the property of his intellectual effort, and through the lack of sound legislation, the writer is exposed to all kinds of piracy by unscrupulous publishers". Antonio Aita to Henri Bonnet, 8.4.1936, UNESCO FR PUNES AG 1-IICI F-I-1-1a, doc. 239-242.

25. Antonio Aita to Henri Bonnet, 3.3.1938, UNESCO FR PUNES AG 1-IICI A-III-37.

26. Antonio Aita to Henri Bonnet, 24.5.1939, UNESCO FR PUNES AG 1-IICI A-III-37.

27. Ibid.

28. "You will have noticed that it is with great care that we proceed in choosing our books, the prefaces, the translators, always seeking expert opinions. As far as Argentina is concerned, we agree that we have diverged from the programme that we wanted to achieve, from the mission that we had-you in Argentina, I here. You cannot leave us, Aita, you must not. We have undertaken our work together; you have to be with us until we have brought it to an end". Dominique Braga to Antonio Aita, 7.6.1939, UNESCO FR PUNES AG 1-IICI F-VI-5.

29. Antonio Aita to Henri Bonnet, 19.10.1939, UNESCO FR PUNES AG 1-IICI A-III-37.

30. Miguel Ozório de Almeida to the IICI, 16.9.1939, UNESCO FR PUNES AG 1-IICI F-II-1-3, doc. 308-316.

31. "Rest assured that if I could provide service to a country that I love as my own, it would be me myself who would be very grateful to you for providing me with the opportunity to do so". Victoria Ocampo to Henri Bonnet, 30.9.1939, UNESCO FR PUNES AG 1-IICI F-II-1-3, doc. 281-282. 
32. A copy of Aita's and Rojas's responses is enclosed in a letter sent from Antonio Aita to Henri Bonnet, 9.5.1940, UNESCO FR PUNES AG 1-IICI F-II-2.

33. Henri Bonnet to Antonio Aita, 6.4.1939, UNESCO FR PUNES AG 1-IICI F-VIII-1.

34. For further information about the Ibero-American Collection, see Roig-Sanz, "The International Institute of Intellectual Cooperation: Translation Policies in the Interwar Period (1925-1946)". In Christopher Rundel (Ed.), Routledge Handbook on Translation History. London: Routledge, foth.

35. This volume was actually sent to print in April 1940, just a couple of months before the German occupation of Paris. The last letter in the archive folder of the volume dates from 27 April 1940. We have found no record of the book in the catalogue of the National Library of France and assume that it never left the press.

36. As Dominique Braga reminded Antonio Aita, “[. . .] Ainsi que l'indiquait notamment M. Ronze, Secrétaire général du Groupement des Universités et Grandes Ecoles de France pour les relations avec l'Amérique latine, Facundo, publié par nous, donne lieu à des conférences en Sorbonne et la traduction de Marcel Bataillon, lui-même professeur de littérature espagnole à la Sorbonne, fait l'objet des travaux des jeunes étudiants en France". Dominique Braga to Antonio Aita, 22.12.1938, UNESCO FR PUNES AG 1-IICI F-VI-5, doc. 16-17.

37. "A historical work that would shed light on the period of Argentine life in which Sarmiento has set the scene of his classical work Facundo". Henri Bonnet to Antonio Aita, 6.4.1939, UNESCO FR PUNES AG 1-IICI F-VIII-1.

\section{References}

Casanova, Pascale. 1999. La république mondiale des lettres. Paris: Editions du Seuil.

Comisión Argentina de Cooperación Intelectual. 1939. La vida y la cultura en Argentina. Buenos Aires: Comisión Argentina de Cooperación Intelecutal.

Herrera León, Fabián. 2009. “México y el Instituto Internacional de Cooperación Intelectual 1926-1939." Tzintzun 49. www.scielo.org.mx/scielo.php?script= sci_arttext\&pid=S0188-28722009000100007.

Lemke, Ute. 2007. "La correspondance entre Freud et Einstein 'Pourquoi La Guerre?'-quel enjeu pour l'éditeur, l'Institut International de Coopération Intellectuelle?." In Les mouvements pacifistes américains et français, hier et aujourd'hui, edited by Francis McCollum Feeley, 203-210. Chambéry: Université de Savoie.

Mistral, Gabriela, and Victoria Ocampo. 2007. Esta América nuestra. Correspondencia 1926-1956. Buenos Aires: El cuenco de plata.

Ocampo, Victoria. 1939. "Contestaciones a una carta de Ozorio de Almeida.” Sur 61: 115-121.

Pernet, Corinne. 2007. "La cultura como política: los intercambios culturales entre Europa y América Latina en los años de entreguerras.” Puente@Europa 3-3: 66-73.

Roig-Sanz, Diana. forth. "The International Institute of Intellectual Cooperation: Translation Policies in the Interwar Period (1925-1946)." In Routledge Handbook on Translation History, edited by Christopher Rundle. London: Routledge. 
Roig-Sanz, Diana, and Reine Meylaerts. 2018. Literary Translation and Cultural Mediators in 'Peripheral' Cultures. London/New York: Palgrave Macmillan.

Sarlo, Beatriz. 1997. "Vanguardia y criollismo: la aventura de Martín Fierro." In Ensayos argentinos. de Sarmiento a la vanguardia, edited by Beatriz Sarlo and Carlos Altamirano. Buenos Aires: Ariel. . 2007. "Victoria Ocampo o el amor de la cita." In La máquina cultural. Maestras, traductores y vanguardistas, 75-148. Buenos Aires: Seix Barral. 


\title{
14 Torres Bodet and the "Male Pedagogies"
}

\author{
Radiography of a Thought of \\ Transcultural and Transnational \\ Circulation ${ }^{1}$
}

\section{Mauricio Zabalgoitia Herrera}

Jaime Torres Bodet (Mexico City, 1902-1974) is considered one of the main educators, intellectuals, political figures and, in a lesser sense, poets and writers of Mexico. Also, he is highly valued as a diplomat and international and influential figure who helped to build-and rebuild-the Hispanic and transnational world during the 20th century. According to all these avatars, Torres Bodet is one of the male creators of the Mexican cultural and educational institutions, but also one of the men who took the reins of the world in the interwar period and mostly after the Second World War. As a man educated in the lettered minorities of the time, the Mexican knew how to reconcile the cultural, artistic and educational needs of an unequal society with the modernizing movements of the world in this international context, and from Mexico City, Madrid, Paris, Buenos Aires, The Hague, Brussels and other places of the international cooperation.

Torres Bodet formed his own ideal of humanism, renewed according to his own experience as a lettered and international subject and also as a man who witnessed in Europe the fall of the pillars of humanity and its most appreciated symbolic cultural assets. This "new humanism" was configured in his literary texts, in the transnational spaces of men of his same education and rank, but above all in the speeches he gave in international forums. These places were created as emergency spaces to save humanity from barbarism. And all this he did, we have to say, reading, thinking and arguing with other men. Together they decided to take the categorical Man of history and knowledge to renewed places, such as that of international education, thus writing a new chapter not only in the history of humanity but of the genre and its characters: men and women (without thinking on marginal identities, as expected).

In what is presented subsequently is carried out a radiograph of a thought of transcultural and transnational circulation. This work is done by dividing the personal, cultural, literary, political and diplomatic life of Torres Bodet into three moments. His first youth (training period in Mexico), his second youth (his first international period) and his international 
adulthood (period in which he directs UNESCO). In this regard, the biography of Torres Bodet is taken as an example because it is, perhaps, the greatest case of a cultural mediator and a man "between worlds". In any case, to work with a biography invites us to go inside some private spaces, but as feminists say years later: the personal is political. And we can add: the political is cultural. Briefly, the main intention of this approach is the idea that if we apply a (strong) gender point of view, this can reveal new methods of transcultural mediation in representative spaces, new edges in the framework of transatlantic relations and new means of grasping and reading the past of cultural globalization.

\section{First Youth. Homosociability as a Strategy and National Pedagogy}

The revolutionary process (1910-1917) during which a young Torres Bodet lives in the sumptuous streets of downtown Mexico City and in the classrooms of elite schools for the new cultural gentleman brings to him a new disorder of ideals and male possibilities. With this, the new men of the nation and the arts will have to negotiate from a cultural sexo-politics inherited from the Ateneo de la Juventud as well as from other more restricted areas of homosocial power privileged by the State between 1900 and 1914. These areas are the ones that make his identity and those of his "close friends" possible.

In Mexico, homosociability is shaped from the Colonial era through the Porfiriato as a conglomerate of male social networks, agreements, family relationships and friendships. This project, as contradictory as it may seem-as opposed to liberalism and its promises-is about reinforcing sentiments and functions of racial, social, economic and gender differences. An idea of nation is born from the empowerment of the selfconsciousness of the criollo or criollo-mestizo, turned into bourgeoisie. This works as a metonymy of normativity between men and towards women. Citizen and individual-male gendered not exclusively in a grammatical way-represent the most elaborate tailoring of the national unification process (1750-1921.)

By 1913, a coming-of-age Torres Bodet attends Escuela Nacional Preparatoria in San Ildefonso. He still wears short pants while his mother walks him to the Cathedral (Zertuche 2011, 30). However, this stillchildish gender burden does not prevent him from inserting himself in the great teacher's league. By 1914, he gives Enrique Fernández Granados his first poem to read, and he is a fervent listener of young but vigorous teachers: Alberto Vázquez del Mercado, Manuel Toussaint and Antonio Castro Leal (31). In this environment, a shy and bullied Torres Bodet - he was still a fat boy-starts to develop and wins himself a place in one of the most privileged environments by the generic-sex logic of the elites, that of passionate friendship among males with similar interests: 


\section{4}

Bernardo Ortiz de Montellano, José Gorostiza, Carlos Pellicer and Luis Garrido, among others.

Another factor that promotes the building of Torres Bodet as a novel trope of intellectual masculinity is a proposal from the government itself to renovate the Mexican civil service with "new young people". During this period, "youth had moral, aesthetical and symbolic connotations that attached to the Joven the most generous human ideals: he should be active, audacious, ambitious, adventurer, capable of great emotions, the creator" (Blanco 1996, 163). ${ }^{2}$ As a political gender artifact, the joven varón is a construction promoted by bourgeois liberalism and the educational national project. Both Escuela Nacional Preparatoria and Escuela de Jurisprudencia - which Torres Bodet entered in 1920—and the worlds around ateneos, clubs, cafes and groups-and their manifestos-became the settings for the practice of a place where functions of validations of race and class are discovered, as well as those of national transformation beyond the boundaries of capital. This is the ideal of masculinity that takes on great significance in the face of educator-intellectuals and conservatives of previous decades such as José Roa Bárcena, Ignacio M. Altamirano or José Tomás Pérez de Cuellar. They saw in the emerging youngsters a threat to the masculinizing Mexican empire. Thereby, the old cachetitos de manzana (small apple cheeks) becomes an elegant

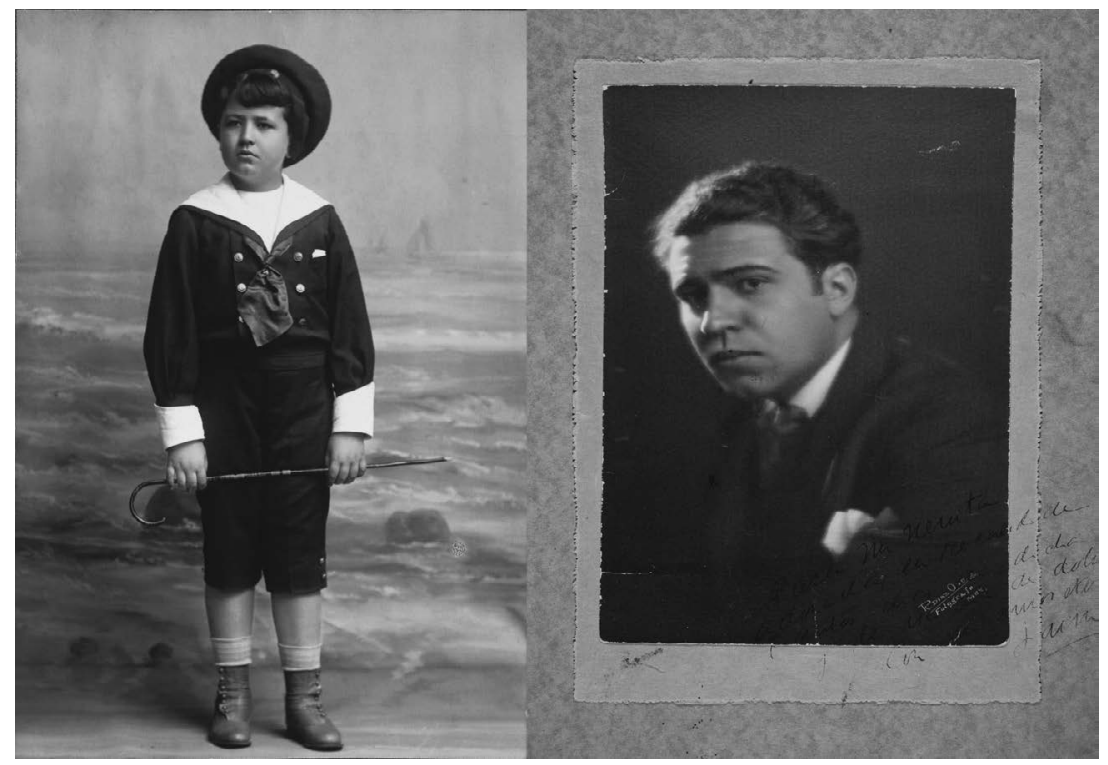

Figure 14.1 The Little Sailor Becomes an Elegant Caballerito.

Source: (IISUE/AHUNAM/Fondo Incorporado Jaime Torres Bodet, Caja 2, Foto 32/Caja 11, Foto 54$)$ 
gentleman who wears high life or El Palacio de Hierro suits (Zertuche 2011, 40).

Around that time, he goes from being a young man and efficient secretary of Escuela Nacional Preparatoria to being secretary to his admired José Vasconcelos in the presidency of the Universidad Nacional. It was 1921 and he was only 19 years old. The figure of Vasconcelos, his writing, actions and political decisions, each one of his educational creations in a broad spectrum: schools, libraries and his "cultural missions", transform the ethical and cultural ideal of the young Torres Bodet. Vasconcelos's move from the University to the Ministry of Public Education does no more than invigorate the life of his young mentee, who continues to work for him.

Torres Bodet's professionalization advances at the same time as his experience in public service. The period of revolutionary crisis, although it complicates the publication and circulation of cultural goods, also enlivens some groups, their ideas and the not always transparent relation between modernity and vanguard. Those paradoxical relations may be coded in several magazines in which Torres Bodet and his passionate friends collaborate. To many of them, Madrid and Paris-based Spanish and Hispanic American authors also contribute, a transatlantic dynamic network of transcultural flow, a concept used by Alastair Pennycock about the contacts between tongues to "address the ways in which cultural forms move, change and are reused to fashion new identities in diverse contexts. This is not, therefore, a question merely of cultural movement but of take-up, appropriation, change and refashioning" $(2006,7)$. It's in this dynamic framework where many of the national identities of class and gender in an international frame were negotiated. Standing out, of course, are the definitions of educated men, as well as a still-in-the-making idea of citizen and intellectual. Both of them are generic categories that exclude women, as we will see in Torres Bodet's educational speeches given in transnational environments.

Some of those publications are the weekly Pegaso, founded in 1917 by Enrique González Martínez, Ramón López Velarde and Efrén Rebolledo, to which a young Carlos Pellicer and Torres Bodet contributed, as well as in Revista Nueva, published by José Gorostiza and Enrique González Rojo in 1919 (Zertuche 2011, 49). Or, from 1920 to 1923, the monthly magazine México Moderno, also published by González Martínez, with later collaborations by the ateneistas and the newcomers Gorostiza and Torres Bodet as critics and recipients of French literature: André Gide, Marcel Proust, Jean Cocteau, Paul Valéry and others. As a highlight, in 1922, La Falange was launched, which with a continental scope sought to bring together the voices of Latin American men (and only some women) beyond rules and races. Poets, painters and muralists from both sides of the ideological spectrum collaborated democratically. However, later on we will see a break-up in terms of ideals of masculinity. 
However, these new literary gentlemen are not only created as an ideal of educated masculinity inside homosocial spaces; they take their versions of sex-culture into practice in banquets, opera and theater shows, award ceremonies and so on. Both in private and in public, the new "referees of elegance", as named by Macías-González (2006), show off their modernity and class superiority. This class is not exclusively based on the accumulation-circulation of capital, but in postures, sensibilities, mentalities and real-life teachings opposing the ideals of elitist masculinity that used to be promoted in magazines, display windows and private rooms. If, as Macías-González (2006) or González Romero (2015) have noticed, male gender performance went across the literary sphere (whether educated or popular) - to a reduced number of readers-the new Contemporáneos educated not just from their writings and publications, but also from their notorious social presence. In an image that brings them together with their "padres", the Ateneístas, Antonieta Rivas Mercadoa patron for the younger ones-is the only woman with privileged access to a close knit of homosocial fabric.

It is in that world where Torres Bodet, Ortiz de Montellano and Gorostiza promote the creation of the Nuevo Ateneo de la Juventud. While this group that sought to renovate the poetic spirits of masculine relations of the old Ateneo does not get too far, the so-called group Contemporáneos achieves that goal: the climax of a version of a Mexican homosocial culture of those born during the Porfiriato. Now, with the Ateneistas, what did the youngsters recover from the old gentlemen of letters? As the base of a masculine sex-culture, we can think it was the vital impulse"'knowledge as action, intelligence as sensibility and moral as aesthetics', as said by Jorge Cuesta" (Monsiváis 2016, 35), ${ }^{3}$ and also what Monsiváis calls the "moral revolution", which organizes around the idea of "the hero" (from Maurice Blanchot to Alfonso Reyes and from there to José Enrique Rodó and other Latin Americanists) (36). This hero is no other than the poet-the male poet-who from the Western classics goes to the values of the liberal male subject. In these definitions shine the readings of Ortega y Gasset. His most influential writings, such as La deshumanización del arte (1925), had a great impact on the young literati. Another topic to underline is the idea of morale as a civilizing force in which male poets are almost soldiers. Torres Bodet will later recover many of these ideas in his poems, but mostly in his writings and speeches about education in a European warlike environment.

Torres Bodet and the caballeritos letrados, as we can call them from a gender perspective, make strides in national impact from the publishing of poetry books. Some intellectuals from older generations react to it. One of them, Júlio Jiménez Rueda, gives the conference "The Effeminacy of Mexican Literature" (1924). Maples Arce and los estridentistas deny the possibility of such a construction: they call them "a group without a group" (Villaurrutia 1924; italics from the original). They don't believe 
the youngsters have a proposal-beyond a simple doubt of the national manhood. At the bottom of that critique, as shown by Irwin (2015) or Del Toro (2015), was the rejection of a manly possibility, a homosexual one feared by an equally manly culture, but that of the survivors of the "old Mexican regime", organized on the rigid homosocial bonds centered on political parties and both right- and left-wing groups.

On the other hand, in the world of his personal affections, Torres Bodet meets Josefina Suárez Montañés in 1922. This is a non-archetypal woman of the era. She lived on her own and was studying piano and English. The relationship with the woman who will become his compañera-according to the definition of the times and as it will go down in history-has been coded in correspondence from different time periods. Torres Bodet, as an educated man of his time, expresses many of his passions in letters to his woman and friends. In 1934, after his European travels, he writes to Josefina: "I love you as I did in our juvenile years, but with more tenderness still as my girlfriend, as my sister, as my daughter [...] thus you have loved me as a lover, you have comforted me as my sister, and filled me with joy as a daughter" 4 (Torres Bodet in Zertuche 2011, 67).

Back to the relations between the lettered men, beyond the known (and criticized) homosexuality of Virraurrutia, Pellicer, Nandido, Novo ... a matter that is heavily in Torres Bodet's gender practice is "passionate friendships" (Macías-González). It is about a deep homosocial strategy

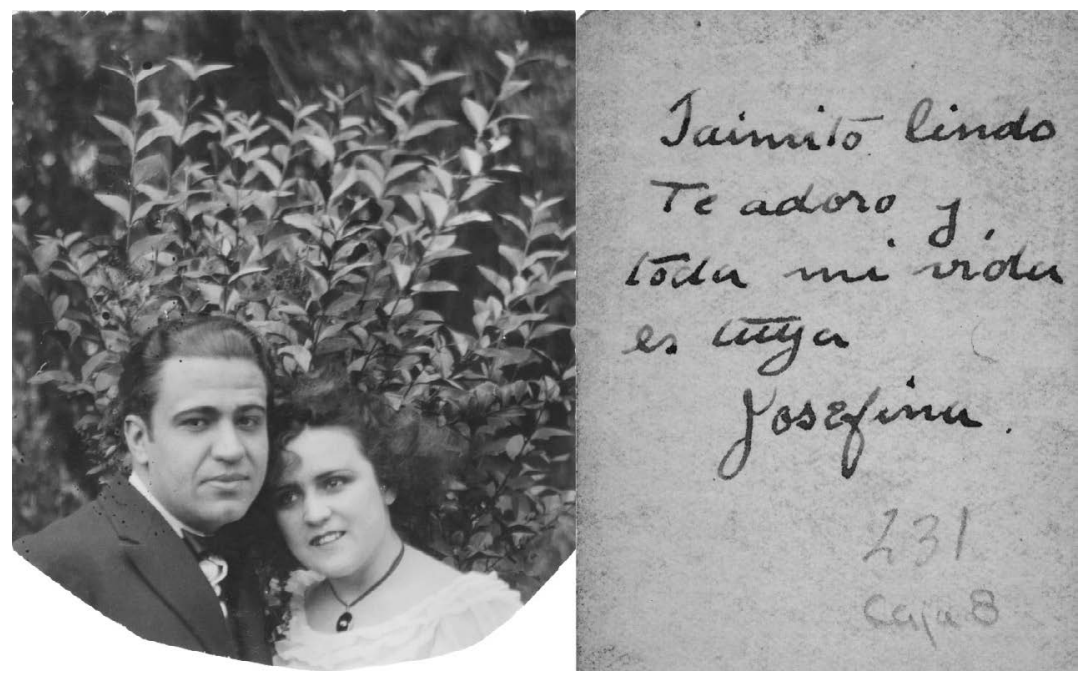

Figure 14.2 Jaime and Josefina, a Romantic Young Couple. She dedicates the postcard to her beloved: "Cute Jaimito, I adore you and all my life belongs to you. Josefina." México, 11-21-1928).

Source: (IISUE/AHUNAM/Fondo Incorporado Jaime Torres Bodet, Caja 8, Foto 232 / Caja 8 , Foto 231) 
defined as a "friendship with a high level of intimacy, which was asserted by the exchange of ideas and opinions, which created a strong emotional connection and a close fellowship" (Macías-González 2008, 21). From the Colonial years to post-revolutionary Mexico, the Mexican male elite used interpersonal relations through passionate affective connections; a sort of "social wisdom" of males without precedent (21). A letter from Josefina to Torres Bodet, already in his international period, makes note of this fact, disturbing if seen from the compañera position. It refers to her husband's relationship with Bernardo Ortíz de Montellano, also one of the Contemporáneos:

today [. . .] I was delivered the bad news that Bernardo is parting to New York [. . .] surely, he will meet to at the station and you will be happier. How could I possibly be missed? [. . .] I can't sleep [. . .] which concerns me the most is knowing that you worry so much about Bernardo, it never occurred to me that you would love him so much, to the point that you can't live without him. I am so jealous of Bernardo.

(Zertuche 2011, 67)

\section{Second Youth: The International Period. A Thought of Transcultural and Transnational Circulation}

Torres Bodet, who we suggest as a joven vivo of his time, will have to wait after his residencies in Madrid, Paris, Brussels, The Hague and Buenos Aires to build an ideal of man, both local and international-generic as the modern male. Such models, while having been forged during his intense youth as an intellectual and poet in Mexico, will find a full space in the scenarios of institutional communication, in the public offices he held and in the practice of international diplomacy. We will see how this is the image of a man of history and knowledge, a man of literature and poetry, the educator and the educated, the proletarian man in the process of instruction and citizenship. In other words, a series of avatars of masculinity in which there is no proof-neither as textual marks nor sexual-that there was a place for women. Nor are there spaces for men outside the boundaries of formal education.

From a brief genealogy, we suggest that his early militancy in a small but intense educated bourgeois culture, as well as his membership in the Contemporáneos with the idea of freedom as an axis, influenced him as a specific type of Mexican masculine subjectivity that had to be projected to a transnational arena. Torres Bodet and his passionate friends represent the ideal of educated, cultured and refined man with an eye on the outside world, especially Europe. These are middle- and upperclass gentlemen who share their knowledge in urban centers as well as in novel spaces of homosocial education, such as the well-known Escuela 
Nacional Preparatoria. The revolutionary process, more than affecting, benefits them in terms of the consolidation of a new model of masculinity, culture and consumption. They are readers and critics and have fully modern convictions. They build networks of readers and cultural construction through publications that intend to forge a sense of literary and philosophical transatlantic ideals. The circuits of mail correspondence are notable. In those letters, the negotiation of ideals can be decoded, as well as the positions that different world capitals were gaining: Paristhe center of the Hispanic world, regardless of the French-Madrid, Buenos Aires, Mexico City and also the capitals of international cooperation during the interwar period: Brussels, The Hague, New York. Torres Bodet lived as an attaché and diplomat in most of these capitals, perhaps following in the steps of his admired Alfonso Reyes.

By the late 1920s, Mexico tries to reinforce its international situation. The requirements to access diplomatic positions include tough tests of Mexican history and geography and local current affairs, as well as international culture, especially European and French cultures, and furthermore, fluency in a foreign language. Torres Bodet prepared energetically for those exams. It was not a big deal to him. His mother, with French ancestors, was bilingual. Because of his father's origins, he was able to read and carry on a conversation in Italian. He did have to prepare himself in accounting and international law, which was easy to do. By mid1929, he was already a third secretary in Madrid. He advanced quickly and by 1931 was second secretary. In letters to his admired Alfonso Reyes, he tells him about his suffering Madrid's hot weather, but also enjoying with his poet, thinker and intellectual friends: Pedro Salinas, Benjamín Jarnés, Melchor Fernández Almagro, Claudio de la Torre, Juan José Domenchina, Max Aub and Ramón del Valle-Inclán. They make up a group of spokesmen who get together in a homosocial space of the greatest importance: the literary club in Café Regina. Among other things, they theorize over the future of the man-the poet-from Modernism and the rise of Hispano-American literature in the new world order.

The Madrid experience lasted less than two years. With great satisfaction, he finds out he is being transferred to Paris. He arrives in Paris with his mother and Josefina (Zertuche 2011, 69). There, he works alongside three respectable Mexican revolutionaries: Arturo J. Pani, general counsel; Marte R. Gómez and the "estridentista” poet Luis Quintanilla (69). Parisian life fascinates the Torres Bodet family. Correspondence from that period tells of a fulfilling cultural life: museums, concerts, cinematography (69). Just as he had done in Mexico City and Madrid, he gets in touch with the intellectual elite, mainly immigrants from the Hispanic worlds.

In 1932, he is temporarily transferred to The Hague in charge of business. While there, he lives a less intense life than in Paris, because his responsibilities include being a spokesperson to the kingdom authorities 


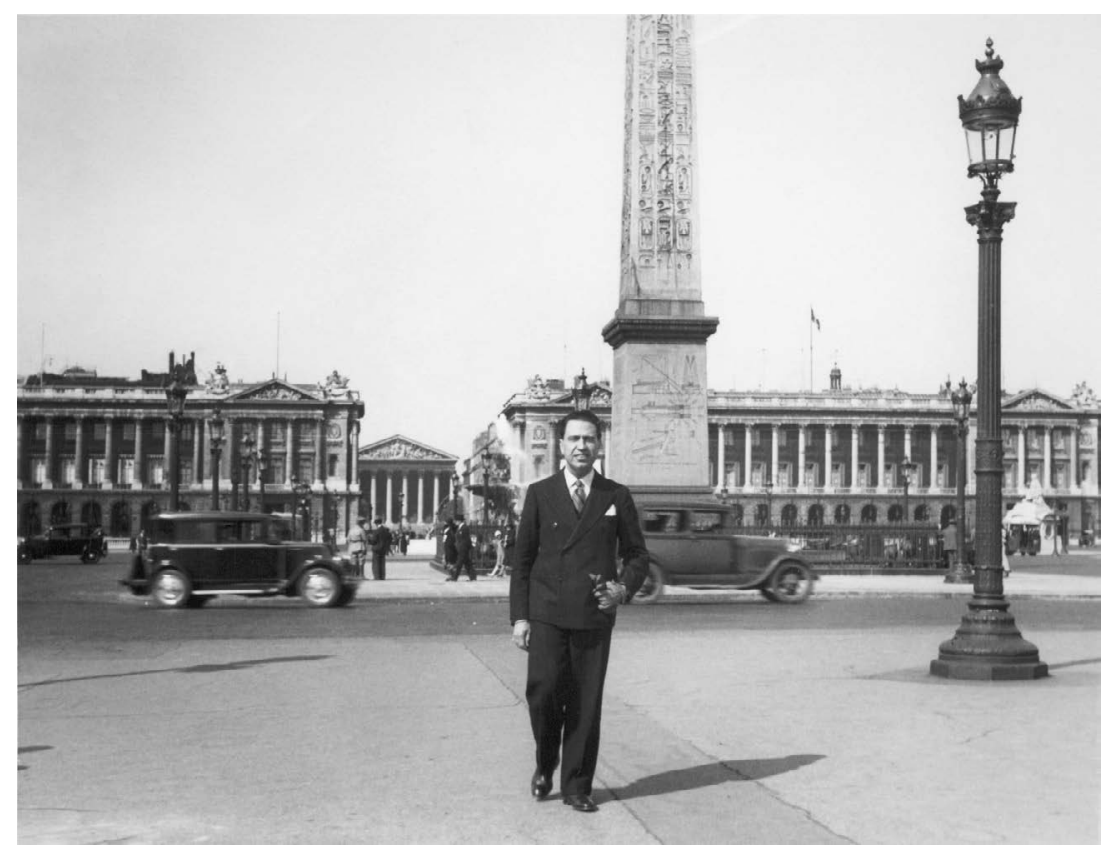

Figure 14.3 Torres Bodet as a Flâneur in Paris.

Source: (IISUE/AHUNAM/Fondo Incorporado Jaime Torres Bodet, Caja 10, Foto 12)

and establishing relations with representatives of partner countries, as well as authorizing and renovating visas (70). While he is not fluent in the language, he spends his time writing, visiting museums and the city surroundings. He is back in Paris by September. He attends in wonder, as do all the intellectuals of the time, the unfortunate events that shape European life (70). Torres Bodet, as we can see, meets the definition of Sanz Roig (et al.) for the cultural mediator, where he presents himself as a "cultural actor active across linguistic, cultural and geographical borders, occupying strategic positions within large networks and acting as a carrier of cultural transfer" $(2017,67)$.

Hence, as an outstanding man of mexicanidad/hispanidad, he undertook cultural actions without precedent. In 1934, for instance, he is invited by the Instituto de Estudios Hispánicos of the Sorbonne to give a conference on Mexican poetry, from Sor Juana Inés de la Cruz through Ramón López Velarde (Zertuche 2011, 70-71). Beyond language and national borders, the viewpoint of Sanz Roig (et al.) insists on processes of transference, role overlap and transgression in cultural fields (2017, 67). So, we can say: the poet is a diplomat, the diplomat is a translator, the translator is an educator, the educator is a public speaker and this is, then again, a poet. 
The summer of that year, he received some news with sadness. He had to leave Paris and move to Buenos Aires. Only the couple travels to Argentina, as the mother decides to move back to Mexico. As a "between worlds" man of the era, more so after the Parisian experience, Torres Bodet considers himself a "European in America." The idea of French superiority blossoms in him, as well as the unprecedented legacy of its thinkers and writers (Zertuche 2011, 71). This radical standpoint begins to morph during his time in Buenos Aires. There, a new and mobile sense of mexicanidad starts to shape in a Torres Bodet who comes into contact with "other versions" of European culture in America and ideals of nation. Leopoldo Lugones, Jorge Luis Borges, Eduardo Maella, Ezequiel Martínez Estrada, Ricardo Molinari and Arturo Capdevila represent the new group of educated men. Almost as an exemption, Norah Lange stands out. The great absentee in his transnational dialogue will be Silvina Ocampo; at that time, she was not there (78). If Buenos Aires' openness of the homosocial fabric to women was innovative, Torres Bodet did not seem to react to this fact.

The Buenos Aires experience is short but intense. With Mexican President Lázaro Cárdenas in office, the Torres Bodets return to France. By 1936, while living between Paris and The Hague, the Mexican educator lives with fear of the rise of Hitler and the European environment (73). $\mathrm{He}$, as will many other international mediators, will discuss from their discursive trenches matters of supremacy and racial segregation, as well as the new definitions of the imperial and the national. In 1937, Lázaro Cárdenas appoints him to Belgium, a privileged spot for understanding the conflict of the European momentum. In 1938, he is a staunch supporter in Europe of the president's social and national policies, such as the expropriation of the oil companies (74). By 1939, he lives fearful of bombings and the instability of his loved European life. During his trip back to New York by boat, for which they departed from Lisbon, Torres Bodet wrote the following:

an entire world already beaten, before the facts defeated it. And a world defeated by the worst of the epidemics: that of anguish. Free Europe had not only been disintegrated at the time of the attack. It had been diminished, for years, by the uncertainty of the democracies towards the forces of fascism and communism, by the inertia in the face of the satraps of international blackmailing, by the indifference of the great powers towards the powerless and by their intolerance towards the insults of a Hitler who believed himself to be Bonaparte, and a Mussolini who dreamt of being Julius Caesar.

(Torres Bodet 1974, 228) ${ }^{6}$

In 1940, he returns to Mexico and decides to stay, opting for a counseling position in the Foreign Service. In 1943, President Ávila Camacho appoints him secretary of public education (a position he holds through 


\section{2}

the end of the administration in 1946). From 1946 to 1948, he is secretary of foreign affairs. Finally, the climax of the educator's universal career comes when he is appointed head of UNESCO (1948-1952).

But, we can think: what ideal of man and masculinity coded the most international of the Mexican intellectual-educators after his transatlantic mediation? On one side, it could be considered what Pablo Latapí reconstructs, through writings and speeches, as the hombre cabal (Man of fullness) (Latapí 2005, 25). The greatest humanist ideal of Torres Bodes is that of a whole and rounded man who develops his abilities to the fullest; his model is Leonardo da Vinci, the "universal man." As an ideal of education, the man of this educator can be summarized in nine characteristic qualities: integrity, self esteem, honorable existence, virtue, dignity, elegance, simplicity, probity and honorability (25). He is a synthesis of culture and technical specialization (25). We could say: a masculine machine with reason, sentiments, ethics and aesthetics. This is, without a doubt, a response to the strong man, hermetic and hardened by Mexican history proposed by some post-revolutionary intellectuals. But we can ask if this man includes the Mexican woman, the uneducated peasant or only the men educated in literature, the groups and the classrooms?

In 1959, Torres Bodet says:

A Mexican is someone in whom education harmoniously stimulates the diversity of his faculties: understanding, sensitivity, character, imagination and creation. A Mexican ready for the moral test of democracy [. . .] who, faithful to the aspirations and designs of his country, knows how to offer an authentic contest to the collective work [...] that concerns the whole humanity, same within the family, the city and the nation. ${ }^{7}$

(Latapí 2005, 35)

The woman would be among these last categories, we think. Before that, in the inaugural talk on the Magisterial Unification Conference, in 1943, he speaks about the man as a result of "an integral education". He also speaks of the worker, the farmer, the artisan, the artist, the professional and the savant (Torres Septién 1985, 17). To this he adds that "humanity needs men, complete men; not docile servants. The nation does not crave subjects. She wants children and, like all mothers, covets for her children a joy founded on freedom" ${ }^{8}(31)$. As can be seen, the materials with which this international educator works are the interconnections between urbanization, literature, capitalism, education, citizenship and homosocial culture. As an example of a modern life option, Torres Bodet joins the "male pedagogies" discourse that is rehearsed in the transnational projection and from select spaces of national bourgeois education. 
In terms of a gender transcultural flow, we propose that the categorical ideal of man, whose maximum expression would be encrypted in the possibility of a legal citizenship, conducted to the progress by the intellectuals in positions of instruction and administration, had its greatest expression in the transnational networks of the first half of the 20th century. In this context, Torres Bodet is the most prominent Mexican example, perhaps after Alfonso Reyes. Both of them crossed the borders of language, occupied strategic positions and reinforced multiple intellectual networks. From there they participated in the negotiation about who should be the Man — with capital letter-and who the men in ranks, positions and spaces of a new order of global circulation. In their intimate relations with poets, writers, politicians and diplomats between Europe, South America and Mexico, they placed themselves and defined a sex/ gender system to come.

\section{Adulthood. The Second International Period and Direction of UNESCO}

In 1948, he was appointed as director of UNESCO after a period in Mexico where he had to hold high public office, such as Secretary of Foreign Affairs. This allowed him to explore his idea of internationalization of education and knowledge, as well as his own definitions of humanism, the man and international relations itself. This decision was made during the Third General Conference, held that year in Beirut. Torres Bodet will be the successor of the scientist Julian Huxley, who had carried out some decisive actions for the configuration of the Organization. This scientist had been elected at the First International Conference, held in 1946 in Paris. In fact, this influential founder was the one who added the " $\mathrm{S}$ " of "Science" to the name of the association. For him, science had to be linked to culture and education as a transformative and non-destructive instance. The debate came from the recent atomic bombings of Japan by the United States. It is in the line of this reflection for peace, and for the reconduction of the powers of science towards human well-being, that the initial sentence of the Preamble of the UNESCO Constitution arises: "Since wars are born in the mind of men, it is in the minds of men that the bastions of peace must be erected"9 (Latapí 2006, 117). In the preparation of this text, Torres Bodet participated as a Mexican representative, and this principle, without a doubt, marked him as a cultural mediator in post-war times.

Torres Bodet will later mention in his memoirs how between Huxley's administration and his, there was a disparate vision of international cultural mediation: "Huxley, he says, hoped that peace would be consolidated by the actions of UNESCO in a diffuse distant horizon, while he poses the problem of world peace in the context of active economic and political interests. For him, the Organization had to be truly universal 


\section{Mauricio Zabalgoitia Herrera}

and plural"10 (Latapí 2006, 120). "The alert and vigilant conscience of the new world" 11 (Torres Bodet in Latapí 2006, 120). He lowered this new vision, and in front of his predecessor, the Mexican proposed, in terms of economics and administration, to reduce an enormous multiplicity of projects and concentrate the pacifist and transformative forces of education on a few but efficient fronts. Upon his appointment, the Mexican educator will say in the Memoirs: "a chapter of my life had been closed. And that chapter that seemed to me so monotonous at times was suddenly the summary of an incomparable time, that could never live again - and that I had suddenly closed, because of that eagerness to be another that leads the man within himself" 12 (Torres Bodet 2012, 337).

It is during this period that the diplomat not only configured his international thinking but also reaffirmed some teachings of his childhood and youth formed in the lettered minorities of Mexico. Some of these notions, made in spaces of male homosocial culture, as we have seen, found parallelism in similar constructs in European or Latin American capitals. Among the contents of these positions are ideas central to the definition of the categorical Man, as well as men, and their trades and

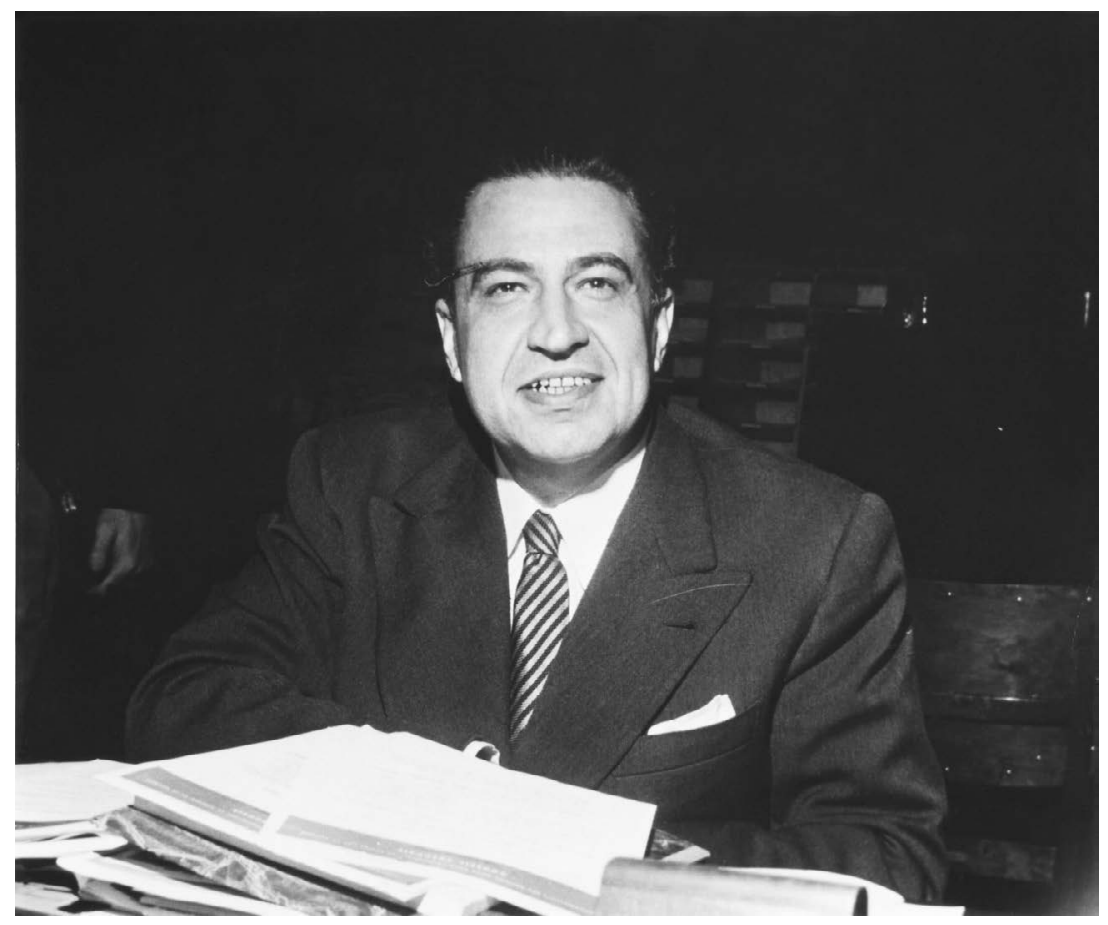

Figure 14.4 The UNESCO Director at His Desk in Paris (c. 1950).

Source: (IISUE/AHUNAM/Fondo Incorporado Jaime Torres Bodet, Caja 10, Foto 32) 
professions. All this was before the defiant movement of a new world order in the final process of globalization and the definitive instance to reach the ends of a new humanity: a humanism perfected and redefined in transnational environments. Within his participation as director of UNESCO, these issues will be central in the speeches and actions of the Mexican, as will an interest in benefiting less advantaged geographies through education.

Now, in that international order in which cultural mediators register their self as subjects of knowledge, we think that bourgeois elites-with a marked interest in culture-should not be so different. Finally, it is all about the world resulting from the acceleration of the globalizing forces that poets, writers, diplomats, intellectuals and subjects of international cultural and educational policy inhabit. In any case, sparing the distances, Spain was under the weight of a dark dictatorship, and the Parisian interlocutors would never stop being in a higher stage of knowledge and reflection about the Man, his culture and his sciences. In any case, where we want to go with this is to the initial proposal that figures between worlds, and on two poles of the vibrant transatlantic space, undertook a work without precedent of hybridization. With this, they wrote the world to come.

However, even though Torres Bodet found the fullness of his thought in the time of UNESCO, we must not forget that for him this stage represented a time of "bitter" years, a period of "tragic loneliness". Hence, he calls this time the International Desert in his memoirs (Karsen 1977, 507). In his own words: "I had the impression of finding myself in a desert. The powerful continued to develop their policy of domination, and the weak let their representatives speak of peace, without bravely associating in order to fight to maintain it" (Torres Bodet in Karsen 1977, 507). ${ }^{13}$

The foregoing expresses the early disenchantment that the transnational economic and political logic imprinted on the universal consciences that awoke after the disastrous events of Nazi Germany and World War II. But it also indicates an early suspicion, on the part of the Mexican diplomat, of a dead end to the hopes of a more just universal order and of the impossible evolution fueled by peace, democracy and humanism. However, despite the disenchantment that the lack of budget generated as constant in those four years, Torres Bodet did not falter in presenting his ideals and weapons for a wiser, more educated and more human worlda world, we must say, whose reins men took once more. Apparently they are the only ones truly capable of inhabiting the worlds in which high discussions about the present and the future of humanity take place. In any case, this paradox between the proven benefits of a task that transcends borders, on the one hand, and the sharp reality of postwar and Cold War politics, on the other, defined Torres Bodet's place of speech as a transnational male subject. In one way or another, this crossroads once 


\section{6}

again placed men of culture and knowledge, recognized as equals, in a network of male homosociability without borders.

Despite his scandalous renunciation of UNESCO in 1952, and beyond his constant complaints about the lack of economic support to make education am instance of world transformation, the Mexican poet ended up shaping the character of the Organization from this fundamental idea: the education as a global problem, hence some of its well-valued actions, such as the establishment of a universal network of centers of fundamental education as an international measure against illiteracy. That is to say, at that time, more than half of the world's population did not know how to read or write (Karsen 1977, 507). The first of these centers was opened in Patzcuaro (Mexico). It is the Regional Center for Fundamental Education for Latin America (CREFAL), a space that to this day continues to operate with enormous prestige and regional impact.

In his memoirs, in any case, he always contrasted the achievements against the impotence generated by inequality, as well as the deepening backwardness into which the New World was plunged. In a brief sketch, as general director of UNESCO, and as Pablo Latapí summarizes from the reading of his aforementioned memoirs, Torres Bodet focused on the education of adults, the study of a possible instance that would determine as mandatory the Universal Declaration of Human Rights regarding education, a better-organized struggle against prejudice and discrimination (especially in terms of race), as well in the protection of literary works, the multiplication of libraries, the revitalization of the various publications of the Organization and many other administrative aspects (Latapí 2006, 120). His stone in his shoe, the ghost that plagued him in such praiseworthy ends, was the reluctance of the world powers. From this arose a metaphor that he used constantly and which Latapí recalls: "The director general speaks quaintly of 'the Wise Men'-the United States, the United Kingdom and France-and of 'the shepherds'-the group of developing countries" (2006, 120-121).

Finally, that is how he ended up defining his stay at UNESCO: "Bitter years I lived in UNESCO, those who were making the Cold War turbulent [. . . Through thousands of faces and incessant advice, promises and exhortations, which I noticed in many circumstances it was a tragic loneliness" ${ }^{14}$ (Torres Bodet in Latapí 2006, 121).

\section{Conclusions}

The synthesis of a thought of transcultural and transnational circulation that would have its maximum expression in the direction of the highest international organ for management of education and culture, UNESCO, would go through different stages. These are those of the life of a Western man. From a young Torres Bodet who is trained as a caballerito de las letras in the classrooms of the Escuela Nacional Preparatoria, in clubs, 
workshops and lodges of the male bourgeoisie, it forms a world model, an ideal of man (metaphor of the Man-male-men) in certain spaces of education and in certain functions of nation-building, but mainly of a new humanism coming from the constructing spirits, from the male rulers of the world who would make education the engine of a new life-a life negotiated in an international context. This second stage, the first of an international nature, as we have seen, leads him to confront his vision of the world with like-minded men of the same cultural rank-especially poets and diplomats. These are well-placed men in the international swings of a world that would collapse a few years later.

However, the fall of an international knowledge regime would not discourage the survivors. These men would rebuild the world from new trenches of dialogue, and above all from specific actions on education, culture and science for peace. In this regard, some central ideas of the speech delivered in Beirut in 1948, on the occasion of the direction of the organization, are very representative, for example, the idea that the future of the civilization could not remain in the hands of hatred and ignorance (Torres Bodet 1948-1949, 4), and that notion that was built from his first public and diplomatic positions: that the educator and the diplomat had to be one, a new man beyond the borders, and a practitioner of the new humanism. In addition, a certainty that worked as an engine for his work: "There are still men and groups that place on the ideal of freedom, that of equality. And there are also groups and men who place, above the ideal of equality, that of freedom"15 (1948-1949, 4). That man, as "character of civilization", is: "the whole and the individual, the nature and the atom, the sea and the drop of water, the discourse of time and the syllable of the minute"16 $(1948-1949,4)$. And in that total and at the same time particular climate, the State must be the bridge of understanding between man and Humanity (4). Perhaps, a scale of values of those Man-male-men, rectors, builders, educators, poets ...

From these affirmations, a question arises: did these gentlemen really think that the categorical man included women? Or at least an immense majority? And also the poor men beyond the limits of education and economy? That "new humanism" had to start from privileged spaces like UNESCO. And it had to bring together "wise men and educators" (5) for the exercise of unlimited plurality while respecting the personality of each country. With these ideals, we seem to respond to the question of whom the speeches were addressing and to whom they appealed in their harangues. Finally, those in charge of rebuilding, once again, the world. Men from a new place without borders.

\section{Notes}

1. This book chapter has received the support of the research project "Pedagogías masculinas. Educación superior, género y nación a la luz de los campos 
universitario e intelectual en México (S. XIX-XX)" (PAPIIT: IA400618; DGAPA-UNAM.

2. "La juventud tuvo connotaciones morales, estéticas y simbólicas propias, que depositaban en el Joven los más generosos ideales humanos: es el activo, el audaz, el ambicioso, el experimentador, el capaz de las grandes emociones, el creador" (Blanco 1996, 163; italics in original). (All the translations from Spanish are ours).

3. "el conocimiento como acción, la inteligencia como sensibilidad y la moral como estética, como clamaba Jorge Cuesta” (Monsiváis 2016, 35).

4. “Te amo como en nuestros años más juveniles, pero con más ternura todavía como a mi novia, como a mi hermana, como a mi hija [ . . ] pues me has querido como amante, me has consolado como mi hermana y me has colmado de alegría como una hija" (Torres Bodet in Zertuche 2011, 67).

5. "hoy [. . . ] me dieron la mala noticia de que sale para Nueva York Bernardo [...] seguramente va a recibirte a la estación y tú estarás más contento. ¿Para qué puedo hacerte yo falta? [. . .] No puedo dormir [. . .] lo que más me inquieta es saber por qué te preocupas tanto por Bernardo, nunca creí que lo quisieras tanto, al grado de que no puedas vivir sin él. Estoy tan celosa de Bernardo" (Zertuche 2011, 67).

6. "todo un mundo vencido ya, antes de lo que los hechos lo derrotasen. Y un mundo vencido por la peor de las epidemias: la de la angustia. La Europa libre no había sido sólo desintegrada en la hora de la agresión. Había sido minada, durante años, por la indecisión de las democracias ante las fuerzas del fascismo y del comunismo, por su inercia frente a los sátrapas del chantaje internacional, por la indiferencia de las grandes potencias para los pueblos débiles y por su intolerancia ante los desplantes de un Hitler que se creyó Bonaparte y un Mussolini que se soñó Júlio César” (Torres Bodet 1974, 228).

7. "Un mexicano es en quien la enseñanza estimule armónicamente la diversidad de sus facultades: de comprensión, de sensibilidad, de carácter, de imaginación y creación. Un mexicano dispuesto a la prueba moral de la democracia [. . . ] que, fiel a las aspiraciones y a los designios de su país, sepa ofrecer un concurso auténtico a la obra colectiva [. . .] que incumbe a la humanidad entera, lo mismo en el seno de la familia, de la ciudad y de la nación" (Latapí 2005, 35).

8. "la humanidad necesita hombres, hombres completos; no siervos dóciles. La patria no ansía súbditos, sino hijos y, como todas las madres, ambiciona para sus hijos una dicha fundada en la libertad" (Latapí 2005, 31).

9. "Puesto que las guerras nacen en la mente de los hombres, es en la mente de los hombres donde deben erigirse los baluartes de la paz" (Latapí 2006, 117).

10. "Huxley, dice, esperaba que la paz se consolidase por las acciones de la UNESCO en un difuso horizonte lejano, en tanto que él plantea el problema de la paz mundial en el contexto de los intereses económicos y políticos actuantes" (Torres Bodet in Latapí 2006, 120).

11. "la conciencia alerta y vigilante del mundo nuevo" (Torres Bodet en Latapí 2006, 120).

12. "se había cerrado un capítulo de mi vida. Y ese capítulo que me pareció tan monótono a veces, resultaba de pronto el resumen de una época incomparable, que no podría nunca vivir de nuevo-y que yo había clausurado súbitamente, por esa avidez de ser otro que lleva el hombre dentro de sí” (Torres Bodet 2012, 337).

13. "tuve la impresión de encontrarme en un desierto. Los poderosos continuaban desarrollando su política de dominio, y los débiles dejaban que sus representantes hablasen de paz, sin asociarse valientemente a fin de luchar para mantenerla” (Torres Bodet en Karsen 1977, 507). 
14. “Amargos años viví en la UNESCO, los que enturbiaban la guerra fría [. . .] A través de millares de rostros y de incesantes consejos, promesas y exhortaciones, lo que advertí en múltiples circunstancias fue una trágica soledad" (Torres Bodet en Latapí 2006, 121).

15. "Hay todavía hombres y grupos que colocan sobre el ideal de la libertad, el de la igualdad. Y existen, asimismo, grupos y hombres que sitúan, por encima del ideal de igualdad, el de libertad" (1948-1949, 4).

16. "el todo y el individuo, la naturaleza y el átomo, el mar y la gota de agua, el discurso del tiempo y la sílaba del minute” (1948-1949, 4).

\section{Bibliography}

Blanco, José Joaquín. 1996. "La juventud de los Contemporáneos”. In Crónica literaria. Un siglo de escritores mexicanos. México: Cal y Arena.

del Castillo, Alberto. 2004. "Imágenes y representaciones de la niñez en México a principios del siglo XX”. In Historia de la vida cotidiana en México, tomo V, v. 2: Siglo XX. La imagen, ¿espejo de la vida? México: FCE/COLMEX.

del Toro, José. 2015. El cuerpo rosa. Literatura gay, homosexualidad y ciudad. Los espacios de entretenimiento de Ciudad de México a través de la novela. Madrid: Verbum.

González Romero, Martín H. 2015. "Literatura y masculinidad en la primera modernidad mexicana: apuntes de investigación en torno a tres novelas del México independiente”. Revista interdisciplinaria de estudio de género 1 (1): 157-169.

Irwin, Robert McKee. 2015. "'Colores nunca vistos sobre una tela': nuevos erotismos masculinos de la cultura posrevolucionaria". In Modernidad, vanguardia y revolución en la poesía mexica (1919-1930), edited by Anthony Stanton. México: COLMEX: n/p.

Karsen, Sonja P. 1977. "Las memorias de Jaime Torres Bodet". In Actas del Quinto Congreso Internacional de Hispanistas. Burdeos: Instituto de Estudios Ibéricos e Iberoamericanos, Université de Bordeaux III: 501-510.

Latapí, Pablo. 2005. "El pensamiento educativo de Torres Bodet: una apreciación crítica". Revista Latinoamericana de Estudios Educativos 3: 13-44.

Latapí, Pablo. 2006. "60 años de la UNESCO: un aniversario en el que México tiene mucho que celebrar". Perfiles Educativos 33 (111): 112-123.

Macías-González, Víctor M. 2006. "Hombres de mundo: la masculinidad, el consumo y los manuales de urbanidad y buenas maneras". In Orden social e identidad de género. México siglos XIX y XX, coordinated by María Teresa Fernández Aceves, Carmen Ramos Escandón y Susie Porter. México: Universidad de Guadalajara/Centro de Investigaciones y Estudios Superiores en Antropología Social.

- 2008. "Las amistades apasionadas y la homosociabilidad en la primera mitad del siglo XIX”. Historia y Grafía 31: 19-48.

Monsiváis, Carlos. 2016. Historia mínima de la cultura mexicana en el siglo XX. México: El Colegio de México.

Pennycook, Alastair. 2006. Global Englishes and Transcultural Flows. New York: Routledge.

Poniatowska, Elena. 2002. "Las enseñanzas de Torres Bodet”. In La Jornada. México: n/p. 


\section{Mauricio Zabalgoitia Herrera}

Sanz Roig, Diana (et al.). 2017. "Cultural Mediators in Cultural History: What Do We Learn from Studying Mediators Complex Transfer Activities in Interwar Belgium?". In Doing Double Dutch: The International Circulation of Literature from the Low Countries, edited by Elke Brems, Orsolya Réthelyi and Ton van Kalmthout. Leuven: Leuven University Press: 67-91.

Torres Bodet, Jaime. 1948-1949. "Discurso en la Conferencia General de la Unesco en Beirut”. In El Correo. Publicación de la organización de la UNESCO. Paris, vol. 1, no. 11-12: 4-5.

-1974. Memorias. Equinoccio. México: Porrúa.

- 2012. La victoria sin alas. México: Fundación Miguel Alemán.

Torres Septién, Valentina. 1985. Pensamiento educativo de Jaime Torres Bodet. México: SEP/Ed. El Caballito.

Villaurrutia, Xavier. 1966. "La poesía de los jóvenes en México". In Obras. Poesía/Teatro/Prosas varias/Crítica. México: Fondo de Cultura Económica.

Zertuche, Fernando. 2011. Jaime Torres Bodet. Realidad y destino. México: SEP/ APA. 


\section{Universalisms in Debate During the 1940s}

International Organizations and the Dynamics of International Intellectual Cooperation in the View of Brazilian Intellectual Miguel Ozório de Almeida

\section{Letícia Pumar}

\section{Introduction}

The Brazilian intellectual Miguel Ozório de Almeida (1890-1953) graduated in medical studies in the early 20th century but worked as an experimental physiologist during his entire life. During his career, he participated in several intellectual and scientific societies in Brazil and abroad and gained prominence both at the national and international levels. He was a member of the economic and intellectual elite of Rio de Janeiro at a time of great changes in Brazil's educational, political and economic structures and was engaged in the creation of institutions for the enhancement of intellectual life in the country, such as the Brazilian Academy of Sciences and Brazilian Academy of Education. The social network that Ozório de Almeida sought to weave within Brazilian and French intellectual circles in the 1920s was instrumental in his involvement in international intellectual cooperation projects in the 1930s and 1940s. ${ }^{1}$

In the interwar period, Miguel Ozório de Almeida took part in the League of Nations' international intellectual cooperation project as a member of the International Institute of Intellectual Cooperation (IIIC) and the International Committee on Intellectual Cooperation (ICIC). His role in these organizations shows how some of the League of Nations' projects became a forum for Latin American intellectuals to develop their internationalism. In the early 1940s, when Germany invaded Paris and the IIIC's activities were interrupted, the French diplomat and director of the IIIC Henri Bonnet went to the United States with the support of the Rockefeller Foundation. There Bonnet became involved in debates to maintain intellectual cooperation activities during the war. The establishment of a temporary center for international cooperation in the Americas was placed on the agenda, and Ozório de Almeida took part in the debates. 
Later, as a former member of the IIIC and ICIC, Ozório de Almeida participated in the early years of UNESCO. Until his death in 1953, he took part in some of UNESCO's activities and was one of the Brazilian candidates for the position of head of the Natural Sciences Sector and director-general of the organization. At UNESCO, Ozório de Almeida criticized the idea of cooperation as assistance rather than mutual support between intellectuals and scientists from different countries.

In this chapter, I follow Miguel Ozório de Almeida's activities in the last years of the League of Nations' International Institute of Intellectual Cooperation and in the early years of UNESCO to discuss how internationalist projects may raise debates on the dynamics of international intellectual relations. For this purpose, I examine official and personal correspondences that were researched at some Brazilian historical archives, such as Itamaraty and Fiocruz's Archives, Rockefeller Archive Center and UNESCO Archives.

\section{An International Center on Intellectual Cooperation in the Americas}

In the mid-1940s, Ozório de Almeida went on one of his trips to France to conduct research at his collaborators' experimental physiology laboratories. ${ }^{2} \mathrm{He}$ was in Paris when the city was occupied by Germany. This story is told in his 1943 book Ambiente de guerra na Europa [War Environment in Europe, free translation]. ${ }^{3}$ During this period, which he called "the battle of civilization", Ozório de Almeida participated in radio programs and wrote articles on the war for French journals. In his book, he described his activities at the IIIC, the dinners of the Cercle de la rue Tournon ${ }^{4}$ and conversations held with his Brazilian friends living in Paris, among them the chemist Paulo Berredo de Carneiro. ${ }^{5}$ Ozório de Almeida described the IIIC's last activities as follows:

On Monday, 10th, around eleven o'clock, I went to the International Institute. The last preparations for everybody's evacuation was under way. Henri Bonnet told me that he would leave in two hours. He tried his utmost to convince me to leave too, whatever way, to reach somewhere at least sixty or seventy kilometers away from Paris. As everywhere else, at the Institute they considered it extremely dangerous to remain in Paris. One should expect the worse to happen. In my case the situation was even more critical because even if the city would be occupied without great sacrifices, the Germans would hold against me many crucial elements: my speeches on the radio, the article just recently published in Temps, my papers and manuscripts. Bonnet and I were immensely sad about having to separate after such a long-term collaboration in a perfect spirit of goodwill. None of us knew what would happen to this Intellectual Cooperation to which 
Bonnet had given the best of his efforts and all the brightness of his intelligence. ${ }^{6}$

The following days were even sadder for the scientist, who had to burn the war journal he had been writing since September 1939, the copies of the replies to his letter to intellectuals in neutral countries, which would be part of his new volume of the IIIC's Intellectual Cooperation Bulletin, the speeches he made on the radio, besides his articles. ${ }^{7}$ A few days later, Ozório de Almeida returned to Rio de Janeiro but kept himself informed on the course of intellectual cooperation. In a letter to Paulo Carneiro, who remained in Paris, he discussed the attempt to appoint the chemist to substitute the deceased Brazilian diplomat E. Montarroyos as representative of Brazil to the IIIC:

Here in Rio there is no resolution on Montarroyos' substitute. At this point the International Institute practically does not exist. All its documents are dispersed. [. . .] I received a letter from Henri Bonnet who is currently in New York. He told me that he is only establishing the first contacts with the North Americans to then see what can be done. As for your case, you can be sure: your application has our full support. No one can perform this function better than you. I would like you to tell me as soon as possible if you would accept the position in case the Institute would be located in another city instead of Paris, even if temporarily. ${ }^{8}$

The effort to include Paulo Carneiro in the intellectual cooperation project succeeded only some years later with the creation of UNESCO, to which the chemist became the Brazilian delegate.

When the IIIC activities ended, Henri Bonnet traveled to the United States with the support of the Rockefeller Foundation. Together with James Shotwell, head of the National Committee of the United States of America on International Intellectual Cooperation (linked to the League of Nations' IIIC), Bonnet became involved in the debates to maintain the intellectual cooperation activities during the war. ${ }^{9}$ At this point, the development of a temporary intellectual cooperation center in the Americas became part of the agenda of a group of intellectuals in the United States and some Latin American countries.

Bonnet's experience and his relationship with members of national commissions of Latin American countries were initially seen as positive by staff members of the Rockefeller Foundation, who sought to keep him in the United States:

During his stay in this country Mr. Bonnet has been collaborating with Professor James T. Shotwell, the Chairman of the United States Committee on International Intellectual Cooperation, and with Dr. 
Waldo G. Leland, Director of the American Council of Learned Societies with regard to the international activities of the Council.

In view of the growing importance of these activities $\mathrm{Mr}$ Leland has requested the grant-in-aid now recommended to enable him to secure the services of Mr. Bonnet for the Council and for the United States Committee as a consultant on matters relating to international intellectual cooperation. Such an arrangement Mr Leland and $\mathrm{Mr}$ Shotwell believe especially desirable because of the fact that the German government has now taken over the IIIC in Paris and has appointed a commissioner to continue its work. To reorganize activities of this kind in the Western Hemisphere, the United States Committee is now endeavoring to arrange a conference of all North and South American committees of intellectual cooperation, which will probably be held in Havana early in 1941. Mr. Leland and Mr. Shotwell feel that Mr. Bonnet's knowledge of earlier work of this type would be invaluable in this effort, particularly because of his previous contacts with South American committees. ${ }^{10}$

Ozório de Almeida participated in the debates and was appointed president of the committee to study the possibility of establishing a temporary center of intellectual cooperation in the Americas. The committee was created at the Second American Conference of National Committees on Intellectual Cooperation held in Havana in November 15-21, 1941. ${ }^{11}$ At this Conference, Brazil was represented by ambassador João Carlos Muñiz, Miguel Ozório de Almeida and Ruy Ribeiro Couto. Ozório de Almeida presented the report "Considerations on measures that should be adopted with the purpose of facilitating and coordinating the relations between the national commissions on intellectual cooperation in the Americas", in which he highlighted the importance of:

Offering the International Institute on Intellectual Cooperation a shelter in a country in the Americas in such a way that it may resume its activities, even if partially. This would enable, among many other aspects, the continuity of the general work on intellectual cooperation without a too long discontinuity. This would also help us to organize on broader and more humane bases the very inter-American cooperation. Finally, we would thus clear all doubts about the real significance and deep meaning of the cooperation movement in the western hemisphere, making evident the principle of universal solidarity that should characterize it. ${ }^{12}$

The other members of the Committee were: James T. Shotwell (United States), Cosme de la Torriente y Peraza (Cuba), Julián Nogueira (Uruguay), Victor Lascano (Argentina), Francisco Walker Linares (Chile) and Alfonso Reyes (Mexico). The appointed technical advisers were: 
Malcolm Davis (United States), Henri Bonnet (France), Antonio Castro Leal (Mexico) and Mariano Brull (Cuba). ${ }^{13}$

The meeting "America in face of the world crisis" was held on November 23-25, 1941. Ozório de Almeida was the first participant to take the floor:

I believe that at an intellectuals' meeting it is not out of place to draw attention to the phenomenon that has occurred in Europe and to what is happening in this side of the Atlantic. Freedom of thought is under threat all over; but this threat is greater to men who have some possibility of thought. ${ }^{14}$

The debate continued with the intellectuals' increasing concern about the risk posed to democracy not only in Europe but also in the Americas, with the strengthening of authoritarian governments and the support of many intellectuals to antidemocratic thought. The meeting resulted in a manifest, which was signed and translated into Portuguese by Ozório de Almeida, with the purpose of defending democracy and opposing authoritarian regimes. ${ }^{15}$

Ozório de Almeida was the only Brazilian to sign the Declaration. The anti-authoritarian character of the document most likely caused constraints to the Brazilian government, which since 1937 had assumed a dictatorial character with the so-called Estado Novo [New State] promulgated by Getúlio Vargas. It seems that the Brazilian government was at that point losing interest in the issues concerning the IIIC and was no longer supporting its actions. In a letter to Paulo Carneiro, Ozório de Almeida explained the situation of the Intellectual Cooperation:

This is what there is concerning the International Institute on Cooperation. Despite all efforts, Henri Bonnet did not succeed in creating in the United States a Secretariat or whatever kind of organization that could give the impression of the Institute's real survival. He had absolutely no resources for this and the North Americans did not want to or could not support him with this issue. Therefore, the Institute has but a symbolic existence now. It has no place, no staff, it has nothing at all; it has only the representation of its director: $\mathrm{H}$. Bonnet. At the Conference on Intellectual Cooperation in Cuba last November, with this situation clearly understood, a resolution was unanimously voted for the creation of a seven members Commission for the installation of the Institute of Paris in one of the American countries. I was elected as the Commission's president. A few weeks later the war with the United States started. The Commission could do nothing and we are now taking steps for another decision under the new instances. Thus, you understand that the Brazilian government never again thought of fulfilling the vacancy left with the death 
of our poor Montarroyos. Having in fact no Institute, in principle there could be no government's delegate to the Institute. ${ }^{16}$

Ozório de Almeida's relationship with Vargas's administration was ambiguous. It is possible to notice that as president of the Brazilian Commission on Intellectual Cooperation [Comissão Brasileira de Cooperação Intelectual-CBCI] since 1935, he sought to keep a close relationship with the Ministry of Foreign Affairs so as to obtain the necessary support to participate in the events of his international network of scientists and organizations with an internationalist character and in which he was involved, such as the IIIC. Nevertheless, in these national and international forums on intellectual cooperation, he made a stand against authoritarian regimes and the lack of autonomy and freedom of expression during Vargas's dictatorship. ${ }^{17}$

At the same time that in the international context Ozório de Almeida defended the maintenance of intellectual cooperation, in the national context he reinforced the importance of the University's role as a place for the development of pure science and complete autonomy of researchers. Ozório de Almeida repudiated the State's interference in the University and research institutions and manifested his opposition to the authoritarian dimension of Vargas' government by defending the intellectuals' autonomy of thought. Therefore, autonomy was not only a practical demand from a group of intellectuals and scientists organized in the Brazilian Academy of Sciences (Academia Brasileira de Ciências) and the Brazilian Academy of Education (Academia Brasileira de Educação), it was also understood as a moral value that characterized the group. For Ozório de Almeida, the intellectual who deserved to bear this name would have a free consciousness in the face of any authority, political or intellectual, national or international. ${ }^{18}$

The post-war period opened new possibilities for international intellectual cooperation, especially with the debate on the creation and development of UNESCO. However, the Brazilian government's growing lack of interest in issues related to the IIIC's intellectual cooperation also marked the early negotiations with UNESCO. In a letter from June 1951 to Paulo Carneiro, Ozório de Almeida was clear about this feeling: "The president [Getúlio Vargas] already had a deep antipathy towards the Intellectual Cooperation and has undoubtedly transferred this antipathy to UNESCO. The watchword is to be economical and it will always produce a good effect by pretending to be economical with UNESCO's issues, while there is waste with other issues." 19

\section{“The Old Cooperation” and UNESCO}

After the liberation of Paris from the German occupation, the International Institute on Intellectual Cooperation sought the restoration of its 
activities. Ozório de Almeida received a letter from French politician Édouard Herriot inviting him to the IIIC's Administrative Council to be held in October 1945 in Lyon. In a letter from September 10, 1945, to Paulo Carneiro, Ozório de Almeida asked the Brazilian chemist, who was living in Paris, to attend the Council in his place in case he could not get the government's authorization and financial support in time to go himself to the event. The letter was written in French to "make things easier if by any chance there still is any kind of postal censorship" ${ }^{20}$ and described the difficulties he was facing with the government, which appeared not to give much importance to issues related to the international intellectual cooperation. Ozório de Almeida mentioned the request he received from the French fellows to support and legitimate the intellectual cooperation model that was being used by them in that Council. According to Herriot, the Council was being scheduled so that the IIIC would affirm its existence and the interest it still manifested regarding the intellectual cooperation cause before the London meeting to be held in November that same year, in which the shape of the new international organization on intellectual cooperation would be decided. In the letter to Paulo Carneiro, Ozório de Almeida transcribed parts of Herriot's letter and presented an idea about how he would behave regarding this issue:

I write to you, my dear Paulo, to ask you to substitute me in this meeting and to say on my behalf, in the sense indicated by Herriot in his letter, what you already very well know. You know very well my ideas on this, they are also yours. For the rest, you should let yourself be oriented by Herriot, who is man of great moral and intellectual integrity. Naturally, it should be necessary to deal in great depth with the issue of cooperation in the scientific domain. In the last organization, whose principles are excellent, science occupied a secondary level. We are only beginning to seek the bases. Something similar was done in Paris in 1937 and in Geneva in 1939, but there was not enough time to mature the plans. The war has shown what research may offer when organized in a defined sense and with the necessary resources. But I very much persist with the idea that on an organizational plan, even when very well organized, one still leaves a phase for individual, free and disinterested research. I have exposed these ideas in an article in the Free World of 1942. Perhaps you can find it in Paris. Therefore, I do not know what can be done and even if it will possible for me to attend the London Conference. Tell the colleagues of the cooperation that, in this case, I am willing to confirm by telegram the resolutions made in accordance with the bases and tradition of the intellectual cooperation organization. ${ }^{21}$

It is clear that although he supported some IIIC's bases, Ozório de Almeida wished to see a much greater role for sciences within this new 
international organization that would be created. Even before the end of the war, the scientist had already had the opportunity to stress this point in the article mentioned in his letter, Scientific Research in a Free World, published in the North American journal Free World. Upon exposing his ideas on the importance of applied and pure science in the modern world, the scientist highlighted the moral role of science in a free world. At the end of the article, Ozório de Almeida stated:

If the free world of the future wishes to remain a really free world, it should reserve an important place for pure science, one of the highest and most useful manifestations of human liberty. But it will have to create the sort of mental climate in which science can develop unhindered. Pure Science is the work of a few individuals, the selection of whom is an extremely delicate matter, and this work is not possible without co-operative effort. It is highly desirable that from now on this effort should be studied and prepared. ${ }^{22}$

Pure science was defined as a crucial aspect of the modern world, and its development was seen as an essential element to maintain a free world. Moral qualities of men of science-who cultivated pure science, such as the search for truth, cooperation and autonomy and freedom in the face of any kind of intellectual or political authority-were valued by Ozório de Almeida as essential elements for the devolvement of peace in the postwar period. These matters will be recovered in his statements during his first years in UNESCO.

It is possible to notice in the letters exchanged between the two Brazilian scientists the difficulties and controversies engendered by the creation of UNESCO and how Ozório de Almeida felt out of place at the meetings held in London in mid-1946. In a letter dated June 3, 1946, Ozório de Almeida asked Paulo Carneiro's opinion about the need to participate in all the meetings of UNESCO's committees and asked whether it would not be better to participate only at the final part of the Preparatory Commission in London. ${ }^{23}$ In a previous letter, the scientist had already demonstrated his concern about spending too much time in London taking part in all the meetings for the preparation of UNESCO, considering that his ticket had been paid for by the French government and, therefore, he would like to spend more time in Paris. ${ }^{24}$ However, in the letter from June 3, Ozório de Almeida showed signs of the uneasiness he felt in the meetings taking place in London regarding the opposition between the group of old collaborators of the League of Nations' intellectual cooperation project and the new group of UNESCO's creation:

On my side, I confess that I have been feeling a lack of interest in all these issues. This is a new time and I feel that we, those from 
the old Cooperation (this is not your case), especially the members of the Geneva Commission and those who worked directly at the Institute of Paris, would show a lack of tact if we insisted in actively participating in the new organization. I much prefer to keep myself reserved and discreet and wait for the evolution of things. Therefore, my wish is not to be present in London, but in the last case I would go to the meeting from 5 to 12 July, much more as an observer than as an active participant. It should be noted that I make no opposition to UNESCO and that I wish that it will be totally successful. Still, I would not feel good about making advances or [illegible] drawing attention to myself. ${ }^{25}$

Ozório de Almeida did not receive a prompt reply from Paulo Carneiro; thus, on June 12, 1946, he wrote another letter telling about the contents of his previous one and that he thought it would not even be useful to go to the last plenary sessions of UNESCO's Preparatory Commission in London:

I think it is preferable to preserve myself for the definitive Conference to be held in Paris in November, when the permanent UNESCO organization will be decided and in which I could perhaps have some action. There is something unpleasant about the attitude of the new participants concerning the old collaborators of the Intellectual Cooperation and I would not like to lose myself in transitory discussions. It will be better to discuss it in one occasion only and speak my mind, being ready and willing to collaborate in case it seems reasonable to me, or I would rather return if the new tendencies do not please me. [...] Have you been with Huxley after his return from the countries in the American continent? What are his impressions? Why were the North Americans removed from the Intellectual Cooperation? Are they really determined to leave aside all that has been achieved and start a new or apparently new life? You understand that in issues of this nature I do not cling to the past, but I consider that it would be a loss of time and effort to throw out the significant study material gathered as a result of much work. The real problem is the same; the circumstances have changed. The ideal thing would be to put together some of those who have the knowledge of the problem and know the circumstances with those who know the circumstances but do not understand the problem yet. ${ }^{26}$

It seems that Ozório de Almeida preserved himself for the First UNESCO Conference held in Paris in November 1946, where he could make his stand. Though UNESCO represented the achievement of his international cooperation ideals, especially due to the inclusion of sciences as 
one of its main concerns, the way in which it was done bothered him somehow. This was made very clear when the scientist addressed the First Paris Conference.

\section{Universalisms in Debate During the Early Years of UNESCO}

UNESCO draw on the League of Nations' intellectual cooperation project; however, it sought distance from what were understood as defects and causes of the failure of the previous project, especially concerning its tendency to be considered elitist and Eurocentric. ${ }^{27}$

UNESCO inherited from the IIIC and ICIC some of the staff and cultural programs, such as the revision of school manuals, international university exchange, translation of literary works, the coordination of libraries and archives, among others. Furthermore, French intellectuals who participated in its creation followed a classical and European conception of culture, inspired by the IIIC, and conceived UNESCO's action mainly centered on the intellectual domain. However, the IIIC also played the role of "countermodel", and many of UNESCO's founders, especially British and North American, tried to avoid the new organization reproducing the problems of its predecessor. Thus, UNESCO was created with the concern of attending the masses, not only an elite (the "société des esprits" of Paul Valéry), and with the objective of having a worldwide dimension instead of a European dimension only.

The previous actions of the IIIC were seen as elitist because they were restricted to a public composed of specialists and had little concrete achievements; besides, education was not included in its attributions. In contrast, UNESCO gave great importance to education and science, problems of the so-called "underdeveloped" countries and modern mass communication techniques. ${ }^{28}$

At the moment of its creation, the initial conflict was related to the debate between those who defended that the new organization should have a non-governmental character and those who supported the idea that it should have an intergovernmental nature. ${ }^{29}$ Over time, the last tendency was strengthened.

The British government was highly interested in the creation of this organization, contributing in a decisive way to the reflections that actually led to it, especially by means of the Conference of Allied Ministers of Education (CAME) between 1942 and 1945. Two well-known British scientists, zoologist Julian Huxley (1887-1975) and biochemist Joseph Needham (1900-1995), played an active role in UNESCO's early years, namely in the process of including the term "science" in its name and valorizing the reflection on the social importance of science by this international organization. ${ }^{30}$

In the memorandum "The place of science and international scientific cooperation in post-war world organisation", of April 1945, Needham 
used for the first time the term UNESCO - United Nations Educational, Scientific and Cultural Organization (in opposition to UNECO), thus including the "S" for "science". In this document, Needham highlighted the importance that the new international organization could bring to the domain of international scientific cooperation, especially by providing support to scientists and technicians in distant areas of what he named "bright zones", i.e., countries in Europe and North America. According to Needham, there was a universal desire among scientists to see better international contacts after the end of the war, but the international cooperation domain was marked by a certain "laissez-faire", which could function very well for North American and European scientists but did not make communication easy between scientists from other regions of the world.

At the November 1945 Conference, the term "science" was officialized in the name of the organization. ${ }^{31}$ From 1946 to 1948, Julian Huxley was the first UNESCO's director-general, and Joseph Needham was the head of the Natural Sciences Sector.

Huxley's term as director-general was marked by his evolutionist and positivist ideas; his trust in science to explain phenomena and solve natural and social problems; his advocacy of a better comprehension of science, particularly biology and psychology and his belief in science as the main factor of progress and harmony between the peoples. ${ }^{32}$ As UNESCO's director-general, he acted as a mediator between pragmatic liberal forces and leftist forces present in the new organization's debates. ${ }^{33}$

Needham's actions were in accordance with his "periphery principle" fundaments and was marked by his experience in China as responsible for the Committee on Scientific Cooperation between China and the United Kingdom in the 1940s. A Christian Marxist, Needham was a Bernalist; that is, he followed the ideas of the British physician John Bernal, a Marxist who had developed works on the social function of science since the 1930s. ${ }^{34}$ Needham demanded better planning and greater social responsibility in UNESCO's actions, especially concerning the social role of science. With this international organization, he sought to strengthen independence, economic development and enlargement of scientific knowledge bases in places that had been colonized by Western nations. ${ }^{35}$

Huxley and Needham had been involved in the movement Social Relation of Science (SRS) in the 1930s. This movement of British scientists defended science and socialism, stressing the social responsibility of science. ${ }^{36}$ The ideas of this group were influenced by the contact with the history of Soviet science presented at the Second International Congress of the History of Science, held in 1931, especially the Marxist interpretation of Boris Hessen in the work "The Social and Economic Roots of Newton's Principia". ${ }^{37}$

As highlighted by Elzinga, UNESCO's declared intention was universality, that is, the understanding that science is a common product of 
humankind, a public good that exists for the benefit of humanity. ${ }^{38} \mathrm{How}-$ ever, when mentioning universality, there are many projects at stake and UNESCO was the stage of debates on various universalisms.

Huxley's and Needham's ideas brought about proposals and criticism from intellectuals like the Brazilian Miguel Ozório de Almeida and enabled the creation of a space for debates. ${ }^{39}$ Considering their life experience, the founders of UNESCO as well as Ozório de Almeida affirmed that the so-called "international scientific community" was unfinished, incomplete, deficient and Eurocentric and saw scientific universalism as a project to be built. There were, however, different proposals for the development of this project.

UNESCO mentioned unity and universalism for the area of science but drew on a conception that considered the scientific production in the "not enlightened zones" practically nonexistent. What sort of universality would that be? What kind of international intellectual cooperation does this idea reveal? Perhaps this was the question that Ozório de Almeida posed himself at the time. And this was indeed the question that he openly posed when making his stand at the First UNESCO Conference in November 1946.

Ozório de Almeida participated as a delegate from Brazil, together with Olimpio da Fonseca, Paulo Carneiro and Carlos Chagas Filho. The head of the delegation was Moniz de Aragão, the secretary-general was Georges Maciel, and as experts there were Maria Eugenia Franco, Beatrix Veiga, Isabel de Prado, Jorge Maia, Paulo E. Salles Gomes and Mario Barata. During the Conference, Ozório de Almeida was elected vicepresident of the Sub-Commission on Exact and Natural Sciences, and Paulo Carneiro presented the project to create an International Institute of the Amazon Hylea that was discussed and approved. ${ }^{40}$ In May 1946, Paulo Carneiro had proposed creating a research center in the Amazon that was included in a scientific program being designed by the Committee on Natural Sciences of the UNESCO Preparatory Commission under Needham's coordination.

When opening the session of the Sub-Commission on Exact and Natural Sciences held on November 30, 1946, as head of UNESCO's Natural Sciences Sector, Needham reinforced in his speech the importance of his "periphery principle". He stated that he had the opportunity to spend a significant part of his scientific life in different parts of the world, especially in China, where he could have new ideas and open new horizons on certain aspects of science. According to him, those experiences led him to a better understanding of the difficulties encountered in certain parts of the world in the domain of science and technology: "I was able to realize the deadening and sometimes even demoralizing effect produced by the isolation in which certain scientists have to live.”41 Needham mentioned the two brochures handed to the participants with ideas and proposals for 
the Sub-Commission on Exact and Natural Sciences, in which appeared the idea of bright zones and dark zones dividing the scientific world. This division, in his view, resulted from purely historical circumstances, and the bright zones should understand how precious their help could be to the less bright zones, both in the material and moral aspects. Needham stressed that the problem was related not only to the isolation in which those regions were, but it also referred to the uneven distribution of natural and industrial resources: "In other words, it is necessary to raise the standard of life in a large part of the word and the living conditions of the non-industrialized peoples". ${ }^{42}$

He emphasized, therefore, that an international organization's action should have a double aspect: "on the one hand, it must reach the farthest outposts of the world, the less favoured areas; on the other hand, it must also work in the "bright zone"". ${ }^{43}$ Regarding the first aspect, one initial action of the Exact and Natural Sciences Sector should be the installation of three Intellectual Cooperation Offices in countries of the so-called periphery, namely in the East, Near East and Latin America. In the "more favored or bright zone", although there were already many international associations on specific branches of scientific knowledge, Needham reinforced the importance of the creation of new associations and the financial support they should receive.

The differentiated lines of action regarding the bright zones and the dark zones should be highlighted. It is likely that this rigid distinction between the actions to be carried out in the different areas did not please Ozório de Almeida. The different conceptions of universalism that were at stake are quite noticeable. While the formulators of UNESCO defended the idea that scientific knowledge was a common good for everyone, Ozório de Almeida understood that the scientific knowledge was made by everyone; thus, it was the result of cooperation.

At the second session of the Sub-Commission on Exact and Natural Sciences held on December 2, 1946, Carlos Chagas Filho praised UNESCO's program for the area of science, stressing the significance of the project proposed by Paulo Carneiro for the creation of the International Institute of the Amazon Hylea. Chagas Filho stressed that the Brazilian delegation did not see it as a national project only but also as an international work. Therefore, the Institute would serve not only all of South America but also the entire civilized world: "We do not consider it as a centre of pure research only, for obtaining new biological and geological data, but as a centre of active research which, in the near future, would be able to solve problems of interest to the whole world" ${ }^{44}$ Finally, the scientist stated: "I should also like to draw your attention to certain points which might limit the effectiveness our work. In the 'dark zones' it is often impossible to find either the men or the material required. Scientists should therefore sometimes be sent to laboratories which are already established there". ${ }^{45}$ 
In a discreet manner, Chagas Filho sought to indicate the existence of research centers in the so-called dark zones. ${ }^{46}$ This idea was later recalled by Ozório de Almeida in a more incisive speech.

Ozório de Almeida started his speech, as did Carlos Chagas Filho, reaffirming the relevance of the project of the International Institute of the Amazon Hylea for Latin America countries as well as for European countries such as France, The Netherlands and England. Then the scientist presented his view on UNESCO's proposal for the area of sciences:

It is felt that in the projects submitted by the Secretariat too much importance cannot be attached to what are described as the two zones in the civilized world, the "bright zone" and the "dark zone". I think that this division of the world into two zones is not only necessary but obvious. In fact, the history of scientific development shows that progress has always been made in somewhat limited areas. In the world today, however, UNESCO's main function is to spread these "bright zones" and enlighten the "dark zones". This will produce excellent results, but the great question is whether these results will be permanent or only temporary. The interesting question is why has science not developed as it should have done in the countries classified as belonging to "dark zones"? There are countries in these zones which have in the past produced remarkable scientists but have now fallen back to the "dark zones" class. What has been the cause of this decadence? (. . .) We have noticed that, even in "dark zones" countries, some scientific work has been done and that certain personalities have attained the highest standards of scientific research. What are the obstacles which have hampered scientific development and what conditions should be realized to make such development possible? Is there an answer to this question? It depends on practical organization; and if this is so, could UNESCO not assist these countries? ${ }^{47}$

It is possible to notice in Ozório de Almeida's speech that he relativized the idea of bright zones and dark zones by stressing the transitory character of these zones through time. Moreover, he highlighted the existence of scientific works in the dark zones and the importance of UNESCO turning to these scientists to learn about their opinion on this matter. This idea marked Ozório de Almeida's participation at UNESCO. The scientist continued his speech by emphasizing what he called the moral aspect of the issue:

These questions are rather delicate, but we must take them into account. A sort of "scientific imperialism" is practiced by countries which only believe in what has been done in their own country and sometimes despise work done elsewhere. I think it is this state of 
mind, when it still exists, which has to some extent prevented scientific development in countries of the "dark zones". ${ }^{48}$

This is the central point of Ozório de Almeida's speech. The scientist presented one of the elements that might explain the dark zone condition in some countries: a certain scientific imperialism. Therefore, he attributed the responsibility for the "darkness" of certain zones to the very dynamics of international intellectual relations, marked by historical asymmetries. After mentioning this aspect, the Brazilian scientist highlighted the internal hindrances encountered in these dark zone countries:

I may quote a man who has had a distinguished career, great success in research and who belongs to one of the countries of the "dark zones". He used to say: "when working in a great scientific country one can afford to be slightly melancholic, or to have doubts which may be favorable to work; but it is painful to realize that in poorer countries ideas have to be proportioned to the material resources at one's disposal, whereas in other countries the resources are available corresponding to one's ideas." This is a fundamental difference in the conditions in which scientific work is carried out. ${ }^{49}$

Therefore, scientists from the dark zones would need to overcome a double obstacle: the material hindrances of the institutions in their countries and the nationalist (or even Eurocentric) tendency regarding international scientific relations. It was a way to say: yes, we need help to counterbalance the asymmetric dynamics of international intellectual relations, but before that, you must listen to us.

Ozório de Almeida and Needham affirmed that the so-called "international scientific community" was incomplete and Eurocentric and considered scientific universalism a project to be built, but their proposals for the solution of the historical discrepancy between regions were quite different.

UNESCO's projects for the dark zones drew on the idea of science directed to the applicability and replicability of methods and knowledge of the so-called bright zones. According to this conception, the scientific method would offer the possibility to produce "universal" knowledge, that is, that could be applied in different parts of the world, taking progress to different peoples. Thus, cooperation was understood as support to the so-called "dark zones", instead of mutual support between scientists from different nations. The idea of cooperation would be associated with assistance, rather than to the idea of exchange between scientist from different countries.

This was a very different vision from that professed by Ozório de Almeida, to whom universalization was a process that drew on the cooperation between intellectuals and scientists from different places. Thus, 
European scientists would need scientists from the so-called non-bright zones as much as these would need scientists from the bright zones. After all, the non-bright zones were actually not that dark. Ozório de Almeida's concern was to valorize what already existed in the non-bright zones. How could one say to a scientist who had spent his entire life creating space for the production of "pure science" in the area of physiology in Brazil, coming from a family of Rio de Janeiro's intellectual elite involved in debates on the development of the educational and scientific system in the country, that his country belonged to a non-bright zone so darkly pictured by Needham?

In December 1946, the First UNESCO Conference held in Paris approved the project of the International Institute of the Amazon Hylea and the creation of Scientific Cooperation Offices in underdeveloped regions, namely Latin America, Asia and Africa, thus materializing Needham's periphery principle. It is likely that in Ozório de Almeida's view, Needham's periphery principle was applied with no consideration to the real situation of the so-called dark zones of the scientific world, which were actually not always that dark. This idea was latter retrieved by Ozório de Almeida and other Latin American scientists.

Despite the divergence, it is possible to notice Ozório de Almeida's interest in having more effective participation in the new international organization. Paulo Carneiro, who occupied the position of Brazilian delegate to UNESCO, became Ozório de Almeida's strongest link with the institution. While, as previously mentioned, Ozório de Almeida had initially been responsible for the inclusion of Carneiro in the international intellectual cooperation, the Brazilian chemist became the one responsible for keeping a space for Ozório de Almeida in the new international organization. In his letters to Paulo Carneiro, the scientist frequently asked about the situation of UNESCO and how he could help. He was always ready to support Carneiro in whatever way possible and asked for his friend's help to resolve his situation in regard to UNESCO: "I count on you to resolve my position at UNESCO so that I can return to Paris as soon as possible. I am waiting for the title that will enable me to start the survey we have agreed upon on scientific research in Latin America". ${ }^{50}$

In March 1947, Ozório de Almeida sent a letter mentioning that he was anxious to receive some news about UNESCO: "Thus, I am waiting for news from you. I have done nothing yet on the survey about the conditions of scientific work in Latin America because I have not received the necessary official authorization from UNESCO". ${ }^{51}$ The scientist constantly demonstrated his dissatisfaction with the Brazilian intellectual environment and gave the impression that he would like to live in Paris. Most likely he saw in UNESCO the possibility to have this idea turned into reality.

During 1947 and 1948, negotiations between Paulo Carneiro and Itamaraty ${ }^{52}$ regarded the possibility that Brazilians could occupy positions at 
UNESCO. There was a constant concern of Paulo Carneiro about Ozório de Almeida's application for important positions at the organization.

In an official letter dated January 24, 1947, to the Minister of Foreign Affairs, Raul Fernandes, Paulo Carneiro informed him that until that moment, the Brazilian citizens working at UNESCO were Anisio Teixeira (adviser at the Education Sector), Celia Neves (budget directory) and Isadora de Andrade Falcão (assistant at the Music Sector). However, he stated that Huxley, UNESCO's director-general, had the intention of appointing two other advisers to whom he had already sent invitations: Miguel Ozório de Almeida (Natural Sciences Sector) and Rodolfo Paula Lopes (Social Sciences Sector).

In an official letter dated March 14, 1947, to Raul Fernandes, following a list of positions to be occupied in the course of two years, Paulo Carneiro indicated the first great opportunity for Ozório de Almeida:

For the place of Head of the Natural Sciences Sector, which will be vacant in July due to Dr Joseph Needham's return to the University of Cambridge, one of the names most in view is that of Professor Miguel Ozório de Almeida. In a letter sent to me, Dr Joseph Needham expresses the satisfaction he would have by having as his successor the eminent Brazilian scientist. ${ }^{53}$

The negotiations between Paulo Carneiro and UNESCO might have been in the right direction; however, he needed the support from and the fast and efficient action of the Ministry of Foreign Affairs:

But the director-general will have to consider for this position the applications presented by several member states and their National Commissions. Therefore, I plea to Your Excellency to please support, on behalf of the Brazilian government, the election of Professor Miguel Ozório de Almeida, whose titles and works indicate him, without any possible competition, to represent Brazil in this high position. ${ }^{54}$

The application did not progress. The position of head of the Natural Sciences Sector was occupied in 1948 by Pierre Auger, a left-wing French physician. This was not the only time that Ozório de Almeida's application presented by Paulo Carneiro failed. In 1948, Paulo Carneiro was involved in an intense campaign for Ozório de Almeida's application for the position of UNESCO's director-general, which did not succeed either.

Although the campaigns for Ozório de Almeida's application for important positions at UNESCO were not successful, the scientist participated as a Brazilian delegate to the 1946 General Conference, previously mentioned, and to the 1949,1950 and 1952 Conferences. ${ }^{55}$ During this period, he also presented the initial reports for the development of 
two UNESCO projects: the History of Humanity and the International Brain Institute.

\section{Final Considerations}

The performance of Brazilian physiologist Miguel Ozório de Almeida in international intellectual cooperation projects was marked by the defense of the idea of the universal and peaceful character of intellectual and scientific work. This idea was shared by other researchers at that moment. Negotiations for the creation of a temporary intellectual cooperation center in the Americas soon after the occupation of Paris by Germany in June 1940 showed the increasing role of Latin American intellectuals in the international intellectual network since the interwar period, demonstrated by the role played by Brazilian Miguel Ozório de Almeida at that moment. Nevertheless, the failure of the initiative and the negotiations in UNESCO's early years also point to the asymmetries that constituted the dynamics of international intellectual relations. Anyhow, the intellectual cooperation project of the League of Nations was used as a forum for Ozório de Almeida's criticism of Getúlio Vargas's authoritarian government in Brazil and for his defense of intellectual work autonomy; it was also crucial for the strengthening of relations between the Brazilian scientist Ozório de Almeida and European and Latin American intellectuals. UNESCO was also an important forum for the development of that network of intellectuals, and Ozório de Almeida used it for his criticism of what he understood as a certain "scientific imperialism" that hindered the international relations of intellectuals.

\section{Notes}

1. This article was part of my PhD thesis that was assisted by the scholarship from Capes-Coordination for the Improvement of Higher Education (Brazil) and the Grant-in-aid of the Rockefeller Archive Center (New York).

2. On Miguel Ozório de Almeida's intellectual and scientific trajectory, see Letícia Pumar, "The Idea of Science of Brazilian Physiologist Miguel Ozório de Almeida (1890-1953)", Transversal, n. 3 (2017): 51-67.

3. Miguel Ozório de Almeida, Ambiente de guerra na Europa (Rio de Janeiro: Atlântica, 1943).

4. A group of intellectuals, diplomats and scientists from France, including Bonnet, Paul Rivet, Madame Vacher, Henri Laugier, Louis Lapicque, Paul Langevin, Henri Piéron, Pierre Janet, Jacques Hadamard, Jean and Francis Perrin, Louis Rapkine, Marcel Mauss, Paul Valéry and Henri Focillon, who normally met once a month to dine and debate.

5. Paulo Estevão de Berredo Carneiro (1901-1982), under family influence, since very early in life had contact with positivism and became one of its greatest adepts in Brazil. He had a significant role at UNESCO as Brazil's permanent representative. On different aspects of his trajectory, see Marcos Chor Maio, Ciência, politica e relações científicas internacionais: ensaios sobre Paulo Carneiro (Rio de Janeiro: Ed. Fiocruz; Unesco, 2004).

6. Ozório de Almeida, Ambiente de guerra na Europa, 167-168. 
7. On his participation at the IIIC and ICIC, his articles in the Intellectual Cooperation Bulletin and his correspondence with Henri Bonnet in the 1930s, see Letícia Pumar, "Between National and International Science and Education: Miguel Ozório de Almeida and the League of Nations' Intellectual Cooperation Project," in Beyond Geopolitics: New histories of Latin America at the League of Nations, ed. Alan McPherson and Yannick Wehrli (New Mexico: New Mexico Press, 2015), 169-184.

8. Miguel Ozório de Almeida to Paulo Carneiro, 3 October 1940, Rio de Janeiro, Fundo Paulo Carneiro, Departamento de Arquivo e Documentação da Casa de Oswaldo Cruz/Fiocruz, Rio de Janeiro.

9. Bonnet, Henri-refugee scholars (1940-1941), RF. RG1.1 Series 200, box 48, Rockefeller Archive Center, Sleepy Hollow, New York.

10. Memorandum signed by David H. Stevens, Director for the Humanities, 20 November 1940, Bonnet, Henri-refugee scholars (1940-1941), RF. RG1.1 Series 200, box 48, folder 554, Rockefeller Archive Center, Sleepy Hollow, New York.

11. R.F. R.G. 1.1 Series 100S, box 111, Rockefeller Archive Center, Sleepy Hollow, New York.; E. E. Ware, Second American Conference of National Committees on Intellectual Cooperation. Havana, Cuba, November 15-22, 1941; and Report to the National Committee of the United States of America on International Intellectual Cooperation (New York, 1942).

12. Miguel Ozório de Almeida, "Considerações das medidas que devem ser adoptadas com o fim de facilitar e coordenar as relações entre as comissões nacionais de cooperação intelectual na América”, box 142.6, folder 1688, file 3528.3, 10, Brazilian Ministry of Foreign Affairs Historial Archives, Rio de Janeiro.

13. E. E. Ware, Second American Conference of National Committees on Intellectual Cooperation. Havana, Cuba, November 15-22, 1941. Report to the National Committee of the United States of America on International Intellectual Cooperation (New York, 1942), 61.

14. Comissão Cubana de Cooperación Intelectual, Plática de la Havana: América ante la crisis mundial (Havana: La Habana, 1942), 68-69.

15. The manifest was signed on November 25, 1941, by the following American and European intellectuals: Count Sforza, Henri Focillón, Henri Bonnet, Arnold Raestad, Henri Laugier, R. P. Mckeon, G. A. Borgese, Joseph W. Krutch, Stringfellow Barr, Marshall H. Stone, George F. Zook, Louis Adamic, W. E. Burghardt du Bois, Freda Kirchwey, Cosme de la Torriente, Afonso Reys, Miguel Ozório de Almeida, María Zambrano, Dantés Bellegarde, César Barja, Pere Bosch-Gimpera, Juan Marinello, Jorge Manach, Fernando Ortiz, Salvador Massip, Hermínio Portell Vilá. See E. E. Ware, Second American Conference of National Committees on Intellectual Cooperation. Havana, Cuba, November 15-22, 1941. Report to the National Committee of the United States of America on International Intellectual Cooperation (New York, 1942), 37.

16. Miguel Ozório de Almeida to Paulo Carneiro. 6 January 1942, Rio de Janeiro, Fundo Paulo Carneiro, Departamento de Arquivo e Documentação da Casa de Oswaldo Cruz/Fiocruz, Rio de Janeiro.

17. Pumar, "Between National and International Science and Education," 169-184.

18. Letícia Pumar Alves de Souza, A ciência e seus fins: internacionalismo, universalismo e autonomia na trajetória do fisiologista Miguel Ozório de Almeida (1890-1953). Thesis. Ph.D. in History of Sciences and Health. (Casa de Oswaldo Cruz/Fiocruz, Rio de Janeiro, 2015).

19. Miguel Ozório de Almeida to Paulo Carneiro. 14 June 1951, Rio de Janeiro, Fundo Paulo Carneiro, Departamento de Arquivo e Documentação da Casa de Oswaldo Cruz/Fiocruz, Rio de Janeiro. 
20. Miguel Ozório de Almeida to Paulo Carneiro. 6 September 1945, Rio de Janeiro, Fundo Paulo Carneiro, Departamento de Arquivo e Documentação da Casa de Oswaldo Cruz/Fiocruz, Rio de Janeiro.

21. Ibid.

22. Miguel Ozório de Almeida, "Scientific Research in a Free World," Free World, v. 2, n. 4, (May, 1942).

23. Miguel Ozório de Almeida to Paulo Carneiro. 3 June 1946, Rio de Janeiro, Fundo Paulo Carneiro, Departamento de Arquivo e Documentação da Casa de Oswaldo Cruz/Fiocruz, Rio de Janeiro.

24. Miguel Ozório de Almeida to Paulo Carneiro, 25 April 1946, Rio de Janeiro, Fundo Paulo Carneiro, Departamento de Arquivo e Documentação da Casa de Oswaldo Cruz/Fiocruz, Rio de Janeiro.

25. Miguel Ozório de Almeida to Paulo Carneiro. 3 June 1946, Rio de Janeiro, Fundo Paulo Carneiro, Departamento de Arquivo e Documentação da Casa de Oswaldo Cruz/Fiocruz, Rio de Janeiro.

26. Miguel Ozório de Almeida to Paulo Carneiro, 12 June 1946, Rio de Janeiro, Fundo Paulo Carneiro, Departamento de Arquivo e Documentação da Casa de Oswaldo Cruz/Fiocruz, Rio de Janeiro.

27. Maurel Chloé, L’Unesco de 1945 à 1974. Thesis, Ph.D. in History. (École Normale Supérieure de Paris, Université Panthéon-Sorbonne-Paris I, Paris, 2006).

28. Ibid.

29. Aant Elzinga, “A Unesco e a política de cooperação internacional no campo da ciência," in Ciência, política e relações científicas internacionais: ensaios sobre Paulo Carneiro, ed. Marcos Chor Maio (Rio de Janeiro: Ed. Fiocruz; Unesco, 2004), 89-144.

30. Ibid.

31. ECO/CONF./29. Conference for the Establishment of the United Nations Educational, Scientific and Cultural Organisation, Held at the Institute of Civil Engineers, London, from the 1st to the 16th November 1945, 102.

32. On his defense of "evolutionary humanism" and his engagement, together with other biologists of the time, in a movement that sought to unify biology and integrate the sciences into the traditional humanistic concerns, see Vassiliki Betty Smocovitis, "The Unifying Vision: Julian Huxley, Evolutionary Humanism, and the Evolutionary Synthesis," in Pursuing the Unity of Science: Ideology and Scientific Practice Between the Great War and the Cold War, ed. Geert Somsen and Harmke Kamminga (Aldershot: Ashgate, 2008).

33. Elzinga, "A Unesco e a política de cooperação internacional no campo da ciência”.

34. John Bernal, The Social Function of Science (London: George Routledge \& Sons, 1939).

35. Elzinga, "A Unesco e a política de cooperação internacional no campo da ciência”.

36. Patrick Petitjean, "Needham, Anglo-French Civilities and Ecumenical Science," in Situating the History of Science: Dialogues with Joseph Needham, ed. S. Irfan Habib and Dhruv Raina (New Delhi: Oxford University Press, 1999), 152-197.

37. Gideon Freudenthal and Peter McLaughlin, The Social and Economic Roots of the Scientific Revolution (Berlin: Springer, 2009).

38. Elzinga. "A Unesco e a política de cooperação internacional no campo da ciência”.

39. On the relationship of Brazilian scientists with UNESCO, see Heloisa Bertol Domingues and Patrick Petitjean, "International Science, Brazil and Diplomacy in Unesco (1946-50)," Science, Technology \& Society, v. 9, n. 1 (2004); 
Marcos Chor Maio, Ciência, política e relações científicas internacionais: ensaios sobre Paulo Carneiro (Rio de Janeiro: Ed. Fiocruz; Unesco, 2004); Patrick Petitjean, "Le Département des Sciences naturelles de l'UNESCO et les scientifiques latino-américains à la fin des années 1940," Boletim do Museu Paraense Emílio Goeldi. Ciências Humanas, Belém, v. 4, n. 3 (2009): 437-452.

40. On the International Institute of the Amazon Hylea, see: Marcos Chor Maio and Magali Romero Sá, "Ciência na periferia: a Unesco, a proposta de criação do Instituto Internacional da Hileia Amazônica e as origens do Inpa," História, Ciências, Saúde-Manguinhos, Rio de Janeiro, v. 6, supl. (set. 2000): 975-1017; Patrick Petitjean and Heloísa M. B. Domingues, "A redescoberta da Amazônia num projeto da UNESCO: o Instituto Internacional da Hileia Amazônica," Estudos Históricos, Rio de Janeiro, v. 14, n. 26 (2000): 265-292.

41. UNESCO. General Conference; 1st; 1946, Programme Commission/Subcommission on Natural Sciences: Provisional verbatim record of the Second meeting Publ: 1946; UNESCO/C/Prog.Com./S.C.Nat.Sci./V.R.1, 4.

42. Ibid., 5 .

43. Ibid.

44. Ibid., UNESCO/C/Prog.Com./S.C.Nat.Sci./V.R.2, 7.

45. Ibid., 8 .

46. Carlos Chagas Filho (1910-2000), son of the scientist Carlos Chagas, of Oswaldo Cruz Institute, was the founder of the Institute of Biophysics at the University of Brazil, considered a landmark in the institutionalization of science in Brazil. As the director of the Institute of Biophysics, which received foreigners to conduct researches in Brazil, Chagas Filho indicated that "centers of excellence" existed in the dark zones.

47. UNESCO. General Conference; 1st; 1946, Programme Commission/ Subcommission on Natural Sciences: Provisional verbatim record of the Second meeting Publ: 1946; UNESCO/C/Prog.Com./S.C.Nat.Sci./V.R.2, .9-11.

48. Ibid., 11.

49. Ibid., 12.

50. Miguel Ozório de Almeida to Paulo Carneiro. 12 February 1947, Rio de Janeiro, Fundo Paulo Carneiro, Departamento de Arquivo e Documentação da Casa de Oswaldo Cruz/Fiocruz, Rio de Janeiro.

51. Miguel Ozório de Almeida to Paulo Carneiro, 15 March 1947, Rio de Janeiro, Fundo Paulo Carneiro, Departamento de Arquivo e Documentação da Casa de Oswaldo Cruz/Fiocruz, Rio de Janeiro.

52. The Foreign Ministry of Affairs, also known as Itamaraty, is responsible for Brazilian foreign policy and international relations in bilateral, regional and multilateral levels.

53. Paulo Carneiro to Raul Fernandes, 14 March 1947, Unesco delegação do Brasil (Ofícios 1947-1948), no. 80/4/1, Brazilian Ministry of Foreign Affairs Historial Archives (Itamaraty), Rio de Janeiro, 1.

54. Ibid., 2.

55. Curriculum vitae: Miguel Ozório de Almeida. Unesco 2.512 (3), Delegations of Member States-SCHM, UNESCO Archives, Paris.

\section{References}

American Conference of National Committees on Intellectual Cooperation. Havana, Cuba, November 15-22, 1941. Report to the National Committee of the United States of America on International Intellectual Cooperation (New York, 1942). 


\section{Letícia Pumar}

Bernal, John, The Social Function of Science (London: George Routledge \& Sons, 1939).

Chloé, Maurel, L'Unesco de 1945 à 1974. Thesis, Ph.D. in History. (École Normale Supérieure de Paris, Université Panthéon-Sorbonne-Paris I, Paris, 2006).

Comissão Cubana de Cooperación Intelectual. Plática de la Havana: América ante la crisis mundial (Havana: La Habana, 1942).

de Souza, Letícia Pumar Alves, A ciência e seus fins: internacionalismo, universalismo e autonomia na trajetória do fisiologista Miguel Ozório de Almeida (1890-1953). Thesis. Ph.D. in History of Sciences and Health. (Casa de Oswaldo Cruz/Fiocruz, Rio de Janeiro, 2015).

Domingues, Heloisa Bertol and Patrick Petitjean, "International Science, Brazil and Diplomacy in Unesco (1946-50)," Science, Technology \& Society, v. 9, n. 1 (2004).

ECO/CONF./29. Conference for the Establishment of the United Nations Educational, Scientific and Cultural Organisation, Held at the Institute of Civil Engineers, London, from the 1st to the 16th November 1945.

Elzinga, Aant, "A Unesco e a política de cooperação internacional no campo da ciência," in Ciência, politica e relações científicas internacionais: ensaios sobre Paulo Carneiro, ed. Marcos Chor Maio (Rio de Janeiro: Ed. Fiocruz; Unesco, 2004): 89-144.

Freudenthal, Gideon and Peter McLaughlin, The Social and Economic Roots of the Scientific Revolution (Berlin: Springer, 2009).

Maio, Marcos Chor, Ciência, política e relações científicas internacionais: ensaios sobre Paulo Carneiro (Rio de Janeiro: Ed. Fiocruz; Unesco, 2004).

Maio, Marcos Chor and Magali Romero Sá, "Ciência na periferia: a Unesco, a proposta de criação do Instituto Internacional da Hileia Amazônica e as origens do Inpa," História, Ciências, Saúde-Manguinhos, Rio de Janeiro, v. 6, supl. (set. 2000): 975-1017.

Ozório de Almeida, Miguel, Ambiente de guerra na Europa (Rio de Janeiro: Atlântica, 1943).

Ozório de Almeida, Miguel, "Scientific Research in a Free World," Free World, v. 2, n. 4 (May, 1942).

Petitjean, Patrick, "Le Département des Sciences naturelles de l'UNESCO et les scientifiques latino-américains à la fin des années 1940," Boletim do Museu Paraense Emílio Goeldi. Ciências Humanas, Belém, v. 4, n. 3 (2009): 437-452. Petitjean, Patrick, "Needham, Anglo-French Civilities and Ecumenical Science," in Situating the History of Science: Dialogues with Joseph Needham, ed. S. Irfan Habib and Dhruv Raina (New Delhi: Oxford University Press, 1999), 152-197.

Petitjean, Patrick and Heloísa M. B. Domingues, "A redescoberta da Amazônia num projeto da UNESCO: o Instituto Internacional da Hileia Amazônica," Estudos Históricos, Rio de Janeiro, v. 14, n. 26 (2000): 265-292.

Pumar, Letícia, "Between National and International Science and Education: Miguel Ozório de Almeida and the League of Nations' Intellectual Cooperation Project," in Beyond Geopolitics: New Histories of Latin America at the League of Nations, ed. Alan McPherson and Yannick Wehrli (New Mexico: New Mexico Press, 2015), 169-184.

Pumar, Letícia, “The Idea of Science of Brazilian Physiologist Miguel Ozório de Almeida (1890-1953)," Transversal, n. 3 (2017): 51-67. 
Smocovitis, Vassiliki Betty, “The Unifying Vision: Julian Huxley, Evolutionary Humanism, and the Evolutionary Synthesis," in Pursuing the Unity of Science: Ideology and Scientific Practice Between the Great War and the Cold War, ed. Geert Somsen and Harmke Kamminga (Aldershot: Ashgate, 2008).

UNESCO. General Conference; 1st; 1946, Programme Commission/Subcommission on Natural Sciences: Provisional verbatim record of the Second meeting Publ: 1946; UNESCO/C/Prog.Com./S.C.Nat.Sci./V.R.1. 


\section{Contributors}

Christophe Charle is Professor of Contemporary History at Paris 1 Panthéon-Sorbonne University and former director of the Institut d'histoire moderne et contemporaine (CNRS and Ecole normale supérieure). His main publications (more than forty volumes as editor or unique author) treat European social and cultural history in a comparative approach. Last volumes: ed. La vie intellectuelle en France, 2016, paperback 2018, 3 vol. (with Laurent Jeanpierre); L'Europe, encyclopédie historique, $2018 \mathrm{ed}$. with D. Roche and many others. He is preparing a book on Paris in the 19th century.

Sílvia Coll-Vinent has earned her PhD from Oxford University and her BA in Catalan philology from Universitat Autònoma de Barcelona. She currently teaches contemporary European literature at the Faculty of Philosophy at the Universitat Ramon Llull and coordinates the G. K. Chesterton Study and Documentation Center in Barcelona. She has researched on translation and reception of Victorian and Edwardian literature and on a number of Catalan intellectuals and their cultural activity during the twenties and early thirties. She has recently published "Joan Estelrich, entre el humanismo y la política" and, with Alejandro Coroleu, "Joan Estelrich and the Reception of Vives in Interwar Europe” (2018).

Ângela Fernandes is Assistant Professor at the Department of Romance Literatures of the Faculty of Arts and Humanities of the University of Lisbon, where she teaches courses on literary theory, comparative literature and Hispanic studies. At the Centre for Comparative Studies of ULisbon, she coordinates the research cluster DIIA, devoted to the study of Iberian and Ibero-American literary and cultural dialogues. Recent publications include the book A Ideia de Humanidade na Literatura do Início do Século XX. Huxley, Malraux, Gómez de la Serna (2013); the edited volume, with S. Pérez Isasi, Looking at Iberia. A Comparative European Perspective (2013); and the themed issues "Borges en perspectiva portuguesa y comparada", Variaciones Borges 
44 (2017), and "Iberian Studies: New Spaces of Inquiry", International Journal of Iberian Studies 32: 1-2 (2019).

Laura Fólica is a postdoctoral researcher in the Department of Arts and Humanities at the Universitat Oberta de Catalunya and an assistant professor in the Department of Language Sciences and Translation at the Universitat Pompeu Fabra. She specializes in sociology of translation, Latin-American literature, periodical publications, and digital humanities. She is a current member of the Global Literary Studies Research Group (GlobaLS) and the ERC Project "Social Networks of the Past. Mapping Hispanic and Lusophone Literary Modernity". Besides her academic activity, she has translated more than twenty-five books for Ibero-American publishing houses focused on humanities and social sciences (Chartier, Roudinesco, Sapiro, Schaeffer, among other authors). She has been a member of the "Mapping Hispanic Modernity. Cross-Border Literary Networks and Cultural Mediators (1908-1939)" research project (2016-2019).

Gabriella Gavagnin is Associate Professor of Italian Studies at the University of Barcelona. Her research interests cover translation studies, cultural studies, literary reception, Catalan literature and textual criticism. She is a founding member of ASELIT, Asociación Española de Lengua Italiana y Traducción, and since 2001, she has been codirector of peer-reviewed journal Quaderns d'Italià. From 1995-2009, she worked in the research team of Progetto Boscán, a digital catalog of Spanish translations of Italian literature. Recent publications about translation studies: "Prime traduzioni di Borges in Italia (1927-1937)" (Rassegna iberistica, 41/109, 2018) and "L'Antologia minima di lirica italiana di Sebastià Sànchez-Juan" (in Novecento e dintorni. Grilli in Catalogna, 2016). She has been a member of the "Mapping Hispanic Modernity. Cross-Border Literary Networks and Cultural Mediators (1908-1939)" research project (2016-2019).

Alejandra Giuliani holds a doctorate in history issued by the Universidad de Buenos Aires (UBA). She does research on history of books, on publishing and on reading. She is Associate Lecturer in the subject society and state of the Introductory Cycle at UBA and main lecturer of history of books at Universidad Pedagógica Nacional; she also teaches Introduction to Publishing at the Major on Publishing at the Facutlad de Filosofía y Letras, UBA. At the Universidad Nacional de Quilmes, she lectures on history, publishing and circulation at the postgraduate course on public history and history dissemination. Her PhD has been published under the title: Editores y politica. Entre el Mercado latinoamericano de libros y el primer peronismo (1938-1955) (Tren en movimiento ediciones, 2018). She also coauthored with Leandro de Sagastizábal Un editor Argentino. Arturo Peña Lillo (Eudeba, 2014), 
"El Primer Congreso de Editores e Impresores Argentinos" (Anuario CEEED, 2016) and "El mercado interno en la edad de oro del libro argentino: Libros y Primer Peronismo" (Revista Cultura Editorial, 2016).

Martin Grandjean is Junior Lecturer in Contemporary History at the University of Lausanne, Switzerland. His research focuses on the structuring of scientific circles in the interwar period. He specializes in the analysis of large volumes of archival data and works on the uses of network analysis and data visualization in history.

Ventsislav Ikoff is a postdoctoral researcher at the Department of Arts and Humanities at the Universitat Oberta de Catalunya. He is a member of the Global Literary Studies Research Group (GlobaLS) and the project "Social Networks of the Past. Mapping Hispanic and Lusophone Literary Modernity, 1898-1959". He obtained a PhD in translation and language sciences from Pompeu Fabra University with research on literary translations and cultural mediators between Bulgaria and the Spanish-speaking world. His research interests are in sociology of translation, circulation of translated literature, cultural mediators and digital humanities. He has been a member of the "Mapping Hispanic Modernity. Cross-Border Literary Networks and Cultural Mediators (1908-1939)" research project (2016-2019).

Laurie-Anne Laget is a senior lecturer at Sorbonne University (CRIMIC) and junior fellow of the IUF (2019-2024). She has published numerous works on Ramón Gómez de la Serna's literary work and essays, particularly in relation to the cultural context of the time, such as: $L a$ Fabrique de l'écrivain (Casa de Velázquez, 2012) or her recent critical edition and French translation of Greguerias (Classiques Garnier, 2018). Her latest work aims at understanding how the literary society works by gaining a broader historical-cultural understanding of the literary phenomenon.

Reine Meylaerts is Full Professor of Comparative Literature and Translation Studies at KU Leuven, where she teaches courses on European literature, comparative literature and translation and plurilingualism in literature. She is currently (2017-2021) vice-rector of research policy at KU Leuven. Her current research interests concern translation policy, intercultural mediation and transfer in multilingual cultures, past and present. She is the author of numerous articles and chapters on these topics. She was director of CETRA (Centre for Translation Studies; www.arts.kuleuven.be/cetra) from 2006-2014 and is now a board member. She was also review editor of Target. International Journal of Translation Studies (2011-2017). She was coordinator of 2011-2014: FP7-PEOPLE-2010-ITN: TIME: Translation Research Training: An integrated and intersectoral model for Europe. She is former Secretary 
General (2004-2007) of the European Society for Translation Studies (EST) and Chair of the Doctoral Studies Committee of EST.

Rachel Potter is a professor of modern literature at the University of East Anglia. She writes on modernist literature and early twentieth-century culture, literature and censorship and free expression and organizations. Her books include Obscene Modernism: Literary Censorship and Experiment 1900-1940 (Oxford University Press, 2013), The Edinburgh Guide to Modernist Literature (Edinburgh University Press, 2012) and Modernism and Democracy: Literary Culture 1900-1930 (Oxford University Press, 2006). She is currently completing a book on literature and freedom of expression, with reference to the early history of the writers' organization International PEN, and is Principal Investigator on a collaborative AHRC four-year project on international writers' organizations and freedom of expression 1921-present day.

Letícia Pumar lives and works in Rio de Janeiro, Brazil. She acquired a $\mathrm{PhD}$ at the postgraduate program on the history of science and health at the Casa de Oswaldo Cruz/Fiocruz in 2015. Her doctoral research was supported by scholarships from the Coordination for the Improvement of Higher Education in Capes, Brazil, which included an internship at l'École des hautes études en sciences sociales-EHESS, Paris. In 2013, she did some archive research at the Rockefeller Archive Center (NY) supported by their Grant-in-aid program. She is currently on a postdoctoral position at Federal Rural University of Rio de Janeiro-UFRRJ.

Diana Roig-Sanz is an ERC Starting Grant holder and a Ramón y Cajal senior research fellow at Universitat Oberta de Catalunya (UOC). She has been visiting professor at the Oxford Internet Institute, at the University of Oxford, and has developed research residencies and postdoctoral fellowships at top-ranked institutions worldwide (KU Leuven, École Normale Supérieure, Università di La Sapienza, Amsterdam School for Cultural Analyses). Her research interests deal with cultural history and sociology of translation from a global and digital humanities approach, and her successive projects have been based on a consistent research line on cultural transfer and the circulation of cultural goods in which she has strived to challenge and revise former scholarly interpretations and develop new original approaches. She is the coordinator of the Global Literary Studies Research Group (GlobaLS). Her publications include Bourdieu after Bourdieu (Arco Libros, 2014), Literary Translation in 'Peripheral' Cultures. Customs Officers or Smugglers? (Palgrave, 2018, co-edited with Reine Meylaerts), and Mapping Global Literary Translation Flows. Literature Across Boundaries (in preparation). She directed (2016-2019) the 
"Mapping Hispanic Modernity. Cross-Border Literary Networks and Cultural Mediators (1908-1939)" research project.

Joan Safont Plumed has a bachelor in law from Pompeu Fabra University (Barcelona) and a master in journalism and advanced reporting at the Faculty of Communication Blanquerna-Ramon Llull University (Barcelona) and is a $\mathrm{PhD}$ candidate at the University of Girona. He is working on a PhD dissertation, directed by Dr. Xavier Pla, about the lawyer, politician, writer and newspaper publisher Amadeu Hurtado Miró. He is a member of the research project "The world of yesterday: The figure of the writer-journalist before the crisis of the new humanism (1918-1945)" (ref. FFI2015-67751). He collaborates with different media in Catalonia and has published several books. He is the author of PEN Català. An example of cultural diplomacy (2018).

Simona Škrabec was born in Ljubljana, Slovenia. She has lived in Barcelona since 1992, where she obtained a PhD in literary theory in 2002. She teaches at Universitat Oberta de Catalunya (UOC). She is the author of the essays L'estirp de la solitud ('Lineage of Solitude', 2003), L'atzar de la lluita ('Of Chance and Struggle', 2005) and Pàtria prestada ('Borrowed homeland', 2017). With Arnau Pons, she directed an extensive project about cultural exchange between Germany and Catalonia in the twentieth century (Grenzen sind Straßen, 2007-2008, $2 \mathrm{vol})$. She has translated more than thirty books of Serbian and Slovenian authors into Catalan and Spanish and the most important Catalan authors into Slovenian. In the field of translation, she participated in the collective research, To be translated or not to be (2007, directed by Esther Allen) and directed the PEN International report “Culture's Oxygen”, commissioned by UNESCO (2016). In 2014, she was elected Chair of PEN International's Translation and Linguistic Rights Committee.

Jaume Subirana is Associate Professor of Literature at Pompeu Fabra University (Barcelona). He holds a $\mathrm{PhD}$ in Catalan language and literature from Universitat Autònoma de Barcelona (1999). Has been Visiting Professor at the University of British Columbia; Brown University; Università Cà Foscari-Venezia and Trinity College, Hartford. $\mathrm{He}$ is a member and was a founder of the research group IdentiCat. Language, Culture and Identity in the Global Age. His research interests include literature, cultural history, space and identity, Barcelona, Catalan studies, and contemporary Catalan literature. His last books are Construir con palabras. Escritores, literatura e identidad en Cataluña, 1859-2019 (2018) and The Barcelona Reader. Cultural Readings of a City (2017), edited with Enric Bou. He was director of Institució de les Lletres Catalanes (2004-2006), and is a founding member of the International Society for Polysystem Studies. He has been a member of 
the "Mapping Hispanic Modernity. Cross-Border Literary Networks and Cultural Mediators (1908-1939)" research project (2016-2019).

Mauricio Zabalgoitia Herrera has a $\mathrm{PhD}$ in Spanish philology from the Autonomous University of Barcelona and a degree in Hispanic literature from the University of Guadalajara (Mexico). Currently, he is a researcher at the Institute of Research on the University and Education in the theory and educational thought area of the National Autonomous University of Mexico, and a professor of gender at the Faculty of Philosophy and Literature in the same university. He is also a member of the National System of Researchers. He made a postdoctoral research stay at the Ibero-American Institute in Berlin (2014-2016) with a grant from the Alexander von Humboldt Foundation. From an interdisciplinary view, he works issues of education, gender, masculinities, culture and literature. Since 2017, he has been the Principal Investigator of the group: "Pedagogías de género. Educación, literatura y cultura en México (s. XIX y XX)", where he conducts two projects. $\mathrm{He}$ is codirector of the magazine Mitologías hoy. Revista de pensamiento, crítica y estudios literarios latinoamericanos and has published books and specialized articles in Germany, Spain, the United Kingdom and Mexico. 


\section{Index}

Note: Numbers in bold indicate a table. Numbers in italics indicate a figure.

XIII International Congress of the PEN Clubs (Barcelona)(Congress of 1935) 102, 111-112, 117, 176, 197-198, 221-228; see also Estelrich, Joan; Canby, Henry Seidel

XIV International Congress of the PEN Clubs (Buenos Aires) (Congress of 1936) 113, 122-123, 127-128, 227, 232-233, 252; and cultural relations between Europe and Latin America 134-138; networks 140-141; participants 138-140; see also entretien; PEN Clubs International Congress

Achaval, Guillermo de 227

Action française 30, 177

Adamic, Louis 91-92, 94-95

Adriaensen, Brigitte 200, 206

Africa 43, 306; pan- 121; South Africa 108,225

African American 137

agency, conceptualization of 58-59

Aguilar, Màrius 219

Aita, Antonio 127, 129, 134; and Argentine International Cooperation 251-265; on Europe and American 266; and the International Institute of Intellectual Cooperation 247-248

Alba, Pedro de 80

Albania 93-94

Alfaro, José María 181

Almada Negreiros, José de 234, 240

Almagro San Martín, Melchor de 117, 122-123, 204

Almeida, Virginia de Castro e 80, 82,237
Alomar, Gabriel 122

Alòs-Moner, Ramon d' 218, 225

Altamirano, Ignacio 274

American Indian 136-137

Americanism 15, 247, 262;

Americanization 25

Amics de la Poesia 150, 155, 217

Ammers-Küller, Jo van 97, 105

Amnesty International 110

Andrade Falcão, Isadora de 307

Andrić, Ivo 93, 95, 104-105

Anglés, Higinio 169, 170

Anschluss 27

Arab world 43

Arderiu, Clementina 213-215, 220

Arendt, Hannah 42

Argentina 84; and Aita 127, 251-265, 266; Cankar in 94; cultural and political spaces of 128-130;

delegates 225, 255, 257; and Gómez Carrillo 249-251; and Mallea 128; and Romero 138; Spanish exiles in 136; Torres Bodet in 281; and Henríquez Ureña 137; see also Buenos Aires; Ocampo, Victoria

Argentine National Committee on Intellectual Cooperation 250, 253, 257, 261-265

Arguedas, Alcides 127-128, 139-140, 257, 262

Arocha, Manuel 82

Aron, Raymond 42

Asch, Schalom 99

Asia, Asians 72-73, 77, 83; barbarism of 25

Asociación Amigos del Arte (Friends of the Arts Association) 127 
ateneístas 275-276

Ateneo de la Juventud 273, 276

Ateneu Barcelonès 155, 162, 180, 215, 217

Athayde, Tristán de 262

Attolico, Bernardo 71

Aub, Max 279

Aubrun, Charles-Vincent 265

Auger, Pierre 307

Austria 27, 68; delegates from 97, 127, 139; extreme right in 43; scientists from, boycott of 34; writers fleeing 121; see also Zweig, Stefan

Austria-Hungary 37, 94

Avermaete, Roger 57-58

Azorín [pseudonym of José Martínez Ruiz] 180-181, 200-202, 206-207

Báez, Cecilio 69

Bagaría, Luis 208

Balcells, Albert 158

Balcells, Joaquim 168, 170, 217

Balkans 41, 92, 95-96; conflicts 91

Bandrowski, Kanden 100

Bannerjea, Debendra Nath 71-72

Barata, Mario 302

Barbey, Josep 213

Barcelona 99, 177-178; Estelrich in 175; see also XIII International Congress of the PEN Clubs; Conferentia Club

Bárcena, José Roa 274

Barrès, Maurice 29

Barthélémy, Joseph 27

Bataillon, Marcel 264

Batista Roca, Josep Maria 213, 218, 221, 223

Bauër, Gérard 148, 165, 170

Bekri, Chikh 76

Belaúnde, Victor Andrés 80

Belgian literature 46, 54, 58; bilingualism of 48

Belgium, Belgians 20, 43, 68, 225; at the Conferentia Club 153, 156; cultural history of 54-59; delegates 99, 114, 127, 139, 225; interwar 46-48, 55; literary translations in 51; multilingual 55; Surrealism in 42; views 72

Benda, Julien 30, 33

Benjamin, René 148, 165, 169, 170

Benjamin, Walter 26

Benlliure y Tuero, Mariano 207-208

Bergson, Henri 25, 65, 70-71, 82, 247
Berlin 41; Gómez de la Serna in 202; regime, Mann's letter of protest 227; universities in 38; see also PEN clubs and centres

Berlin Wall 43

Bernat Metge Foundation 155, 175, 177,217

Bertran Güell, Josep 166, 170

Bertran Pijoan, Lluís 214

"between the wars" see interwar period 24

Bevk, France 102

Bidou, Henry 164, 170

bilingualism 47-48, 57-58; editions 175,264

bilingual literature see Belgian literature

Billy, André 148, 163, 170

binary thinking 53; oppositions 54-56

Bioy Casares, Adolfo 252, 254

Blanco Fombona, Rufino 262

Bloch, Marc 35

Blum, Léon 27, 176

Bofill i Mates, Jaume 215-216

Boissy, Gabriel 176, 178

Bolivia 127, 139-140, 257, 262; see also Arguedas, Alcides

Bolivar, Simon 93

Bolshevism 25, 41

Bonnet, Henri 84, 237, 252, 254-256, 259-265, 291-295

Bonnevie, Kristine 69, 82

Bontempelli, Massimo 155, 168, 170

Borel, Émile 27, 33

Borges, Jorge Luis 132, 252, 281

Bosch-Gimpera, Pere 167, 170, 217

Bourdieu, Pierre 109, 115, 208

Bourgeois, Léon 67, 69-70

bourgeoisie 94; Barcelona 178; Catalan 147, 151; elites 285; Mexican 273-274, 278, 282, 287; women 146

Bovet, Ernest 155, 162, 163, 170

Braga, Dominique 82, 254-255, 258, 260-261, 265

Brazil, Brazilians 66, 72-73, 79-80; Barrios 262; Braga 82; Cárcano 265; Castro, Aloysio de 69-70, 75; committee 261; delegates 82-84, 127, 256; Figueiredo in 241; Peixoto 80; see also Ozório de Almeida, Miguel

Brazilian Academy of Education 291, 296

Brazilian Academy of Sciences 291, 296 


\section{Index}

Brazilian Commission on Intellectual Cooperation 296

Breton, André 42

Briand, Aristide 25-27

Briand project (1929-30) 25-26

Britain see Great Britain

Broch, Hermann 98

Brod, Max 26

Broz Josip 94

Brull, Mariano 262, 295

Brunschvicg, Léon 33, 176

Bruylants, Jan 56

Buchenwald concentration camp 12,226

Budé, Guillaume 177

Buenos Aires; in the 1930s 42; see also Cankar in 94; cultural world of 128-129; and the International Institute of Intellectual Cooperation; and Hispanic writers 122; Museo Nacional 69; Nación, La 73, 139, 249; PEN centre 112, 132-134; publishing houses in 128, 131; see also XIV International Congress of the PEN Clubs; homosociability; Seventh Conversation of the Organization of Intellectual Cooperation of the Society of Nations (entretien)

Buero, Juan Antonio 79

Bulgaria, Bulgarians 37, 40, 41, 225

Burgos government 177

Burte, Hermann 98

Byrne, David 48, 52

Cabrera, Blas 82

Cairney, Paul 48

Calderón, Francisco García see García Calderón, Francisco

Callaghan, Gill 48, 52

Camacho, Ávila 281

Cambó, Francesc 146, 151-152, 159, 175-180

Canada 94

Canals, Josep 218

Canby, Henry Seidel 91-92, 95, 98-99, 117-118; on PEN's $13^{\text {th }}$ Congress 180-181; on Roumain case 121

Canby Resolution 118

Cankar, Izidor 93-94, 98

Cansinos Assens, Rafael 206

Canteloube, Joseph 148, 168, 170

Capdevila, Arturo 281

Čapek, Karel 113-114, 255
Carayon, Marcel 264

Cárcano, Miguel Ángel 265

Cárcano, Ramón José 265

Cárdenas, Lázaro 281

Cardona Puig, Félix 168, 170

Carnegie Endowment for International Peace 30

Carneiro, Paolo Berredo de 292-293, 295-298, 302-303, 306-307

Casal del Metge 226-227

Casals, Pau 103, 197-198, 226

Casanova, Pascale 109

Casares, Julio 75-77, 80-83, 248

Cassou, Jean 165, 170, 202

Castagna, Giancarlo 148, 155, 164, 170

Castillejo, José 75-76, 82-83

Castro, Aloysio de 69-70, 75, 79, 80, 83

Castro, Ferreira de 237

Castro Leal, Antonio 273, 295

Català, Víctor 215

Catalonia 13, 16, 41, 96-103; authors in $181,219,221$; conferences in 145; and the Conferentia Club 152; culture and language 144, 176, 214; elections in 147; Generalitat of 223, 226; literary position of $112-113$; Mancomunitat of 213-217; and Noucentisme 144; writers 117, 123; see also Estelrich, Joan

Catalonia PEN club 117, 120, 184-185, 191-196, 197, 214, 218, 220; history of 176

Ceballos Viro, Álvaro 200, 206

Cercle de la rue Tournon 292

Cercle Littéraire International 204

Chagall, Marc 42

Chagas, Joâo Pinheiro 73

Chagas, Carlos (Filho) 302-304

Challaye, Félicien 168, 170

Charensol, Georges 166, 170

chauvinism 91, 93

Chevalier, Jacques 164, 170

Chile 67, 80, 84, 130, 255; see also Barrios 262; Ercilla publishing house 131, 139-140; Mistral 259, 261; Walker Linares 294

China 84, 108; Needham in 301-302

Citroën, André 235

civilization 26, 41; "battle of" 292; future of 21, 287; New World 135-137, 258, 266 ; threats to 32,34

Claudel, Paul 27

Cocteau, Jean 235, 275 
Colección Americana 141

Colombia 68-69, 76, 84, 127, 255-256; see also Sanín Cano, Baldomero

Comert, Pierre 71

Commission internationale de coopération intellectuelle (CICI) 247-248

Commission of National Minorities 176-177

Committee on Intellectual Cooperation of the League of Nations 65

communism 30, 42, 281

Companys, Lluís 120

complexity theory $48,49-53,55-60$; epistemology of 48-54

Conferentia Club 144-145, 178, 180, 220; conference format of 145-152; international dimensions of 152-156; lectures organized by 162-172

Conference of Allied Ministers of Education (CAME) 300

Congrès international des écrivains pour la défense de la culture 42, 118

Congrès International des Pen Clubs (XIIIe) 222-224; see also XIII International Congress of the PEN Clubs

Conrad, Joseph 108

Cornejo Zenteno, Mariano 76, 82

Los Contemporáneos 276, 278

Corominas, Pedro 153

Cortot, Alfred 148, 168, 170

Costa, Afonso da 69

Costa du Rels, Adolfo 262

Costa Rica 84

Coudenhove-Kalergi (count of) 25-27

creacionistas 202-203

Crémieux, Benjamin 99, 114-115, 117, 226, 228

Crexells, Joan 213-214, 218

Cruz, Juana Inés de la (Sor) see Sor Juana

Croce, Benedetto 176

Croisset, Francis de (Franz Wiener) 160n39, 166, 170

Cuba, Cubans 84, 135, 153-155; see also Brull 262, 295; journals of 249; Torriente y Peraza 294

Cuesta, Jorge 276

Curie, Marie 25, 31, 34, 65, 70, 82,240

Czechoslovakia 27, 41, 68-69, 72, 225 ; sovereignty $113-114$; Susta 82
D’Annunzio, Gabriele 235

Dantas, Júlio 76, 78, 80, 232-234, 237; conservative stance of 240-242; and national culture 234

Däubler, Theodor 154-155, 162, 163, 170

Davis, Malcolm 295

Dawson Scott, Catharine Amy 100, 108-109

Delaisi, Francis 27

Demangeon, Albert 24

Denmark 225

Deonna, Waldemar 168, 170

descriptive translation studies (DTS) 46-48, 57

Destrée, Jules 70, 82

Deutsches Akademisches Austausch Dienst (DAAD) 38

Díaz-Plaja, Guillermo 153, 158, 166,170

Diehl, Charles 166, 170

Díez Canedo, Enrique 117, 122, 127, 132, 256

Domènech, Cristòfor de 217

Domenchina, Juan José 279

Domingo, Marcelino 236

Dominican Republic, Dominicans 84, 127-128, 135-137, 141

Dos Passos, John 238

Dubech, Lucien 165, 170

Dubrovnik PEN Congress of 1933 90-103, 117-118; Foix 96, 222;

Frischauer 98; German letter to 100; international delegations attending 90-93

Dučić, Jovan 93

Duhamel, Georges 33, 127, 148, 165, 170,257

Dumont, Juliette 66

Dussane, Béatrix (Madame) 148-149, 164-166

Dussel, Enrique 138, 141

Drummond, Eric 68

Dwelshauvers, Georges 217

Echagüe, Juan Pablo 129

Ecuador 79, 84, 262

Edinburgh Congress of 1934 98, 118,223

Eekhoud, Georges 56

Egypt 40, 84, 122

Einstein, Albert 25, 42, 65, 70-71, 73, 77,247

Elias, Norbert 42 


\section{Index}

Elster, Hanns Martin 97, 100, 105

Emecé publishing house 131

England 258, 261, 263, 304;

Chesterton 221; delegates 127 , 225, 257; International PEN in 202; see also Great Britain; London

Entretien Europe-Amérique Latine 254-257, 261-262

entretiens 177; see Seventh Conversation of the Organization of Intellectual Cooperation of the Society of Nations (entretien)

Entwistle, William J. 117, 127, 255,257

Ercilla publishing house 128, 131, 139

Estelrich, Joan 127, 134-135, 149, $168,170,256$; and the $13^{\text {th }}$ PEN Congress 176, 180; and Bernat Metge Foundation 217; and Catalan PEN 214, 225; as cultural agent 175-181; and Lliga Catalonia 124; and Morales 153

eurocentrism 264, 266, 300, 302, 305

Europe: decline of 24; Gide on 29; "intellectual" 25-28; interwar 24-28, 42; Mann on 28-30; nationalism 28; public space, deficiencies of 42-43

Expansió Catalana 175-181, 182, 187, 194

Fabra, Pompeu 117, 120, 179, 214, 223-228

Fages de Climent, Carles 217

Fairbanks, Douglas 235

Falange, La 275

Falgairolle, Albert de 176-177

Farinelli, Arturo 155, 169, 170

Farran Mayoral, Josep 214, 218

Farrère, Claude (Frédéric-Charles Bargone) 169, 170

fascism 34-35, 128, 281; advance of 133, 135; anti- 41-42, 118, 121; dictatorship 92; in Italy 97, 113, 227; and Nazism 117; networks 122,124

Fascist Confederation of writers 123

Febvre, Lucien 35

Fédération pour l'Entente européenne 27

Fernandes, Raul 307

Fernández Almagro, Melchor 117, 279

Ferro, António 232-234; and the avant-garde 234-238
Figueiredo, Fidelino de 127, 232-234, 237, 241-242, 256

First UNESCO Conference (1946) (Paris) 293, 299, 300, 302, 306; see also UNESCO

First World War see World War I

Flake, Otto 26

Flanders 47, 54

Flaubert, Gustave 109

Flemish language and literature 46-47, 114; novelists writing in 57,59 ; theater 58; translations into/from French 46-48, 58

Flemish Movement 57

Focillon, Henri 33, 155, 164, 170

Foix, J.V. 96, 98-99, 101-103, 222, 225,227

Folch i Torres, Joaquim 146, 165, 170

Folguera, Joaquim 179

Fondo de Cultura Económica 141

France 37, 68, 250, 255, 304; “amis de la" 264; Argentine book production in 259; Calderón's views on 263; culture and journalism in 177; delegates 99, 256-257, 295; intellectuals 36, 42, 72; and International Institute of Intellectual Cooperation 84; Larbaud's introduction of Gómez de la Serna to 201-202; Ozório de Almeida in 292, 304; Portuguese culture, importance to 237; students in/from 39-41, 39-40; Torres Bodet in 281; and WWI 24, 26; see also Paris; Surrealism

France, Anatole 140, 215

Franco, Francisco 103, 122; rebellion 42

Franco, Maria Eugenia 302

Franco-German reconciliation 27, 30

Francophilia 250, 256

Francophone 56-57; Belgian literature 46-47, 54-59

freedom of speech and expression 108-109, 132, 227; PEN resolution on 119; writer's 116, 122, 225, 228

Freud, Sigmund 42

Frischauer, Paul 98

Frontin, Paulo de 79

Fuimi, Maria Luisa 220

Fundació Bernat Metge see Bernat Metge Foundation

Gache, Roberto 82

Galí, Alexandre 155, 214 
Gallardo, Ángel 69, 249

Galsworthy, John 97, 108, 111,115-116; as PEN Club of London president 214-216; resolution 118

Gálvez, Manuel 129

Gamillscheg, Ernest 150, 154, 155, 165,170

Garcés, Tomàs 218

García Calderón, Francisco 14, 80, $82,84,262-263$

García Calderón Rey, Francisco 76

García Gómez, Emilio 168, 171

García Lorca, Federico 148, 166, 171

García Morente, Manuel 31, 165, 167, 171

García Sanchiz, Federico 165, 171

Garrido, Luis 274

Gasch, Sebastià 149

Gassol, Ventura 214, 222-223, 224, 226

Gastão da Cunha, Miguel 66

gaucho language and literature 265, 266

gender 149; class and 275; and joven varón 274 ; male 276 ; practice 277 ; and point of view 273; system 283

George, Stefan 28

Gerhard, Robert 226

German-Jewish writers 118; see also writers of Jewish descent

German language 112-113, 179, 192

Germany, Germans 215; boycott of scientists from 34-35; culture 72; delegates 91, 114; and the International Committee on Intellectual Cooperation 75; Paris, invasion by 84 ; students in/from 37-39, 40; ultra-nationalism and the extreme right in 36,43 ; writers-inexile, writer-refugees 117, 120-121, 225, 227; see also Einstein, Albert; Nazi Germany

German Spring 97

Gide, André 29, 275

Gili, Victoria 98

Gilroy, Paul 121

Goetel, Ferdinand 116

Goethe, Johann Wolfgang von 26, 28, 30-31

Gómez Carrillo, Enrique 16, 19, 267; and Antonio Aita 252, 257, 264; as cultural mediator 265; eurocentrism of 266; and International Institute of Intellectual Cooperation 247-251; see also Argentine Committee on Intellectual Cooperation

Gómez de la Serna, Ramón 148, 171, 201-205, 207-209

Gómez, Marte R. 279

Gonne, Maud 56

González, Joaquín 264

Gorky, Maxim 215, 219

Gorostiza, José 274-276

Goya, Francisco de 93

Great Britain 25-26, 36, 41-42, 68, 113

Gropius, Walter 148, 154, 165, 171

Gual, Adrià 217-218

Guasch Miró, Joan Maria 215

Guatemala, Guatemalans 84-85, 248

Güell i López, Joan Antoni 169, 171

Güell (viscount of) 151

Guimerà, Àngel 215, 217-218

Guyau, Jean-Marie 26

Haiti 84, 120; Communist Party 121

Haldane, J.B.S. 34

Hale, George Ellery 71, 77

Hall, Radclyffe 108

Hamsun, Knut 108

Harden, Maximilien 26

Hardy, Thomas 215

Hatherly, Ana 237-238

Hauptmann, Gerhart 24, 28, 215, 219

Hazard, Paul 160, 176

Heidenreich, Gurt 91

Heineman, Dannie N. 147, 164, 171

Henriques, Raquel Pereira 239

Henríquez Ureña, Pedro 127-128, 132, 134; dissertation by 139 ; at the entretien 134-138; and the Fondo de Cultura Económica 141

Hernández, José 264-265

Herriot, Édouard 25, 27, 297

hierarchy, conceptualization of 50-51

Hiller, Kurt 26

Hispanic-American 136, 140, 256; authors 275

Hispanic world 94, 272, 279; book market 128; literature 265; literary connections 111,122 ; modernity 200

Hitler, Adolf 35-36, 38; consolidation of power under 117; government of 92, 99, 222; writers under 227, 235,281

Hofmannsthal, Hugo von 29

Hölderlin, Friedrich 213

Holland 100, 225 


\section{Index}

homosexuality 277

homosociability 273-278, 279, 281-282, 284

Horta Conill, Joaquim 214

Hoste, Julius 56

Houssay, Bernardo 253, 260

Hughes, Langston 121

Huizinga, Johan 25, 33

Husserl, Edmund 29

Huxley, Aldous 33, 133, 255-256

Huxley, Julian 283, 299-302, 307

Ibarguren, Carlos 127, 129-130, 137, 252, 257, 260

Ibero-American: networks 65-83; context 248; experts 83; literature 255; personalities $66,69,73,74,82$

Ibero-American Collection 249, 252, 264, 266

Iglesias, Miguel A. 200

India, Indians 68-69, 71-72, 77, 82; British rule of 225; literature 111; Wadia 117, 122

Insúa, Alberto 206

International Committee on Intellectual Cooperation (ICIC) 42, 65-84; in composition of $69,71-78,74,84$; constitution of 65-68; creation of 67; definition of 70; First Committee 68-71; Frankfurt 30; in Madrid 31, 34; meetings 81 ; non-member participants 79-83; and Ocampo 259-261; in Paris 32-33; and UNESCO 300; see also Commission internationale de coopération intellectuelle (CICI)

International Institute of Intellectual Cooperation (IIIC; IICI) 79, 82-84, 292-297; archives 247-248; creation of 72 ; founding 66, 247-248; and PEN clubs 129; and UNESCO 247, 300; during WWII 291; see also Aita, Antonio; Gómez Carrillo, Enrique

International Institute of the Amazon Hylea 302-304, 306

internationalism 124-125, 153, 238, 240; and Americanism 247, 262 Barrès's rejection of 29 ; chauvinism vs 91 ; contestation and debate in PEN over 102-117; cultural 116; League of Nations 115; literary 116; "treason" of 24

International Labor Organization 67 International Museums Office 82
International PEN 98, 114, 179, 200-202, 204, 220; and the Republic of Literature 108-125; see also MacCarthy, Desmond; Spanish Center of the International PEN; Wells, H.G.

interwar period 24, 144, 291; in Belgium 46, 54-55, 57-58; in Catalonia 217, 220; in Europe 43; in Flanders 47, 54; in France 39, 54; international intellectuals 279, 308; and Latin American intellectuals 247, 267; literary culture 110-111; in Mexico 272; see also Conferentia Club

Iorga, Nicolae 163, 171

Iriye, Akira 110

Irwin, Robert McKee 277

Ishii (Viscount) 75

Italy, Italians 36, 42, 68, 250; antifascists 41; Bevk in 102; Stepanow in 153; Ungaretti 127; see also fascism; Marinetti

isolationism 262, 264, 267

Jacob, Berthold 120

Jameson, Margaret Storm see Storm Jameson, Margaret

Japan, Japanese 35, 44, 65, 75, 77; bombing of 283; conferences on 155 Jarnés, Benjamin 279

Jean-Aubry, Georges 148, 164, 171

Jewish writers see writers of Jewish decent

Junoy, Josep Maria 169, 171, 220-221

Justo, Agustín P. 252-254

Kaelble, Hartmut 43

Kandinsky, Wassily 42

Kaussen, Valerie 121

Keller, Adolf 155, 166, 171

Kemal Atatürk, Mustapha 235

Keyserling, Hermann von 32, 153, 164, $168,171,176,255$

Komroff, Manuel 108

Kosovel, Srečko 102

Koyré, Alexandre 42

Krleža, Miroslav 94

Kulturbund 27

Kulturträger 90

Kus-Nikolajev, Mirko 90

Lagerlöff, Selma 33, 108, 111

Landowska, Wanda 166, 169, 171 
Landsberg, Paul Ludwig 145, 169, 171

Langdon-Davies, John 213

Lange, Norah 17, 281

Langevin, Paul 31-32

language question, the 46 ; see also bilingualism; Belgium

Lanterne Sourde, La 58-59

Lantier, Raymond 155, 164, 171

Laqua, Daniel 65

Larbaud, Valery 201

Latin America 43, 303; culture and identity 135-138; and Europe 247-267; Francophilia 250 ; intellectuals $267,276,291$, 306,308 ; and the International Committee on Intellectual Cooperation 78, 84; and the International Institute of Intellectual Cooperation 66; late rise of 83-84; and the League of Nations 69, 84; men and maleness 275 ; networks 150; as "New World" 266; perceptions of 247; UNESCO in 306

Lascano, Victor 294

Latapí, Pablo 282, 286

League Against Banquets (Liga contra el banquete) 206-209

League of Nations (LN) 25-26, 30, 32 ; dominant nations of 124 ; establishment of 110; International Committee on Intellectual Cooperation 247; International Institute for Intellectual Cooperation within 179, 217, 232-233, 237, 241, 251, 265; internationalism of 115 ; in Madrid 1933 240; nascent 65; and PEN 110-111; political failure of 35 ; role and structure, debates over 113-114, 124; universalism 39; see also Committee on Intellectual Cooperation of the League of Nations

Leconte de Lisle, Charles Marie René 249

Leland, Waldo G. 83, 294

Leonardo da Vinci 282

Lerroux, Alejandro 235

Levene, Ricardo 254

Levi, Ezio 165, 171

Lévi-Strauss, Claude 42

Lewis, Sinclair 238

Liess, Andreas 148, 154, 167, 171

Lisbon 233, 237, 281

Lithuania 225

Llates, Rossend 166, 171, 217, 218
Lliga Regionalista de Catalunya 123,175

Llorach, Isabel 146-147, 151

Locarno Treaties 25-26, 37, 39

Löhr, Isabella 76

London: first International Congress of PEN club in 214; International Board in 100; UNESCOs Preparatory Commission in 298-299; Yugoslavian government in exile in 94

Lopes, Ricardo Paula 307

López-Picó, Josep Maria 112, 213-218, 223, 225

López Velarde, Ramón 275, 280

Lorand, Arnold 154, 167, 171

Lorentz, Hendrik 25, 73

Lorey, Eustache de 148, 169, 171

Losada publishing house 131, 140-141

Losada, Gonzalo 141

Loucheur, Louis 27

Luchaire, Julien 248-250

Ludwig, Emil 27, 127, 148, 155, 167, $169,171,256$

Lugones, Leopoldo 73, 75, 79, 82, 247

Lupi, Dario 148, 165, 171

Luz León, José de la 153, 155, 169, 170 Lyr, René 99

MacCarthy, Desmond 108

Macías-González, Victor 276

Maciel, Georges 302

Madariaga, Salvador de 32-33, 66, 82, $168,171,255-256,261$

Madrilenian PEN Club see PEN clubs

Maella, Eduardo 281

Maeterlinck, Maurice 108, 215, 218, 237

Magrinyà, Carles 217

Maia, Jorge 302

Maksimović, Desanka 93

Mallea, Eduardo 128-129, 132, 138

Mallorca 91, 217, 228

Malye, Jean 155, 160, 163, 171

Manent, Albert 145

Manent, Marià 181, 214, 223, 225

"Manifesto of the Ninety-Three" 34-35

Mann, Heinrich 26, 29, 108

Mann, Klaus 16, 117, 120, 225, 227

Mann, Thomas 24, 27-28, 30, 33, 108, 225, 238

Mansfield, Katherine 238

Mansilla, Lucio 265

Maples Arce, Manuel 276

Maragall, Joan 228 


\section{Index}

Marais, Kobus 48, 52

Marañón, Gregorio 32, 169, 171, 204

Marinel·lo, Manuel 225

Marinetti, Filippo Tommaso 102, 117, $122,127,225,238$; fascism of 133 , 180, 227-228

Maritain, Jacques 127, 233, 237

Maroević, Tonko 102

Marquina, Eduardo 145, 165, 171

Martí i Pol, Miquel 102

Martí, José 136, 169

Martínez Estrada, Ezequiel 281

Martínez Ferrando, Enric 214

Martínez Pedroso, Manuel 82

Martínez Ruiz, José 117

Maseras, Alfons 177, 217, 225

Matan, Branko 90-91

Maurois, André 148, 150-151, 155, $167,169,171$

Maurras, Charles 177

Mazon, Paul 155, 160, 162, 163, 171

Mazower, Mark 113

Meillet, Antoine 155, 162, 163, 171

Melfi, Domingo 139-140

Melloy, Camille 57-58

Membré, Henri 237

Menéndez Pidal, Ramón 69

Meštrović, Ivan 93

Meunier, Mario 148, 162, 163, 171

mexicanidad/hispanidad 280-281

Mexico 42, 283; and Alba, Pedro de 80; delegates from 127, 248, 255-257, 261; Enríquez Ureña in 135; homosociability of 276-277; at the International Committee on Intellectual Cooperation 84; minorities of 284; see also Reyes, Alfonso; Torres Bodet, Jaime

Mexico City 108, 112, 273, 279;

Roumain in 121 ; writers in 122

México Moderno 275

Meyer-Lübke, Wilhelm 150

Millàs-Raurell, Josep Maria 181, 213-220, 222-225

Millikan, Robert Andrew 71, 77, 83

Mínguez, Joan 217-218

Miomandre, Francis de 148, 165, 171

Miró, Joan 103

Misciattelli, Piero 155, 167, 171

Mistral, Fréderic 164, 171

Mistral, Gabriela 204, 237, 259, 261

Moch, Gaston 27

Molinari, Ricardo 281

Monaco 84
Montarroyos, Elizeu de 79, 82-83, 293, 296

Montero Alonso, José 209

Morales, María Luz 147-148, 151, 153, $158,167,171$

Morera i Galícia, Magí 214, 215, 220

Moret, Alexandre 155, 162, 163, 171

Morin, Edgar 49; see also complexity theory

Morocco, war in 215

Mottram, Ralph Hale 127, 255

Muir, Edwin 98

Muir, Willa 98

Müller, Hermann 27

multilingualism 46, 53, 56, 130

Muñiz, João Carlos 294

Musil, Robert 108

Mussolini, Benito 35, 91-93, 235, 281

Murray, Gilbert 25, 70, 78, 82

Mutel, Charlotte 165, 171

Nascimento, Carlos 140

"national committees" of intellectual cooperation (NCICs) 79-80, 82

nationalism 28-31, 43; and the avant-garde 238, 240; cultural 113; Czech 114; versus internationalism 118, 122; literary 135; see also internationalism

Nazi Germany 38, 94, 117, 222, 285; anti- 41; Belgrade, bombardment of 93; condemnation of 98-100; ideology of 97,101 ; persecution of writers by 225-226; victims of 16 ; see also fascism

Needham, Joseph 300-307

Nehru, Jawaharlal 225

Neruda, Pablo 140

Netherlands, The 25, 43, 84, 304

Neves, Celia 307

New Zealand 225

Nicolau d'Olwer, Lluís 180, 214, 220, 225

Nieto Caballero, Agustín 80

Nietzsche, Friedrich 26, 28

Nin, Joaquim 145, 168, 172

Nitobe, Inazo $65,68-71,75,82$

Nobel Prize 215; laureates 25, 53, 67, 69, 94, 95, 111, 219

non-governmental organisations

(NGOs) 110-111

non-linearity 51-52

Nogueira, Julián 252, 294

Northedge, Frederick 65 
Norway 68-69, 225

Novak, Slobodan 91

Novalis [Georg Philipp Friedrich Freiherr von Hardenberg] 28

Obermaier, Hugo 145, 148, 164, 172

Obiols, Josep 228

Obregón, Antonio de 117

Ocampo, Silvina 281

Ocampo, Victoria 76, 80, 128-138, 141, 259-261, 264, 266

Olivar, Marçal 225

Oliveira Viana, Francisco José de 69

Oller, Narcís 215

Ortega y Gasset, José 117, 122, 138, 141, 153, 235, 255, 276

Ortiz de Montellano, Bernardo 274, 276, 278

Oslo: Historical Congress 35; PEN International Conference of 1928155

Ossietzky, Carl von 28, 120

Otlet, Paul 67

Otto, Fritz 97, 100

Ould, Hermon 12, 98, 100, 114, 222, 224-225

Oulmont, Charles 148, 169, 172

Ozenfant, Amédée 168, 172

Ozório de Almeida, Miguel 76, 261, 291-308

pacifism 24-27, 28, 66, 124

Pact of Non-Agression among writers 123-124

Painlevé, Paul 25

Palestine 99, 225

Panama 84

PanAmerican conference 79

Paneuropa (manifesto) 25

Paneuropean Union 27

Paneuropean Movement 25-26, 28

Pani, Arturo J. 279

paradigms: Newtonian 49; of order and simplicity 49, 54, 56

Paraguay, Paraguayans 69, 84

Pardo, Carlos Alberto 80

Paris 37, 77, 109, 112; diplomatic conference (1933) 14; Estelrich in 177; foreign students in 39-41, 40; "future of the European spirit" talks in 1933 32, 232, 240; Gómez de la Serna in 202, 204; Mann's conference 30; occupation by Germany 308; see also International Institute of Intellectual Cooperation
Paris Peace Conference of 1919113

Parra-Pérez, Caracciolo 73

peace, peaceful 38, 285; coexistence 66,99 ; literature as a means of achieving 124; Nazi views of 101 ; Nobel Peace Prize 67, 69; science as a means of achieving 287, 308; among writers 124; world 237, 283

Peixoto, Júlio Afrânio 80, 127, 255-256

Pellicer, Carlos 274-275, 277

Pelliot, Paul 162, 163, 172; PEN centres and clubs 41, 99, 102, 123; All-India 122; Argentina 127; Austria 97-98; Barcelona 112, 117, 120, 179; Berlin 92, 97, 99-101; Board 100; Brussels 112; Catalonia 41, 117, 176, 184-196, 220; Catalan 179, 213-228; Croatian 90; and dictatorships 41; Edinburgh 115; England 213; founding members of 111; German 91, 99, 155; Italy 218; London 112, 184, 200; Madrid 112, 117, 179, 200, 203, 207-210; Nazi support by 97; New York 112; non-western 122; Paris 112; Poland 115-116; Prague 113; Rome 122; Santiago 112; Serbia 90, 94, 97; Spain 179, 204, 219; “spirit of" 115; Stockholm 112; Vienna 97; Warsaw 114; Yugoslavia 222; Zagreb 94, 105n5, 225; see also Buenos Aires; Estelrich, Joan; International PEN PEN Clubs International Congress 90, 127-129, 135, 141; Barcelona 92, 117-118, 179-180, 221-228; Berlin 114, 117; book about 140; Brussels 59, 98, 114, 222; Chilean delegation to 139; Croatia 90; London 204, 214; and Sur magazine 131, 134, 138; see also XIII International Congress of the PEN Clubs; Dubrovnik PEN Congress

Pérez de Ayala, Ramón 200, 204

Pérez de Cuéllar, José Tomás 274

Permanent Committee of Arts and Letters 127

Permanent Court of International Justice 69

Pernet, Corinne 66

Peru, Peruvians 75-76, 82, 84, 255

Pétain, Philippe 235

Pham, Thi-Tu 65, 76

Piaget, Jean 155, 164, 172

Pich Pon (Pich y Pon), Juan (Joan) 226 
Piérard, Luis 114, 127, 139, 156, 167, 172, 256

Pierat, Marie-Therèse 166, 172

Pijoan, Josep 145, 167, 172

Pilsudski, Josef 225

Pirandello, Luigi 160, 218-219, 238

Pi Sunyer, August 1218

Pittaluga, Gustavo 145, 154, 169, 172, 218-219

Pla, Josep 213

plagiarism 56

Plana, Alexandre 214, 217-218

Planas, Ramon 156

Poland: delegates from 100, 114; extreme right in 43; and the International Institute of Intellectual Cooperation 84; Jewish community 114; students from 37-38, 40, 225; Yiddish chapter of PEN Center 114-115, 225

polyglots 43,154

polysystem theory (PST) 46-47, 59

Ponç, Joan 103

Portugal 84, 127, 232-242, 256

Pous i Pagès, Josep 225

Prado, Isabel de 302

Prigogine, Ilya 60

Primo de Rivera, Miguel 176, 214, 221, 235

Proust, Marcel 275

Puig i Cadafalch, Josep 166, 172, 218-219, 228

Puig i Ferrater, Joan 180, 214

Pujol, Emili 162, 163, 172

Pulings, Gaston 58-59

Quiñones de León, José María 14, 67, 70,73

Quintanilla, Luis 279

Radhakrishnan, Sarvepalli 82

Rado, Antal 100

Ramón y Cajal, Santiago 69

Rathenau, Walter 71

Raymond Resolution 118

Raynal, Maurice 168, 172

Rebolledo, Efrén 275

Reboux, Paul (André Amillet) 166, 172

Recouly, Raymond 168, 172

Regional Center for Fundamental Education for Latin America (CREFAL) 286

Remarque, Erich Maria 36

Renaissance (European) 31-32
Renaixença (Catalan) 214, 226

Renn, Ludwig 120

Renoliet, Jean-Jacques 76

Republic of Letters 31, 108-110, 249

Restrepo, Antonio José 80

Réval (Logerot), Gabrielle 148, 165,172

Reyes, Alfonso 108, 112, 127-128, 141, 248, 255-257, 261, 276; and the Second American Conference of National Committees on Intellectual Cooperation 294; and Torres Bodet 279, 283

Reyles, Carlos 127-128, 138-139, 256-257

Reynold, Gonzague de 71, 77, 82, 239

Riba, Carles 155, 167, 172, 213-214, 220, 222-225

Ribalta, Josep Carner 225

Ribera, Antoni 145, 167, 172

Riber, Llorenç 167, 172

Richert, Gertrud 145, 148, 154, 167, 172

Riquer, Martí de 226

Rio de Janeiro 291, 293, 306; Polytechnic school of 79; University of 69,80

Rivas Mercado, Antonieta 276

Rivas Vicuña, Manuel 67, 80

Rodó, José Enrique 255, 276

Rohan, Karl Anton von 27

Roig-Sanz, Diana 66

Rojas, Ricardo 262-264, 267

Rolland, Romain 24, 28

Romains, Jules 27-28, 178, 214; denunciation of war 28, 131-132; in Buenos Aires 1936 127, 129; in Madrid 1933 31-34

Romanelli, Pietro 155, 162, 163, 172

Romania, Romanians 37, 84, 153, 219, 225 ; delegates 72 ; new 38 ; students in France from 40, 41; writers 73

Romero, Francisco 127-128, 130, $132,138,141,257$

Romier, Lucien 27

Roumain, Jacques 120-121

Rovira i Virgili, Antoni 166, 172; Rubió i Tuduri, Nicolau Maria 164, 172

Rubió, Jordi 165, 172

Rueda, Julio Jiménez 276

Ruffini, Francesco 69

Russia 37, 40, 43, 92, 228; Soviet 41

Russian Revolution 32

Ruyssen, Théodore 167, 172 
Sá-Carneiro, Mário de 234

Sachs, Curt 167, 172

Sackville-West, Vita 108

Sáez Delgado, Antonio 239-240

Sagarra, Josep Maria de 164, 172, 214, 218-220, 225, 228

Šalamun, Tomaž 95, 105

Salinas, Pedro 167, 172, 279

Salles Gomes, Paulo E. 302

Salten, Felix 97

Saltor, Octavi 153, 166, 172

Salaverría, José María 117, 122

Sánchez García, Raquel 200

Sánchez, Luis Alberto 139

Sanín Cano, Baldomero 75-76, 80, 127, 255-256, 261

San Martín see Almagro San Martín, Melchor de

Santamaria, Joan 225

Santiago de Chili 79, 140

Sarlo, Beatriz 131

Sarmiento, Domingo Faustino 252

Schmidt-Pauli, Edgar 97, 100

Schneider-Kainer, Lene 145, 165, 172

scientific imperialism 305, 308

Scott, Marjorie 217, 219-220

Scotland, Scottish 116, 127, 225

Scottish Congress 197

Second American Conference of National Committees on Intellectual Cooperation (1941)(Havana) 294

Second General Conference of the National Committees on Intellectual Cooperation (July 1937) 257

Second International 24

Second International Congress of the History of Science (1931) 301

Second Spanish Republic 120, 222

Secretariado de Propaganda Nacional (SPN) 232-234, 238-239

Seidel Canby, Henry see Canby, Henry Seidel

Serbia 72, 90, 93; see also Stefanović, Svetislav

Serra Húnter, Jaume 162, 163, 172

Seventh Conversation of the Organization of Intellectual Cooperation of the Society of Nations (entretien) (Buenos Aires) 127-130, 134-138, 233, 252; participants in 138-140; and Rayles 139; and Romero 138

Shaw, George Bernard 216

Shotwell, James T. 77, 83, 293-294
Simic, Charles 94

Simon Kra publishing house 202

Sinclair, May 108

Sitjà, Francesc 225

Sluga, Glenda 110

Soldevila, Carles 145, 152-156, 166, 172, 213-214, 217-220, 225

Soldevila, Ferran 150, 169, 172

Solé de Sojo, Vicenç 217

Sordelli, Alfredo 260

Sor Juana Inés de la Cruz 280

South America, South Americans 73, 76-77; and Mexico 283; writers 111-112, 176

Spanish Center of the International PEN 200-201; criticism and debate over 205-210; and Gómez de la Serna 201-205

Spanish Civil War 41, 117, 122-124, 128-129, 144-145; Enríquez Ureña views of 136; and Estelrich 177;

Ocampo's views of 132, 134

Spengler, Oswald 25, 28-29, 31, 33

Stalinism 41

Stefanović, Svetislav 90, 93-94, 97, 100

Stelè, France 102

Stepanow, Giovanni 148, 153, 162, 163, 166, 167, 172

Storm Jameson, Margaret 98, 117

Stresemann, Gustav 27

Suárez Montañés, Josefina 277-279

Sub-Commission on Exact and Natural Sciences 302-303

Subirana, Jaume 176, 179

Sur group 128-129, 266

Sur magazine 128-141, 259, 261, 266

Suriñach Senties, Ramon 215, 225

Surrealism 42, 201

Susta, Joseph 82

Sweden 121, 225

Switzerland, the Swiss 27, 37, 43, 256; Gómez de la Serna in 202; Ludwig 127, 256; support for International Institute of Intellectual Cooperation 84; students in France from 39, 40

Tagore, Rabindranath 108, 111, 213, 219

Tanakadate, Aikitu 75

Taracena y Aguirre, Blas 166, 172

Tasis i Marca, Rafael 148, 228

Tcheng, Cheng 153, 172

Teirlinck, Herman 59

'telluric forces' 33 


\section{Index}

Terán, Juan B. 127, 130, 252-254, 257

Teixeira, Anisio 307

Tito see Broz Tito, Josip

Toller, Ernst 11, 92, 96, 99-100, 103, 148,156 ; suicide 90

Toomer, Jean 121

Toro, José del 277

Torre, Claudio de la 279

Torre, Guillermo de 250

Torres Bodet, Jaime 19, 272, 281; adulthood 283-286; first and second youth 273-283, 286-287

Torres y Quevedo, Leonardo 69-70, $73,75,77,80$

Torriente y Peraza, Cosme de la 294

totalitarianism 35, 131, 178, 227, 264

Toury, Gideon 48

Toussaint, Manuel 273

Trabal, Francesc 12

translation studies 48

"translation" and "translator", conceptualization of 56-58

Treaty of Saint-Germain-en-Laye 39

Treaty of Trianon 35, 39

Treaty of Versailles 28, 39

Trigueiros, Luís Forjaz 237, 243

Turkey 37, 94, 235

Unamuno, Miguel de 31, 235

UNESCO 66, 110, 175-176, 287; early years of 300-308; and the International Institute of Intellectual Cooperation 248, 292; library 247; and the "Old Cooperation" 296-300; and Ozório de Almeida 292-296, 308; and Torres Bodet 273, 282, 283-286, 284

Ungaretti, Giuseppe 127, 148, 166, $167,172,257$

Union of International Associations (UIA) 67

United Kingdom 98, 286, 301; see also Great Britain

United States of America 41, 77, 113; Aita's views of 256, 266; bombing of Japan by 283; Bonnet in 291, 293-294; Dučić in 93; Europe and 129; Ferro in 236; Figueiredo in 241; Šalamun in 95; Ureña in 135; as "Yankees" 255; as one of three 'Wise Men' 286

United States of Europe project 26

Universal Declaration of Human Rights 286 universalism 24, 43, 118, 291; and UNESCO 300-308

Unsain, Alejandro 79

Urbanitzky, Grete von 97-98

Urrutia Olano, Francisco-José 69

Uruguay $69,73,79,84,127-128$, $138,255,257$

Uslar Pietri, Arturo 262

Văcărescu, Elena 73, 148, 150, 169, 172

Valdés, Palacio 202-203

Valéry, Paul 25, 27-34, 127, 130, 167, 172; at Amics de Poesia 155; in Barcelona 216-217; and the Conferentia Club 148, 150; on the "crisis of the spirit' 28; fame of 176; and Ferro 232, 236

Valle-Inclán, Ramón del

Vanderborght, Paul 58-59

Vanderhaeghe, René 99

Vargas, Getúlio 295-296, 308

Vasconcelos, José 275

Vaz Ferreira, Carlos 69, 262

Vázquez del Mercado, Alberto 273

Vedia, Joaquín de 251

Veiga, Beatrix 302

Vejarano, Felix 82

Venezuela, Venezuelans 73, 84; Blanco Fombona 262; Zérego Fombona 79

Venturi, Lionello 148, 165, 172

Verband für europäische Verstandigung (1926) 27

Verlaine, Paul 249

Vidal i Jové, Joan Francesc 225

Vildrac, Charles 218-220

Violet, Gustave 168, 172

Virraurrutia, Xavier 277

Vlaamsche Volkstooneel 58

Voltaire 26

Vossler, Karl 154, 155, 162, 163 , 172, 213

Wadia, Sophia 117, 122

Walker Linares, Francisco 80, 294

Walpole, Horace 256

Weimar, wise man of 30

Weissberger, José Arnaldo 145, 154, 160, 168, 172

Wells, H.G. 33, 123-124, 180, 216, 225-228, 255-256; and International PEN 108, 117-118; PEN presidency of $95,100,108$; resignation of 102, 117; and world peace 237 
Welter, Gabriel 162, 163, 172

Werfel, Franz 27

West, Rebecca 95, 108

Westerman, W. M. 100

Wilde, Oscar 249

Wilson, Edmund 121

Wiskeman, Atina 145, 148, 167, 172

Woolf, Virginia 132-133, 255-256

World War I 24, 36, 65; Barcelona since the end of 177-178; end of 66; and the League of Nations 11; and Yugoslavia 93; see also interwar period

World War II 72, 90, 110, 266-267, 285; and Dučić 93; Latin America during 84; see also Nazi Germany writers of Jewish descent 97; in Berlin 117; persecution of 118 ; in Poland 114

Yan, Mari 139

Yeats, William Butler 108, 111, 215

Yiddish Center see Poland

Yrigoyen, Hipólito 249, 252

Yugoslavia 37, 41, 97-98, 22; in 1933 91-96

Zaldumbide, Gonzalo 79, 82, 262

Zérega Fombona, Alberto 79

Zieliński, Tadeusz 155, 162, 163, 172

Zweig, Stefan 33, 101, 127, 139, 257 


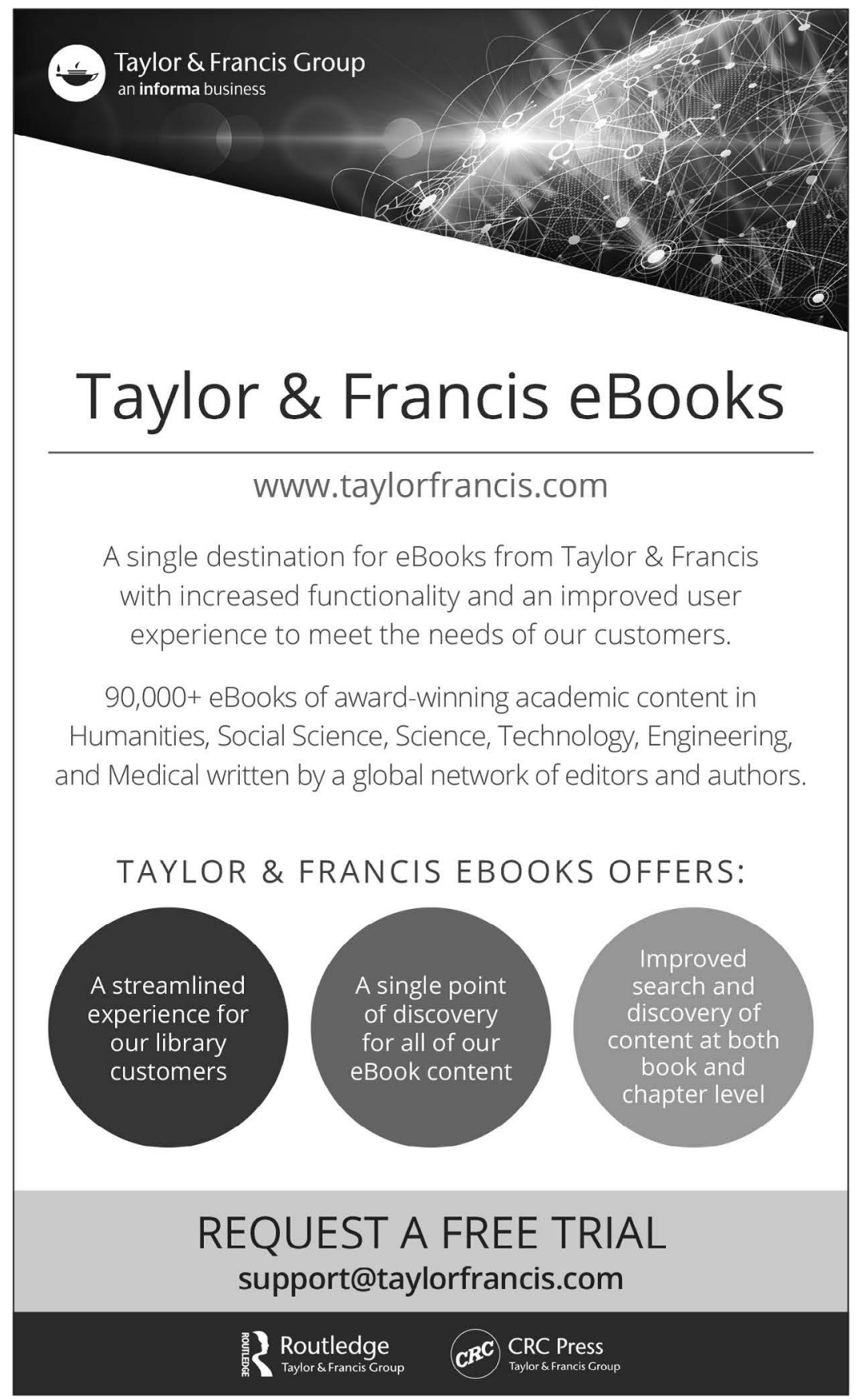

